
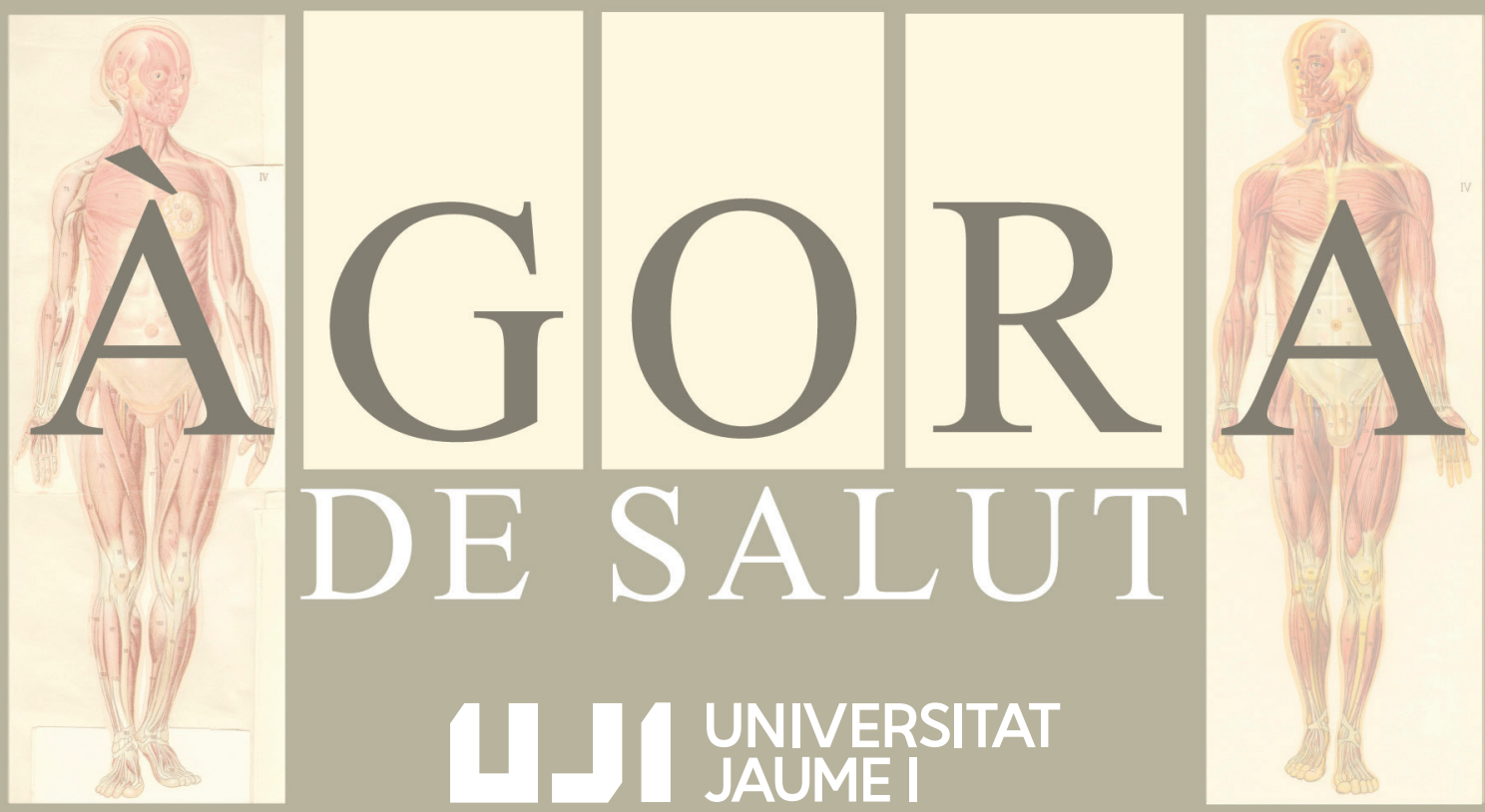

$\mathrm{DEST}$

SALUT

UT

UJI UNYIESITAT

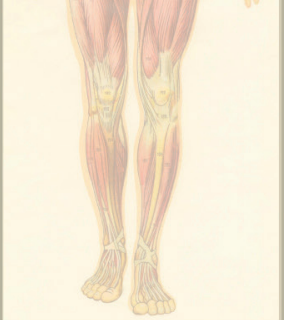

Facultat de Ciències de la Salut. Vol. V, any 2018. ISSN 2443-9827 

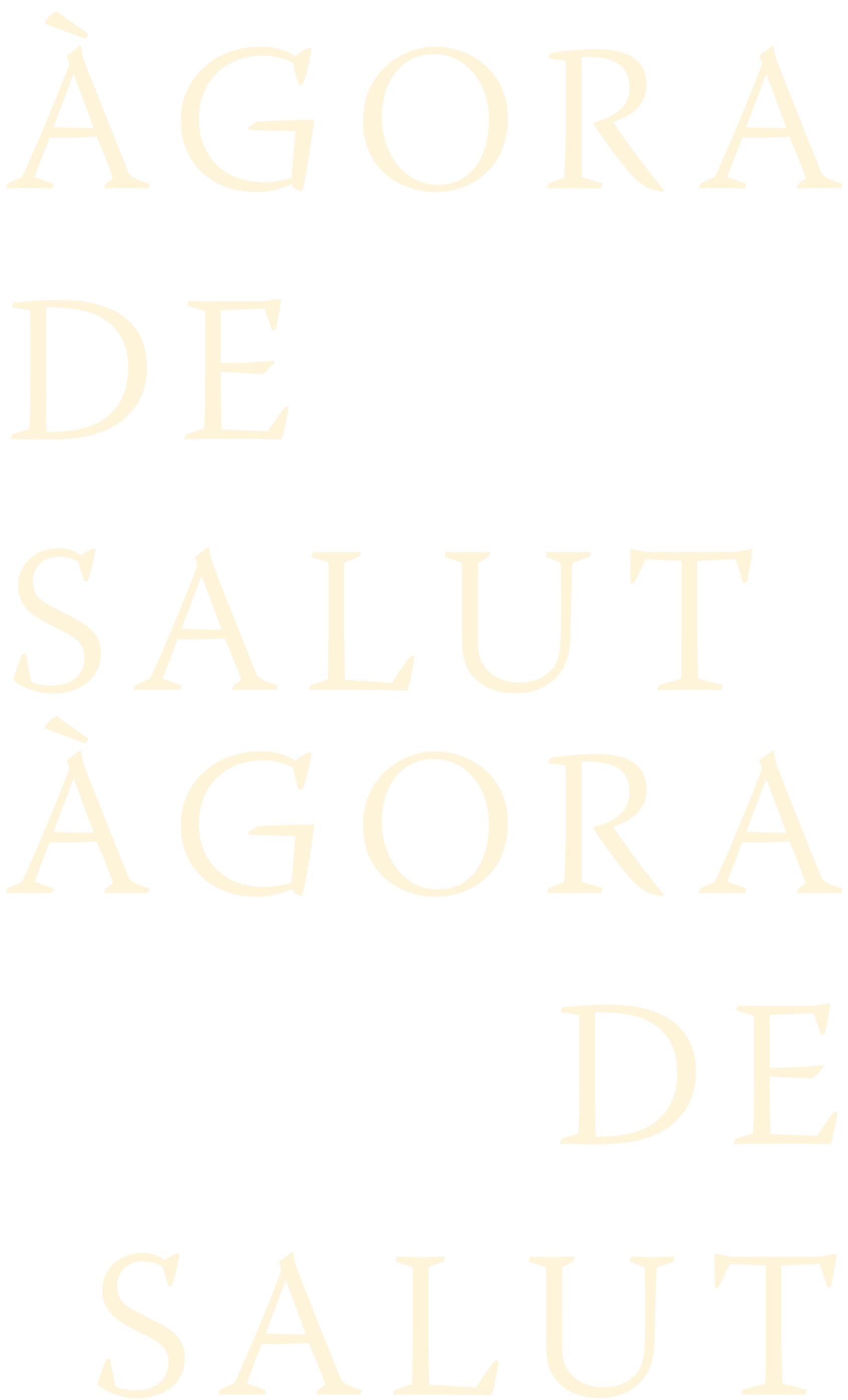


\section{ÀGORA DE SALUT}

V

\section{IINIVERSITAT}

Facultat de Ciències de la Salut

Any 2018 
ÀGORA DE SALUT. Àgora de salut pretén ser un instrument o un mitjà perquè els joves investigadors i investigadores de les nostres titulacions, i d'altres que en un futur puguen unir-se en el camí, publiquen els seus primers treballs, aquells que hagen realitzat per ser presentats en les jornades d'investigació de la Facultat de Ciències de la Salut. La millora de la salut i el benestar de la població és l'objectiu final que dóna sentit a la psicologia, la infermeria i la medicina, allò que la societat espera de nosaltres.

«Àgora» fa referència al substantiu grec provinent del verb ó $\gamma \varepsilon i ́ \rho \omega$, que significa 'reunir, ajuntar, agrupar, convocar' i això és el que pretenem fer amb la revista, convocar i reunir els nostres joves estudiants i estudiantes, perquè presenten les seues investigacions, dirigits pel professorat que treballa en les diverses línies de les diferents titulacions.

Direcció: Rafael Ballester Arnal

\section{Consell redacció:}

Berenice Serrano

Estefanía Ruiz

\section{Consell assessor:}

$\begin{array}{lll}\text { Ana Alarcón } & \text { Eladio J. Collado } & \text { Fernando Martínez } \\ \text { Conrado Martínez } & \text { Eva Cifre } & \text { Soledad Quero }\end{array}$

\section{Consell revisió:}

$\begin{array}{lll}\text { Águeda Cervera } & \text { Cristina Giménez } & \text { María Desamparados Bernat } \\ \text { Ana Alarcón } & \text { David Aguado } & \text { María Juan } \\ \text { Ana Folch } & \text { Desirée Mena } & \text { María Lidón Villanueva } \\ \text { Ana María Sánchez } & \text { Francisco E. Olucha } & \text { María Pilar Molés } \\ \text { Aurora Esteve } & \text { Francisco Ros } & \text { Pablo Salas } \\ \text { Conrado Martínez } & \text { Hugo Salais } & \text { Víctor M. González }\end{array}$

(C) Del text: els autors i les autores, 2018

(C) D’aquesta edició: Publicacions de la Universitat Jaume I, 2018

Edita: Publicacions de la Universitat Jaume I. Servei de Comunicació i Publicacions. Campus del Riu Sec. Edifici Rectorat i Serveis Centrals. 12071 Castelló de la Plana Fax: 964728832 http://www.tenda.uji.es - e-mail: publicacions@uji.es

ISSN: 2443-9827

DOI revista: http://dx.doi.org/10.6035/AgoraSalut

DoI volum: http://dx.doi.org/10.6035/AgoraSalut.2018.5

Cap part d'aquesta publicació, incloent-hi el disseny de la coberta, no pot ser reproduïda, emmagatzenada, ni transmesa de cap manera, ni per cap mitjà (elèctric, químic, mecànic, òptic, de gravació o bé fotocòpia) sense autorització prèvia de la marca editorial. 


\section{ÍNDEX}

ACTITUDES HACIA LA TRANSEXUALIDAD EN JÓVENES

MARTA GaRCíA-BARBA; NAROA SERRANO-MORAgÓN; JoAN CAMAÑES-MARTORELL;

Estefanía RUIZ-PALOMINO; RAFAEL BALleSter-ARNAL

ALIMENTACIÓN EN PACIENTES DIAGNOSTICADOS DE INSUFICIENCIA RENAL CRÓNICA EN TRATAMIENTO CON DIÁLISIS

Alba GonzÁlez Gallego; Paula TaRongi Vidal; Eladio Joaquín Collado Boira

ASOCIACIÓN DE LA PERSONALIDAD, LOS EVENTOS VITALES

ESTRESANTES Y EL USO Y ABUSO DE DROGAS EN ADOLESCENTES

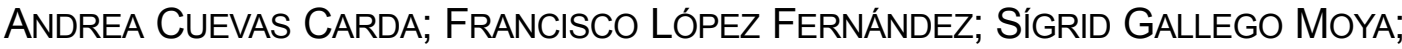

JORDI ORTET WALKER; LAURA MEZQUITA GUILLAMÓN

PRÁCTICA DEPORTIVA, CONDICIÓN FÍSICA Y SALUD

EN LA ADOLESCENCIA: PROYECTO DADOS

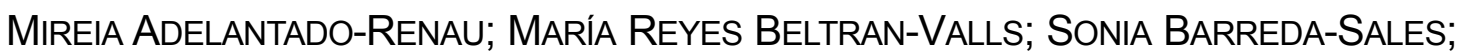

VICENTE JAVIER AYALA-TAJUELO; DIEGo MOLINER-URDIALES

\section{CALIDAD DE VIDA EN PACIENTES CON ERCA EN TRATAMIENTO}

CON HEMODIÁLISIS VS DIÁLISIS PERITONEAL. REVISIÓN

INTEGRADORA

María Oriola Alba; SeRgio Pascual Romero Lecha; Eladio JoAquín

COLLADO BOIRA

COMPORTAMIENTOS HOMOSEXUALES EN JÓVENES

HETEROSEXUALES: DIFERENCIAS DE GÉNERO

Juan EnRIQUe Nebot-Garcia; MarTa García-Barba; Beatriz GIL-JuliÁ; Cristina

GimÉnEZ-GARCía; RAFAEL BALLESTER-ARNAL

CONDUCTAS SEXUALES ONLINE EN POBLACIÓN JUVENIL:

DIFERENCIAS DE GÉNERO Y RELACIÓN CON LA BÚSQUEDA

DE SENSACIONES SEXUALES

MaRTa García-BaRba; JuAn EnRIQUe Nebot-García; Jesús Castro-Calvo;

CRISTINA GIMÉNEZ-GARCíA; RAFAEL BALleSteR-ARNAL

CONOCIMIENTOS DE LA POBLACIÓN ESTUDIANTIL EN REANIMACIÓN

CARDIOVASCULAR BÁSICA

Marina Alonso Gómez; María de los Ángeles Alonso García; Pablo

SALAS MEDINA 
CUIDADOS DE ENFERMERÍA EN PACIENTES DIAGNOSTICADOS

DE VÉRTIGO POSICIONAL PAROXÍSTICO BENIGNO

Alba GonzÁlez Gallego; Lledó Guillamón Gimeno

DAÑO MUSCULAR Y RECUPERACIÓN TRAS UNA MARATÓN. RELACIÓN CON EL SEXO BIOLÓGICO

RANIA ACHOUAK HAFSI; ELADIO J. COLLADO BOIRA

DIAGNÓSTICO DE SALUD POBLACIONAL: LUCENA DEL CID

MIRIAM IZQUIERDO MARTíNEZ; AITOR LUJÁN RONDA; ÁGUEDA CERVERA GASCH;

PABLO SALAS MEDINA

DISEÑO DE UNA INTERVENCIÓN BASADA EN TÉCNICAS DE REGULACIÓN EMOCIONAL Y PSICOLOGÍA POSITIVA PARA UN CASO DE TRASTORNO

DE DEPRESIÓN MAYOR Y RASGOS DE PERSONALIDAD LÍMITE

ANDREA DELGADO CARRETERO; BERENICE SERRANo ZÁrATE

EFICACIA ANALGÉSICA DEL TRATAMIENTO INVASIVO MIOFASCIAL (PUNCIÓN SECA) EN FIBROMIALGIA

JuAN VICENTE MAMPEL; FRANCISCO ROS BERnaL

EL APRENDIZAJE EMOCIONAL CON REFORZADORES SECUNDARIOS NO FORTALECE EL RECUERDO RETROACTIVO DE EVENTOS RELACIONADOS

CARolina CuADRADO-GómeZ; Elisenda Bueichekú; CÉsar ÁVILA

EL BIENESTAR PSICOLÓGICO Y LA FELICIDAD COMO VARIABLES PROTECTORAS EN LOS TRASTORNOS ADAPTATIVOS. UN ESTUDIO EXPLORATORIO

CINTIA TUR DOMENECH; IRYNA RACHYLA; ALBA LÓPEZ MONTOYO; SOlEDAD

QUERO CASTELLANO

EL PAPEL DE LA PERSONALIDAD Y EL ACOSO ESCOLAR

EN EL DESARROLLO DE SÍNTOMAS INTERNALIZANTES EN LA ADOLESCENCIA

DaVinia SÁnChez Miguel; Sígrid Gallego Moya; Generós OrTet Fabregat; MANUEL IGNACIO IBÁÑEZ RIBES

EL PAPEL PROTECTOR DE LAS VARIABLES PSICOLÓGICAS POSITIVAS Y SU RELACIÓN CON EL CAMBIO CLÍNICO TRAS LA INTERVENCIÓN EN LOS TRASTORNOS ADAPTATIVOS

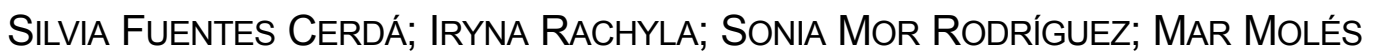
AMPOSTA; SOLEDAD QUERO CASTELLANO 
¿ES LA PUBLICIDAD UN FACTOR DE RIESGO PARA EL TRASTORNO POR ATRACÓN O LAS CONDUCTAS DE COMER EMOCIONAL?

ROCío RodRíGuez RódenAS; BERENICE SERRANo ZÁRATE

ESTRATEGIAS DE AFRONTAMIENTO COMO VARIABLES PREDICTIVAS DE LA INTENSIDAD SINTOMATOLÓGICA Y EL CAMBIO CLÍNICO TRAS UN TRATAMIENTO COGNITIVO-CONDUCTUAL PARA EL TRASTORNO ADAPTATIVO

FABIOLA REYES-TORRES; IRYNA RACHYLA; SILVIA FueNTES-CERDA; MAR MOLÉS AMPOSTA; SOLEDAD QUERO CASTELLANO

ESTRATEGIAS DE BÚSQUEDA DE EMPLEO EN JÓVENES: ¿EXISTEN DIFERENCIAS POR GÉNERO?

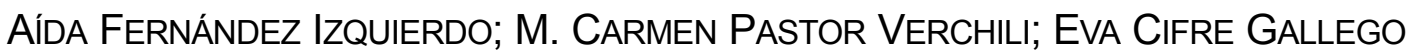

ESTRUCTURA FACTORIAL DE LA ESCALA DE ACTITUDES HACIA LA METODOLOGÍA

Rocio Viegas Garcia; Simona Román; Antonio Caballer Miedes

ESTUDIO DE LA ESPECIFICIDAD DE VÍAS DE INSULINA/IGF-1

EN LOS PATRONES DE ARBORIZACIÓN Y SEÑALIZACIÓN MEDIANTE EL USO DE VIRUS ASOCIADOS A ADENOVIRUS

Ribes-NAVARRo Alberto; SÁnCHez PÉrez ANA

ESTUDIO DE LA INFLUENCIA DE LA PERICIAL EN LOS PROCESOS

DE FAMILIA

AINHOA RODRÍGUEZ ZAFRA; LIDÓN VILLANUEVA BADENES

EVALUACIÓN DE LA COMPETENCIA EMOCIONAL

EN NIÑAS/OS CON TRASTORNO DEL ESPECTRO AUTISTA A TRAVÉS

DE UNA APP NOVEDOSA

laura García Arnanz ; Melisa Herráez Aón; Estefanía Olivares Romero;

MARI CARMen Selma SÁnCHEZ ; ClaRA ANDRÉs-ROQUeta

EXPERIENCIA, PERCEPCIÓN Y EXPECTATIVAS DE ADOLESCENTES

ABSENTISTAS GITANOS

LAURA Bitrí́N FerRer; Ma RAQuel Agost FeliP

FAMILIA Y DIVERSIDAD FUNCIONAL: BIENVENIDO A HOLANDA.

LA PRIMERA NOTICIA

GuAdALUPE PAVÓN RodRÍGUeZ; Ma RAQUEL AgOST-FeliP

IDENTIFICACIÓN DE VARIANTES GENÉTICAS ASOCIADAS

A LA SENSIBILIDAD SOLAR

JULIO AlBERTO DESERIO-CUESTA; RAQUEL SORIA-NAVARRO; INCA VILAR-SASTRE;

Bárbara Hernando; ConRado Martínez-Cadenas 
INFLUENCIA DE LA AUTOESTIMA E IMAGEN CORPORAL EN LA SATISFACCIÓN SEXUAL DE JÓVENES UNIVERSITARIOS 253

VERÓNICA MARTíNEZ-BORBA; LARA SALVADOR-BOIX; BEATRIZ GIL-JULIÀ; JESÚS CASTRO-CALVO; RAFAEL BALLESTER-ARNAL

INFLUENCIA DEL APOYO POR PARTE DEL TERAPEUTA EN LA SATISFACCIÓN DE UN PROGRAMA AUTO-APLICADO A TRAVÉS DE INTERNET PARA LA DEPRESIÓN

Clara Miguel Sanz; Laura díaz Sanahuja; Adriana Mira Pastor; Juana María BRETÓN LÓPEZ; CRISTINA BOTELLA ARBONA

INTELIGENCIA EMOCIONAL PARA FRENAR EL RECHAZO EN LAS AULAS

MARTín SÁnCHEZ GómEZ; Edgar BREsó EsteVE

LA DIABETES MELLITUS. HERRAMIENTA PARA LA TOMA DE DECISIONES COMPARTIDAS EN LA DIABETES MELLITUS TIPO II LETICIA GIMENO PITARCH; ROSA ÁlVARO BALlESTER; GLORIA DE LA TORRE MONFORT; MARIANA CLAUDIA MATEI ; LUIS VICENTE LIZÁN TUDELA

PARTO ACUÁTICO: COMPLICACIONES Y BENEFICIOS MÁS RELEVANTES RESPECTO AL PARTO VAGINAL CONVENCIONAL. REVISIÓN INTEGRADORA

Sergio Pascual Romero lecha; Maria Oriola Alba; Soledad Carregui Vilar ; ELADIO JOAQUIN COLLADO BOIRA

PERCEPCIÓN SOBRE EL TRASTORNO DEL ESPECTRO AUTISTA. ¿ESTAMOS PREPARADOS PARA LA REALIDAD DE LAS AULAS INCLUSIVAS?

Irene Garcia Molina; Raquel Nieto Garoz; Aida Sanahuja Ribés; Alicia Benet GIL

PLAN DE CUIDADOS SOBRE LA DONACIÓN DE ÓRGANOS EN PACIENTES CON MUERTE ENCEFÁLICA

$M^{a}$ DE los Ángeles Alonso García; Marina Alonso Gómez; Maa Desamparados BERNAT ADELL

PAGA SETMANAL I AMICS ANTINORMATIUS. EFECTES ADDITIUS I DE MODERACIÓ EN LA PREDICCIÓ DE L'ÚS DE SUBSTÀNCIES PER PART D'ADOLESCENTS

JoRDI ORTET WALKER; ANDREA CUEVAS CARDA; Francisco JAVIER LÓPEZ FERNÁNDEZ; SígRID GaLlEgo MOYA; LAURA MEZQUITA GUILLAMÓN

PROGRAMA DE TRATAMIENTO INTEGRATIVO PARA LA FIBROMIALGIA: ESTUDIO PRELIMINAR

Amanda Díaz-García; Guadalupe MolinarI; Adriana MiRA; Macarena EsPinOzA; AZUCENA GARCIA-PALACIOS 
PROTOCOLO DE ACTUACIÓN ANTE CASOS DE ACOSO ESCOLAR: UNA PROPUESTA DE INTERVENCIÓN INTEGRAL

Remei Monzó Hervás; Silvia Calero Valencia; Ana Belén Górriz Plumed

PROGRAMA DE SALUD PARA LA PREVENCIÓN DE ENFERMEDADES

DERIVADAS DE LA EXPOSICIÓN SOLAR EN LA INFANCIA

BELÉn MORENO GUILLAMÓN; BELÉn FLOS EXPÓSITO; AdRIÁN FONTA DE LA FUENTE;

Pablo Salas Medina; Águeda Cervera Gasch

PROYECTO SHE: SCHOOL AND HOME EMOTIONS

José Francisco Santas Bona; NieVES Fuentes-SÁNCHEZ; IRENE JaÉn PARRILLA; JAHEL MOLINA UlLDEMOLINS; M. CARMEN PASTOR VERCHILI

REHABILITACIÓN DE LA MARCHA EN EL PACIENTE CON ICTUS REVISIÓN BIBLIOGRÁFICA

ManUel José Pinazo Llobet; María ARANTZAZU Ruescas Nicolau

RELACIÓN ENTRE LA REGULACIÓN EMOCIONAL Y LA AUTOESTIMA

NúRIa Balaguer Pich; Martín SÁnChez Gómez; AZUCEna GaRCía Palacios

\section{RESPUESTA CARDÍACA DE DEFENSA Y EMOCIONALIDAD NEGATIVA} EN POBLACIÓN NORMAL

NieVES FuentEs-SÁNCHEZ; IRENE JAÉn; BEATRIZ GaRCíA-CARRIÓN; EVA CIFRE;

M. CARMEN PASTOR

REVISIÓ D'ESTUDIS QUALITATIUS SOBRE VIOLĖNCIA LABORAL EN ELS SERVEIS D'URGĖNCIES HOSPITALÀRIES

Karen Sorribes Ortí; Pablo Salas Medina; Alicia de los Ángeles

TORRES GONZÁLEZ

SEXO Y AMOR: CUANDO LA FORMA DE ENTENDER EL AMOR SE CONVIERTE EN UN RIESGO PARA LA SALUD SEXUAL DE LOS JÓVENES

Juan EnRIQUe Nebot-Garcia; MARTA Garcia-Barba; Estefanía Ruiz-Palomino;

CRISTINA GIMÉNEZ-GARCÍA

USO DE NUEVOS ANTICOAGULANTES ORALES (NACO)

EN LA PREVENCIÓN DEL ICTUS Y LA EMBOLIA SISTÉMICA EN

PACIENTES CON FIBRILACIÓN AURICULAR NO VALVULAR (FANV)

Paula Rodríguez Gálvez; laura Valero Verche; Sonia PI Ruano; Alba Sánchez MARTÍN; LUIS LIZÁN TUDELA 



\title{
Actitudes hacia la transexualidad en jóvenes
}

\author{
MARTA GARCÍA-BARBA \\ barbam@uji.es \\ NAROA SERRANO-MORAGÓN \\ al225879@uji.es \\ JoAN CAMAÑES-MARTORELL \\ al239830@uji.es \\ ESTEFANÍA RUIZ-PALOMINO \\ eruiz@uji.es \\ RAFAEL BALLESTER-ARNAL \\ rballest@uji.es
}

\section{Resumen}

Introducción: La transexualidad se define como un malestar o disforia con el sexo anatómico e identificación con el otro sexo. La discriminación hacia el colectivo transexual (transfobia) se expresa a través de actitudes negativas, incomodidad o sentimientos de rechazo hacia estas personas, que pueden manifestarse en experiencias de acoso escolar, discriminación laboral, aislamiento social, entre otras. Estas situaciones generan problemas como baja autoestima, depresión, ansiedad e incluso tentativa de suicidio. Nuestro objetivo es explorar las actitudes hacia la transexualidad en jóvenes de entre 18 y 32 años. Método: La muestra se compone de 179 participantes: 103 mujeres y 76 hombres $(M=22,79, D T=2,23)$. Se utilizó la Escala de Actitudes hacia la Transexualidad (Nagoshi y cols., 2008) y unas preguntas sobre datos sociodemográficos. Resultados: Los resultados demuestran porcentajes significativos de jóvenes con actitudes negativas hacia la transexualidad. Por ejemplo, el $24,1 \%$ de la muestra afirmó que la dicotomía entre hombre-mujer es lo natural. Existen diferencias estadísticamente significativas entre hombres y mujeres en la puntuación media de transfobia $(\mathrm{t}=4,56 ; \mathrm{p}<.001)$, siendo los hombres los que obtienen actitudes más negativas. Además, el hecho de conocer a una persona transexual influye significativamente en estos resultados $(t=3,20 ; p=.002)$, siendo los jóvenes que no conocen a ningún transexual, los que obtienen puntuaciones medias superiores. Conclusiones: Factores como el desconocimiento y la existencia de esquemas sociales rígidos sobre las personas con identidades de género no-normativas favorecen la discriminación hacia los/ as transexuales. Resulta necesario una educación afectivo-sexual orientada hacia la diversidad sexual.

Palabras clave: Transfobia, transexualidad, identidad de género, actitudes, jóvenes. 


\section{Abstract}

Introduction: Transsexuality is defined as the discomfort with one's anatomical gender and the self-identification with the other gender. Discrimination towards the transgender collective (transphobia) is expressed through negative attitudes, displeasure or feelings of rejection towards these people, bullying, discrimination at work and social isolation, among others. These situations generate problems such as a low self-esteem, depression, anxiety and even suicidal ideation. Our aim is to explore attitudes toward transsexuality in young people between the ages of 18 and 32. Method: The sample consists of 179 participants: 103 women and 76 men $(M=22.79, S D=2.23)$. The instrument used was The Attitudes Scale Toward Transsexuality (Nagoshi y cols., 2008) and other questions about sociodemographic data. Results: The results showed significant percentages of negative attitudes towards transsexuality in young people. For example, $24.1 \%$ of the sample said that the dichotomy between man and woman is the right. There were significant differences between men and women in the average transphobia score $(t=4.56, p<.001)$, men obtained more negative attitudes than women. In addition, knowing a transsexual person influenced significantly $(t=3.20 ; p=.002)$. Young people who did not know any transsexual obtained higher average scores. Conclusions: Factors such as lack of knowledge and rigid social schemes on people with non-normative gender identities favor discrimination towards this group. An affective-sexual education oriented towards sexual diversity is necessary.

Key Words: Transphobia, transsexuality, gender identity, attitudes, young people.

\section{Introducción}

El constructo de identidad refleja el sentimiento de pertenencia ante una colectividad concreta (Ariosa, 2014). En este sentido, entendemos la identidad de género como el modo en el que una persona se considera perteneciente de una forma biológica, psicológica o social, al género masculino o femenino (Burn, 2016). Sin embargo, este sentido de identidad no siempre es congruente con el sexo biológico asignado en el nacimiento, lo que puede generar un cierto malestar o angustia psicológica conocida como «disforia de género» (Knudson, De Cuypere y Bockting, 2010). Ello se acompaña de un distrés y un intenso malestar que conlleva un sentimiento de profundo rechazo hacia las características sexuales primarias y secundarias de su sexo biológico, y la persona busca adecuar su cuerpo mediante tratamientos hormonales y quirúrgicos con el fin de conseguir vivir y ser tratada de acorde al género que desea (Hengstschläger y cols., 2003).

Esta realidad, que se aleja del modelo normativo de dos sexos/géneros, en ocasiones puede ser severamente cuestionada y castigada socialmente (Carrera-Fernández y cols., 2013), dando lugar a lo que se conoce como «Transfobia».

Hill y Willoughby (2005) definen dicho fenómeno como «una repugnancia emocional hacia los individuos que no se ajustan a las expectativas de género de la sociedad». Estos autores defienden distintas formas de expresión de la Transfobia, distinguiendo un componente cognitivo -sistema social de creencias que refuerzan la evaluación negativa de los individuos que no se ajustan a sus roles de género-, actitudinal -expresión de sentimientos negati- 
vos, aversión o miedo hacia las personas que transgreden el modelo rígido de dos sexos- y conductual -manifestación de conductas hostigadoras hacia este colectivo.

Estos componentes de rechazo hacia el colectivo transexual se pueden manifestar con acciones como acoso escolar, discriminación en el empleo, agresiones verbales y físicas, e incluso homicidios (Miller y Grollman, 2015). Además de estas formas manifiestas de discriminación, se encuentran otras más sutiles denominadas «microagresiones», y definidas por Nadal y cols. (2010) como expresiones verbales, conductuales o ambientales, intencionadas o no intencionadas, que comunican actos hostiles, despectivos o negativos hacia una minoría (en este caso el colectivo transexual). Según este autor, un ejemplo muy común de este tipo de microagresiones es el lenguaje estereotipado.

Por otra parte, la literatura científica ha encontrado una relación entre discriminación transfóbica y consecuencias negativas para la salud. Por ejemplo, Walter y cols. (2013) evaluaron a 1093 personas transexuales estadounidenses, con edades superiores a 18 años a través de una encuesta online, la cual además de explorar la vivencia de situaciones discriminantes, incluía medidas estandarizadas de salud mental, encontrando relaciones positivas estadísticamente significativas entre estigma social y problemas de la salud mental tales como depresión, ansiedad y somatización.

Otros estudios como el de Poscoe y Richman (2009), han encontrado que las personas que se enfrentan a esta discriminación tienden a involucrarse en comportamientos dañinos para la salud como autolesiones o consumo de sustancias. En definitiva, el estigma que sufren las personas transexuales tiene un impacto negativo en la autoestima, las relaciones sociales, los comportamientos de afrontamiento y la salud física y mental (Mizock y cols., 2017), convirtiéndose en un factor asociado a las altas tasas de tendencia suicida propias de este colectivo (Grossman, Park y Russell, 2016).

Algunas investigaciones han observado una clara diferencia de género en la expresión de las actitudes transfóbicas. Trabajos como los de Hill y Willoughby (2005) o Nagoshi y cols., (2008), muestran mayores niveles de transfobia en los hombres que en las mujeres. Siguiendo esta línea, otro dato de gran relevancia es la observación de niveles de hostilidad más altos en hombres heterosexuales hacia los transexuales que transitan de hombre a mujer, que a los que transitan de mujer a hombre (Gerhardstein y Anderson, 2010; Serano, 2007). Varios autores hipotetizan que estas diferencias pueden encontrarse en la influencia de una socialización de género más estricta para los varones, es decir, una deseabilidad social asimétrica que favorece los rasgos, valores y comportamientos masculinos, -predominación del patriarcado(Connell, 2000; Nagoshi y cols., 2008). De este modo la literatura científica defiende que la rigidez en la socialización diferencial de género, basada en la existencia de dos sexos, y una orientación heterosexual, parece ser el trasfondo del desarrollo de actitudes discriminatorias hacia la diversidad sexual (Carrera, Lameiras, DePalma y Ricoy, 2013).

Debido a la alarma social que supone la existencia de tales actitudes discriminatorias en nuestros tiempos, con el presente trabajo se pretende explorar qué tipo de actitudes presenta la población joven hacia la transexualidad, con el fin de diseñar medidas eficaces para la prevención de la transfobia. Teniendo en cuenta lo apuntado anteriormente, planteamos como hipótesis que los hombres presentarán actitudes más negativas hacia la transexualidad que las mujeres siendo, además, aquellos que no conocen a ningún transexual quienes puntuarán más alto en transfobia. 


\section{Método}

\section{Participantes}

La muestra está compuesta por un total de 179 jóvenes con edades comprendidas entre los 18 y los 32 años. La media de edad es de 22,79 años con una desviación típica de 2,23. La distribución por edades y género es homogénea $\left(X^{2}=13,96, p=.377\right)$.

La nacionalidad de los participantes es, en su mayoría, española (93,9\%). El 6,4\% restante se divide en las siguientes nacionalidades: argentina $(2,8 \%)$, rumana $(2,2 \%)$ y peruana $(2,2 \%)$.

La distribución según el nivel de estudios de los participantes es la siguiente: un $78,8 \%$ del total tiene estudios universitarios, $12,8 \%$ bachillerato y un $2,2 \%$ graduado escolar. El $6,2 \%$ restante ha contestado la opción «otros».

En cuanto a la orientación sexual, un $80,4 \%$ del total se identifican como heterosexuales, un $10,1 \%$ como bisexuales y un $9,5 \%$ como homosexuales.

\section{Instrumentos}

Para la realización del estudio se empleó la Escala de Actitudes hacia la Transexualidad (Nagoshi y cols., 2008), traducida por Salusex-Unisexsida, que evalúa la transfobia. Se trata de una escala tipo Likert formada por 9 ítems directos. Se valora cada ítem del 1 al 7 en función del grado de acuerdo con la afirmación presentada, siendo 1 «totalmente en desacuerdo» y 7 «totalmente de acuerdo». Las puntuaciones más altas en esta escala indican actitudes más negativas hacia la transexualidad. Este instrumento mostró en nuestra muestra una buena fiabilidad $(\alpha=.762)$. Por otro lado, se realizaron una serie de preguntas sociodemográficas previas tales como la edad, el género, la nacionalidad, el nivel de estudios y la orientación sexual.

\section{Procedimiento}

Se trata de un estudio transversal descriptivo en el que se pretendía analizar la prevalencia de actitudes de transfobia en jóvenes. Para realizar dicho estudio, inicialmente se escogió el cuestionario mencionado en el punto anterior y las preguntas sociodemográficas más adecuadas para nuestros objetivos. Todas las cuestiones se diseñaron en formato online por la comodidad, eficiencia y menor deseabilidad social que tiene esta modalidad de administración. La difusión se realizó a través de las redes sociales pidiendo la participación voluntaria de todo aquel que quisiera colaborar garantizando el anonimato y la confidencialidad. En el cuestionario se incluía una presentación, en la que aparecía una breve descripción del objetivo del trabajo, el motivo de la realización del mismo, así como la duración estimada de cumplimentación, el compromiso de confidencialidad y el consentimiento informado.

El enlace al cuestionario estuvo activo durante dos semanas aproximadamente y obtuvimos un total de 186 respuestas. De todas ellas, se decidió escoger el rango de edad de 18 a 32 años debido a que la gran mayoría de sujetos se concentraban en este grupo etario, por lo que se eliminaron a 7 personas que no cumplían este criterio.

Posteriormente se analizaron los datos mediante el programa SPSS Statistics 22. Además de medias, desviaciones típicas y porcentajes, se emplearon la prueba $t$ de Student para comparar la diferencia en variables cuantitativas en dos muestras independientes (por 
ejemplo: media de transfobia entre hombres y mujeres) y la prueba de Chi-cuadrado $\left(X^{2}\right)$ para comparar la diferencia en variables cualitativas en dos muestras independientes (por ejemplo: grado de acuerdo en los ítems entre hombres y mujeres).

\section{Resultados}

Con el objetivo de conocer las actitudes hacia la transexualidad de los jóvenes, inicialmente calculamos las puntuaciones totales obtenidas en la escala de actitudes negativas hacia la transexualidad. Obtuvimos una media de 21,62 sobre un máximo de 63 puntos en la muestra general $(D T=9,62)$. En función del género, los hombres presentaban puntuaciones más elevadas $(M=25,24 ; D T=10,13)$ que las mujeres $(M=18,95$; $D T=8,31)$, resultando esta diferencia estadísticamente significativa $(t=4,56 ; p<.001)$.

Por otra parte, las respuestas merecen ser descritas a nivel descriptivo puesto que puntuaciones iguales o mayores a 4 implican actitudes negativas hacia la transexualidad. Con este propósito, dicotomizamos la escala de respuestas otorgando el valor de 0 a las respuestas comprendidas entre "totalmente en desacuerdo" y "ni de acuerdo ni en desacuerdo», que corresponden con las puntuaciones 1, 2, 3 y 4; y el valor de 1 a las respuestas comprendidas entre "algo de acuerdo» y "totalmente de acuerdo», que corresponden con laspuntuaciones 5, 6 y 7 . En la Tabla 1 aparecen los porcentajes de respuesta que implican acuerdo con las actitudes negativas hacia la transexualidad.

En todas las actitudes analizadas, los hombres presentan porcentajes más altos que las mujeres. Casi a la mitad de los hombres $(47,4 \%)$ «no les gusta que, cuando alguien está coqueteando con ellos, no puedan decir si es un hombre o una mujer» (ítem 1) frente al 29,1\% de las mujeres ( $p=.012$ ) Además, el $31,6 \%$ de los hombres y el $16,5 \%$ de las mujeres opinan que, "cuando conocen a alguien, es importante para ellos/as ser capaz de identificar a la otra persona como un hombre o una mujer» (ítem 5) ( $p=.018)$. Ambas cuestiones describen la discriminación en el ámbito interpersonal. Encontramos, por otro lado, diferencias estadísticamente significativas en función del género en cuestiones relacionadas con la construcción social del género. Por ejemplo, la necesidad de definirse como hombre o mujer (ítem 2; $27,6 \%$ de hombres y $14,6 \%$ de mujeres, $p=.031$ ); las creencias asociadas a la dicotomía normativa de hombre-mujer (ítem $6 ; 31,6 \%$ de hombres $18,4 \%$ de mujeres, $p=.042$ ); la imposibilidad de cambiar el género (ítem $8 ; 11,8 \%$ de hombres, $3,9 \%$ de mujeres, $p=.043$ ) y la genitalidad como definición del género (ítem $9 ; 30,3 \%$ de hombres $9,7 \%$ de mujeres $p=.000$ ) (ver Tabla 1).

Por último, analizamos cómo afectaba el hecho de conocer a una persona transexual en las actitudes hacia la transexualidad. Como podemos ver en la Tabla 2, las personas que no conocen a ninguna persona transexual $(M=23,57, D T=9,32)$ muestran actitudes más negativas hacia la transexualidad que las personas que sí que conocen a algún transexual $(M=19,04$, $D T=9,45)$, siendo estas diferencias significativas a nivel estadístico $(t=3,20, p=.002)$. En función del género observamos que tanto los hombres como las mujeres que no conocen a personas transexuales muestran medias más altas en transfobia, que los que sí conocen, siendo estas diferencias estadísticamente significativas en el caso de los hombres $(p=.005)$. 
Tabla 1

Diferencias de género en respuestas transfóbicas en cada uno de los ítems de la escala

\begin{tabular}{|c|c|c|c|c|c|}
\hline Ítems & Total & $\begin{array}{l}\text { Hombre } \\
(\mathrm{N}=76)\end{array}$ & $\begin{array}{l}\text { Mujer } \\
(\mathrm{N}=103)\end{array}$ & $x^{2}$ & Sig. \\
\hline $\begin{array}{l}\text { 1. No me gusta cuando alguien está coqueteando } \\
\text { conmigo y no puedo decir si es un hombre o una } \\
\text { mujer. }\end{array}$ & $36,9 \%$ & $47,4 \%$ & $29,1 \%$ & 6,252 & 012 \\
\hline $\begin{array}{l}\text { 2. Creo que algo anda mal en una persona que dice que } \\
\text { no es ni un hombre ni una mujer. }\end{array}$ & $20,1 \%$ & $27,6 \%$ & $14,6 \%$ & 4,649 & 031 \\
\hline $\begin{array}{l}\text { 3. Me sentiría molesto/a si alguien que conozco desde } \\
\text { hace tiempo me revelara que anteriormente tenía } \\
\text { otro género. }\end{array}$ & $9,5 \%$ & $13,2 \%$ & $6,8 \%$ & 2,059 & ,151 \\
\hline $\begin{array}{l}\text { 4. Evito a la gente de la calle cuyo género no esta claro } \\
\text { para mí. }\end{array}$ & $3,4 \%$ & $3,9 \%$ & $2,9 \%$ & 0,145 & ,704 \\
\hline $\begin{array}{l}\text { 5. Cuando conozco a alguien es importante para mi ser } \\
\text { capaz de identificarle como un hombre o una mujer. }\end{array}$ & $22,9 \%$ & $31,6 \%$ & $16,5 \%$ & 5,627 & ,018 \\
\hline 6. Creo que la dicotomía hombre-mujer es lo natural. & $24,1 \%$ & $31,6 \%$ & $18,4 \%$ & 4,132 & ,042 \\
\hline $\begin{array}{l}\text { 7. Me siento incómodo/a alrededor de personas que } \\
\text { no se ajustan a los roles tradicionales de género, } \\
\text { por ejemplo, las mujeres agresivas o los hombres } \\
\text { emocionales. }\end{array}$ & $3,9 \%$ & $6,6 \%$ & $1,9 \%$ & 2,503 &, 114 \\
\hline 8. Creo que una persona no puede cambiar su género. & $7,3 \%$ & $11,8 \%$ & $3,9 \%$ & 4,113 & ,043 \\
\hline $\begin{array}{l}\text { 9. Los genitales de una persona definen el género que } \\
\text { tienen, por ejemplo, un pene define a una persona } \\
\text { como hombre; una vagina define a una persona } \\
\text { como una mujer. }\end{array}$ & $18,4 \%$ & $30,3 \%$ & $9,7 \%$ & 12,287 & ,000 \\
\hline
\end{tabular}

Tabla 2

Diferencias en las medias en transfobia en función de conocer a alguna persona transexual para la muestra total y para cada género por separado

\begin{tabular}{ccccccccccc}
\hline & \multicolumn{3}{c}{ Total } & \multicolumn{4}{c}{ Hombre } & \multicolumn{3}{c}{ Mujer } \\
\hline $\begin{array}{c}\text { ¿Conoces a algún } \\
\text { transexual? }\end{array}$ & $M$ & $D T$ & $t$ & Sig & $M(D T)$ & $t$ & Sig & $M(D T)$ & $t$ & sig \\
\hline No & 23,57 & 9,32 & 3,20 & ,002 & $28,07(9,16)$ & 2,92 &, 005 & $20,29(8,03)$ & 1,92 & ,058 \\
Sí & 19,04 & 9,45 & & & $21,55(10,27)$ & & & $17,16(8,43)$ & & \\
\hline
\end{tabular}




\section{Discusión y conclusiones}

En general, en nuestro estudio aparecen porcentajes destacables de transfobia entre los jóvenes. Estos resultados siguen la línea de algunos de los estudios comentados previamente (Hill y Willoughby, 2005; Nagoshi y cols., 2008), en los que se encuentra un mayor porcentaje de actitudes negativas hacia el colectivo transexual en hombres que en mujeres. De acuerdo con algunos autores (Carrera, Lameiras, DePalma y Ricoy, 2013; Connell, 2000; Nagoshi y cols., 2008) podemos explicar tales diferencias por factores como la existencia de una sociedad donde predomina el patriarcado y por tanto, unos esquemas sociales rígidos que ejercen una mayor presión en los hombres. Estos esquemas se encuentran marcados en la construcción social del género viéndose reflejados en una mayor intransigencia con la dicotomía hombre-mujer. Como podemos ver en nuestro estudio, ítems relacionados con la exclusividad e inamovilidad de estos géneros (ítem 2 e ítem 6), presentan porcentajes altos en respuestas transfóbicas, además de presentar diferencias significativas de género, siendo los hombres quienes obtienen porcentajes más altos en transfobia.

Como hemos señalado al principio de este artículo, todas estas actitudes negativas hacia la transexualidad pueden traducirse en discriminación hacia las personas que forman parte de este colectivo. Es frecuente encontrar muchos casos de discriminación -tanto de forma manifiesta, como agresiones físicas, como otras más sutiles como acciones no inclusivas (Nadal y cols., 2010)- en el ámbito escolar, laboral, e incluso a nivel legal. Las personas que sufren este tipo de discriminación pueden sufrir consecuencias negativas tales como depresión, ansiedad, consumo de sustancias, autolesiones (Dhejne, Van Vlerken, Heylens y Arcelus, 2016) e incluso ideación suicida (Grossman, Park y Russell, 2016).

Uno de los posibles motivos que llevan a las personas a tener tales actitudes discriminatorias hacia este colectivo puede ser una educación afectivo-sexual limitada (Rasmussen y cols., 2015), que conlleva un desconocimiento sobre la situación de estas personas y que a su vez facilita la aparición de prejuicios negativos. En nuestro estudio, encontramos que el hecho de conocer a personas transexuales afecta positivamente en las actitudes hacia la transexualidad. Esto se podría justificar por una mayor empatía y un mayor conocimiento de la situación concreta del individuo transgénero. Además, cabría esperar que las personas que puntuaran alto en transfobia se mostraran más reticentes a mantener relación con una persona transexual, retroalimentando la discriminación y la falta de información.

La principal limitación del presente estudio es la inexistencia de medidas de evaluación con adecuadas propiedades psicométricas validadas en nuestro contexto. Por ello, con el propósito de subsanar estas limitaciones e ir más allá en el estudio de esta problemática, consideramos oportuno desarrollar una escala adaptada al castellano que refleje el amplio rango de actitudes y creencias que se encuentran detrás de lo que denominamos transfobia, y pueda emplearse en personas de población española. También creemos oportuno que, del mismo modo que encontramos baterías sobre homofobia que diferencia la discriminación sutil y manifiesta (Quiles y cols, 2003), ésta también considere diferenciar estos tipos de discriminación en cuanto a la transfobia.

Por otra parte, como destacamos en la descripción de la muestra, la mayoría de ellos son universitarios. Aunque cabría esperar que las personas que tienen estudios superiores poseen mayor información, conocimiento y mayor apertura a la diversidad, y por lo tanto menos transfobia, los resultados indican que resulta necesario realizar intervenciones preventivas también en el contexto universitario, y de integrar como objetivo prioritario acciones dirigidas a eliminar cualquier forma de estigma hacia la diversidad sexual en los planes o normativas de igualdad. 
Como conclusión, resulta necesaria una educación afectivo-sexual orientada hacia la diversidad sexual. Por ello, creemos que debería ser prioritario invertir en una educación que permita a los niños crecer con actitudes tolerantes hacia la gran diversidad presente en la población, así como concienciar a los adultos de la misma necesidad desde un punto de vista más maduro y critico, con respecto a la sociedad a la que nos adaptamos y que nos influye, algunas veces de una manera tan sutil que ni siquiera se percibe.

\section{Referencias bibliográficas}

Ariosa, M. A. P. (2014). La identidad como objeto de estudio de la antropología. Alteridades, (2), 3-5.

Corona, G., Jannini, E. y Maggi, M. (Eds.). (2014). Emotional, Physical and Sexual Abuse: Impact in Children and Social Minorities. Springer. (pp. 49-70). New York, NY: Springer International.

Bockting, W. O., Miner, M. H., Swinburne Romine, R. E., Hamilton, A. y Coleman, E. (2013). Stigma, mental health, and resilience in an online sample of the US transgender population. American journal of public health, 103(5), 943-951.

Burn, S. M. (2016). Gender Identification. The Wiley Blackwell Encyclopedia of Gender and Sexuality Studies.

Carrera, M. V., DePalma, R. y Lameiras, M. (2012). Sex/gender identity: Moving beyond fixed and «natural» categories. Sexualities, 15(8), $995-1016$.

Carrera, M. V., Lameiras, M., DePalma, R. y Ricoy, R. (2013). Pathologizing gender identity: An analysis of Spanish law and the regulation of gender recognition. Journal of Gender Studies. Advance online publication.

Carrera, M. V., Lameiras, M., DePalma, R.y Ricoy, R. (2013). Pathologizing gender identity: An analysis of Spanish law and the regulation of gender recognition. Journal of Gender Studies. Advance online publication.

Dhejne, C., Van Vlerken, R., Heylens, G. y Arcelus, J. (2016). Mental health and gender dysphoria: A review of the literature. International Review of Psychiatry, 28(1), 44-57.

Grossman, A. H., Park, J. Y. y Russell, S. T. (2016). Transgender youth and suicidal behaviors: Applying the interpersonal psychological theory of suicide. Journal of Gay \& Lesbian Mental Health, 20(4), 329-349

Hengstschläger, M., van Trotsenburg, M., Repa, C., Marton, E., Huber, J. C y Bernaschek, G. (2003). Sex chromosome aberrations and transsexualism. Fertility and sterility, 79(3), 639-640.

Hill, D. B., y Willoughby, B. (2005). The development and validation of the Genderism and Transphobia Scale. Sex Roles, 53, 531-545.

Knudson, G., De Cuypere, G. y Bockting, W. (2010). Recommendations for revision of the DSM diagnoses of gender identity disorders: Consensus statement of the World Professional Association for Transgender Health. International Journal of Transgenderism, 12, 115118.

Miller, L. R., y Grollman, E. A. (2015). The social costs of gender nonconformity for transgender adults: Implications for discrimination and health. Sociological. Forum, 30, 809-831.

Nadal, K. L., Rivera, D. P. y Corpus, M. J. H. 2010. Sexual orientation and transgender microaggressions in everyday life: Experiences of lesbians, gays, bisexuals, and transgender individuals. Microaggressions and marginality: Manifestation, dynamics, and impact, 217-240. 
Nadal, K. L., Skolnik, A. y Wong, Y. (2012). Interpersonal and systemic microaggressions toward transgender people: Implications for counseling. Journal of LGBT Issues in Counseling, 6(1), 55-82.

Pascoe, E. A. y Smart Richman, L. (2009). Perceived discrimination and health: a meta-analytic review. Psychological bulletin, 135(4), 531.

Quiles, M. N., Rodríguez, V. B., y Torres, R. R. (2003). La medida de la homofobia manifiesta y sutil. Psicothema, 15, 197-204.

Rasmussen, M. L., Sanjakdar, F., Allen, L., Quinlivan, K. y Bromdal, A. (2017). Homophobia, transphobia, young people and the question of responsibility.Discourse: Studies in the Cultural Politics of Education, 38(1), 30-42.

Talley, A. E. y Bettencourt, B. A. (2011). The moderator roles of coping style and identity disclosure in the relationship between perceived sexual stigma and psychological distress. Journal of Applied Social Psychology, 41(12), 2883-2903.

Worthen, M. G. F. (2016). Hetero-cis-normativity and the gendering of transphobia. International Journal of Transgenderism, 17(1), 31-57. 



\title{
Alimentación en pacientes diagnosticados de insuficiencia renal crónica en tratamiento con diálisis
}

\author{
AlBA GonZÁlez Gallego \\ al286552@uji.es \\ PAULA TARONGI VIDAL \\ al286598@uji.es \\ ELADIO JOAQUÍN COLLADO BOIRA \\ colladoe@uji.es
}

\section{Resumen}

Introducción: La insuficiencia renal crónica (IRC) es una enfermedad progresiva que implica una pérdida gradual de los riñones para realizar sus funciones principales durante al menos tres meses. En las fases avanzadas, se realizan terapias de reemplazo renal, en las cuales se considera una parte fundamental el seguimiento de las recomendaciones alimentarias, y principalmente de las sustancias esenciales y agua. Como objetivo principal del trabajo se ha establecido conocer las recomendaciones alimentarias específicas para los pacientes diagnosticados de IRC con el fin de aumentar sus conocimientos, mejorar su cumplimentación y adhesión al tratamiento nutricional prescrito e incrementar su estado de salud y calidad de vida. Metodología: Se desarrolló una revisión integradora de la literatura, mediante la consulta de cuatro bases de datos científicas (Preevid, PubMed, BVS, Biblioteca Cochrane Plus) y el uso de dos páginas web oficiales. Se escogieron un total de cuatro artículos científicos, cinco guías de práctica clínica y tres resultados encontrados en las páginas webs oficiales. Resultados: La información utilizada muestra que la importancia de la alimentación en el tratamiento de la IRC, recomendando el inicio temprano, a través de un equipo multidisciplinar. Conclusiones: La alimentación en los pacientes con IRC es uno de los puntos clave en su tratamiento de remplazo de la función renal, con el fin de mejorar su salud y calidad de vida. Los profesionales enfermeros se consideran elementos imprescindibles en la educación para la salud, sin olvidar el aspecto psicológico.

Palabras clave: dieta, insuficiencia renal crónica, diálisis.

\section{Abstract}

Introduction: Chronic renal failure (CRF) is a progressive disease that involves a gradual loss of the kidneys' functions. Kidneys' alterations produces accumulations of waste products in the organism. During the later stages of the pathology, renal replacement therapies are used, in which is important to follow dietary recommendations, mainly of essential substances and water. The main objective is to know the specific 
dietary recommendations for patients diagnosed with CRF in order to increase their knowledge about the disease, improve their completion and adherence to the prescribed nutritional therapy and increase their state of health and quality of life. Methodology: An integrative review was carried out. A total of four databases were used (Preevid, Pubmed, BVS, Biblioteca Cochrane Plus), and two official web pages. A total of four scientific articles, five clinical practice guides and three results of official web pages were used to carry out the work. Results: The information shows the importance of diet in the CRF's treatment, recommended their early onset through multidisciplinary team. Conclusion: Nutrition is one of the key points in the treatment of chronic renal failure to maintain good health and quality of life. Nursing staff is considered a key element in health education, without forgetting their psychological aspect.

Keywords: diet, chronic renal insufficiency, renal dialysis.

\section{Introducción}

La insuficiencia renal crónica (IRC) es una enfermedad progresiva que implica una pérdida gradual de los riñones para realizar sus funciones principales durante al menos tres meses (Cantero et al., 2004, De las Heras, et al., 2015;). Es una enfermedad que alcanza una prevalencia en la población española relativamente elevada, afectando a casi el $10 \%$ de la población. Su incidencia aumenta con la edad, siendo de un $20 \%$ en personas mayores de 60 años y de un $35 \%$ en mayores de 70; y, en caso de padecer diabetes o enfermedad cardiovascular, aumenta hasta un $50 \%$.

El riñón es un órgano vital del cuerpo que se encarga de filtrar y limpiar la sangre de las toxinas y sustancias de desecho que se producen como consecuencia del metabolismo, y de regular el exceso de líquido (balance hidroelectrolítico) a través de la orina. Presenta también otras funciones imprescindibles: estimular la producción de glóbulos rojos de la sangre, regular la presión arterial y modificar sustancias como la vitamina D, dando fuerza a los huesos (Cantero et al., 2004; Diaverum, 2010; National Kidney Foundation, 2015). Cuando se produce un fallo en este órgano, aparece la IRC, generando un almacenamiento en el organismo de productos de desecho, acompañado de la sintomatología propia: náuseas, vómitos, diarreas, pérdida de apetito, cansancio, alteración del sueño, acidez o ardor de estómago, dolor de cabeza, decaimiento general, picor en la piel, etc. (Crespo et al., 2008).

En las fases más avanzadas, estados terminales de la patología, existen hasta tres opciones de terapia de remplazo renal: la hemodiálisis realizada a través de un acceso vascular (fístula o catéter central); la diálisis peritoneal en la que se emplea la membrana peritoneal para separar las sustancias; y, por último, el trasplante renal (Diaverum, 2010).

En los pacientes diagnosticados de IRC y durante cualquier tipo de diálisis, la alimentación presenta una gran relevancia (Hospital Universitario Reina Sofía, 2013; Hospital Universitario Donostia, 2013):

- Mejora la calidad de vida del paciente

- Permite que el resultado de la diálisis sea mucho más óptimo

- Mejora el estado de salud del paciente para un futuro trasplante renal. 
Por tanto, modificar la alimentación, no solo es una recomendación saludable sino que es parte fundamental del tratamiento de los pacientes diagnosticados de IRC (National Kidney Foundation, 2015). Para ello, es esencial la educación sanitaria y los cuidados enfermeros, destinados principalmente a mantener en niveles adecuados las sustancias esenciales para el organismo: proteínas, hidratos de carbono, minerales (sodio, potasio, fósforo y calcio) y agua (Crespo et al., 2008).

De este modo, se establece como objetivo general del presente trabajo: conocer las recomendaciones alimentarias específicas para los pacientes diagnosticados de Insuficiencia Renal Crónica con el fin de aumentar sus conocimientos, mejorar su cumplimentación y adhesión al tratamiento nutricional prescrito e incrementar su estado de salud y calidad de vida. Así mismo, los objetivos específicos son:

- Aumentar y mejorar los conocimientos que los pacientes con IRC presentan en relación a las proteínas, hidratos de carbono, minerales y líquido.

- Informar acerca de las complicaciones que conllevaría un desajuste en los niveles de las sustancias anteriores.

- Asesorar a los pacientes sobre los alimentos convenientes a consumir y los alimentos a evitar por su patología.

- Dar a conocer las recomendaciones relacionadas con una óptima preparación de los alimentos para mantener estables los niveles de dichas sustancias.

\section{Metodología}

Con el fin de obtener la mejor evidencia científica disponible sobre el tema planteado, se establecieron los DeCS (Descriptores en Ciencias de la Salud) «Dieta», «Insuficiencia Renal Crónica» y «Diálisis»; y los MESH (Medical Subject Headings) «Diet», «Renal insufficiency, chronic» y "Renal dialysis». A partir de estas palabras, se realiza una búsqueda de información científica útil, fiable y relevante en un total de cuatro bases de datos (Preevid, PubMed, Biblioteca Virtual en Salud (BVS), Biblioteca Cochrane Plus), mediante el uso de filtros: idioma español e inglés, texto completo disponible y últimos 5 años (2011-2016). Toda esta información relacionada con la estrategia de búsqueda se muestra en la Tabla 1.

Tabla 1

Estrategia de búsqueda por bases de datos (Fuente: Elaboración propia)

\begin{tabular}{ccc}
\hline Base de datos & Estrategia de búsqueda & Resultados \\
\hline Preevid & «Insuficiencia renal crónica» & 37 \\
& «Diálisis» & 25 \\
PubMed & «Dieta» & 34 \\
BVS & «Renal insufficiency, chronic AND Renal dialysis AND & 31 \\
Biblioteca Cochrane Plus & «Insuficiencia renal crónica AND Diálisis AND Dieta» & 138 \\
\hline
\end{tabular}


Por último, ha sido utilizada tanto la página web de la Fundación Renal Española como la página web Norte-Americana de la Fundación Nacional del Riñón dedicada a la sensibilización, prevención y tratamiento de la enfermedad renal.

\section{Resultados}

Tras la realización de la búsqueda en las diferentes bases de datos, se utilizaron un total de cuatro artículos científicos (1 de Preevid, 2 de PubMed y 1 de Biblioteca Cochrane Plus). Así mismo, se utilizaron unas guías de práctica clínica y diferentes resultados de las páginas web oficiales comentadas anteriormente.

En todos ellos, la alimentación se considera uno de los puntos clave en el tratamiento de la Insuficiencia Renal Crónica. Aunque en general no se especifica la etapa concreta de la enfermedad en el que se deben empezar las intervenciones de educación dietética/nutricional, sí se recomienda que comience de forma temprana y basada en información de los diferentes nutrientes (proteínas, hidratos de carbono, sodio, potasio, fósforo, calcio y líquido) (Murciasalud, 2015; D'Alessandro et al., 2015).

Las proteínas se encargan de la construcción y renovación de células y tejidos, y de combatir infecciones (Crespo $R$ et al., 2008). De forma general, la ingesta recomendada para un paciente tratado con diálisis es de 1-1,2 $\mathrm{g} / \mathrm{kg}$ de peso por día, debiendo ser aproximadamente el $50 \%$ de elevado valor biológico.

Los hidratos de carbono son el único grupo de alimentos cuyo consumo no está limitado en los pacientes en tratamiento con diálisis, salvo si el paciente presenta un diagnóstico de diabetes. Debe recomendarse consumir hidratos de carbono complejos y evitar los simples, los cuales favorecen el incremento de los valores de colesterol, triglicéridos, obesidad, etc. (Hospital Universitario Reina Sofía, 2013; Hospital Universitario Donostia, 2013).

Los valores elevados de sodio en el cuerpo son los responsables del aumento de la tensión arterial, el aumento de peso, edemas en piernas, cara, ojos, Ilegando incluso a la insuficiencia cardiaca y al edema de pulmón (National Kidney Foundation, 2015; Cresp et al., 2008; Hospital Universitario Reina Sofía, 2013). Durante el tratamiento con diálisis, debe seguirse una dieta pobre en sal, recomendando un consumo entre 1.300 y $1.700 \mathrm{mg}$. diarios. Para su consecución, entre las recomendaciones encontramos (Hospital Universitario Donostia, 2013; National Kidney Foundation):

- Evitar la utilización de sal de mesa. Utilizar otras especias o zumo de limón que dan sabor a los platos y los hace más apetecibles.

- Comer pan sin sal.

- No utilizar concentrados para carnes o pescados, ni sopas de sobre.

En relación al potasio, éste se puede acumular en la sangre pudiendo provocar alteraciones en la actividad muscular, calambres, hormigueos, debilidad, arritmias e incluso parada cardiaca (National Kidney Foundation). Con el fin de que los pacientes consigan reducir las cantidades de potasio, consumiendo entre 1.800 y $2.000 \mathrm{mg}$ al día, pueden ser proporcionadas una serie de recomendaciones (Diaverum, 2010; Crespo et al., 2008; Hospital Universitario Reina Sofía, 2013; Hospital Universitario Donostia, 2013):

- Ingerir como máximo una pieza de fruta cruda al día y dejarla en remojo como mínimo entre tres y ocho horas, cambiando el agua en varias ocasiones. 
- Cocer la fruta para reducir la cantidad de potasio hasta la mitad.

- Las verduras y hortalizas deberán ser hervidas una o dos ocasiones con abundante agua, tirando ésta a mitad de cocción y repitiendo la operación.

- Las setas deben consumirse como máximo cada quince días y las legumbres dos veces a la semana, medidas en un plato de café y cocinarlas con el proceso de doble ebullición.

- Desechar el jugo de las conservas ya que presenta gran cantidad de potasio.

- Consumir la carne en estofados o en salsas, dado que pierde la mitad de potasio si se desecha el agua de cocción.

- Hacer la salsa de tomate casera, con tomate natural escaldado o con tomate envasado entero, eliminando la piel y el jugo.

- No utilizar levaduras para los rebozados o repostería.

Tanto el fósforo como el calcio, son el principal componente de los huesos (National Kidney Foundation). Un exceso de fósforo en la sangre produce una salida de calcio de los huesos, quedando éstos más frágiles (National Kidney Foundation, 2015). El consumo recomendado de fósforo se encuentra entre 800 y $1.200 \mathrm{mg}$.; mientras que el de calcio entre 1.400 y $1.600 \mathrm{mg}$ al día. Entre las recomendaciones dietéticas a seguir, encontramos (Crespo et al., 2008; Hospital Universitario Donostia, 2013):

- Consumir productos lácteos enteros, evitando los desnatados. Se debe tomar como máximo un vaso de leche al día. Fomentar el consumo de leche de soja y de almendras, ya que están compuestas de una menor cantidad de fósforo.

- No consumir más de dos o tres yogures, flanes, mousses o cuajadas, o $100 \mathrm{~g}$ de requesón o queso fresco a la semana y tomar como máximo dos huevos.

- Aumentar la ingesta de pescado blanco.

Además, durante el tratamiento de diálisis, el paciente debe controlar la cantidad de líquidos que consume para evitar complicaciones como: tensión arterial elevada, edemas, dificultad para respirar y calambres y mareos durante la sesión de diálisis. Este concepto de "líquidos» no sólo se incluye el agua, sino también los aquellos alimentos con un alto contenido en ésta. Como regla práctica, se debe recomendar consumir $500 \mathrm{ml}$ de líquido más de los que el paciente orina en 24 horas. Entre las pautas a seguir encontramos (Diaverum, 2010; Crespo et al., 2008; Hospital Universitario Reina Sofía, 2013; Hospital Universitario Donostia, 2013):

- Medir la cantidad de líquido total que debe consumir al día, teniendo en cuenta situaciones especiales como la fiebre, diarrea o sudoración importante.

- Eliminar el agua de las verduras salteándolas después de hervirlas.

- Consumir pan tostado, ya que presenta un $35 \%$ menos de agua.

- Utilizar rodajas de limón para estimular la salivación y reducir la sensación de sed, limitando su consumo a dos rodajas al día, ya que el limón contiene potasio. Además, se puede consumir chicles y caramelos de menta.

- Remplazar las bebidas por cubitos de hielo en los días más calurosos.

- Limitar la ingesta de comidas saladas que aumentan la sensación de sed.

Por último, con el fin de establecer una pequeña diferencia entre la hemodiálisis y la diálisis peritoneal, cabe destacar que los pacientes tratados con esta última pueden 
disfrutar de una mayor libertad en la dieta, ya que al no existir periodos interdiálisis tan prolongados no se acumulan en el organismo tantos productos tóxicos. Sin embargo, deben seguir las mismas recomendaciones en lo que se refiere a los alimentos previamente expuestos y sus componentes (Crespo et al., 2008)

\section{Discusión y conclusiones}

Como se puede observar con la información, la alimentación en los pacientes diagnosticados de IRC es uno de los puntos clave e imprescindibles en su tratamiento de remplazo renal, con el fin de mantener un buen estado de salud y calidad de vida.

Para alcanzar estos objetivos, y considerando a los profesionales enfermeros como elementos claves en la educación para la salud, es esencial proporcionar a los pacientes los conocimientos necesarios y suficientes con el fin de capacitarlos para seleccionar aquellos alimentos que son adecuados para su patología, las técnicas más óptimas para una correcta preparación y consumición; así como detectar y evitar el consumo de aquellos alimentos inadecuados y perjudiciales para su salud.

Como profesionales, y de forma multidisciplinar, consideramos imprescindible realizar una valoración inicial tanto del paciente como de los familiares o cuidadores, con el fin de valorar la capacidad de compresión y detectar los recursos de éstos para seguir todas las recomendaciones. Éstas deberán ser explicadas con ejemplos gráficos de fácil comprensión, suprimiendo las recomendaciones complejas en forma de gramos o miligramos.

Por último, no debemos olvidar el aspecto psicológico del paciente, ni el estrés y ansiedad que conlleva el seguimiento de una dieta tan estricta. De esta forma, los familiares deben ser involucrados en el proceso de la enfermedad y su tratamiento, intentando que el cumplimiento de los consejos dietéticos no aísle al paciente a la hora de realizar las comidas; instruyendo de que, con pequeñas modificaciones, la dieta puede ser satisfactoria para todos los componentes de la familia.

\section{Referencias bibliográficas}

Cantero, P. \& Ruano, A. (2009). Eficacia y efectividad del inicio precoz del tratamiento renal sustitutivo en la insuficiencia renal crónica avanzada. Recuperado en abril 25, 2016 de: http://www.bibliotecacochrane.com/BCPGetDocument.asp?SessionID=\%2010553771 \&DocumentID=AEG000045

Crespo, R., Casas, R. \& Contreras MD. (2008). Guía para el paciente renal según modalidades de tratamiento ( $1^{\text {a }}$ edición). Córdoba: Alcer-Córdoba.

D’Alessandro C., Piccoli, G. B. \& Cupisti, A. (2015). The «phosphorus pyramid»: a visual tool for dietary phosphate management in dialysis and CKD patients. BMC Nephrolog, 16, 1-6.

De las Heras, M. T. \& Martínez, C. (2015). Conocimiento y percepción nutricional en diálisis: su influencia en la transgresión y adherencia. Estudio inicial. Nutrición Hospitalaria, 31, 1366-1375.

Diaverum (2010). Manual Informativo para el paciente renal ( $2^{\mathrm{a}}$ edición). Madrid.

Fundación renal. (2013). Disponible en: https://www.friat.es 
Hospital Universitario Donostia: Unidad de Nefrología-Diálisis (2013). Guía de Alimentación en pacientes con Insuficiencia Renal ( $1^{\mathrm{a}}$ edición). Donostia: Unidad de Comunicación del Hospital Universitario Donostia.

Hospital Universitario Reina Sofía. Servicio de Nefrología. (2013). Guía para pacientes con tratamiento de hemodiálisis ( $1^{a}$ edición). Córdoba: Alcer-Córdoba.

Murciasalud. (2015) ¿Con qué grado de insuficiencia renal hay que comenzar la educación dietética renal para una correcta prevención? Recuperado en abril 25, 2016 de: https:// www.murciasalud.es/preevid.php?op=mostrar_pregunta\&id=20357\&idsec=453

National Kidney Foundation. New York. Disponible en: https://www.kidney.org/

National Kidney Foundation (2015). Nutrición e insuficiencia renal crónica. Abril 25, 2016, de National Kidney Foundation, Sitio web: https://www.kidney.org/sites/default/files/docs/1150-1105_aai_patbro_nutritionandckd_3-5_pharmanet_nkf_span_jan08.pdf 



\title{
Asociación de la personalidad, los eventos vitales estresantes y el uso y abuso de drogas en adolescentes
}

\author{
ANDREa Cuevas CaRda \\ andrea.cuevas@uji.es \\ FRANCISCO LÓPEZ FERNÁNDEZ \\ al225790@uji.es \\ SíGRID GALLEGO MOYA \\ sigridgallego@gmail.com \\ JORDI ORTET WALKER \\ al260584@uji.es \\ LAURA MEZQUITA GUILLAMÓN \\ Imezquit@uji.es
}

\section{Resumen}

Introducción: Características de personalidad de extraversión, baja amabilidad y baja responsabilidad se han asociado con el consumo de drogas en la adolescencia, mientras que los eventos vitales estresantes (EVE) se han asociado de forma poco consistente. No obstante, existirían dos tipos de EVE, los independientes y los dependientes (dependen de características de personalidad), es posible que únicamente sean los EVE dependientes los que se asocien con el uso de sustancias. Por ello, el objetivo del presente estudio es explorar en qué medida la personalidad y los EVE dependientes se asocian en el consumo de sustancias y en los problemas derivados del consumo. Método: En 2016, 196 adolescentes (edad media = 15'46 DT= 1'15, 48,5\% chicas) del IES Caminàs de Castellón completaron el cuestionario de personalidad JSNEO, el inventario de eventos vitales para adolescentes ISVA, el cuestionario CODIS sobre el consumo de drogas y los cuestionarios de problemas relacionados con el consumo AUDIT, CPQ-SF y Test de Fagerström. Para alcanzar el objetivo, se realizaron análisis de regresión por pasos. Resultados: La extraversión y los EVE dependientes predijeron tanto la frecuencia y cantidad de consumo como los problemas derivados del consumo de alcohol, cannabis y tabaco. El efecto de los EVE dependientes sobre el consumo y los problemas se mantuvo significativo cuando se controló el efecto de la personalidad. Discusión: Los resultados del estudio indican que el efecto de los EVE dependientes en el consumo y problemas asociados con el consumo de alcohol, tabaco y cannabis no se produce únicamente por la influencia de la personalidad, sino que estos tendrían un impacto directo en el desarrollo del consumo patológico.

Palabras clave: personalidad, eventos vitales, alcohol, tabaco y cannabis. 


\section{Abstract}

Introduction: Extraversion, low agreeableness and low conscientiousness have been associated with drug use in adolescence. On the other hand, dependent life events, those that depend on personality characteristics of disinhibition, have been associated with an increase in drug use. Therefore, the aim of the present study is to explore if the influence of life events on substance use and consumption problems is due to a third variable, personality. Method: In 2016, 196 adolescents (mean age $=15$ '46 DT $=1.15$, $48.5 \%$ girls) from IES Caminàs de Castellón completed the personality questionnaire JSNEO, the life events inventory for adolescents ISVA, the questionnaire on drug consumption CODIS and questionnaires of problems related to consumption AUDIT, CPQSF and Fagestrom test. To achieve the goal, stepwise regression analyses were performed. Results: Extraversion and dependent life events predicted the frequency and quantity of consumption as well as the problems related with alcohol, cannabis and tobacco consumption. The effect of dependent life events on consumption and problems remained significant when controlling the effect of personality. Discussion: The results of the study indicate that the effect of dependent life events on consumption and problems associated with alcohol, tobacco and cannabis use is not only due to the influence of the personality, but that these would have a direct impact on the development of pathological consumption.

Keywords: personality, life events, alcohol, tobacco and cannabis.

\section{Introducción}

Consideramos eventos vitales a aquellos acontecimientos que ocurren en un momento puntual de la vida y causan niveles de estrés elevado, como la muerte de un familiar, la separación conyugal, etc. Aunque durante bastante tiempo se pensó que la presencia de eventos vitales negativos ocurría de forma aleatoria, esta creencia es errónea; no todos los eventos vitales ocurren de forma azarosa. De hecho, el número de eventos vitales reportados por una persona en distintos periodos de su vida presentan una relación significativa (Saudino, Pedersen, Lichtenstein, McClearn, y Plomin, 1997).

Cuando se intentan analizar las causas de la ocurrencia de los eventos vitales desde un punto de vista genético-epidemiológico se encuentra que los eventos vitales que se dan a lo largo de la vida muestran una correlación significativa entre pares de gemelos y esta correlación es significativamente mayor en gemelos monozigóticos que en dizigóticos (Plomin, DeFries, y Loehlin, 1997). Estudios longitudinales también han demostrado una continuidad significativa en la frecuencia con la que una determinada persona experimenta determinados eventos vitales, y a su vez, los rasgos de personalidad parecen tener un papel relevante en la probabilidad de experimentar determinados eventos vitales, así como en su recurrencia (Andrews, 2009; Headey y Wearing, 1989). Por tanto, investigaciones previas muestran la existencia de factores hereditarios, que condicionarian las diferencias individuales entre las personas (Kendler y Neale, 1993; Plomin y Lichtenstein, 1990). Es decir, la personalidad está influenciada por factores genéticos, que afectan a experimentar en mayor medida eventos vitales negativos (Kendler y Greenspan, 2006). 
Cuando se habla de eventos vitales estresantes (EVE), es importante diferenciar entre eventos dependientes e independientes. Los EVE independientes son eventos bastante independientes del comportamiento o respuestas del sujeto; mientras que los EVE dependientes son potencialmente dependientes del comportamiento del propio sujeto. Por lo que respecta a los EVE independientes, estos parecen no estar tan afectados por la influencia genética, sino más bien por aspectos del ambiente no compartido. En cambio, los EVE dependientes sí están significativamente influenciados por factores genéticos (Kendler y Greenspan, 2006). Estas influencias genéticas en los eventos vitales se dan, posiblemente, a través de la personalidad (Kandler y cols., 2010).

Algunos autores han investigado específicamente la relación entre características específicas de personalidad y los eventos vitales. El neuroticismo se asocia con un mayor número de EVE dependientes (Kendler y Greenspan, 2006); niveles altos de extraversión se relacionan con un mayor número de eventos vitales dependientes de tipo positivo; la apertura a la experiencia predispone a más eventos vitales dependientes tanto positivos como negativos y la baja amabilidad se asocia también con EVE de tipo dependiente (Kandler, Bleidorn, Riemann, Angleitner, y Spinath, 2012). Recientemente, en una muestra de adolescentes Moya y cols. (2015) encontraron que los EVE dependientes estaban predichos por niveles altos de extraversión y niveles bajos de amabilidad y responsabilidad. Por lo que respecta a los EVE independientes, en la mayor parte de estudios no se encuentra relación entre personalidad y este tipo de eventos vitales, apoyando el hecho de que son eventos bastante independientes del comportamiento del sujeto. (Kandler y cols., 2012; Kendler y Greenspan, 2006; Kendler y Neale, 1993). Finalmente, existen pocos estudios que aborden la influencia de los eventos vitales en la personalidad. Los resultados apuntan a que los EVE dependientes predicen niveles más altos de apertura a la experiencia y niveles más bajos de amabilidad; mientras que los EVE independientes se asociarían con mayor neuroticismo (Kandler y cols., 2012).

Por otra parte, también existe una asociación entre las distintas dimensiones de personalidad y el uso y abuso de drogas. Estudios de meta-análisis muestran que la desinhibición, la baja amabilidad, la irresponsabilidad y el neuroticismo se relacionarían con los trastornos de control de impulsos y con el consumo de sustancias (Kotov, Gamez, Schmidt, y Watson, 2010; Maclaren, Fugelsang, Harrigan, y Dixon, 2011; Malouff, Thorsteinsson, Rooke, y Schutte, 2007). Por otra parte, en un estudio longitudinal reciente, Mezquita y cols. (2015) encontraron que la baja amabilidad y baja responsabilidad serían factores de vulnerabilidad para el desarrollo de patología externalizante, entre la que se encuentra el consumo de sustancias. Por lo que respecta a la adolescencia, los resultados de los estudios de Klimstra y cols. (2010, 2011) siguen esta misma línea e indican que son los niveles bajos en amabilidad, extraversión y responsabilidad los que se asocian con el consumo de drogas en la adolescencia, así como con más problemas derivados de ese consumo.

En relación al papel de los EVE en el consumo de sustancias, la evidencia es escasa y poco clara. Así, algunos estudios han encontrado como el uso y abuso de drogas en la dolescencia se ha asociado a una mayor probabilidad de haber experimentado EVE en el pasado, aunque otros no encuentran relación (Veenstra y cols., 2006). Cuando se encuentra, el consumo de sustancias sería en este caso una estrategia de afrontamiento (coping) para reducir el estrés y malestar. Este afrontamiento desadaptativo unido a la ocurrencia previa de EVE son predictores de un consumo mayor y más frecuente de alcohol, tabaco y cannabis durante la adolescencia y a lo largo del ciclo vital. Además, algunos autores también sugieren que el consumo de sustancias en la adolescencia se relacionaría con una mayor vulnerabilidad para experimentar EVE en el futuro (Cooke y cols., 2015; Jessup y cols., 2014).

Como se ha mencionado anteriormente, la diferenciación entre eventos dependientes e independientes es importante, y en el caso del consumo de sustancias podría serlo aún 
más., Ya que los estudios exitentes no relacionan el consumo de sustancias con estos tipos de de eventos vitales. No obstante, parece que son los eventos vitales de tipo interpersonal relacionados con la pareja, familia o amigos muestran una mayor relevancia (McConnell, Memetovic, y Richardson, 2014; Veenstra y cols., 2006). Por tanto, este es un campo de investigación poco explorado, pero que sugiere que son los EVE de tipo dependiente los que pueden estar jugando un papel en el consumo de sustancias.

Del mismo modo, también existen pocos estudios previos que relacionen la personalidad, los eventos vitales y el consumo de sustancias. En ellos, la personalidad se asocia con la probabilidad de experimentar eventos vitales en mayor o menor medida y esto a su vez con el patrón de consumo de drogas y con los problemas relacionados con este consumo (Heinrich, Schumann, Flor, y Nees, 2016) .

Por tanto, el objetivo del presente estudio fue explorar en qué medida la personalidad y los EVE se asocian con en el consumo de sustancias y con los problemas derivados del consumo, así como la interrelación entre ambas. La hipótesis de la que partimos fue que los EVE dependientes tienen un papel relevante en el uso y abuso de sustancias, pero no los EVE independientes. A su vez, la personalidad se asociaría con el uso de sustancias, especialmente la extraversión, la baja responsabilidad y la baja amabilidad. Finalmente, los EVE mediarían entre la personalidad y un mayor consumo y problemas asociados al consumo de cannabis, alcohol y tabaco.

\section{Método}

\section{Participantes}

La muestra está compuesta por 196 adolescentes (49\% eran chicas), con una media de edad de 14,30 años $(S D=1,62)$. El rango de edad de la muestra va de los 12 a los 21 años.

\section{Procedimiento}

Durante el año 2016 los participantes completaron los distintos cuestionarios del presente estudio en varias sesiones de tutoría. Finalmente, para el presente estudio se seleccionaron 196 alumnos de la muestra inicial; aquellos que a lo largo de todas las sesiones habían completado el JS-NEO-S, el ISVA y los cuestionarios de uso y abuso de drogas CODIS, AUDIT, CPQ-SF y Test de Fagerström. Todos los instrumentos se administraron de forma presencial. Los participantes fueron informados del proyecto, de la confidencialidad con la que se tratarían sus datos y de la posibilidad de abandonar la investigación en el momento que quisiesen. Además, al trabajar con adolescentes, se pidió la autorización paterna. Ningún participante recibió remuneración por su participación. El presente estudio fue aprobado por la comisión deontológica de la Universidad Jaume I.

\section{Instrumentos}

Versión corta de la adaptación española para adolescentes del NEO-PI-R (JS NEO-S; Ortet y cols., 2007). Este instrumento evalúa los principales factores de personalidad siguiendo el modelo de los Cinco Grandes: Neuroticismo, Extraversión, Apertura, Amabilidad y Responsabilidad. Cada dimensión se compone de seis facetas, medidas por cinco ítems de tipo 
Likert con cinco opciones de respuesta $(0=$ totalmente en desacuerdo a $5=$ totalmente de acuerdo), lo que hace un total de 150 ítems. La puntuación para cada dimensión se obtiene mediante la suma de las 6 facetas que la integran, mientras que la puntuación en cada faceta se obtiene agregando las puntuaciones de sus cinco ítems. También se incluyen cuatro ítems repetidos para controlar las respuestas al azar.

Inventario de Sucesos Vitales en Adolescentes (ISVA; Moya, 2016). Este inventario está formado por 74 EVE de distinta naturaleza, tanto que han experimentado los propios adolescentes como su entorno más cercano. Los EV informados deben haber ocurrido en el trascurso de los últimos 12 meses. En caso de haber experimentado un determinado EV hay que informar sobre el grado de afectación negativa del mismo a través de una escala Likert de 5 puntos $(0=$ no me afectó hasta $4=$ me afecto muy negativamente). En el presente estudio, los ítems de este cuestionario se sometieron al juicio de expertos para determinar la dependencia o independencia de los distintos sucesos vitales.

El Cannabis and Other Drugs Intake Scale (CODIS; IDAP, 2016) es un instrumento diseñado por el grupo de investigación para evaluar el consumo de cannabis y otras drogas de uno mismo, del grupo de amigos, del mejor amigo, de la pareja y de la familia. En el presente estudio se utilizaron las escalas de frecuencia ( 0 = ningún día de la semana hasta $7=$ todos los días de la semana) y cantidad semanal del consumo propio de cannabis, alcohol y tabaco.

El Cuestionario de Identificación de los Trastornos debidos al Consumo de Alcohol (AUDIT; Babor y Higgins-Biddle, 2001) es un autoinforme de 10 ítems que a través de una escala tipo Likert evalúa el consumo de alcohol, las conductas de dependencia y los problemas derivados del consumo durante el último año.

El Cuestionario De Problemas Asociados Al Consumo De Cannabis (CPQ; Copeland, Gilmour, Gates, y Swift, 2005). Este cuestionario mide los problemas asociados al consumo de cannabis. Consta de 12 ítems de respuesta tipo Likert de 4 puntos $(0=$ casi nunca/nunca hasta $3=$ casi siempre/siempre). Los que los participantes responden acerca de sus experiencias derivadas del consumo del cannabis en los últimos tres meses.

El Test de Fagerström (Fagerström, 1978) es un cuestionario que evalúa los problemas asociados al consumo de tabaco. Consta de 7 ítems, 5 de ellos se responden a través de preguntas dicotómicas, mientras que el resto se responden a través de una escala Likert de 4 puntos. La puntuación global del test va de 0 a $10(0=$ dependencia muy baja; $10=$ dependencia muy alta).

\section{Análisis}

Mediante el uso del software SPSS versión 23, se realizaron análisis descriptivos de la muestra total, para hombres y para mujeres; posteriormente se calcularon las diferencias de sexo mediante una prueba $t$ y también el tamaño del efecto de estas diferencias a través de la $d$ de Cohen (1992), mediante la calculadora online del tamaño del efecto (Becker, 1999). Posteriormente, se obtuvieron las correlaciones entre las distintas variables y se realizaron análisis de regresión lineal simple por pasos, siendo las variables dependientes la cantidad, frecuencia y problemas asociados al consumo de alcohol, cannabis y tabaco. Tras controlar el efecto de la edad y el género, se introdujeron las variables predictoras. En el segundo paso se introdujeron los EVE dependientes e independientes ocurridos en el último año. Finalmente en el último paso se introdujeron las dimensiones de personalidad. 


\section{Resultados}

Análisis descriptivos: Los análisis descriptivos aparecen en la Tabla 1. Las chicas puntuaron significativamente más alto en neuroticismo, apertura a la experiencia, amabilidad, responsabilidad, frecuencia de consumo de tabaco y problemas asociados al consumo de tabaco que los chicos.

Análisis correlacionales: Los análisis correlacionales aparecen en la Tabla 2. En ella su pueden observar las relaciones entre los distintos tipos de EVE, la personalidad y la cantidad, frecuencia y problemas asociados al consumo de alcohol, cannabis y tabaco.

Análisis de regresión: Los análisis de regresión mostraron que los EVE dependientes y la extraversión predijeron la frecuencia, cantidad y problemas asociados al consumo de cannabis alcohol y tabaco; mientras que la baja responsabilidad predijo la frecuencia de consumo de tabaco y la baja apertura a la experiencia predijo la frecuencia y cantidad de consumo de cannabis. Todos los efectos de los EVE dependientes sobre el consumo se mantuvieron significativos cuando se controló la personalidad, excepto en los problemas asociados al consumo de alcohol (véase Tabla 3).

Tabla 1

Análisis descriptivos de la muestra total y diferenciando por sexo

\begin{tabular}{lccccc}
\hline & $\begin{array}{c}\text { Muestra total } \\
(\mathrm{N}=196) \\
\mathrm{M}(\mathrm{SD})\end{array}$ & $\begin{array}{c}\text { Hombres } \\
(\mathrm{N}=101) \\
\mathrm{M}(\mathrm{SD})\end{array}$ & $\begin{array}{c}\text { Mujeres } \\
(\mathrm{N}=95) \\
\mathrm{M}(\mathrm{SD})\end{array}$ & $t$ & $d$ \\
\hline Neuroticismo & $57,55(15,62)$ & $53,10(14,91)$ & $62,27(15,03)$ & $-4,29^{* * *}$ & 0,61 \\
Extraversión & $76,28(14,92)$ & $75,61(15,55)$ & $77,00(14,26)$ & $-0,65$ & 0,09 \\
Apertura a la & $72,62(14,03)$ & $68,09(12,80)$ & $77,44(13,73)$ & $-4,94^{* * *}$ & 0,70 \\
experiencia & $74,01(14,44)$ & $71,93(15,38)$ & $76,22(13,11)$ & $-2,10^{*}$ & 0,30 \\
Amabilidad & $71,24(17,59)$ & $68,41(17,63)$ & $74,26(17,12)$ & $-2,36^{* *}$ & 0,34 \\
Responsabilidad & $3,98(3,62)$ & $3,45(3,09)$ & $4,56(4,05)$ & $-2,17^{*}$ & 0,31 \\
\hline EV independientes & $4,68(4,03)$ & $4,85(4,20)$ & $4,49(3,86)$ & 0,62 & 0,09 \\
\hline EV dependientes & $0,62(1,47)$ & $0,37(1,18)$ & $0,88(1,69)$ & $-2,50^{* *}$ & 0,35 \\
\hline Frecuencia tabaco & $2,99(12,80)$ & $1,48(5,93)$ & $4,59(17,20)$ & $-1,70$ & 0,24 \\
Cantidad tabaco & $1,01(2,55)$ & $0,65(2,14)$ & $1,40(2,89)$ & $-2,06^{*}$ & 0,30 \\
\hline Problemas tabaco & $0,91(1,13)$ & $0,81(1,14)$ & $1,02(1,11)$ & $-1,30$ & 0,19 \\
\hline Frecuencia alcohol & $3,05(8,05)$ & $3,28(9,68)$ & $2,80(5,88)$ & 0,41 & 0,06 \\
Cantidad alcohol & $2,59(3,81)$ & $2,14(3,84)$ & $0,23(0,83)$ & $-1,71$ & 0,24 \\
\hline Problemas alcohol & $0,19(0,73)$ & $0,15(0,63)$ & $-0,22(0,63)$ & $-0,70$ & 0,10 \\
\hline Frecuencia cannabis & $0,55(3,96)$ & $0,41(2,45)$ & $0,71(5,11)$ & $-0,51$ & 0,07 \\
Cantidad cannabis & $0,94(2,91)$ & $0,69(2,49)$ & $1,21(3,30)$ & $-1,24$ & 0,18 \\
\hline Problemas cannabis & 0,94 & & &
\end{tabular}

Nota. Los valores de la $\mathrm{d}$ de Cohen 0.20 .0 .50 y 0.80 corresponden a efectos pequeños, medianos y grandes respectivamente (Cohen, 1992). ${ }^{*} p<0.05 .{ }^{* *} p<0.01$. ${ }^{* * *} p<0.001$. 
Tabla 2

Análisis correlacionales

\begin{tabular}{|c|c|c|c|c|c|c|c|c|c|c|c|}
\hline & $\begin{array}{l}\text { 음 } \frac{\text { m }}{<} \\
\text { 蛋 } \\
\text { 心 } \\
\frac{\mathbb{D}}{\mathbb{D}} \\
\frac{\mathbb{D}}{?}\end{array}$ & 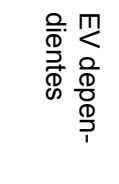 & 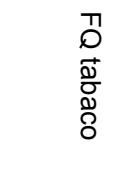 & 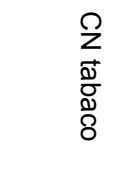 & 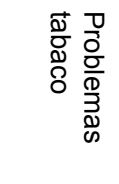 & $\begin{array}{l}\text { Tొ } \\
0 \\
\underline{0} \\
\underline{0} \\
\underline{0}\end{array}$ & $\begin{array}{l}\Omega \\
2 \\
\frac{0}{\overline{0}} \\
\underline{0} \\
\underline{0}\end{array}$ & 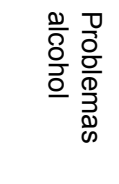 & 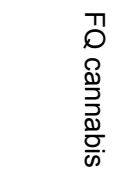 & 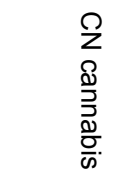 & 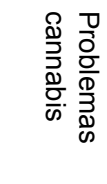 \\
\hline Neuroticismo & $0,14^{*}$ & $0,21^{* *}$ & 0,10 & 0,04 & $0,14^{*}$ & 0,02 & $-0,06$ & 0,04 & $-0,02$ & $-0,03$ & 0,01 \\
\hline Extraversión & $-0,02$ & $-0,03$ & $0,24^{* *}$ & $0,15^{*}$ & $0,24^{\star *}$ & $0,23^{* *}$ & $0,24^{* *}$ & $0,15^{*}$ & $0,21^{\star *}$ & $0,17^{*}$ & $0,22^{\star *}$ \\
\hline $\begin{array}{l}\text { Apertura a la } \\
\text { experiencia }\end{array}$ & 0,12 & 0,10 & 0,05 & 0,07 & 0,09 & $-0,01$ & $-0,04$ & 0,07 & $-0,07$ & $-0,10$ & 0,11 \\
\hline Amabilidad & 0,01 & $-0,24^{* *}$ & $-0,18^{*}$ & $-0,04$ & $-0,14^{*}$ & $-0,19^{\star *}$ & $-0,16^{*}$ & $-0,04$ & $-0,12$ & $-0,12$ & $-0,09$ \\
\hline Responsabilidad & 0,03 & $-0,17^{*}$ & $-0,17^{*}$ & $-0,11$ & $-0,13$ & $-0,17^{\text {** }}$ & -0.03 & $-0,11$ & $-0,03$ & $-0,01$ & $-0,02$ \\
\hline $\begin{array}{l}\text { EV independien- } \\
\text { tes }\end{array}$ & 1 & $0.55^{\star * *}$ & $0,17^{*}$ & $0,25^{\star * *}$ & 0,11 & $0,19^{* * *}$ & $-0,14$ & $0,20^{* *}$ & $0,22^{* *}$ & $0,15^{*}$ & $0,27^{* * *}$ \\
\hline $\begin{array}{l}\text { EV dependien- } \\
\text { tes }\end{array}$ & & 1 & $0,28^{* * *}$ & $0,29^{* * *}$ & $0,25^{\star * *}$ & $0,32^{* * *}$ & $0,25^{\star * *}$ & $0,27^{\star \star *}$ & $0,36^{\star * *}$ & $0,31^{\star \star *}$ & $0,33^{* * *}$ \\
\hline $\begin{array}{l}\text { Frecuencia } \\
\text { tabaco }\end{array}$ & & & 1 & $0,64^{* * *}$ & $0,86^{\star * *}$ & $0,53^{* * *}$ & $0,38^{* * *}$ & $0,37^{* * *}$ & $0,52^{\star \star *}$ & $0,77^{\star \star \star}$ & $0,48^{* * *}$ \\
\hline Cantidad tabaco & & & & 1 & $0,48^{* * *}$ & $0,41^{* * *}$ & $0,31^{* * *}$ & $0,33^{* * *}$ & $0,64^{* * *}$ & $0,37^{* * *}$ & $0,54^{\star \star *}$ \\
\hline $\begin{array}{l}\text { Problemas ta- } \\
\text { baco }\end{array}$ & & & & & 1 & $0,41^{* * *}$ & $0,31^{* * *}$ & $0,30^{* * *}$ & $0,35^{\star \star \star}$ & $0,25^{\star * \star}$ & $0,45^{\star \star *}$ \\
\hline $\begin{array}{l}\text { Frecuencia } \\
\text { alcohol }\end{array}$ & & & & & & 1 & $0,66^{* * *}$ & $0,66^{\star \star *}$ & $0,45^{\star \star \star}$ & $0,30^{* * *}$ & $0,41^{* * *}$ \\
\hline Cantidad alcohol & & & & & & & 1 & $0,61^{* \star *}$ & $0,55^{\star \star \star}$ & $0,31^{* \star *}$ & $0,48^{\star * *}$ \\
\hline $\begin{array}{l}\text { Problemas } \\
\text { alcohol }\end{array}$ & & & & & & & & 1 & $0,34^{* *}$ & $0,15^{*}$ & $0,52^{* * *}$ \\
\hline $\begin{array}{l}\text { Frecuencia } \\
\text { cannabis }\end{array}$ & & & & & & & & & 1 & $0,80^{* * *}$ & $0,63^{* * *}$ \\
\hline $\begin{array}{l}\text { Cantidad } \\
\text { cannabis }\end{array}$ & & & & & & & & & & 1 & $0,38^{\star * *}$ \\
\hline $\begin{array}{l}\text { Problemas } \\
\text { cannabis }\end{array}$ & & & & & & & & & & & 1 \\
\hline
\end{tabular}

Nota. ${ }^{*} p<0.05{ }^{* *} p<0.01{ }^{* * *} p<0.001$. 
Tabla 3

Análisis de regresión

\begin{tabular}{|c|c|c|c|c|c|c|c|}
\hline & \multirow[b]{3}{*}{ Variables independientes } & \multicolumn{4}{|c|}{ Variables dependientes } & & \\
\hline & & \multicolumn{2}{|c|}{ Cantidad tabaco } & \multicolumn{2}{|c|}{ Frecuencia tabaco } & \multicolumn{2}{|c|}{ Problemas tabaco } \\
\hline & & $\beta$ & $\Delta \mathrm{R}^{2}$ & $\beta$ & $\Delta \mathrm{R}^{2}$ & $\beta$ & $\Delta R^{2}$ \\
\hline \multirow{4}{*}{1} & Edad & 0,05 & $0,11^{* * *}$ & 0,13 & $0,13^{* * *}$ & 0,08 & $0,10^{* * *}$ \\
\hline & Género & 0,12 & & $0,19^{* *}$ & & $0,17^{*}$ & \\
\hline & EV dependientes & $0,23^{*}$ & & $0,27^{* *}$ & & $0,28^{* *}$ & \\
\hline & EV independientes & 0,09 & & $-0,04$ & & $-0,09$ & \\
\hline \multirow{12}{*}{2} & Edad & 0,03 & $0,15^{\star \star *}$ & 0,11 & $0,23^{* * *}$ & 0,08 & $0,19^{* * *}$ \\
\hline & Género & 0,14 & & $0,20^{* *}$ & & 0,14 & \\
\hline & EV dependientes & $0,21^{*}$ & & $0,20^{*}$ & & $0,20^{*}$ & \\
\hline & EV independientes & 0,12 & & 0,01 & & $-0,05$ & \\
\hline & Neuroticismo & $-0,04$ & & 0,06 & & 0,13 & \\
\hline & Extraversión & $0,18^{*}$ & & $0,30^{* * *}$ & & $0,31^{* * *}$ & \\
\hline & Apertura a la experiencia & $-0,01$ & & $-0,04$ & & 0,01 & \\
\hline & Amabilidad & 0,04 & & $-0,09$ & & $-0,06$ & \\
\hline & Responsabilidad & $-0,16$ & & $-0,16^{*}$ & & $-0,12$ & \\
\hline & \multicolumn{7}{|c|}{ Variables dependientes } \\
\hline & & \multicolumn{2}{|c|}{ Cantidad cannabis } & \multicolumn{2}{|c|}{ Frecuencia cannabis } & \multicolumn{2}{|c|}{ Problemas cannabis } \\
\hline & Variables independientes & $\beta$ & $\Delta R^{2}$ & $\beta$ & $\Delta \mathrm{R}^{2}$ & $\beta$ & $\Delta \mathrm{R}^{2}$ \\
\hline \multirow{4}{*}{1} & Edad & 0,13 & $0,11^{* * *}$ & $0,16^{*}$ & $0,15^{\star * *}$ & 0,01 & $0,13^{* * *}$ \\
\hline & Género & 0,06 & & 0,06 & & 0,08 & \\
\hline & EV dependientes & $0,31^{* * *}$ & & $0,32^{* * *}$ & & $0,27^{\star *}$ & \\
\hline & EV independientes & $-0,07$ & & $-0,02$ & & 0,11 & \\
\hline \multirow{9}{*}{2} & Edad & 0,14 & $0,18^{\star \star *}$ & $0,17^{*}$ & $0,23^{* * *}$ & 0,02 & $0,19^{* * *}$ \\
\hline & Género & 0,11 & & 0,10 & & 0,08 & \\
\hline & EV dependientes & $0,33^{* \star *}$ & & $0,34^{\star * *}$ & & $0,26^{\star *}$ & \\
\hline & EV independientes & $-0,06$ & & $-0,01$ & & 0,12 & \\
\hline & Neuroticismo & $-0,01$ & & $-0,01$ & & $-0,04$ & \\
\hline & Extraversión & $0,19^{* *}$ & & $0,23^{* *}$ & & $0,22^{* *}$ & \\
\hline & Apertura a la experiencia & $-0,17^{*}$ & & $-0,15^{*}$ & & 0,06 & \\
\hline & Amabilidad & $-0,03$ & & $-0,01$ & & $-0,06$ & \\
\hline & Responsabilidad & 0,05 & & 0,02 & & $-0,02$ & \\
\hline
\end{tabular}




\begin{tabular}{|c|c|c|c|c|c|c|c|}
\hline & \multirow[b]{3}{*}{ Variables independientes } & \multicolumn{4}{|c|}{ Variables dependientes } & & \\
\hline & & \multicolumn{2}{|c|}{ Cantidad alcohol } & \multicolumn{2}{|c|}{ Frecuencia alcohol } & \multicolumn{2}{|c|}{ Problemas alcohol } \\
\hline & & $\beta$ & $\Delta \mathrm{R}^{2}$ & $\beta$ & $\Delta \mathrm{R}^{2}$ & $\beta$ & $\Delta \mathrm{R}^{2}$ \\
\hline \multirow{4}{*}{1} & Edad & $0,27^{\star * *}$ & $0,13^{* * *}$ & $0,33^{\star * *}$ & $0,21^{* \star *}$ & $0,18^{*}$ & $0,12^{* * *}$ \\
\hline & Género & $-0,02$ & & 0,11 & & 0,13 & \\
\hline & EV dependientes & $0,19^{*}$ & & $0,26^{* *}$ & & $0,21^{*}$ & \\
\hline & EV independientes & $-0,04$ & & $-0,07$ & & 0,01 & \\
\hline \multirow{9}{*}{2} & Edad & $0,29^{* * *}$ & $0,21^{* * *}$ & $0,33^{* * *}$ & $0,30^{* * *}$ & $0,18^{*}$ & $0,24^{* * *}$ \\
\hline & Género & $-0,01$ & & 0,14 & & 0,10 & \\
\hline & EV dependientes & $0,18^{*}$ & & $0,22^{* *}$ & & 0,15 & \\
\hline & EV independientes & $-0,03$ & & $-0,03$ & & 0,04 & \\
\hline & Neuroticismo & 0,01 & & 0,02 & & 0,06 & \\
\hline & Extraversión & $0,27^{\star * *}$ & & $0,29^{* * *}$ & & $0,35^{* *}$ & \\
\hline & Apertura a la experiencia & $-0,06$ & & $-0,07$ & & 0,03 & \\
\hline & Amabilidad & $-0,10$ & & $-0,05$ & & $-0,04$ & \\
\hline & Responsabilidad & 0,06 & & $-0,12$ & & $-0,13$ & \\
\hline
\end{tabular}

Nota. ${ }^{*} p<0,05^{* *} p<0,01{ }^{* * *} p<0,001$

\section{Discusión y conclusiones}

El presente estudio tenía como objetivo principal explorar la influencia de los EVE en el consumo de sustancias y en los problemas derivados este, en base a la personalidad.

En lo relativo a la relación de personalidad con el consumo, en este estudio se ha encontrado que, de forma consistente con estudios previos, la alta extraversión predijo tanto la frecuencia y cantidad de consumo como los problemas derivados del consumo de alcohol, cannabis y tabaco (Klimstra y cols., 2010, 2011). Además, algunas dimensiones de personalidad se relacionaron con consumos específicos; mientras que la baja responsabilidad se asoció con una mayor frecuencia de consumo de tabaco (Kotov y cols., 2010), la baja apertura a la experiencia, en contra de lo hipotetizado, se relacionó tanto con una mayor frecuencia de consumo de cannabis como con una mayor cantidad de consumo del mismo.

Por lo que respecta a los EVE de tipo dependiente se asociaron de forma consistente con la frecuencia, cantidad y problemas asociados al consumo de cannabis, alcochol y tabaco. Este hecho sigue la línea de estudios previos que indican que los EVE generan mayor estrés y formas de coping menos adaptativas, aumentando así el riesgo de desarrollar consumo de drogas en adolescentes (Cooke y cols., 2015; Jessup y cols., 2014). Además, estos resultados permiten esclarecer en cierta medida qué tipo de EVE son los asociados con el consumo, ya que en estudios previos se utilizaba el constructo EVE como algo general sin diferenciar entre EVE dependientes e independientes. (McConnell, Memetovic, y Richardson, 2014; Veenstra y cols., 2006). Por otra parte, el efecto de EVE dependientes sobre el consumo y los problemas asociados al consumo se mantuvo significativo cuando se controló el efecto de la personali- 
dad; excepto en el caso de los problemas asociados al consumo de alcohol. Por tanto, en contra de nuestra hipótesis inicial, no encontramos efecto de mediación de los EVE dependientes entre la personalidad y el consumo (Heinrich y cols., 2016). En este caso, los EVE de tipo dependiente son predictores independientes del consumo de sustancias en adolescentes. Es decir, parece ser que existen un tipo de personalidad vulnerable al consumo, ya que disminuye la magnitud de la relación entre los EVE dependientes y el consumo cuando se controla el efecto de la personalidad. No obstante, también se mantienen las relaciones entre EVE y consumo, aún cuando se controla la personalidad, indicando la existencia de un impacto ambiental sobre el consumo.

Como conclusión, los resultados del estudio indican que el efecto de los EVE dependientes en el consumo y problemas asociados con el consumo de alcohol, tabaco y cannabis no se produce únicamente a través de la personalidad, sino que los EVE dependientes tendrían también un impacto directo en el desarrollo del consumo patológico.

\section{Referencias bibliográficas}

Andrews, G. (2009). A prospective study of life events and psychological symptoms. Psychological Medicine, 11, 795.

Babor, T., y Higgins-Biddle, J. (2001). AUDIT: the alcohol use disorders identification test: guidelines for use in primary health care.

Cohen, J. (1992). A power primer. Psychological Bulletin, 112, 155-159.

Cooke, E., Meyers, L., Latvala, A., Korhonen, T., Rose, J., Kaprio, J., y Dick, M. (2015). GeneEnvironment Interaction Effects of Peer Deviance, Parental Knowledge and Stressful Life Events on Adolescent Alcohol Use. Twin Research and Human Genetics : The Official Journal of the International Society for Twin Studies, 18, 507.

Copeland, J., Gilmour, S., Gates, P., y Swift, W. (2005). The Cannabis Problems Questionnaire: factor structure, reliability, and validity. Drug and Alcohol Dependence, 80, 313-9.

Headey, B., y Wearing, A. (1989). Personality, life events, and subjective well-being: Toward a dynamic equilibrium model. Journal of Personality and Social Psychology, 57, 731-739.

Heinrich, A., Schumann, G., Flor, H., y Nees, F. (2016). Identification of key items regarding personality, environment, and life events to assess risk and resilience factors for harmful alcohol drinking in adolescents. Alcohol and Alcoholism, 51, 710-715.

Jessup, M. A., Ross, T. B., Jones, A. L., Satre, D. D., Weisner, C., Chi, F., y Mertens, J. R. (2014). Significant Life Events and Their Impact on Alcohol and Drug Use: A Qualitative Study. J Psychoactive Drugs, 46, 450-459.

Kandler, C., Bleidorn, W., Riemann, R., Angleitner, A., y Spinath, F. M. (2012). Life events as environmental States and genetic traits and the role of personality: a longitudinal twin study. Behavior Genetics, 42, 57-72.

Kandler, C., Bleidorn, W., Riemann, R., Spinath, F. M., Thiel, W., y Angleitner, A. (2010). Sources of cumulative continuity in personality: A longitudinal multiple-rater twin study. Journal of Personality and Social Psychology, 98, 995-1008.

Kendler, K., y Greenspan, R. (2006). The nature of genetic influences on behavior: Lessons from «simpler» organisms. American Journal of Psychiatry, 163, 1683-1694.

Kendler, K., y Neale, M. (1993). A twin study of recent life events and difficulties. Archives of General Psychiatry, 50, 789-796.

Klimstra, T. A., Akse, J., Hale, W., Raaijmakers, W., y Meeus, J. (2010). Longitudinal associations between personality traits and problem behavior symptoms in adolescence. Journal of Research in Personality, 44, 273-284. 
Klimstra, T. A., Crocetti, E., Hale, W., Fermani, A., y Meeus, J. (2011). Big Five personality dimensions in Italian and Dutch adolescents: A cross-cultural comparison of mean-levels, sex differences, and associations with internalizing symptoms. Journal of Research in Personality, 45, 285-296.

Kotov, R., Gamez, W., Schmidt, F., y Watson, D. (2010). Linking «big» personality traits to anxiety, depressive, and substance use disorders: a meta-analysis. Psychological Bulletin, 136, 768-821.

Maclaren, V. V, Fugelsang, J. A., Harrigan, K. A., y Dixon, M. J. (2011). The personality of pathological gamblers: a meta-analysis. Clinical Psychology Review, 31, 1057-67.

Malouff, J., Thorsteinsson, E., Rooke, S., y Schutte, N. (2007). Alcohol Involvement and the Five-Factor Model of Personality: A Meta-Analysis. Journal of Drug Education, 37, $277-$ 294.

McConnell, M. M., Memetovic, J., Richardson, C. G. (2014). Coping style and substance use intention and behavior patterns in a cohort of BC adolescents. Addictive Behaviors, 39, 1394-1397.

Mezquita, L., Ibáñez, M. I., Villa, H., Fañanás, L., Moya-Higueras, J., y Ortet, G. (2015). Fivefactor model and internalizing and externalizing syndromes: A 5-year prospective study. Personality and Individual Differences, 79, 98-103.

Moya, J., Gallego, S., Viruela, A., Mezquita, L., Villa,H., Ibáñez, M. I. y Ortet, G. (2015). Predicción de la sintomatología internalizante y externalizante a través de la personalidad y los eventos vitales negativos en adolescentes. En Asociación Española de Psicología Conductual (Eds.), Avances en psicología clínica, 2014. En prensa.

Plomin, R., DeFries, J. C., y Loehlin, J. C. (1977). Genotype-environment interaction and correlation in the analysis of human behavior. Psychological Bulletin, 84,309-322.

Plomin, R., y Lichtenstein, P. (1990). Genetic influence on life events during the last half of the life span. Psychology and Aging, 5, 25-30.

Saudino, K. J., Pedersen, N. L., Lichtenstein, P., McClearn, G. E., y Plomin, R. (1997). Can personality explain genetic influences on life events? Journal of Personality and Social Psychology, 72, 196-206.

Veenstra, M. Y., Lemmens, P. H., Friesema, I. H., Garretsen, H. F., Knottnerus, J. A., y Zwietering, P. J. (2006). A literature overview of the relationship between life-events and alcohol use in the general population. Alcohol and Alcoholism, 41, 455-463. 



\title{
Práctica deportiva, condición física y salud en la adolescencia: Proyecto DADOS
}

\author{
Mireia Adelantado-Renau \\ adelantm@uji.es \\ María Reyes Beltran-Valls \\ vallsm@uji.es \\ SONIA BARREDA-SALES \\ soniabarreda@hotmail.com \\ Vicente JaVier Ayala-TAJUElo \\ vayala@uji.es \\ Diego MolineR-URDIALES \\ dmoliner@uji.es
}

\section{Resumen}

Introducción: La condición física (CF) es un potente marcador de salud durante la adolescencia. La participación en actividades deportivas organizadas es la forma más común de actividad física, reportando múltiples beneficios para la salud. La contribución de la práctica deportiva a la CF depende de las características de dicha práctica. El objetivo de nuestro estudio fue examinar la asociación entre las especialidades deportivas y la CF en atletas adolescentes. Métodos: 164 atletas (101 chicos) de $13.9 \pm 0.3$ años, participantes del Proyecto DADOS, fueron incluidos en el análisis. La fuerza muscular se evaluó con las pruebas de fuerza de prensión manual y salto horizontal. La velocidad-agilidad se evaluó mediante el test $4 \times 10 \mathrm{~m}$. La resistencia cardiorrespiratoria se evaluó con el test de ida y vuelta de $20 \mathrm{~m}$. Los participantes autoreportaron la especialidad deportiva practicada (deportes continuos vs. intermitentes) y el número de sesiones de entrenamiento semanal. Resultados: Los chicos presentaron mayores niveles de CF para todas las variables estudiadas $(P<0.05)$. Análisis adicionales según la especialidad deportiva mostraron que los deportes continuos requerían un mayor número de sesiones de entrenamiento. Los mayores niveles de fuerza muscular y resistencia cardiorrespiratoria fueron observados en los atletas practicantes de deportes continuos $(\mathrm{P}<0.05)$. Conclusiones: Los principales hallazgos de nuestro estudio indican que la práctica de deportes continuos conlleva una mayor dedicación y parece reportar mayores niveles de CF respecto a los deportes intermitentes. Futuras investigaciones que traten de explicar los motivos de las diferencias encontradas resultan necesarias para comprender el impacto de la práctica deportiva durante la adolescencia.

Palabras clave: deporte, actividad física, adolescencia, fuerza, resistencia cardiorrespiratoria 


\section{Abstract}

Introduction: Physical fitness (PF) is a powerful marker of physical and mental health in youth. Participation in organized-sports is the most common form of leisure time physical activity, reporting many health benefits. The contribution of sport practice to PF depends on the specific characteristics of the activity. The aim of our study was to examine the association of sport characteristics with PF in healthy adolescents. Methods: A sample of 164 athletes (101 males) aged 13.9 $\pm 0.3 y$ from DADOS Study was selected. Muscular strength was measured with the handgrip and the standing long jump tests. Speed-agility was measured with the $4 \times 10 \mathrm{~m}$ shuttle run test. Cardiorespiratory fitness was measured with the $20 \mathrm{~m}$ shuttle run test. Sport speciality and weekly sessions were self-reported by participants. Sport specialities were dichotomized as continuous and intermittent sports. Results: Boys showed higher levels of PF than girls for all studied variables, with no differences in the number of organized-sports weekly sessions (all $\mathrm{P}<0.05$ ). Additional analysis according to sport speciality showed that athletes from continuous sports completed more weekly sessions compared with intermittent sports. Comparisons of sport speciality by gender revealed higher levels of muscular and cardiorespiratory fitness for boys and girls practising continuous sports (e.g. swimming, cycling) compared with intermittent sports (e.g. basketball) (all $\mathrm{P}<0.05)$. Conclusions: The main findings of our study indicate that continuous sports are more time demanding than intermittent ones. Moreover, athletes from continuous sports seem to be fitter than adolescents from intermittent sports. Further research is needed to clarify the reason of our results.

Key Words: sport, physical activity, adolescence, strength, cardiorespiratory fitness

\section{Introducción}

La condición física (CF) se puede definir como una medida integral de casi todas las funciones corporales involucradas en la práctica diaria de actividad física y/o la realización de ejercicio físico (Ortega, Ruiz, Castillo y Sjöström, 2008). Una buena CF se asocia con un menor riesgo de enfermedades crónicas y muerte prematura. En la actualidad la CF es considerada ya en los primeros años de vida como un poderoso marcador de salud (Ortega y cols., 2008), siendo además un predictor de morbilidad y mortalidad en la etapa adulta (MartínezVizcaíno y Sánchez-López, 2008; Ortega y cols., 2005). Aunque parte de la variabilidad del nivel de CF de una persona viene determinada por aspectos genéticos, los factores ambientales y en especial la práctica de ejercicio físico tienen una influencia muy relevante desde la infancia (Martínez-Vizcaíno y Sánchez-López, 2008).

La adolescencia es un periodo crítico caracterizado por múltiples cambios psicológicos y fisiológicos, en el que se adquieren hábitos de vida con el consiguiente beneficio o riesgo para la salud (Ortega y cols., 2008). La participación en actividades deportivas organizadas es la forma más común de práctica de actividad física durante esta etapa (Eime, Harvey, Charity, Casey, Westerbeek y Payne, 2016), aportando numerosos beneficios para la salud que podrían estar en gran medida relacionados con las características específicas de dichas actividades (Esteban-Cornejo, Tejero-Gonzalez, Sallis y Veiga, 2015; Pedersen y Saltin, 2006; Vella, Swann, Allen, Schweickle y Magee, 2016). 
Numerosas investigaciones han analizado la relación entre la CF, la práctica de actividad física y la salud. Algunos estudios han examinado la influencia del tipo de deporte (individual o colectivo) sobre el bienestar psicológico y social (Eime, Young, Harvey, Charity y Payne, 2013). Sin embargo, hasta la fecha no hemos localizado ningún estudio que analice la influencia de la práctica de diferentes especialidades deportivas sobre la CF. En base a estos antecedentes, el objetivo de nuestro estudio fue analizar la relación de la CF con la especialidad deportiva (deportes continuos vs. intermitentes) en atletas adolescentes.

\section{Métodos}

\section{Diseño del estudio y participantes}

El proyecto de investigación DADOS (Deporte, ADOlescencia y Salud) es un estudio longitudinal de 3 años cuyo objetivo principal es analizar la influencia de la práctica de actividad física sobre la salud física, el nivel de bienestar psicológico y el rendimiento académico durante la etapa de Educación Secundaria Obligatoria (ESO). Los participantes fueron seleccionados a través de clubs deportivos y de centros educativos de la provincia de Castellón (España). Los criterios de inclusión en el estudio fueron los siguientes: haber nacido en 2001, estar matriculado en segundo de ESO durante el curso 2014/2015 y no padecer ninguna enfermedad crónica. De los 274 adolescentes participantes en el estudio DADOS, 164 adolescentes (101 chicos) clasificados como atletas y con valores válidos para CF y práctica deportiva fueron incluidos en los análisis.

El proyecto DADOS se ha desarrollado cumpliendo las recomendaciones éticas de la Declaración de Helsinki 1961 (última revisión de Fortaleza, Brasil, 2013), y su protocolo de investigación ha sido aprobado por la Comisión Deontológica de la Universidad Jaume I de Castellón. Todos los participantes y sus padres o tutores legales recibieron una explicación detalla del protocolo de investigación y firmaron un consentimiento informado.

\section{Desarrollo madurativo}

El desarrollo madurativo fue autoreportado por los adolescentes según los 5 estadíos definidos por Tanner y Whitehouse (1976).

\section{Condición física}

La condición física relacionada con la salud se evaluó mediante cuatro pruebas integradas dentro de la batería ALPHA-Fitness (Ruiz y cols., 2011).

La fuerza de prensión manual se evaluó mediante un dinamómetro con agarre ajustable (T.K.K. 5401 Grip-D; Japan). Cada participante presiona el dinamómetro de forma gradual y continua, utilizando su agarre óptimo. Esta prueba se realizó por duplicado con cada mano. Para el análisis se calculó la media de los valores máximos de cada una de las manos. La fuerza muscular del tren inferior se evaluó con la prueba de salto de longitud. El participante se coloca detrás de la línea de partida y salta tan lejos como le es posible. La prueba se realizó dos veces y para el análisis se utilizó la mayor distancia alcanzada registrada en centímetros. Mediante la suma de los valores estandarizados de fuerza de prensión manual y salto de longitud se calculó un índice general de fuerza muscular. 
La velocidad-agilidad se evaluó con la prueba de 4×10 m. El participante corre tan rápido como puede desde la línea de salida hasta otra línea situada a 10 metros de distancia, y vuelve hasta la línea de salida. Esto se realiza dos veces, cruzando siempre las líneas con los dos pies de modo que el adolescente recorre $40 \mathrm{~m}$. La prueba se realizó por duplicado y en el análisis se empleó el menor tiempo registrado en segundos.

La resistencia cardiorrespiratoria se evaluó mediante el test de $20 \mathrm{~m}$ de ida y vuelta (Course-Navette). Este test consiste en ir y volver corriendo una distancia de 20 metros. Se usan señales de audio para indicar el ritmo que se debe seguir. La velocidad inicial es de $8.5 \mathrm{~km} / \mathrm{h}$, con un incremento de $0.5 \mathrm{~km} / \mathrm{h} / \mathrm{min}$. Se registró el número de rectas completadas. El consumo máximo de oxígeno $\left(\mathrm{VO}_{2 \max }, \mathrm{mL} / \mathrm{kg} / \mathrm{min}\right)$ se calculó usando las ecuaciones descritas por Léger y Lambert (1982).

El índice general de CF se calculó a partir de la suma de los valores estandarizados de fuerza muscular y de $\mathrm{VO}_{2 \max }$.

\section{Especialidad deportiva y sesiones por semana}

La especialidad deportiva practicada y el número de sesiones de entrenamiento semanal fueron autoreportados por los participantes. Las diferentes especialidades deportivas fueron clasificadas como deportes intermitentes o deportes continuos. Los deportes intermitentes combinan fases de intensidad elevada y muy elevada de corta duración con pausas intercaladas (ej. básquet, fútbol o voleibol). Los deportes continuos implican el mantenimiento de un esfuerzo a intensidad constante durante un tiempo prolongado (ej. ciclismo, atletismo o natación).

\section{Análisis estadístico}

Los datos se presentan como medias \pm desviación estándar. Mediante análisis de covarianza (ANCOVA) controlando por desarrollo madurativo, se examinó si las variables de estudio (fuerza de prensión manual, capacidad de salto, velocidad-agilidad, resistencia cardiorrespiratoria, $\mathrm{VO}_{2 \max }$, índice general de fuerza muscular, índice general de $\mathrm{CF}$ y sesiones de entrenamiento semanal) presentaban diferencias significativas entre sexos y especialidades deportivas. Todos los análisis se realizaron utilizando el software IBM SPSS V. 22.0 (Armonk, NY: IBM Corp), y se estableció un nivel de significación de $\mathrm{P}<0.05$.

\section{Resultados}

Las características descriptivas de la CF por sexos se muestran en la Tabla 1. En general, los chicos muestran mayores niveles de CF que las chicas (todos los $P$ valores $<0.05$ ). No se encontraron diferencias significativas entre sexos respecto al número de sesiones de entrenamiento semanal $(3.9 \pm 0.8$ vs. $4.0 \pm 0.9)$. 
Tabla 1

Análisis de covarianza (ANCOVA) examinando diferencias de la CF entre sexos, ajustando por desarrollo madurativo

\begin{tabular}{lcccc}
\hline & $\begin{array}{c}\text { Chicas } \\
(\mathrm{n}=63)\end{array}$ & $\begin{array}{c}\text { Chicos } \\
(\mathrm{n}=101)\end{array}$ & $\begin{array}{c}\text { Todos } \\
(\mathrm{n}=164)\end{array}$ & P-valor \\
\hline Fuerza de prensión manual $(\mathrm{kg})$ & $27,5 \pm 4,5$ & $32,0 \pm 6,8$ & $30,3 \pm 6,4$ & 0,000 \\
Capacidad de salto $(\mathrm{cm})$ & $173,9 \pm 22,9$ & $183,4 \pm 22,4$ & $179,7 \pm 23,0$ & 0,027 \\
Velocidad-agilidad $(\mathrm{s})$ & $12,6 \pm 0,8$ & $11,9 \pm 0,6$ & $12,2 \pm 0,8$ & 0,000 \\
Resistencia cardiorrespiratoria (rectas) & $62,2 \pm 19,3$ & $84,2 \pm 17,3$ & $75,7 \pm 21,0$ & 0,000 \\
$\mathrm{VO}_{2 \max }(\mathrm{ml} / \mathrm{kg} / \mathrm{min})$ & $49,7 \pm 5,3$ & $55,6 \pm 4,3$ & $53,3 \pm 5,5$ & 0,000 \\
Índice general de Fuerza muscular & $-0,1 \pm 1,5$ & $1,0 \pm 1,6$ & $0,6 \pm 1,6$ & 0,000 \\
Índice general de CF & $-0,2 \pm 2,1$ & $1,7 \pm 2,0$ & $1,0 \pm 2,2$ & 0,000 \\
Sesiones de entrenamiento semanal & $4,0 \pm 0,9$ & $3,9 \pm 0,8$ & $3,9 \pm 0,9$ & 0,366 \\
\hline
\end{tabular}

Los datos se presentan como media $\pm \mathrm{DE} ; \mathrm{VO}_{2 \max }$ : Consumo máximo de oxígeno

Los adolescentes que practicaban deportes continuos presentaban mayores niveles de fuerza en el tren inferior y realizaban un mayor número de sesiones de entrenamiento semanal que aquellos que practicaban deportes intermitentes (todos los $\mathrm{P}$ valores $\leq 0.001$; ver Tabla 2 ).

Tabla 2

Análisis de covarianza (ANCOVA) examinando diferencias de la CF entre especialidades deportivas, ajustando por desarrollo madurativo.

\begin{tabular}{lrrrr}
\hline & $\begin{array}{c}\text { Deporte conti- } \\
\text { nuo }(\mathrm{n}=74)\end{array}$ & $\begin{array}{r}\text { Deporte inter- } \\
\text { mitente }(\mathrm{n}=90)\end{array}$ & Todos $(\mathrm{n}=164)$ & P-valor \\
\hline Fuerza de prensión manual $(\mathrm{kg})$ & $30,5 \pm 6,6$ & $30,1 \pm 6,2$ & $30,3 \pm 6,4$ & 0,000 \\
Capacidad de salto (cm) & $186,3 \pm 25,0$ & $174,4 \pm 19,9$ & $179,7 \pm 23,0$ & 0,027 \\
Velocidad-agilidad (s) & $12,2 \pm 0,8$ & $12,2 \pm 0,8$ & $12,2 \pm 0,8$ & 0,000 \\
$\begin{array}{l}\text { Resistencia cardiorrespiratoria } \\
\text { (rectas) }\end{array}$ & $77,6 \pm 22,6$ & $74,1 \pm 19,6$ & $75,7 \pm 21,0$ & 0,000 \\
VO $_{2 \text { max }}$ (ml/kg/min) & $53,7 \pm 6,0$ & $53,0 \pm 5,0$ & $53,3 \pm 5,5$ & 0,000 \\
Índice general de Fuerza muscular & $0,9 \pm 1,7$ & $0,3 \pm 1,5$ & $0,6 \pm 1,6$ & 0,000 \\
Índice general de CF & $1,4 \pm 2,3$ & $0,7 \pm 2,1$ & $1,0 \pm 2,2$ & 0,000 \\
Sesiones de entrenamiento semanal & $4,3 \pm 0,8$ & $3,5 \pm 0,7$ & $3,9 \pm 0,9$ & 0,366 \\
\hline
\end{tabular}

Los datos se presentan como media $\pm \mathrm{DE} ; \mathrm{VO}_{2 \max }$ : Consumo máximo de oxígeno 
Las diferencias entre sexos por especialidades deportivas indicaron que tanto los chicos que practicaban deportes continuos como los que practicaban deportes intermitentes presentaban mayores niveles de condición física que las chicas (todos los $\mathrm{P}$ valores <0.05; ver Tabla 3 ).

Tabla 3

Análisis de covarianza (ANCOVA) examinando diferencias de la CF entre sexos por especialidades deportivas, ajustando por desarrollo madurativo

\begin{tabular}{|c|c|c|c|c|c|c|}
\hline & \multicolumn{2}{|c|}{ Deporte continuo $(n=74)$} & \multicolumn{4}{|c|}{ Deporte intermitente $(n=90)$} \\
\hline & $\begin{array}{l}\text { Chicas } \\
(n=38)\end{array}$ & $\begin{array}{l}\text { Chicos } \\
(n=36)\end{array}$ & $\mathrm{P}$ & $\begin{array}{l}\text { Chicas } \\
(n=25)\end{array}$ & $\begin{array}{l}\text { Chicos } \\
(n=65)\end{array}$ & $P$ \\
\hline $\begin{array}{l}\text { Fuerza de prensión ma- } \\
\text { nual }(\mathrm{kg})\end{array}$ & $28,2 \pm 4,7$ & $33,0 \pm 7,5$ & 0,001 & $26,5 \pm 3,9$ & $31,5 \pm 6,4$ & 0,001 \\
\hline Capacidad de salto (cm) & $179,2 \pm 22,6$ & $194,1 \pm 25,4$ & 0,018 & $166,0 \pm 21,4$ & $177,6 \pm 18,4$ & 0,029 \\
\hline Velocidad-agilidad (s) & $12,5 \pm 0,7$ & $11,8 \pm 0,6$ & 0,000 & $12,7 \pm 0,9$ & $12,0 \pm 0,6$ & 0,000 \\
\hline $\begin{array}{l}\text { Resistencia cardiorrespira- } \\
\text { toria (rectas) }\end{array}$ & $65,8 \pm 20,1$ & $90,4 \pm 17,9$ & 0,000 & $56,8 \pm 17,0$ & $80,8 \pm 16,2$ & 0,000 \\
\hline $\mathrm{VO}_{2 \max }(\mathrm{ml} / \mathrm{kg} / \mathrm{min})$ & $50,6 \pm 5,4$ & $57,2 \pm 4,6$ & 0,000 & $48,5 \pm 4,8$ & $54,8 \pm 3,8$ & 0,000 \\
\hline $\begin{array}{l}\text { Índice general de Fuerza } \\
\text { muscular }\end{array}$ & $0,3 \pm 1,5$ & $1,6 \pm 1,6$ & 0,001 & $-0,6 \pm 1,5$ & $0,6 \pm 1,4$ & 0,001 \\
\hline Índice general de CF & $0,3 \pm 2,1$ & $2,6 \pm 2,0$ & 0,000 & $-0,9 \pm 2,0$ & $1,3 \pm 1,8$ & 0,000 \\
\hline $\begin{array}{l}\text { Sesiones de entrenamien- } \\
\text { to semanal }\end{array}$ & $4,2 \pm 0,8$ & $4,4 \pm 0,8$ & 0,164 & $3,6 \pm 0,8$ & $3,5 \pm 0,7$ & 0,598 \\
\hline
\end{tabular}

Los datos se presentan como media $\pm \mathrm{DE} ; \mathrm{VO}_{2 \max }$ : Consumo máximo de oxígeno

Las diferencias entre las especialidades deportivas por sexos indicaron que tanto los chicos como las chicas que practicaban deportes continuos presentaban mayores niveles de fuerza muscular del tren inferior y de resistencia cardiorrespiratoria que aquellos que practicaban un deporte intermitente (todos los $p$ valores $<0.05$ ). Para ambos sexos, aquellos adolescentes que practicaban deportes continuos presentaban un mayor número de sesiones de entrenamiento semanal que los que realizaban deportes intermitentes (todos los $p$ valores $<0.01$; ver tabla 4). 
Tabla 4

Análisis de covarianza (ANCOVA) examinando diferencias de la CF entre especialidades deportivas por sexos, ajustando por desarrollo madurativo

\begin{tabular}{lcccccc}
\hline & \multicolumn{2}{c}{ Chicas $(\mathrm{n}=63)$} & \multicolumn{3}{c}{ Chicos $(\mathrm{n}=101)$} \\
\hline & $\begin{array}{c}\text { Deportes } \\
\text { continuo } \\
(\mathrm{n}=38)\end{array}$ & $\begin{array}{c}\text { Deporte } \\
\text { intermitente } \\
(\mathrm{n}=25)\end{array}$ & $P$ & $\begin{array}{c}\text { Deporte } \\
\text { continuo } \\
(\mathrm{n}=36)\end{array}$ & $\begin{array}{c}\text { Deporte } \\
\text { intermitente } \\
(\mathrm{n}=65)\end{array}$ & $\mathrm{P}$ \\
\hline $\begin{array}{l}\text { Fuerza de prensión ma- } \\
\text { nual (kg) }\end{array}$ & $28,2 \pm 4,7$ & $26,5 \pm 3,9$ & 0,179 & $33,0 \pm 7,5$ & $31,5 \pm 6,4$ & 0,168 \\
Capacidad de salto (cm) & $179,2 \pm 22,6$ & $166,0 \pm 21,4$ & 0,029 & $194,1 \pm 25,4$ & $177,6 \pm 18,4$ & 0,000 \\
Velocidad-agilidad (s) & $12,5 \pm 0,7$ & $12,7 \pm 0,9$ & 0,370 & $11,8 \pm 0,6$ & $12,0 \pm 0,6$ & 0,186 \\
$\begin{array}{l}\text { Resistencia cardiorrespi- } \\
\text { ratoria (rectas) }\end{array}$ & $65,8 \pm 20,1$ & $56,8 \pm 17,0$ & 0,029 & $90,4 \pm 17,9$ & $80,8 \pm 16,2$ & 0,012 \\
VO ${ }_{2 \text { max }}$ (ml/kg/min) & $50,6 \pm 5,4$ & $48,5 \pm 4,8$ & 0,056 & $57,2 \pm 4,6$ & $54,8 \pm 3,8$ & 0,012 \\
$\begin{array}{l}\text { Índice general de Fuerza } \\
\text { muscular }\end{array}$ & $0,3 \pm 1,5$ & $-0,6 \pm 1,5$ & 0,021 & $1,6 \pm 1,6$ & $0,6 \pm 1,4$ & 0,002 \\
Índice general de CF & $0,3 \pm 2,1$ & $-0,9 \pm 2,0$ & 0,017 & $2,6 \pm 2,0$ & $1,3 \pm 1,8$ & 0,001 \\
$\begin{array}{l}\text { Sesiones de entrenamien- } \\
\text { to semanal }\end{array}$ & $4,2 \pm 0,8$ & $3,6 \pm 0,8$ & 0,005 & $4,4 \pm 0,8$ & $3,5 \pm 0,7$ & 0,000 \\
\hline
\end{tabular}

Los datos se presentan como media $\pm \mathrm{DE} ; \mathrm{VO}_{2 \max }:$ Consumo máximo de oxígeno

\section{Discusión y conclusiones}

La contribución principal de este trabajo ha sido analizar la asociación de la CF y sus componentes de forma individual con la especialidad deportiva practicada en atletas adolescentes. Los principals hallazgos de nuestro estudio sugieren que aquellos adoelscentes que practican deportes continuos presentan mayores niveles de CF que aquellos que practican deportes intermitentes. Nuestros resultados ponen de maniefisesto que los deportes continuos conllevan mayor dedicación, y que los chicos presentan de forma sistemática mayores niveles de CF que las chicas.

Nuestros resultados coinciden con la literatura científica establecida poniendo de manifiesto mayores niveles de CF en los chicos respecto a las chicas independientemente de la especialidad deportiva practicada. Sin embargo, no se encontraron diferencias en el número de sesiones de entrenamiento semanal tanto al analizar a todos los atletas conjuntamente (tabla 1) como al realizar el análisis segmetado por especialidad deportiva (tabla 3). Estas diferencias pueden ser explicadas por los cambios propios de la etapa de la adolescencia, en la que los cambios hormonales provocan incrementos significativos de la masa muscular entre los chicos e incrementos significativos del tejido adiposo entre las chicas (Weiss, 2004).

Los deportes continuos pueden definirse como la realización de ejercicio físico manteniendo un esfuerzo a intensidad constante durante un tiempo prolongado. Por otro lado, los deportes intermitentes se definen como el ejercicio físico que combina fases de intensidad elevada o muy elevada y de corta duración con pausas intercaladas. Entre nuestros adoles- 
centes, aquellos que practicaban deportes continuos presentaron mayores niveles de CF general, tanto al analizar a todos los atletas conjuntamente (tabla 2) como al realizar el análisis segmentado por sexos (tabla 4). Las adaptaciones derivadas del entrenamiento están en gran medida condicionadas por el volumen y la intensidad del mismo. Los adolescentes de deportes continuos presentaron mayores volúmenes de entrenamiento (sesiones semanales) independientemente de su sexo. Por tanto, resulta lógico pensar que las mayores adaptaciones de la CF encontradas entre los adolescentes de deportes continuos vienen explicadas en gran medida por su mayor dedicación deportiva (Wilmore y Costill, 2004).

Nuestros resultados han de ser interpretados con cautela debido a que se trata de un estudio de diseño transversal en el que no es posible establecer relaciones causa-efecto. Además, al tratarse de una muestra homogénea formada por atletas adolescentes, las conclusiones no pueden extrapolarse directamente a la población adolescente en general con menor dedicación deportiva. Sin embargo, nuestro estudio presenta diversas fortalezas entre las que cabe destacar la homogenidad de los participantes en relación a su edad y nivel de entrenamiento, el uso de una batería de condición física científicamente validadada (ALPHA-Fitness tests), y el control de la influencia del nivel de desarrollo madurativo en los análisis estadísticos realizados.

Dado el gran número de beneficios que la práctica deportiva reporta sobre la CF relacionada con la salud y el bienestar de los adolescentes, especialmente la práctica de deportes continuos, las familias y las instituciones educativas deberían tener en cuenta estas evidencias a la hora de tomar decisiones orientadas a la promoción de la salud durante la infancia y la adolescencia. La creación de nuevas estrategias de promoción de la salud en la infancia y la adolescencia, deberían contemplar la práctica de deportes continuos de forma regular. Futuros estudios que analicen los efectos de las diferentes prácticas deportivas tanto sobre la salud física como la salud psicológica son necesarios para implementar programas de promoción de la salud más eficaces.

\section{Agradecimientos}

El proyecto DADOS está financiado por el Ministerio de Economía y Competitividad (DEP2013-45515-R) y por la Universitat Jaume I de Castellón (P1-1A2015-05). Este trabajo ha sido parcialmente financiado por una beca de investigación Sunny Sport de la compañía Schweppes Suntory Spain. M.A.R cuenta con una ayuda predoctoral para la formación de personal investigacor de la Universitat Jaume I (PREDOC/2015/13).

\section{Referencias bibliográficas}

Eime, R. M., Harvey, J. T., Charity, M. J., Casey, M. M., Westerbeek, H. y Payne, W. R. (2016). Age profiles of sport participants. BMC Sports Science, Medicine and Rehabilitation, 8(6), 1-10.

Eime, R. M., Young, J. A., Harvey, J. T., Charity, M. J. y Payne, W. R. (2013). A systematic review of the psychological and social benefits of participation in sport for children and adolescents: informing development of a conceptual model of health through sport. The International Journal of Behavioral Nutrition and Physical Activity, 10, 98.

Esteban-Cornejo, I., Tejero-Gonzalez, C. M., Sallis, J. F. y Veiga, O. L. (2015). Physical activity and cognition in adolescents: A systematic review. Journal of Science and Medicine in Sport, 18(5), 534-539. 
Léger, L. A. y Lambert, J. (1982). A Maximal Multistage 20-m Shuttle Run Test to Predict VO2 max. Eur J Appl Physiol, 49, 1-12.

Martínez-Vizcaíno, V. y Sánchez-López, M. (2008). Relación entre actividad física y condición física en niños y adolescentes. Revista Española de Cardiología, 61(2), 108-111.

Ortega, F. B. y cols. (2005). Bajo nivel de forma física en los adolescentes españoles . Importancia para la salud cardiovascular futura ( Estudio AVENA ). Rev Esp Cardiol, 58(8), 898-909.

Ortega, F. B., Ruiz, J. R., Castillo, M. J. y Sjöström, M. (2008). Physical fitness in childhood and adolescence: a powerful marker of health. International Journal of Obesity, 32(1), $1-11$.

Pedersen, B. K. y Saltin, B. (2006). Evidence for prescribing exercise as therapy in chronic disease. Scandinavian Journal of Medicine \& Science in Sports, 16 Suppl 1, 3-63.

Ruiz, J. y cols. (2011). Batería ALPHA-Fitness : test de campo para la evaluación de la condición física relacionada con la salud en niños y adolescentes. Nutrición Hospitalaria, 26(6), 1210-1215.

Tanner, J. M. y Whitehouse, R. H. (1976). Clinical longitudinal standards for height, weight, height velocity, weight velocity, and stages of puberty. Archives of Disease in Childhood, 51(3), 170-179.

Vella, S. A., Swann, C., Allen, M. S., Schweickle, M. y Magee, C. A. (2016). Bidirectional Associations between Sport Involvement and Mental Health in Adolescence. Medicine and Science in Sports and Exercise, (19), 687-694.

Weiss, M. R. (2004). Developmental Sport and Exercise Psychology: A Lifespan Perspective. Morgantown: Fitness Information Technology.

Wilmore, J. H. y Costill, D. L. (2004). Physiology of sport and exercise. Barcelona: Human Kinetics. 



\title{
Calidad de vida en pacientes con ERCA en tratamiento con hemodiálisis vs diálisis peritoneal
}

\author{
Revisión integradora
}

\author{
MARÍA ORIOLA ALBA \\ al205257@uji.es \\ Sergio Pascual Romero Lecha \\ al286989@uji.es \\ ELADIO JOAQUÍN COLLADO BOIRA \\ colladoe@uji.es
}

\section{Resumen}

Introducción: La enfermedad renal crónica avanzada (ERCA) es una patología con elevada prevalencia e incidencia a nivel mundial, suponiendo un grave problema de salud pública que va en aumento. En la última etapa de la ERCA, las funciones del riñón deben ser reemplazadas. Las técnicas de sustitución renal tienen un fuerte impacto sobre el estilo de vida de los pacientes, y por tanto un cambio en su calidad de vida (QOL). Objetivos: Objetivo general: comparar la calidad de vida de los pacientes con ERCA tratados con hemodiálisis Vs los tratados con diálisis peritoneal. Objetivos específicos: Ayudar a los profesionales sanitarios a conocer las últimas evidencias científicas en relación a la calidad de vida que proporcionan los distintos métodos de diálisis, para compartir la información y poder realizar recomendaciones a los pacientes de ERCA y seleccionar el método de diálisis más adecuado; y determinar las principales variables clínicas y sociodemográficas relacionadas con la calidad de vida en los pacientes sometidos a HD y DP. Metodología: Revisión integradora de la bibliografía. Bases de datos: CINAHL, PubMed, Scopus y ProQuest. Criterios de inclusión: revisiones, estudios cuantitativos, descriptivos observacionales y ensayos clínicos. Últimos 5 años. Herramienta de calidad metodológica CASPe y Strobe. Resultados: Se obtuvieron 14 estudios con los que realizar la revisión integradora. De los cuales hay 2 revisiones sistemática y 12 estudios observacionales. Conclusiones: No se encuentran diferencias estadísticamente significativas en la QOL en términos de salud en cuanto a un tipo de tratamiento $u$ otro.

Palabras clave: hemodiálisis, diálisis, diálisis peritoneal, calidad de vida. 


\section{Abstract}

Introduction: Advanced chronic kidney disease (ACKD) is a pathology with high prevalence and presence worldwide, posing an increasing serious public health issue. In the last stage of the ACKD kidney functions should be replaced. Renal replacement techniques have a strong impact on the patients' lifestyle and thus imply a change in their quality of life (QOL). Objectives: Overall objective: Comparing the patients' quality of life with ACKD treated with hemodialysis vs. those treated with peritoneal dialysis. Specific objectives: Helping health professionals to know the latest scientific evidence regarding the quality of life offered by different diagnostic methods in order to share information and make recommendations to ACKD patients while choosing the best dialysis method for them; and conclude the main clinical and socio-demographical variables associated to the quality of life in patients treated to HD and PD. Methodology: Unifying review of the bibliography. Databases: CINAHL, PubMed, Scopus and ProQuest. Inclusion criteria: reviews, quantitative studies, observational descriptions and clinical trials. Last 5 years. Tool of methodological quality CASPe and Strobe. Results: 14 studies were obtained to perform the unifying review. From them, 2 systematic reviews and 12 observational studies were made. Conclusions: There are no significant differences in QOL in terms of health while talking about one type of treatment or another.

Keywords: hemodialysis, haemodialysis, dialysis, peritoneal dialysis, quality of life.

\section{Introducción}

La función que desarrolla el riñón en el organismo, consiste en filtrar los desechos del metabolismo celular y el exceso de líquidos que transporta la sangre, los cuales posteriormente son excretados en la orina. La pérdida gradual de la función renal es lo que se denomina enfermedad renal crónica o insuficiencia renal crónica. («OPS OMS | Enfermedad crónica del riñón,» n.d.)

La enfermedad renal crónica (ERC) se define como la alteración de la estructura renal o de su función, evidenciado por indicadores biológicos de daño renal en orina y sangre o a través de pruebas de imagen, durante un periodo igual o mayor a 3 meses, o por un filtrado glomerular teórico (FGt) menor a $60 \mathrm{ml} / \mathrm{min} / 1,73 \mathrm{~m}^{2}$, independientemente de la etiología del proceso (Lorenzo-Sellarés, n.d.; Martínez-Castelao, Górriz, \& Bover, 2014; Urrutia \& Mella, 2014) y se ha convertido en un importante problema de salud pública, que ha adquirido proporciones epidémicas. (Flores, Alvo, Borja, Morales, \& Vega, 2009; Martínez-Castelao et al., 2014; Urrutia \& Mella, 2014) afecta a un porcentaje significativo de la población, hecho justificable debido a que los principales factores etiológicos suponen trastornos de alta prevalencia como el envejecimiento, la hipertensión arterial (HTA), la diabetes Mellitus (DM) y la enfermedad vascular (Urrutia \& Mella, 2014).

Según los resultados del estudio epidemiológico sobre la insuficiencia renal crónica en España (EPIRCE), el 9,24 \% de la población adulta sufre algún grado de ERC1. El 6,83\% de la población presenta una disminución del filtrado glomerular (FG) por debajo de60 ml/min/1,73 m², siendo este porcentaje del 20,6 \% en mayores de 64 años (Martínez-Castelao et al., 2014).

Las técnicas de terapia renal sustitutiva son aquellas cuya finalidad es suplir la función del riñón, cuando este presenta un deterioro grande de sus funciones. Existe dos tipos princi- 
pales de terapia renal sustitutiva, la terapia con hemodiálisis extracorpórea convencional (HD), y la terapia con diálisis peritoneal (PD). El uso de estas técnicas, imprescindibles para la supervivencia de estos enfermos, mejora la fisiología general del organismo, y la sensación de bienestar. La selección de la técnica de depuración renal a utilizar se realizará en función de las características del paciente y de las recomendaciones del nefrólogo. Los tratamientos de sustitución de la función renal, generan un cambio en el estilo de vida de los pacientes, y por lo tanto una modificación de la calidad de vida (QOL). La Organización Mundial de la Salud (OMS) en 1994 definió la calidad de vida como: «la percepción del individuo de su posición en la vida en el contexto de la cultura y el sistema de valores en los que vive y en relación con sus objetivos, expectativas, valores y preocupaciones» (Ho \& Li, 2016; Rebollo-Rubio, Morales-Asencio, Pons-Raventos \& Mansilla-Francisco, 2015).

La valoración de la QOL se suele utilizar para obtener información sobre el bienestar del paciente, y es utilizada para el control de la calidad de los cuidados y la atención prestada a los pacientes en tratamiento de diálisis (Ho \& Li, 2016). La QOL es un factor importante a tener en cuenta a la hora de aplicar un tratamiento u otro de sustitución renal.

Por ello el objetivo general de este estudio era realizar una revisión de la literatura para informar sobre el estado actual de la calidad de vida de los pacientes con ERCA tratados con hemodiálisis Vs los tratados con diálisis peritoneal. Además de dos objetivos específicos que eran ayudar a los profesionales médicos a conocer las discrepancias en cuanto a la calidad de vida que proporcionan los distintos métodos de diálisis, para compartir la información y poder realizar recomendaciones a los pacientes de ERCA y seleccionar el método de diálisis adecuado; y determinar las principales variables clínicas y sociodemográficas relacionadas con la calidad de vida en los pacientes sometidos a hemodiálisis y diálisis peritoneal.

\section{Metodología}

La metodología empleada para la realización de este estudio se ha basado en una revisión integradora de la literatura con el fin de elaborar un análisis sobre las evidencias científicas acerca de la calidad de vida de pacientes con ERCA sometidos a tratamientos de depuración renal.

Para ello, en primer lugar, se realizó la siguiente pregunta de investigación en estilo PICO: ¿Las personas con ERCA tratadas con hemodiálisis tienen la misma calidad de vida que las tratadas con diálisis peritoneal? En la Tabla 1 se puede ver el desglose de la pregunta. Posteriormente se realizó la búsqueda de la literatura científica con los descriptores MeSH "QoL», «Quality of Life», «Peritoneal dialysis», «Haemodilysis» y «Dialysis» en las bases de datos CINAHL, PubMed, Scopus y ProQuest. El rango de fecha de publicación de los artículos se delimitó entre el 2012-2017. En todas las bases de datos consultadas se utilizó el operador booleano OR para buscar un mismo descriptor, y el operador booleano AND para combinar los tres descriptores.

Para admitir los estudios encontrados se establecieron como criterios de inclusión aquellos artículos cuya publicación se encuentre dentro de los últimos cinco años, se encuentren publicados en castellano o inglés, estén disponible en texto completo, traten la calidad de vida de los pacientes tratados en hemodiálisis y diálisis peritoneal, las personas a estudio tengan la mayoría de edad y los tipos de estudio sean revisiones de la literatura, estudios cuantitativos, ensayos clínicos o estudios descriptivos observacionales. 
Tabla 1

Desglose de la pregunta PICO

\begin{tabular}{ll}
\hline P (patient) & Personas con ERCA \\
I (intervention) & Tratadas con hemodiálisis \\
C (comparation) & Tratadas con diálisis peritoneal \\
O (outcoms) & Calidad de Vida \\
\hline
\end{tabular}

\section{Resultados}

Al realizar la búsqueda bibliográfica en las cuatro bases de datos seleccionadas, como se puede ver en la Tabla 2, sin aplicar ningún tipo de limitador, se obtuvieron 1,304 documentos, y aplicando los limitadores correspondientes en cada una de las bases de datos, el número total de artículos recuperados fueron 70 .

Tabla 2

Número de artículos encontrados en la búsqueda

\begin{tabular}{|c|c|c|}
\hline $\begin{array}{l}\text { Bases de } \\
\text { datos }\end{array}$ & Artículos encontrados sin limitadores & $\begin{array}{l}\text { Artículos recuperados con la aplicación } \\
\text { de limitadores }\end{array}$ \\
\hline \multirow[t]{2}{*}{ CINAHL } & $\begin{array}{l}\text { (haemodialysis or hemodialysis or } \\
\text { dialysis) AND peritoneal dialysis AND } \\
\text { (qol or quiality of life) }\end{array}$ & $\begin{array}{l}\text { Limitadores: TI; Texto completo; Fecha } \\
\text { de publicación 2012-2017 }\end{array}$ \\
\hline & $N=201$ & $N=6$ \\
\hline \multirow[t]{2}{*}{ PubMed } & $\begin{array}{l}\text { (haemodialysis OR dialysis) AND } \\
\text { (peritoneal dialysis AND qol) }\end{array}$ & $\begin{array}{l}\text { Limitadores: Free full text; published in the } \\
\text { lasst } 5 \text { years. }\end{array}$ \\
\hline & $N=113$ & $N=11$ \\
\hline \multirow[t]{2}{*}{ ProQuest } & $\begin{array}{c}\text { (hemodialysis OR dialysis) AND peri- } \\
\text { toneal dialysis AND qol }\end{array}$ & $\begin{array}{l}\text { Limitadores: Ab; Fecha de publicación } \\
\text { 2012-2017; Texto completo incluido. }\end{array}$ \\
\hline & $N=847$ & $N=15$ \\
\hline \multirow[t]{3}{*}{ Scopus } & $\begin{array}{l}\text { Title-abs-key (haemodialysis OR } \\
\text { dialysis) AND Title-abs-key (peritoneal } \\
\text { dialysis) AND Title-abs-key (qol) }\end{array}$ & $\begin{array}{l}\text { Limitadores: Fecha de publicación } \\
\text { 2012-2017; Review, Article. }\end{array}$ \\
\hline & $N=143$ & $N=38$ \\
\hline & Total 1.304 & Total 70 \\
\hline
\end{tabular}


De los 70 estudios obtenidos en las bases de datos, no todos fueron seleccionados. Por no encontrarse disponible el texto completo de forma abierta $(n=24)$, por encontrarse repetidos $(n=12)$, y por no adecuarse al tema en título y resumen $(n=20)$ se excluyeron un total de 56 estudios, dejando un número final de 14 estudios con los que continuar la revisión y a los que realizar la lectura reflexiva.

Los estudios incluidos fueron evaluados a través de dos herramientas metodológicas. Las revisiones incluidas en los estudios escogidos, se evaluaron a través de la herramienta de lectura crítica CASPe («Instrumentos para la lectura crítica | CASPe,» n.d.), mientras que los estudios observacionales se evaluaron a través de STROBE(«STROBE Statement: Home,» n.d.), que consta de una lista de verificación de 22 puntos.

\section{Discusión y conclusiones}

La calidad de vida es un factor transcendental para los pacientes con ERCA. Para medirla existe una serie de cuestionarios validados internacionalmente y de amplio uso que han sido aplicados en los estudios recopilados en esta revisión. Los cuestionarios más ampliamente utilizados son el Cuestionario de calidad de vida específico para la enfermedad renal: KDQOL -SF (Tannor, Archer, Kapembwa, van Schalkwyk \& Davids, 2017; Wakeel, Harbi, Bayoumi, Al-Suwaida \& Ghonaim, 2012; Wright \& Wilson, 2015) y sus versiones cortas: SF-36 y SF-12 (Griva et al., 2014; Ikonomou et al., 2015; Iyasere et al., 2016; Oren \& Enç, 2013; Ramos, Santos, Zanini, \& Ramos, 2015; Wu et al., 2013); y el Cuestionario de calidad de vida de la OMS: WHOQOLBREF (Barata, 2015; Griva et al., 2014; Theofilou, n.d.).

La calidad de vida es una media multidimensional y a la hora de valorarla, se tiene en cuenta tanto el componente físico como el mental. Las principales variables sociodemográficas y clínicas que muestran una relación estadística significativa para la población de estudio con la QOL según los estudios recopilados son, la edad (Makkar, Kumar, Mahaja, \& Khaira, 2015; Oren \& Enç, 2013; Wakeel et al., 2012); el sexo (Oren \& Enç, 2013; Wakeel et al., 2012); la educación (Oren \& Enç, 2013); factores sociales y económicos (Ikonomou et al., 2015; Tannor et al., 2017); los niveles séricos de prealbúmina (Ramos et al., 2015; Wright \& Wilson, 2015); la presencia de comorbilidades (Makkar et al., 201; Oren \& Enç, 2013); la capacidad de llevar a cabo el tratamiento (Makkar et al., 2015) y; el tiempo de duración de la diálisis (Joshi, 2014; Wakeel et al., 2012). Algunos de estos autores, referencian la gran importancia del apoyo social tanto de familiares, compañeros y amigos, como del personal sanitario (Makkar et al., 2015; Tannor et al., 2017). Según Makkar et al. (2015) los pacientes con mayor apoyo social serían candidatos para optar por el tratamiento con PD, y aquellos pacientes con menor independencia sería más recomendable el tratamiento con HD.

En relación a la percepción de la vida sexual, en ambos tipos de tratamiento, los pacientes manifestaron una disminución del deseo sexual (Tannor et al., 2017), además de una disfunción eréctil en los pacientes masculinos tratados con HD (Tannor et al., 2017). Los pacientes en PD afirman que éste se ve afectado por la imagen corporal, debido al catéter peritoneal, aunque según los resultados obtenidos por Wright los pacientes en PD manifestaron mayor disfunción eréctil (Wright \& Wilson, 2015).

Según los resultados obtenidos por Griva \& Theofilou existen tasas de depresión sustancialmente mayores en los pacientes de PD (Griva et al., 2014; Theofilou, n.d.). Sin embargo, en cuanto a los síntomas de ansiedad o tasas de posibles casos de ansiedad, no hay diferencias entre modalidades de diálisis (Griva et al., 2014). Estos hallazgos, entran en controversia con los obtenidos por Makkar et al. (2015) que afirman que los pacientes en HD tienen mayores tasas de depresión y suicidio. En las tasas de suicidio se incluyen las violaciones de la 
dieta, puesto que un incumplimiento excesivo de la dieta produce perjuicios para la salud de estos pacientes agravando en gran medida su estado.

La tasa de reingreso hospitalario es otra variable que se muestra decisiva en la percepción de la calidad de vida por parte de los pacientes. En el tratamiento con PD la tasa de hospitalización es mayor que en HD, debido a los casos reincidentes de peritonitis que se producen en este grupo (Makkar et al., 2015; Oren \& Enç, 2013; Ramos et al., 2015) y relacionada con una falta de asepsia en la manipulación del catéter peritoneal en el proceso de los recambios.

En cuanto a la capacidad de trabajar, los pacientes en PD tienen más posibilidad de continuar con su trabajo, y hay una mayor tasa de desempleo en los pacientes tratados con HD (Oren \& Enç, 2013; Tannor et al., 2017). Aunque Tannor et al. (2017) puntualizan que a pesar de que es cierto que los paciente en PD tienen mejor puntuaciones en la continuidad de trabajo también reportaron dificultades para encontrar trabajo y poder realizar intercambios de bolsa en el puesto de trabajo.

En la calidad del sueño medida a través del sub-apartado específico del cuestionario KDQOL-SF, los pacientes en PD suelen tener menor puntuación que los pacientes de HD (Tannor et al., 2017; Wright \& Wilson, 2015), esto es razonables debido a que el tratamiento de PD suele ser nocturno, y los intercambios se realizan mientras el paciente duerme.

Un gran número de estudios (Ho \& Li, 2016; lyasere et al., 2016; Ramos et al., 2015; Tannor et al., 2017; Wright \& Wilson, 2015; Wu et al., 2013), presentan entre sus conclusiones que los pacientes tratados con PD obtuvieron mayor puntuación en gran parte de las escalas de los cuestionarios, pero estos resultados no mostraron una significación estadística concluyente. Hay que tener en cuenta, que los pacientes en PD suelen ser más jóvenes y presentar menos comorbilidades que los pacientes en $\mathrm{HD}$, donde suelen encontrarse pacientes más longevos con una autonomía limitada para llevar el tratamiento domiciliario, además de la mayor independencia y el poder autogestionar el tratamiento (Ho \& Li, 2016).

Según lyasere et al. (2016) quienes comparan la QOL de los pacientes de edad avanzada en ambos tipos de diálisis estudiados (HD y PD), en el único apartado en el que hay una diferencia significativa es con la satisfacción del tratamiento, siendo mayor en la PD asistida. Como se menciona en el párrafo anterior, los pacientes de mayor edad suelen ser tratados en $\mathrm{HD}$, pero se debería plantear como alternativa para estas personas, el tratamiento con PD asistida desde el punto de vista de la QOL.

A la hora de aconsejar un tratamiento u otro, es de gran importancia que los profesionales de la salud tengan en cuenta además los síntomas de la enfermedad que presentan los pacientes, la anemia y los niveles bajos de albúmina. En pacientes con anemia grave sería más adecuado recibir PD y la HD sería más adecuada en los pacientes con bajos niveles de albúmina (Ho \& Li, 2016).

Por último, Joshi (2014) concluye su revisión cuestionando que igual habría que tener en cuenta si lo que realmente afecta a la percepción de la calidad de vida es el tipo de tratamiento, o la duración de este, puesto que una gran parte de los pacientes que en un principio inician el tratamiento de sustitución renal en PD, acaban siendo tratados con HD.

\section{Conclusiones}

No encontramos evidencias científicas en la literatura actual que nos permita afirmar categóricamente que un tipo de tratamiento de sustitución renal resulte mejor que otro, en relación al impacto que produce el mismo sobre la calidad de vida. 
Los profesionales sanitarios deben analizar cada paciente individualmente y las variables que pueden influir a la hora de prescribir un tipo de tratamiento $u$ otro. Es necesario que realicen periódicamente una evaluación del paciente para controlar si se han modificado sus variables y necesidades, y adaptar el tratamiento a estas. Los pacientes que padezcan anemia grave sería más recomendable un tratamiento con PD, y aquellos pacientes que presenten bajos niveles de albúmina deberían ser tratados con HD.

Las principales variables sociodemográficas y clínicas que muestran una relación estadística significativa para la población de estudio con la QOL según los estudios recopilados son, la edad, el sexo, la educación, factores sociales y económicos, los niveles séricos de prealbúmina, la presencia de comorbilidades, la capacidad de llevar a cabo el tratamiento y el tiempo de duración de la diálisis.

Para concluir, considero que es necesario continuar con más estudios de investigación en este campo de actuación y así poder observar si hay una variación de la percepción de la calidad de vida de los pacientes con el paso de los años en tratamiento de sustitución de la función renal, por lo que sería conveniente el diseño de estudios de cohortes de tipo longitudinal.

\section{Referencias bibliográficas}

Barata, N. E. (2015). Dyadic Relationship and Quality of Life Patients with Chronic Kidney Disease. Jornal Brasileiro de Nefrologia, 37(3), 315-22, doi: https://doi.org/10.5935/01012800.20150051

CASPe. (n.d.). Instrumentos para la lectura crítica. Recuperado el 14 de mayo, 2017, de: http:// www.redcaspe.org/herramientas/instrumentos

Flores, J., Alvo, M., Borja, H., Morales, J. \& Vega, J. (2009). Enfermedad renal crónica: Clasificación, identificación, manejo y complicaciones. Médica de Chile. Recuperado de: http://www.scielo.cl/scielo.php?pid=S0034-98872009000100026\&script=sci_arttext

Fundación Renal. (n.d.). Tratamientos: hemodiálisis y diálisis peritoneal. Recuperado el 1 de marzo, 2017, de: https://www.friat.es/la-enfermedad-renal/insuficiencia-renal-cronica/ tratamientos-hemodialisis-y-dialisis-peritoneal/

Griva, K., Yu, Z., Chan, S., Krisnasamy, T., Yamin, R. B., Zakaria, F. B., ... Foo, M. (2014). Age is not a contraindication to home-based dialysis - Quality-of-Life outcomes favour older patients on peritoneal dialysis regimes relative to younger patients. Journal of Advanced Nursing, 70(8), 1902-14, doi: https://doi.org/10.1111/jan.12355

Ho, Y. F. \& Li, I. C. (2016). The influence of different dialysis modalities on the quality of life of patients with end-stage renal disease: A systematic literature review. Psychology \& Health, 31(12), 1435-1465, doi: https://doi.org/10.1080/08870446.2016.1226307

Ikonomou, M., Skapinakis, P., Balafa, O., Eleftheroudi, M., Damigos, D., \& Siamopoulos, K. C. (2015). The impact of socioeconomic factors on quality of life of patients with chronic kidney disease in Greece. Journal of Renal Care, 41(4), 239-246, doi: https://doi. org/10.1111/jorc.12132

lyasere, O. U., Brown, E. A., Johansson, L., Huson, L., Smee, J., Maxwell, A. P., ... Davenport, A. (2016). Quality of Life and Physical Function in Older Patients on Dialysis: A Comparison of Assisted Peritoneal Dialysis with Hemodialysis. Clinical Journal of the American Society of Nephrology, 11(3), 423-30, doi: https://doi.org/10.2215/CJN.01050115

Joshi, V. D. (2014). Quality of life in end stage renal disease patients. World Journal of Nephrology, 3(4), 308-16, doi: https://doi.org/10.5527/wjn.v3.i4.308 
Lorenzo-Sellarés, V. (n.d.). Enfermedad renal crónica. Recuperado el 1 de marzo, 2017, de: http://www.revistanefrologia.com/es-publicacion-nefrologia-articulo-enfermedad-renalcronica-XX342164212000426

Makkar, V., Kumar, M., Mahajan, R. \& Khaira, N. S. (2015). Comparison of Outcomes and Quality of Life between Hemodialysis and Peritoneal Dialysis Patients in Indian ESRD Population. Journal of Clinical and Diagnostic Research, 9(3), OC28-31, doi: https://doi. org/10.7860/JCDR/2015/11472.5709

Martínez-Castelao, A., Górriz, J. \& Bover, J. (2014). Documento de consenso para la detección y manejo de la enfermedad renal crónica. Atención Primaria. Recuperado de: http://www. sciencedirect.com/science/article/pii/S021265671400273X

OPS-OMS. (n.d.). Enfermedad crónica del riñón. Recuperado el 1 de marzo, 2017, de: http://www. paho.org/hq/index.php?option=com_topics\&view=article\&id=349\&ltemid=40937\&lang=es

Oren, B., \& Enç, N. (2013). Quality of life in chronic haemodialysis and peritoneal dialysis patients in Turkey and related factors. International Journal of Nursing Practice, 19(6), 547-56, doi: https://doi.org/10.1111/ijn.12098

Ramos, E. C., Santos, I., Zanini, R. de V. \& Ramos, J. M. (2015). Quality of life of chronic renal patients in peritoneal dialysis and hemodialysis. Jornal Brasileiro de Nefrologia, 37(3), 297-305, doi: https://doi.org/10.5935/0101-2800.20150049

Rebollo-Rubio, A., Morales-Asencio, J. M., Pons-Raventos, M. E. \& Mansilla-Francisco, J. J. (2015). Revisión de estudios sobre calidad de vida relacionada con la salud en la enfermedad renal crónica avanzada en España. Nefrologia, 35(1), 92-109, doi: https://doi. org/10.3265/Nefrologia.pre2014.Jul.12133

STROBE. Statement: Home. Recuperado el 14 de mayo, 2017, de: https://www.strobe-statement.org/index.php?id=strobe-home

Tannor, E. K., Archer, E., Kapembwa, K., van Schalkwyk, S. C. \& Davids, M. R. (2017). Quality of life in patients on chronic dialysis in South Africa: a comparative mixed methods study. BMC Nephrology, 18(1), 4, doi: https://doi.org/10.1186/s12882-016-0425-1

Theofilou, P. (n.d.). Quality of life and mental health in hemodialysis and peritoneal dialysis patients: the role of health beliefs. Recuperado de: https://doi.org/10.1007/s11255-011-9975-0

Tipos de tratamiento. Recuperado el 12 de mayo, 2017, de: https://www.diaverum.com/es-ES/ Informacion-sobre-los-rinones/Tipos-de-tratamiento/

Urrutia, C. N. \& Mella, P. O. (2014). Función renal y factores asociados en el desarrollo de la enfermedad renal crónica en adultos. Recuperado de: http://scielo.sld.cu/scielo. php?script=sci_arttext\&pid=S0864-03192014000400004

Wakeel, Jamal Al; Harbi, Ali Al; Bayoumi, Magda; Al-Suwaida, Karaem; Ghonaim, M. A. et al. (2012). Quality of life in hemodialysis and peritoneal dialysis patients in Saudi Arabia. Recuperado de: https://doi.org/10.5144/0256-4947.2012.570

Wright, L. \& Wilson, L. (2015). Quality of life and self-efficacy in three dialysis modalities: incenter hemodialysis, home hemodialysis, and home peritoneal dialysis. Nephrology Nursing Journal. Recuperado de: http://search.proquest.com/openview/e1222ca947511631b d099ead56032e2b/1?pq-origsite $=$ gscholar \&cbl $=45638$

Wu, F., Cui, L., Gao, X., Zhou, H., Yang, M., Pan, J., ... Wang, B. (2013). Quality of life in peritoneal and hemodialysis patients in China. Renal Failure, 35(4), 456-9, doi: https://doi. org/10.3109/0886022X.2013.766573 


\title{
Comportamientos homosexuales en jóvenes heterosexuales: diferencias de género
}

\author{
JUAN ENRIQUE NEBOT-GARCIA \\ juan.nebot@uji.es \\ MARTA GARCÍA-BARBA \\ barbam@uji.es \\ BEATRIZ GIL-JULIÁ \\ bgil@uji.es \\ CRISTINA GIMÉNEZ-GARCíA \\ gimenezc@uji.es \\ RAFAEL BALLESTER-ARNAL \\ rballest@uji.es
}

\section{Resumen}

Introducción: Tradicionalmente, la sexualidad se ha construido desde una perspectiva rígida que ha dificultado su expresión y vivencia en nuestra sociedad. La orientación sexual ha sido una de las dimensiones más afectadas por una dicotomización forzada. Sin embargo, la experiencia real de las personas parece ser mucho más compleja. Método: Los participantes cumplimentaron un Cuestionario ad hoc sobre Orientación Sexual desarrollado por Salusex-Unisexsida. De la muestra total, se seleccionaron aquellos jóvenes que se autoidentificaron como heterosexuales $(N=514)$. La edad promedio fue de 21 años (DT=2,24), siendo el 25,3\% hombres y el $74,7 \%$ mujeres. Resultados: El $28,4 \%$ de mujeres y el $18,5 \%$ de hombres autoidentificados como heterosexuales siente algún tipo de atracción sexual hacia personas de su mismo sexo $(p=0,016)$. También se observa mayor disposición de las mujeres heterosexuales a tener conductas homosexuales como besos (Hombre $=43,1 \%$, Mujer $=84,1 \% ; p=0,000$ ), caricias (Hombre $=14,6 \%$, Mujer $=39,6 \% ; p=0,000)$ o recibir sexo oral (Hombre $=16,9 \%$, Mujer $=25,8 \% ; p=0,008)$. No obstante, no existen diferencias de género en cuanto a la realización de prácticas homosexuales, es decir, el 4,6\% de hombres y el 3,6\% de mujeres heterosexuales las han practicado $(p=0,394)$. Conclusiones: Se observa cómo la sexualidad es más compleja de lo que se estimaba tradicionalmente. Los jóvenes heterosexuales, manifiestan conductas homosexuales en el plano de la atracción, la intención de conducta y la realización de la misma. En línea con otros estudios, las mujeres muestran mayor prevalencia en atracción e intención de conducta homosexual, mientras que no hay diferencias en las conductas entre hombres y mujeres.

Palabras clave: orientación homosexual, conducta homosexual, atracción homosexual, diferencias de género, jóvenes heterosexuales. 


\section{Abstract}

Introduction: Traditionally, sexuality has been built from a rigid perspective which has complicated its expression and experience in our society. Sexual orientation has been one of the most affected dimensions by a forced dichotomisation. Nevertheless, the real experience seems to be much more complex. Method: The participants completed an ad hoc Sexual Orientation Questionnaire, which was developed by Salusex-Unisexsida. From the overall sample we selected those young people who identified themselves as heterosexuals $(\mathrm{N}=514)$. The mean age was $21,0(\mathrm{DT}=2,24): 25,3 \%$ participants were male and $74,7 \%$ female. Results: $28,4 \%$ of women and $18,5 \%$ of men self-identified as heterosexual feel a kind of attraction towards the same sex people $(p=0,016)$. Heterosexual women are more likely to show a homosexual behaviour such as giving kisses (Male $=43,1 \%$, Female $=84,1 \%$; $p=0,000$ ), caresses (Male $=14,6 \%$, Female $=39,6 \%$; $p=0,000$ ) or receiving oral sex (Male $=16,9 \%$, Female $=25,8 \% ; p=0,008$ ). However, no differences by gender were found with regard to the realization of homosexual practices, that is, $4,6 \%$ of men and $3,6 \%$ of heterosexual women were involved in those practices $(p=0,394)$. Conclusion: Sexuality is more complex than was estimated traditionally. Heterosexual young people show homosexual behaviour in different levels: the attraction, behaviour intention and realization of that behaviour. In line with previous studies, women show more prevalence in attraction and homosexual behaviour intention, whereas no differences in behaviour between men and women were found.

Key Words: Homosexual orientation, homosexual behaviour, homosexual attraction, gender differences, heterosexual youth.

\section{Introducción}

La Asociación Americana de Psicología (APA, 2017) entiende la orientación sexual como una atracción emocional, romántica, sexual o afectiva duradera hacia otros. Esta atracción abarca todo un continuo que va desde la heterosexualidad exclusiva hasta la homosexualidad exclusiva, incluyendo diversas formas de bisexualidad. No obstante, la orientación sexual no siempre ha estado concebida así. Tradicionalmente, era considerada como un constructo binario (Callis, 2014), donde solo existían dos posibilidades: heterosexual u homosexual. Sin embargo, solo la heterosexualidad era considerada como una opción aceptable, siendo la homosexualidad tratada como una perversión o una enfermedad (Callis, 2014; Carroll, 2015).

En 1948, Alfred Kinsey realizó un estudio sobre la conducta sexual en los hombres que tuvo un gran impacto en la sociedad de aquella época. Su estudio mostró que la prevalencia de conductas, deseos y experiencias homosexuales era mucho más común de lo que la gente esperaba (Kinsey, 1948). Años más tarde replicó el estudio con una muestra femenina (Kinsey, 1953). Entre los datos que obtuvo en estos estudios, destacó que el $37 \%$ de los hombres y el $13 \%$ de las mujeres habían tenido al menos una relación sexual con alguien de su mismo sexo, que había terminado en orgasmo. Por otra parte, también se observó que el $4 \%$ de los hombres y el $3 \%$ de las mujeres se habían considerado homosexuales durante toda su vida adulta.

Además de estos hallazgos, algo que resultó muy novedoso en el estudio de Kinsey fue la utilización de una nueva escala para evaluar la orientación sexual. En lugar de recurrir a categorías cerradas, se utilizó una escala de 7 puntos, que iba de «exclusivamente heterosexual» a "exclusivamente homosexual», pasando por valores intermedios (Ver Figura 1). Posteriormente, se añadió otra opción para englobar también a la asexualidad: «No contactos o reacciones socio-sexuales». 


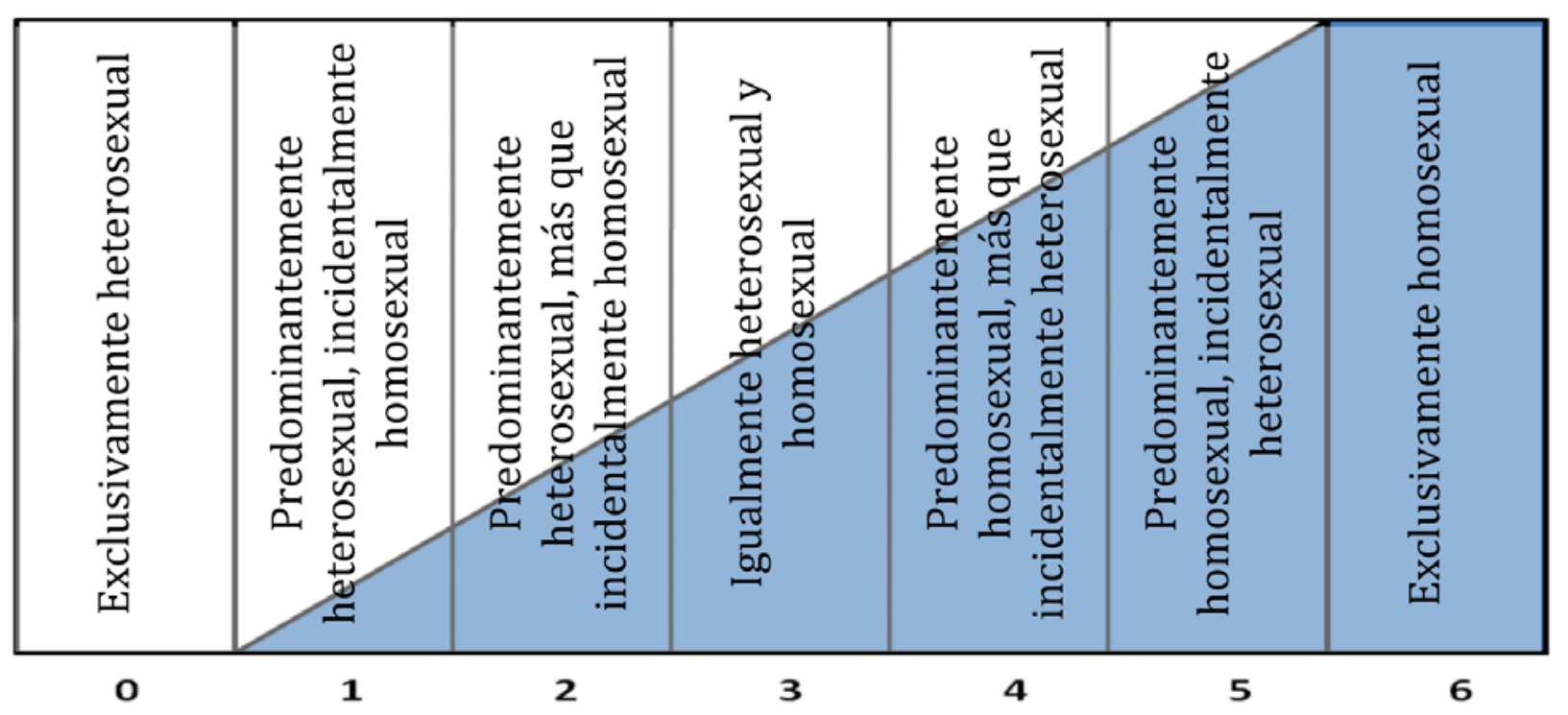

Figura 1. Escala de orientación sexual creada por Kinsey

El estudio de Kinsey, si bien fue considerado muy original e incluso transgresor en su época, no estuvo exento de críticas, sobre todo relacionadas con la muestra y la metodología utilizadas para la investigación (Cochran, Mosteller y Tukey, 1953). Además, algunos autores criticaron que Kinsey solamente se había centrado en la conducta sexual, dejando de lado otras dimensiones igualmente importantes como la atracción emocional, la atracción romántica o las propias fantasías (Carroll, 2015).

Con la intención de atender estas limitaciones, Klein (1978) elaboró un nuevo instrumento, la llamada «Klein Sexual Orientation Grid (KSOG)». Esta escala, además de evaluar la conducta sexual, examina otras variables importantes relacionadas con la orientación sexual, como la atracción sexual, las fantasías sexuales, la preferencia emocional, la preferencia social, el estilo de vida y la auto-identificación. Además, Klein considera que la orientación sexual no es estática sino flexibile en el tiempo. Por ello, incluye también la variable temporal (presente, pasado y futuro ideal).

Abordar el tema de la orientación sexual hace necesario considerar algunos conceptos clave, como por ejemplo, el género. La mera atención del género como binario, y sin necesidad de ir más allá, ya permite comprobar que existen diferencias entre hombres y mujeres en cómo viven su sexualidad y su orientación sexual. Si atendemos a las orientaciones sexuales tradicionales «heterosexualidad, homosexualidad y bisexualidad «, la más prevalente es la heterosexualidad, tanto en hombres como en mujeres. Sin embargo, en cuanto a la segunda más común, es más probable que las mujeres se identifiquen como bisexuales y los hombres como homosexuales (Copen, Chandra y Febo-Vazquez, 2016; Petersen y Hyde, 2011; Smith, Rissel, Richters, Grulich y Visser, 2003;). Como vemos, los hombres suelen posicionarse más en los extremos y las mujeres tienden a ubicarse más a lo largo de todo el continuo.

Otro aspecto a destacar relacionado con la orientación sexual es la identidad, si bien se trata de un constructo demasiado complejo como para ser medido mendiante una escala (Galupo, Davis, Grynkiewicz y Mitchell, 2014). Pese a que se intentan mejorar los instrumentos y se amplían las dimensiones a examinar, algunos aspectos siguen quedándose fuera. Tal es el caso de las orientaciones «minoritarias» o menos conocidas, como son la pansexualidad (Ca- 
Ilis, 2014; Flanders, 2017), la demisexualidad (Carrigan, 2015; Pinto, 2014), el arromanticismo (MacNeela y Murphy, 2015; Scherrer, 2008), etc. No obstante, no siempre hay concordancia entre la identidad de género/sexo y las prácticas sexuales, es decir, pese a identificarse como heterosexuales, hay personas que manifiestan atracción sexual por otras de su mismo sexo o, incluso, haber tenido experiencias homosexuales (Pathela y cols., 2006), lo cual si cabe es todavía más evidente en las mujeres (Copen y cols., 2016; Smith y cols., 2003).

Todo ello evidencia la gran diversidad que puede existir incluso dentro de un mismo grupo de personas, como puede ser el caso de aquellas que se consideran heterosexuales. Es un claro ejemplo de que las etiquetas, a veces, pueden resultar demasiado rígidas, agrupando en ellas a personas muy diferentes.

Profundizar en el estudio de la orientación sexual requiere tener en cuenta la gran diversidad afectivo-sexual existente. Por ello, el objetivo de nuestro trabajo ha sido analizar, en población joven, posibles diferencias dentro del propio colectivo heterosexual en cuanto a tipo de atracción sexual, si han tenido o no alguna relación sexual homosexual, y qué conductas sexuales estarían dispuestos a realizar con alguien de su mismo sexo. Además, otro de los objetivos ha sido explorar las diferencias en función del género en todas las variables que acabamos de citar.

A partir de la revisión de la literatura y teniendo en cuenta los resultados de estudios preliminares nos planteamos las siguientes hipótesis: 1) Mayor porcentaje de mujeres heterosexuales sentirán atracción sexual homosexual, en comparación con los hombres. 2) Mayor porcentaje de mujeres heterosexuales estarán dispuestas a realizar ciertas conductas sexuales con alguien de su mismo sexo, en comparación con los hombres. 3) Mayor porcentaje de mujeres heterosexuales habrán tenido relaciones sexuales homosexuales, en comparación con los hombres.

\section{Método}

\section{Participantes}

La muestra final constó de 514 jóvenes hispanohablantes, de los cuales un 25,3\% eran hombres y un $74,7 \%$ eran mujeres. La edad promedio de los participantes fue de 21,0 (DT=2,24). Para poder participar en el estudio, los jóvenes debían tener entre 18 y 26 años y autoidentificarse como heterosexuales. En la tabla 1 podemos ver las principales características sociodemográficas de la muestra. 
Tabla 1

Principales características sociodemográficas de la muestra

\begin{tabular}{|c|c|c|c|}
\hline \multirow[t]{2}{*}{ Datos sociodemográficos } & \multicolumn{3}{|c|}{ Participantes $(\mathrm{N}=514)$} \\
\hline & & $x$ & DT \\
\hline \multirow[t]{2}{*}{ Edad } & & 21 & 2,24 \\
\hline & & $\mathrm{N}$ & $\%$ \\
\hline \multirow[t]{2}{*}{ Género } & Hombres & 130 & 25,3 \\
\hline & Mujeres & 384 & 74,7 \\
\hline \multirow[t]{5}{*}{ Nivel de estudios } & Primarios & 3 & 0,6 \\
\hline & Secundarios & 86 & 16,7 \\
\hline & Formación profesional & 67 & 13 \\
\hline & Universitarios & 318 & 61,9 \\
\hline & Máster/doctorado & 40 & 7,8 \\
\hline \multirow{4}{*}{$\begin{array}{l}\text { Lugar de residencia durante infancia/adoles- } \\
\text { cencia }\end{array}$} & Urbana de costa & 154 & 30 \\
\hline & Urbana de interior & 198 & 38,5 \\
\hline & Rural de costa & 31 & $6 \%$ \\
\hline & Rural de interior & 131 & 25,5 \\
\hline
\end{tabular}

\section{Instrumentos}

Para este estudio se utilizó un Cuestionario ad hoc sobre Orientación Sexual (SalusexUnisexsida, 2016), resultado de la adaptación de varios instrumentos. Este instrumento consta de tres escalas:

- Atracción sexual. Esta escala está formada por un ítem en el que se pregunta «¿cuál de las siguientes afirmaciones describe mejor hacia quién te sientes atraído/a sexualmente?». Los participantes han de contestar siguiendo una escal tipo Likert (1= «Me siento atraído/a solo hacia el otro sexo» y $7=$ «Me siento atraído/a solo hacia mi mismo sexo»).

- Intención de conducta. Se presentan varias conductas (besos en la boca, caricias y abrazos desnudos, masturbar a la otra persona, ser masturbado, realizar sexo oral a otra persona, y recibir sexo oral) y se debe decir si estaría dispuesto a realizarlas con alguien del mismo sexo, atendiendo a las siguientes opciones de respuesta: «De ninguna manera», "Solo si es atractivo/a», "Solo si es de confianza» O «Fácilmente».

- Relaciones sexuales pasadas. Esta escala está representada por el siguiente ítem: "¿con qué personas has mantenido relaciones sexuales (incluyendo masturbación y/o tocamientos)?». Al igual que los anteriores, este ítem tambien se responde de acuerdo a una escala tipo Likert, ( $1=$ «solo personas del otro sexo» y $7=$ «solo personas de $\mathrm{mi}$ mismo sexo»). 


\section{Procedimiento}

Como paso inicial de esta investigación, se elaboró un Cuestionario ad hoc sobre Orientación Sexual (Salusex-Unisexsida, 2016), haciendo disponible una versión on line a través de la plataforma de Google. Para la recogida de la muestra, previamente se hizo difusión por redes sociales y foros de interés con la finalidad de llegar a un amplio abanico de población joven.

Una vez recogidos los datos y siguiendo los criterios de inclusión descritos anteriormente, seleccionamos la muestra objeto de estudio y procedimos a realizar los análisis estadísticos pertinenentes.

\section{Analisis estadísticos}

Se realizaron distintos análisis mediante el programa estadístico SPSS versión 22. En primer lugar se realizaron análisis de frecuencias y descriptivos para obtener los datos demográficos de la muestra. Asimismo, para analizar las diferencias de género en la atracción sexual, en la intención de conducta y en las conductas sexuales pasadas, se realizaron tablas de contingencias y pruebas de Chi cuadrado.

\section{Resultados}

Para facilitar la interpretación de los resultados, todas las respuestas de los ítems que incluye el instrumento fueron recodificadas. Por su parte, las respuestas al ítem de "Atracción Sexual» se dicotomizaron en dos grupos: Sin Atracción Homosexual («Me siento atraído/a solo hacia el otro sexo» y «No me siento atraído/a hacia ningún sexo») y Algún Grado de Atracción Homosexual (El resto de respuestas). Por lo que respecta a las respuestas de la escala de «Intención de Conducta», se dividieron en dos categorias: De Ninguna Manera («De ninguna manera») y Existe Posibilidad («Solo si es atractivo/a», "Solo si es de confianza» y "Fácilmente»). Por último, las «Conductas Sexuales Pasadas» se recodificaron de la siguiente manera: Sin Conducta Sexual Homosexual («Solo personas del sexo opuesto» y «Ninguna persona de ningún sexo») y Alguna Conducta Sexual Homosexual (El resto de respuestas).

Los resultados sobre la atracción sexual muestran que el $28,4 \%$ de las mujeres y el $18,5 \%$ de los hombres tenían algún tipo de atracción sexual homosexual (Ver Figura 2), siendo estas diferencias significativas $\left(x^{2}=4,987 ; p=0,026\right)$.

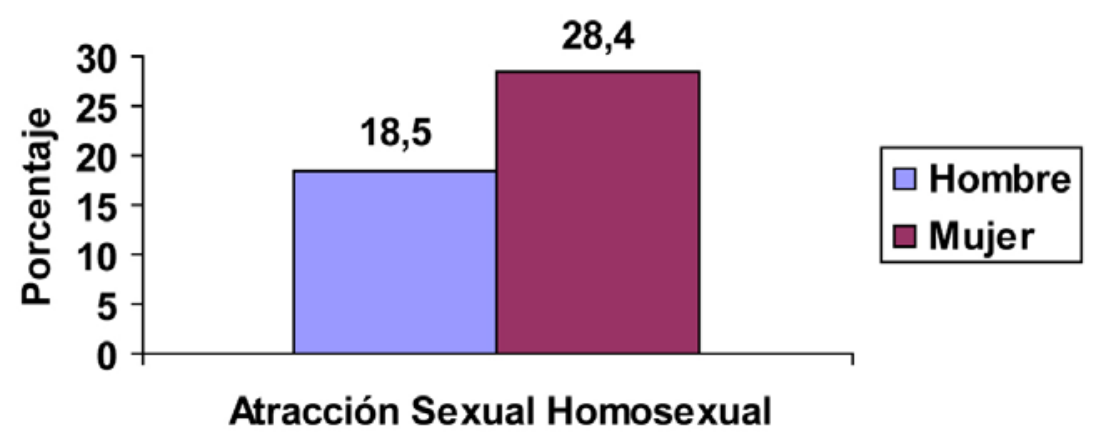


Por lo que respecta a la intención de conducta, las prácticas en las que se observó mayor disposición a realizarse con alguien del mismo sexo fueron «besos en los labios» $(73,7 \%)$, "abrazos y caricias desnudos» (33\%) y "ser masturbado/a» (30,9\%). Si analizamos los resultados en función del género, observamos diferencias significativas en todas las conductas analizadas. Como podemos ver en la Figura 3 , el $84,1 \%$ de las mujeres y el $43,1 \%$ de los hombres heterosexuales estarían dispuestos, en mayor o menor medida, a darse besos en los labios con alguien de su mismo sexo $\left(X^{2}=84,456 ; p=0,000\right)$; el $39,6 \%$ de las mujeres y el $14,6 \%$ de los hombres darían abrazos y caricias desnudos a alguien de su mismo sexo $\left(x^{2}=27,272\right.$; $p=0,000$ ); el $28,1 \%$ de las mujeres y el $11,5 \%$ de los hombres estarían dispuestos a masturbar a alguien de su mismo sexo $\left(X^{2}=14,678 ; p=0,000\right)$; el $35,4 \%$ de las mujeres y el $17,7 \%$ de los hombres aceptarían ser masturbados por alguien de su mismo sexo $\left(X^{2}=14,281 ; p=0,000\right)$; el $25,8 \%$ de las mujeres y el $9,2 \%$ de los hombres se plantearían realizar sexo oral a alguien de su mismo sexo $\left(X^{2}=15,712 ; p=0,000\right)$; y el $32 \%$ de las mujeres y el $16,9 \%$ de los hombres aceptarían recibir sexo oral de alguien de su mismo sexo $\left(X^{2}=10,946 ; p=0,001\right)$.

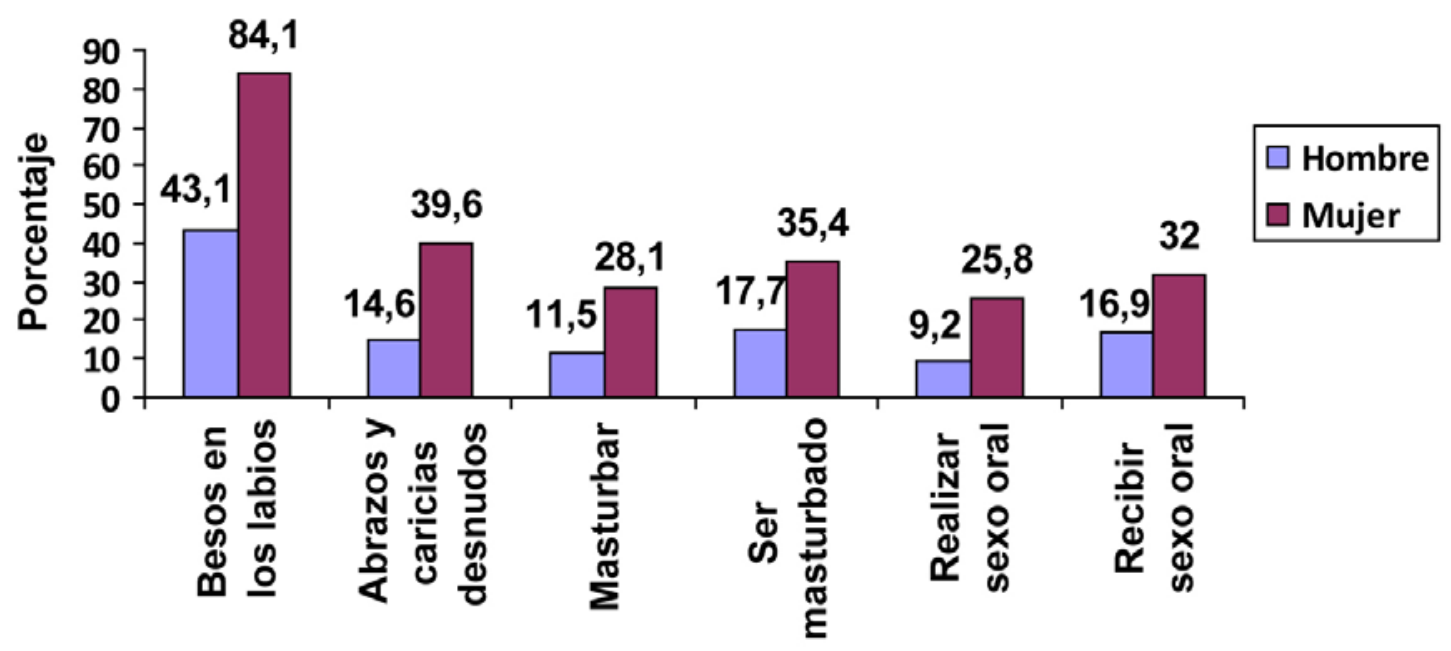

Por último, en cuanto a las relaciones sexuales pasadas, se observó que el $4,6 \%$ de los hombres heterosexuales tuvo alguna relación sexual con otro hombre en el pasado, frente al $3,6 \%$ de mujeres que hicieron lo mismo con una mujer (Ver Figura 4). En este caso, las diferencias no fueron significativas $\left(x^{2}=0,244 ; p=0,621\right)$.

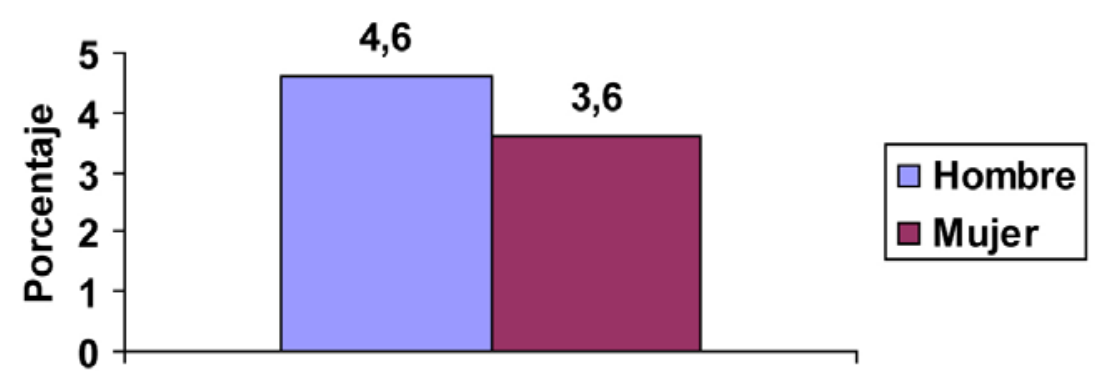

Relaciones Sexuales Homosexuales 


\section{Discusión y conclusiones}

A la luz de los resultados, podemos confirmar que la sexualidad es mucho más compleja de lo que se estimaba tradicionalmente. Los jóvenes heterosexuales, manifiestan conductas homosexuales en el plano de la atracción, la intención de conducta y la realización de la misma, siendo las mujeres quienes muestran mayor prevalencia en atracción e intención de conducta homosexual.

En este sentido, los datos obtenidos apoyarían la primera hipótesis sobre la existencia de mayor porcentaje de mujeres que sientan atracción sexual homosexual, en comparación con los hombres. De la misma forma, también apoyarían la hipótesis dos sobre la existencia de mayor porcentaje de mujeres que estarían dispuestas a realizar ciertas conductas sexuales con alguien de su mismo sexo, en comparación con los hombres.

Estos hallazgos van en la línea de otras investigaciones anteriores (Copen y cols., 2016; Smith y cols., 2003), lo cual en parte podría tener relación con que las mujeres suelen ser más abiertas y tolerantes con la homosexualidad (Petersen y Hyde, 2011). En cambio, los chicos presentan más prejuicios hacia los homosexuales, incluso en edades tempranas (Poteat y Anderson, 2012). Este prejuicio podría estar ligado con la rigidez de los roles de género, el sentido de la masculinidad y, sobre todo, de la antifeminidad (Parrott, 2009; Parrott y Zeichner, 2008). Algunos hombres heterosexuales perciben a los gays como una amenaza a su masculinidad (Carnaghi, Maass y Fasoli, 2011; Glick, Gangl, Gibb, Klumpner y Weinberg, 2007), ya que asocian la homosexualidad con lo femenino y eso hace que la masculinidad, que consideran inherente en los hombres, pierda fuerza y se vea como difusa (Carnaghi y cols., 2011). Esto a menos que las prácticas homosexuales se sitúen dentro de algún juego (Esterline y Galupo, 2013). Todos estos prejuicios provocan emociones negativas y agresividad hacia los homosexuales (Glick y cols., 2007; Parrott, 2009; Parrott y Zeichner, 2005; Parrott y Zeichner, 2008).

Al parecer, la sociedad percibe la homosexualidad de los hombres como una violación de los roles de género tradicionales, aunque no ocurre de la misma manera con la homosexualidad en las mujeres (Petersen y Hyde, 2011), que incluso son animadas por los hombres a tener conductas homosexuales «como besos o caricias «, considerándolas como un juego sexual excitante. Por su parte, las mujeres están más dispuestas a realizar estas conductas que los hombres. Ellas lo conciben como una forma de experimentar libremente su sexualidad y no ven ningún problema en realizarlo.

En cuanto a las relaciones sexuales homosexuales en el pasado, vemos que los hombres han mantenido más relaciones homosexuales que las mujeres aunque las diferencias no resultan significativas. Estos datos no respaldarían la hipótesis tres, y podría estar relacionado con que los hombres suelen «descubrir» su homosexualidad o su bisexualidad a una edad temprana, mientras que las mujeres suelen tardar más en darse cuenta (Petersen y Hyde, 2011). Como la edad de nuestra muestra es de 18 a 26 años, cabe la posibilidad de que las mujeres aún no hayan sentido esa atracción homosexual. Sería necesario ampliar la edad de la muestra para comprobarlo. Otra posibilidad sería que los datos reflejaran una mayor exploración en los hombres congruente con el rol sexual activo que la sociedad les atribuye.

Si bien este estudio ofrece información valiosa sobre el comportamiento homosexual en los jóvenes heterosexuales, no está exento de algunas limitaciones. Una de ellas tiene que ver con la disparidad de la muestra entre hombres y mujeres. Otro inconveniente es que no se tuvo en cuenta si los participantes tenían pareja o no, y dado que en una pregunta se les pide que digan si estarían dispuestos/as a realizar ciertas conductas sexuales, las respuestas pueden estar condicionadas por su estatus de pareja. 
En el futuro habría que tener en cuenta estas consideraciones para mejorar esta línea de investigación. Además, también sería interesante incluir otras variables como por ejemplo, cuándo tuvieron la primera relación homosexual, para así conocer la edad de inicio.

Otro aspecto que se podría modificar, tal y como hemos dicho antes, sería el de la edad de la muestra. Además de aumentar el rango de edad para ver si de esta manera hay más conductas homosexuales en las mujeres, también se podría comprobar si se siguen los mismos patrones en diferentes etapas de la vida.

Del mismo modo, también sería conveniente equiparar los participantes en cuanto al nivel de estudios, ya que la muestra estaba parcialmente sesgada hacia la población universitaria.

Y por último, este mismo estudio podría replicarse con población homosexual, para ver si se obtienen datos similares a los encontrados en la población joven heterosexual.

En cualquier caso, parece clara la necesidad de seguir investigando acerca de ese complejo constructo que es el de la orientación sexual y que la diversidad afectivo-sexual que caracteriza a la población sea tenida en cuenta en todos los estudios sobre la sexualidad humana.

\section{Referencias bibliográficas}

American Psychological Association (2017). Orientación sexual y identidad de género. Recuperado el 15 Abril, 2017, de: http://www.apa.org/centrodeapoyo/sexual.aspx

Callis, A. S. (2014). Bisexual, pansexual, queer: Non-binary identities and the sexual borderlands. Sexualities, 17(1-2), 63-80.

Carnaghi, A., Maass, A. y Fasoli, F. (2011). Enhancing masculinity by slandering homosexuals: The role of homophobic epithets in heterosexual gender identity. Personality and Social Psychology Bulletin, 37(12), 1655-1665.

Carrigan, M. (2015). Asexuality. In The Palgrave Handbook of the Psychology of Sexuality and Gender (pp. 7-23). Palgrave Macmillan UK.

Carroll, J. L. (2015). Sexuality now: Embracing diversity (5th edition). EE UU: Cengage Learning.

Cochran, W. G., Mosteller, F. y Tukey, J. W. (1953). Statistical problems of the Kinsey report. Journal of the American Statistical Association, 48(264), 673-716.

Copen, C. E., Chandra, A. y Febo-Vazquez, I. (2016). Sexual Behavior, Sexual Attraction, and Sexual Orientation Among Adults Aged 18-44 in the United States: Data From the 20112013 National Survey of Family Growth. National health statistics reports, 88, 1-14.

Esterline, K. M. y Galupo, M. P. (2013). «Drunken curiosity» and "gay chicken»: Gender differences in same-sex performativity. Journal of Bisexuality, 13(1), 106-121.

Flanders, C. E. (2017). Under the Bisexual Umbrella: Diversity of Identity and Experience. Journal of Bisexuality, 17(1), 1-6.

Galupo, M. P., Davis, K. S., Grynkiewicz, A. L. y Mitchell, R. C. (2014). Conceptualization of sexual orientation identity among sexual minorities: Patterns across sexual and gender identity. Journal of Bisexuality, 14(3-4), 433-456.

Glick, P., Gangl, C., Gibb, S., Klumpner, S. y Weinberg, E. (2007). Defensive reactions to masculinity threat: More negative affect toward effeminate (but not masculine) gay men. Sex Roles, 57(1-2), 55-59.

Kinsey, A. (1948). Sexual Behavior in the Human Male. Bloomington, W. B. Saunders Company.

Kinsey, A. (1953). Sexual Behavior in the Human Female. Bloomington, W. B. Saunders Company 
Klein, F. (1978). The Bisexual Option: A Concept of One Hundred Percent Intimacy. EE UU: Arbor house.

MacNeela, P. y Murphy, A. (2015). Freedom, invisibility, and community: A qualitative study of self-identification with asexuality. Archives of sexual behavior, 44(3), 799-812.

Parrott, D. J. (2009). Aggression toward gay men as gender role enforcement: Effects of male role norms, sexual prejudice, and masculine gender role stress. Journal of personality, 77(4), 1137-1166.

Parrott, D. J. y Zeichner, A. (2005). Effects of Sexual Prejudice and Anger on Physical Aggression Toward Gay and Heterosexual Men. Psychology of Men y Masculinity, 6(1), 3.

Parrott, D. J. y Zeichner, A. (2008). Determinants of anger and physical aggression based on sexual orientation: An experimental examination of hypermasculinity and exposure to male gender role violations. Archives of Sexual Behavior, 37(6), 891-901.

Pathela, P., Hajat, A., Schillinger, J., Blank, S., Sell, R. y Mostashari, F. (2006). Discordance between sexual behavior and self-reported sexual identity: a population-based survey of New York City men. Annals of Internal Medicine, 145(6), 416-425.

Petersen, J. L. y Hyde, J. S. (2011). Gender differences in sexual attitudes and behaviors: A review of meta-analytic results and large datasets. Journal of sex research, 48(2-3), 149165.

Pinto, S. A. (2014). ASEXUally: On being an ally to the asexual community. Journal of LGBT Issues in Counseling, 8(4), 331-343.

Poteat, V. P. y Anderson, C. J. (2012). Developmental changes in sexual prejudice from early to late adolescence: The effects of gender, race, and ideology on different patterns of change. Developmental psychology, 48(5), 1403-1415.

Scherrer, K. S. (2008). Coming to an asexual identity: Negotiating identity, negotiating desire. Sexualities, 11(5), 621-641.

Smith, A., Rissel, C. E., Richters, J., Grulich, A. E. y Visser, R. O. (2003). Sex in Australia: sexual identity, sexual attraction and sexual experience among a representative sample of adults. Australian and New Zealand journal of public health, 27(2), 138-145. 


\title{
Conductas sexuales online en población juvenil: diferencias de género y relación con la búsqueda de sensaciones sexuales
}

\author{
MARTA GARCÍA-BARBA \\ barbam@uji.es \\ JUAN ENRIQUE NEBOT-GARCía \\ juan.nebot@uji.es \\ Jesús Castro-Calvo \\ castroj@uji.es \\ CRISTINA GIMÉNEZ-GARCÍA \\ gimenezc@uji.es \\ RAFAEL BALLESTER-ARNAL \\ rballest@uji.es
}

\section{Resumen}

Introducción: El cibersexo (uso de internet con fines sexuales) puede mejorar la sexualidad de la población, pero también puede contribuir a generar problemas psicológicos/físicos. El uso del cibersexo en interacción con ciertos rasgos de personalidad o disposiciones sexuales (como la búsqueda de sensaciones sexuales) podrían influir en la aparición de estos problemas. Sin embargo, todavía son pocos los estudios que analizan esta relación. El objetivo es analizar si hay diferencias entre hombres y mujeres en el uso de cibersexo y comprobar la posible relación con la búsqueda de sensaciones sexuales. Método: 325 personas entre 18 y 26 años $(M=22,17 ; D T=2,056)$ cumplimentaron de forma online la adaptación española del Internet Sex Screening Test (ISST) y la escala revisada de Búsqueda de Sensaciones Sexuales (BSS) de manera voluntaria, confidencial y anónima. Resultados: La media en las dimensiones de compulsividad sexual online y gravedad percibida es mayor en hombres, particularmente, en conductas relacionadas con experimentar la sexualidad, utilizar el cibersexo como premio por haber conseguido algo o pasar más de 5 horas/semana usando internet con fines sexuales. Además, el $22 \%$ de la varianza de la compulsividad sexual online podría explicarse mediante la BSS y el hecho de ser hombre. Conclusiones: Los hombres manifiestan conductas sexuales online con mayor frecuencia, así como un mayor consumo patológico del mismo. Además del género masculino, la BSS parece estar relacionada con este comportamiento. Ambos factores deberían considerarse a la hora de desarrollar intervenciones preventivas y de detección temprana de posibles problemas asociados.

Paraules clau: Cibersexo, compulsividad sexual online, búsqueda de sensaciones sexuales, genero, jóvenes. 


\section{Abstract}

Introduction: Cybersex (Internet use for sexual purposes) can improve the sexuality of the population, but can also contribute to generating psychological/physical problems. The use of cybersex in interaction with certain personality traits or sexual dispositions (such as sexual sensation seeking) may influence the onset of these problems. However, there are still few studies analysing this association. The objective is to analyse if there are differences between men and women in the use of cybersex and to verify the possible relation with the Sexual Sensation Seeking. Method: 325 people aged between 18 and $26(M=22,17 ; D T=2,056)$ completed, in an online form, the Spanish adaptation of the Internet Sex Screening Test (ISST) and the revised scale of Sexual Sensation Seeking (SSS) in a voluntary, confidential and anonymous way. Results: In general terms, the mean in online sexual compulsivity and perceived severity is higher in men, particularly in behaviours related to experiencing different aspects of sexuality, using cybersex as a reward for having achieved something or spending more than 5 hours/week using the internet for sexual purposes. In addition, $22 \%$ of the variance of online sexual compulsivity could be explained by the SSS and the fact of being a man. Conclusions: Men report online sexual behaviour more frequently as well as greater pathological consumption of it. Besides the masculine gender, SSS seems to be related to this behaviour. Both factors should be considerate when it comes to developing preventive interventions and in the early detection of possible problems associated with it.

Key Words: Cybersex, online sexual compulsivity, sexual sensation seeking, gender, young people.

\section{Introducción}

El uso de las tecnologías de la información y comunicación (TIC) ha cambiado por completo nuestra forma de vivir y de relacionarnos con otras personas. Concretamente en España, el $96,7 \%$ de los hogares disponen de teléfono móvil y el $97 \%$ disponen de acceso a internet en las viviendas (INE, 2016). Uno de los fenómenos emergentes relacionado con las TIC es el cibersexo, que se define como el uso de internet con objetivos de gratificación sexual (Cooper y Griffin-Shelley, 2002). Las actividades sexuales online (ASO) se suelen clasificar en tres categorías dependiendo del objeto de la excitación: actividades que no buscan la excitación (como la busqueda de información sexual), actividades sexuales online en solitario (visionado de imágenes y videos pornográficos, lectura de relatos eróticos, etc.) y actividades sexuales online con terceras personas, es decir, que requieren la intervención de otro usuario (por ejemplo, el uso de chats sexuales, videollamadas, etc.) (Shaughnessy, Byers y Walsh, 2011). Todas las actividades excitadoras se englobarían en lo que conocemos como cibersexo.

En cuanto a la prevalencia de las diferentes actividades sexuales online, encontramos pocos estudios. Además, éstos se centran principalmente en jóvenes y/o adolescentes, por lo que es difícil establecer la prevalencia en otros sectores de población. Döring y cols. (2015) realizaron un estudio con 2690 participantes universitarios de 4 países y encontraron que el $76,5 \%$ de la muestra utilizaba internet para realizar algún tipo de actividad sexual online (ASO). La mayoría de los participantes informaron haber usado internet para buscar informa- 
ción sexual $(89,8 \%)$ y entretenimiento sexual online $(76.5 \%)$. Casi la mitad $(48.5 \%)$ reportó haber estado buscando productos sexuales, y un porcentaje algo inferior informó realizado chateado con otros usuarios con fines sexuales $(30,8 \%)$.

Uno de los aspectos más estudiados es cómo influye el género en la actividad sexual online (ASO). Los hallazgos encontrados en distintas investigaciones indican que son más los hombres los que utilizan internet para visualizar imágenes/vídeos pornográficos (Hald y Štulhofer, 2016; Shaughness y cols., 2011; Shaughnessy, Fudge y Byers, 2017; Weinstein y cols., 2015) y que además lo suelen hacer con el objetivo de autoestimularse (Ballester-Arnal y cols., 2016; Morgan, 2011). Sin embargo, en cuanto al contacto sexual online con otros usuarios, las prevalencias oscilan entre el 9,4-30\% en hombres y el 14,9-34\% en mujeres en función del estudio pero no se encontrarían grandes diferencias entre géneros (Daneback, Cooper, y Mansson, 2005; Goodson, McCormick, y Evans, 2001; Shaughnessy y cols., 2011).

El uso de internet con fines sexuales tiene ciertas ventajas como el fácil acceso a la información sobre sexualidad (Simon, Daneback, y Sevcikova, 2014), el incremento de la satisfacción y placer sexual (Daneback, Sevcikova, Mansson, y Ross, 2013), la facilitación a la hora de encontrar parejas más afines, mejorar las relaciones de pareja y la realización de prácticas sexuales seguras (ya que son online), entre otras. Pero, por otro lado, también encontramos algunas desventajas destacando el establecimiento de relaciones no basadas en la realidad, la lectura de información sobre sexualidad errónea, la necesidad de buscar cada vez material que produzcan mayores niveles de excitación debido a la saciación, el ciberacoso, la formación de actitudes y creencias sexuales disfuncionales, el modelado negativo de ciertas prácticas sexuales, las experiencias sexuales de riesgo offline y, sobre todo, la posibilidad de desarrollar una adicción.

El cibersexo posee ciertas características como el anonimato, la accesibilidad o el bajo coste que lo hacen potencialmente adictivo. Otros factores como la baja autoestima, timidez, imagen corporal distorsionada, disfunciones sexuales no tratadas, otras adicciones han sido relacionados con la predisposición a sufrir adicción al cibersexo. Además, factores de personalidad como la búsqueda de sensaciones sexuales están relacionados con las prácticas sexuales de riesgo (Luder y cols., 2011)

Por ello, se diferencian tres tipos de perfiles de consumo del cibersexo que irían en un continuo en función de la gravedad y del consumo que de éste se haga (Cooper, Putnam, Planchon y Boies, 1999). Estos perfiles serían: usuarios recreativos (personas que consumen cibersexo de forma moderada y responsable y que no experimentan ningún perjuicio), usuarios de riesgo (usuarios habituales que muestran los primeros signos de patología) y adictos al cibersexo (personas con una verdadera obsesión hacia el cibersexo, que muestran una pérdida de la capacidad para controlar el inicio/finalización de la actividad sexual online y que persisten en el uso a pesar de las consecuencias negativas). La prevalencia en cuanto a los diferentes tipos de perfiles es muy difícil de determinar. Los estudios que han intentado hacerlo, además de escasos, se centran en un rango poblacional determinado (adolescentes/jóvenes). Los hallazgos encontrados en dichos estudios situarían la prevalencia de usuarios de riesgo en torno al $9-10 \%$ y el perfil de adictos en torno al $1,7 \%$ en chicos y 0,1 en chicas (Ballester-Arnal y cols., 2016; Giordano y Cashwell, 2017).

Por todo ello, nuestro estudio tiene como objetivo explorar las conductas sexuales online en jóvenes, sobre todo centrándonos en las diferencias entre géneros y en la relación con la búsqueda de sensaciones sexuales. Partiendo de los hallazgos presentados a la largo de la introducción, proponemos que los hombres serán quienes puntúen más alto en las conductas relacionadas con la compulsividad sexual online y la percepción de gravedad del comportamiento online. Además, consideramos que la variable búsqueda de sensaciones sexuales tendrá cierta capacidad predictiva sobre la compulsividad sexual online. 


\section{Método}

\section{Participantes}

En este estudio participaron 325 jóvenes con edades comprendidas entre los 18 y los 26 años. El 43,4\% del total eran hombres y el 56,6\% restante mujeres (141 hombres y 184 mujeres). La media de edad es de 22,17 años, con una desviación típica de 2,06. La distribución por edades y género es homogénea $(t=1,919, p=.056)$.

Con respecto a la orientación sexual autoinformada, la mayoría (el $83,1 \%$ ) se identifican como heterosexuales, seguido de un $10,5 \%$ que lo hace como bisexuales, un 5,8\% como homosexuales y, finalmente, únicamente un $0,6 \%$ se identifican como asexuales.

En cuanto al nivel de estudios, aproximadamente la mitad de la muestra $(53,5 \%)$ tiene estudios universitarios de grado/licenciatura y el $14,8 \%$ de máster; el $9,2 \%$ ciclos formativos, el $20 \%$ bachillerato y el $2,5 \%$ únicamente graduado escolar.

\section{Instrumentos}

Los instrumentos empleados para realizar el presente estudio fueron dos: las adaptaciones españolas del Cuestionario de Adicción al Cibersexo (ISST) (Ballester, Gil, Gómez, Gil, 2010) y de la Escala de Búsqueda de Sensaciones sexuales (BSS)(Teva y Bermúdez, 2008). Además, se realizaron algunas preguntas sociodemográficas como el sexo, la edad, la orientación sexual y el nivel de estudios.

El Cuestionario de Adicción al Cibersexo (ISST) está formado por 25 ítems con opción de respuesta dicotómica (verdadero o falso). Estos ítems se agrupan en cinco componentes: compulsividad sexual online (ítems $2,6,7,15,16,18,19$ y 25), comportamiento online solitario no compulsivo (ítems 1, 5, 10, 11, 13, 14), comportamiento online social (ítems 8, 9, 20, 22, 23, 24), gasto económico online (ítems 3 y 4 ) y percepción de gravedad del comportamiento online (ítems $12,17,21)$. Este cuestionario tiene una alta consistencia interna $(\alpha=0,88)$ y una buena validez convergente y discriminante. (Ballester, Gil, Gómez y Gil, 2010).

La Escala de Búsqueda de Sensaciones sexuales (BSS) comprende 11 ítems con 4 opciones de respuesta que van de 1 (nada característico de mi) a 4 (muy característico de mi). Se emplea para evaluar la tendencia a experimentar con prácticas sexuales nuevas y variadas, independientemente del riesgo que supongan. Esta escala presenta una buena consistencia interna $(\alpha=0,76)$ y una validez externa aceptable. (Teva y Bermúdez, 2008)

\section{Procedimiento}

Los cuestionarios utilizados se trasladaron a una plataforma de evaluación online (Google Encuestas) que se difundió por diferentes redes sociales, pidiendo la participación voluntaria y el consentimiento informado. Junto al enlace del cuestionario, se adjuntaba un escrito en el que se explicaba el objetivo del estudio y se garantizaban anonimato y confidencialidad.

El cuestionario recibió un total de 378 respuestas de las cuales se descartaron a 53 participantes por no cumplir el criterio de inclusión de la edad (tener entre 18 y 32 años). Posteriormente, se volcaron todos los resultados en una base de datos y se realizaron los análisis estadísticos pertinentes mediante el programa estadístico SPSS versión 23.0. 


\section{Resultados}

Con el objetivo de conocer si existen diferencias entre hombres y mujeres en cuanto al uso problemático o adictivo del cibersexo, escogimos únicamente dos de los factores que comprende la escala ISST de adicción al cibersexo: el de compulsividad sexual online y el de percepción de la gravedad del comportamiento online. Una vez hecho esto, por su importancia clínica, se compararon los porcentajes de respuesta a cada uno de los ítems en hombres y en mujeres, comprobando mediante la prueba chi-cuadrado cuáles de estas diferencias eran significativas.

Como vemos en la Tabla 1, en cuanto al factor de compulsividad sexual online, son los hombres quienes presentan un mayor porcentaje de respuestas verdaderas a todos los ítems. Además, estas diferencias son significativas en el ítem «Paso más de 5 horas a la semana usando mi ordenador con fines sexuales $\left(x^{2}=23,12, p<.000\right)$ », "Utilizo Internet para experimentar con diferentes aspectos de la sexualidad (esclavitud sexual, homosexualidad, sexo anal, etc. $)$ » $\left(X^{2}=13,85, p<.000\right)$, "tengo mi propio sitio web que contiene algún material sexual.» $\left(x^{2}=8,09, p=.004\right)$, «En ocasiones utilizo cibersexo como un premio por haber conseguido algo (acabar un proyecto, un día estresante, etc.)» $\left(X^{2}=23,38, p<.000\right)$ y en el de "Cuando no consigo acceder a información sexual online me siento ansioso, enfadado o decepcionado.» $\left(X^{2}=4,80, p=.028\right)$.

Respecto a la percepción de la gravedad del comportamiento online, tal y como se muestra en la Tabla 2, son los hombres quienes también presentan porcentajes mayores de respuestas verdaderas a cada uno de los ítems con respecto a las mujeres, si bien estas diferencias únicamente son significativas en el ítem «Me he prometido a mí mismo dejar de usar Internet con fines sexuales» $\left(x^{2}=6,68, p=.010\right)$. Es importante destacar que los porcentajes más elevados se dan, tanto en hombres como mujeres, en el ítem «Nadie sabe que uso el ordenador para propósitos sexuales.» (25,5\% para hombres y $23,4 \%$ para mujeres).

Tabla 1

Porcentaje de respuestas en función del género a los ítems de compulsividad sexual online

\begin{tabular}{lcccc}
\hline \multicolumn{1}{c}{ Ítems } & Hombres & Mujeres & $X^{2}$ & Sig. \\
\hline $\begin{array}{l}\text { 2. Paso más de } 5 \text { horas a la semana usando mi or- } \\
\text { denador con fines sexuales. }\end{array}$ & $13,5 \%$ & $0,5 \%$ & 23,12 &, 000 \\
$\begin{array}{l}\text { 6. He gastado más dinero en material sexual online } \\
\text { de lo que había planeado. }\end{array}$ & $2,1 \%$ & $1,1 \%$ &, 57 &, 450 \\
$\begin{array}{l}\text { 7. El sexo en Internet ha interferido alguna vez con } \\
\quad \text { ciertos aspectos de mi vida. }\end{array}$ & $14,9 \%$ & $10,3 \%$ & 1,54 &, 214 \\
$\begin{array}{l}\text { 15. Utilizo Internet para experimentar con diferentes } \\
\text { aspectos de la sexualidad (esclavitud sexual, ho- } \\
\text { mosexualidad, sexo anal, etc.). }\end{array}$ & $36,2 \%$ & $17,9 \%$ & 13,85 &, 000 \\
$\begin{array}{l}\text { 16. Tengo mi propio sitio web que contiene algún ma- } \\
\text { terial sexual. }\end{array}$ & $7,1 \%$ & $1,1 \%$ & 8,09 &, 004 \\
$\begin{array}{l}\text { 18. En ocasiones utilizo cibersexo como un premio } \\
\text { por haber conseguido algo (acabar un proyecto, } \\
\text { un día estresante, etc.). }\end{array}$ & $16,3 \%$ & $1,6 \%$ & 23,38 &, 000
\end{tabular}




\begin{tabular}{lcccc}
\hline \multicolumn{1}{c}{ Ítems } & Hombres & Mujeres & $X^{2}$ & Sig. \\
\hline $\begin{array}{l}\text { 19. Cuando no consigo acceder a información sexual } \\
\text { online me siento ansioso, enfadado o decepcio- } \\
\text { nado. }\end{array}$ & $10,6 \%$ & $4,3 \%$ & 4,80 &, 028 \\
$\begin{array}{l}\text { 24. He tropezado con material sexual ilegal estando } \\
\text { en Internet. }\end{array}$ & $25,5 \%$ & $18,5 \%$ & 2,35 &, 125 \\
\hline
\end{tabular}

Tabla 2

Porcentaje de respuestas en función del género a los ítems de percepción de la gravedad del comportamiento online

\begin{tabular}{lcccc}
\hline \multicolumn{1}{c}{ Ítems } & Hombres & Mujeres & $X^{2}$ & Sig. \\
\hline $\begin{array}{l}\text { 12. Nadie sabe que uso el ordenador para propósitos } \\
\text { sexuales. }\end{array}$ & $25,5 \%$ & $23,4 \%$ &, 203 &, 652 \\
$\begin{array}{l}\text { 17. Me he prometido a mí mismo dejar de usar Inter- } \\
\text { net con fines sexuales. }\end{array}$ & $12,1 \%$ & $4,3 \%$ & 6,68 &, 010 \\
$\begin{array}{l}\text { 21. Me he castigado a mí mismo cuando uso Internet } \\
\text { con fines sexuales (por ejemplo, no utilizar el or- } \\
\text { denador, cancelar mi suscripción a Internet, etc.) }\end{array}$ & $3,5 \%$ & $1,1 \%$ & 2,291 &, 130 \\
\hline
\end{tabular}

Finalmente, quisimos comprobar si la búsqueda de sensaciones sexuales y el género predecían el uso compulsivo y patológico del cibersexo. Para ello, se realizó una regresión lineal utilizando como variable dependiente (VD) la compulsividad sexual online y como variables independientes (VI) el género y la búsqueda de sensaciones sexuales, comprobando que tanto la búsqueda de sensaciones sexuales como el hecho de ser hombre influían de manera significativa ( $B$ de .387 y .187 respectivamente) sobre el nivel de compulsividad sexual online (puntuación total del factor). Concretamente, estas dos variables explican el $22,3 \%$ de la varianza de la variable dependiente. Individualmente, la búsqueda de sensaciones sexuales explica el $19,1 \%$ de la varianza, mientras que el hecho de ser hombre el $3,2 \%$.

\section{Discusión y conclusiones}

Tal como hemos comprobado en este estudio, las investigaciones sobre el uso del cibersexo así como sobre sus consecuencias y problemas asociados están en pleno auge. Son muchos los aspectos que todavía no se han explorado de modo sifuciente, entre los que destacan especialmente los predictores del consumo problemático o compulsivo de cibersexo (objetivo del presente trabajo).

Como proponíamos en nuestra hipótesis inicial, son los hombres quienes manifiestan conductas sexuales online con mayor frecuencia en comparación con las mujeres. Concretamente en nuestros resultados observamos que los hombres destacan particularmente en conductas relacionadas con experimentar diferentes aspectos de la sexualidad, utilizar el cibersexo como premio por haber conseguido algo o pasar más de 5 horas/semana usando internet 
con fines sexuales. Estos resultados siguen la misma línea que los hallados en investigaciones precedentes (Hald y Štulhofer, 2016; Shaughness y cols., 2011; Shaughnessy, Fudge y Byers, 2017; Weinstein y cols., 2015) y que indican que son los hombres quienes utilizan internet, en mayor medida que las mujeres, para realizar conductas sexuales online, concretamente, visualizar imágenes/vídeos pornográficos.

Por otra parte, otro de nuestros objetivos era comprobar si la búsqueda de sensaciones sexuales podría predecir el consumo compulsivo de cibersexo. Tal y como indican nuestros resultados, la búsqueda de sensaciones sexuales explicaría un $19,1 \%$ del total de la varianza de la compulsividad sexual online esta variable. Unida al hecho de ser hombre, ambas variables explicarían el $22,3 \%$ de la varianza de dicho constructo. En esta línea, encontramos el estudio realizado por Zheng y Zheng (2014), quienes encontraron que la búsqueda de sensaciones sexuales predecía la actividad sexual online (ASO).

Estos hallazgos guardan importantes implicaciones en la práctica clínica y en la prevención de la adicción al cibersexo. Teniendo en cuenta las consecuencias negativas que puede tener el uso del cibersexo, poder identificar factores de riesgo -como la búsqueda de sensaciones sexuales- podría ser de gran ayuda para evitar problemas mayores y/o ayudar a tratar diversos problemas asociados.

En cualquier caso, este estudio no está exento de limitaciones. Para mejorar la investigación, la muestra debería ser mayor, contando con un rango de edades más amplio. Además, nuestros participantes no presentan un perfil patológico del uso del cibersexo lo que consideramos que puede ser una limitación sobre todo a la hora de comprobar cuánta varianza de la cmpulsividad sexual online podría explicarse mediante las variables búsqueda de sensaciones sexuales y género. Por último, creemos que sería aconsejable introducir un mayor rango de actividades sexuales online para explorar de forma más exhaustiva toda la conducta sexual online.

Aparte de subsanar estas limitaciones, como futuras líneas de investigación proponemos diferenciar entre perfiles patológicos y no patológicos a la hora de realizar estudios sobre el uso del cibersexo para ver las diferencias entre ambos grupos, analizar la influencia que puede tener el uso del cibersexo en las prácticas sexuales de riesgo e indagar sobre las motivaciones para el uso de internet con fines sexuales.

\section{Referencias bibliográficas}

Ballester R., Gil, M. D., Gómez, S., \& Gil, B. (2010). Propiedades psicométricas de un instrumento de evaluación de la adicción al cibersexo. Psicothema, 22(4), 1048-1053.

Ballester-Arnal, R., Castro Calvo, J., Gil-Llario, M. D., \& Gil-Julia, B. (2016). Cybersex addiction: a study on Spanish college students. Journal of sex \& marital therapy, 1-19.

Ballester-Arnal, R., Giménez-García, C., Gil-Llario, M. D., \& Castro-Calvo, J. (2016). Cybersex in the «Net generation»: Online sexual activities among Spanish adolescents. Computers in Human Behavior, 57, 261-266.

Cooper, A., Putnam, D. A., Planchon, L. A. y Boies, S. C. (1999). Online sexual compulsivity: Getting tangled in the net. Sexual Adicction \& Compulsivity, 6(2), 79-104.

Cooper, A. y Griffin-Shelley, E. (2002). Introduction. The internet: The next sexual revolution. En A. Cooper (Ed.) Sex \& the internet: A guidebook for clinicians (pp. 1-15). Ney York: Brunner routledge.

Daneback, K., Cooper, A., \& Månsson, S. A. (2005). An Internet study of cybersex participants. Archives of Sexual Behavior, 34(3), 321-328. 
Döring, N., Daneback, K., Shaughnessy, K., Grov, C., \& Byers, E. S. (2015). Online sexual activity experiences among college students: A four-country comparison. Archives of sexual behavior, 1-12.

Giordano, A. L., \& Cashwell, C. S. (2017). Cybersex Addiction Among College Students: A Prevalence Study. Sexual Addiction \& Compulsivity, 1-11.

Goodson, P., McCormick, D., \& Evans, A. (2001). Searching for sexually explicit materials on the Internet: An exploratory study of college students' behavior and attitudes. Archives of sexual behavior, 30(2), 101-118.

Hald, G. M., \& Štulhofer, A. (2016). What types of pornography do people use and do they cluster? Assessing types and categories of pornography consumption in a large-scale online sample. The Journal of Sex Research, 53(7), 849-859.

Luder, M. T., Pittet, I., Berchtold, A., Akre, C., Michaud, P. A., \& Suris, J. C. (2011). Associations between online pornography and sexual behavior among adolescents: Myth or reality? Archives of Sexual Behavior, 40, 1027-1035.

Morgan, E. M. (2011). Associations between Young Adults' Use of Sexually Explicit Materials and Their Sexual Preferences, Behaviors, and Satisfaction. The Journal of Sex Research, 48(6), 520-530.

Shaughnessy, K., Byers, E. S., \& Walsh, L. (2011). Online sexual activity experience of heterosexual students: Gender similarities and differences. Archives of Sexual Behavior, 40(2), 419-427.

Shaughnessy, K., Fudge, M., \& Byers, E. S. (2017). An exploration of prevalence, variety, and frequency data to quantify online sexual activity experience. The Canadian Journal of Human Sexuality, 1-16.

Simon, L. E., Daneback, K., \& Ševčíková, A. (2014). The Educational Dimension of Pornography: Adolescents' Use of New Media for Sexual Purposes. Living in the digital age, 33.

Teva, I., \& Bermúdez, M. P. (2008). Adaptación castellana y propiedades psicométricas de la escala de búsqueda de sensaciones sexuales en adolescentes españoles. Revista Mexicana de Psicología, 25(1), 129-137.

Weinstein, A. M., Zolek, R., Babkin, A., Cohen, K., \& Lejoyeux, M. (2015). Factors predicting cybersex use and difficulties in forming intimate relationships among male and female users of cybersex. Frontiers in psychiatry, 6.

Zheng, L., \& Zheng, Y. (2014). Online sexual activity in Mainland China: Relationship to sexual sensation seeking and sociosexuality. Computers in Human Behavior, 36, 323-329. 


\title{
Conocimientos de la población estudiantil en Reanimación Cardiovascular Básica
}

\author{
MARINA ALONSO GÓMEZ \\ al289095@uji.es \\ MARÍA de los Ángeles Alonso García \\ al286591@uji.es \\ PABlo SALAs MEdina \\ psalas@uji.es
}

\section{Resumen}

Introducción: La Parada Cardiorrespiratoria (PCR) es la interrupción brusca, inesperada y potencialmente reversible de la respiración y la circulación espontánea. A nivel mundial se producen entre 4 y 5 millones de PCR al año. España tiene un ratio de una parada cada 20 minutos. Un $80 \%$ de las PCRs extrahospitalarias se producen en presencia de testigos, por ello la importancia de formación en de reanimación cardiopulmonar (RCP). Objetivo: Determinar la adquisición de competencias en RCP Básica en alumnos de primero del grado de enfermería de la Universidad Jaume I. Metodología: Estudio observacional transversal, en alumnos de primero del Grado de Enfermería de la Universidad Jaume I, con una población de 54 alumnos y una muestra de estudio del $94,44 \%(n=51)$, distribuida en tres grupos. El estudio se llevó a cabo en diciembre del 2016, mediante la cumplimentación de un pretest y un postest auto cumplimentable. El pretest previo a la realización de unas sesiones teórico-prácticas de RCP, y el postest tras la realización de estas sesiones teórico-prácticas. Los cuestionarios empleados, fueron de elaboración ad hoc evaluando su adecuación mediante grupo nominal de expertos, compuesto por seis profesionales. Para la explotación de los datos fue empleado el programa estadístico SPSS v.20 OSX. Resultados: La nota media obtenida en la sesión pretest fue de 5'5 puntos, un 29,41\% $(n=15)$ de los alumnos no superó la prueba. En éste, la nota mínima obtenida fue de 2,5 puntos y la máxima de 8 puntos. La nota media obtenida en la sesión postest fue de 7,72 puntos, un $100 \%$ $(n=50)$ superaron la prueba. En este, la nota mínima obtenida fue de 6,5 puntos y la máxima de 9 puntos. Conclusión: Se demuestra un aumento de los conocimientos medios en RCP del estudiantado participante, apreciándose un porcentaje mayor de calificaciones en el LAB-3.

Palabras clave: Parada Cardiorrespiratoria, Reanimación cardiopulmonar, Formación, Educación enfermera, Supervivencia. 


\section{Abstract}

Introduction: Cardiorespiratory arrest is the sudden, unexpected and potentially reversible disruption of breathing and spontaneous circulation. Between 4 and 5 million cardiorespiratory arrest occur all around the world each year. Every 20 minutes someone suffers from them in Spain. $80 \%$ of out of hospital cardiorespiratory arrests occur in the presence of witnesses, that is the reason why effective training in cardiopulmonary resuscitation (CPR) is very important. Objective: To determine the acquisition of basic CPR skills among first year nursing students at Universitat Jaume I. Methods: Cross-sectional study conducted on first year nursing students at Universistat Jaume I, involving 54 students and a sample of $94,44 \%(n=51)$ distributes into 3 groups. The study took place in December 2016, by filling a pretest and a postest. The pretest was answered before some theoretical and practical CPR sessions and the postest after finishing those sessions. Ad hoc questionnaries were used by evaluating their suitability by means of a nominal group of experts, made up of six professionals on that field. The statistical programme SPSS v.20 OSX was used for the data exploitation. Results: The average mark on the pretest sessions was 5,5, 29,4\% ( $n=15)$ of the students did not pass the test. The lowest mark was 2,5 and the highest 8 . The average mark on the postest was $7,72,100 \%$ of the students passed the test. The lowest mark was 6,5 and the highest 9. Conclusion: The study shows that CPR knowledge has higher marks among the LAB-3 students than among the other groups.

Keywords: hearth arrest, cardiopulmonary resuscitation, education, nursing education, survival.

\section{Introducción}

La parada cardiorrespiratoria (PCR) es «la interrupción brusca, inesperada y potencialmente reversible de la respiración y la circulación espontánea» (Carmona Torres, 2014; Castellano, 2009; European Resuscitation Council, 2015; Jiménez Murillo y Montero Pérez, 2015; Lopes, 2014; Ruano, 2005; Tíscar González, 2014).

Hay una gran diversidad de causas que pueden llevar a un individuo a una PCR, la causa principal es la cardiopatía isquémica, aproximadamente un $80 \%$, seguido de enfermedades de las válvulas cardiacas o del músculo cardiaco, aproximadamente un $15 \%$ y de trastornos genéticos, aproximadamente un $5 \%$. Otras causas pueden ser las arritmias, podrían estar ocasionadas por alteraciones electrolíticas o intoxicaciones, un traumatismo, hemorragia masiva, hipoxia, como por ejemplo en casos de ahogamiento, atragantamiento y patologías como el asma, Shock cardiogénico y accidentes cerebrovasculares. (Cardiologia, 2013; Castellano, 2009; De Asmundis, 2013; Ercilla Martín y Crovetto de la Torre, 2014; Montagud, 2015)

La PCR es más frecuente en hombres que en mujeres, con edad comprendida entre los 45 y 75 años. El riesgo de sufrir una parada aumenta considerablemente si el individuo presenta patología cardiaca, obesidad, hipertensión arterial, diabetes, o en aquellos que han sufrido un infarto agudo de miocardio anteriormente o que han sufrido con anterioridad una PCR. (De Asmundis, 2013; European Resuscitation Council, 2015; Junta Andalucía, 2015; Márquez, Garza, Asensio, y Ortíz, 2016; Montagud, 2015; Morentin y Audicana, 2011) 
La PCR es un problema sanitario de primera magnitud. A nivel mundial se estima que la incidencia ronda entre 4 y 5 millones al año. Además según el Consejo Español de Reanimación Cardiopulmonar (CERCP) revelan que en Europa se producen más de 350.000 PCRs al año. (Boston Scientific, 2013; Junta Andalucía, 2015; Lopes, 2014; Tíscar González, 2014)

En España, se estima que se producen 24.500 PCRs al año, lo que equivale aproximadamente a un ratio de una parada cada 20 minutos (European Resuscitation Council, 2015; Gracias Pérez y Ibáñez Moreno, 2011; Junta Andalucía, 2015; Lopes, 2014). Extrapolando los datos, en la provincia de Castellón en el 2014 se han producido 311 PCRs por causas isquémicas, y aproximadamente 70 PCRs por miocardiopatías y trastornos congénitos.

Un $60 \%$ de las PCRs se producen en el medio extrahospitalario, de las cuales un $80 \%$ son en presencia de testigos, y únicamente un $15 \%$ de estos testigos cuentan con conocimientos suficientes para llevar a cabo una Reanimación Cardiopulmonar Básica. (RCP) (Boe, 2009; Lopes, 2014; Márquez y cols., 2016).Un 85\% de las PCRs extrahospitalarias se deben a la FV, una arritmia potencialmente mortal (Boston Scientific, 2013; Flisfisch, Aguiló, y Leal, 2014; Gracias Pérez y Ibáñez Moreno, 2011; Márquez y cols., 2016; Montagud, 2015; Ruano, 2005).

La PCR cuenta con tres métodos de tratamiento, los cuales están relacionados entre si. El primero de ellos son las maniobras de RCP, se tratan de un conjunto de medidas que se realizan de manera secuencial para revertir el paro cardiaco y respiratorio. Hay tres tipos de RCP, la básica, la instrumentada y la avanzada. El segundo método es la desfibrilación, eficaz para la finalización de arritmias potencialmente mortales como FV y a TVSP. Éste consiste en la aplicación de una descarga eléctrica breve entre dos electrodos situados en el tórax del paciente (principalmente en el área paraesternal derecha y la zona apexiana) (Carmona Torres, 2014; Ercilla Martín y Crovetto de la Torre, 2014; Lopes, 2014; López Messa y cols., 2008; Ruano, 2005; Secher y cols., 2012). Y por último está la administración de fármacos, los principales son el oxígeno, el cual permite revertir la anoxia en la medida de lo posible y la adrenalina que permite el tratamiento de ritmos tanto desfibrilables como no desfibrilables. Otros fármacos utilizados son la atropina, lidocaína, amiodarona, bicarbonato sódico y magnesio. Su utilización dependerá de la situación del paciente (Ercilla Martín y Crovetto de la Torre, 2014; Flisfisch y cols., 2014).

En aquellas personas que padecen una PCR, la tasa de supervivencia aumenta con la activación temprana de la cadena de supervivencia por parte de cualquier persona. Ésta consta de cuatro eslabones, el primero de ellos es la activación precoz del servicio de emergencias médicas, los testigos deben identificar los signos de PCR y llamar pidiendo ayuda a los servicios de emergencias. El segundo eslabón de la cadena de supervivencia es el inicio precoz de la RCP Básica, puede doblar o triplicar la supervivencia, ya que a partir de 5 minutos la supervivencia disminuye rápidamente y a partir de los 9 minutos puede haber lesiones cerebrales debido a la anoxia. El tercer eslabón es la desfibrilación precoz, para revertir la FV y la TVSP, de no realizar una desfibrilación precoz, el paciente puede pasar a asistolia, un ritmo más difícil de revertir. La desfibrilación junto con la RCP básica realizada en los 3-5 primeros minutos pueden llegar a conseguir entre un $50-75 \%$ de supervivencias, cada minuto de retraso ésta disminuye un $10 \%$. Para que el mismo testigo de la PCR pueda realizar la desfibrilación, el Ministerio de sanidad y consumo en el Real Decreto 365/2009 de 20 de marzo, regula la instalación de desfibriladores externos semiautomáticos en instalaciones públicas fuera del ámbito sanitario. El último eslabón de la cadena de supervivencia es la instauración del soporte vital avanzado y cuidados postresucitación por parte del personal sanitario para actuar sobre las causas que han desencadenado esta situación (Boe, 2009; Gracias Pérez y lbáñez Moreno, 2011; López Messa y cols., 2008; Ruano, 2005; Tíscar González, 2014).

Por todo ello, debido a la alta incidencia de la PCR en la población, produciendo un gran número de muertes al año, y teniendo en cuenta que un $60 \%$ de las cuales ocurre fuera del 
medio extrahospitalario, y en presencia de testigos. Considero que es de suma importancia la formación de los ciudadanos en RCP Básica, para de eso modo poder aumentar el índice de supervivencia.

De ahí el motivo de mi investigación, conocer el nivel de conocimiento de la RCP con el fin de detectar posibles carencias en la población a la hora de actuar frente a una PCR. Para ello se utilizó una muestra de estudiantes, y más concretamente de estudiantes de primero de Enfermería.

La formación a los ciudadanos, debería ser llevada a cabo por profesionales expertos en la materia, donde el personal de enfermería juega un papel de suma importancia debido a sus conocimientos sobre la materia, y a su labor educativa de la población.

\section{Objetivo General}

Determinar la adquisición de competencias en Reanimación Cardiopulmonar Básica en alumnos de primero del Grado de Enfermería de la Universidad Jaume I.

\section{Objetivos Específicos}

- Determinar los aspectos sociodemográficos que representan el alumnado.

- Analizar las diferencias en la adquisición de conocimientos en los diferentes grupos de seminarios.

- Determinar la influencia de conocimientos previos a la hora de adquirir nuevos conocimientos en las sesiones teóricas y prácticas.

\section{Método}

Diseño y ámbito: Se realizó un estudio observacional transversal, se llevó a cabo en la Universidad Jaume I. La recogida de datos fue realizada en el mes de diciembre de 2016, mediante la auto cumplimentación de un cuestionario ad hoc repetidos en dos cortes empleando un pretest y un postest.

Población y muestra: La población de estudio fue formada por los estudiantes de primero del Grado de Enfermería de la Universidad Jaume I, 54 alumnos, matriculados en la asignatura de Fisiología Humana, divididos en tres grupos de seminarios según el orden de matriculación con los criterios impuestos por la universidad. Para la determinación del tamaño de la muestra, se utilizó la calculadora de Granmo para estimación poblacional. Para el grupo general se determinó una muestra de 45 individuos, para el grupo de laboratorio "A» se determinó una muestra de 15 individuos, para el grupo de laboratorio «B» 24 individuos y para el grupo de laboratorio «C» 13 individuos.

Criterios de inclusión: Fue incluido todo alumno matriculado en el Grado en Enfermería de la Universitat Jaume I desde octubre de 2016 dentro de la asignatura de Fisiología Humana.

Criterios de exclusión: Se excluyó a todo alumno matriculado a partir de diciembre de 2016 en la asignatura de Fisiología Humana de la Universitat Jaume I , y a todo alumno que se dio de baja en dicha asignatura a partir de diciembre de 2016. También se excluyó a todo alumno que no participo en alguna de las sesiones formativas, tanto teóricas como prácticas relacionadas con la RCP básica dentro de la asignatura de Fisiología Humana. 
Variables: Las variables recogidas en los cuestionarios del estudio fueron agrupadas en 5 epígrafes en función de las variables generales, variables sociodemográficas, variables relacionadas con la encuesta, variables relacionadas con la satisfacción y variables de resultados.

Intrumentos utilizados: Se emplearon dos cuestionarios ad-hoc, uno pretest y otro postest. Al inicio de cada encuesta se cumplimenta un aparatado de codificación, donde el alumnado generó un código anonimatizado introduciendo la primera letra del nombre, los tres últimos números de DNI/NIE y la letra de este documento. La elaboración de ambas encuestas fue valorada por un grupo de personas expertas en la materia. Ambos cuestionarios cuentan con las mismas preguntas, 20 en cada uno, en las cuales la temática versó en la Reanimación Cardiopulmonar Básica. Se tratan de preguntas tipo test con 4 posibles respuestas. Las preguntas se encuentran divididas en 6 categoría, Parada Cardiorrespiratoria, Servicios de Emergencias, Vía Aérea, Algoritmo de Soporte Vital Básico, Ventilaciones de Rescate y Compresiones Torácicas. El cuestionario pre-intervención cuenta con un apartado de datos sociodemográficos, en el cual se pregunta por el grupo de seminario, sexo, fecha de nacimiento, trabajo en sanidad, formación previa en RCP y si han presenciado alguna RCP, en total 6 preguntas. La encuesta post-intervención, cuenta únicamente con 3 de las preguntas del apartado sociodemográfico (grupo de seminario, sexo y fecha de nacimiento) y cuenta también con un apartado de preguntas de satisfacción, 12 preguntas, valoradas con las siguiente puntuación: 1- muy en desacuerdo, 2- en desacuerdo, 3- ni acuerdo ni desacuerdo, 4- de acuerdo y 5- muy de acuerdo.

Procedimiento: El plan de intervención se compuso por una sesión teórica y otra práctica. Para la sesión teórica, se utilizó una presentación Power Point con la materia, esta sesión se impartió por la profesora de Fisiología Humana a todo el grupo conjuntamente, con una duración de 120 minutos. Al principio de esta sesión, se explico al alumnado el proyecto, y se solicitó su autorización. Los contenidos teóricos fueron obtenidos de la European Resource Council del 2015, respecto a los adultos. La sesión práctica, se impartió en 6 grupos con aproximadamente 8 alumnos por cada uno, respetando los grupos de seminario. Fue impartida por la misma profesora, la cual realizó una demostración, y posteriormente, los alumnos practicaron por parejas e individualmente. Ambas sesiones fueron impartidas en las aulas de la Facultad de Ciencias de la Salud de la Universidad Jaume I.

Análisis de los datos: Los datos obtenidos se analizaron con el programa estadístico Statistical Package for the Social Sciences (SPSS) v. 20 OSX. Para la realización del análisis descriptivo de los datos, los resultados obtenidos en las encuestas fueron recodificados para obtener las variables de resultados. Aquellas respuestas correctas fueron calificadas con un punto, y aquellas respuestas erróneas o no contestadas fueron calificadas con un cero.

Consideraciones éticas: Para la realización de este proyecto en la Universidad Jaume I, se solicitó permiso mediante correo electrónico al Vicedecano de la Facultad y a la Directora del departamento del Grado de Enfermería. Las encuestas proporcionadas contaban con un texto introductorio e informativo, en el cual se especificaban la estructura de la encuesta, los motivos del estudio, el anonimato y su autorización. Éstas eran anónimas, ya que contaban con un código creado por los estudiantes, para así asegurar la confidencialidad de los datos. Las encuestas fueron protegidas, y únicamente tenía acceso a ellas el tutor del proyecto. Para mantener el anonimato, los grupos de laboratorio fueron codificados en Laboratorio «A», Laboratorio «B» y Laboratorio «C». 


\section{Resultados}

La muestra final que participó en el estudio es del 94,44\% $(n=51)$ del total de la clase. Los participantes, se dividieron en tres grupos según el seminario. De estos un $29,4 \%$ forman parte del grupo de Laboratorio "A», un $45,1 \%$ pertenecen al grupo de Laboratorio "B» y un $25,5 \%$ pertenece al grupo de Laboratorio «C». Estos valores pueden observarse en la Tabla 1. En relación al sexo de los estudiantes, un $70,6 \%(n=36)$ del total de la muestra son mujeres, el restante, un $29,4 \%(n=15)$ son hombres. Respecto a la pregunta del trabajo en sanidad realizada a los alumnos participes en el estudio ( $n=50,1$ valores perdidos), únicamente un 3,9 $\%$ del total de la muestra ha trabajado en sanidad. Un $21,6 \%$ de la muestra de estudio realizó anteriormente un cursos de RCP. Del total de cursos realizados, un 11,8\% se trata de RCP Básica, un 3,9\% han realizado un curso de RCP Instrumentada, un $2 \%$ realizó un curso de DESA, y otro $3,9 \%$ se trata de RCP Avanzada. Todos los cursos realizados, han sido impartidos por la formación científica ERC según el alumnado.

Respecto al año de realización de los cursos, un $4 \%$ se realizaron antes de las nuevas modificaciones del 2015 , y un $13,8 \%$ se han realizado tras estas modificaciones. En relación a cuantos alumnos de enfermería han presenciado anteriormente una RCP $(n=50,1$ valores perdidos) ha respondido de forma positiva únicamente el $10 \%$, y todas estas se han producido en el medio extrahospitalario.

Tabla 1

Tasa cumplimentación de la encuesta

\begin{tabular}{|c|c|c|c|c|c|c|c|c|c|}
\hline & & \multicolumn{2}{|c|}{$L A » A »$} & \multicolumn{2}{|c|}{$L A » B »$} & \multicolumn{2}{|c|}{$L A » C »$} & \multicolumn{2}{|c|}{ GLOBAL } \\
\hline & & $\mathrm{n}$ & $\%$ & $\mathrm{n}$ & $\%$ & $\mathrm{n}$ & $\%$ & $\mathrm{n}$ & $\%$ \\
\hline \multirow{5}{*}{$\stackrel{\varrho}{0}$} & Respondido & 15 & 100 & 23 & 88,46 & 12 & 100 & 51 & 94,44 \\
\hline & $\begin{array}{l}\text { No respondi- } \\
\text { do }\end{array}$ & - & - & 3 & 11,54 & - & - & 3 & 5,88 \\
\hline & TOTAL & 15 & - & 26 & - & 13 & - & 54 & 100 \\
\hline & & \multicolumn{2}{|c|}{ LA1 } & \multicolumn{2}{|c|}{ LA2 } & \multicolumn{2}{|c|}{ LA3 } & \multicolumn{2}{|c|}{ GLOBAL } \\
\hline & & $\mathrm{n}$ & $\%$ & $\mathrm{n}$ & $\%$ & $\mathrm{n}$ & $\%$ & $\mathrm{n}$ & $\%$ \\
\hline \multirow{3}{*}{$\begin{array}{l}\bar{c} \\
0 \\
0\end{array}$} & Respondido & 15 & 100 & 23 & 88,46 & 13 & 100 & 51 & 94,44 \\
\hline & $\begin{array}{l}\text { No respondi- } \\
\text { do }\end{array}$ & - & - & 3 & 11,54 & - & - & 3 & 5,88 \\
\hline & TOTAL & 15 & - & 26 & - & 13 & - & 54 & 100 \\
\hline
\end{tabular}

Aquellas preguntas que han destacado son la 7,8 y 10.

Respecto a la pregunta 7 (Si se sospecha una lesión cervical, cual es la maniobra recomendada para abrir la vía aérea en un adulto) En relación a los resultados globales obtenidos, en la encuesta pre se observa un porcentaje de aciertos del $6,4 \%$ ( $n=47,4$ valores perdidos), con una media de $0,06 \mathrm{dt} \pm 0,283$. En la encuesta post se observa un $94 \%$ de aciertos ( $\mathrm{n}=$ 50, 1 valores perdidos), una media de 0,92 dt $\pm 0,272$. En ambas encuestas se ha obtenido un mínimo de 0 y máximo de 1 . En el Laboratorio «A», en la encuesta pre se ha obtenido un 
porcentaje de aciertos del 6,7\%, una media de $0,07 \mathrm{dt} \pm 0,258$, y en la encuesta post se ha obtenido un porcentaje de aciertos del $85,8 \%$, una media de $0,8 \mathrm{dt} \pm 0,414$, en ambas encuestas se ha obtenido un mínimo de 0 y máximo de 1 . En el Laboratorio «B», en la encuesta pre se ha obtenido un $9,1 \%$ de aciertos una media de $0,09 \mathrm{dt} \pm 0,288$, mínimo 0 y máximo 1 . En la encuesta post se ha obtenido un porcentaje de aciertos del $100 \%$ con una media de $1 \mathrm{dt} \pm 0,0$, mínimo y máximo de 1. Por último, en el Laboratorio "C», en la encuesta pre se ha obtenido un porcentaje de aciertos de $0 \%$ con una media de $0 \mathrm{dt} \pm 0$, mínimo y máximo de 0 , y en la encuesta post un $92,3 \%$ de aciertos $(n=13)$, una media de $0,92 \mathrm{dt} \pm 0,277$, se ha obtenido un mínimo de 0 y máximo de 1.

En la pregunta 8 de la encuesta (Si un paciente está en el suelo consciente y responde ¿Qué haremos?) los resultados globales obtenidos, en la encuesta pre se observa un porcentaje de aciertos del 18,4\% ( $n=49,2$ valores perdidos), con una media de 0,18 dt $\pm 0,385$. En la encuesta post se observa un $4 \%$ de aciertos ( $n=50,1$ valores perdidos), una media de $0,04 \mathrm{dt}$ $\pm 0,196$. En ambas encuestas se ha obtenido un mínimo de 0 y máximo de 1 .

En el Laboratorio «A», en la encuesta pre se ha obtenido un porcentaje de aciertos del $13.3 \%$, una media de $0,13 \mathrm{dt} \pm 0,352$, mínimo de 0 y máximo de 1 , y en la encuesta post se ha obtenido un porcentaje de aciertos del $0 \%$, una media de $0 \mathrm{dt} \pm 0,0$, en ambas encuestas se ha obtenido un mínimo y máximo de 0 . En el Laboratorio «B», en la encuesta pre se ha obtenido un $30,4 \%$ de aciertos una media de $0,3 \mathrm{dt} \pm 0,470$. En la encuesta post se ha obtenido un porcentaje de aciertos del 8,7\% con una media de 0,09 dt $\pm 0,288$, en ambas encuestas se ha obtenido un mínimo de 0 y máximo de 1 . Por último, en el Laboratorio «C», en ambas encuestas se ha obtenido un porcentaje de aciertos del $0 \%$, con una media de $0 \mathrm{dt} \pm 0,0$, mínimo y máximo de 0 .

En la relación a la pregunta 10 de la encuesta (Hay un transeúnte tirado en el suelo y no responde. ¿Qué haríamos en primer lugar?), los resultados globales obtenidos en relación a este ítem, en la encuesta pre se observa un porcentaje de aciertos del $20 \%$ ( $n=50,1$ valores perdidos), con una media de $0,2 \mathrm{dt} \pm 0,401$. En la encuesta post se observa un $40 \%$ de aciertos ( $n=50,1$ valores perdidos), una media de 0,39 dt $\pm 0,493$. En ambas encuestas se ha obtenido un mínimo de 0 y máximo de 1.

En el Laboratorio «A», en la encuesta pre se ha obtenido un porcentaje de aciertos del $0 \%$, una media de $0 \mathrm{dt} \pm 0,0$, con un mínimo y máximo de 0 , y en la encuesta post se ha obtenido un porcentaje de aciertos del $42,9 \%$, una media de 0,4 dt $\pm 0,507$, con un mínimo de 0 y máximo de 1. En el Laboratorio «B», en la encuesta pre se ha obtenido un $39,1 \%$ de aciertos, una media de 0,39 dt $\pm 0,499$. En la encuesta post se ha obtenido un porcentaje de aciertos del $34,8 \%$ con una media de $0,35 \mathrm{dt} \pm 0,487$, en ambas encuestas se ha obtenido un mínimo de 0 y máximo de 1 . Por último, en el Laboratorio « $\mathrm{C}$ », en la encuesta pre se ha obtenido un porcentaje de aciertos de $8,3 \%$ con una media de $0,08 \mathrm{dt} \pm 0,277$, y en la encuesta post un 46,2 $\%$ de aciertos, una media de 0,46 dt $\pm 0,519$, en ambas encuestas se ha obtenido un mínimo de 0 y máximo de 1 .

\section{Discusión y conclusión}

Tras el análisis de los datos, se observa un aumento del porcentaje de aciertos tras la sesión teorico-práctica en las preguntas de la encuesta que componen las categorías Parada Cardiorrespiratoria, Servicios de Emergencias. El elevado número de aciertos que se obtiene en las preguntas de esta categoría, posiblemente sea debido a las numerosas campañas que se realizan tanto por parte del personal sanitario como por parte de los Cuerpos de Emergencias del Estado (bomberos, policía, militares, etc.) en cuanto a información respecto al Teléfo- 
no Europeo de Emergencias 1.1.2. (Generalitat de Catalunya, s. f.; Govern Illes Balears, s. f.).

En las categorías Vía Aérea, Ventilaciones de Rescate y Compresiones Torácicas, se observa un aumento del porcentaje de aciertos en la encuesta post, esta mejora es posible que se deba a la motivación de los alumnos en la adquisición de conocimientos y el asentamiento de éstos de forma práctica en los seminarios con los torsos de maniquís, ya que como se observa en el estudio realizado por María Jesús Durá Ros, la simulación clínica facilita el aprendizaje y la adquisición de competencias (Durá Ros, 2013).

En la categoría Algoritmo de Soporte Vital Básico, se observa un aumento del porcentaje de aciertos en seis de las siete preguntas que componen esta categoría. En la pregunta 8 de la encuesta ( $\mathrm{Si}$ un paciente está en el suelo consciente y responde ¿Qué haremos?) se observa una disminución del número de aciertos tras la intervención, ya que un gran porcentaje de los alumnos, consideró como respuesta correcta colocar al individuo en posición lateral de seguridad, en cambio, la bibliografía utilizada, determina que aquel individuo que se encuentre en el suelo consciente debe dejarse en la posición que se encuentra, siempre que no corra peligro, y se debe reevaluar periódicamente (European Resuscitation Council, 2015; Gracias Pérez e Ibáñez Moreno, 2011; López Messa y cols., 2008). Estos resultados pueden deberse a una falta de la comprensión de los resultados o un error en la interpretación del alumnados en el algoritmo de SVB. En esta categoría, también cabe reseñar que en la décima pregunta del cuestionario, aunque se produce una mejora de los resultados, tan solo un $40 \%$ del alumnado a logrado una respuesta correcta. Estos resultados pueden deberse a la diversidad de algoritmos de SVB que podemos encontrar al alcance de los ciudadanos o para el personal sanitario. La guía de la American Hearth Association y la guía de la ERC consideran que aquel personal que no posé entrenamiento, debe gritar pidiendo ayuda tras comprobar que el paciente no respira, aunque la guía de la ERC considera que si el reanimador se encuentra solo también es posible llamar al 1.1.2. al mismo tiempo que se comprueba si el paciente respira (American Heart Association, 2015; European Resuscitation Council, 2015).

\section{Limitaciones del estudio}

- La intervención realizada, únicamente duró tres horas (dos teóricas y una práctica) cuando normalmente un curso de RCP Básica tiene una duración de 12,5 horas.

- La encuesta post fue cumplimentada inmediatamente tras la sesión práctica, por lo tanto no se ha valorado los conocimiento adquiridos en un periodo posterior a la intervención.

- El grupo se distribuye en diferentes subgrupos, los cuales no tiene un numero equitativo de alumnos.

Conclusión: Tras el análisis de los datos y la valoración de los resultados obtenidos, podemos decir que el alumnado participe en el estudio ha adquirido conocimientos respecto a las maniobras de RCP tras la sesión teórico-práctica. Estos conocimientos, pueden ayudar a aumentar la supervivencia de la población que padece una PCR, ya que se produce la activación precoz de la cadena de supervivencia. El grupo de Laboratorio " $C$ » es aquel que muestra un mayor porcentaje de aciertos respecto a los otros grupos, por lo tanto, aquellos grupos con un menor número de alumnos los resultados demuestran una mejor calificación en la adquisición de conocimientos. El alumnado se muestra un alto nivel de satisfacción con la realización de la sesión teórico-práctica tras la realización de las mismas. La sesión práctica facilita la conso- 
lidación de los conocimientos del alumnado tras la sesión teórica obteniendo mejor resultado tras las mismas.

\section{Referencias bibliográficas}

American Heart Association. (2015). 2015 AHA Guidelines update for CPR and ECC.

Boe. (2009). Real Decreto 365/2009, de 20 de marzo, por el que se establecen las condiciones y requisitos mínimos de seguridad y calidad en la utilización de desfibriladores automáticos y semiautomáticos externos fuera del ámbito sanitario.

Boston Scientific. (2013). La insuficiencia cardíaca y la muerte súbita cardíaca : datos fundamentales y motivos por los que es importante la longevidad del dispositivo, 1-4.

Cardiologia, S. española de. (2013). ficha-paciente-parada-cardiaca.pdf.

Carmona Torres, J. M. (2014). Cuestionario de conocimientos enfermeros sobre las actuales recomendaciones de reanimación cardio-pulmonar 2010. Enfermeria Clinica, 24(5), $1-55$.

Castellano, N. P. (2009). la resucitacion cardiaca. Libro de la salud cardiovascular, 427-434.

De Asmundis, C. (2013). Epidemiología de la muerte súbita cardiaca. Revista española de cardiología, 13, 2-6.

Durá Ros, M. J. (2013). La Simulación Clínica como Metodología de Aprendizaje y Adquisición de Competencias en Enfermería., 15-23.

Ercilla Martín, J., y Crovetto de la Torre, M. Á. (2014). Características clínicas de la parada caridiorrespiratoria en españa desde 1990 a 2014: una revisión bibliográfica.

European Resuscitation Council. (2015). Recomendaciones para la Resucitación 2015 del Consejo Europeo de Resucitación (ERC).

Flisfisch, H., Aguiló, J., y Leal, I. (2014). Actualización en paro cardiorespiratorio y resucitación cardiopulmonar. Medicina y Humanidades, VI, 29-36.

Generalitat de Catalunya. (s. f.). Apps para dispositivos móviles. 112. Generalitat de Catalunya.

Govern Illes Balears. (s. f.). 112 Islas Baleares-112 en las Escuelas.

Gracias Pérez, R., y Ibáñez Moreno, R. (2011). CURSO RCP Y MANEJO DEL DESA. Delegación de deportes ayuntamiento Leganés, 1-21.

Jiménez Murillo, L., y Montero Pérez, F. J. (2015). Medicina de urgencias y emergencias (Elvesier). Barcelona :

Junta Andaluciía. (2015). Dossier_Presentacion_Proyecto_OHSCAR.pdf.

Lopes, P. (2014). Reanimación cardiopulmonar (RCP) en los Institutos de Educación Secundaria (IES): ¿Tienen los alumnos los conocimientos suficientes?1. Lopes P. Reanimación cardiopulmonar (RCP) en los Institutos de Educación Secundaria (IES): ¿Tienen los alumnos los conoc, 37.

López Messa, J. B., Perales Rodríguez de Viguri, N., Ruano Marco, M., Tormo Calandín, C., y Tamayo Lomas, L. (2008). Manual para la enseñanza de monitores en soporte vital básico y desfibrilación externa semiautomática. (Elvesier M). Barcelona :

Márquez, M. F., Garza, G. P., Asensio, E., y Ortíz, F. (2016). Muerte súbita cardiaca . Estratificación de riesgo, prevención y tratamiento Sudden cardiac death. Risk stratification , prevention and treatment, 85(4), 1-8.

Montagud, V. (2015). Muerte súbita.

Morentin, B., y Audicana, C. (2011). Estudio poblacional de la muerte s??bita cardiovascular extrahospitalaria: incidencia y causas de muerte en adultos de edad mediana. Revista Espanola de Cardiologia, 64(1), 28-34. 
Ruano, M. C. T. (2005). Manual de Soporte Vital Avanzado (Masson). Barcelona :

Secher, N., Mikkelsen, M. M., Adelborg, K., Mikkelsen, R., Grove, E. L., Rubak, J. M., Løfgren, B. (2012). Direct mail improves knowledge of basic life support guidelines in general practice: a randomised study. Scandinavian journal of trauma, resuscitation and emergency medicine, 20(1), 72.

Tíscar González, V. (2014). Cuestionario sobre conocimientos y actitud de enfermería ante la PCR ., 1-56. 


\title{
Cuidados de enfermería en pacientes diagnosticados de vértigo posicional paroxístico benigno
}

\author{
Alba GonZÁlez Gallego \\ al286552@uji.es \\ LLEDÓ GUILLAMÓN GIMENO \\ guillamm@uji.es
}

\section{Resumen}

Introducción: El vértigo posicional paroxístico benigno (VPPB), producido por cambios de posición, es el tipo de vértigo más frecuente que representa un $40 \%$ de las consultas. Sin embargo, hoy en día sigue sin existir información científica suficiente que muestre la labor de enfermería en estos trastornos otorrinolaringológicos. En base a ello, se establece como objetivo conocer cuáles son los cuidados de enfermería en pacientes diagnosticados de VPPB con el fin de mejorar su calidad de vida. Metodología: Se desarrolló una revisión de la literatura, consultando cuatro bases de datos científicas (PubMed, Biblioteca Cochrane Plus, Joanna Briggs Institute, Biblioteca Virtual de Salud), la biblioteca electrónica Scielo y la página web oficial de la Conselleria de Sanitat Universal i Salud Pública; así como también fuentes primarias. Resultados: Se obtuvieron un total de 545 artículos de los que se escogieron 7 para la síntesis. Las temáticas muestran los cuidados de enfermería durante las fases más agudas de la enfermedad; durante la administración del tratamiento farmacológico; durante la realización de las maniobras de reposición otolítica; y durante el pre, intra y post-operatorio en caso de intervención quirúrgica. También se destaca el papel de la enfermera como figura de apoyo educativo. Conclusión y aplicaciones en la práctica clínica: Las intervenciones de enfermería repercuten en la mejora de la salud y calidad de vida de pacientes diagnosticados de VPPB, principalmente en el proceso educativo. Una mayor investigación en estos trastornos, desde la perspectiva enfermera, permitirá mejorar y optimizar los cuidados necesarios.

Palabras clave: vértigo posicional paroxístico benigno, atención de enfermería, calidad de vida.

\section{Abstract}

Introduction: Benign paroxysmal positional vertigo (BPPV), caused by positional changes, is the most frequent type of vertigo that comes up to $40 \%$ of the visits. However, nowadays there is still no sufficient scientific evidence to show the nursing importance in these otorhinolaryngological disorders. Based on this, it is established as objective to know which are the nursing care in patients diagnosed with BPPV in order to improve their quality of life. Methodology: A review of the literature was carried out, 
consulting four scientific databases (PubMed, Cochrane Plus Library, Joanna Briggs Institute, Biblioteca Virtual de Salud), the Scielo electronic library and the official website of "Consellería de Sanitat Universal i Salud Pública»; as well as primary sources. Results: A total of 545 articles were obtained from which 7 were chosen for the synthesis. The themes show the importance of nursing care during the most acute phases of the disease; during the administration of pharmacological treatment; during the accomplishment of the otolytic repositioning maneuvers; and during the pre, intra and postoperative periods in case of surgical intervention. It also highlights the role of the nurse as an educational support figure. Conclusion and applications in clinical practice: Nursing interventions have an impact on improving the health and quality of life of patients diagnosed with BPPV, mainly in the educational process. Further research into these disorders, from the nurse perspective, will allow to improve and optimize the necessary care.

Key words: Benign paroxismal positional vertigo, nursing care, quality of life.

\section{Introducción}

El vértigo se define como un síntoma caracterizado por la percepción anómala del movimiento que crea una sensación subjetiva de desplazamiento rotatorio (Pertusa, Gomis \& Pérez, 2002). Generalmente, el vértigo no se presenta como único síntoma, sino que está incluido dentro del denominado síndrome vertiginoso, presentando manifestaciones motoras (nistagmo, desequilibrio) y vegetativas (palidez, diaforesis, náuseas, vómitos, hipotensión e hipersalivación) (Rubiales \& Palmar, 2009).

Desde el punto de vista etiológico, el vértigo se clasifica en: vértigo central y vértigo periférico. Este último representa el $85-90 \%$ del total de casos. Tiene una prevalencia estimada del $5 \%$ por año y es más frecuente a partir de la cuarta década de la vida. Presenta las siguientes características: inicio repentino con evolución paroxística, duración de segundos o minutos e influencia postural (Pertusa, Gomis \& Pérez, 2002).

Formando parte del vértigo periférico, el vértigo posicional paroxístico benigno (VPPB) es el más frecuente, ocurriendo en más del $50 \%$ de casos totales de vértigo, con una incidencia entre 11 y 64 casos por 100.000 habitantes por año, siendo más frecuente en mujeres entre los 40-60 años y representando hasta un $40 \%$ de las consultas sanitarias (Alcalá, Lambert \& Suárez, 2014). EI VPPB, producido por la existencia de otolitos en el canal semicircular posterior (CSP), se define como episodios de vértigo intenso con una duración entre 1 y 60 segundo desencadenados por cambios de posición, al levantarse y tumbarse en la cama, al adoptar la posición de decúbito lateral, al inclinarse o extender el cuello (Morera \& Marco, 2006). Su resolución es espontánea, y se suele recuperar en un plazo aproximado de tres meses (Jennifer M., 2000).

La importancia del estudio de los cuidados de enfermería en el VPPB reside en la frustración que esta patología puede causar al enfermo que ve afectada tanto su capacidad para realizar las actividades básicas de la vida diaria como el descanso apropiado y satisfactorio (Jennifer,2000). Por otra parte, con el aumento de la esperanza de vida, el vértigo y los trastornos del equilibrio en general se han convertido en un motivo muy frecuente de consulta en Atención Primaria y Servicios de Urgencia (Alcalá, Lambert \& Suárez, 2014). Sin embargo, y desde un punto de vista enfermero, no existe evidencia científica suficiente que muestre los 
cuidados que el profesional de enfermería puede proporcionar, siendo la enfermera uno de los puntos clave en la educación sanitaria y en los cuidados que los pacientes requieren para mejorar su calidad de vida y estado de salud.

Con todo ello, se establece como objetivo de la presente revisión de la bibliografía el siguiente: conocer cuáles son los cuidados de enfermería más adecuados que deben ser proporcionados a los pacientes diagnosticados de VPPB con el fin de mejorar su calidad de vida.

\section{Metodología}

El presente trabajo se basa en la realización de una revisión de la literatura científica disponible sobre los cuidados de enfermería más adecuadas que deben ser proporcionados a los pacientes diagnosticados de VPPB.

A fin de obtener información relevante fueron utilizadas cuatro bases de datos científicas (PubMed, Biblioteca Cochrane Plus, Joanna Briggs Institute y Biblioteca Virtual en Salud), la biblioteca electrónica Scielo, la página web de la Consellería de Sanitat Universal i Salud Pública, y fuentes primarias de la biblioteca de la Universitat Jaume I. La definición de cada fuente de información utilizada y la justificación de su uso de muestra en la siguiente tabla (Tabla 1).

Tabla 1

Fuentes de información y justificación de uso (Fuente: Elaboración propia)

\begin{tabular}{|ll|}
\hline \multicolumn{1}{|c|}{$\begin{array}{c}\text { Fuente de } \\
\text { información }\end{array}$} & \multicolumn{1}{c|}{ Características y justificación } \\
\hline PubMed & $\begin{array}{l}\text { Fuente de datos secundaria de libre acceso que proporciona gran cantidad de } \\
\text { artículos de investigación biomédica. } \\
\text { Se trata de un motor de búsqueda sencillo, con una gran calidad en la } \\
\text { información, y opcionalmente utilizar el lenguaje controlado tipo Medical } \\
\text { Subject Headings (MeSH). }\end{array}$ \\
\hline $\begin{array}{l}\text { Biblioteca } \\
\text { Cochrane Plus }\end{array}$ & $\begin{array}{l}\text { Fuente de datos terciaria muy sencilla en su uso, que proporciona revisiones } \\
\text { sistemáticas. Se trata de una base de datos de revisiones sistemáticas } \\
\text { traducida al español. }\end{array}$ \\
$\begin{array}{l}\text { Joanna Briggs } \\
\text { Institute }\end{array}$ & $\begin{array}{l}\text { Fuente de datos terciaria, exclusiva de enfermería basada en la evidencia } \\
\text { (EBE), que proporciona revisiones sistemáticas mediante un proceso de } \\
\text { búsqueda sencillo. }\end{array}$ \\
\hline $\begin{array}{l}\text { Biblioteca Virtual } \\
\text { en Salud }\end{array}$ & $\begin{array}{l}\text { Fuente de datos secundaria que incluye información y artículos de diversas } \\
\text { bases de datos, con un fácil manejo de las acotaciones. }\end{array}$ \\
Scielo & $\begin{array}{l}\text { Fuente de datos secundaria formada por una colección de revistas científicas } \\
\text { de ciencias de la salud. }\end{array}$ \\
\hline $\begin{array}{l}\text { Fuentes primarias } \\
\text { de la biblioteca } \\
\text { de la Universitat } \\
\text { Jaume I }\end{array}$ & $\begin{array}{l}\text { Fuente de datos primaria que permite obtener información básica, útil y fiable } \\
\text { sobe un tema a tratar, en este caso sobre otorrinolagingología. }\end{array}$ \\
\hline
\end{tabular}

Las búsquedas de información científica fueron realizadas durante la segunda mitad de febrero del año 2016 hasta el día 05 de marzo del año 2016, considerándose como criterios de inclusión de los estudios los siguientes: 
- Texto completo disponible para su lectura y posible descarga

- Límite temporal: 2000-2016

- Población de estudio: humana

- Límite idiomático: Español e Ingles

Para poder realizar la búsqueda de información útil y relevante se establecieron como palabras clave los descriptores Descriptores en Ciencias de la Salud (DeCS) siguientes: Vértigo Posicional Paroxístico Benigno, Atención de enfermería y Calidad de vida. Por su parte, se establecieron también los descriptores MeSH siguientes: Benign Paroxysmal Positional Vertigo, Nursing care, Quality of life.

Estas palabras clave fueron utilizadas en las cuatro bases de datos; mientras que en Scielo y en la página web de la Consellería de Sanitat Universal i Salut Pública fue usado el lenguaje natural «vértigo».

Ante la imposibilidad inicial de obtener información científica relevante y suficiente mediante la combinación de los tres descriptores, se decide llevar a cabo en todas las bases de datos una única búsqueda científica basada en el descriptor principal Vértigo Posicional Paroxístico Benigno/Benign Paroxysmal Positional Vertigo y los limitadores basados en los criterios de inclusión del presente estudio.

De esta forma, se obtuvieron un total de 59 resultados en PubMed, 94 resultados en la Biblioteca Cochrane Plus, 1 resultado en Joanna Briggs Institute y 290 resultados en la Biblioteca Virtual en Salud.

Por su parte, en Scielo, mediante búsqueda de información científica con el uso del lenguaje natural y los filtros oportunos según los criterios de inclusión se obtuvieron un total de 101 resultados.

Posteriormente, fue realizada la búsqueda en la página web de la Conselleria de Sanitat Universal i Salud Pública, y en la biblioteca de la Universitat Jaume I.

\section{Resultados}

Se obtuvieron un total de 545 resultados. De todos ellos, un total de 542 estudios fueron rechazados por no cumplir los criterios de inclusión establecidos en el presente estudios o por no aportar información útil sobre el tema central de estudio. De esta forma, se utilizaron un total de cuatro artículos científicos de gran utilidad. Por otro lado, se obtuvo una guía de práctica clínica de la página web de la Conselleria de Sanitat Universal i Salud Pública; y dos libros de la biblioteca de la Universitat Jaume I.

Todos estos resultados, tanto estudios, guías de práctica clínica como libros, fueron seleccionados por el punto de vista enfermero que proporcionaban y por la importancia que éstos resaltaban del tratamiento de la patología y de la educación sanitaria en la enfermedad.

En los artículos obtenidos y utilizados, se resalta la importancia de realizar una anamnesis enfermera en profundidad, permitiendo determinar la sintomatología que presenta el paciente, la forma y el momento de comienzo, la intensidad, la evolución y los factores desencadenantes y atenuantes (Pertusa, Gomis \& Pérez, 2002). Se deberá recoger información sobre la forma en la que la patología ha influido en su estilo de vida, haciendo hincapié en las relaciones sociales, la seguridad y su autoestima (Rubiales \& Palmar, ,2009). Además, y de forma inicial, debe realizarse una valoración del estado del paciente: valoración general (PA, FC) y otoneurológica (estudios del nistagmo) (Jennifer, 2000).

Durante las fases más agudas, resultará prioritario tranquilizar al paciente y conseguir las condiciones ambientales apropiadas para el reposo y la adopción de una postura relajada que 
permita disminuir la sensación de vértigo. Esto deberá ser realizado en decúbito, inmóvil y lejos de ruidos y excesos de luz, manteniendo una dieta absoluta (Pertusa, Gomis \& Pérez, 2002).

Como muestran diversos estudios, la eficacia del tratamiento farmacológico en el VPPB es bastante dudosa, excepto que el vértigo sea muy frecuente o intenso. En estos casos, y siempre por preinscripción del facultativo responsable, el tratamiento farmacológico principal (neurolépticos, antihistamínicos, benzodiacepinas y antagonistas del calcio) será administrado por el personal de enfermería (Jennifer, 2000).

Una vez finalizado el proceso agudo de la enfermedad, la relevancia de los cuidados de los profesionales enfermeros se muestran en el apoyo educativo proporcionado al paciente con el fin de que conozca todas las recomendaciones específicas del autocuidado para su patología y principalmente, debido al diagnóstico enfermero más habitual: «Riesgo de lesión». La enfermera recomendará realizar lentamente los cambios de posición y sentarse o tumbarse cuando comience la sintomatología del vértigo (Rubiales \& Palmar, 2009).

Como tratamiento básico para el VPPB, la bibliografía muestra que, siempre y cuando el profesional de enfermería esté formado para ello, es de gran utilidad efectuar las maniobras de reposición otolítica liberadoras de Semont o las de Epley (RACGP,2013):

- Maniobra de Semont: sentado en la camilla con la cabeza girada $45^{\circ}$ hacia el lado afecto, se lleva al paciente con la energía sobre el hombro enfermo permaneciendo durante 30 segundo en esta posición para, desde aquí, llevarla rápidamente sobre el hombro contrario, y finalmente retornando a la posición inicial. Al finalizar la sesión, la enfermera indicará al paciente que debe evitar tanto grandes movimientos de cabeza como descansar o dormir sobre el lado afecto hasta dos días después de la realización de la maniobra.

- Maniobra de recolocación de partículas de Epley: sentado longitudinalmente en la camilla con la cabeza girada $45^{\circ}$ hacia el lado afecto, dejamos caer rápida y bruscamente al paciente hacia atrás, manteniendo el giro cefálico hasta que la cabeza quede colgando en hiperextensión por el borde de la camilla, manteniéndolo 30 segundos. A continuación giramos la cabeza del paciente $90^{\circ}$ hacia el otro lado y esperamos en esta nueva posición otros 30 segundos. Giramos al paciente hasta colocarlo en decúbito lateral, manteniendo su cabeza rotada $45^{\circ} \mathrm{y}$, finalmente, sentamos al paciente en la camilla. Deberán ser proporcionadas las mismas indicaciones que en la maniobra de Semont.

Para fomentar la mejora y el autocuidado del paciente, la enfermera, teniendo en cuenta las capacidades de comprensión y aprendizaje del paciente, puede proporcionar unos conocimientos básicos de ejercicios a realizar en el propio domicilio: ejercicios Brandt-Daroff. En estos ejercicios la persona parte de la posición sentada y pasará a acostarse sobre un lado con la cabeza girada unos $45^{\circ}$ hacia el techo, permaneciendo aproximadamente 30 segundos y volviendo de nuevo a la posición de partida; finalmente, realizará el mismo proceso sobre el otro lado, repitiéndose 3 veces al día durante 2 semanas (Martínez \& Nicolás, 2000).

En los casos de VPPB que no responden a las maniobras de reposición otolítica anteriormente descritas, existe la posibilidad de ocluir quirúrgicamente el canal semicircular posterior para evitar los vértigos, proporcionando en este caso los cuidados de enfermería pre, intra y postoperatorios generales (Rubiales \& Palmar, 2009). En la fase postoperatoria inmediata, se elevará el cabecero de la cama y se colocará al paciente sobre el lado sano para reducir la presión sobre el lado afectado. Asimismo, se valorará el grado de afectación de la audición y del equilibrio, ya que pueden comprometer la seguridad y la capacidad de comunicación del paciente. Le enfermera deberá recomendarle que no realice movimientos bruscos en la cama, 
así como acompañarle cuando inicie la deambulación. En el momento del alta hospitalaria, el profesional de enfermería enseñará al paciente y a la familia los cuidados postoperatorios necesarios para evitar la aparición de complicaciones, entre las que podríamos encontrar: mantener limpio y seco el taponamiento ótico externo, evitar mover con brusquedad la cabeza en las primeras semanas, administrarse la medicación respetando la pauta establecida y acudir al médico en caso de aparición de supuración, dolor intenso, mareo, presencia de ruidos, etc. (Rubiales \& Palmar, 2009)

\section{Discusión y conclusiones}

La enfermera es uno de los elementos imprescindibles en la mejora del estado de salud del paciente con VPPB, en cada una de las fases de la patología: fase aguda, administración del tratamiento farmacológico, fase crónica, realización de las maniobras de reposición otolítica, tratamiento quirúrgico. La enfermera resalta por su papel educador, sobre las recomendaciones de autocuidado, evitando la aparición del riesgo de lesión que puede padecer y mejorando su calidad de vida.

Aún considerando la dificultad que existe al obtener información científica centrada en los cuidados de enfermería para pacientes con vértigo posicional paroxístico benigno para mejorar su calidad de vida, y considerando al VPPB una patología con una incidencia elevada y que provoca grandes modificaciones en el estado de salud tanto físico como psicológico del paciente, un aspecto a tener en cuenta es la necesidad de realización de mayores investigaciones y publicaciones científicas con una perspectiva enfermera. Sin embargo, es una profesión que ve limitada su actuación en este campo y principalmente en Atención Primaria de Salud, donde con una formación adecuada y con una buena definición de los cuidados a realizar, podrían asistir a un número elevado de pacientes con este trastorno, evitando la necesidad de consultas médicas otorrinolaringológicas frecuentes.

\section{Referencias bibliográficas}

Alcalá, T., Lambert, M. \& Suárez, A. (2014). Enfoque clínico del vértigo desde la Atención Primaria de Salud. Revista Habanera de Ciencias Médicas, 13(3), 394-405.

Jennifer, M. (2000). Diagnóstico y tratamiento del vértigo. Revista Cubana de Medicina, 39(4), 238-253.

Martínez, J. L. \& Nicolás, L. (2008). Tratamiento Manual del vértigo posicional paroxístico benigno. Revista de Fisioterapia (Guadalupe), 7(1), 43-52.

Morera, C. \& Marco, J. (2006). Lecciones de Otorrinolaringología aplicada. Madrid: Editorial Glosa.

Pertusa, S., Gomis, J. \& Pérez, H. (2002). Vértigo: Guía de Actuación Clínica en A. P.

RACGP. (2013). The Epley manoeuvre: For benign paroxysmal positional vértigo. Royal Australian College of General Practitioners, 42(1), 36-37. Recuperado el 3 abril, 2016, de: http://www.san.gva.es/documents/246911/251004/guiasap037vertigo.pdf

Rubiales, M. D. \& Palmar, A.M. (2009). Enfermería del adulto. Volumen II. Madrid: Editorial Centro de Estudios Ramón Areces. 


\title{
Daño muscular y recuperación tras una maratón
}

\author{
Relación con el sexo biológico
}

\author{
RANIA ACHOUAK HAFSI \\ al339149@uji.es \\ ELADIO J. COLLADO BOIRA \\ colladoe@uji.es
}

\section{Resumen}

Introducción: Las carreras de resistencia han incrementado su índice de participación en los últimos años, sobre todo en corredores amateurs. La maratón, prueba estrella entre las carreras de larga duración, lleva asociado un fuerte estrés fisiológico debido al esfuerzo requerido por el organismo, lo cual está ligado a un elevado daño muscular. Tal daño se puede cuantificar hemátológicamente mediante la enzima CK. Objetivo: Medir el desgaste y el tiempo de recuperación muscular en 100 corredores voluntarios de la Maratón de Valencia, así como estudiar la relación existente entre variables como la pérdida de peso, el Índice de Masa Corporal (IMC), la edad y el tiempo real de maratón. Además de buscar si existen diferencias estadísticamente significativas en función del sexo biológico. Método: Estudio analítico descriptivo observacional. Resultados y discusión: Se obtuvieron aumentos significativos de la enzima CK, con mayor proporción en hombres que mujeres. De igual modo, la recuperación fue más lenta en los varones, los cuales precisan de un mínimo de 196 horas frente a las 96 -144 horas del grupo femenino. Se ha evidenciado una correlación significativa $(P<$ $0,05)$ positiva entre la pérdida de peso y el IMC. Mientras que la relación entre las variables pérdida de peso respecto a la edad y el tiempo total invertido ha resultado negativa en ambos casos, con una significación del $99 \%$. El sexo biológico se ha comportado como una variable determinante a la hora de la obtención de resultados en una maratón.

Palabras clave: maratón, CK, recuperación fisiológica, corredor amateur.

\section{Abstract}

Introduction: Endurance races have increased their participation rate in recent years, especially in amateur runners. The marathon, the prefered race by the runners, is associated with a strong physiological stress due to the effort required by the body; this is linked to the high muscle damage that can be quantified hematologically by the enzyme CK. Purpose: To measure the wear and muscle and muscle recovery time in 100 volunteer runners of the Valencia Marathon, as well as to study the relationship between variables such as weight loss, Body Mass Index (BMI), age and marathon time. 
Also looking for if there are statistically significant differences based on the biological sex. Methods: Analytical descriptive observational study. Results and conclusions: Significant increases in CK enzyme were obtained, with a higher proportion in men than women. The recovery was slower in males, which required a minimum of 196 hours compared to the 96-144 hours in the female group. There were a significant positive correlation between weight loss and BMI $(P<0.05)$. The relation between the variable weight loss respect to age and total invested time has been negative, with a significance of $99 \%$. Biological sex has behaved as a determinant variable in obtaining results in a marathon.

Keywords: marathon, CK, physiological recovery, amateur runner.

\section{Introducción}

Las carreras de larga duración, cuyo esfuerzo requerido es elevado, han incrementado exponencialmente el número de participantes (Chan-Roper, 2012), acentuándose la presencia de corredores amateurs, muchas veces careciendo de entrenamiento controlado ni supervisado. El cambio en la tendencia de participación en este tipo de actividad se observa en las inscripciones a las maratones, que ha evidenciado un aumento exponencial de estas en los últimos años. La Maratón de Valencia, única prueba española galardonada con el distintivo Gold Label por la IAAF, ha sumado en su última edición más de 17.500 inscritos.

Recorrer la distancia predeterminada, $42.195 \mathrm{~m}$, en el menor tiempo posible supone una situación de alarma y desgaste del propio organismo. Diferentes estudios corroboran una serie de variaciones en el hemograma sanguíneo debido al esfuerzo extremo que tal prueba supone, caracterizándose por un descenso en la fuerza muscular, la aparición de indicadores indirectos de daño muscular tales como la CK en sangre y variaciones a nivel leucocitario (Del Coso, Salinero, et al., 2013; Lippi et al., 2010; Ruiz-Vicente et al., 2013). Además, está ligado a una pérdida de peso asociada a la deshidratación, aunque no se conoce relación entre dicha variable y el rendimiento a lo largo de la prueba.

Generalmente se recuperan los valores de normalidad a nivel de hemograma en un margen de 24-48 h tras la carrera (Duca et al., 2006; Uchakin et al. 2003). Si más no, existen discrepancias en anteriores estudios ya que las variables objeto de estudio varían en función de la concentración hemática, la cual depende a su vez del nivel de hidratación. Por ello, agentes tales como temperatura, humedad, orografía del terreno y número de puntos de avituallamiento en la carrera influirán en el estudio.

Respecto a los efectos de la bioquímica tras una maratón hallamos numerosos estudios que corroboran que los lípidos son la principal fuente de energía visto que los valores de triglicéridos disminuyen (Callow et al., 1986; Kratz et al., 2002; Sánchez-González et al., 2003). Los niveles de glucosa, en cambio, dependen de la ingesta de carbohidratos a lo largo de la prueba.

Cabe destacar que gran parte del daño recae sobre la musculatura debido a la fatiga, a las continuas contracciones concéntricas y excéntricas, y a los miles de impactos contra el suelo que se producen en estas carreras. Tal daño se cuantifica mediante una enzima sanguínea denominada creatina quinasa $(\mathrm{CK})$, resultante del proceso de obtención de energía por los miocitos a lo largo de ejercicio extenuante, lo cual permite monitorizar la fatiga y el daño 
muscular del organismo, así como su posterior recuperación. Los valores normales de CK, se sitúan entre 22 y $198 \mathrm{UI} / \mathrm{L}$.

\section{Objetivos}

\section{Principal}

- Monitorizar, mediante los valores de la CK, la fatiga, el daño muscular y su posterior recuperación, en una muestra de 100 corredores amateurs voluntarios de la Maratón de Valencia.

\section{Secundarios}

- Analizar si están relacionadas entre sí, diferentes variables de estudio como el IMC, la edad, la pérdida de peso en la prueba y el tiempo en la prueba.

- Analizar si existen diferencias de género entre las variables de estudio de la muestra.

\section{Población de estudio}

La muestra incluye 100 corredores voluntarios participantes en la Maratón Trinidad Alfonso de Valencia de la edición del 2016. Se excluyeron aquellos que padecieran algún tipo de patología renal o cardiológica diagnosticada, dislipemia o tomaran medicación de forma continuada. También se restringía la participación como voluntarios a aquellos con antecedentes de cardiopatía isquémica en familiares de primer grado. Los criterios de inclusión engloban individuos entre 30 y 44 años de edad que hayan superado con anterioridad una maratón con una marca acreditada inferior a las 4 horas en hombres y 4:30 horas en el caso de las mujeres.

\section{Metodología}

\section{Diseño del estudio}

Se trata de un estudio de investigación analítico descriptivo observacional

\section{Procedimiento}

Se realizó una encuesta para conocer los hábitos de entrenamiento de cada sujeto. Se determinó el IMC tomando la altura con un estadiómetro SECA-123 y la masa corporal con una báscula de suelo digital modelo SECA-770. La masa corporal se evaluó pre y post-maratón. Además, se llevaron a cabo un total de siete determinaciones sanguíneas de una vena anterocubital, alternando los brazos en cada extracción. La muestra de sangre fue recogida en tubos Vacutainer específicos para este tipo de analíticas. En concreto, se emplearon tubos secos con gel de tapón amarillo con una presión de vacío que admite $7 \mathrm{ml}$ de sangre. El análisis de los cuales quedó a cargo del laboratorio del Hospital 9 d'Octubre de Valencia. La pri- 
mera toma se realizó $24 \mathrm{~h}$ antes de la carrera, en la Feria del Corredor (Ciutat de les Arts i de les Ciències). La siguiente fue en Meta y se reiteró el procedimiento a las 24, 48, 96, 144 y 192 horas tras la misma.

Este proyecto contó con la aprobación por parte de la Comisión Deontológica de la Universitat Jaume I, de acuerdo a la última versión de la Declaración de Helsinki para estudios con seres humanos. Los voluntarios fueron informados de los objetivos de la investigación, de los riesgos y beneficios de la misma, y firmaron un consentimiento informado autorizando su participación en el presente estudio.

\section{Análisis de Datos}

Para el análisis de los datos, se empleó el programa estadístico IBM SPSS STATISTICS V24 para Windows. Se presentan la media y desviación estándar de las puntuaciones en cada una de las variables estudiadas. Los datos analizados en este estudio son considerados como variables cuantitativas continuas.

Se presentan media y desviación estándar de las puntuaciones en cada una de las variables estudiadas. El análisis conjunto de las mismas se realizó a través del cálculo del coeficiente de correlación de Pearson. Para contrastar la diferencia de las variables relacionadas con el género, se utilizó un análisis de la varianza (ANOVA) a través la prueba T para muestras independientes. El supuesto de normalidad de la muestra se estableció a través las pruebas de normalidad Shapiro_Wilk y la de homogeniedad de la varianza a través de Leven. El nivel de significación se estableció para $p<0,05$.

\section{Resultados}

Se contó con una muestra de 100 participantes, teniendo en cuenta los abandonos y quienes no finalizaron las extracciones determinadas, la muestra final estaba compuesta por 82 corredores. De estos, 69 eran hombres y 14 mujeres, $83 \%$ y $17 \%$ respectivamente (ver Tabla 1). Pese a las diferencias respecto a la distribución de la muestra por género, ésta es representativa teniendo en cuenta que los participantes totales de la Maratón se encuentran organizados en $85,43 \%$ hombres y $14,57 \%$ mujeres.

Las variables objeto de estudio han sido el sexo, la edad, el IMC, el tiempo real de carrera, la pérdida de peso y la variación de las CK pre maratón, en meta y a las $24,48,96,144$ y $196 \mathrm{~h}$ post.

Los tiempos de carrera totales fueron de $3 \mathrm{~h} 30 \mathrm{~min} 35 \mathrm{seg}$, para el grupo formado por los varones y de $3 \mathrm{~h} 54 \mathrm{~min} 30 \mathrm{seg}$ para el grupo femenino. Tras la carrera, ambos grupos llegaron a meta con una notable pérdida de peso, siendo mayor en el grupo de varones, con una disminución media de $2,20 \mathrm{~kg}$, frente a $1,08 \mathrm{~kg}$ del grupo femenino (Figura 1). La misma relación se mantiene respecto el IMC, siendo $23,17 \mathrm{~kg} / \mathrm{m}^{2}$ la media del grupo masculino y $21,65 \mathrm{~kg} / \mathrm{m}^{2}$ para las mujeres. El tiempo real de carrera en función al sexo se representa en la Tabla 2.

Los valores obtenidos en las tomas de CK se muestran en la Figura 2 diferenciados por sexos. Se observa que al finalizar la maratón se produjo un aumento en la concentración de tal enzima, sin hallarse diferencias significativas entre ambos grupos. En cambio, los valores absolutos de las mismas son notablemente más elevados en hombres. Los valores más elevados coinciden en ambos grupos, $24 \mathrm{~h}$ tras la carrera, siguiendo así el mismo patrón de funcionamiento. 
Los resultados relacionados con las correlaciones entre dichas variables, empleando la correlación de Pearson, se representan en la tabla 3.

Tabla 1

Distribución de la muestra por género

GENERO

\begin{tabular}{llr|r|r|r} 
& & & & \multicolumn{1}{c}{$\begin{array}{c}\text { Porcentaje } \\
\text { válido }\end{array}$} & \multicolumn{1}{c}{$\begin{array}{l}\text { Porcentaje } \\
\text { acumulado }\end{array}$} \\
\hline Válido & Masculino & 68 & 68,7 & 82,9 & 82,9 \\
\cline { 2 - 6 } & Femenino & 14 & 14,1 & 17,1 & 100,0 \\
\cline { 2 - 6 } & Total & 82 & 82,8 & 100,0 & \\
\hline Perdidos & Sistema & 17 & 17,2 & & \\
\hline Total & & 99 & 100,0 & & \\
\hline
\end{tabular}

Tabla 2

Edad participantes r/c periodos y sexo

EDAD PARTICIPANTES POR PERIODOS Y SEXOS

\begin{tabular}{|c|c|c|c|c|c|c|}
\hline GENERO & & & Frecuencia & Porcentaje & $\begin{array}{c}\text { Porcentaje } \\
\text { válido }\end{array}$ & $\begin{array}{l}\text { Porcentaje } \\
\text { acumulado }\end{array}$ \\
\hline & Perdidos & Sistema & 17 & 100,0 & & \\
\hline \multirow[t]{4}{*}{ MASCULINO } & \multirow[t]{4}{*}{ Válido } & Entre $30-35$ & 10 & 14,7 & 14,7 & 14,7 \\
\hline & & Entre $35-40$ & 37 & 54,4 & 54,4 & 69,1 \\
\hline & & $40-45$ & 21 & 30,9 & 30,9 & 100,0 \\
\hline & & Total & 68 & 100,0 & 100,0 & \\
\hline \multirow[t]{4}{*}{ FEMENINO } & \multirow[t]{4}{*}{ Válido } & Entre $30-35$ & 1 & 7,1 & 7,1 & 7,1 \\
\hline & & Entre $35-40$ & 7 & 50,0 & 50,0 & 57,1 \\
\hline & & $40-45$ & 6 & 42,9 & 42,9 & 100,0 \\
\hline & & Total & 14 & 100,0 & 100,0 & \\
\hline
\end{tabular}




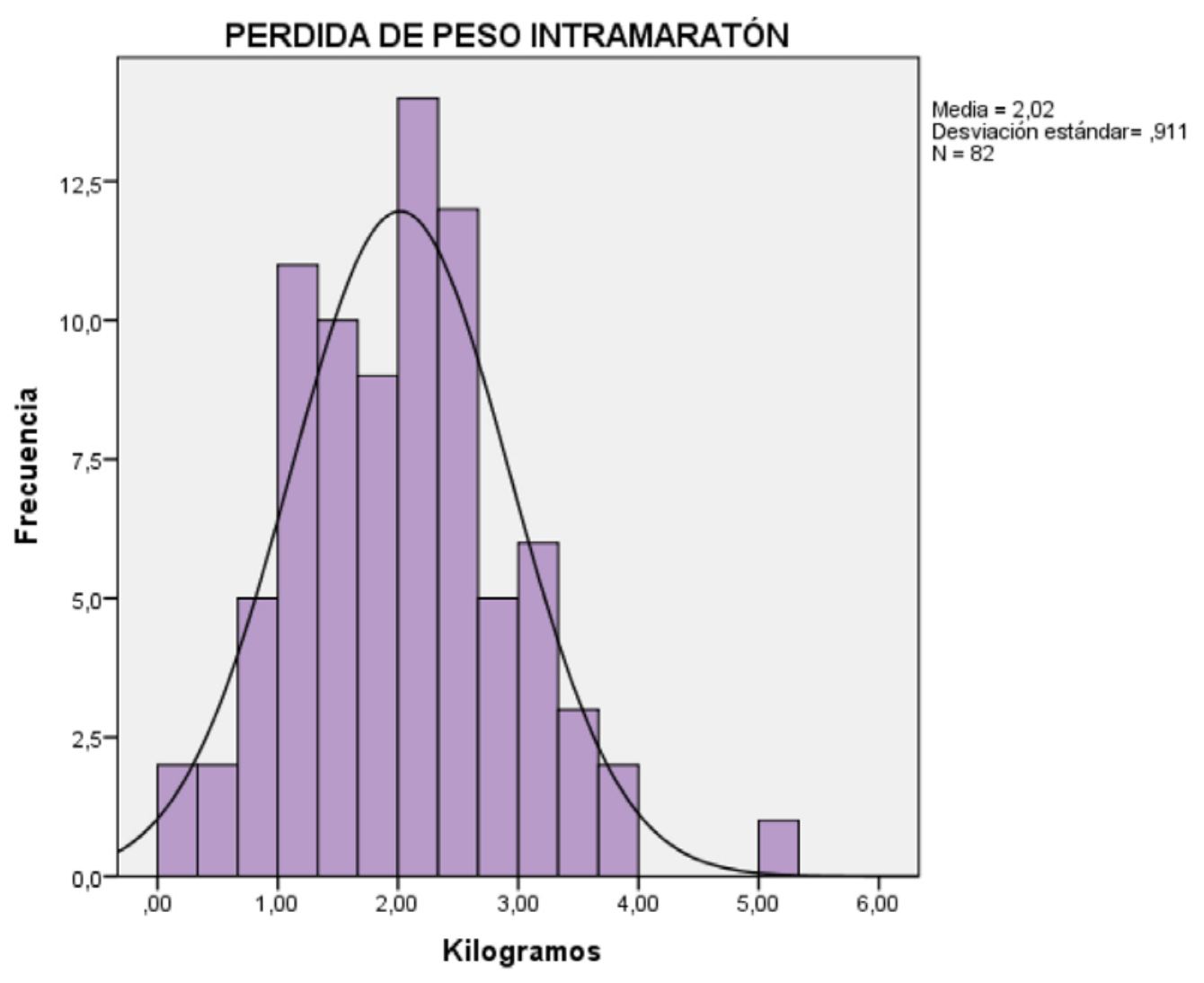

Figura 1. Pérdida de peso intramaratón

\section{Evolución de las CK Maratón de Valencia 2016}

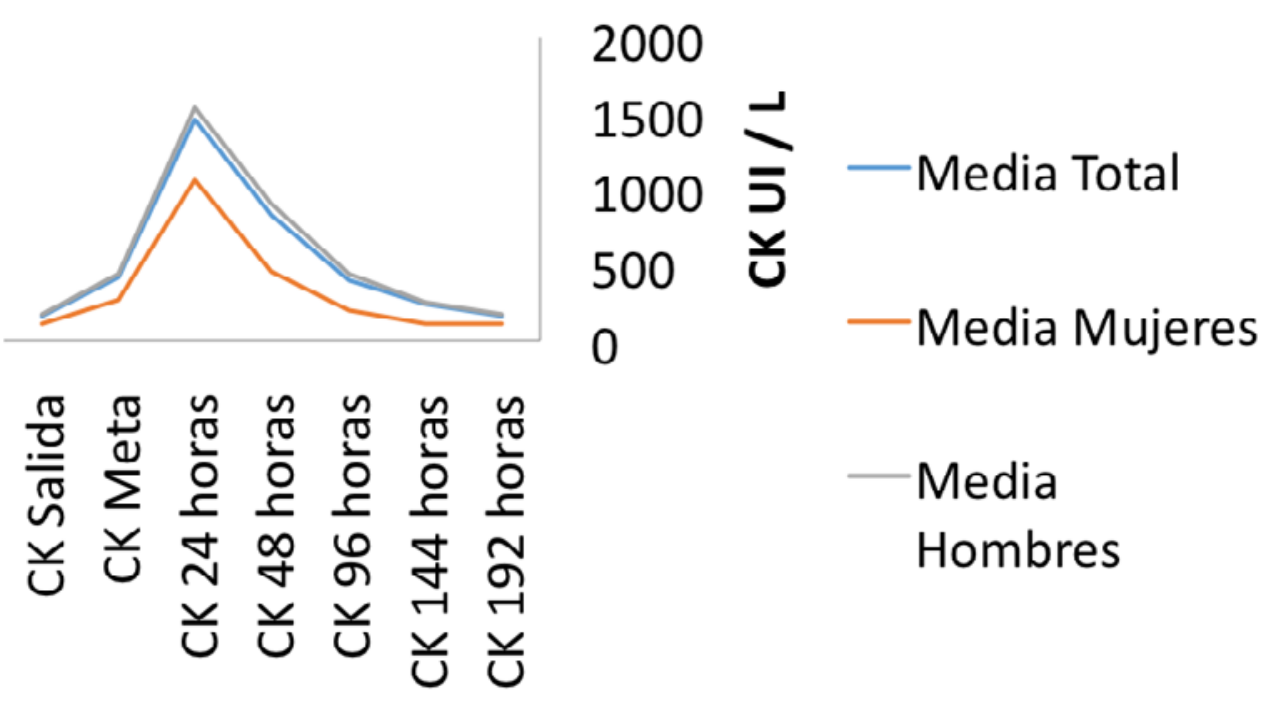

Figura 2. Evolución de las CK 
Tabla 3

Correlaciones entre variables

\begin{tabular}{|c|c|c|c|c|c|c|c|c|c|c|c|c|}
\hline \multicolumn{13}{|c|}{ Correlaciones } \\
\hline & & EDAD & TIEIPOREAL & $\begin{array}{c}\text { PERDIDADE } \\
\text { PESO }\end{array}$ & CK SALIDA & CK META & $\begin{array}{l}\text { CK } 24 \\
\text { HORAS }\end{array}$ & $\begin{array}{l}\text { CK } 48 \\
\text { HORAS }\end{array}$ & $\begin{array}{l}\text { CK } 96 \\
\text { HORAS }\end{array}$ & $\begin{array}{l}\text { CK } 144 \\
\text { HORAS }\end{array}$ & $\begin{array}{l}\text { CK } 192 \\
\text { HORAS }\end{array}$ & IMC \\
\hline \multirow[t]{3}{*}{ EDAD } & Correlación de Pearson & 1 & .076 & $-318^{\prime \prime}$ & .029 & -.137 & -.155 & -.103 & -.005 & .017 & -.120 &,- 156 \\
\hline & Sig. (bilateral) & & ,498 & .004 & .795 & .227 & 166 & 358 & 966 & 882 & .282 & 163 \\
\hline & $\mathrm{N}$ & 82 & 82 & 82 & 82 & 80 & 81 & 82 & 82 & 82 & 82 & 82 \\
\hline \multirow[t]{3}{*}{ TIEIPOREAL } & Correlación de Pearson & .076 & 1 & $.256^{\circ}$ & $-236^{\circ}$ & .088 &,- 171 & .067 & .008 & .081 & -.192 & .164 \\
\hline & Sig. (bilateral) & .498 & & .020 & .032 & .436 & .126 & .550 & .946 & .469 & .084 & .141 \\
\hline & $\mathrm{N}$ & 82 & 82 & 82 & 82 & 80 & 81 & 82 & 82 & 82 & 82 & 82 \\
\hline \multirow[t]{3}{*}{ PERDIDADE PESO } & Correlación de Pearson & $-318^{\prime \prime}$ & $.256^{\circ}$ & 1 & .172 & .180 & .162 & .138 & .025 & .035 & .140 & $.255^{\circ}$ \\
\hline & Sig. (bilateral) & .004 & ,020 & & .123 & 110 & 150 & .216 & 827 & .754 & .210 & .021 \\
\hline & $\mathrm{N}$ & 82 & 82 & 82 & 82 & 80 & 81 & 82 & 82 & 82 & 82 & 82 \\
\hline \multirow[t]{3}{*}{ CK SALUDA } & Correlación de Pearson & .029 & $-236^{\circ}$ & .172 & 1 & $297^{*}$ & .151 & .172 & .145 & .168 & $.269^{\circ}$ & .215 \\
\hline & Sig. (bilateral) & .795 & .032 & .123 & & .007 & .178 & .122 & .194 & .131 & .014 & .052 \\
\hline & $\mathrm{N}$ & 82 & 82 & 82 & 82 & 80 & 81 & 82 & 82 & $B 2$ & 82 & 82 \\
\hline \multirow[t]{3}{*}{ CK META } & Correlación de Pearson & -.137 & .088 & .180 & $.297^{*}$ & 1 & $.394^{* \prime}$ & $.351^{\prime \prime}$ & .191 & $.339^{\prime \prime}$ & $498^{\prime \prime}$ & $.253^{\circ}$ \\
\hline & Sig. (bilateral) & .227 & .436 & .110 & .007 & & .000 & .001 & .090 & .002 & .000 & .023 \\
\hline & N & 80 & 80 & 80 & 80 & 80 & 79 & 80 & 80 & 80 & 80 & 80 \\
\hline \multirow[t]{3}{*}{ CK 24 HORAS } & Correlación de Pearson & -.155 & -171 & .162 & .151 & $.394^{\prime \prime}$ & 1 & $.787^{-}$ & $.429^{\circ}$ & $.519^{*}$ & $632^{*}$ & .037 \\
\hline & Sig. (bilateral) & .166 & .126 & .150 & .178 & .000 & & .000 & .000 & .000 & .000 & .743 \\
\hline & $\mathrm{N}$ & 81 & 81 & 81 & 81 & 79 & 81 & 81 & 81 & 81 & 81 & 81 \\
\hline \multirow[t]{3}{*}{ CK 48 HORAS } & Correlación de Pearson &,- 103 &,- 067 &, 138 & .172 & $.351^{\prime \prime}$ & $.787^{*}$ & 1 & $853^{\circ}$ & $.795^{\prime \prime}$ & $686^{-\prime}$ & .172 \\
\hline & Sig. (bilateral) & 358 &, 550 & .216 & .122 & .001 & .000 & & .000 & .000 & .000 & ,123 \\
\hline & $\mathrm{N}$ & 82 & 82 & 82 & 82 & 80 & 81 & 82 & 82 & 82 & 82 & 82 \\
\hline \multirow[t]{3}{*}{ CK 96 HORAS } & Correlación de Pearson & -.005 & -.008 & .025 & .145 & .191 & $.429^{\prime \prime}$ & $.858^{\prime \prime}$ & 1 & $871^{*}$ & $558^{\circ}$ & .189 \\
\hline & Sig. (bilateral) & .966 & .946 & 827 & .194 & .090 & .000 & .000 & & .000 & .000 & .089 \\
\hline & N & 82 & 82 & 82 & 82 & 80 & 81 & 82 & 82 & 82 & 82 & 82 \\
\hline \multirow[t]{3}{*}{ CK 144 HORAS } & Correlación de Pearson &,- 017 &,- 081 & .035 & .168 &, $339^{\prime \prime}$ & $.519^{\prime \prime}$ & $.795^{\prime \prime}$ & $871^{\prime \prime}$ & 1 & $.771^{\circ}$ & .160 \\
\hline & Sig. (bilateral) & .882 & .469 & .754 & 131 & .002 & .000 & .000 & .000 & & .000 & 152 \\
\hline & $\mathrm{N}$ & 82 & 82 & 82 & 82 & 80 & 81 & 82 & 82 & 82 & 82 & 82 \\
\hline \multirow[t]{3}{*}{ CK 192 HORAS } & Correlación de Pearson &,- 120 & -192 & .140 & $269^{\circ}$ & $.498^{\circ}$ & $.632^{*}$ & $686^{\prime \prime}$ &, $558^{\circ}$ & $.771^{*}$ & 1 & .119 \\
\hline & Sig. (bilateral) & .282 & .084 & .210 & .014 & .000 & .000 & .000 & .000 & .000 & & .288 \\
\hline & $\mathrm{N}$ & 82 & 82 & 82 & 82 & 80 & 81 & 82 & 82 & 82 & 82 & 82 \\
\hline \multirow[t]{3}{*}{ IMC } & Correlación de Pearson & -.156 & .164 & $.255^{\circ}$ & .215 & $.253^{\circ}$ & .037 & .172 & .189 & .160 & .119 & 1 \\
\hline & Sig. (billateral) & .163 & .141 & 021 & .052 & .023 & .743 & .123 & .089 & .152 & .288 & \\
\hline & $\mathrm{N}$ & 82 & 82 & 82 & 82 & 80 & 81 & 82 & 82 & 82 & 82 & 82 \\
\hline
\end{tabular}

\section{Discusión y conclusiones}

Se ha podido observar el gran impacto que tiene una prueba de resistencia como la maratón sobre la musculatura del organismo. Resultaron unos valores de CK medios postcarrera de $1537 \mathrm{UI} / \mathrm{L}$ en varones y $1059 \mathrm{UI} / \mathrm{L}$ en mujeres., un 776,26 \% por encima de las cifras máximas consideradas dentro de los rangos de normalidad (entre 22 y198 UI/L). Hecho que muestra el gran daño muscular al cual se expone el organismo, de forma que justifica la necesidad de un entrenamiento controlado y supervisado, sobre todo, en corredores amateurs.

Los resultados de la presente investigación determinan, con una evidencia estadística del $95 \%$, la existencia de una correlación significativa y positiva entre la pérdida de peso y el IMC de la persona. La pérdida de peso se encuentra relacionada también, aunque inversamente, con la edad. Así, con un error del $1 \%$, podemos afirmar que una menor edad se asocia ligeramente a una mayor pérdida de peso visto que la magnitud de asociación es relativamente baja $(r=0.255)$. Del mismo modo, la correlación entre las variables pérdida de peso y tiempo real invertido resulta estadísticamente significativa $(p=0,02)$, siendo esta una magnitud negativa y relativamente baja $(r=-0,256)$.

Bajo el mismo nivel de evidencia, $95 \%$, se ha observado que el género es un factor determinante en diverses variables. Queda evidenciado que el género influye en el tiempo invertido en la prueba, en el IMC y en la pérdida de peso intraprueba, así como en los valores de CK en la salida. Se ha podido determinar un comportamiento distinto de la evolución de las 
CK en la semana posterior a la carrera, siendo la recuperación más rápida en mujeres, entre 96 y 144 horas, mientras que los varones precisan un mínimo de 192 horas para restablecer los valores iniciales.

En este estudio hemos obtenido que la recuperación fisiológica precisa de un mínimo de 96 horas, en mujeres y 192 horas en hombres, con lo cual nuestros resultados no coinciden con la literatura, la cual determina un margen entre 24 y 48 horas para volver al estado basal (Duca et al., 2006; Uchakin et al., 2003). La variación puede ser debida a la diferencia en la muestra, siendo nuestro estudio el primero que presenta una muestra tan extensa para un estudio de estas características en una carrera de maratón, según nuestro conocimiento.

Por ello, es preciso continuar investigando en este ámbito con poblaciones mayores y así propiciar la obtención de datos más concluyentes que permitan dirigir la investigación relacionada con la recuperación fisiológica.

\section{Referencias bibliográficas}

Callow, M., Morton, A. \& Guppy. M. (1986) Marathon fatigue: the role of plasma fatty acids, muscle glycogen and blood glucose. European Journal of Applied Physiology 55, 654-661.

Chan, M. H., Myrer, J., Egett, D. \& Seeley, M. (2012). Kinematic changes during a marathon for fast and slow runners. Journal of Sports Science and Medecine 11 (77-82).

Del Coso, J., Salinero, J. J., Abián-Vicén, J., Gonzalez-Millan, C., Garde, S., Vega, P., \& Pérez-Gonzalez, B. (2013). Influence of body mass loss and myoglobinuria on the development of muscle fatigue after a marathon in a warm environment. Applied Physiology, Nutririon and Metabolism, 38(3), 286-291. doi: 10.1139/apnm-2012-0241.

Duca, L., Da Ponte, A., Cozzi, M., Carbone, A., Pomati, M. \& Nava, I. (2006). Changes in erythropoiesis, iron metabolism and oxidative stress after half-marathon. Intern Emerg Med, 1(1) 30-4.

Kratz, A., Lewandowski, K. B. Siegel, A. J., Chun, K. Y., Van Cott, E. M. \& Lee-Lewandowski E. (2002). Effect of Marathon Running on Hematologie and Biochemical Laboratory Parameters. Including Cardiac Markers. American Journal of Clinical Pathology 118(6). 856-863.

Lippi, G., Banfi, G., Montagnana, M., Salvagno, G. L., Schena, F. \& Guidi, G. C. (2010). Acute variation of leucocytes counts following a half-marathon run. International Journal of Laboratory Hematology, 32(1), 117-121. doi: 10.1111/j.1751-553X.2008.01133.x

Ruiz-Vicente, D., Salinero, J. J., Coso, J. D., González-Millán, C., Abián-Vicén, J., Areces, F., . . . Fernández, D. (2013). Efectos de una maratón en valores hematológicos. Archivos de Medicina del Deporte, 30 (3), 150-155

Sánchez-González, J., Rivera-Cisneros, A. \& Tovar-Luz, J. (2003) Asociación de las respuestas fisiológicas a los cambios metabólicos, en el ejercicio físico extenuante. Cirugía y Cirujanos 71, 217-225.

Uchakin P. N., Gotovtseva E., Stray-Gundersen J. (2003) Immune and neuroendocrine alterations in marathon runners. J Appl Res, 3(4) 483-94. 


\title{
Diagnóstico de salud poblacional: Lucena del Cid
}

\author{
MIRIAM IZQUIERDO MARTÍNEZ \\ al339178@uji.es \\ AITOR LUJÁN RONDA \\ al343695@uji.es \\ Águeda Cervera Gasch \\ cerveraa@uji.es \\ PABlo SALAs MEdina \\ psalas@uji.es
}

\section{Resumen}

Introducción: Lucena del Cid es una población de montaña que basa su economía en la industria y servicios, y con una población de 1417 habitantes con una distribución de $50,2 \%$ de hombres y $49,82 \%$ de mujeres. La tasa de natalidad de la población es del $2,12 \%$ y la tasa de mortalidad del $19,05 \%$. Cuenta con un centro de salud con referencia de especialidades y hospital a $45 \mathrm{~km}$. Metodología: Se desarrolla un estudio observacional-descriptivo-transversal, realizado por alumnos de segundo de Enfermería de la Universitat Jaume I, entre los meses de noviembre de 2016 y enero de 2017. Para llevar a cabo dicho estudio, se han utilizado tanto fuentes de documentación primarias como fuentes secundarias. A su vez se realizó una búsqueda de datos estadísticos en el Instituto Nacional de Estadística y en Instituto Valenciano de Estadístico. Resultados: La primera causa de mortalidad son las enfermedades del sistema circulatorio $(27 \%)$ seguida de neoplasias $(23 \%)$ y enfermedades respiratorias (8 $\%)$. El nivel de dependencia juvenil es del $17,1 \%$ y de un $42,9 \%$ en ancianos. La población activa es de 418 personas distribuidas en un 38,03 \% de mujeres y un 61,96 $\%$ de hombres. Conclusiones: Lucena tiene una población longeva (53 \%) y con elevadas tasas de dependencia $(60 \%)$. Es necesaria una restructuración de los servicios sanitarios, facilitando la cobertura de las necesidades de una población envejecida.

Palabras clave: diagnóstico, salud, poblacional, Lucena del Cid, descriptivo

\section{Abstract}

Introduction: Lucena del $\mathrm{Cid}$ is a mountain village that bases its economy on industry and services. It has a population of 1417 inhabitants with a distribution of $50.2 \%$ males and $49.82 \%$ females. The birth rate of its population is $2.12 \%$ and it has a mortality rate of $19.05 \%$. Lucena del Cid has a health centre with reference of specialties and a hospital $45 \mathrm{~km}$ away. Methodology: It is an observational-descriptive-transversal study carried out by students of the Nursing Department of the Universitat Jaume I, between November 2016 and January 2017. In order to carry out this research study, 
both primary and secondary sources of documentation were used. In turn, we carried out a search of statistical data in the National Institute of Statistics and in the Valencian Institute of Statistics. Results: The first cause of mortality are diseases of the circulatory system ( $27 \%$ ) followed by neoplasias $(23 \%)$, and respiratory diseases ( $8 \%)$. The level of juvenile dependency is $17.1 \%$ and $42.9 \%$ in the elderly. The active population (418 people) is distributed in $38.03 \%$ of women and $61.96 \%$ of men. Conclusion: Lucena has an aged population (53\%) and with high dependency rates (60\%). There is a need for a restructuring of health services, facilitating the coverage of the needs of an aging population.

Keywords: diagnosis, health, population, Lucena del Cid, descriptive.

\section{Introducción}

Un diagnóstico de salud es un estudio que tiene como objetivo conocer cuál es el estado de salud de una población mediante el análisis exhaustivo de sus principales problemas de salud y las necesidades la misma, así como conocer los recursos con los que se cuenta dicha población para solucionar las variables problemáticas. Por tanto, un diagnóstico de salud es el inicio del proceso de planificación de una intervención sanitaria y resulta una herramienta fundamental para la investigación en salud pública (Arenas-Monreal, Cortez-Lugo, ParadaToro, Pacheco-Magaña \& Magaña-Valladares, 2015).

El presente estudio se realizará sobre la población de Lucena del Cid, que se encuentra en el interior de la provincia de Castellón, en la Comunidad Valenciana. Concretamente está situado en la comarca de l'Alcalatén, limitando con la provincia de Teruel (Lucenadelcid.es, 2016). Este diagnóstico de salud tiene como propósito presentar y analizar la situación de la población de Lucena del Cid. Lo que se quiere conseguir con este estudio poblacional de salud es detectar los principales problemas sanitarios en la comunidad, así como proponer soluciones de mejora para cada uno de ellos.

Se eligió este municipio por su geografía, pasado histórico, economía y, sobre todo, por la situación de la población en materia de salud, ya que cuenta con una infraestructura mínima para el desarrollo de las actividades sanitarias.

El objetivo general de este estudio era conocer y caracterizar el estado real de salud del municipio de Lucena del Cid mediante el análisis del estudio estadístico de la población, con el fin de enunciar propuestas de actuación acordes con la realidad de la población.

En cuanto a los objetivos específicos fueron los siguientes:

- Realizar un estudio de los indicadores de salud más relevantes de Lucena del Cid con el fin de obtener datos acerca de la situación actual en la población de estudio.

- Estudiar la situación demográfica, económica y social del municipio, y comprobar si existe alguna relación entre los indicadores de salud que se han obtenido con el estado de salud actual de la población de Lucena del Cid.

- Conocer las enfermedades más prevalentes de dicha población y sus principales causas con el fin de enfocar las pertinentes medidas sanitarias hacia la prevención de dichas enfermedades con el fin de disminuir su incidencia.

- Conocer los recursos sociales y económicos con los que cuenta Lucena del Cid. 
- Estudiar las necesidades y los déficits que tienen los habitantes del municipio en todas las áreas de estudio que se han mencionado anteriormente.

- Plantear programas de salud adaptados a las enfermedades más relevantes de dicha población, en el caso que sea necesario.

\section{Método}

Se desarrolla un estudio observacional-descriptivo-transversal, realizado por alumnos de segundo de Enfermería de la Universitat Jaume I en el espacio temporal comprendido desde noviembre de 2016 a enero de 2017. El lugar que se ha elegido para realizar el estudio es Lucena del Cid, un municipio de la provincia de Castellón. El estudio permitirá valorar el nivel de salud del municipio, así como examinar el tipo de enfermedades en función de la población, en un determinado espacio de tiempo.

Para llevar a cabo dicho estudio, se han utilizado tanto fuentes de documentación primarias como fuentes secundarias. Se realizó una búsqueda de datos estadísticos en el Instituto Nacional de Estadística (INE) y en Instituto Valenciano de Estadístico (IVE) (Conselleria de Sanidad, 2016). Se utilizaron los datos del 2014 puesto que, aunque sí que estaban disponibles los datos del empadronamiento del 2015, los demás datos estadísticos no se encontraban publicados. Además, se contactó varias veces con el punto de atención continuada de Lucena del Cid y se acudió al municipio el día 28 de diciembre de 2016 para obtener más información. Se visitó todo el municipio y se acudió tanto al Ayuntamiento de Lucena del Cid como al punto de atención continuada.

- Punto de atención continuada de Lucena del Cid. Plaza España, 22, 12120 Lucena del Cid, Castellón. Teléfono: 96473820

- Ayuntamiento de Lucena del Cid. Plaza España, 22, 12120 Lucena del Cid, Castellón. Teléfono: 964380001.

Los datos estadísticos, así como las variables objetivo del estudio, han sido obtenidos mediante los institutos estadísticos tanto a nivel nacional como a nivel comunitario, como se ha mencionado anteriormente. Sin embargo, al tratarse de un municipio con una población pequeña, algunos datos no se han podido obtener directamente, por lo que se debió realizar una extrapolación con los datos de Castellón, provincia a la que pertenece Lucena del Cid.

El rango de población del estudio comprende toda la población empadronada en 2014 en Lucena del Cid $(n=1417)$, con independencia de la edad, sexo, procedencia y nivel socioeconómico. Por ende, se excluye a todos aquellos que no se encuentren empadronados en el municipio de Lucena del cid en dicho año.

Las variables objeto de estudio, extraídas del IVE, son las siguientes: tasa de natalidad, tasa de mortalidad, dependencia tanto juvenil como anciana, envejecimiento, longevidad, tasa de maternidad, tendencia de la población, renovación de la población activa, esperanza de vida en el nacimiento, población activa económicamente, padrón municipal y, finalmente, renta per cápita.

Las variables objeto de estudio extrapoladas son: enfermedades más relevantes que causan muerte, a partir de los datos obtenidos de la provincia de Castellón a través del IVE y el PIB, sumatorio de inversión, consumo, gasto y exportaciones netas, obtenidas a partir de la renta per cápita. 


\section{Resultados}

Lucena del Cid cuenta con un total de 1417 personas empadronadas según los últimos datos disponibles en el Instituto Valenciano de Estadística (2014). De estas 1417 personas censadas 711 son de hombres $(50,18 \%)$ y 706 son mujeres $(49,82 \%)$ [5]. El municipio presenta una tasa de natalidad del $2,12 \%$ y una tasa de mortalidad del $19,05 \%$. Como se puede apreciar con los datos anteriores, es mucho mayor la tasa de mortalidad que la de natalidad.

Para poder conocer las enfermedades más relevantes que causan esta elevada cifra de mortalidad, se ha tenido que extrapolar los datos existentes de la provincia de Castellón de 2014, ya que no se dispone de estos datos para Lucena del Cid. Los datos que se obtuvieron fueron los siguientes como se presenta en la Tabla 1.

En cuanto a los indicadores demográficos, cabe destacar que la esperanza de vida al nacimiento en Lucena del Cid en hombres es de 80,32 años y en mujeres 85,12 años, siendo el valor de los hombres mayor que la media española $(80,1$ años) y el de las mujeres menos a la media española (85,6 años) en el año 2014 (INE, 2017).

Para conocer con exactitud las características demográficas de la población, se estudian los indicadores demográficos y muestran los siguientes valores: envejecimiento $(249,7 \%)$, longevidad (53\%). dependencia (60\%), de la cual un $17,1 \%$ es juvenil y un $42,9 \%$ anciana, maternidad $(17,8 \%)$, tendencia $(86,4 \%)$, renovación de población activa $(79,5 \%)$.

Tabla 1

Tasa de mortalidad de diferentes enfermedades

\begin{tabular}{lcccc}
\hline \multicolumn{1}{c}{ Enfermedades } & Hombres & Mujeres & Total & $\begin{array}{c}\text { Extrapolación a Lucena } \\
\text { del Cid en \% }\end{array}$ \\
\hline Sistema circulatorio & 719 & 887 & 1596 & 27,166 \\
\hline Neoplasias & 853 & 524 & 1377 & 23,438 \\
\hline Sistema respiratorio & 272 & 196 & 468 & 7,946 \\
\hline $\begin{array}{l}\text { Sistema nervioso y órganos de los } \\
\text { sentidos }\end{array}$ & 137 & 220 & 357 & 6,077 \\
\hline $\begin{array}{l}\text { De la cavidad bucal, de las glándulas } \\
\text { salivales y de los maxilares }\end{array}$ & 137 & 112 & 249 & 4,238 \\
\hline Mentales y de comportamiento & 83 & 152 & 235 & 3,9999 \\
\hline $\begin{array}{l}\text { Endocrinas, nutricionales y metabólicas } \\
\text { Causas externas de mortalidad y }\end{array}$ & 75 & 105 & 180 & 3,0808 \\
\hline $\begin{array}{l}\text { morbilidad } \\
\text { Del sistema genitourinario }\end{array}$ & 104 & 67 & 171 & 2,9106 \\
\hline Infecciosas y parasitarias & 70 & 68 & 138 & 2,3489 \\
\hline
\end{tabular}

En lo referente a las migraciones, se observa que ha habido un total de 52 emigraciones, siendo 37 a la Comunidad Valenciana (71,15\%), 6 emigraciones a otras comunidades autónomas de España $(11,53 \%$ y y 9 al extranjero (17,30 \%). En cuanto a las inmigraciones, se han registrado un total de 26 , donde 20 de ellas han sido procedentes de la Comunidad Valencia- 
na $(76,92 \%), 5$ de otras comunidades autónomas de España $(19,23 \%)$ y 1 persona del extranjero (3,84\%). Dichos datos son de 2013.

Respecto a los indicadores socioeconómicos y de empleo de la población de Lucena del Cid, se obtiene que hay un total de 130 parados, de estos: 0,8\% pertenecen al sector de la agricultura, $13,8 \%$ perteneciente de la construcción, 45,4 \% provenientes de las industrias, $36,2 \%$ corresponden al sector servicios, 3,8 \% sin ocupación anterior.

Por otro lado, la población activa económicamente (PAE) es de 876 personas. Hay un total de 418 personas trabajadoras afiliadas a la seguridad social, de los cuales 259 son hombres $(61,96 \%)$ y 159 mujeres $(38,03 \%)$. Estos datos, se han obtenido calculando la media de los cuatro trimestres de 2014, cuyas cifras se encuentran disponibles en el IVE. La renta per cápita de Lucena del Cid asciende a un total de 14.002 euros. Por otra parte, el PIB es de 19.840.834 euros; éste se obtiene al multiplicar la renta per cápita por el número de habitantes en ese año, puesto que la relación de éste y el número de habitantes es la renta per cápita.

Como se ha comentado en la introducción, Lucena del Cid cuenta con un punto de atención continuada el cual depende del departamento de Castellón. El hospital de referencia es el Hospital General Universitario de Castellón el cual se encuentra a 35,1 km del municipio. Además, este departamento cuenta con otros hospitales como el Consorcio Hospitalario Provincial de Castellón y el Hospital la Magdalena, localizados en Castellón de la Plana. Se cuenta también con el centro de especialidades Jaume I, así como el centro de diálisis Nefroplana, que se localizan también en la capital de la provincia. Cabe destacar que un día a la semana pasan por Lucena un fisioterapeuta y un podólogo. Los servicios ofrecidos por estos sanitarios no tienen cobertura pública. Por último, el municipio también cuenta con una residencia de ancianos, Residencia Servicio de Teleasistencia de Lucena del Cid.

\section{Discusión y conclusiones}

Lucena del Cid es un municipio con una población envejecida, siendo la tasa de longevidad de un $53 \%$. Este hecho hace aumentar la tasa de dependencia que, en su totalidad, es del $60 \%$. Aun así, se debe tener en cuenta que existe también población juvenil, la cual también es dependiente y que supone un $17,1 \%$ del porcentaje anterior. El hecho de que haya una gran tasa de longevidad conlleva la afloración de enfermedades crónicas las cuales se deberán tratar tanto en atención primaria como en atención secundaria.

En lo referente a la situación laboral, en 2014 había un total de 130 personas en el paro de las 876 personas activas, lo que supone un $14,84 \%$. Al tratarse de un municipio pequeño, no se generan los suficientes puestos de trabajo para cubrir las necesidades laborales, de forma que cada vez hay más emigraciones por parte de los habitantes más jóvenes. La emigración implica que la población de Lucena del Cid disminuya, puesto que las emigraciones son mayores (52) que las inmigraciones (26) (año 2013). Este hecho, además, conlleva a que la población esté cada vez más envejecida, siendo la tasa de envejecimiento de $249,7 \%$.

En cuanto al estado de salud de la población de Lucena, se realizó un estudio para conocer cuáles son las enfermedades con mayor índice de prevalencia. Los resultados que se obtuvieron fueron los siguientes:

Las enfermedades cardiovasculares son las afecciones más prevalentes en la población lucenense $(27,166 \%)$. En lo referente a la prevención y tratamiento de estas enfermedades, el punto de atención continuada de Lucena lleva a cabo distintos programas de salud, comprendidos en el programa de salud de adultos publicado por la Conselleria de Sanitat Universal i Salut Pública (Conselleria de Sanitat, 1998), para intentar abordar de forma primaria dichas afecciones, así como la realización de controles periódicos de forma que pueda llevarse 
un control correcto de enfermedades como la hipertensión arterial. Además, aunque se trata de un municipio pequeño y no dispone de una ruta para caminar, sí que existe un camino desde Lucena hasta una ermita que se encuentra a las afueras y por donde los habitantes pueden caminar y así realizar el ejercicio diario recomendado. En Lucena del Cid, también hay varios parques, uno de ellos con maquinaria para que las personas mayores puedan ejercitarse sin necesidad de desplazarse muy lejos.

En cuanto a las necesidades de las enfermedades oncológicas, las segundas más prevalentes $(23,43 \%)$, la prevención primaria se realiza siguiendo el programa de salud de adultos. Sin embargo, es en el hospital donde se realizan las distintas técnicas de cribado para los diferentes cánceres como el de mama y el de colón, así como el tratamiento de éstas.

En tercer lugar, se encuentran las enfermedades respiratorias con una prevalencia del $7,94 \%$, cuyas necesidades quedan cubiertas con los programas de salud realizados por los profesionales sanitarios del municipio. Además, Lucena del Cid es un municipio situado a la ladera de una montaña, rodeado de vegetación y sin demasiada presencia industrial por lo que el aire es bastante limpio y sin contaminación.

Por lo que respecta a los programas de salud que se desarrollan en la población, se contactó por teléfono con el centro de salud de Lucena del Cid, y tras varios intentos se obtuvo información sobre los programas de salud que se llevan a cabo en el municipio. Éstos son el Programa de Salud del Niño Sano (Fullana, de Hevia, Jordá, Momparler, Moreno \& Redondo, 1999) y el Programa de Adultos publicado por la Conselleria de Sanitat Universal i Salut Pública (Conselleria de Sanitat, 1998). Nos comentaron que con estos programas las necesidades de la población del municipio estaban cubiertas.

Aun así, se piensan diferentes mejoras para obtener un mejor nivel de salud de la población:

1. Con respecto a las enfermedades cardiovasculares, mejorar el servicio del que se dispone creando una consulta mensual donde haya un cardiólogo que controle con mayor facilidad a los enfermos con dichas afecciones.

2. En el caso del cribado de las enfermedades neoplásicas, se hará llegar de forma anual una unidad móvil con el instrumental necesario para realizar los cribados. Esta mejora sería conveniente, debido a que las patologías oncológicas son las segundas más prevalentes en Lucena. También, se debe tener en cuenta que un 30,5\% de la población masculina del municipio tiene una edad comprendida entre los 50 y 69 años, edades en las que se realiza el cribado de colon (AECC, 2016a). En el caso de las mujeres, un $20,11 \%$ de la población se encuentra entre la franja de edad de los 50-65 años, edad a la que se realizan las mamografías. Se debe tener en cuenta también, la población femenina en la que a partir de 45 años se recomienda la realización de este cribado por presentar factores de riesgo (AECC, 2016b).

3. Por último, se cree conveniente que se mejore el transporte público y se amplíen los horarios para que la población tenga más posibilidades de acudir a los centros de especialidades y a los hospitales de Castellón de la Plana.

\section{Referencias bibliográficas}

Asociación Española contra el Cáncer. (2016a). Contra el cáncer, contigo somos más fuertes [Internet]. [consultado 2 de enero de 2017]. Disponible en:

https://www.aecc.es/msites/tusalud/Paginas/Anteriores/Marzo2016/index.html 
Asociación Española contra el Cáncer. (2016b). Diagnóstico precoz del cáncer de mama [Internet]. [consultado 5 de enero de 2017]. Disponible en:

https://www.aecc.es/SobreEICancer/CancerPorLocalizacion/CancerMama/Paginas/diagnosticoprecoz.aspx

Arenas-Monreal, L., Cortez-Lugo, M., Parada-Toro, I., Pacheco-Magaña, L., \& Magaña-Valladares, L. (2015). Population health diagnosis with an ecohealth approach. Revista De Saúde Pública, 49(0). http://dx.doi.org/10.1590/s0034-8910.2015049005842

Conselleria de Sanitat (1998). Portal Estadístico de la Generalitat Valenciana - Generalitat Valenciana. Salud del adulto [Internet]. [citado 4 de enero de 2017]. Disponible en: http:// www2.san.gva.es/cas/prof/recomendaciones.html\#1

Conselleria de Sanidad. (2016) Portal Estadístico de la Generalitat Valenciana - Generalitat Valenciana [Internet]. [consultado 30 de diciembre de 2016]. Disponible en: http://www. pegv.gva.es/

Fullana, A. M., de Hevia, R., Jordá, D., Momparler, P., Moreno, M. P., \& Redondo Gallego, M. J. (1999) Programa de supervisión de la Salud Infantil [Internet]. [consultado 4 enero de 2017], 2, 5-92

Instituto Nacional de Estadística. (2017). Instituto Nacional de Estadística. (Spanish Statistical Office). Productos y Servicios / Publicaciones / Productos y Servicios / Publicaciones /Publicaciones de descarga gratuita [Internet]. [consultado 2 de enero de 2017]. Disponible en: http://www.ine.es/ss/Satellite?L=es_ES\&c=INESeccion_C\&cid=1259926380048\&p=125 4735110672\&pagename=ProductosYServicios/PYSLayout

Lucenadelcid.es. (2016). Ajuntament de Lucena del Cid [Internet]. [acceso 23 de diciembre de 2016]. Disponible en: http://www.lucenadelcid.es/ 



\title{
Diseño de una intervención basada en técnicas de regulación emocional y psicología positiva para un caso de trastorno de depresión mayor y rasgos de personalidad límite
}

\author{
ANDREA DELGado CARRETERo \\ al350090@uji.es \\ BERENICE SERRANO ZÁRATE \\ bserrano@uji.es
}

\section{Resumen}

La depresión está muy asociada con sintomatología en personas con trastorno límite de la personalidad (TLP), se estima que el $32 \%$ de pacientes con TLP padecen un trastorno de depresión mayor (TDM). Por otra parte, se ha evidenciado la eficacia de intervenciones basadas en regulación emocional y psicología positiva para la reducción de la sintomatología depresiva. Objetivo: Diseñar una intervención para un caso diagnosticado con TDM y rasgos de TLP, basada en técnicas de regulación emocional y psicología positiva. Método: La intervención se llevó a cabo con una mujer de 23 años quien experimentaba sintomatología depresiva, dificultades de regulación emocional, y rasgos límite de la personalidad. Se ha diseñado un protocolo de evaluación el cual mide antes y después de la intervención el estado de ánimo, autoestima, ansiedad, síntomas de trastorno de personalidad, regulación emocional, expectativas y opinión del tratamiento, alianza terapéutica y gravedad valorada por el terapeuta. Asimismo, se evaluó semanalmente a través de registros específicos para este estudio. También se ha diseñado un protocolo de intervención, integrado por: psicoeducación, toma de conciencia, regulación emocional, psicología positiva, y prevención de recaídas. La intervención se realizó durante 13 sesiones con una duración de 60 min., con periodicidad semanal. Resultados: Se produjo una diminución de la sintomatología depresiva y ansiosa, un incremento de la autoestima, y mejoras en la regulación emocional. Conclusiones: El uso de técnicas como la regulación emocional y la psicología positiva, podrían resultar de gran utilidad en el tratamiento del TDM en comorbilidad con problemas de la personalidad.

Palabras clave: depresión, trastorno límite de personalidad, regulación emocional, psicología positiva, autoestima.

\section{Abstract}

Depression are highly associated with Borderline Personality Disorder (BPD) symptoms, being estimated that a $32 \%$ of BPD patients suffer major depressive disorder 
(MDD). Furthermore, interventions based on emotional regulation and positive psychology have shown their effectiveness in the depressive symptomatology reduction. Purpose: To design an intervention based on emotional regulation techniques and positive psychology for a case diagnosed with MDD and BPD traits. Methods: The intervention is applied to a 23-year-old woman who experiences depressive symptomatology, difficulties in emotional regulation, and BPD traits. An evaluation protocol for mood, selfesteem, anxiety and personality disorder symptoms, emotional regulation, expectative and treatment opinion, therapeutic alliance and severity evaluated by the therapist was designed and applied previous and after the intervention, including a weekly evaluation through specific registers designed for this studio. The designed intervention protocol was composed by psychoeducation, consciousness, emotional regulation, positive psychology, and relapse prevention. The intervention was applied through 60 minutes weekly sessions, during an intervention period of 13 sessions. Results: Clinical significant changes in patient symptomatology were observed, showing anxiety and depressive symptomatology reduction, self- esteem increment and improvement of emotional regulation. Conclusion: The use of techniques such as emotional regulation and positive psychology could be very useful in the treatment of MDD in comorbidity with personality problems.

Keywords: depression, borderline personality disorder, emotional regulation, positive psychology, self-esteem.

\section{Introducción}

El estado de ánimo sufre oscilaciones a lo largo del tiempo y presenta una estrecha relación con la personalidad. Personas con determinados rasgos de personalidad, son más vulnerables a experimentar un estado de ánimo u otro (Hervás \& Vázquez, 2006). Asimismo, circunstancias vividas, ya sean aquellas que favorecen el desarrollo o lo dificultan, suponen una repercusión en nuestro ajuste emocional. Se ha estudiado que las dificultades vitales presentan una estrecha relación con la ocurrencia de sintomatología depresiva, características de personalidad desadaptativas y dificultades en la regulación emocional. A menudo los episodios de sintomatología depresiva acontecen tras un estrés psicosocial grave, por lo que se estima que desempeñan un papel importante en la precipitación del primer episodio (Lloyd, Klinteberg \& DeMarinis, 2016). En la misma línea, ambientes muy invalidantes a nivel familiar (problemas en la interacción y el apego, experiencias traumáticas o negligencias emocionales) suponen factores de riesgo para el desarrollo de rasgos desadaptativos o trastornos de personalidad. Todo ello influye en nuestro desarrollo personal, sistema emocional, autoestima, regulación afectiva, capacidad de afrontamiento y resolución de problemas y por lo tanto en nuestro estado de ánimo. Dicha sintomatología se relacionaría principalmente con la psicopatología del trastorno límite de personalidad (TLP) (Fruzzetti, Shenk \& Hoffman, 2005; Hankin, 2010). Además, se estima que un $32 \%$ de pacientes con TLP padece depresión (Widiger \& Trull, 1993). En el ámbito de la intervención se ha evidenciado la eficacia de las técnicas de psicología positiva para fomentar las emociones positivas, la calidad de vida, y la disminución del estado de ánimo negativo. Se considera que las intervencions positivas son eficaces para elevar los niveles de felicidad y que tienen un impacto significativo sobre la depresión (Seligman, Steen, Park \& Peterson, 2005; Vázquez, 2006; Vázquez, Hervás \& Ho, 2006). Un estudio 
realizado por Seligman, Rashid \& Parks (2006) evidenció que pacientes en terapia de grupo con psicoterapia positiva, reportaron mayor felicidad durante una semana y la sintomatología depresiva se redujo de forma significativa durante seis meses. Los resultados mostraron además que cuando la terapia positiva se personalizaba, ésta era más eficaz que la psicoterapia tradicional sola o con antidepresivos. Por otro lado, un meta-análisis realizado por Sin \& Lyubomirsky (2009), donde se analizaron 51 intervenciones basadas en psicología positiva, reveló que las intervenciones mejoraban de manera significativa el bienestar $(r=0,29)$ y dismuia las sintomatología depresiva $(r=0,31)$. Se realizó una comparativa entre grupos: (1) grupo control sin tratamiento, (2) tratamiento estándar y placebo; se encontró que las intervenciones positivas fueron más eficaces. A través de las actividades positivas el paciente crea conjunto de recursos de afrontamiento adaptativos que le permiten manejar situaciones o cogniciones negativas, disminuyendo los factores de riesgo de enfermedad metal (Layous, Chancellor \& Lyubomirsky 2014; Layous \& Lyubomirsky 2014). Por otro lado las aportaciones de Linehan (2003), con la terapia dialectico- conductual, suponen una contribución importante en la intervención con personas con TLP y por consiguiente para la intervención sobre aspectos específicos de regulación emocional. A través de su módulo de habilidades de regulación emocional, propone un modelo donde se enseña a identificar y etiquetar las emociones, reducir la vulnerabilidad negativa e incrementar acontecimientos positivos.

El objetivo de este trabajo es diseñar un protocolo de intervención adaptado a la problemática de la paciente para intervenir sobre problemas del estado de ánimo y rasgos de un possible TLP. El programa se compone de técnicas de regulación emocional y psicología positiva; se pretende someter a prueba su utilidad para la mejora de sintomatología. Asimismo se contempla el tratamiento como una intervención de carácter preventivo para futuras posibles psicopatologías. Previo al tratamiento se hipotetizó que las dos técnicas utilizadas darían lugar a cambios significativos en la sintomatología clínica.

\section{Método}

\section{Diseño}

Este estudio se basa en un diseño cuasi-experimental de estudio de caso único con pre y post evaluación.

\section{Participante}

María (nombre figurado), es una joven adulta de 23 años. Es la menor de dos hermanos y ambos viven en el domicilio del abuelo paterno.

Motivo de consulta: Acude demandando atención por problemas de autoestima, tristeza y celos. Cuenta que esto le genera un gran malestar y problemas en su estado de ánimo. Subraya antecedentes de depresión.

Descripción del caso: La paciente refiere que su vida ha estado marcada por fuertes acontecimientos estresantes, relacionados con su ambiente familiar. Fue abandonada en un centro de atención a menores, con cuatro años por su madre, la cual estaba diagnosticada de esquizofrenia. Tras un año en el centro, comenzó la convivencia con su padre. Con 12 años fallece su abuela paterna, ocasionando que ella asumiera el rol de ama de casa. Durante la misma franja temporal su padre inicia una nueva relación, que no fue aprobada por María. A 
la edad de 17 años su padre es diagnosticado de cáncer, asumiendo ella su cuidado y fallece al poco tiempo. Afirma que supuso el acontecimiento vital más importante, ocasionándole un periodo de depresión. Durante la misma época relata haber sufrido malos tratos por parte de su expareja. Actualmente vive con su abuelo paterno y su hermano y existe un conflictivo ambiente familiar. El hermano presenta antecedentes delictivos y consumo de sustancias. En la actualidad María refiere sentirse decaída, irritable, ansiosa, con sentimientos de inutilidad, y problemas de autoestima; comparándose continuamente con los demás. Afirma que sus problemas, están afectando a la relación con su pareja.

Anàlisis funcional: Se identifica la presencia de factores de riesgo (acontecimientos vitales estresantes) y esquemas cognitivos desadaptativos. Existe una retroalimentación entre las variables psicopatológicas y una vulnerabilidad psicológica generalizada que retroalimentan al mismo tiempo a la sintomatología depresiva. Sus dificultades en la regulación emocional juegan un papel importante en la fenomenología de los trastornos del estado de ánimo, contribuyendo al mantenimiento de los síntomas.

\section{Evaluación}

Se centró la evaluación en la medida de las siguientes variables: estado de ánimo; autoestima; personalidad; regulación emocional; expectativa y opinión sobre el tratamiento, y alianza terapéutica. Para ello se utilizó:

(1) Inventario de depresión de Beck (BDI-II). Auto-informe con 21 ítems de tipo Likert que proporciona una medida de la presencia y gravedad de la depresión (Beck, Steer \& Brown, 1996); validada en población española por Vázquez \& Sanz (1998).

(2) Escala de ansiedad estado/rasgo (STAI). Escala autoaplicada destinada a medir y evaluar el actual nivel de ansiedad y la predisposición a responder al estrés. Fue creada y validada para población española por Spielberger, Gorsuch \& Lushene (1982).

(3) Escala de autoestima de Rosenberg. Cuestionario auto-aplicado que evalúa la autoestima. Diseñada por Rosenberg (1965) y adaptada a población española por Echeburúa (1995). Consta de 10 ítems (5 planteados de forma positiva y los otros de forma negativa).

(4) Cuestionario multidimensional de personalidad (PAI). Cuestionario que permite la evaluación de la psicopatología de adultos. Tiene 22 escalas (4 de control, 11 clínicas, 5 de tratamiento y 2 de relaciones interpersonales). Fue diseñado por Morey (1991), y validado en población española por Ortiz-Tallo, Santamaría, Cardenal \& Sánchez (2011).

(5) Escala de dificultades en la regulación emocional (DERS). Escala autoaplicada, dirigida a evaluar y medir los procesos involucrados en la regulación afectiva. Fue diseñada por Gratz y Roemer (2004), y validada en población española por Hervás \& Jodar (2008).

(6) Entrevista neuropsiquiátrica internacional (M.I.N.I). Entrevista breve y estructurada, dirigida a explorar los principales trastornos psiquiátricos Sheehan et al., 1998).

(7) Expectativas y opinión del tratamiento. Escala que evalúa las expectativas del tratamiento antes de empezar, y el grado de satisfacción al finalizarlo, por parte del paciente (adaptado de Borkovec \& Nau, 1972). 
(8) Escala de gravedad valorada por el terapeuta. Adaptación de la escala Clinician Rating de Öst, Salkovskis \& Hellström (1991), realizada por Labpsitec. Está compuesta por 8 frases que indican la gravedad del paciente, y que el terapeuta debe valorar en el pre-tratamiento y post-tratamiento.

Asimismo se establecieron otras medidas a través de un registro semanal diseñado específicamente para este estudio. Se realizó un registro, que a través de la valoración diaria por parte de la paciente nos permitía evaluar: el grado de tristeza; el grado de aprecio por sí misma, y el grado de percepción del afrontamiento de los problemas. La evaluación se realizó semanalmente, todos los días, en un rango de 0-10.

\section{Diagnóstico}

Nos encontramos ante un perfil de personalidad, marcado por la desregulación emocional, la impulsividad, y la presencia de estrés, ansiedad y depresión. Presenta dificultades en el control de la ira, baja tolerancia a la frustración, sentimientos de tristeza y labilidad emocional. Se trata de una persona con rasgos de personalidad límite sin llegar a cumplir criterios diagnósticos. Como diagnóstico principal se obtiene un trastorno de depresión mayor con episodio único de tipo moderado 296.23 (F32.2) y en remisión total, con ansiedad moderada. Cabe añadir que pese a que en las evaluaciones de estado de ánimo ha puntuado alto, de acuerdo a los criterios diagnósticos del DSM-5, cumple criterios para un TDM moderado.

\section{Procedimiento}

Los resultados de la evaluación inicial aportaron información para el diseño de una intervención personalizada. Posteriormente se aplicó el tratamiento, y se realizó la evaluación post-tratamiento a fin de observar los cambios producidos en las variables de medida objetivo. La paciente contactó vía telefónica con el centro, se le explicaron los objetivos y características del estudio y se requirió el consentimiento informado de su participación voluntaria. El protocolo de intervención diseñado gira entorno a dos ejes principales: la regulación emocional y la psicología positiva. La duración total del tratamiento fue de 13 sesiones con una periodicidad semanal y una duración de 60 min. Está compuesto por cinco módulos: psicoeducación (2 sesiones), toma de conciencia (2 sesiones), regulación emocional (5 sesiones), psicología positiva (3 sesiones) y prevención de recaídas (1 sesión). Para el diseño del protocolo tomamos como referencia las aportaciones de Linehan (2003) para el tratamiento de personas con TLP, adaptando su módulo de regulación emocional a las características sintomatológicas de la paciente. El módulo de psicología positiva fue también una adaptación de las aportaciones sobre intervenciones positivas de Seligman (2002).

\section{Resultados}

Se realizó un análisis de la eficacia del tratamiento a través del estudio de las oscilaciones de las puntuaciones de cada instrumento de evaluación. Se compararon los resultados obtenidos en la evaluación inicial con los del final del tratamiento. Asimismo se analizó la evolución de la paciente a lo largo de todo el tratamiento atendiendo a las medidas de los registros semanales. En la Tabla 1 se muestra la evolución de la paciente, teniendo en cuenta las varia- 
bles de medida respecto al estado de ánimo (depresión y ansiedad), autoestima y regulación emocional. Los rasgos de personalidad es una variable que se tuvo en cuenta a la hora de la evaluación, sin embargo no se realizó una evaluación post-tratamiento ya que no fue el foco de la intervención. Nuestro objetivo fue trabajar sobre las variables que influyen en el estado de ánimo. En la evaluación pre-tratamiento la paciente presentaba una depresión grave y ansiedad estado y rasgo por encima de la media. Esto nos indica la presencia de ansiedad en el momento de la evaluación, así como su tendencia general a experimentar estados de ansiedad, existiendo pues, una relación con respecto a los niveles de intensidad en que la experimenta. Asimismo presenta una autoestima muy baja y dificultades de regulación emocional. Las puntuaciones en las tres primeras escalas del DERS (Confusión, Desatención y Rechazo) aluden a dificultades en los procesos de regulación. Las puntuaciones de Confusión y Rechazo se encuentran por encima de la media, siendo esta 7,9 y 14,9 respectivamente. La puntuación en Desatención se encuentra por debajo de la media $(9,6)$. Por su parte, las puntuaciones en Rechazo e Interferencia, son índices generales de desregulación emocional. Los resultados muestran puntuaciones por encima de la media española en ambas sub-escalas, siendo esta 16,5 y 10,2 respectivamente. Estos resultados se relacionan con la incapacidad percibida para el manejo de emociones y su influencia en la vida cotidiana.

Tras la evaluación post-tratamiento observamos una reducción significativa de la sintomatología. La puntuación total en la última evaluación, refleja una depresión mínima, autoestima media, y una reducción de la ansiedad, así como mejoras en su regulación emocional.

Las puntuaciones post-tratamiento en las sub-escalas del DERS, disminuyen ajustándose a la media. Por su parte se produce una mejora significativa en el manejo de la ansiedad, ajustándose tanto la ansiedad estado como la ansiedad rasgo a la media (atendiendo a la baremación española). Se observan, por tanto, cambios a nivel cuantitativo. No obstante, observamos puntuaciones muy polarizadas, disminuciones abultas que se relacionarían con su patrón de cambio emocional rápido y extremo, propio de su inestabilidad emocional. Seguidamente se muestra en la Figura 2 y Figura 3, la evolución a través de los registros semanales. La distribución de los módulos semanalmente fue: psicoeducación (sesiones 1 y 2), toma de conciencia (sesiones 3 y 4), regulación emocional (sesiones 5-9) y psicología positiva (sesiones 10-12). Cabe añadir que de la sesión 10 no pudieron recogerse datos debido a que la paciente no cumplimentó el registro.

Tabla 1

Resultados de la evaluación pre-tratamiento y post-tratamiento

\begin{tabular}{|c|c|c|c|c|c|}
\hline Variable & Test & \multicolumn{2}{|c|}{ Pre-Tratamiento } & \multicolumn{2}{|c|}{ Post-Tratamiento } \\
\hline Depresión & BDI-II & \multicolumn{2}{|c|}{$\begin{array}{l}\text { PT32 } \\
\text { Depresión grave }\end{array}$} & \multicolumn{2}{|c|}{$\begin{array}{l}\text { PT6 } \\
\text { Mínima depresión }\end{array}$} \\
\hline \multirow[t]{2}{*}{ Ansiedad } & STAI & Estado & Rasgo & Estado & Rasgo \\
\hline & & $\begin{array}{l}\text { PT34 } \\
\text { Centil } 80\end{array}$ & $\begin{array}{l}\text { PT44 } \\
\text { Centil } 96\end{array}$ & $\begin{array}{l}\text { PT7 } \\
\text { Centil } 5\end{array}$ & $\begin{array}{l}\text { PT14 } \\
\text { Centil } 15\end{array}$ \\
\hline Autoestima & Autoestima Rosenberg & $\begin{array}{l}\text { PT10 } \\
\text { Autoestim }\end{array}$ & & $\begin{array}{l}\text { PT26 } \\
\text { Autoestir }\end{array}$ & edia \\
\hline
\end{tabular}




\begin{tabular}{|c|c|c|c|}
\hline Variable & Test & Pre-Tratamiento & Post-Tratamiento \\
\hline $\begin{array}{l}\text { Regulación Emoci- } \\
\text { onal }\end{array}$ & DERS & $\begin{array}{l}\text { Confusión: PT11 } \\
\text { Desatención: PT9 } \\
\text { Rechazo: PT22 } \\
\text { Descontrol: PT35 } \\
\text { Interferencia: PT19 }\end{array}$ & $\begin{array}{l}\text { Confusión: PT7 } \\
\text { Desatención: PT18 } \\
\text { Rechazo: PT7 } \\
\text { Descontrol: PT15 } \\
\text { Interferencia: PT7 }\end{array}$ \\
\hline Gravedad & $\begin{array}{l}\text { Escala de gravedad } \\
\text { Valorada por el terapeuta }\end{array}$ & $\begin{array}{l}\text { PT6 Grave con síntomas } \\
\text { incapacitantes en diferen- } \\
\text { tes formas }\end{array}$ & $\begin{array}{l}\text { PT1 Leve los síntomas } \\
\text { pueden estar ocasional- } \\
\text { mente presentes pero } \\
\text { apenas son percibidos } \\
\text { por el paciente }\end{array}$ \\
\hline
\end{tabular}

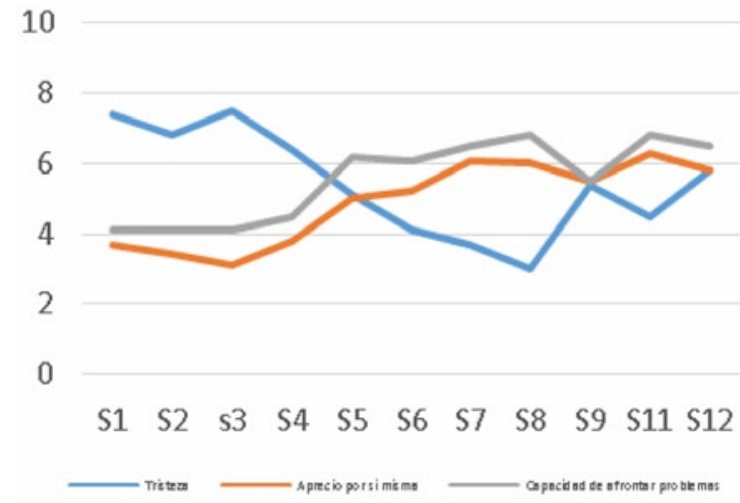

Figura 2. Tendencia en el tiempo del cambio de las variables

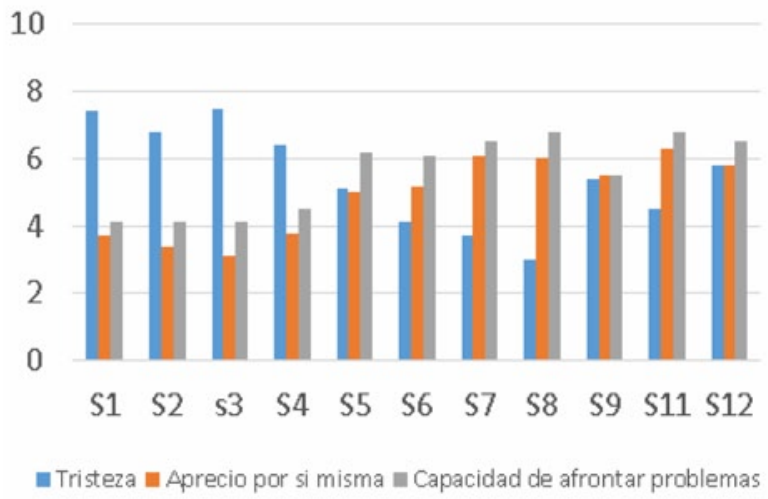

Figura 3. Comparación de los valores de las variables

Se observa como la tristeza presenta oscilaciones y que a partir de la primera sesión de toma de conciencia comienza a disminuir. Durante las sesiones de regulación emocional se mantiene relativamente estable llegando a una puntuación de 3 respecto al 7,5 obtenido en la primera semana. Sin embargo, a partir de la semana 8 (S8) los resultados muestran un aumento de los niveles de tristeza obteniendo una puntuación de 5,4 en la semana. Estos resultados se deben a circunstancias externas a la intervención, acontecimientos personales que acaecieron en torno a la vida de la paciente: su mascota, (siendo uno de sus pilares más importantes) enfermó, por lo que los niveles de tristeza aumentaron notablemente.

No obstante, pese al aumento en las últimas semanas, los niveles de tristeza presentan cambios positivos, que se observan además durante las sesiones de intervención. La paciente manifiesta mejoras en las relaciones interpersonales, mejoras en el ambiente familiar, sentirse más animada y afirma que los cambios son reconocidos por las personas que se encuentran a su alrededor (amigos y pareja). El resto de variables sufre también modificaciones significativas: la capacidad de afrontamiento de problemas aumenta tras las estrategias de regulación emocional, donde se le enseña a identificar emociones, aceptarlas y regularlas. Del mismo modo, las técnicas de psicología positiva parecen ejercer también una gran influencia en la visión positiva de los problemas y de sí misma. Asimismo, y pese a que estas variables descienden en la última semana, viéndose influidas por la muerte de su mascota, llama 
la atención: el aumento de su capacidad para afrontar situaciones difíciles con respecto al principio de la intervención, la disminución de la tristeza y el incremento en su autoestima. La Figura 3 es un gráfico de columnas agrupadas que se utiliza para comparar valores entre algunas categorías, muestra una comparativa en relación a la evolución de cada una de las variables. Se observa como la tendencia a la baja de la tristeza se relaciona con el aumento de la visión positiva de sí misma y la capacidad de afrontamiento de los problemas. Se infiere por tanto, la influencia de unas variables sobre otras, así como la estrecha relación de la capacidad de afrontar problemas con las mejoras en autoestima, aprecio y sentimientos de valía personal. Los resultados post-tratamiento sobre la opinión de la intervención se relacionan con los resultados pre-tratamiento respecto a las expectativas del mismo por parte de la paciente. Asimismo, se obtuvo una buena puntuación en alianza terapéutica tanto pre como post-tratamiento.

\section{Discusión y conclusiones}

En primer lugar y atendiendo a los resultados de la evaluación pre-tratamiento y al análisis funcional de la paciente observamos una fuerte vulnerabilidad asociada a un conjunto significativo de factores de riesgo. Tal y como afirman y demuestran otros estudios, los acontecimientos vitales estresantes suponen factores de riesgo para el desarrollo de depresión: esto se puede ver potenciado por características de personalidad desadaptativas (p. ej., rasgos latentes de personalidad limite), que ocasionan dificultades en la regulación emocional, alteraciones en del sistema emocional, e inestabilidad afectiva (Fruzzetti et al., 2005; Hankin, 2010; Lloyd et al., 2015). Se observa un cambio en los valores del BDI-II, pasando de una depresión grave a mínima. Estos resultados se relacionan con lo identificado en otros estudios sobre la eficacia de la psicología positiva sobre la disminución de la sintomatología depresiva (Seligman et al., 2005; Vázquez, 2006; Vázquez et al., 2006). Por ejemplo, el estudio llevado a cabo por Seligman et al. (2006), mostró como la psicoterapia basada en técnicas de psicología positiva fue altamente eficaz en la reducción de los síntomas depresivos y que además lo era aún más de forma individualizada. Por otro lado los resultados proporcionados por el meta-análisis de Sin \& Lyubomirsky (2009), mostraron también una reducción significativa de los síntomas de depresión y una mejora del bienestar emocional, tras el análisis de 51 intervenciones basadas en psicología positiva. Por su parte la regulación emocional de la paciente se ha visto también mejorada, obteniendo cambios positivos y evidenciando mejoras en la solución de problemas, aceptación, y gestión de emociones. Estos resultados, se relacionan con los beneficios reportados por Linehan (2003), respecto a enseñar habilidades de regulación emocional para entender, conocer y aceptar las propias emociones, reducir la vulnerabilidad y sufrimiento emocional y potenciar las experiencias positivas de la vida diaria. Realizando un análisis general de los resultados obtenidos, se concluye por un lado que el aumento en la percepción de capacidad de solución de problemas por parte de la paciente, presenta un aumento significativo durante el módulo de regulación emocional. Estos resultados nos hacen suponer la importancia e influencia de la gestión emocional adaptativa, como base para el aprendizaje y desarrollo de habilidades funcionales de resolución de conflictos. Del mismo modo otra conclusión extraída de dichos resultados es la eficacia de la psicología positiva, no solo para el bienestar emocional sino también para la autoestima y la visión positiva de los problemas. Los resultados de los registros semanales muestran un aumento de esta variable coincidiendo con las últimas sesiones y relacionándose al mismo tiempo con la mejora en la solución de problemas. Asimismo es importante tener en cuenta que pese a que en un principio la muerte de su mascota pueda haberse considerado como una interferencia en la intervención, finalmente 
analizando los resultados, observamos que ha sido una condición externa que nos ha ayudado a comprobar que efectivamente ha mejorado sus competencias y habilidades personales respecto a su capacidad para gestionar las emociones y hacer frente a situaciones adversas; aumentando su autoeficacia y sentimientos de valía personal. No obstante es importante tener en cuenta que pese a ello, la paciente presenta una elevada vulnerabilidad a experimentar los acontecimientos negativos con una mayor intensidad emocional, debida principalmente a los rasgos de personalidad que la caracterizan. Es por ello por lo que observamos niveles de tristeza muy intensos tras la muerte de su mascota, que se contrastaron y relacionaron con las manifestaciones en sesión de la paciente.

\section{Limitaciones y sugerencias}

El diseño se ciñe a la intervención individual, por lo tanto, estos resultados se extrapolan solo al efecto particular sobre el caso en cuestión. Cabe mencionar que la paciente llegaba tarde en numerosas ocasiones, lo que limitaba el tiempo de intervención. Esto podría relacionarse con el carácter gratuito de la intervención, ocasionando así percepción de menor implicación y responsabilidad. En la misma línea la paciente no cumplimentó los registros correspondientes a la semana 10, por lo que no hemos podido realizar un análisis de los mismos. Otras interferencias destacadas son la no realización de todas las tareas y la cancelación de diferentes sesiones que supusieron alargar el tratamiento. No obstante, estos comportamientos se relacionarían de forma significativa con su patrón de personalidad. El estudio presentado puede tomarse como una investigación preliminar e individual, que podría ponerse en práctica a nivel grupal. Asimismo, se podrían llevar a cabo futuras investigaciones con grupo control, a fin de realizar una comparativa de la eficacia conjunta de estas técnicas respecto a su uso de forma independiente.

\section{Referencias bibliográficas}

Beck, A. T., Steer, R. A. \& Brown, G. K. (1996). Manual for the Beck Depression Inventory-II. San Antonio, TX: Psychological Corporation.

Borkovec, T. D. \& Nau, S. D. (1972). Credibility of analogue therapy rationales. Journal of Behavior Therapy and Experimental Psychiatry 3, 257-260.

Echeburúa, E. (1995). Evaluación y tratamiento de la fobia social. Barcelona: Martínez Roca.

Fruzzetti, A. E., Shenk, C., y Hoffman, P. D. (2005). Family interaction and the development of borderline personality disorder: A transactional model. Development and Psychopathology, 17(04), 1007-1030.

Gratz, K. L. \& Roemer, L. (2004). Multidimensional assessment of emotion regulation and deregulation: Development, factor structure, and initial validation of the difficulties in emotion regulation scale. Journal of Psychopathology and Behavioral assessment, 26(1), 41-54.

Hankin, B. L. (2010). Personality and depressive symptoms: Stress generation and cognitive vulnerabilities to depression in a prospective daily diary study. Journal of Social and Clinical Psychology, 29(4), 369-401.

Hervás, G. \& Jódar, R. (2008). Adaptación al castellano de la Escala de Dificultades en la Regulación Emocional. Clínica y Salud, 19(2), 139-156. 
Hervás, G. \& Vázquez, C. (2006). La regulación afectiva: Modelos, investigación e implicaciones para la salud mental y física. Revista de Psicología General y Aplicada, 59(1-2), 9-36.

Layous, K., Chancellor, J. \& Lyubomirsky S. (2014). Positive activities as protective factors against mental health conditions. Journal of Abnormal Psychology, 123(1), 3-12.

Layous, K. \& Lyubomirsky S. (2014). The how, why what, when, and who of happiness: Mechanisms underlying the success of positive activity interventions. Positive emotion: Integrating the light sides and dark sides, 473-495.

Linehan, M. (2003). Manual de tratamiento de los trastornos de personalidad límite. Madrid: Paidós.

Lloyd, C., Klinteberg, B. \& DeMarinis, V. (2016). Emotion regulation and existential meaningmaking in young women with mental ill-health concerns-a qualitative study. International Journal of Psychology and Behavioral Sciences, 1(1), 1-11.

Morey L. C. (1991). The Personality Assessment Inventory: Professional manual. Odessa. FL: Psychological Assessment Resources.

Ortiz-Tallo, M., Santamaría, P., Cardenal, V. \& Sánchez, M. P. (2011). Adaptación española del Inventario de Evaluación de la Personalidad (PAl). Madrid: Ediciones TEA.

Öst, L. G., Salkovskis, P. \& Hellström, K. (1991). One-session therapist directed exposure vs. self-exposure in the treatment of spider phobia. Behavior Therapy, 22(3), 407-422.

Rosenberg, M. (1965). Society and the adolescent self-image. Princeton, N J: Princeton University.

Sanz, J. \& Vázquez, C. (1998). Fiabilidad, validez y datos normativos del Inventario para la Depresión de Beck. Psicothema, 10(2), 303-318.

Seligman, M. E. (2002). Positive psychology positive prevention and positive therapy. Handbook of Positive Psychology, 2, 3-12.

Seligman, M. E., Rashid, T., y Parks, A. C. (2006). Positive psychotherapy. American Psychologist, 61(8), 774-788.

Seligman, M. E., Steen, T. A., Park, N. \& Peterson, C. (2005). Positive psychology progress: Empirical validation of interventions. American Psychologist, 60(5), 410-421.

Sheehan, D. V., Janavs, J., Baker, R., Harnett-Sheehan, K., Knapp, E., Sheehan, M. \& Bonora, L. I. (1998). MINI-Mini International neuropsychiatric interview-english version 5.0. 0-DSM-IV. Journal of Clinical Psychiatry, 59, 34-57.

Sin, N. L. \& Lyubomirsky S. (2009). Enhancing well-being and alleviating depressive symptoms with positive psychology interventions: A practice-friendly meta-analysis. Journal of Clinical Psychology, 65(5), 467-487.

Spielberger, C. D., Gorsuch, R. L. \& Lushene, R. (1982). Manual del Cuestionario de Ansiedad Estado/Rasgo (STAI). Madrid, España: TEA Ediciones

Vázquez, C. (2006). La psicología positiva en perspectiva. Papeles del Psicólogo, 27(1), 1-2.

Vázquez, C., Hervás, G. \& Ho, S. (2006). Intervenciones clínicas basadas en la psicología positiva: fundamentos y aplicaciones. Psicología Conductual, 14(3), 401-432.

Widiger, T. A. \& Trull, T. J. (1993). Borderline and narcissistic personality disorders. En P. B. Sutker \& H. E. Adams (dirs.), Comprehensive handbook of psychopathology (pp. 371394). Nueva York: Plenum. 


\title{
Eficacia analgésica del tratamiento invasivo miofascial (punción seca) en fibromialgia
}

\author{
JUAN VICENTE MAMPEL \\ Juanvicentemampel@yahoo.es \\ FRANCISCO ROS BERNAL \\ fros@uji.es
}

\section{Resumen}

Introducción. La fibromialgia (FM) es una entidad clínica caracterizada por un dolor crónico generalizado. La sensibilización central del sistema nervioso se considera la explicación más plausible al dolor crónico generalizado que afecta a las personas con FM. La nueva neurobiología del dolor establece que los puntos gatillo miofasciales puede ser fuente periférica capaz de originar el dolor. El tratamiento de los PGM puede disminuir el dolor de los pacientes con FM. Metodología. Se realizó un ensayo clínico aleatorizado con 120 participantes, se diseñaron 3 grupos con el objetivo de comprobar la eficacia de la intervención. Resultados. Los resultados obtenidos determinan diferencias significativas entre el grupo Tratamiento y grupo Placebo $(p=0,01)$. Conclusiones. Los pacientes sometidos a la técnica de punción seca mostraron una disminución de la hiperalgesia local a las 24 horas de la intervención.

Palabras clave: Dolor miofascial, fibromialgia, punción seca, dolor crónico.

\section{Abstract}

Introduction. Fibromyalgia (FM) is a clinical entity characterized by widespread chronic pain. Central sensitization of the nervous system is considered the most plausible explanation for the widespread chronic pain that affects people with FM. The new neurobiology of pain states that myofascial trigger points can be a peripheral source capable of causing pain. Treatment of MTrPs may decrease the pain of patients with FM. Methodology. We designed a randomized clinical trial with 120 participants divided into 3 groups with the objective of checking the effectiveness of the intervention. Results. The results obtained determined significant differences between the treatment and the Placebo group $(p=0.006)$. Conclusions. Patients undergoing the dry needling technique showed a decrease in local hyperalgesia 24 hours after surgery.

Key Words: Myofascial pain, fibromyalgia, dry needling, chronic pain. 


\section{Introducción}

La fibromialgia (FM) es una entidad clínica caracterizada por un dolor crónico generalizado. Su consideración como enfermedad permite abarcar todo el conjunto de componentes comórbidos que acompañan al dolor, entre los que destacan la fatiga, la disfunción cognitiva y los trastornos del sueño (Chinn, Caldwell y Gritsenko, 2016). La FM es una enfermedad que en la actualidad afecta al $2,4 \%$ de la población española generando un gasto sanitario en el territorio español de aproximadamente 11.000 .000 euros al año.

La sensibilización central del sistema nervioso se considera la explicación más plausible al dolor crónico generalizado que afecta a las personas con FM. A pesar de la etiología incierta establecida en la actualidad la evidencia sugiere que la sensibilización central, aunque no es la única causa (Yunus, 2007), origina un estado aumentado de la sensibilidad, que produce un dolor generalizado y difuso en el sujeto con FM (Butler y Moseley, 2010).

La etiopatología anteriormente descrita de la FM se establece a partir del cambio en cuanto al entendimiento del dolor. La concepción del dolor ha estado estrechamente ligada a la teoría darwiniana de la evolución y, recientemente, de un modelo biomédico simplista y obsoleto se ha cambiado a un modelo biopsicosocial donde no solo el componente biológico sino también el psicológico y social forman parte de cualquier proceso álgico.

Esta nueva perspectiva del dolor atribuye al dolor miofascial y concretamente a los puntos gatillos miofasciales (PGM) como estructuras periféricas capaces de mantener la nocicepción en un cuadro de sensibilización central. De esta manera, la información nociceptiva procedente de estas estructuras constituiría un factor predisponente implicado en la neurobiología del dolor crónico.

El dolor miofascial,encuadrado dentro de las mialgias, es una alteración no inflamatoria originada en el sistema músculo-esquelético y con la presencia de PGM, nódulos hiperirritables, situados en las fibras del músculo. Es un dolor de tipo músculo-esquelético, agudo o crónico que a menudo es infradiagnosticado.

Una vez se ha establecido que existe incremento de la sensibilización central originado por una activación del PGM es recomendable reducir la hiperalgesia local en un enfermo de FM a través del tratamiento de los PGM. Al tratar el componente periférico se obtiene una mejora, tanto del dolor local como generalizado, disminuyendo y reduciendo la sensibilización periférica. El objetivo principal del presente estudio fue valorar los efectos de la punción seca en la hiperalgesia local de pacientes con FM.

\section{Material y método}

Realizamos un ensayo clínico aleatorizado con tres grupos de pacientes diagnosticadas con FM: i) un grupo experimental, ii) un grupo control placebo y iii) un grupo control sin intervención. El grupo experimental (Tratamiento) lo constituyeron los sujetos a los que se les realizó la técnica de punción seca. A las pacientes del grupo control placebo (Placebo), se les simuló la punción. Por último, al grupo control sin intervención (No intervención), no se les realizó nada.

Se utilizó la guía CONSORT, con las recomendaciones STRICTA (MacPherson y cols., 2010) para establecer las directrices del proceso experimental y evitar cualquier sesgo durante todo el proceso. Todo el protocolo del estudio fue aprobado por la Comisión Deontológica de la Universitat Jaume I (Castellón), de acuerdo con la Declaración de Helsinki de 1975, revisada en 1983. 
Se empleó la técnica de enmascaramiento (doble ciego). La asignación al grupo se determinó a través del programa EPIDAT 3.1 (Xunta de Galicia). Los criterios de inclusión para participar en el estudio fueron: i) ser mujer, ii) haber recibido un diagnóstico de FM por un reumatólogo, iii) tener entre 35 y 80 años, iv) ser capaz de entender el español y v) haber firmado el consentimiento informado por decisión propia. Por otro lado, los criterios de exclusión fueron: i) sufrir belonefobia, ii) presentar un linfedema en la zona a tratar, ya que éste aumenta el riesgo de infección por la punción, iii) estar en estado de gestación o con la posibilidad de estarlo, iv) personas sometidas con anterioridad a técnicas de punción seca o v) diagnosticadas de enfermedades neoplásicas.

En todas las participantes pertenecientes a los grupos tratamiento y placebo se localizaron los PGM del músculo infraespinoso del brazo dominante. En el grupo tratamiento se realizó la técnica de entradas y salidas rápidas de Hong (Hong, 1994) una vez obtenida la primera reacción de espasmo local (REL) la aguja se movió unos 2-3 mm en vertical de forma rápida y realizándose aproximadamente 25 inserciones sin salir de la piel, con una frecuencia aproximada de $1 \mathrm{~Hz}$ durante 25 a 30 segundos (Arias-Buría y cols., 2015). Los pacientes del grupo Placebo fueron sometidos a una intervención que simulaba la punción empleando una aguja placebo de mango retraíble (Streitberger y Kleinhenz, 1998). El grupo de No intervención se diseñó para dilucidar si la intervención era una técnica de enmascaramiento de la punción seca. A las pacientes no se les localizaron los PGM, ni se les realizó punción seca, ni la simulación de la misma.

La algometría por presión fue el método utilizado para valorar la eficacia de la punción seca. Para ello empleamos un instrumento denominado algómetro con un manómetro adherido a una punta de goma cilíndrica. La fiabilidad de la algometría por presión es relativamente alta, con coeficientes de 0,9 y 0,95 (Chesterton, Sim, Wright y Foster, 2007). Se aplicó la medición algométrica en el epicóndilo lateral del brazo ipsilateral que corresponde al esclerotoma de la raíz C5-C6, cuyo miotoma se asocia al lugar de la intervención (músculo infraespinoso). Se realizaron mediciones antes del tratamiento/placebo, 5 minutos después y a las 24 horas post tratamiento.

La variable algometría local se describió empleando una medida de tendencia central (media), de dispersión (desviación típica), coeficiente de Curtosis y coeficiente de Asimetría. Las medias se compararon mediante el test exacto de ANOVA (corrección con Bartlett's test) y si la diferencia era significativa, se realizaron consecuentes contrastes post hoc (comparaciones múltiples). Se aceptó un nivel de riesgo alfa del 0,05. Todos los análisis estadísticos se realizaron empleando el programa Statistical Package for the Social Sciences (SPSS) versión 23.0 IBM® para Windows XP.

\section{Resultados}

De los 250 sujetos reclutados en el estudio se excluyeron 130 participantes. Los principales motivos por los cuales se descartaron fueron: i) el no cumplimiento de los criterios de inclusión $(19,9 \%)$, ii) negativa a participar a pesar de cumplir los criterios de inclusión $(28,4 \%)$ y iii) otros motivos (4\%). Con los 120 participantes aptos para el estudio se conformaron los tres grupos y una vez iniciado el estudio de campo, tras la firma del consentimiento informado, finalizaron el estudio de manera completa 34 sujetos del grupo tratamiento, 30 sujetos del grupo placebo y 32 sujetos del grupo no intervención. De esta manera la tasa de abandono del estudio fue de un $20 \%$.

Tras la realización del análisis inferencial de las variables antropométricas de los sujetos pertenecientes al estudio se desprende que la aleatorización fue existosa (ver Tabla1). 
Tabla 1

Comparación de las variables antropométricas entre grupos. Se realizó la prueba de ANOVA para determinar si existian diferencias significativas en los grupos para las variables edad, peso, talla e IMC

\begin{tabular}{ccc}
\hline & ANOVA (Entre grupos) & \\
\hline Variable & $\mathrm{F}$ & p-valor \\
\hline Edad & 1,19 & 0,31 \\
Peso & 0,69 & 0,50 \\
Talla & 2,29 & 0,12 \\
IMC & 0,08 & 0,92 \\
\hline
\end{tabular}

F: estimación varianza poblacional; No se observaron diferencias significativas en ninguna de las variables analizadas $p>0,050$. El análisis descriptivo de la algometría local desprendió los valores mostrados a continuación (ver Tabla 2).

Tabla 2

Estadísticos descriptivos de la algometría local. Representación de la media, desviación estándar, Asimetría y Curtosis

\begin{tabular}{cccccc}
\hline \multicolumn{5}{c}{ Algometría local (pretratamiento) } \\
\hline Tratamiento & $\mathrm{N}$ & Media & $\begin{array}{c}\text { Desviación } \\
\text { estándar }\end{array}$ & Asimetría & Curtosis \\
Placebo & 34 & 25,57 & 7,54 & 0,49 & $-0,49$ \\
No intervención & 30 & 22,68 & 8,48 & 0,35 & $-0,62$ \\
\hline & 32 & 27,00 & 8,82 & 0,16 & $-0,70$ \\
\hline Tratamiento & $\mathrm{N}$ & Algometría local (postratamiento) & & \\
Placebo & 34 & 26,63 & 7,95 & 0,12 & 0,11 \\
No intervención & 30 & 22,23 & 7,51 & 0,59 & 0,57 \\
\hline Tratamiento & 32 & 25,30 & 8,85 & $-0,15$ & $-1,24$ \\
\hline Placebo & Algometría local (post24 horas tratamiento) & & \\
\hline No intervención & 34 & 26,77 & 7,94 & 0,54 & $-0,43$ \\
\hline
\end{tabular}

Pretratamiento: medición antes intervención: postratamiento: medición tomada 5 minutos después y post-24 horas tratamiento: medición tomada a las 24 horas de la intervención. 
Al realizar el análisis estadístico a través de la ANOVA de un factor no se demostró la existencia de diferencias significativas entre grupos dentro del valor algometría local post intervención según el tratamiento recibido $(p=0,10)$. En cambio, sí existen diferencias significativas entre los grupos al analizar la algometría local 24 horas post intervención $(p=0,01)$ (ver Tabla 3 y Figura 2).

Tabla 3

Análisis ANOVA. Comparación de variables de la VFC entre grupos. Comparación variable algometría local postratamiento y algometría local post 24 horas entre grupos. Se realizó la prueba ANOVA para comprobar si existian diferencias significativas entre los grupos

\begin{tabular}{ccc}
\hline & ANOVA (Entre grupos) & \\
\hline Variable & $\mathrm{F}$ & p-valor \\
\hline Algometría local Post & 2,42 & 0,10 \\
Algometría local post 24 horas & 5,04 & $\underline{0,01}$ \\
\hline
\end{tabular}

F: estimación varianza poblacional. En este caso, se observaron dichas diferencias en la algometría local post 24 horas p $>0,01$.

Una vez comprobado la significancia obtenida tras el análisis ANOVA, se procedió a realizar la prueba post hoc utilizando la HDS de Tukey al comprobar la homogeneidad de varianzas. Los resultados obtenidos determinan diferencias significativas entre el grupo Tratamiento y grupo Placebo $(p=0,01)$. Sin embargo, no existían diferencias significativas entre el grupo Placebo o el grupo tratado frente al no intervenido $(p=0,17)$ (ver Tabla 4). Aun así, las tendencias de las medias determinan un efecto mayor sobre los valores de la algometría local a las 24 horas de la intervención en el grupo tratado con punción seca (ver Figura 2).

Tabla 4

Análisis post hoc. Comparación entre grupos algometría local post 24 horas

\begin{tabular}{ccc}
\hline \multicolumn{3}{c}{ Comparaciones múltiples (HSD Tukey) } \\
\hline Grupos & Algometría Local Post & Algometría Local Post 24h \\
\hline Tto/placebo & $p=0,08$ & $p=\underline{0.01}$ \\
Tto/no int & $p=0,78$ & $p=0,37$ \\
Placebo/no int & $p=0,30$ & $p=0,17$ \\
\hline
\end{tabular}

Tto: Grupo Tratamiento; Placebo: Grupo intervención simulada; no int: Grupo No intervención. En esta variable se muestra una diferencia entre el grupo Tratamiento y el grupo Placebo $p=0,01$. Además, en esta misma variable no se muestra diferencia entre el grupo Placebo y no intervención $p=0,17$. 


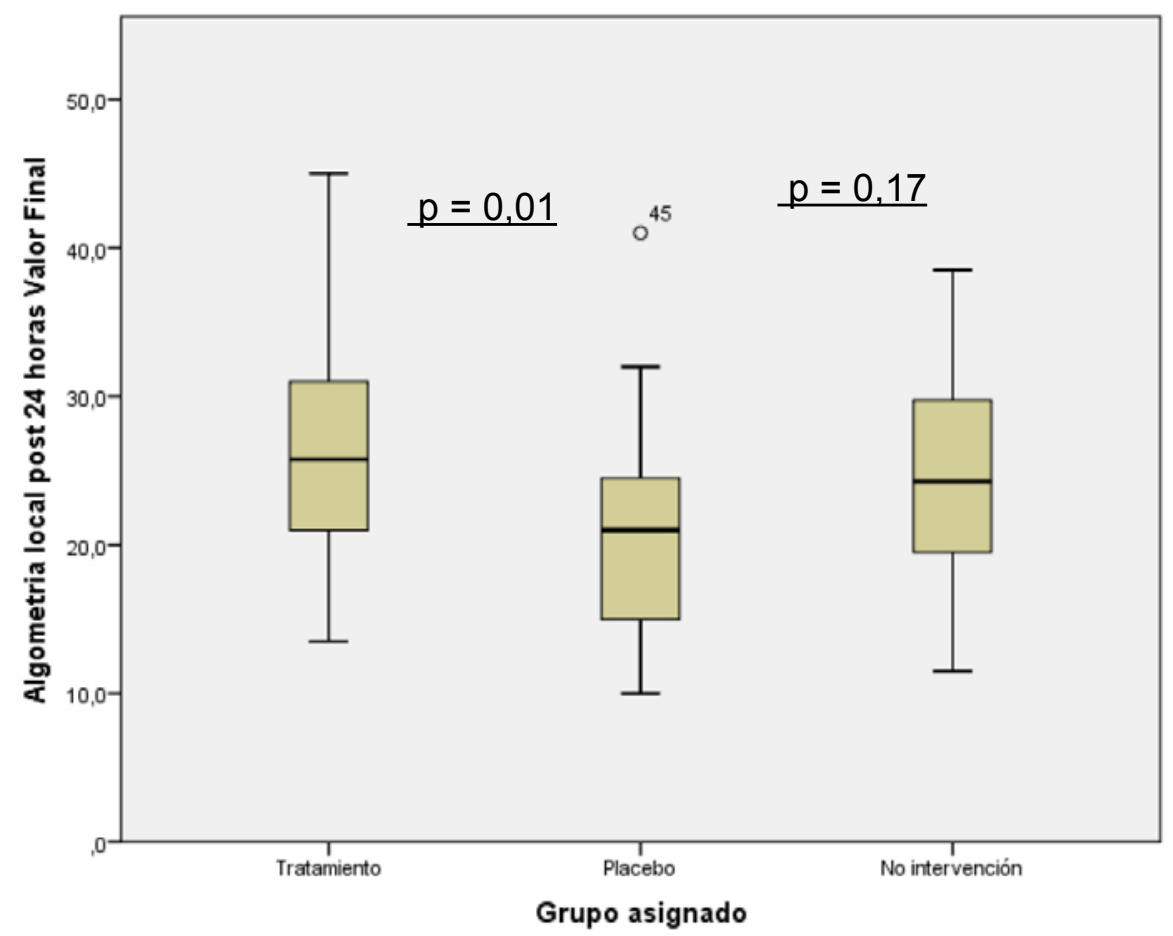

Figura 2. Representación gráfica de la media de los tres grupos algometría local post 24 horas. El diagrama de cajas muestra las diferencias significativas entre las medias de los distintos grupos de intervención

\section{Discusión y conclusiones}

Con los resultados obtenidos y representados con anterioridad, a primera vista se podría dilucidar una disminución de los efectos de los valores de la hiperalgesia local tras la punción seca en en personas con fibromialgia. Pero, ¿este tratamiento sería capaz de producir analgesia en este tipo de pacientes?

Los componentes de cada segmento espinal se denominan dermatoma, miotoma y esclerotoma. La importancia de los PGM en la fisiopatología de la sensibilización periférica es clave a la hora de determinar el daño de los tejidos a través de la liberación de sustancias algógenas. Todo el diseño experimental está basado en la sensibilización espinal segmentaria, el segmento espinal utilizado para el estudio fue la raíz nerviosa C5-C6 cuyo miotoma corresponde al musculo infraespinoso, y el esclerotoma al epicóndilo lateral (Fischer, 2002). Los PGM del músculo infraespinoso (raíz C6) se consideran focos irritativos capaces de generar un alto flujo de estímulos nociceptivos hacia el ganglio dorsal sensitivo de la médula espinal ( Bonica, 1990) manteniendo un cuadro de sensibilización central.

La técnica de punción fue elegida con el objetivo de conseguir la REL puesto que se ha comprobado un aumento de la eficacia de la técnica al provocar dicho efecto fisiológico (Rha y cols., 2011). En ningún momento de la intervención el paciente pudo percibir visualmente cómo fueron introducidas las agujas al estar colocado en decúbito lateral y realizar la intervención en el vientre muscular del músculo infraespinoso, siguiendo el procedimiento realizado en otros estudios de punción seca (Huguenin y cols., 2005). En esta línea, estudios previos han constatado que el hecho de ver la aguja simuladora por parte del paciente puede originar un 
fracaso de la técnica de enmascaramiento para el grupo placebo (Wong, Leung y Zhang, 2015).

En relación con la técnica de enmascaramiento algunos estudios no consideran que la técnica de punción simulada pueda ser útil como método de enmascaramiento ya que la relación con el agente inactivo asociado al componente psicológico puede generar efectos semejantes al tratamiento. La presión ejercida con la punta roma de la aguja y la presión durante la palpación del PGM activan la estimulación neurosensorial y las vías aferentes que inervan la piel, llegando hasta los centros superiores, por tanto esta estimulación sensorial podría tener un posible efecto terapéutico (Lund y Lundeberg, 2006; Lund, Näslund y Lundeberg, 2009; Lundeberg, Lund, Näslund y Thomas, 2008). De igual manera, en estudios de acupuntura se considera la técnica con aguja de punción simulada una herramienta de enmascaramiento útil ante el grupo de intervención (Tough, White, Richards, Lord y Campbell, 2009).

Aunque no se han encontrado estudios que analizaran el uso y los posibles efectos (psicológicos y fisiológicos) de la técnica de punción simulada, como método de enmascaramiento de la punción seca, esta herramienta se ha empleado para cegar los ensayos clínicos que comprueban la eficacia del tratamiento invasivo miofascial (Dıraçoğlu, Vural, Karan y Aksoy, 2012; Tekin y cols., 2013). Por este motivo, en el presente estudio, se ha añadido un tercer grupo, el grupo No tratamiento, al que no se le ha introducido ninguna aguja, ya fuese experimental o sham. Además, en este último grupo no se realizó la localización a través de la palpación de los PGM. De esta forma se pudo dilucidar si la herramienta de punción simulada era útil para la intervención como técnica de enmascaramiento en los estudios de punción seca.

El dolor es el síntoma distintivo de la FM y, tal y como se estableció en el marco teórico, no depende del grado de daño o inflamación en los tejidos periféricos. La alteración del procesamiento sensorial que caracteriza a estos individuos crea una situación final de anormalidad local, aumentando la sensibilidad de los pacientes con FM (Cassisi y cols., 2014). Por ello, se considera que el umbral de dolor a la presión, medida que se ha tomado con un algómetro, es clave en la evaluación clínica de los sujetos con FM (Gómez-Perretta, Triñanes, GonzálezVillar y Carrillo-de-la-Peña, 2016).

Con la algometría local se cuantificó de manera objetiva y numérica el grado de hiperalgesia mecánica de los sujetos que participaron en el estudio. Se valoró si la amplificación dolorosa, la disminución del umbral de dolor a la presión (Jespersen y cols., 2007) característica de estos pacientes, se modificaba tras el tratamiento con punción seca. Staud y cols publicaron un estudio similar al de la presente tesis introduciendo infiltraciones de un anestésico local (lidocaína) en zonas frecuentes de dolor referidas por pacientes con FM. Sus resultados fueron concluyentes y demostraron la importancia del componente periférico para el mantenimiento de la hiperalgesia mecánica y térmica en FM. A pesar de que sus resultados fueron positivos y consiguieron cambios en cuanto a la clínica del dolor, determinaron que un alto porcentaje de la reducción del mismo se debía a interferencias tales como la analgesia producida por el efecto placebo y la analgesia producida por la propia inserción de la aguja dependiente de algún modo de la profundidad a la cual se insertaba (Staud, Weyl, Bartley, Price y Robinson, 2014).

En cuanto a los resultados que se obtuvieron respecto a la algometría local se mostró que la técnica de punción seca poseía efecto analgésico a las 24 horas de la intervención. El efecto analgésico fue mayor en el grupo Tratamiento y la diferencia fue estadísticamente significativa respecto al grupo Placebo. En cambio, no hubo diferencias entre el grupo Placebo y No intervención, determinando así una ausencia de la analgesia placebo producida por las interferencias de las creencias y pensamientos derivados de ser sometidos a una técnica de punción. Estos resultados positivos en cuanto a la efectividad del enmascaramiento con la técnica que simula la punción contrastan con resultados obtenidos en otros estudios de acu- 
puntura, donde no se encontraron diferencias entre el grupo Tratamiento y la técnica placebo utilizada (Deare y cols., 2013). La aplicación de la técnica en el PGM localizado a través de la palpación y confirmada su localización a través de la REL puede ser responsable del éxito actual del proceso de enmascaramiento. Así pues, la técnica utilizada para simular la punción es útil para introducirla en estudios con punción seca.

Hay que señalar que en el grupo Tratamiento fue en el único donde el umbral de dolor a la presión mostró un aumento en la comparación antes/después y antes/a las 24 horas. En los otros dos grupos este umbral descendió después de la intervención. Por lo tanto, se concluye que los pacientes sometidos a la técnica de punción seca mostraron una disminución de la hiperalgesia local a las 24 horas de la intervención en relación al grupo Placebo y al No intervención. Este efecto no se encontró en la valoración realizada inmediatamente después del tratamiento. La importancia del presente estudio reside en la disminución de la hiperalgesia en los pacientes con fibromialgia después de realizarles el tratamiento con punción seca. Es decir, el tratamiento de componente periférico, concretamente, de los PGM a través de la técnica elegida ha demostrado un efecto neuromodulador del dolor en este cuadro de sensibilización central.

\section{Referencias bibliográficas}

Arias-Buría, J. L., Valero-Alcaide, R., Cleland, J. A., Salom-Moreno, J., Ortega-Santiago, R., Atín-Arratibel, M. A., y Fernández-de-las-Peñas, C. (2015). Inclusion of trigger point dry needling in a multimodal physical therapy program for postoperative shoulder pain: a randomized clinical trial. Journal of Manipulative and Physiological Therapeutics, 38(3), 179-187. https://doi.org/10.1016/j.jmpt.2014.11.007

Butler, D. S. y Moseley, G. L. (2010). Explicando el Dolor. Noigroup Publications.

Cassisi, G., Sarzi-Puttini, P., Casale, R., Cazzola, M., Boccassini, L., Atzeni, F., y Stisi, S. (2014). Pain in fibromyalgia and related conditions. Reumatismo, 66(1), 72-86.

Chesterton, L. S., Sim, J., Wright, C. C. y Foster, N. E. (2007). Interrater reliability of algometry in measuring pressure pain thresholds in healthy humans, using multiple raters. The Clinical Journal of Pain, 23(9), 760-766. https://doi.org/10.1097/AJP.0b013e318154b6ae

Chinn, S., Caldwell, W. y Gritsenko, K. (2016). Fibromyalgia Pathogenesis and Treatment Options Update. Current Pain and Headache Reports, 20(4), 25. https://doi.org/10.1007/ s11916-016-0556-x

Deare, J. C., Zheng, Z., Xue, C. C. L., Liu, J. P., Shang, J., Scott, S. W., y Littlejohn, G. (2013). Acupuncture for treating fibromyalgia. The Cochrane Database of Systematic Reviews, (5), CD007070. https://doi.org/10.1002/14651858.CD007070.pub2

Dıraçoğlu, D., Vural, M., Karan, A., y Aksoy, C. (2012). Effectiveness of dry needling for the treatment of temporomandibular myofascial pain: a double-blind, randomized, placebo controlled study. Journal of Back and Musculoskeletal Rehabilitation, 25(4), 285-290. https://doi.org/10.3233/BMR-2012-0338

Fischer, A.A. (2002). Functional Diagnosis of musculoskeletal pain and evaluation of treatment results by quantitative and objetive techniques. In Myofascial Pain and Fibromyalgia. Trigger Point Management (2nd ed., pp. 145-173). Rachlin.

Gómez-Perretta, C., Triñanes, Y., González-Villar, A. J., y Carrillo-de-la-Peña, M. T. (2016). Evaluation of the accuracy of several symptoms and domains in distinguishing patients diagnosed with fibromyalgia from healthy controls. Clinical and Experimental Rheumatology, 34(2 Suppl 96), S14-25. 
Hong, C. Z. (1994). Lidocaine injection versus dry needling to myofascial trigger point. The importance of the local twitch response. American Journal of Physical Medicine y Rehabilitation / Association of Academic Physiatrists, 73(4), 256-263.

Huguenin, L., Brukner, P. D., McCrory, P., Smith, P., Wajswelner, H., y Bennell, K. (2005). Effect of dry needling of gluteal muscles on straight leg raise: a randomised, placebo controlled, double blind trial. British Journal of Sports Medicine, 39(2), 84-90. https://doi.org/10.1136/ bjsm.2003.009431

Jespersen, A., Dreyer, L., Kendall, S., Graven-Nielsen, T., Arendt-Nielsen, L., Bliddal, H., y Danneskiold-Samsoe, B. (2007). Computerized cuff pressure algometry: A new method to assess deep-tissue hypersensitivity in fibromyalgia. Pain, 131(1-2), 57-62. https://doi. org/10.1016/j.pain.2006.12.012

Bonica, J.J. (1990). The management of pain (2nd ed.). Philadelphia: Lea y Febiger.

Lund, I., y Lundeberg, T. (2006). Are minimal, superficial or sham acupuncture procedures acceptable as inert placebo controls? Acupuncture in Medicine: Journal of the British Medical Acupuncture Society, 24(1), 13-15.

Lund, I., Näslund, J., y Lundeberg, T. (2009). Minimal acupuncture is not a valid placebo control in randomised controlled trials of acupuncture: a physiologist's perspective. Chinese Medicine, 4, 1. https://doi.org/10.1186/1749-8546-4-1

Lundeberg, T., Lund, I., Näslund, J., y Thomas, M. (2008). The Emperors sham - wrong assumption that sham needling is sham. Acupuncture in Medicine: Journal of the British Medical Acupuncture Society, 26(4), 239-242.

MacPherson, H., Altman, D. G., Hammerschlag, R., Youping, L., Taixiang, W., White, A., ... on behalf of the STRICTA Revision Group. (2010). Revised STandards for Reporting Interventions in Clinical Trials of Acupuncture (STRICTA): Extending the CONSORT Statement. Journal of Evidence-Based Medicine, 3(3), 140-155. https://doi. org/10.1111/j.1756-5391.2010.01086.x

Rha, D., Shin, J. C., Kim, Y.-K., Jung, J. H., Kim, Y. U., y Lee, S. C. (2011). Detecting local twitch responses of myofascial trigger points in the lower-back muscles using ultrasonography. Archives of Physical Medicine and Rehabilitation, 92(10), 1576-1580.e1. https:// doi.org/10.1016/j.apmr.2011.05.005

Staud, R., Weyl, E. E., Bartley, E., Price, D. D., y Robinson, M. E. (2014). Analgesic and antihyperalgesic effects of muscle injections with lidocaine or saline in patients with fibromyalgia syndrome. European Journal of Pain (London, England), 18(6), 803-812. https:// doi.org/10.1002/j.1532-2149.2013.00422.x

Streitberger, K., y Kleinhenz, J. (1998). Introducing a placebo needle into acupuncture research. Lancet (London, England), 352(9125), 364-365. https://doi.org/10.1016/S01406736(97)10471-8

Tekin, L., Akarsu, S., Durmuş, O., Cakar, E., Dinçer, U., y Kıralp, M. Z. (2013). The effect of dry needling in the treatment of myofascial pain syndrome: a randomized double-blinded placebo-controlled trial. Clinical Rheumatology, 32(3), 309-315. https://doi.org/10.1007/ s10067-012-2112-3

Tough, E. A., White, A. R., Richards, S. H., Lord, B., y Campbell, J. L. (2009). Developing and validating a sham acupuncture needle. Acupuncture in Medicine: Journal of the British Medical Acupuncture Society, 27(3), 118-122. https://doi.org/10.1136/aim.2009.000737

Wong, E. L.-Y., Leung, P.-C., y Zhang, L. (2015). Placebo acupuncture in an acupuncture clinical trial. How good is the blinding effect? Journal of Acupuncture and Meridian Studies, 8(1), 40-43. https://doi.org/10.1016/j.jams.2014.10.010 
Yunus, M. B. (2007). Role of central sensitization in symptoms beyond muscle pain, and the evaluation of a patient with widespread pain. Best Practice y Research. Clinical Rheumatology, 21(3), 481-497. https://doi.org/10.1016/j.berh.2007.03.006 


\title{
El aprendizaje emocional con reforzadores secundarios no fortalece el recuerdo retroactivo de eventos relacionados
}

\author{
CAROLINA CuADRADO-GÓmEZ \\ al262441@uji.es \\ ELISENDA BUEICHEKÚ \\ bueichek@uji.es \\ CÉSAR ÁVILA \\ avila@uji.es
}

\begin{abstract}
Resumen
Introducción: Vivir experiencias con gran impacto emocional tiene un efecto trascendental sobre la memoria, así lo demuestran diversos estudios donde se defiende que los eventos emocionales se retienen mejor que los eventos neutros. Un tema de interés científico es el efecto de las nuevas experiencias emocionales sobre recuerdos relacionados previos. El presente estudio tuvo como objetivo investigar el efecto que tiene un evento emocional sobre el recuerdo retroactivo de eventos relacionados conceptualmente. Método: 25 estudiantes universitarios sanos completaron una tarea de codificación (compuesta por dos fases: pre-condicionamiento y condicionamiento) y una tarea de reconocimiento. El pre-condicionamiento consistía en clasificar categóricamente 90 imágenes de animales o herramientas. En el condicionamiento se presentaron 45 imágenes nuevas de cada categoría, una de las cuales fue asociada a un castigo monetario/social. Los participantes debían indicar si esperaban perder dinero en cada ensayo. Finalmente, $24 \mathrm{~h}$ después, se realizó la tarea de reconocimiento sorpresa. Resultados: Los resultados indicaron un mejor recuerdo a las 24 horas de la categoría castigada en el condicionamiento, sin embargo los ítems de esta categoría presentados en el pre-condicionamiento se recordaron peor. Conclusión: De manera novedosa, los resultados sugieren que el castigo mediante reforzador secundario causa un efecto inhibitorio de recuerdo en el pre-condicionamiento de la categoría castigada. Es decir, un evento emocional futuro puede afectar al recuerdo de eventos relacionados, que han sido codificados anteriormente, haciendo que estos se recuerden peor.
\end{abstract}

Palabras clave: emoción, aprendizaje, recuerdo, memoria retroactiva, condicionamiento 


\begin{abstract}
Introduction: Living experiences with great emotional impact has a transcendental effect on memory, as shown by several studies where it is argued that emotional events are retained better than neutral events than neutral events. A topic of scientific interest is the effect of new emotional experiences on previous related memories. The presented study aimed to investigate the effect of an emotional event on the retroactive memory of conceptually related events. Methodology: 25 healthy university students completed encoding task (composed of two phases: pre-conditioning and conditioning) and a recognition task. In the pre-conditioning, participants had to classify 90 images into animals and tools. Later, in the conditioning stage, 45 new images of each category were presented, one of which was associated with monetary / social punishment. Participants should indicate whether they expected to lose money or not in each trial. Finally, 24 hours later, the task of surprise recognition was performed. Results: The results replicated a better memory at 24 hours for the category punished in the conditioning, but the items of this category presented in the pre-conditioning, were worse remembered. Conclusion: Newly manner, the results suggest that punishment by a secondary reinforcement provokes an inhibitor effect of memory in the pre-conditioning of the punished category. That is, a future emotional event can affect the memory of related events, which have been previously codified, making them remember worse.
\end{abstract}

Key words: emotion, learning, memory, retroactive memory, conditioning

\title{
Introducción
}

A menudo los eventos emocionales se recuerdan con mayor exactitud y viveza que los eventos que carecen de un componente emocional (Buchanan, 2007). Este sesgo del recuerdo a favor de los estímulos emocionales, tiene una explicación evolutiva, ya que es un mecanismo de supervivencia (Dunsmoor, Martin y LaBar, 2012). Este mecanismo nos ha ayudado a acercarnos a lo apetitivo (como pueden ser fuentes de energía) y alejarnos de lo aversivo (depredadores), a dar respuestas óptimas ante un entorno cambiante. Es decir, la función biológica primaria de las emociones es la adaptación de la conducta a situaciones que resulten relevantes para el individuo (Aguado, 2002). Un tema de gran relevancia científica, en el cual se ha centrado este estudio, es conocer como los eventos emocionales afectan al recuerdo de otros eventos relacionados.

Las emociones son reacciones psicofisiológicas que nos permiten adaptarnos a los estímulos ambientales o de uno mismo. Involucran un conjunto de pensamientos, actitudes y creencias sobre el mundo que utilizamos para valorar una situación concreta y, por tanto, influyen en el modo en el que se percibe dicha situación. Sirven para establecer nuestra posición con respecto a nuestro entorno, y nos impulsan hacia ciertas personas, objetos, acciones, ideas y nos alejan de otros (Levenson, 1999). Las emociones tienen un papel fundamental en la memoria, puesto que son factores alertadores a través de los cuales la memoria se fija con mayor facilidad (Justel, Psyrdellis, y Ruetti, 2013; Loubon y Franco, 2010). De hecho, la estrecha relación existente entre las emociones y la memoria, está sustentada por numerosas investigaciones (Christianson y Loftus, 1987; Bradley, Greenwald, Petry, y Lang, 1992; LaBar, Gatenby, Gore, LeDoux, y Phelps, 1998; Quevedo et al., 2003; Bobes García, Bousoño Gar- 
cía, Calcedo Barba, y González García-Portilla, 2003; Buchanan, 2007; Knight y Mather, 2009; Justel, Psyrdellis, y Ruetti, 2013). En términos generales, es posible afirmar que los eventos emocionales se recuerdan mejor que los sucesos más triviales. De hecho, la memoria de sucesos asociados a diferentes emociones se adquiere con mayor facilidad y se mantiene a lo largo del tiempo (Christianson y Loftus, 1987).

A pesar de esta estrecha relación entre la emoción y la memoria, existen pocos estímulos de gran relevancia emocional. Es decir, la mayoría de los estímulos se procesan como eventos triviales, sin relevancia y, por tanto, se recuerdan poco. Ahora bien, puede ocurrir que un evento emocional presente facilite el recuerdo de los sucesos que inicialmente eran triviales (Dunsmoor, Murty, Davachi y Phelps, 2015). Desde la perspectiva de la memoria adaptativa es fundamental que los detalles aparentemente sin importancia puedan almacenarse en la memoria, al menos temporalmente, en caso de que esta información adquiera relevancia algún tiempo después. Dunsmoor y cols. (2015), intentaron demostrar como memorias inicialmente débiles pueden fortalecerse si esta información posteriormente adquiere significado. En su estudio proporcionan pruebas de un aumento de la memoria retroactiva en los seres humanos, que es selectiva a la información conceptual relacionada con un evento emocional futuro. Para ello, emplean dos tareas, una de codificación y otra de reconocimiento sorpresa a las $24 \mathrm{~h}$. La primera tarea constaba de tres fases, pre-condicionamiento, condicionamiento y post-condicionamiento. A lo largo de las tres fases se presentaban imágenes de dos categorías (animales y herramientas). Tanto en la primera fase (pre-condicionamiento) como en la última (post-condicionamiento), las imágenes no estaban vinculadas a ningún tipo de castigo. Sólo la fase de condicionamiento se asociaba una categoría (animal o herramienta) a una descarga (de forma contrabalanceada). A las $24 \mathrm{~h}$ se realizaba un reconocimiento sorpresa. Los resultados señalaron que no sólo se recordaban mejor los estímulos emocionales, es decir, los que habían sido asociados a la descarga, sino que este efecto se transladaba a nivel retroactivo. Es decir, se recuerdan también mejor los estímulos que pertenecen a la categoría castigada (EC+) del pre-condicionamiento a pesar de que estos no fueron asociados al castigo.

El impacto de un estímulo emocional sobre eventos codificados anteriormente ha sido poco estudiado. Por tanto, el objetivo del presente estudio es comprobar si el recuerdo de eventos, que no estaban vinculados con una emoción, pueden fortalecerse si en el futuro aparece un acontecimiento emocionalmente fuerte que se vincule conceptualmente con el primero (Dunsmoor, et al., 2015). Nuestra primera hipótesis es que habrá un mayor recuerdo de la categoría castigada $(\mathrm{EC}+)$ frente al recuerdo de la categoría no castigada (EC-) para los ítems del condicionamiento. La segunda hipótesis es que también habrá un mayor recuerdo de la categoría castigada $(E C+)$ frente al recuerdo de la categoría no castigada (EC-) para los ítems del pre-condicionamiento.

\section{Método}

\section{Diseño}

Estudio experimental controlado y aleatorizado, con ocultación de la asignación a 8 versiones diferentes del experimento y enmascaramiento en el análisis de datos. El estudio estaba aprobado por el Comité Ético de la Universidad Jaume I. 


\section{Población y muestra}

Se seleccionaron 33 alumnos de la Universidad Jaume I. Los criterios de inclusión fueron: ser mayor de 18 años, firmar el consentimiento informado una vez entendida la finalidad del estudio y la metodología a emplear, no presentar enfermedad mental y no haber sido incluido anteriormente.La muestra final estaba compuesta por 25 participantes ( 9 hombres y 16 mujeres) con una edad de 21,92 $\pm 1,5$ años (media \pm desviación típica). Todos los participantes recibieron una remuneración económica tras finalizar el estudio.

\section{Materiales}

Imágenes

Las 8 versiones diferentes a las que fueron asignados los participantes del estudio, se elaboraron seleccionando un total de 360 imágenes: 180 imágenes de animales y 180 de herramientas, todas ellas a color sobre un fondo blanco (para evitar que el fondo pueda intervenir en el reconocimiento) y con una resolución de 800 x 600 píxeles. Los ítems estaban situados en el centro de la pantalla. Los estímulos fueron presentados mediante el software E-Prime 2.0, en un portátil Toshiba Satellite, con una pantalla de 15,6». Las imágenes se obtuvieron de recursos de libre acceso en internet. Durante el experimento ninguna imagen se presentaba más de una vez.

Los criterios para seleccionar las imágenes y contrabalancear las categorías fueron el número de sílabas y la frecuencia de uso de las palabras que denominan las imágenes. La selección se hizo mediante el programa EsPal (Duchon, Perea, Sebastián-Gallés, Martí \& Carreiras, 2013). Todas las imágenes se denominaban con una palabra simple (por ejemplo: gato o, martillo), no había palabras compuestas (por ejemplo: bicho palo o sierra mecánica).

\section{Tarea experimental}

El estudio estaba compuesto de dos sesiones experimentales (Figura 1). En la primera sesión se realizó una tarea denominada tarea de codificación, dónde se produjo el aprendizaje, y en la segunda sesión se realizó una tarea de reconocimiento, dónde se midió el recuerdo.

La tarea de codificación estaba compuesta por dos fases: pre-condicionamiento y condicionamiento. El pre-condicionamiento estaba formado por un total de 90 imágenes, 45 de animales y 45 de herramientas, que fueron presentadas durante 2,5 segundos con un intervalo inter-estimular de $6 \pm 2$ segundos en el que está incluida la pantalla en blanco con el punto de fijación, que aparece entre estímulos. La duración total del pre-condicionamiento fue de unos 8 minutos aproximadamente. En esta fase los participantes debían clasificar las imágenes en las dos categorías: animal o herramienta. Para ello, empleaba las teclas del teclado Z (animal) y M (herramienta). En esta fase, ninguna imagen fue asociada al castigo. A continuación, se llevó a cabo una asignación económica, en esta se presentaba en la pantalla del ordenador unas cifras que pasaban rápidamente y de forma aleatoria, estas cifras estaban en un rango de 20 a 140 euros, que es la cantidad que se les había indicado a los participantes que podían ganar en el experimento. Los participantes debían detener la presentación empleando la letra $\mathrm{H}$ del teclado, una vez detenida la presentación aparecía en pantalla la cifra que habían ganado. En todos los casos eran 90 euros. El dinero se les otorgaba en monedas de dos euros, ya que era una condición necesaria para desempeñar el castigo. 
El condicionamiento estaba formado por 90 imágenes, 45 de animales y 45 de herramientas. Todas ellas distintas a las del pre-condicionamiento. En esta parte, las imágenes se presentaban durante 4,2 segundos con un intervalo inter-estimular de $8 \pm 2$ segundos. Con una duración aproximada de 12 minutos. En esta fase los participantes debían indicar si esperaban perder dinero con la imagen que aparecía. Para ello, la tarea estaba diseñada de la siguiente forma: primero aparecía la imagen (de animal o herramienta), seguidamente la pregunta ¿Esperas perder dinero? Los participantes debían indicar sus respuestas empleando las teclas $Z$ (sí) y M (no). Después podía aparecer, o no, una señal de castigo. La señal de castigo era una cara roja triste, que indicaba una pérdida monetaria de dos euros. Esta cantidad era retirada por el experimentador, dando lugar al castigo monetario/social. Se castigaban 30 imágenes de 45 , dependiendo de la versión experimental se castigaba una categoría u otra. Estas estaban contrabalanceadas. En las versiones 1, 3, 5 y 7 se castigaba la categoría animales y en las versiones 2, 4, 6 y 8 se castigaba la categoría herramienta.

En la segunda sesión se realizaba un reconocimiento sorpresa. Se les explicaba a los participantes, que se les iba a presentar las imágenes visualizadas el día anterior, sin ningún tipo de modificación, junto a otras imágenes de animales y herramientas que no habían visto anteriormente. Los participantes debían indicar si la imagen la habían visto el día anterior o era nueva.

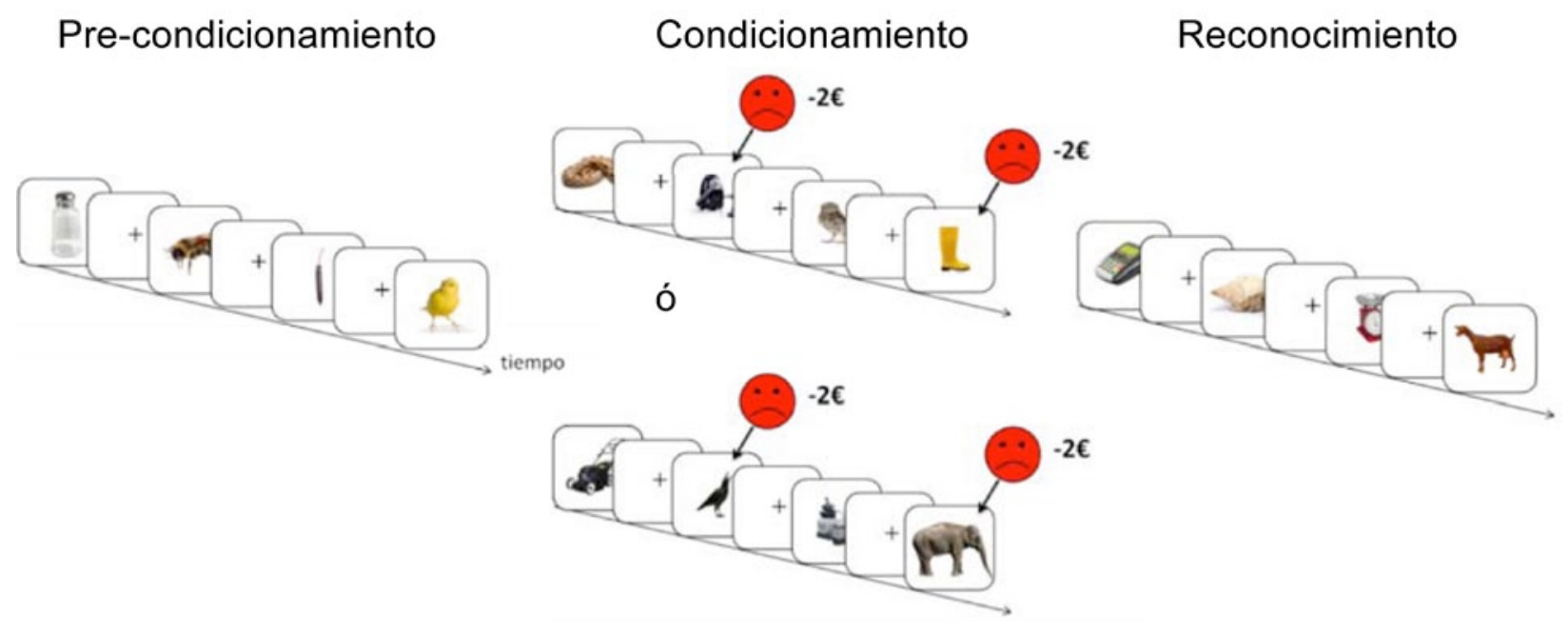

Figura 1. Tarea de codificación y tarea de reconocimiento

En la primera sesión realizaban una tarea de codificación. La tarea de codificación estaba compuesta por dos fases: pre-condicionamiento y condicionamiento. En el pre-condicionamiento ninguna imagen estaba asociada a un castigo. En la fase de condicionamiento una categoría era asociada a un castigo monetario/social. En la segunda sesión se realizaba un test de reconocimiento sorpresa a las 24 horas. 30 
Procedimiento

Antes de empezar la sesión experimental, los participantes debían firmar el consentimiento informado. Seguidamente, se procedía a iniciar la sesión experimental. En la primera sesión se realizaba la tarea de codificación. La sesión se iniciaba con la fase de pre-condicionamiento, dónde los participantes debían clasificar las imágenes en animales y herramientas. Una vez finalizada esta fase, se procedía a la asignación económica donde los sujetos recibían 90 euros. Se les explicaba que en la fase que de condicionamiento podían perder parte de este dinero y esto dependería de la señal de castigo. En el condicionamiento, 30 imágenes de una de las categorías estaban emparejadas con la señal de castigo. Por tanto, al finalizar el condicionamiento todos los participantes se quedaban con 30 euros, ya que cada vez que aparecía la señal de castigo se retiraban dos euros de los 90 euros asignados inicialmente. La segunda sesión se llevaba a cabo a las 24 horas, era una tarea de reconocimiento sorpresa. En esta sesión aparecían las imágenes de la tarea de codificación junto con las imágenes nuevas, también de las categorías de animales y herramientas, los participantes debían indicar si las imágenes presentadas eran nuevas o no.

\section{Análisis estadístico}

El análisis estadístico de los datos se realizó mediante un ANOVA 2x2 de medidas repetidas. El primer factor fue Fase (Pre-condicionamiento vs. Condicionamiento) y el segundo factor fue Categoría (Categoría castigada vs. Categoría no castigada). Calculamos los estadísticos descriptivos, la media y la desviación típica, para comparar el aprendizaje entre categorías en el pre-condicionamiento y en el condicionamiento. Para medir el tamaño del efecto empleamos la eta parcial al cuadrado $(\eta 2 p)$.

\section{Resultados}

La muestra final estaba compuesta por 25 participantes ( 9 hombres y 16 mujeres) con una edad de 21,92 $\pm 1,5$ años (media \pm desviación típica). Los resultados del ANOVA $2 \times 2$ señalan una interacción significativa entre los factores Fase $x$ Categoría $[F(1,24)=8,24, p=0,008$, $\eta 2 p=0,25]$, aunque los efectos principales de cada uno no alcazaran la significación mínima $(p>0.05)$. Esta interacción indica que se recuerdan más ítems de la categoría castigada en el condicionamiento $(\bar{x}=0,441 ; \sigma=0,128)$ en comparación con la categoría no castigada $(\bar{x}=0,41$; $\sigma=0,127)$. Sin embargo, este efecto se revierte en la fase de pre-condicionamiento, donde la categoría castigada se recuerda peor $(\bar{x}=0,4202 ; \sigma=0,136)$ que la categoría no castigada $(\bar{x}=0,469 ; \sigma=0,121$ ) ( ver Figura 2). 


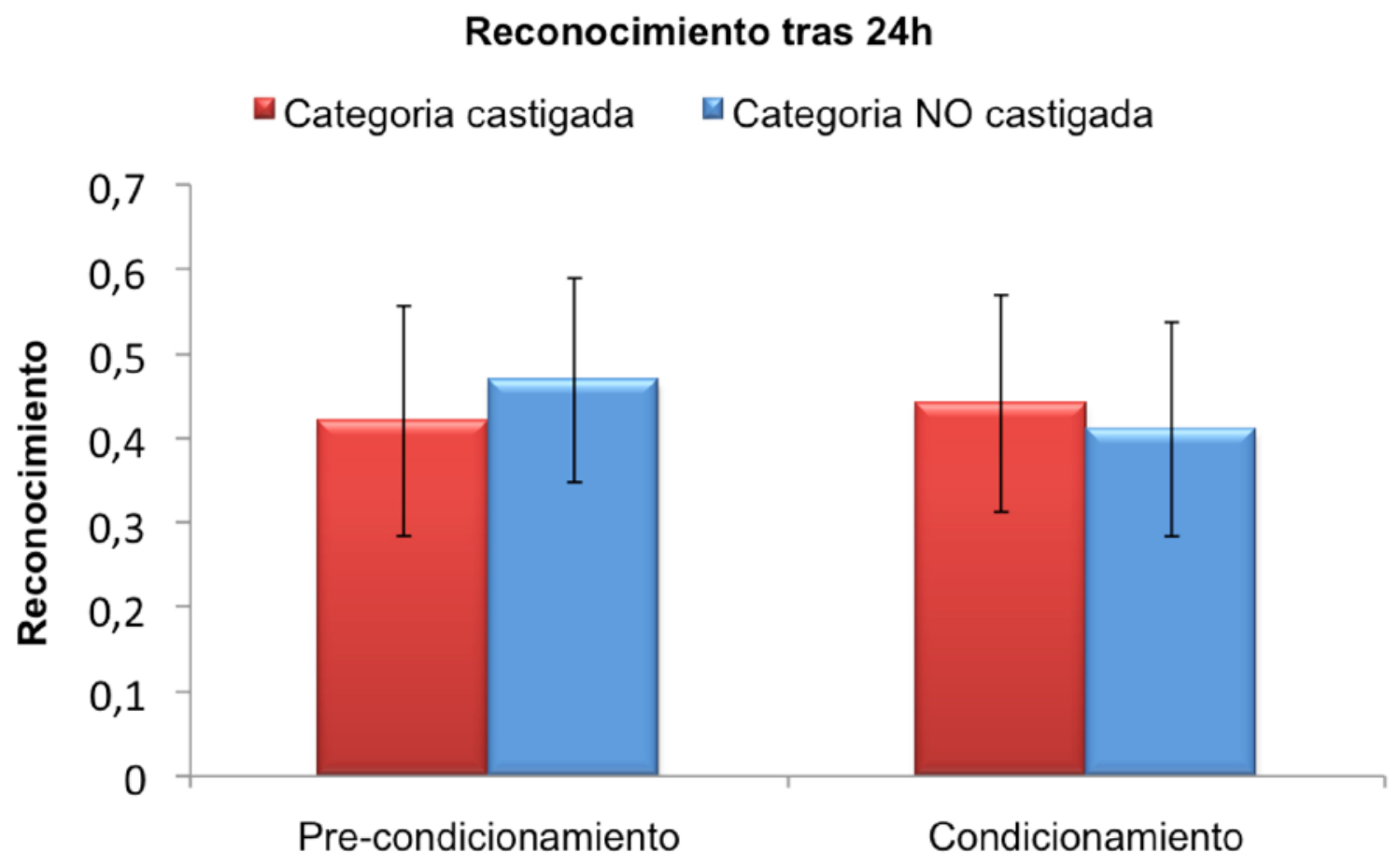

Figura 2. Reconocimiento tras las 24 horas

\section{Discusión y conclusión}

El objetivo del presente estudio fue investigar el efecto que tiene un evento emocional, elicitado con un reforzador secundario: monetario/social, sobre el recuerdo retroactivo de eventos relacionados conceptualmente. Para ello, el estudio estaba compuesto por una tarea de codificación y una tarea de reconocimiento sorpresa a las 24 horas. Los resultados de la tarea de reconocimiento indicaron que se recordaba mejor la categoría castigada en el condicionamiento y peor en el pre-condicionamiento. La novedad de este estudio es aportar evidencias sobre el impacto que tiene un evento emocional, a partir de un castigo monetario/social, sobre el recuerdo de eventos anteriores relacionados conceptualmente.

Numerosa literatura sustenta que los eventos emocionales se retienen mejor que los eventos neutros (Christianson y Loftus, 1987), y nuestros resultados también aportan datos a favor de esta afirmación. Sin embargo, no ha sido tan estudiado el efecto que tiene un evento emocional sobre eventos que han sido codificados anteriormente, y que guarden relación conceptual con el estímulo emocional. Dunsmoor y cols. (2015) demostraron que un evento emocional elicitado con un reforzador primario (una descarga eléctrica) produce una mejora en el recuerdo a nivel retroactivo de eventos relacionado. No obstante, a diferencia de estos autores nosotros no encontramos el mismo efecto en el pre-condicionamiento.

A partir de nuestros resultados podemos confirmar nuestra primera hipótesis, ya que se produce un mayor recuerdo de la categoría castigada $(E C+)$ frente al recuerdo de la categoría no castigada (EC-) para los ítems del condicionamiento. Por otra parte, debemos rechazar la segunda hipótesis, ya que no se produce una mejora a nivel retroactivo para los ítems del pre-condicionamiento que pertenecen a la categoría castigada. Por tanto, no encontramos el mismo efecto a nivel retroactivo que Dunsmoor y cols. (2015). Nuestros resultados sugieren 
que el castigo tiene un efecto inhibitorio en el reconocimiento de la categoría castigada, haciendo que los ítems que corresponden a la categoría castigada del pre-condicionamiento se recuerden menos.

Posiblemente estas diferencias se puedan atribuir a la emoción generada. En el estudio planteado por Dunsmoor y cols. (2015), emplean como estímulo incondicionado (EI) aversivo un reforzador primario, una descarga. Sin embargo, en nuestro estudio hemos empleado un reforzador secundario, concretamente un castigo monetario/social. Los resultados de un estudio realizado por Delgado, Labouliere y Phelps (2006) demostraron cómo un reforzador secundario, como el dinero, podía ser un estímulo incondicionado efectivo para un paradigma de condicionamiento aversivo. Sin embargo, no era tan efectivo como un reforzador primario. No obstante, Delgado y cols. (2006) no comparaban el efecto de los reforzadores en la consolidación de ítems previos. Ahora bien, para poder explicar que las diferencias de los resultados son atribuibles al tipo de reforzador, es necesaria más literatura al respecto. A partir de los resultados que disponemos, podemos interpretar que un reforzador secundario (monetario/ social) no presenta la fuerza necesaria para producir la mejora a nivel retroactivo.

Otra diferencia importante es que estamos realizando una comparación entre dos estudios con una diferencia muestral considerable, ya que el estudio de Dunsmoor y cols. (2015) dispone de una muestra de 119 sujetos frente a los 25 participantes que componen nuestro estudio. Futuros estudios podrían dirigirse a salvar estas diferencias $y$, además, incorporar el uso de reforzadores primarios con el objetivo de registrar el valor aversivo el castigo

En conclusión, debido a la escasez de estudios que integren emoción, aprendizaje y memoria a nivel de categorías conceptuales y que evalúen su efecto a nivel retroactivo, la aportación que podemos hacer a partir de los resultados de nuestro estudio es que un reforzador secundario no produce una mejora en el recuerdo anterior para categorías relacionadas conceptualmente.

\section{Referencias bibliográficas}

Aguado, L. (2002). Procesos cognitivos y sistemas cerebrales de la emoción. Revista de Neurología, 34(12), 1161-1170.

Bobes García, J., Bousoño García, M., Calcedo Barba, A. y González García-Portilla, M. P. (2003). Trastorno de Estrés Postraumático. Barcelona: Masson.

Bradley, M. M., Greenwald, M. K., Petry, M. C., y Lang, P. J. (1992). Remembering Pictures: Pleasure and Arousal in Memory. Journal of Experimental Psychology: Learning, Memory and Cognition, 2, 379-390.

Buchanan, T. W. (2007). Retrieval of Emotional Memories. Psychological Bulletin, 133(5), 761779. doi: 10.1037/0033-2909.133.5.761.

Christianson, S., y Loftus, E. (1987). Memory for Traumatic Events. Applied Cognitive Psychology, 1, 225-239.

Delgado, M. R., Labouliere, C. D., y Phelps, E. A. (2006). Fear of losing Money? Aversive conditioning with secondary reinforcers. SCAN, 1, 250-259. doi:10.1093/scan/nsI025.

Duchon, A., Perea, M., Sebastián-Gallés, Martí, A. y Carreiras, M. (2013). EsPal: One-stop shopping for Spanish Word properties. Behavior Research Methods, 45, 1246-1258. doi. 10.3758/s13428-013-0326-1

Dunsmoor, J. E., Martin, A., y LaBar, K. S. (2012). Role of conceptual knowledge in learning and retention of conditioned fear. Biological Psychology, 89(2), 300-305. doi: 10.1016/j. biopsycho.2011.11.002. 
Dunsmoor, J. E., Murty, V. P., Davachi, L., y Phelps, E. A. (2015). Emotional learning selectively and retroactively strengthens memories for related events. Nature, 520 (7547), 345-348. doi: 10.1038/nature14106.

Justel, N., Psyrdellis, M., y Ruetti, E. (2013). Modulación de la memoria emocional: Una revisión de los principales factores que afectan los recuerdos. Suma Psicológica, 20, 163174. doi: $10.14349 /$ sumapsi2013.1276.

Knight, M., y Mather, M. (2009). Reconciling findings of emotion-induced memory enhancement and impairment of preceding ítems. Emotion, 9(6), 763-781. doi:10.1037/ a0017281.

LaBar, K. S., Gatenby, C., Gore, J. C., LeDoux, J. E., y Phelps, E. A. (1988). Human Amygdala Activation during Conditioned Fear Acquisition and Extintion: a Mixed- Trial fMRI Study. Cell Press, 20, 937-945.

Levenson, R. W. (1999). The Intrapersonal Functions of Emotion. Cognition and Emotion, 13(5), 481-504.

Loubon, C. O., y Franco, J. C. (2010). Neurofisiología del aprendizaje y la memoria. Plasticidad neuronal. IMedPub Journals, 6(1), 2. doi: 10.3823/048.

Quevedo, J., Sant'Anna, M. K., Madruga, M., Lovato, I., De-Paris, F., Kapczinski, F., Izquierdo, I., y Cahill, L. (2003). Differential effects of emotional arousal in short- and long-term memory in healthy adults. Neurobiology of Learning and Memory, 79, 132-135.

Ruetti, E., Mustaca, A., y Bentosela, M. (2008). Memoria emocional: Efectos de la corticosterona sobre los recuerdos. Revista Latinoamericana de Psicología, 40 (3), 461-474. 



\title{
El bienestar psicológico y la felicidad como variables protectoras en los Trastornos Adaptativos
}

\author{
Un estudio exploratorio
}

\author{
CinTIA TUR DOMENECH \\ al229482@uji.es \\ IRYNA RACHYLA \\ rachyla@uji.es \\ AlBA LÓPEZ MONTOYO \\ montoyo@uji.es \\ SOLEDAD QUERO CASTELLANO \\ squero@uji.es
}

\section{Resumen}

Introducción: La relación existente entre la satisfacción con la vida y la felicidad con respecto a variables psicológicas clínicas ha sido ampliamente estudiada. Existen estudios que muestran al afecto positivo como amortiguador del estrés y de otros síntomas clínicos, así como potenciador de comportamientos saludables y calidad de vida. Objetivo: Explorar las relaciones existentes entre las variables de satisfacción con la vida y felicidad subjetiva como factores protectores de síntomas clínicos en una muestra de pacientes diagnosticados de Trastorno Adaptativo (TA). Método: La muestra incluyó 46 participantes (media de edad=33.2; DT= 8.47). Como medidas positivas se incluyeron las escalas de felicidad subjetiva (SHS) y satisfacción con la vida (SWLS). Las medidas clínicas fueron: depresión, síntomas de estrés y pérdida y percepción de capacidad para afrontar el problema. Resultados: Se obtuvieron correlaciones significativas en la dirección esperada entre las variables positivas y las variables clínicas de depresión y autoeficacia. Los síntomas de estrés y pérdida solamente correlacionaron significativamente con la felicidad. Los resultados posteriores mediante regresión lineal reflejaron que ambas variables positivas predecían la gravedad de la sintomatología depresiva. Además, la satisfacción con la vida predecía el grado de autoeficacia para afrontar el problema, mientras que la felicidad subjetiva fue predictora de menos síntomas de estrés y pérdida asociados al mismo. Conclusión: Los resultados preliminares obtenidos están en la línea de los hallados en otros trabajos y reflejan la importancia de atender, en pacientes con diagnóstico de TA, a variables psicológicas positivas como las incluidas en este estudio.

Palabras clave: Trastorno adaptativo, satisfacción con la vida, felicidad subjetiva, sintomatología clínica 


\section{Abstract}

Introduction: The relationship between satisfaction with life and the growing happiness of clinical psychological variables has been thoroughly studied. Some studies show positive affection as a shock absorber of stress and other clinical symptoms, as well as an enhancer of healthy behaviors and quality of life. Objective: To explore the relationship between life satisfaction and subjective happiness as protective factors for clinical symptoms in a sample of patients diagnosed with Adjustment Disorder (AD). Method: The sample included 46 participants (mean age $=33.2, \mathrm{SD}=8.47$ ). Positive measures included subjective happiness (SHS) and satisfaction with life (SWLS) scales. The clinical measures were: depression, symptoms of stress and loss, and perception of the ability to cope with the problem. Results: Significant correlations were obtained in the expected direction between the positive variables and the clinical variables of depression and self-efficacy. Symptoms of stress and loss only correlated significantly with happiness. Subsequent linear regression results showed that both positive variables predicted the severity of depressive symptoms. In addition, satisfaction with life predicted the degree of self-efficacy to cope with the problem, while subjective happiness was predictive of less symptoms of stress and loss associated with it. Conclusion: The preliminary results obtained are in line with those found in other studies and reflect the importance of attending, in patients with a diagnosis of $A D$, positive psychological variables such as those included in this study.

Key words: Adjustment disorder, satisfaction with life, subjective happiness, clinical symptoms

\section{Introducción}

La psicología positiva es una corriente que estudia los aspectos positivos que pueden influir en la salud y en las características adaptativas de las personas (Vázquez y Chaves, 2016). Diversos son los conceptos que forman parte de esta corriente. Concretamente, los constructos felicidad, satisfacción con la vida y afecto positivo han sido ampliamente estudiados y aunque se refieren a elementos diferentes, están fuertemente relacionados tanto teórica como empíricamente, es por ello que son indicadores de un mayor grado de bienestar (Howell, Kern, y Lyubomirsky, 2007).

Entre las teorías que apoyan el uso de la psicología positiva como protector de síntomas clínicos, la teoría de la ampliación y la construcción propuesta por Bárbara Fredickson es una de las más conocidas. Uno de los principios centrales de esta teoría expone que; si las emociones negativas precipitadas por el estrés contribuyen a los trastornos del estado de ánimo recurrentes, apoyados por cambios en los circuitos cerebrales afectivos, las emociones positivas repetidas pueden revertir este proceso (Garland y cols., 2010).

Los estudios existentes muestran que las emociones positivas incrementan los recursos personales, recursos psicológicos y recursos físicos, aumentando la visión que las personas tienen del entorno (Fredrickson, 2013; Fredrickson, Cohn, Coffey, Pek y Finkel, 2008). Específicamente los individuos que experimentan mayores emociones positivas, están más satisfechos con sus vidas, presentan mayor bienestar psicológico, afrontamientos más efectivos y predicen mayor salud mental (Fredickson, 2013; Tugade y Fredrickson, 2002). También se 
asocian las cualidades positivas con menor morbilidad, menor mortalidad, mayor supervivencia, mejor calidad de vida y funcionamiento, menores síntomas, menor experiencia de dolor y menor gravedad (Pressman y Cohen, 2012).

Por lo tanto, el afecto positivo funciona como un amortiguador del distrés mediante la reducción de los efectos que éste produce en la salud, facilitando su adaptación y ayudando a que las respuestas fisiológicas vuelvan más rápidamente a un estado normal después de experimentar un evento estresante (Fredrickson, 2009; Lazarus, Kanner y Folkman, 1980; Vazquez Hervás, Rahona, y Gómez 2009). El sistema de afecto positivo se está introduciendo cada vez más, como un objetivo terapéutico potencialmente valioso para condiciones psiquiátricas, que se caracterizan principalmente por emociones negativas elevadas (Dunn, 2012; Taylor, Lyubomirsky y Stein, 2016).

Los Trastornos Adaptativos (TA) se caracterizan por una inadecuada reacción emocional y comportamental ante una situación estresante que produce interferencia y dificultades en las diferentes áreas de funcionamiento. Según el DSM-5, la prevalencia encontrada en pacientes ingresados en áreas de salud mental oscila entre el $5-20 \%$ y este diagnóstico es a menudo el más frecuentemente encontrado en la consulta psiquiátrica, alcanzando casi el 50\% (APA, 2013). También constituye uno de los problemas psicológicos más frecuentes en los ámbitos de atención primaria y hospitalaria (Carta, Balestrieri, Murru y Hardoy, 2009). Sin embargo, no hemos encontrado en la literatura ningún estudio que relacione variables positivas con la sintomatología emocional (ansiedad y depresión) que caracteriza a este trastorno. El objetivo del presente estudio es explorar las relaciones existentes entre las variables de satisfacción con la vida y felicidad subjetiva como factores protectores de síntomas clínicos en una muestra de pacientes con diagnóstico de TA.

\section{Método}

\section{Participantes}

Los participantes que se incluyen en este trabajo formaban parte de un estudio controlado previo en el que se comparaba la eficacia de un tratamiento cognitivo-comportamental (de forma tradicional o apoyado con realidad virtual) frente a un grupo control lista de espera. Todos ellos solicitaron ayuda en el Servicio de Asistencia Psicológica (SAP) de la Universitat Jaume I de Castellón (España). La muestra estaba compuesta por 46 participantes (34 mujeres y 12 hombres) con edades comprendidas entre 18 y 50 años, y una media de edad de 33.28 (DT=8.47). Todos ellos fueron diagnosticados de TA, según los criterios del DSM-5 (APA, 2013). La mayoría de los participantes habían cursado estudios universitarios $(76.1 \%)$ y el $23.9 \%$ tenían estudios primarios o secundarios. En cuanto al estado civil, el $45.7 \%$ eran solteros, el $39.1 \%$ estaban casados o convivían con la pareja y el $15.2 \%$ restante eran viudos o divorciados. En lo que respecta al subtipo de TA, el 78.3\% fueron diagnosticados de TA mixto con ansiedad y depresión, el $15.2 \%$ presentaron TA con estado de ánimo depresivo, un $4.3 \%$ TA con ansiedad y, por último, un $2.2 \%$ presentaban TA con alteración mixta de las emociones y el comportamiento.

\section{Medidas}

Todos los participantes cumplimentaron un protocolo de evaluación más amplio que incluía tanto instrumentos específicamente diseñados por el equipo para los TA, como otros que recogen otras variables clínicas relevantes. A continuación, se describen las medidas de variables positivas y de síntomas clínicos incluidas en este estudio. 
Escala de Satisfacción con la Vida (SWLS: Satisfaction With Life Scale; Diener, Emmons, Larsen y Griffin, 1985). Evalúa aspectos cognitivos de bienestar a partir de una breve escala de 5 ítems. Valora el grado de acuerdo con cada afirmación usando una escala Likert de 7 puntos (de 1= fuertemente en desacuerdo a $7=$ fuertemente de acuerdo). Esta escala ha sido validada en muchos países e idiomas distintos mostrando una alta consistencia interna (Alpha de Cronbach entre 0.79 y 0.83 ). En población general española muestra un coeficiente de Alpha de Cronbach de 0.88 y una validez convergente de 0.44 y 0.31 con otras medidas de bienestar (Vázquez, Duque y Hervás, 2012).

Escala de Felicidad Subjetiva (SHS: Subjective Happiness Scale; Lyubomirsky y Lepper, 1999). Evalúa una categoría molar de bienestar como fenómeno psicológico global. Consta de 4 ítems tipo Likert de 7 puntos (1= «muy poco feliz» a $7=$ «Muy feliz»). La escala original fue validada a través de 14 muestras distintas obteniendo una fiabilidad entre 0.79 y 0.94 . En este estudio se utilizó la escala traducida al español que muestra un Alpha de Cronbach de 0.73 para población general. En cuanto a la fiabilidad test-retest (entre tres semanas y un año) varió entre 0.55 y 0.90 y la validez convergente fue de entre 0.52 y 0.72 con otras medidas de felicidad (Vera-Villarroel, Celis-Atenas y Córdova-Rubio, 2011).

Inventario de Depresión de Beck (BDI-II: Beck Depression Inventory-II; Beck, Steer y Brown, 1996. Adaptación española de Sanz, García-Vera, Espinosa, Fortún, y Vázquez, 2005). Este instrumento evalúa la gravedad de la sintomatología depresiva en adultos y adolescentes, con edad mínima de 13 años. Consta de 21 ítems en los que la persona elige entre cuatro alternativas la frase que mejor describe su estado de ánimo durante las últimas dos semanas incluyendo el día en el que completa el inventario. El rango de puntuación oscila entre 0 y 63 puntos. Sus propiedades psicométricas han sido examinadas tanto en muestras españolas de estudiantes universitarios (Sanz y Navarro, 2003) y de adultos de la población general (Sanz, Perdigón y Vázquez, 2003), como de pacientes con trastornos psicológicos (Sanz y cols., 2005), obteniéndose en todos los casos índices de fiabilidad y validez adecuados. La consistencia interna de la muestra clínica a partir del Alpha de Cronbach fue de 0.89.

Inventario de Estrés y Pérdida (IEP; Quero, Molés, Mor, Baños y Botella, 2014; adaptado del Inventario de Duelo Complicado de Prigerson y cols., 1995). Evalúa situaciones estresantes que interfieren de forma negativa en la vida de una persona. El instrumento es igual que el original, pero se sustituyeron las palabras que hacían referencia a la persona fallecida por las que aluden a la persona/situación que se ha perdido (p.ej., pérdida de trabajo, pérdida de una pareja...). Se trata de un autoinforme de 17 ítems, de escala tipo Likert de 0 (nunca) a 4 (siempre), siendo la puntuación mínima 0 y la máxima 68. Datos preliminares de la validación mostraron excelentes coeficientes de fiabilidad test-retest $(0.90)$ y de consistencia interna en población española tanto general (0.91) como clínica con TA (0.86) (Quero y cols., 2014).

Autoeficacia. Se midió a partir de un ítem específicamente diseñado por el equipo para los TA. Se les pidió a los pacientes que indicaran de 0 (Nada capaz) a 10 (Totalmente capaz) el grado en el que se sentían capaces de afrontar el acontecimiento estresante o problema.

\section{Procedimiento}

Una vez firmado el consentimiento informado por parte de los participantes con TA para formar parte de un estudio controlado de eficacia, se administraron las medidas incluidas en este trabajo, junto con otras medidas de evaluación, y antes de recibir tratamiento psicológico. Seguidamente, se realizaron los análisis estadísticos correlacionales y de regresión correspondientes mediante el Statistics Package for Social Sciences (SPSS-22), versión en español. 


\section{Resultados}

Para explorar la relación entre las variables, en primer lugar, se calcularon correlaciones bivariadas de Pearson. Como se observa en la Tabla 1, las relaciones entre las variables positivas de felicidad y satisfacción con la vida y las variables clínicas fueron altamente significativas para las variables de depresión y auto-eficacia. Por su parte, el IEP mostró una relación significativa solamente con la felicidad.

Tabla 1

Correlación Bivariada de Pearson entre variables positivas y variables clínicas registradas en la fase pre-tratamiento

\begin{tabular}{lccc}
\hline & Autoeficacia & BDI-II & IEP \\
\hline Escala de Satisfacción con la Vida (SWLS) &, $484^{* *}$ &,$- 589^{* *}$ &,- 144 \\
Escala de Felicidad Subjetiva (SHS) &, $409^{\star *}$ &,$- 559^{* \star}$ &,$- 316^{*}$ \\
\hline
\end{tabular}

$\rho<0,01 ;{ }^{*} \rho<0,05$

En segundo lugar, se realizaron análisis de regresión lineal por pasos con el objetivo de explorar en qué medida las variables positivas predecían la intensidad de la sintomatología clínica antes de la intervención. Los resultados obtenidos en las ecuaciones de regresión se presentan en la Tabla 2. Como se puede observar, la satisfacción con la vida predecía tanto la intensidad de la sintomatología depresiva como la autoeficacia percibida por el paciente para afrontar la situación estresante vivida. Por su parte, la felicidad subjetiva resultó ser variable predictora de la sintomatología depresiva y de la sintomatología relacionada al estrés y pérdida.

Tabla 2

Resultados del análisis de regresión entre las variables positivas (SWLS y SHS) y las variables clínicas (BDI, IEP y autoeficacia) registradas en la fase pre-tratamiento

\begin{tabular}{lllccc}
\hline & & $\mathrm{R}^{2}$ & $\beta$ & $\mathrm{t}$ & $\rho$ \\
\hline \multirow{2}{*}{ BDI } & SWLS &, 392 & $-0,40$ & $-2,79$ &, $008^{*}$ \\
& SHS & & $-0,33$ & $-2,29$ &, $027^{*}$ \\
IEP & SHS &, 083 & $-0,32$ & $-2,23$ &, $031^{*}$ \\
Autoeficacia & SWLS &, 216 & 0,48 & 3,58 &, $001^{*}$ \\
\hline
\end{tabular}

$* \rho<0,01 ; * \rho<0,05$ 


\section{Discusión y Conclusiones}

El objetivo de este estudio fue explorar las relaciones existentes entre las variables de satisfacción con la vida y felicidad subjetiva como factores protectores de síntomas clínicos en una muestra de pacientes con diagnóstico de TA. Los resultados obtenidos revelaron que la satisfacción con la vida y la felicidad subjetiva mostraron relación negativa significativa con el estado de ánimo deprimido, mientras que los síntomas de estrés y pérdida lo hicieron únicamente con la felicidad subjetiva, aunque en menor medida. Por último, tanto la satisfacción con la vida como la felicidad subjetiva correlacionaron de forma positiva con la capacidad percibida de afrontar el problema. Análisis de regresión posteriores mostraron que un mayor grado de ambas variables positivas (felicidad subjetiva y satisfacción con la vida) predecía una menor gravedad en la sintomatología depresiva. Por último, se observó que un mayor grado de satisfacción con la vida predecía una mayor autoeficacia percibida para afrontar el problema o la situación, mientras que un mayor grado de felicidad fue predictor de una menor sintomatología de estrés y pérdida relacionada con la misma.

Los resultados preliminares obtenidos están en la línea de los hallados en otros estudios que ponen de manifiesto que las emociones positivas aumentan los recursos personales, psicológicos y físicos (Fredrickson, 2013; Fredrickson, y cols., 2008;). Las personas que experimentan mayores emociones positivas obtienen mayores beneficios para la salud, incluso cuando se consideran estas emociones como efímeras, pueden estar manteniendo el bienestar y las estrategias adecuadas de afrontamiento (Tugade y Fredickson, 2002). Además, mayores puntuaciones en felicidad subjetiva y en satisfacción con la vida pueden, a su vez, estar influyendo en el afecto positivo, el cual se ha relacionado con menores conflictos sociales, mayores redes sociales, mayor apoyo social para lidiar con las situaciones estresantes y, en general, menores factores de estrés que manejar (Fredrickson, 2009; Fredrickson y Levenson, 1998;). En los resultados encontrados en este trabajo, la satisfacción con la vida y la felicidad se relacionan con mayor capacidad subjetiva para afrontar los problemas, por lo tanto, las variables positivas pueden estar facilitando y ampliando el repertorio de respuesta, es decir, pueden estar ayudando a los individuos a adaptarse mejor al entorno, al presentarse un mayor abanico de estrategias de afrontamiento. Asimismo, parece que los sujetos que son más felices y están más satisfechos con sus vidas, presentan menores síntomas depresivos o menor gravedad de los mismos, esto podría ser precisamente porque estas variables permiten generar mayores pensamientos positivos y amortiguar así algunos de los síntomas característicos de la depresión, como la negatividad e incluso la catastrofización cognitiva. En suma, estas variables permitirán amortiguar algunos síntomas ansioso-depresivos, como, por ejemplo, la apatía. Aunque no se conoce con exactitud en qué grado y concretamente qué síntomas son los afectados por las variables positivas, está claro tras este estudio y otros relacionados que su potenciación puede resultar muy beneficiosa para generar herramientas de afrontamiento y prevenir el desarrollo de los síntomas clínicos tras la experiencia de un acontecimiento estresante.

Para finalizar, es importante señalar que los resultados de este trabajo deben tomarse con cautela, pues presenta limitaciones. La más importante es el tamaño de la muestra incluida, que podría ser mayor, para así favorecer la generalización de los resultados a todas las personas que puedan sufrir un TA. En cuanto a líneas futuras de investigación, sería importante explorar la relación de otras variables positivas y clínicas entre sí, para tener una visión más amplia de los factores que pueden ser claves para proteger y prevenir un trastorno adaptativo. También resulta relevante, a partir de estos resultados, analizar en investigaciones futuras la influencia del abordaje de la felicidad subjetiva y la satisfacción con la vida durante el tratamiento, en la mejora de la sintomatología de pacientes con TA. 
En conclusión, los resultados obtenidos reflejan la importancia de atender, en pacientes con diagnóstico de TA, a variables psicológicas positivas como las incluidas en este estudio. La felicidad subjetiva y la satisfacción con la vida parecen ayudar a mitigar la intensidad del malestar y los sentimientos de estrés y pérdida, así como potenciar la autoeficacia en relación al acontecimiento estresante. Por tanto, considerar estas variables en un tratamiento psicológico podría favorecer un afrontamiento adaptativo de la pérdida o situación estresante actual, así como preparar a la persona para problemas que puedan aparecer en un futuro.

\section{Bibliografía}

American Psychiatric Association. (2013). Diagnostic and statistical manual of mental disorders (5th ed.). Washington,DC: American Psychiatric Association.

Beck, A. T., Steer, R. A., Ball, R., y Ranieri, W. F. (1996). Comparison of Beck Depression Inventories-IA and -II in psychiatric outpatients. Journal of Personality Assessment, 67(3), 588-597.

Carta, M. G., Balestrieri, M., Murru. A., y Carolina Hardoy, M. C. (2009). Adjustment disorder: epidemiology, diagnosis and treatment. Clinical Practice and Epidemiology in Mental Health, 5, 1-15.

Diener, E., Emmons, R., Larsen, R. J., y Griffin, S. (1985). The Satisfaction With Life Scale. Journal of Personality Assessment, 49, 7175.

Dunn, BD. (2012). Helping depressed clients reconnect to positive emotion experience: Current insights and future directions. Clinical Psychology \& Psychotherapy, 19(4):326-40.

Fredrickson, B. L. (2009). Positivity: Groundbreaking Research Reveals How to Embrace the Hidden Strength of Positive Emotions, Overcome Negativity, and Thrive. New York: Crown Books.

Fredrickson, B. L. (2013). Updated thinking on positivity ratios. American Psychologist, 68(9), 814-822.

Fredrickson, B. L., Cohn, M. A., Coffey, K. A., Pek, J., y Finkel, S. M. (2008). Open hearts build lives: positive emotions, induced through loving-kindness meditation, build consequential personal resources. Journal of Personality and Social Psychology, 95(5), 1045.

Fredrickson, B. L., y Levenson, R. W. (1998). Positive emotions speed recovery from the cardiovascular sequelae of negative emotions. Cognition \& Emotion, 12(2), 191-220.

Garland, E. L., Fredrickson, B. L., Kring, A. M., Johnson, D. P., Meyer, P. S., y Penn, D. L. (2010). Upward spirals of positive emotions counter downward spirals of negativity: Insights from the broaden-and-build theory and affective neuroscience on the treatment of emotion dysfunctions and deficits in psychopathology. Clinical Psychology Review, 30(7), 849-864.

Howell, R. T., Kern, M. L., y Lyubomirsky, S. (2007). Health benefits: Meta-analytically determining the impact of well-being on objective health outcomes. Health Psychology Review, 1(1), 83-136.

Lazarus, R., Kanner, A., y Folkman, S. (1980). Emotions: A cognitive phenomenological analysis. In R. Plutchik \& H. Kellerman (Eds.), Theories of Emotions. New York: Academic Press.

Lyubomirsky, S., y Lepper, H. S. (1999). A measure of subjective happiness: Preliminary reliability and construct validation. Social Indicators Research, 46, 137-155.

Pressman, S. D., y Cohen, S. (2012). Positive emotion word use and longevity in famous deceased psychologists. Health Psychology 31, 297-305. 
Prigerson, H. G., Maciejewsku, P. K., Reynolds, C. F., Bierhals, A. J., Newsom, J. T., Fasiczka, A., ...Miller, M. (1995). Inventory of Complicated Grief: A scale to measure maladaptive symptoms of loss. Psychiatry Research, 59, 65-79.

Quero, S., Molés, M., Mor, S., Baños, R., y Botella, C. (2014). Spanish Validation of the Complicated Grief Inventory adapted for Adjustment Disorders. Póster presentado en Association for Behavioral and Cognitive Therapies 48th AnnualConvention, Philadelphia, United States.

Sanz, J., García-Vera, M. P., Espinosa, R., Fortún, M., y Vázquez, C. (2005). Adaptación española del Inventario para la Depresión de BeckCII (BDI-II): 3. Propiedades psicométricas en pacientes con trastornos psicológicos. Clínica y Salud, 16(2), 121-142.

Sanz, J., y Navarro, M. E. (2003). Propiedades psicométricas de una versión española del Inventario de Ansiedad de Beck (BAI) en estudiantes universitarios. Ansiedad y Estrés, 9(1), 59-84

Sanz, J., Perdigón, L. A., y Vázquez, C. (2003). Adaptación española del Inventario para la Depresión de BeckClI (BDI-II): 2. Propiedades psicométricas en población general. Clínica y Salud, 14(3), 249-280.

Taylor, C. T., Lyubomirsky, S., y Stein, M. B. (2016). Upregulating the positive affect system in anxiety and depression: Outcomes of a positive activity intervention. Depression and Anxiety, 34(3), 267-280.

Tugade, M. M., y Fredrickson, B. L. (2002). Positive emotions and emotional intelligence. In L. Feldman Barrett \& P. Salovey (Eds.), The Wisdom of Feelings (pp. 319-340). New York, NY: Guilford.

Vázquez, C., y Chaves, C. (2016). Positive Psychology. En HS. Friedman (Ed). Encyclopedia of Mental Health (pp. 290-299). California: Academic Press.

Vázquez, C. Duque, A. y Hervás, G. (2012). Escala de Satisfacción con la Vida (SWLS) en una muestra representativa de españoles adultos: Validación y datos normativos. The Spanish Journal of Psychology, 16, doi: http://dx.doi.org/10.1017/sip.2013.82

Vázquez, C., Hervás, G., Rahona, J. J., y Gómez, D. (2009). Psychological well-being and health. Contributions of positive psychology. Annuary of Clinical and Health Psychology, 5, 15-27.

Vera-Villarroel, P., Celis-Atenas, K., y Córdova-Rubio, N. (2011). Evaluación de la felicidad: Análisis psicométrico de la Escala de Felicidad Subjetiva en población chilena. Evaluation of happiness: Psychometric analysis of the Subjective Happiness Scale in chilean population. Terapia Psicológica, 29(1), 127-133. 


\title{
El papel de la personalidad y el acoso escolar en el desarrollo de síntomas internalizantes en la adolescencia
}

\author{
DAVINIA SÁNCHEZ MIGUEL \\ al260576@uji.es \\ SíGRID GALLEGO MOYA \\ moyam@uji.es \\ Generós Ortet FABREgat \\ ortet@uji.es \\ Manuel Ignacio IBÁÑEZ RIBES \\ iribes@uji.es
}

\section{Resumen}

El acoso escolar es un problema cada vez más frecuente entre los niños y jóvenes, que puede constituir un importante factor de riesgo para un amplio rango de problemas psicológicos. El principal objetivo de este estudio es investigar cómo el hecho de ser víctima puede influir en el desarrollo de síntomas psicológicos negativos asociados a la psicopatología internalizante. Asimismo, pretendemos estudiar la relación entre rasgos de personalidad y la victimización por acoso, ya que, aunque el acoso es responsabilidad exclusiva de los acosadores, existirían algunas características individuales que podrían jugar un cierto papel en la vulnerabilidad a sufrir acoso escolar. Para ello, una muestra de 399 estudiantes del Instituto de Educación Secundaria El Caminàs (Castellón), de edades entre los 12 y 21 años, respondieron a un cuestionario de personalidad para adolescentes, el JS-NEO (Ortet et al., 2007) y un cuestionario de cribaje psicopatológico, el SENA, que evalúa síntomas psicopatológicos del espectro internalizante (depresión, ansiedad, ansiedad social, quejas somáticas y sintomatología postraumática) así como la Victimización. Los análisis de Regresión Lineal mostraron como la Victimización resulto un factor de especial importancia en el desarrollo de síntomas internalizantes, especialmente depresión, estrés postraumático y síntomas somáticos. Además, el Neuroticismo constituyó también un factor muy relevante en la manifestación de síntomas internalizantes. Finalmente, el Neuroticismo, la baja Amabilidad y la baja Extraversión se relacionaron significativamente con la percepción de Victimización. Los resultados de este estudio muestran la importancia de la personalidad en la Victimización y cómo ambas influencias pueden jugar un papel importante sobre la psicopatología internalizante.

Palabras clave: victimización, personalidad, psicopatología internalizante, acoso escolar, adolescencia. 


\section{Abstract}

The bullying is an increasingly frequent problem among children and youths, which could be an important risk factor to a wide range of psychological problems. The main goal of this study was to investigate how being a victim could influence in the negative psychological symptoms associated to internalizing psychopathology. In addition, we will analyze the relation between personality traits and the victimization by bullying, since although that bullying is the sole responsibility of stalkers, there are certain individual characteristics that could play a role in vulnerability to suffer bullying. To this end, a sample of 399 students from the Institute of Secondary Education El Caminàs (Castellón), aged of 12 to 21 years, answered a personality questionnaire for teenagers, the JS-NEO (Ortet et al., 2007), and a psychopathological screening questionnaire, the SENA, which evaluates psychopathological symptoms of the internalizing spectrum (depression, anxiety, social anxiety, somatic complaints and post-traumatic symptomatology) as well as Victimization. Linear Regression analyses showed how victimization was proved a particularly important factor in the development of internalizing symptoms, especially depression, post-traumatic stress and somatic symptoms. In addition, Neuroticism was also a very relevant factor in the manifestation of internalizing symptoms. Finally, high Neuroticism, low Agreeableness, and low Extraversion were significantly related to perception of Victimization. The results of this study show the importance of personality on victimization and how both influences can play a part in internalizing psychopathology.

Keywords: victimization, personality, internalizing psychopathology, bullying, adolescence.

\section{Introducción}

El término «bullying» hace referencia a un comportamiento agresivo que es intencional y que implica un desequilibrio de poder (psicológico o físico), que ocurre entre niños y jóvenes. A menudo, también se caracteriza por su repetición y extensión en el tiempo (Olweus, 1993). Nosotros utilizaremos el término «acoso escolar» con el fin de estar en consonancia con la literatura publicada en nuestro país. El acoso escolar ocurre en todo el mundo con diferentes tasas de prevalencia en cada país. En Europa, la tasa media de prevalencia es de alrededor de 20,6 \% (Analitis et al., 2009). En España, según informes que recogen la incidencia del acoso escolar en nuestro país, la prevalencia es del $25 \%$ aproximadamente (Defensor del Pueblo, 2007). Además, es importante señalar que uno de cada cuatro estudiantes sufre este tipo de acoso y que el $75 \%$ de los casos ocurre repetidamente y se prolonga en el tiempo (Oñate \& Piñuel, 2007). Hace algunos años, el acoso escolar era visto como un comportamiento normal entre los jóvenes y, por lo tanto, sin consecuencias perjudiciales. Sin embargo, los hallazgos actuales en la literatura empírica apuntan cada vez más al hecho de que las consecuencias de ser víctima de acoso escolar no son meras dificultades. Este tipo de experiencia implica un importante factor de riesgo para una amplia gama de problemas psicológicos, como la depresión o los trastornos de ansiedad, en la infancia y la adolescencia (Arseneault, Bowes \& Shakoor, 2010). 
Dada la preocupante prevalencia de las cifras encontradas y las consecuencias negativas asociadas con el acoso escolar, es necesario investigar las causas o factores de riesgo que hacen a los jóvenes vulnerables. De manera anticipada, cabría esperar que los factores ambientales como crecer en una familia problemática y/o el círculo social explicaran la mayor parte de la varianza en la victimización. Sin embargo, los estudios genéticos cuantitativos han demostrado que hasta el 73 \% de la varianza se debe a influencias genéticas (Ball et al., 2008). En este sentido, los estudios han sugerido que ciertos rasgos de la personalidad harían a las personas vulnerables a sufrir acoso escolar. Específicamente, el alto Neuroticismo, la baja Amabilidad y la Baja Responsabilidad forman el perfil común de los rasgos de personalidad observados en aquellos niños y jóvenes que han sufrido acoso escolar (Bolle \& Tackett, 2013; Bollmer, Monica \& Milich, 2006; Georgesen, Harris, Milich \& Young, 1999; JensenCampbell \& Malcolm, 2007; Jensen-Campbell et al., 2002; Lowenstein, 1978; Tani, Greenman, Schneider \& Fregoso, 2003).

Este estudio pretende conocer los mecanismos que se encuentran detrás del fenómeno del acoso escolar. Particularmente, el objetivo es estudiar la relación entre los rasgos de personalidad y la vulnerabilidad a ser víctima del acoso escolar. De la misma manera, otro objetivo es observar cómo el ser la víctima puede influir en el desarrollo de los problemas psicológicos relacionados con la psicopatología internalizante. En concreto, queremos explorar la sintomatología asociada a la depresión, la ansiedad, la ansiedad social, las quejas somáticas y el estrés postraumático.

De acuerdo a ello, hemos establecido las siguientes hipótesis:

1. La experiencia de ser víctima de acoso escolar predice síntomas psicológicos negativos asociados a la psicopatología internalizante, en especial depresión y sintomatología postraumática.

2. La victimización se relaciona con algunos rasgos de personalidad, en concreto con el Alto Neuroticismo, la Baja Amabilidad y la Baja Responsabilidad.

\section{Método}

La muestra fue constituida por 399 alumnos del Instituto de Enseñanza Secundaria Caminàs de Castellón ( $N=399)$, con un total de 209 niños y 191 niñas. El rango de edad de los estudiantes osciló entre 12 a 21, siendo 14,31 la media (DT =1,169). La información se recopiló entre un total de 24 clases distribuidas entre los cursos de ESO, $1^{\circ}$ de Bachiller y Formación Profesional Básica.

La evaluación de la personalidad se llevó a cabo con el JS-NEO, una adaptación de NEO-PI-R de McCraet et al. (2002) para adolescentes. El Cuestionario contiene 154 ítems que evalúan las diferentes dimensiones de la personalidad y sus respectivas facetas según el Modelo de Cinco Factores (FFM). En cuanto a la evaluación de la victimización y la psicopatología internalizante, se utilizó la batería de cribaje psicopatológico SENA (Fernández-Pinto, Santamaría, Sánchez-Sánchez, Carrasco \& del Barrio, 2015) que, por una parte, incluye diferentes escalas para la evaluación de sintomatología asociada a depresión, ansiedad, ansiedad social, quejas somáticas y estrés postraumático y, por otro lado, una escala que evalúa específicamente la percepción de victimización por acoso escolar.

Todos los datos obtenidos se analizaron con el programa estadístico IBM SPSS statistics, versión 21. En primer lugar, se realizó un análisis descriptivo y se calcularon las Correlaciones Bivariadas de Pearson. Por último, se realizaron análisis de regresión lineal jerárquica 
para examinar el papel de los rasgos de personalidad y la victimización como variables predictoras de la psicopatología internalizante.

\section{Resultados}

Relación entre victimización y rasgos de personalidad

Las correlaciones bivariadas de Pearson mostraron que el Neuroticismo $(r=, 286 ; p<$ ,001), la Extraversión $(r=-, 141 ; p<, 01)$ y la Amabilidad $(r=-, 167 ; p<, 01)$ se relacionaban significativamente con la victimización, teniendo el Neuroticismo una relación directa con la variable mientras que la Extraversión y la Amabilidad presentaron una relación inversa como se puede observar en la Tabla 1.

Tabla 1

Correlaciones para los rasgos de personalidad y la Victimización

\begin{tabular}{lc}
\hline & Victimización \\
\hline Neuroticismo &, $286^{* * *}$ \\
Extraversión &,$- 141^{* *}$ \\
Apertura &, 036 \\
Amabilidad &,$- 167^{* *}$ \\
Responsabilidad &,- 095 \\
\hline
\end{tabular}

Nota. ${ }^{*} p<, 05,{ }^{* *} p<, 01,{ }^{* *} p<, 001$.

Relación entre rasgos de personalidad, victimización y psicopatología internalizante

Las correlaciones bivariadas de Pearson mostraron que el Neuroticismo $(\mathrm{N})$ se relacionaba de forma significativa con cada una de las variables del conjunto de sintomatología internalizante, a saber: Depresión ( $r=, 644 ; p<, 001)$, Ansiedad $(r=, 604 ; p<, 001)$, Ansiedad Social $(r$ $=, 546 ; p<, 001)$, quejas somáticas $(r=, 478 ; p<, 001)$, y sintomatología postraumática $(r=, 599$; $p<, 001)$; así como con el constructo Internalizante en sí mismo $(r=, 683 ; p<, 001)$.

Por otro lado, la victimización sólo se relacionó de forma significativa con todas las variables dependientes de tal modo: Depresión $(r=-, 298 ; p<, 001)$, Ansiedad $(r=-, 220 ; p<$ ,001), Ansiedad Social $(r=294 ; p<, 001)$, quejas somáticas $(r=, 324 ; p<, 001)$ y sintomatología postraumática $(r=, 456 ; p<, 001)$, como también con el constructo Internalizante $(r=$ ,434; $p<, 001)$. Todo ello se puede observar a continuación en la Tabla 2. 
Tabla 2

Correlaciones para todas las variables de estudio

\begin{tabular}{lcccccc}
\hline & Depresión & Ansiedad & $\begin{array}{c}\text { Ansiedad } \\
\text { Social }\end{array}$ & Somático & Postraumático & Internalizante \\
\hline $\mathrm{N}$ &, $644^{* * *}$ &, $604^{* * *}$ &, $546^{* * *}$ &, $478^{* * *}$ &, $599^{* * *}$ &, $683^{* * *}$ \\
$\mathrm{E}$ &,$- 205^{* * *}$ &,- 038 & $-268^{* * *}$ &,- 006 &,$- 105^{*}$ &,$- 149^{* *}$ \\
$\mathrm{O}$ &, $191^{* * *}$ &, $269^{* * *}$ &, $176^{* * *}$ &, $143^{* *}$ &,$- 197^{* * *}$ &, $234^{* * *}$ \\
$\mathrm{~A}$ &,$- 221^{* * *}$ &,- 097 &,- 031 &,$- 168^{* *}$ &,$- 135^{* *}$ &,$- 158^{* *}$ \\
$\mathrm{C}$ &,$- 298^{* * *}$ &,$- 220^{* * *}$ &,$- 185^{* * *}$ &,$- 260^{* * *}$ &,$- 224^{* * *}$ &,$- 282^{* * *}$ \\
VIC &, $509^{* * *}$ &, $243^{* * *}$ &, $294^{* * *}$ &, $324^{* * *}$ &, $456^{* * *}$ &, $434^{* * *}$ \\
\hline
\end{tabular}

Nota. ${ }^{*} p<, 05,{ }^{* *} p<, 01,{ }^{* * *} p<, 001$

Los análisis de regresión lineal mostraron que la Victimización predecía de forma significativa la variable Depresión $(\beta=, 365 ; p<, 001)$, Quejas Somáticas $(\beta=, 229 ; p<, 001)$, Estrés Postraumático $(\beta=, 328 ; p<, 001)$ y el constructo general de sintomatología Internalizante $(\beta=, 284 ; p<, 001)$, aun después de controlar la influencia de todos los rasgos de personalidad. Así pues, ente los rasgos de personalidad, el Neuroticismo predijo especial la variable Depresión $(\beta=, 557 ; p<, 001)$, Quejas Somáticas $(\beta=, 399 ; p<, 001)$, Estrés Postraumático $(\beta=, 552 ; p<, 001)$ y el constructo general de sintomatología Internalizante $(\beta=$ ,430; $p<, 001)$. Todo ello puede observarse a continuación en la Tabla 3.

Tabla 3

Análisis de regresión para todas las variables dependientes e independientes

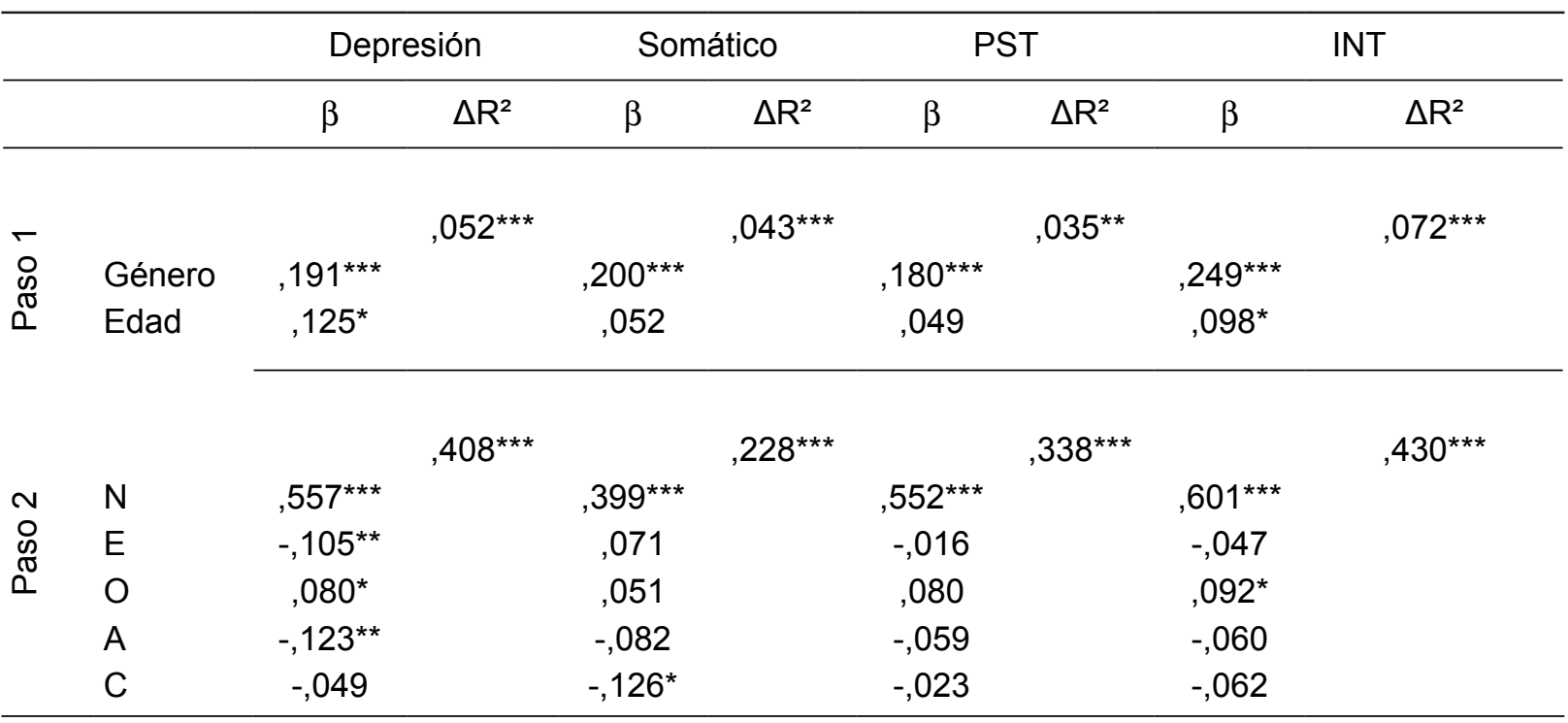




\begin{tabular}{|c|c|c|c|c|c|c|c|c|c|}
\hline & & \multicolumn{2}{|c|}{ Depresión } & \multicolumn{2}{|c|}{ Somático } & \multicolumn{2}{|c|}{ PST } & \multicolumn{2}{|c|}{ INT } \\
\hline & & $\beta$ & $\Delta \mathrm{R}^{2}$ & $\beta$ & $\Delta \mathrm{R}^{2}$ & $\beta$ & $\Delta \mathrm{R}^{2}$ & $\beta$ & $\Delta \mathrm{R}^{2}$ \\
\hline $\begin{array}{l}m \\
8 \\
\infty \\
\pi \\
0\end{array}$ & VIC &, $365^{\star * *}$ &, $115^{\star * *}$ &, $229^{* * *}$ &, $045^{\star * *}$ &, $328^{* * *}$ &, $093^{* * *}$ &, $284^{* * *}$ &, $070^{* * *}$ \\
\hline
\end{tabular}

Nota. ${ }^{*} p<, 05,{ }^{* *} p<, 01,{ }^{* * *} p<, 001$

\section{Discusión y conclusiones}

El objetivo del presente trabajo fue investigar cómo el hecho de ser víctima puede influir en el desarrollo de síntomas psicológicos negativos asociados a la psicopatología internalizante. Además, estudiar la relación entre rasgos de personalidad y la victimización por acoso. En un principio, los resultados obtenidos confirman parcialmente las hipótesis planteadas previamente.

Por un lado, en cuanto a las consecuencias psicológicas negativas, se observaron correlaciones significativas para cada uno de los síntomas del espectro internalizante y la victimización, destacando en especial la depresión y sintomatología postraumática tal como esperábamos, y en menor medida quejas somáticas. Del mismo modo, la victimización se relacionó de forma significativa para el constructo global de psicopatología internalizante. Después de realizar el análisis de regresión lineal destacamos como la victimización predice de forma significativa la psicopatología internalizante, por lo que ser víctima de acoso escolar es una experiencia que comporta importantes consecuencias negativas para la salud mental del adolescente.

Por otro lado, de acuerdo con la literatura científica esperábamos que principalmente el alto Neuroticismo se relacionase de forma significativa con la Victimización, así como en menor medida también lo hiciesen la baja Amabilidad y la baja Responsabilidad. Nuestros resultados mostraron correlaciones con alto Neuroticismo y baja Amabilidad, de acuerdo a los estudios previos, pero no con baja Responsabilidad siendo ésta sustituida por baja Extraversión. Tras realizar los análisis de regresión lineal observamos que dichas correlaciones se mantenían de forma altamente significativa para el alto Neuroticismo, así como, en menor medida, para la baja Amabilidad y baja Extraversión.

El presente estudio muestra como ser víctima de acoso por parte de los compañeros de clase incrementa de forma importante la probabilidad de presentar un amplio rango de síntomas psicopatológicos. Así, y una vez controlado por el Neuroticismo, la característica psicológica más importante en la manifestación de síntomas internalizantes, ser víctima de acoso explicaría una parte relevante de estos síntomas, especialmente los depresivos, postraumáticos y somáticos. Además, aquellos adolescentes que presentan perfiles de personalidad caracterizados por una alta introversión, inestabilidad emocional y baja amabilidad tenderían a evocar conductas de desprecio y acoso por parte de sus compañeros. En definitiva, nuestros resultados muestran la importancia de la personalidad en la vulnerabilidad a sufrir conductas de acoso, así como la importancia de ésta y del acoso en la salud mental de los adolescentes. Por lo tanto, sugerimos que las estrategias para prevenir la conducta de acoso escolar y mejorar el impacto negativo sobre la salud mental que la victimización conlleva se beneficiarían de incluir características de la personalidad en sus programas. 
Cabe añadir una importante limitación de la investigación. La variable relevante del estudio, la Victimización como consecuencia del acoso escolar, resulta difícil de representar. A pesar de que la muestra de nuestra investigación consta de un número considerable de participantes $(\mathrm{N}=399)$, las puntuaciones recogidas en Victimización no son lo suficientemente elevadas como para hallar resultados significativamente consistentes. Este hecho quizá haya podido verse influido por el temor de los alumnos a responder con total sinceridad al cuestionario o simplemente porque la incidencia de acoso escolar en El Caminàs no resulta tan elevada como apuntan los estudios de prevalencias españolas. De modo que, para futuras investigaciones, sería conveniente la inclusión de muestras más amplias que sobrepongan dichos obstáculos y tengan la capacidad de representar a la población que sufre acaso escolar.

Para concluir, es importante destacar que este trabajo no tiene bajo ningún concepto la intención de sugerir que las víctimas son, de alguna manera, responsables de sufrir acoso escolar. El acoso es responsabilidad exclusiva de los acosadores, y los acosados son víctimas de estos censurables comportamientos. De modo que, aclarar en última instancia, que nuestro objetivo estuvo motivado por una mayor comprensión de los factores de riesgo que hacen vulnerables a los niños y adolescentes a ser vistos por sus iguales como diana para ser intimidados, con el único fin de facilitar el desarrollo de programas de detección y prevención de estas situaciones.

\section{Referencias bibliográficas}

Analitis, F., Klein, M., Ravens, U., Detmar, S., Erhart, M. \& Herdman, M. (2009). Being Bullied: Associated factors in children and adolescents 8 to 18 years old in 11 European countries. Pediatrics, 123, 569-577.

Arseneault, L., Bowes, L. \& Shakoor, S. (2010). Bullying victimization in youths and mental health problems: «Much ado about nothing»? Psychological Medicine, 40, 717-729.

Ball, H., Arseneault, L., Taylor, A., Maughan, B., Caspi, A. \& Moffitt, T. (2008). Genetic and environmental influences on victims, bullies and bully-victims in childhood. Journal of Child Psychology and Psychiatry , 49 (1), 104-112.

Bolle, M. D. \& Tackett, J.L. (2013). Anchoring Bullying and Victimization in Children Within a Five-Factor Model-Based Person-Centred Framework. European Journal of Personality , 27, 280-289.

Bollmer, J. M., Monica, J. H. \& Milich, R. (2006). Reactions to bullying and peer victimization: Narratives, psychological arousal, and personality. Journal of Reserach in Personality, 40, 803-828.

Defensor del Pueblo. (2007). Violencia escolar: el maltrato entre iguales en la Educación Secundaria. Madrid: Eduardo Dato.

Fernández-Pinto, I., Santamaría, P., Sánchez-Sánchez, F., Carrasco, M. Á. \& del Barrio, V. (2015). SENA. Sistema de Evaluación de Niños y Adolescentes. Manual técnico. Madrid: TEA Ediciones

Georgesen, J. C., Harris, M. J., Milich, R. \& Young, J. (1999). «Just Teasing . . . »: Personality Effects on Perceptions and Life Narratives of Childhood Teasing. Personality and Social Psychology Bulletin , 25 (10), 1254-1267.

Jensen-Campbell, L. A., Adams, R., Perry, D. G., Workman, K. A., Furdella, J. Q. \& Egan, S. K. (2002). Agreeableness, extraversion, and peer relations in early adolescence: Winning friends and deflecting aggression. Journal of Research in Personality , 36, 224-251. 
Jensen-Campbell, L. \& Malcolm, K. (2007). The Importance of Conscientiousness in Adolescent Interpersonal Relationships. Personality and Social Psychology Bulletin. , 33 (3), 368-383.

Lowenstein, L. F. (1978). The bullied and non bullied child: A contrast between the popular and unpopular child. Home and School, 12, 3-4.

McCrae, R. R., Costa, P. T., Terracciano, A., Parker, V. D., Mills, C. J., De Fruyt, F. \& Mervielde, I. (2002). Personality trait development from age 12 to age 18: Longitudinal crosssectional, and cross-cultural analyses. Journal of Personality and Social Psychology, 83, 1456-1468.

Olweus, D. (1993). Bullying at School: what we know and what we can do. Oxford, UK: Blackwell .

Oñate, A. \& Piñuel, I. (2007). Estudio Cisneros X: Acoso y violencia escolar en España.

Tani, F., Greenman, P., Schneider, B. \& Fregoso, M. (2003). Bullying and the Big Five: A Study of Childhood Personality and Participant Roles in Bullying Incidents. School Psychology International, 24 (2), 131-146. 


\title{
El papel protector de las variables psicológicas positivas y su relación con el cambio clínico tras la intervención en los trastornos adaptativos
}

\author{
SiLVIA Fuentes CERdÁ \\ al287715@uji.es \\ IRYNA RACHYLA \\ rachyla@uji.es \\ SONIA MOR RODRÍGUEZ \\ al189465@uji.es \\ MAR MOLÉS AMPOSTA \\ molesm@uji.es \\ SOLEDAD QUERO CASTELLANO \\ squero@uji.es
}

\section{Resumen}

Introducción: El trastorno adaptativo (TA) es uno de los problemas psicológicos más prevalentes, pero se desconocen los factores que puedan influir en su gravedad o respuesta al tratamiento. Diferentes estudios indican que el bienestar y otras variables positivas pueden influir en la morbilidad y cambio clínico (CC). Objetivos: Analizar la capacidad de algunas variables psicológicas positivas (VP+) para predecir la intensidad de la sintomatología clínica en pacientes con TA, y explorar en qué medida predicen el CC tras la intervención. Método: La muestra incluyó 44 pacientes. Los cuestionarios de autoestima, refuerzos ambientales (EROS) y bienestar psicológico (BP-29) se utilizaron como medidas de VP+ antes del tratamiento psicológico. El CC en síntomas de depresión, estrés y pérdida, y afecto positivo y negativo se evaluó en el posttratamiento y seguimientos (3, 6 y 12 meses). Resultados: Un entorno reforzante predecía la intensidad de la sintomatología clínica, siendo ésta menos grave en pacientes que lo valoraban como más reforzante. Poseer en menor medida VP+ relacionadas con autoestima, refuerzo del entorno y ciertas dimensiones de bienestar psicológico (crecimiento personal y autoaceptación), predecía mayor CC después de la intervención. Conclusiones: Los resultados apoyan la hipótesis de que las VP+, tanto personales como del entorno, funcionan como factores protectores ante la adversidad en pacientes con TA. Sin embargo, el poseer en menor medida dichas cualidades parece no impedir a los pacientes beneficiarse del tratamiento. Esto podría indicar que durante la intervención los pacientes adquieren conocimientos y herramientas necesarias para el cambio, independientemente de sus recursos iniciales.

Palabras clave: Trastornos adaptativos, bienestar psicológico, autoestima, entorno reforzante y cambio clínico 


\section{Abstract}

Introduction: Adjustment Disorders (AD) are one of the most prevalent psychological problems, but the factors that might influence in their severity or response to treatment are unknown. Different studies indicate that well-being and other positive variables may influence morbidity and clinical change (CC). Objectives: To analyze the capacity of some positive psychological variables $(\mathrm{PV}+)$ to predict the intensity of the clinical symptoms in patients with $A D$, and to examine whether they predict the $C C$ after intervention. Method: The sample consisted of 44 patients. The questionnaires of self-esteem, environmental reinforcements (EROS) and well-being (BP-29) were used as measures of $\mathrm{PV}+$ before receiving psychological treatment. The CC in symptoms of depression, stress and loss, and positive and negative affect were assessed at post-treatment and follow-ups (3, 6 and 12 months). Results: A reinforcing environment predicted the intensity of the clinical symptoms, being this less severe in patients who perceived it more reinforcing. Having in a lesser extent $\mathrm{PV}+$ related to self-esteem, environmental reinforcement and certain dimensions of well-being (personal growth and self-acceptance) predicted greater $\mathrm{CC}$ after intervention. Conclusions: Results support the hypothesis that $\mathrm{PV}+$, both personal and environmental, act as protective factors against adversity in patients with $A D$. However, having in a lesser extent these qualities seems not to prevent patients to get benefit from treatment. This could indicate that during the treatment patients acquire the knowledge and tools needed for the change, regardless their initial resources.

Keywords: Adjustment disorders, psychological well-being, self-esteem, environmental reinforcement and clinical change

\section{Introducción}

El Trastorno Adaptativo (TA) se define, según el DSM-5 (APA, 2013), como una reacción emocional y/o comportamental negativa que interfiere en distintas áreas de la vida de la persona y aparece en respuesta a un acontecimiento estresante identificable dentro de los 3 meses siguientes a la aparición de éste.

EI TA es uno de los problemas psicológicos más frecuentes en los ámbitos de atención primaria y hospitalaria (Carta, Balestrieri, Murru, y Hardoy, 2009). Se trata de un importante problema de salud que tiene un gran impacto negativo en la persona y se asocia a un notable deterioro en las áreas social y laboral, causando un alto porcentaje de bajas laborales (Calvo, 2009). Además, se trata de un trastorno en el que existe un alto riesgo de suicidio (Cassey, Jabbar, O'Leary, y Doherty, 2015). Sin embargo, pese a la gran relevancia de los TA en cuanto al sufrimiento personal, gasto sanitario y pérdidas laborales, hay una notable escasez de trabajos existentes sobre su tratamiento (Casey Dowrick, y Wilkinson, 2001).

En los últimos años el interés y la investigación en el campo de Psicología Positiva ha aumentado considerablemente. En este sentido, se considera que una ciencia y práctica completas de la Psicología deben incluir la comprensión tanto del sufrimiento como de la felicidad, así como intervenciones dirigidas no únicamnete a aliviar el sufrimiento sino también a aumentar la felicidad. (Seligman, Steen, Park y Peterson, 2005). En este contexto, por un lado, hay estudios que demuestran que tener una mayor emocionalidad positiva aumenta la flexibilidad 
psicológica y refuerza los recursos físicos, intelectuales y sociales (Fredickson, 1998). Diferentes modelos teóricos sugieren que la emocionalidad positiva es un rasgo de personalidad estable y heredable (Krueger, McGue y lacono, 2001) y que, a bajos niveles, aumenta el riesgo de depresión y agrava el curso de la enfermedad (Clark, 2005; Clark y Watson, 1991; Davidson, 1998; Watson, Stasik, Ellickson-Larew, y Stanton, 2015). Así, las personas deprimidas presentan una tendencia menor a experimentar emociones positivas, incluso ante estímulos y situaciones positivas (Berenbaum y Oltmanns, 1992; Kaviani y cols., 2004; Klein, 1974; McFarland y Klein, 2009; Sloan, Strauss, y Wisner, 2001).

Por otro lado, se ha estudiado la relación existente entre variables psicológicas clínicas y variables psicológicas positivas (VP+), como el bienestar psicológico (Sheung-Tak y cols., 2017; Tseferidi, Griva, y Anagnostopoulos, 2017), el afecto positivo (Li, Starr, y Hershenberg, 2017; Charles, Lyubomirsky y Murray, 2017), la satisfacción con la vida (Küçük y Alemdar, 2017) y la autoestima (Johnson, Galambos, Finn, y Horne, 2017), indicando que estas variables pueden influir en el cambio clínico. Más concretamente, se ha observado que el afecto positivo funciona como amortiguador de la gravedad de la sintomatología clínica (Pressman y Cohen, 2012).

En el caso de los TA no se han encontrado en la literatura artículos que exploren la relación entre $\mathrm{VP}+\mathrm{y}$ la gravedad y respuesta al tratamiento de los pacientes, lo que demuestra una vez más la escasez de estudios sobre estos trastornos pese a su gran relevancia. Por todo ello, los objetivos de este trabajo son, por un lado, analizar la capacidad de algunas VP+ para predecir la intensidad de la sintomatología clínica en pacientes con TA y, por otro, explorar en qué medida estas $\mathrm{VP}+$ predicen el cambio clínico después de un tratamiento cognitivocomportamental (TCC).

\section{Método}

\section{Participantes}

La muestra estaba compuesta por 44 pacientes (33 mujeres y 11 hombres) diagnosticados de TA siguiendo los criterios del DSM-5 (APA, 2013) que habían solicitado ayuda en el Servicio de Asistencia Psicológica de la Universitat Jaume I de Castellón (España). La media de edad fue de 29.09 años (DT=8.95), con un rango que oscilaba entre 18 y 54 . La mayoría de la muestra $(75 \%)$ tenía estudios universitarios y el resto $(25 \%)$ estudios primarios y/o secundarios. Por lo que se refiere al subtipo de TA, la mayoría de los participantes $(70.5 \%)$ fueron diagnosticados de TA mixto con ansiedad y depresión, el 15.9\% tenían TA con estado de ánimo depresivo, el $11.4 \%$ con ansiedad y el $2.3 \%$ con alteración de emociones y de comportamiento. Por último, y con respecto al acontecimiento estresante sufrido, el $37.8 \%$ de la muestra presentaba TA debido a una ruptura/separación/divorcio, el $26.7 \%$ por problemas familiares, el $13.3 \%$ por cambio de residencia, el $12.2 \%$ por problemas laborales y el $6.7 \%$ a causa de un accidente.

\section{Medidas}

Medidas de variables positivas

Escala de Autoestima (Rosenberg, 1965): Se trata de un instrumento breve que permite explorar la autovaloración de uno mismo y los sentimientos de respeto y aceptación personal. 
La consistencia interna de la versión española hallada en el estudio de validación transcultural fue de 0.80 (Schmidt y Allik, 2005).

Bienestar Psicológico (BP-29: Ryff, 1989): Este instrumento proporciona información acerca del nivel de satisfacción de la persona en distintos ámbitos de su vida. La adaptación española del instrumento que fue utilizada en este estudio consta de 39 ítems y se compone de 6 subescalas (autoaceptación, relaciones positivas, autonomía, dominio del entorno, propósito en la vida y crecimiento personal), cuya consistencia interna va de 0.68 a 0.83 (Díaz y cols., 2006).

Environmental reward observation scale (EROS; Armento y Hopko, 2007): Este instrumento de 10 ítems ofrece una medida objetiva de lo reforzante que perceibe la persona su entorno. La adaptación española del instrumento (Barraca y Pérez-Álvarez, 2010) presenta una buena consistencia interna (0.86).

Medidas variables clínicas

Inventario de Depresión de Beck (BDI-II; Beck, Steer y Brown, 1996): Este instrumento es uno de los más utilizados para evaluar la sintomatología depresiva. En este trabajo se utilizó la adaptación española realizada por Sanz, Navarro y Vázquez (2003) que muestra una elevada consistencia interna tanto para la población general (0.87) (Sanz, Perdigon, y Vázquez, 2003) como para la población clínica (0.89) (Sanz, García-Vera, Espinosa, Fortún, y Vázquez, 2005).

Inventario de Estrés y Pérdida (IEP; Quero, Mor, Molés, Rachyla, Baños, y Botella, en revisión): Este instrumento de 17 ítems permite evaluar el malestar que aparecen como consecuencia de vivir una situación difícil y/o estresante.. Datos preliminares de validación mostraron excelentes coeficientes de fiabilidad test-retest $(0.90)$ y de consistencia interna en población española tanto general (9.91) como clínica con TA (0.86) (Quero, Molés, Mor, Baños, y Botella, 2014).

Escala de Afecto Positivo y Afecto Negativo (PANAS; Watson, Clark, y Tellegen, 1988): Se trata de un cuestionario de 20 ítems que evalúa las dimensiones Positiva (p.ej., interesado, ilusionado, satisfecho) y Negativa del Afecto (p.ej., angustiado, culpable, agresivo). Cada ítem se responde en una escala de cinco puntos (1= Nada o muy ligeramente; $5=$ Mucho) indicando el grado en que cada adjetivo describe mejor el estado de ánimo del que responde. El instrumento presenta una alta consistencia interna y una buena fiabilidad test-retest (Watson y cols., 1988).

\section{Tratamiento}

Todos los participantes recibieron un TCC específico para los TA (Botella, Baños, y Guillén, 2008) que contaba con un número variable de sesiones (entre 6 y 8), dependiendo de las necesidades de cada paciente. Las sesiones tenían una duración de 90 minutos y se realizaban con periodicidad semanal. Los componentes terapéuticos incluidos fueron: psicoeducación; exposición; aceptación, afrontamiento y aprendizaje a partir de los problemas; y prevención de recaídas. También se incluyeron estrategias de Psicología Positiva con la finalidad de aumentar la resiliencia de los pacientes. Durante el procesamiento y elaboración del acontecimeintos estresante se utilizó el sistema de RV Ilamado El Mundo de EMMA, un ambiente virtual flexible que permite realizar una representación física de los significados y emociones que la persona asocia a diferentes situaciones problemáticas. Gracias a ello, es posible generar ambientes clínicamente significativos para cada participante, capaces de evocar acontecimientos estresantes diferentes (p.ej., ruptura sentimental, enfermedad, problemas laborales, etc.). Una descripción más detallada del Mundo de EMMA se puede encontrar en Quero y cols. (2017). 


\section{Procedimiento}

Después de ser incluidos en el estudio, y antes de recibir el tratamiento, los participantes completaron las medidas utilizadas en este trabajo. Una vez finalizada la intervención, se volvieron a medir las variables clínicas en el post-tratameinto y seguimiento de los 3,6 y 12 meses. Diferencias entre las puntuaciones directas obtenidas en el pre-tratamiento y cada uno de los momentos de evaluación post-intervención fueron calculadas para obtener indicadores de cambio clínico en cada una de las medidas de variables cínicas (BDI-II, IEP y PANAS).

\section{Resultados}

Con el objetivo de analizar en qué grado las variables psicológicas positivas $(\mathrm{VP}+)$ predecían la intensidad de la sintomatología del TA, se llevó a cabo un análisis de regresión lineal por pasos tomando como variables independientes $(\mathrm{VI})$ las medidas de las $\mathrm{VP}+$ (autoestima, las 6 dimensiones de bienestar psicológico y el grado de refuerzo del entorno) y como variables dependientes (VD) las puntuaciones obtenidas en los instrumentos que evaluaban las variables clínicas (BDI, IEP y PANAS).

Como se puede observar en la Tabla 1, haber percibido el entorno como más reforzante predijo una menor intensidad en la sintomatología depresiva, sintomatología asociada al acontecimiento estresante, afecto negativo, así como, mayor afecto positivo.

Tabla 1

Resultados del análisis de regresión entre las VP+ y las variables clínicas evaluadas en el pre-tratamiento

\begin{tabular}{llcccc}
\hline PRE-tratamiento & & $\mathrm{R}^{2}$ & $\beta$ & $\mathrm{t}$ & $\rho$ \\
\hline BDI & EROS &, 22 & $-0,49$ & $-3,53$ &, $001^{* *}$ \\
IEP & EROS &, 13 & $-0,37$ & $-2,38$ &, $022^{* *}$ \\
PANAS + & EROS &, 34 & 0,59 & 4,60 &, $000^{* *}$ \\
PANAS - & EROS &, 19 & $-0,45$ & $-3,22$ &, $003^{* *}$ \\
\hline
\end{tabular}

${ }^{* *} \rho<0,01 ;{ }^{*} \rho<0,05$

Con el fin de explorar en qué medida poseer VP+ predecía la eficacia del tratamiento para el TA, también se realizó un análisis de regresión por pasos. Las medidas de las VP+ fueron utilizadas nuevamente como $\mathrm{VI}$, mientras que los indicadores de cambio clínico en cada uno de los cuatro momentos de evaluación post-intervención (post-tratamiento, seguimiento de los 3, 6 y 12 meses) fueron utilizados como VD.

La Tabla 2 presenta los resultados referidos al cambio en el BDI-II. Como se puede observar, las personas que habían mostado una autoestima más baja antes de la intervención, presentaron una mayor mejoría en la sintomatología depresiva en el post-tratamiento y los seguimientos de los 3 y 12 meses. La misma relación se encontó entre EROS y el cambio en el BDI-II observado a los 6 meses de finalizar el tratamiento. Por último, la percepción de un mayor dominio del entorno fue predictor de un mayor cambio clínico en el BDI en el seguimiento a los 12 meses. 
Tabla 2

Resultados del análisis de regresión entre las VP+ y el cambio clínico en el BDI

\begin{tabular}{llcccc}
\hline BDI & & $\mathrm{R}^{2}$ & $\beta$ & $\mathrm{t}$ & $\mathrm{\rho}$ \\
\hline Pre-post & Autoestima &, 14 & $-0,37$ & $-2,55$ &, $015^{*}$ \\
Pre-seg3 & Autoestima &, 34 & $-0,61$ & $-4,09$ &, $000^{* *}$ \\
Pre-seg6 & EROS &, 41 & $-0,66$ & $-4,34$ &, $000^{* *}$ \\
& Autoestima & & $-0,85$ & $-5,14$ &, $002^{* *}$ \\
Pre-seg12 & BP-29: Dominio del entorno &, 79 & 0,50 & 3,06 &, $002^{* *}$ \\
\hline
\end{tabular}

${ }^{* *} \rho<0,01 ;{ }^{*} \rho<0,05$

En cuanto a la gravedad de la sintomatología clínica asociada al acontecimiento estresante vivido (ver Tabla 3), se observó que ninguna de las VP+ predecía el cambio clínico en el post-tratamiento ni en el seguimiento de los 3 meses. Sin embargo, se encontró que haber puntuado más bajo en la escala de crecimiento personal y autoaceptación del BP-29 predijo un mayor cambio en el IEP a los 6 y 12 meses, respectivamente, tras la intervención.

Tabla 3

Resultados del análisis de regresión entre VP+ y el cambio clínico en el IEP

\begin{tabular}{llcccc}
\hline IEP & & $\mathrm{R}^{2}$ & $\beta$ & $\mathrm{t}$ & $\mathrm{\rho}$ \\
\hline Pre-seg6 & BP-29: Crecimiento personal &, 16 & $-0,44$ & $-2,36$ &, $027^{*}$ \\
Pre-seg12 & BP-29:Autoaceptación &, 59 & $-0,81$ & $-3,33$ &, $016^{*}$
\end{tabular}

${ }^{* *} \rho<0,01 ;{ }^{*} \rho<0,05$

Por último, los resultados referidos al cambio clínico en la escala PANAS se presentan en las Tablas 4 y 5 . En cuanto al cambio clínico en el afecto positivo (Tabla 4), ninguna de las $\mathrm{VP}+$ resultó ser predictora del cambio tras la intervención ni al año de finalizar el tratamiento. Sin embargo, en el seguimiento de los 3 meses, se encontró que haber puntuado más alto en la autoaceptación y más bajo en autoestima predijo un mayor cambio clínico. Mientras que en el seguimiento de los 6 meses, un mayor cambio en afecto positivo se observó en personas que habían puntuado más bajo en EROS.

En los resultados obtenidos para la escala de afecto negativo se observó que haber puntuado más alto en autonomía antes del tratamiento predecía un mayor cambio en esta medida en el post-tratamiento y el seguimiento a los 3 meses. Nuevamente, en el seguimiento de los 6 meses se observó un mayor cambio en las personas que percibían su entorno menos reforzante en la fase de pre-tratamiento. 
Tabla 4

Resultados del análisis de regresión entre las VP+ y el cambio clínico en el afecto positivo

\begin{tabular}{llcccc}
\hline PANAS+ & & $\mathrm{R}^{2}$ & $\beta$ & $\mathrm{t}$ & $\rho$ \\
\hline Pre-seg3 & Autoestima &, 20 & 0,53 & 2,95 &, $006^{\star *}$ \\
& BP-29: Autoaceptación & & $-0,37$ & $-2,05$ &, $050^{*}$ \\
Pre-seg6 & EROS &, 14 & 0,42 & 2,32 &, $029^{*}$ \\
\hline
\end{tabular}

${ }^{* *} \rho<0,01 ;{ }^{*} \rho<0,05$

Tabla 5

Resultados del análisis de regresión entre las VP+ y el cambio clínico en el afecto negativo

\begin{tabular}{llcccc}
\hline PANAS- & & $\mathrm{R}^{2}$ & $\beta$ & $\mathrm{t}$ & $\rho$ \\
\hline Pre-post & BP-29:Autonomía &, 13 & 0,38 & 2,59 &, $014^{* *}$ \\
Pre-seg3 & BP-29: Autonomía &, 26 & 0,53 & 3,46 &, $002^{* *}$ \\
Pre-seg6 & EROS &, 43 & $-0,67$ & $-4,59$ &, $000^{* *}$ \\
\hline
\end{tabular}

${ }^{* *} \rho<0,01 ;{ }^{*} \rho<0,05$

\section{Discusión}

El objetivo del presente trabajo fue analizar, por un lado, la capacidad de algunas VP+ para predecir la intensidad de la sintomatología clínica en los TA y, por otro, explorar en qué medida dichas variables predecían también el cambio clínico tras la intervención. Los resultados obtenidos según los análisis de regresión lineal indican que las $\mathrm{VP}+$, tanto personales como del entorno, funcionan como factores protectores ante la adversidad en pacientes con TA. Estos resultados van en la misma línea que los hallados en otros trabajos y que sugieren que la respuesta a las situaciones estresantes depende de muchos factores, entre ellos las características de personalidad, el apoyo social y las estrategias de afrontamiento (Wilhelm, Wedgwood, Parker, Geerligs, y Hadzi-Pavlovic, 2010). Así, en el presente estudio se encontró que los pacientes que percibían su vida y sus actividades como más satisfactorias, presentaban una sintomatología clínica menos intensa al vivir una situación adversa. Por lo tanto, los resultados apoyan la utilidad de promover en las personas el desarrollo de rasgos, fortalezas y estrategias relacionados con la calidad de vida así como el crecimiento y madurez personal. De esta forma, los individuos estarían más preparados para superar las distintas situaciones de crísis actuales y futuras.

Otro hallazgo importante del trabajo indica que el hecho de poseer en menor medida los rasgos y características positivas mencionadas en el apartado anterior no impide a los pacientes beneficiarse del tratamiento para su problema. De hecho, se observó que los pacientes que presentaban en menor medida rasgos positivos, tales como autoestima, autoaceptación, percepción de evolución y motivación para el crecimiento personal, o percibían su entorno y sus actividades como menos reforzantes, experimentaban un mayor cambio clínico después de la intervención. Esto podría indicar que durante la intervención los pacientes adquieren co- 
nocimientos y herramientas necesarias para el cambio, independientemente de sus recursos iniciales. En este punto cabe destacar que el TCC recibido por los pacientes no se limitaba únicamente a reducir la sintomatología clínica, sino también a promover el cambio de actitud hacia los problemas, para así aprender de ellos y poder evolucionar. Por tanto, se trata de un programa de tratamiento que integra el enfoque de psicología clínica tradicional, cuyo objetivo es reducir el malestar, con el de psicología positiva, que busca el aumento de bienestar y el desarrollo de fortalezas humanas. Este carácter integrador podría ser clave para el cambio clínico y para prevenir la reaparición de futuros problemas psicológicos (Fava y cols., 2005).

Por último, los resultados revelaron que una mayor sensación de dominio o control del entorno y una mayor sensación de autonomía respecto a la presión social se asociaban a una mayor reducción de la sintomatología depresiva y afecto negativo, respectivamnete. Por tanto, nuevamente resulta evidente la necesidad de desarrollar programas que promuevan el bienestar y proporcionen recursos para afrontar las dificultades y alcanzar las metas personales. En la literatura se pueden encontrar diferentes propuestas para incrementar el bienestar en adolescentes (van Genugten, Dusseldor, Massey, y van Empelen, 2017), jovenes universitarios (Fernandez y cols., 2016), y adultos (Ivandic, Freeman, Birner, Nowak y Sabariego, 2017). Sin embargo, los resultados sobre su eficacia no son del todo concluyentes y hacen falta más estudios, de mayor rigurosidad científica, para poder identificar las mejores estrategias de prevención.

Finalmente, es importante señalar que el trabajo presenta limitaciones. Por ello, como propuestas de mejora para este estudio se proponen, por un lado, el aumento de la muestra, ya que el número total de sujetos con los que contamos para este trabajo fue bastante limitado $\mathrm{y}$, por otro lado, utilizar un indicador de cambio clínico más riguroso, por ejemplo el índice de cambio fiable de Jacobson y Truax (1991). A pesar de estas limitaciones, los resultados de este trabajo suponen un avance tanto en el área de conocimiento de los TA como de Psicología Positiva.

\section{Referencias bibliográficas}

American Psychiatric Association. (APA) (2013). Diagnostic and statistical manual of mental disorders (5th Ed). Washington, DC: American Psychological Association.

Armento, M.E.A. y Hopko, D.R. (2007). The Environmental Reward Observation Scale (EROS): Development, validity, and reliability. Behavior Therapy, 38, 107-119.

Baños, R. M., Guillén, V., Botella, C., García, A., Jorquera, M., y Quero, S. (2008). Un programa de tratamiento para los trastornos adaptativos. Un estudio de caso. Apuntes de Psicología, 26(2), 303-316.

Barraca, J. y Pérez-Álvarez, M. (2010). Adaptación española del Environmental Reward Observation Scale (EROS). Ansiedad y Estrés, 16(1), 95-107.

Beck, A.T., Steer, R.A., y Brown, G.K. (1996). Manual for the Beck Depression Inventory-Second Edition. San Antonio, TX: The Psychological Corporation.

Berenbaum, H., y Oltmanns, T. F. (1992). Emotional experience and expression in schizophrenia and depression. Journal of Abnormal Psychology, 101(1), 37-44.

Botella, C., Baños, R.M., y Guillén, V. (2008). Una propuesta de tratamiento para los trastornos adaptativos: creciendo en la adversidad. En C. Vázquez y G. Hervás (Eds.), Psicología Positiva aplicada (pp. 129-154). Bilbao: Declée de Brouwer.

Calvo, E. (2009). Duración de la incapacidad temporal asociada a diferentes patologías en trabajadores españoles. Recuperado de http://www.seg-social.es/prdi00/groups/public/ documents/binario/146662.pdf 
Pressman, S. D. y Cohen, S. (2012). Positive emotion word use and longevity in famous deceased psychologists. Health Psychology, 31(3), 297-305.

Quero, S., Andreu-Mateu, S., Moragrega, I., Baños, R.M., Molés, M., Nebot, S, y Botella, C. (2017). Un programa cognitivo-conductual que utiliza realidad virtual para el tratamiento de los trastornos adaptatives: una serie de casos. Revista Argentina de Clínica Psicológica, 26(1), 5-18.

Quero, S., Molés, M., Mor, S., Baños, R., y Botella, C. (2014, noviembre). Spanish Validation of Complicated Grief Inventory adapted for Adjustment Disorder. Póster presentado en ABCT's 48th Annual Convention. Philadelphia.

Rosenberg, M. (1965). Society and the adolescent self-image. Princeton, NJ: Princeton University Press.

Ryff, C.D. (1989). Happiness is everything, or is it? Explorations on the measuring of research on hedònic and eudaimonic well-being. Annual Review of Psychology, 52, 141-166.

Sanz, J., García-Vera, M.P., Espinosa, R., Fortún, M., y Vázquez, C. (2005). Adaptación española del Inventario para la Depresión de Beck-II (BDI-II): Propiedades psicométricas en pacientes con trastornos psicológicos. Clínica y Salud, 16(2), 121-142.

Sanz, J., Perdigón, A.L., y Vázquez, C. (2003). Adaptación española del Inventario para la Depresión de Beck-II (BDI-II): Propiedades psicométricas en población general. Clínica y Salud, 14(3), 249-280.

Schmitt, D.P. y Allik, J. (2005). Simultaneous administration of the Rosenberg Self-Esteem Scale in 53 nations: explorin the universal and culture-specific features of global self-esteem. Journal of Personality and Social Psychology, 89(4), 623-642.

Seligman, M.E., Steen, T. A., Park, N., y Peterson, C. (2005). Positive psychology in progress. Empirical validation of interventions. American psychologist, 60, 410-421.

Sheung-Tak, C., Emily, P. M., Helene, H., Timothy, L., Lee, D., y Linda, C. W. (2017). Benefitfinding and effect on caregiver depression: A double-blind randomized controlled trial. Journal of Consulting and Clinical Psychology, 85(5), 521-529.

Sloan, D., Strauss, M. E., y Wisner, K. (2001). Diminished response to pleasant stimuli by depressed women. Journal of Abnormal Psycology, 110(3), 488-493

Tseferidi, S. I., Griva, F., y Anagnostopoulos, F. (2017). Time to get happy: associations of time perspective with indicators of well-being. Psychology, health y medicine, 22(5), 618-624.

Van Genugten, L., Dusseldorp, E., Massey, E.K., y van Empelen, P. (2016). Effective selfregulation change techniques to promote mental wellbeing among adolescents: a metaanalysis. Health Psychology Review, 11(1), 53-71.

Watson, D., Clark, L.A., y Tellegen, A. (1988). Development and validation of brief measures of positive and negative affect: the PANAS Scales. Journal of Personality and Social Psychology, 54(6), 1063-1070.

Watson, D., Stasik, S.M., Ellickson-Larew, S., y Stanton, K. (2015). Extraversion and psychopathology: A facet-level analysis. Journal of Abnormal Psychology, 124, 432-446.

Wilhelm, K., Wedgwood, L., Parker, G., Geerligs, L., y Hadzi-Pavlovic, D. (2010). Predicting mental Health and well-being in adulthood. The Journal of Nervous and Mental Disease, 198(2), 85-90. 
Carta, M. G., Balestrieri, M., Murru, A., y Hardoy, M. C. (2009). Adjustment Disorder: epidemiology, diagnosis and treatment. Clinical Practice and Epidemiology in Mental Health, 5(15).

Cassey, P., Dowrick, C., y Wilkinson, G. (2001). Adjustment disorders. Fault line in the pychiatric glossary. The British Journal of Psychiatry, 179, 479-481.

Cassey, P., Jabbar, F., O'Leary, E., y Doherty, A.M. (2015). Suicidal behaviours in adjustment disorder and depressive episode. Journal of Affective Disorders, 174, 441-446.

Charles, T., Lyubomirsky, S., y Murray, B. (2017). Upregulating the positive affect system in anxiety and depression: outcomes of a positive activity intervention. Depression and anxiety, 34(3), 267-280.

Clark, L. A. (2005). Temperament as a unifying basis for personality and psychopathology. Journal of Abnormal Psychology, 114, 505-521.

Clark, L. A. y Watson, D. (1991). Tripartite model of anxiety and depression: Psychometric Evidence and taxonomic implications. Journal of Abnormal Psychology, 100, 316-336.

Davidson, R.J. (1998). Affective style and affective disorders: Perspectives from affective neuroscience. Cognition and Emotion, 12, 307-330.

Díaz, D., Rodríguez-Carvajal, R., Blanco, A., Moreno-Jiménez, B., Gallardo, I., Valle, C., y van Dierendonck, D. (2006). Adaptación española de las escalas de bienestar psicológico de Ryff. Psicothema, 18(3), 572-577.

Fava, G.A., Ruini, C., Rafanelli, C., Finos, L., Salmaso, L., Mangelli, L., y Sirigatti, S. (2005). Psychotherapy and Psychosomatics, 74(1), 26-30.

Fernandez, A., Howse, E., Rubio-Valera, M., Thorncraft, K., Noone, J., Luu, X., Veness, B., Leech, M., Llewellyn, G., y Salvador-Carulla, L. (2016). Setting-based interventions to promote mental health at the university: a systematic review. International Journal of Public Health, 61(7), 797-807.

Fredrickson, B. L. (1998). What good are positive emotions?. Review of General Psychology, 2(3), 300-319

Ivandic, I., Freeman, A., Birner, U., Nowak, D., y Sabariego, C. (2017). A systematic review of brief mental health and well-being interventions in organizational settings. Scandinavian Journal of Work, Environment y Health, 43(2), 99-108.

Jacobson, N.S. y Truax, P. (1991). Clinical significance: A statistical approach to defining meaningful change in psychotherapy research. Journal of Consulting and Clinical Psychology, 59(1), 12-19

Johnson, M. D., Galambos, N. L., Finn, C., Neyer, F. J., y Horne, R. M. (2017). Pathways between self-esteem and depression in couples. Development psychology, 53(4), 787-799.

Kaviani, H., Gray, J. A., Checkley, S. A., Raven, P. W., Wilson, G. D., y Kumari, V. (2004). Affective modulation of the startle response in depression: Influence of the severity of depression, anhedonia, and anxiety. Journal of Affective Disorders, 83(1), 21-31.

Klein, H. A. (1974). Behavior modification as therapeutic paradox. American Journal of Orthopsychiatry, 44(3), 353-361.

Krueger, R. F., McGue, M., y lacono, W. G. (2001). The higher-order structure of common DSM mental disorders: Internalization, externalization, and their connections to personality. Personality and Individual Differences, 30, 1245-1259.

Küçük, E. E. y Küçük-Alemdar, D. (2017). Life satisfaction and psychological status of mothers with disabled children: a descriptive study. Community mental health journal. doi:10.1007/ s10597-017-0135-6

Li, Y.I., Starr, L.R., y Hershenberg, R. J. (2017). Responses to positive affect in daily life: positive rumination and dampening moderate the association between daily events and depressive symptoms. Journal of Psychopathology Behavioral Assessment, 1-14. 


\title{
¿Es la publicidad un factor de riesgo para el trastorno por atracón o las conductas de comer emocional?
}

\author{
Rocío RODRÍGUEZ RÓdENAS \\ al349389@uji.es \\ BERENICE SERRANo ZÁRATE \\ bserrano@uji.es
}

\section{Resumen}

Estudios sugieren que la publicidad podría influir en el desarrollo de un trastorno de la conducta alimentaria como puede ser el trastorno por atracón (TxA); por razones como la sugestión de su uso como regulador emocional. Objetivo: Discernir el efecto que la publicidad causa sobre la conducta de comer al actuar como regulador emocional; comprobando si constituye un factor de riesgo para el desarrollo del TxA. Método: Se realizaron dos estudios: (1) cualitativo en base a un focus group en el cual participaron 7 voluntarios; posteriormente se construyó una encuesta basada en la literatura revisada y los resultados del focus group. (2) Estudio cuantitativo en el cual participaron 151 voluntarios, $54,3 \%$ mujeres y media de edad de 35,80. Resultados: El focus group mostró que los participantes son conscientes de la influencia que la publicidad tiene sobre sus emociones, y sus posibles efectos sobre las conductas de comer emocional. Los resultados de la encuesta sugieren que la publicidad influye en las conductas de comer emocional y en el riesgo a desarrollar un posible TxA. Conclusiones: La publicidad podría ejercer una influencia de riesgo en la población vulnerable a comer emocionalmente y padecer un TxA. La prevención mediante psicoeducación emocional sería esencial en estas personas. Además de la estructuración de unas normas de rigor profesional dirigidas a antes de lanzar sus anuncios a los medios, para hacerles conscientes del impacto perjudicial para la salud que establecen las relaciones emoción-comida.

Palabras clave: publicidad, trastorno por atracón, regulación emocional, trastornos de la conducta alimentaria, comer emocional.

\section{Abstract}

Studies suggest that advertising could influence the development of an eating disorder as it can be binge eating disorder (BED); and the suggestion of its use as emotional reasons. Objective: Discern the effect that advertising causes on behavior eat acting as emotional regulator; checking whether it constitutes a risk factor for the development of the BED. Method: Two studies were carried out: (1) quality based on a focus group in which participated 7 volunteers; a survey based on the literature reviewed and the results of focus group was subsequently built. (2) a quantitative study in which involved 151 volunteers, $54.3 \%$ female and average age of 35,80. Results: Focus group 
showed that participants are aware of the influence that advertising has on their emotions, and their possible effects on emotional eating behaviors. The results of the survey suggest that advertising influences eating emotional behaviors and the risk to develop a possible BED. Conclusions: Advertising could influence of risk vulnerable people to eat emotionally and suffer a BED. Prevention through psycho-emotional education would be essential in these people. In addition to the structuring of professionalism standards directed to before launching your ads to the media, to make them aware of the harmful impact for health that establish relations emotion - food.

Keywords: advertising, binge eating disorder, emotional regulation, eating disorder, emotional eating.

\section{Introducción}

Las razones por las cuáles decidimos llevar adelante este estudio fueron principalmente las de prevención. Vivimos en un mundo poco educado emocionalmente donde las estrategias de regulación emocional se suelen aprender o desarrollar de forma precaria y, muchas veces, copiadas de modelos poco saludables, como es el caso de la publicidad. Los anuncios enfocados a la venta de comida propician una relación con el mundo de las emociones para facilitar su venta lo cual muchas veces es un arma de doble filo para la población, sobre todo la vulnerable, ya que, al no tener buenas estrategias de regulación emocional, recurren a lo que han visto y conocen: Calmar sus estados negativos con productos que la publicidad nos vende de una forma tan bonita, eficaz y rápida. $Y$ esto puede dar resultados tan perjudiciales para la persona como el llegar a desarrollar un trastorno de la conducta alimentaria (TCA) con todo el impacto que ello implica. Así pues, el propósito de este trabajo es poner sobre la mesa esta asociación y hacerla visible.

Actualmente los trastornos de la conducta alimentaria representan un grave problema de salud pública debido a su gran incidencia y al impacto que tienen en diferentes áreas de la vida del paciente. Estos trastornos se caracterizan por una alteración en la ingesta de alimentos o el comportamiento relacionado con la alimentación que, como consecuencia y como comentábamos antes, dan lugar a un deterioro físico y psicosocial, según el DSM-5 (APA, 2013). EI crecimiento de los TCA ha sido notable en las últimas décadas, lo cual hace saltar la alarma en los países occidentalizados, llegando a considerarse casi una pandemia. Las cifras internacionales según López, Raimann y Gaete (2015) oscilan entre el 0,5 y el $1 \%$ para la anorexia nerviosa (AN) y el 1, 2 y $4 \%$ para la bulimia nerviosa (BN). Existen diversos factores de riesgo a la hora de desarrollar un TCA, aunque para nuestra investigación resultan de gran interés las variables emocionales. En un estudio realizado con una muestra de 48 pacientes Calvo et al. (2014) confirmaron que existen dificultades emocionales, especialmente alexitimia, en este tipo de pacientes. Concluyen con que al comienzo del trastorno existe un déficit de conciencia emocional que se va agravando con el paso de los años, convirtiéndose en un factor de mantenimiento. Un factor de inicio de trastorno sería el de la dificultad para percibir las propias emociones.

Para nuestra investigación nos hemos centrado en el trastorno por atracón (TxA), recientemente incluido en el DSM-5 con entidad propia. el TxA se caracteriza principalmente por atracones sin posterior compensación (como ocurriría en la BN). Algo interesante que pone en relieve el DSM-5 respecto al TxA son algunos de sus disparadores, como el afecto 
negativo, estresores interpersonales o sentimientos negativos respecto al peso, forma corporal o comida (García, 2014). Estos atracones pueden proporcionar un escape fácil y rápido a estos sentimientos, pero, a largo plazo, son evaluados como negativos y llevan también a una evaluación negativa del propio sujeto hacia sí mismo. De cara a nuestra investigación vemos de suma importancia el subcriterio 3 del criterio B del DSM-5, en el que se expresa que las personas con TxA suelen comer grandes cantidades de alimentos cuando no sienten hambre físicamente. A este comportamiento, de recurrir a la comida cuando no se tiene hambre física, con el fin regular o «tapar» una emoción (generalmente negativa, aunque el disfrute y la alegría también pueden tener influencia), se le conoce como «comer emocional» y recientes estudios lo ligan íntimamente con el TxA. Las emociones pueden influir en la motivación para comer, la respuesta emocional hacia algunos alimentos, la elección de la comida, la velocidad a la hora de comer, así como en el metabolismo y la digestión (Macht, 2008). En relación a estudios que confirman esta relación, Gismero-González (2012) llevó a cabo un estudio en el que los propios pacientes atribuían la causa de su TCA. Encontró que los pacientes obesos destacaban los problemas emocionales como el tercer valor con más importancia a la hora de desarrollar su trastorno. Gómez Peresmitré et al. (2013) Ilevaron a cabo un interesante estudio para discernir los factores de riesgo más importantes para la conducta de atracón en México, Argentina y España. Y los resultados fueron que el factor predictor más importante para un atracón en los tres países, es la compensación psicológica. Esto podría confirmar que el estado de ánimo está estrechamente ligado con la conducta de comer y puede ser un factor predictor de mucha importancia. Por otro lado, y en relación al TxA, en el estudio que llevaron a cabo Ricca et al. (2008) acerca de la asociación entre el comer emocional y el TxA, encontraron que este tipo de pacientes obtuvieron los resultados más severos en cuanto a la realización de este tipo de alimentación. En concreto se encontraron resultados significativos en cuanto a depresión, ansiedad e ira. Zeeck, Stelzer, Linster, Joos \& Hartmann (2010) también concluyeron con que las emociones negativas disparaban el deseo de comer en pacientes con TxA, en concreto la ira, la desconfianza, el sentirse herido y la decepción. El hecho de que los atracones se relacionen con el comer emocional se sustenta en que las personas con TxA padecen déficits en la regulación emocional. De hecho, Ruscitti, Rufino, Goodwin \& Wagner (2016) confirmaron mediante su estudio que los pacientes con TxA tienen mayor dificultad en la regulación emocional que los pacientes control, mostrándose resultados significativos en la escala DERS (Difficulties in Emotion regulation). Una de las teorías propuestas para este suceso, conocida como 'teoría de la máscara' propone que los atracones pueden servir para tapar o 'enmascarar' otros problemas, disminuyendo de esta forma el afecto negativo. Por otro lado, la 'teoría del escape' sugiere que el atracón serviría para escapar de situaciones estresantes o estados de ánimo negativos (Munsch, Meyer, Quartier \& Wilhelm, 2011). Wolz et al. (2015) nos dan con la clave final que relaciona el déficit en la regulación emocional, el comer emocional y la publicidad: $Y$ es que la regulación emocional en base a la comida se da por no tener otras estrategias de regulación más adaptativas. Y es que muchas de las estrategias perjudiciales en la regulación emocional se deben a un aprendizaje temprano. En nuestra investigación queremos demostrar que ese aprendizaje es debido a la publicidad en los medios de comunicación, en concreto, a la publicidad emocional.

Según Lodos (2011), en la actualidad a las marcas ya no les basta únicamente con destacar en precio y calidad, en esta sociedad lo que prima a la hora de decantarse por una marca o producto son los factores emocionales y el vínculo que se crea con el consumidor a través de la marca. Cuando compramos algo lo que estamos comprando es el discurso, el trasfondo, lo que nos hacen llegar. Y es por ello que cada vez más y más empresas de marketing apelan a las emociones para poder calar en el consumidor y acercarlo a su producto, estableciendo a veces una de riesgo relación entre emociones y cualquier otra variable, como la alimentación 
en este caso. López-Vázquez (2007) hace una peligrosa asociación entre compulsividad y consumo, sugiriendo que cuanto más compulsivos sean los compradores, más emocional tendrá que ser la publicidad. Lo peligroso radica en nuestro caso particular, donde los pacientes con TA suelen sufrir ingestas compulsivas en las que pierden el control. He ahí la amenaza que puede conllevar implicar a personas con atracones y publicidad emocionalmente sugerente. Trias de Bes (2008), llevó a cabo un estudio en el que analizó 16 marcas de alimentos. En sus resultados encontró que sólo dos de ellos respondían al tipo de publicidad racional, dejando 14 a la publicidad emocional.

Para terminar, queremos pues hacer hincapié en el efecto que tiene la publicidad emocional en los TCA, ya que la publicidad viene siendo indicada como un factor de riesgo para estos trastornos desde hace décadas, tanto desde el punto de vista de la estética como de la dietética. A este respecto, Mas et al. (2016) realizaron un estudio para identificar los valores percibidos por adolescentes en anuncios de dietética. Los anuncios puestos a examen fueron dos de la marca Special K y uno perteneciente a All Bran. Los resultados fueron llamativos, siendo el grupo de TCA, quienes percibían peores valores en estos anuncios, confirmando que quienes padecen estos trastornos identifican en ellos causas que han podido influir en su estado actual.

El objetivo general del estudio fue identificar si existe una relación directa entre la publicidad emocional relacionada con la comida y el desarrollo de un trastorno de la conducta alimentaria, concretamente del trastornos por atracón.

Como objetivos específicos del estudio, se esperaba: (1) Identificar la población vulnerable a desarrollar un trastorno por atracón, al hacer uso de la comida como regulador emocional. (2) identificar si la publicidad relacionada con la comida influye en la relación comida-emoción; es decir, conocer si los participantes han aprendido a relacionar o vincular comida y emociones en base a este tipo de anuncios publicitarios. (3) Identificar si el grupo de participantes que come emocionalmente lo hace en base a la asociación comida-emoción propuesta por la publicidad.

\section{Preguntas de investigación}

¿Los atracones de las personas vulnerables a un trastorno por atracón se basan en comer emocionalmente?

¿Influye la publicidad dirigida al consumo de determinados alimentos, en las conductas de comer emocional?

¿Las personas con vulnerabilidad a padecer un trastorno por atracón, han aprendido a comer emocionalmente en base a la asociación comida-emoción sugerida por los medios?

\section{Hipótesis}

H1: La publicidad emocional relacionada con la comida tiene una relación directa con las conductas de comer emocional.

$\mathrm{H} 2$ : Los participantes con vulnerabilidad a padecer un TxA, utilizan determinados alimentos, promocionados por determinadas marcas para regular sus emociones 


\section{Método}

\section{Participantes}

En el estudio 1 participaron 7 voluntarios y voluntarias, de los cuales el $57 \%$ son mujeres, la media de edad es de 26,29 años. La muestra se eligió aleatoriamente tras un llamamiento inicial teniendo en cuenta la disponibilidad de los y las participantes. En el estudio 2 participaron 151 voluntarios y voluntarias de diferentes nacionalidades (54,3\% mujeres), todos y todas residentes en España, la media de edad fue de 35,8 años. Los criterios de inclusión en el estudio 2 fueron los siguientes: hombres y mujeres de 18 años en adelante; residentes en España y; cualquier nivel de estudios.

\section{Instrumentos y Materiales}

Para la realización del estudio 1 se emplearon dos imágenes pertenecientes a dos anuncios publicitarios (Chocolates Dhul y Pizzas Casa Tarradellas) y dos spots publicitarios actuales (Nocilla y Pizzas Casa Tarradellas). Se elaboró un listado de 11 preguntas que desde la más general hasta la más específica indagaban acerca de la opinión sobre la publicidad, patrones de ingesta y emociones.

Las variables medidas en el estudio 2 fueron la regulación emocional, la vulnerabilidad a padecer un TxA, la conducta de comer emocional y, la influencia de los medios de comunicación en cuanto a patrones de ingesta y emociones percibidas. Se elaboró una batería que contaba con:

- Cuestionario diseñado por Mariana Álvez (Álvez, 2011) para criterios de TxA.

- Escala Emotional Eating Questionnaire (EEQ Stunkard \& Messick, 1985; Validación española de Garaulet et al. 2012).

- Escala de Dificultades en la Regulación Emocional (DERS Gratz \& Roemer, 2004; Validación española de Hervás \& Jódar, 2008).

- Escala de creación propia construida en base a la literatura existente y los resultados del focus group para medir la influencia de los medios de comunicación en las conductas de comer emocional.

\section{Procedimiento}

En el estudio 1 se realizó un estudio cualitativo en base a la realización de un focus group en el cual los participantes acudieron de forma voluntaria tras un llamamiento en redes sociales y firmando un Consentimiento Informado. Tuvo una duración de 2 horas en las cuales gracias al apoyo audiovisual y a las preguntas diseñadas se pudieron extraer unas conclusiones para el desarrollo de una encuesta la cual sería utilizada en el estudio 2. En este segundo estudio, se realizó una encuesta a la cual los particiantes tenían aceso mediante la plataforma online Surveymonkey, a cambio de su participación. El estudio se difundió mediante cartelería en el campus de la Universidad de Valencia y mediante redes sociales, ofreciendo a cambio de la participación un breve informe con sus resultados. 


\section{Resultados}

Del focus group se extrajeron un total de ocho conclusiones:

- La publicidad constituye una herramienta de trabajo.

- La publicidad también es molesta, chocante y nos saturan con ella.

- La publicidad nos manipula, nos convierte en seres manipulables.

- La publicidad se dedica a cubrir algo más que necesidades básicas, crea otras nuevas.

- La publicidad conlleva un componente emocional que incita a la consumición.

- La publicidad relacionada con la alimentación y la bebida, tiene un trato especial.

- La publicidad relacionada con la alimentación no se vende de forma objetiva, hay falsedad.

- La publicidad relacionada con la alimentación es un incitador de conductas.

Los resultados de la encuesta online dieron respuesta tanto a las preguntas de investigación como a nuestras hipótesis de partida. Respecto a nuestras preguntas de investigación, los resultados son los que siguen:

¿Los atracones de las personas vulnerables a un trastorno por atracón se basan en comer emocionalmente?

Para responder a esta pregunta de investigación se realizó una correlación de Pearson entre el sumatorio de la variable comer emocional, proporcionada por el resultado del cuestionario EEQ. Y el sumatorio de la variable trastorno por atracón, proporcionada por el resultado del Cuestionario acerca de vulnerabilidad a un trastorno por atracón. La correlación fue positiva y significativa $(r=0,739 ; p<0,001)$. Estos resultados sugieren que en nuestra muestra existe una asociación entre los atracones y la conducta de comer emocional, es decir, que éstos estarían provocados en su mayoría por el hecho de comer emocionalmente.

¿Influye la publicidad dirigida al consumo de determinados alimentos, en las conductas de comer emocional?

Para responder a esta pregunta se realizó una correlación de Pearson entre el sumatorio de la variable comer emocional y el ítem número 18 de nuestra encuesta de creación propia, al que los encuestados tenían que responder si tendían a paliar algunas emociones con alimentos de las marcas evaluadas. La correlación resultó positiva y significativa $(r=0,571 ; p<$ $0,001)$. Los resultados sugieren que el hecho de que los encuestados intenten regular algunas de sus emociones consumiendo las marcas de alimentos evaluadas, podría estar directamente relacionado con el hecho de que coman emocionalmente.

¿Las personas con vulnerabilidad a padecer un trastorno por atracón, han aprendido a comer emocionalmente en base a la asociación comida-emoción sugerida por los medios?

Se analizó esta pregunta de investigación con una correlación de Pearson entre el sumatorio de la variable trastorno por atracón y el ítem número 18 de nuestra encuesta de creación propia. La correlación resultó positiva y significativa $(r=0,401 ; p<0,001)$. Los resultados sugieren que los encuestados vulnerables a padecer un TxA, lo son en alguna medida, debido a la posible asociación entre la emoción y el consumo de un determinado alimento. 
Respecto a nuestras hipótesis de partida, los resultados son los que siguen:

H1: La publicidad emocional relacionada con la comida tiene una relación directa con las conductas de comer emocional

Esta hipótesis queda confirmada si tenemos en cuenta la correlación positiva y significativa hallada entre las variables del sumatorio del EEQ y el ítem 18 de la encuesta. La correlación fue de $r=0,571 ; p<0,001$, sugiriendo que existe una relación directa positiva entre el hecho de paliar las emociones con marcas de los alimentos encuestados y las conductas de comer emocional. Por lo tanto, confirmamos la hipótesis número uno. Esto puede deberse a que los participantes han aprendido a regular sus emociones inducidos por la publicidad emocional para consumir ciertos alimentos. Muchas marcas relacionan directamente sus productos con una emoción positiva, esto ha podido provocar que, para poder regular ciertas emociones, recurran a sus productos para obtener de ellos la emoción anunciada.

H2: Los participantes con vulnerabilidad a padecer un TxA, utilizan determinados alimentos, promocionados por determinadas marcas, para regular sus emociones

Para comprobar esta hipótesis, se realizó una correlación de Pearson entre el sumatorio de la variable trastorno por atracón y el ítem número 18 de nuestra encuesta de creación propia. Se escogió esta última variable porque en su respuesta se engloba si realizan conductas de comer emocional en base a la asociación emoción-marca realizada anteriormente en el mismo cuestionario. La correlación resultó positiva y significativa $(r=0,401 ; p<0,001)$. Realizamos una segunda correlación de Pearson entre el sumatorio de la variable trastorno por atracón y el ítem número 5 , acerca de si la publicidad emocional proporciona a los encuestados, estrategias útiles para afrontar las situaciones emocionales del día a día. En este caso la correlación no fue significativa; por lo tanto, los resultados sugieren que, si bien la muestra sí recurre al consumo de alimentos de las marcas evaluadas para regular sus emociones, en general no consideran que la publicidad aporte estrategias útiles para solventar los problemas emocionales del día a día. Por lo tanto, confirmamos la hipótesis número dos. La cual sugiere que la muestra encuestada, ha adquirido conductas de comer emocional por aprendizaje embargo, los resultados muestran que no encuentran en ellos estrategias emocionales útiles para la vida diaria.

Se extrajeron también otros resultados útiles pertenecientes a la asociación que los encuestados realizaron entre emociones y marcas de alimentos evaluadas. Los resultados más significativos fueron los pertenecientes a Coca-Cola (Figura 1) y a Nocilla (Figura 2). Como se puede observar en ambas figuras, la alegría es la emoción predominante asociada a estas dos marcas, que precisamente son las que en sus eslóganes utilizan también esta emoción. En Coca-Cola casi supera la mitad de las respuestas, con un 49,67 \% de elección de esta emoción, mientras que en Nocilla el porcentaje es de un 40,40\%.

Del focus group se extrajeron un total de ocho áreas temáticas, a saber:

- La publicidad constituye una herramienta de trabajo.

- La publicidad también es molesta, chocante y nos saturan con ella.

- La publicidad nos manipula, nos convierte en seres manipulables.

- La publicidad se dedica a cubrir algo más que necesidades básicas, crea otras nuevas.

- La publicidad conlleva un componente emocional que incita a la consumición. 
- La publicidad relacionada con la alimentación y la bebida, tiene un trato especial.

- La publicidad relacionada con la alimentación no se vende de forma objetiva, hay falsedad.

- La publicidad relacionada con la alimentación es un incitador de conductas.

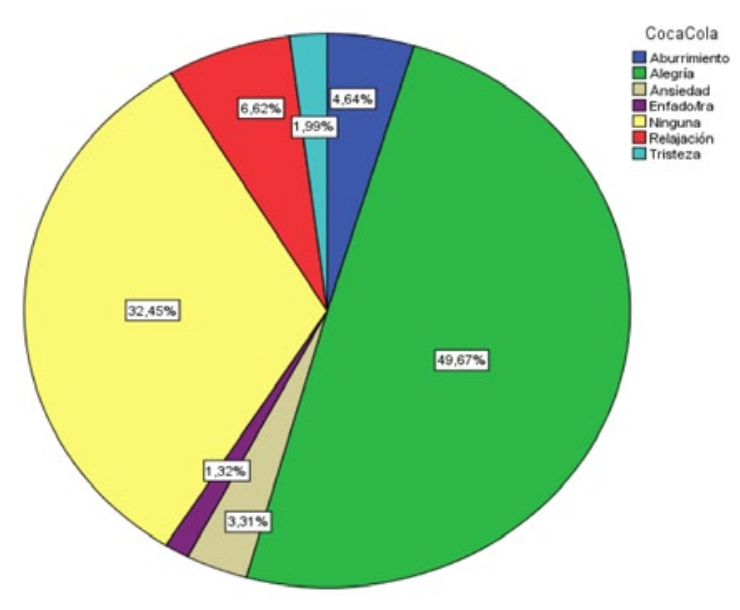

Figura 1. Coca-Cola

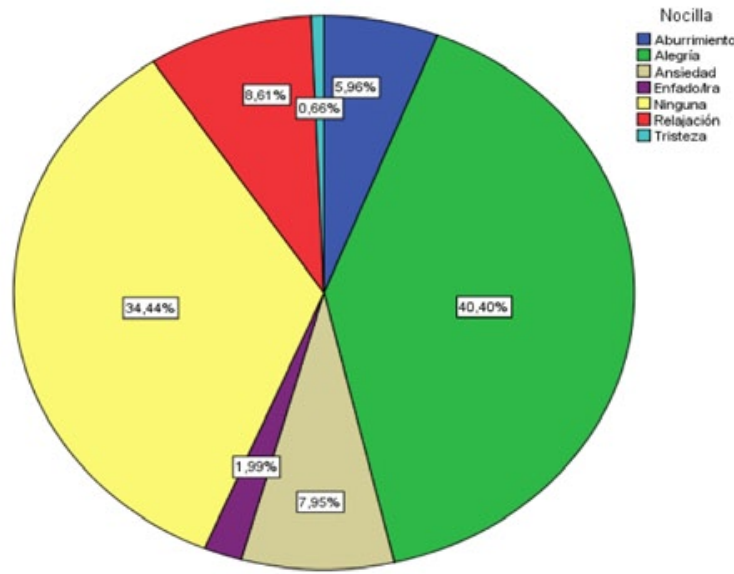

Figura 2. Nocilla

\section{Discusión y conclusiones}

Los resultados de nuestra investigación han servido para poder confirmar y responder todas nuestras hipótesis y preguntas de investigación, relacionándose positivamente con los estudios e investigaciones de los que partíamos como referencia.

Tal como se especificaba en los criterios del DSM-5 respecto al TxA, éstos últimos se deben en su mayoría a respuestas de estados emocionales negativos que no se corresponden con un hambre física. Nuestra primera pregunta de investigación apoya este criterio, ya que la muestra encuestada mostró una relación positiva y significativa respecto a las siguientes conductas: Los posibles atracones de las personas vulnerables a un TxA son explicados por las conductas de comer emocional; por tanto se hace necesario en posteriores investigaciones un programa de prevención basado en este aspecto; una psicoeducación clara y temprana para prevenir las conductas de comer emocional podría estar estrechamente ligada con la reducción de atracones y el peligro que ellos conllevan para desarrollar un TxA.

Otro de los hallazgos encontrados, es que la publicidad posiblemente resulte un factor de riesgo para adquirir conductas de comer emocional, esto está en relación con los resultados encontrados por Lodos (2011) respecto a que las marcas necesitan vincular a los consumidores emocionalmente para que adquieran sus productos. Por ejemplo, Nocilla y Coca-Cola, como comprobamos en los resultados, son las marcas que mayor porcentaje obtuvieron de 'alegría' como emoción asociada, que a su vez son aquellas que utilizan esta emoción en sus eslóganes comerciales. El posible aprendizaje de esta forma de asociar una emoción a un determinado alimento ha sido identificado en nuestra muestra, tal como sugieren los resultados, en los que se deja ver que los participantes consumen alimentos de estas marcas cuando están sintiendo alguna emoción específica, utilizándolas pues como un regulador emocional poco adaptativo. Más específicamente, ha quedado también identificada la asociación que existe en 
la muestra encuestada entre la vulnerabilidad a padecer un TxA y el consumo de las marcas evaluadas para realizar conductas de comer emocional. Esto sugiere refleja la necesidad de elaboración de programas y talleres de rigor profesional donde los publicistas puedan entender la peligrosa baza que juega en la salud de los consumidores el tipo de publicidad que están llevando a cabo. Pues como ha quedado reflejado, la publicidad emocional puede crear un vínculo perjudicial entre las personas vulnerables a desarrollar un TxA y el consumo emocional de sus marcas.

Los resultados cualitativos del focus group pusieron también en auge que la muestra se siente muchas veces manipulada por los medios de comunicación, y que son conscientes además de que la publicidad intenta imponer unas conductas de alimentación instigadas por la forma de presentar el producto y envolverlo en un ambiente emocional que hace que el consumidor acceda a ellos desde esa parte. La falta de estrategias en regulación emocional que padecen muchas personas vulnerables a un TxA, hace que tomen como ejemplo este tipo de asociaciones que además de ser fáciles y rápidas, son accesibles, como comentaban los participantes al focus group, ya que constantemente somos bombardeados con estas ideas. Sería pues necesario tanto un trabajo a nivel psicoeducativo emocional con las personas vulnerables o que ya padecen un TxA como unas normas de rigor profesional que pasaran un filtro a toda la publicidad alimentaria antes de lanzarse a los medios.

Sería interesante también para futuras líneas de investigación, incluir en los programas de intervención a las personas con bulimia nerviosa, ya que también tiene en su diagnóstico esta compulsividad a la hora de comer, y de comer emocionalmente.

\section{Referencias bibliográficas}

Álvez, M. (2011). Cuestionario: ¿Padeces trastorno por atracón? Recuperado el 16 de enero de 2017 de: https://psicologiapositivauruguay.com/2011/03/13/cuestionario$\% \mathrm{C} 2 \%$ BFpadeces-del-trastorno-por-atracon/

Asociación Americana de Psiquiatría. (2013). Manual diagnóstico y estadístico de los trastornos mentales ( $5^{\mathrm{a}}$ ed.). Arlington, VA: American Psychiatric Publishing.

Calvo-Sagardoy, R., Solórzano, G., Morales, C., Kassem, M. S., Codesal, R., Blanco, A. \& Gallego Morales, L. T. (2014). Procesamiento emocional en pacientes TCA adultas vs. adolescentes. Reconocimiento y regulación emocional. Clínica y Salud, 25, 19-37

Garaulet, M., Canteras, M., Morales, E., López-Guimera, G., Sánchez-Carracedo, D. \& Corbalán-Tutau, M.D. (2012). Validation of a questionnaire on emotional eating for use in cases of obesity: the Emotional Eater Questionnaire (EEQ). Nutrición Hospitalaria, 27(2), 645651

García-Palacios, A. (2014). El trastorno por atracón en el DSM-5. Cuadernos de Medicina Psicosomática, 110, 70-74

Gismero-González, M. E. (2012). Factores causales de los trastornos de la conducta alimentaria atribuidos por profesionales sanitarios. Acción Psicológica, 9(2), 77-86

Gómez-Peremistré, G., Acosta-García, V., Gorischnik, R., Cuevas-Renaud, C., Pineda-García, G., Platas-Acevedo, R. S... León Hernández, R. (2013). Un estudio preliminar de los factores predictores de la conducta de atracón en tres culturas: México, Argentina y España. Revista Mexicana de Trastornos Alimentarios, 4, 68-78

Gratz, K. L. \& Roemer, L. (2004). Multidimensional assessment of emotion regulation and dysregulation: Development, factor structure, and initial validation of the difficulties in emotion regulation scale. Journal of Psychopathology and Behavioral Assessment, 26, 41-54. 
Hervás G. \& Jódar, R. (2008). The Spanish version of the Difficulties in Emotion Regulation Scale. Clínica y Salud, 19(2), 139-156

Lodos, H. (2011). Lo emocional en las marcas. Open DC: Universidad de Palermo.

López, C. C., Raimann, T. X. \& Gaete, M. V. (2015). Prevención de los trastornos de conducta alimentaria en la era de la obesidad: rol del clínico. Revista Médica Clínica Las Condes, 24-33.

López-Vázquez, B. (2007). Publicidad emocional, estrategias creativas. Madrid, España: ESIC Editorial.

Macht, M. (2008). How emotions affect eating: A five-way model. Appetite, 50, 1-11

Mas-Manchón, L., Rodríguez-Bravo, A., Montoya-Vilar, N., Morales-Morante, F., López, E. \& Wilson-Salgado, A. (2016). Values perception in food commercials with dietrary strategies. Prisma Social: Revista de Ciencias Sociales, 1, 29-59

Munsch, S., Meyer, A., Quartier, V. \& Wilhelm, F. (2011). Binge eating disorder: A break-down of emotion regulatory process? doi: 10.1016/j.pychres.2011.07.016

Ricca, V., Castellini, G., Lo Sauro, C., Ravaldi, C., Lapi, F., Mannucci, E... Faravelli, C. (2008). Binge and emotional eating in obese subjects seeking weight loss treatment. Nature Precedings: doi: hdl:10101/npre.2008.2125.1

Ruscitti, C., Rufino, K., Goodwin, N. \& Wagner, R. (2016). Difficulties in emotion regulation in patients with eating disorders. doi 10.1186/s40479-016-0037-1

Stunkard, A. J. \& Messick S. (1985) The three-factor Eating Questionnaire to measure dietary restraint, desinhibition and hunger. Journal of Psychosomatic Research, 29, 71-83.

Trias de Bes Agell, E. (2008). La publicidad emocional y su presencia en el sector de la alimentación. Trabajo de final de carrera de ciencias sociales. Barcelona: Universidad Abat Oliva CEU

Wolz, I., Agüera, Z., Granero, R., Jiménez-Murcia, S., Gratz, K., Menchón, J. \& FernándezAranda, F. (2015). Emotion regulation in disordered eating: Psychometric properties of the Difficulties in Emotion Regulation Scale among Spanish adults and its interrelations with personality and clinical severity. Frontiers in Psychology, 6, 907. doi: 10.3389/ fpsyg.2015.00907

Zeeck, A., Stelzer, N., Wolfgang Linster, H., Joos, A. \& Hartmann, A. (2010). Emotion and eating in binge eating disorder and obesity. Wiley Online Library. doi: 10.1002/erv.1066 


\title{
Estrategias de afrontamiento como variables predictivas de la intensidad sintomatológica y el cambio clínico tras un tratamiento cognitivo-conductual para el trastorno adaptativo
}

\author{
FABIOLA REYES-TORRES \\ freyes@uji.es \\ IRYNA RACHYLA \\ rachyla@uji.es \\ SILVIA FUENTES-CERDA \\ al287715@uji.es \\ MAR MOLÉS AMPOSTA \\ molesm@psb.uji.es \\ SOLEDAD QUERO CASTELLANO \\ squero@uji.es
}

\section{Resumen}

Introducción: Se ha encontrado que en el contexto de afecciones médicas el afrontamiento activo se relaciona con una mejor respuesta al tratamiento. Sin embargo, no se ha analizado su influencia en el tratamiento de los Trastornos Adaptativos (TA). Objetivo: Analizar la capacidad predictiva de los estilos de afrontamiento en la intensidad sintomática y en el cambio clínico en pacientes con TA. Método: La muestra incluyó 44 pacientes que recibieron un TCC de 6-8 sesiones para los TA. El cuestionario Brief COPE (Carver, 1997) se utilizó para medir las estrategias de afrontamiento. La sintomatología depresiva y de estrés y pérdida fue evaluada en el post-tratamiento y seguimientos de los 3, 6 y 12 meses. Resultados: Las estrategias de afrontamiento no predijeron la intensidad sintomatológica depresiva pero sí la asociada al estrés y pérdida. Estos síntomas fueron menos intensos en pacientes que utilizaban en mayor grado afrontamiento cognitivo y en menor las estrategias de bloqueo y evitación. En cuanto al cambio clínico, en el post y los seguimientos de los 3 y 12 meses los resultados del tratamiento eran independientes de los estilos de afrontamiento iniciales. No obstante, el mayor uso de apoyo social predijo una mayor mejoría en estrés y pérdida en el seguimiento de los 6 meses. Conclusiones: Los resultados subrayan el papel predictor del afrontamiento activo (cognitivo y social) en la mejoría de los síntomas relacionados con el acontecimiento estresante. Se sugiere promover el uso de estrategias de afrontamiento adaptativas durante el tratamiento de los TA.

Palabras clave: trastorno adaptativo, estrategias de afrontamiento, cambio clínico, depresión, estrés y pérdida. 


\section{Abstract}

Introduction: It has been found that in the field of medical afflictions active coping is related with a better response to treatment. However, the influence of coping strategies on Adjustment Disorder (AD) has not been sufficiently analyzed. Aim: To explore the predictive value of coping styles to predict the severity of symptoms and clinical change in patients with AD. Method: The sample included 44 patients who received a 6-8 session CBT for AD. Brief COPE questionnaire (Carver, 1997) was used to measure coping strategies. Depressive and stress and loss symptoms were assessed at post-intervention and 3, 6 and 12 months follow-ups. Results: Coping strategies did not predict the severity of depressive symptoms, however, they showed significant relationship with the severity of symptoms related to stress and loss. These symptoms were less severe in patients who used more cognitive coping strategies and less blocking or avoidance strategies. Regarding to clinical change, treatment outcomes were independent of the initial coping styles at post-intervention and 3 and 12 months follow-up. Nevertheless, greater use of social support predicted a more significant improvement in stress and loss symptoms at 6 months follow-up. Conclusions: Results highlight the predictive role of active coping (cognitive and social) in the improvement of symptoms related to the stressful event. It is recommended to promote the use of adaptive coping strategies during the treatment of $A D$.

Keywords: adjusment disorder, coping strategies, meaningful change, depression, stress and loss.

\section{Introducción}

Las estrategias de afrontamiento constituyen el conjunto de acciones que un individuo despliega ante situaciones altamente amenazantes con el propósito de detener, atenuar o bien anular sus efectos emocionales facilitando así la adaptación a las mismas (Morán, Landero \& González, 2010). De esta manera, estrategias de afrontamiento adaptativas conducen a un mejor manejo del estrés y a un mayor ajuste a la situación (Lazarus, Delongis, Folkman \& Gruen, 1985). La adopción de un determinado tipo de estrategia dependerá de la forma en que se valore el suceso estresante. Existen dos tipos de afrontamiento: cuando la situación es evaluada como fácil de resolver normalmente se utilizan estrategias centradas en la resolución del problema, por el contrario, cuando la situación es percibida como dañina o desafiante y, por tanto, difícil de cambiar, suelen utilizarse estrategias centradas en la emoción, las cuales se centran específicamente en cambiar las emociones asociadas a la situación (Folkman, 1984).

En el ámbito clínico, la evidencia ha mostrado que las estrategias de afrontamiento determinan la intensidad sintomatológica asociada a diferentes trastornos emocionales. En relación al trastorno depresivo, Burns \& Nolen-Hoeksem (1991) demostraron que las personas que empleaban con menor frecuencia estrategias de afrontamiento positivo presentaban mayor severidad depresiva, en comparación con aquellas que las utilizaban de forma habitual. En un estudio reciente se encontró que la gravedad sintomatológica de los síndromes subclínicos de depresión, trastorno obsesivo compulsivo y paranoia correlacionaba fuertemente con 
el afrontamiento desadaptativo, no obstante, la magnitud de la relación era mucho más fuerte para los síntomas depresivos (Moritz et al., 2016). Estos resultados se confirman con los hallados en el estudio de Potthoff et al. (2016), donde estrategias desadaptativas como la autoinculpación y la catastrofización fueron capaces de predecir altos niveles de depresión.

En cuanto a la relación entre los estilos de afrontamiento y la sintomatología ansiosa; se han encontrado asociaciones fuertes entre la catastrofización, la rumiación, la auto-inculpación y la intensidad de las puntuaciones de ansiedad informadas (Potthoff et al., 2016). Asimismo, una investigación llevada a cabo en pacientes con trastorno de pánico, arrojó que éstos usaban con menor frecuencia estrategias de afrontamiento efectivas (solución de problemas y reevaluación positiva), en comparación con el grupo control (Savoia \& Bernik, 2004).

Los hallazgos anteriores revelan el carácter predictivo de las estrategias de afrontamiento en la gravedad sintomática de trastornos como la depresión y la ansiedad, no obstante, se ha dedicado escasa atención a su influencia en otro tipo de desórdenes como el Trastorno Adaptativo (TA). De acuerdo a los criterios propuestos por el DSM-5 (APA, 2013), el TA puede definirse como una serie de reacciones negativas, tanto en el ámbito emocional como conductal, que se despliegan ante la experiencia de un evento vital estresante o ante la adversidad; generalmente se presenta dentro de los 3 meses posteriores a la ocurrencia del suceso. Uno de los aspectos fundamentales para el diagnóstico es que el malestar emocional debe ser desproporcionado en relación a la intensidad del factor estresante, tomando en cuenta siempre el contexto externo y los aspectos culturales. Además, el malestar debe interferir de forma significativa en el funcionamiento social, laboral, escolar o en las relaciones interpersonales.

Como se ha mencionado, el papel del afrontamiento en el TA no ha sido suficientemente investigado. No obstante, dado que las enfermedades físicas constituyen en la mayoría de los casos un cambio vital acompañado de grandes cargas de estrés, uno de los campos que ha aportado resultados importantes en esta área es el de las afecciones médicas. Por ejemplo, en pacientes con enfermedades cardíacas, el mayor uso de estrategias de afrontamiento desadaptativas se ha relacionado con síntomas depresivos más intensos, en contraste, se ha encontrado que personas con problemas cardíacos crónicos que adoptan estrategias de afrontamiento adaptativas se encuentran menos expuestas a desarrollar depresión (Holahan, Moos, Holahan y Brennan, 1995; Pérez-García, Oliván \& Bover, 2013). En la misma línea, Giammanco \& Gitto (2016) evidenciaron en pacientes cardíacos hospitalizados que el uso de estrategias activas (reinterpretación positiva y crecimiento) correlacionaba negativamente con síntomas de ansiedad y depresión tanto extremos como patológicos. También se observó que las estrategias pasivas de afrontamiento se relacionaban positivamente con puntuaciones altas de ansiedad.

Por otro lado, la investigación empírica también ha encontrado que el afrontamiento guarda relación con la mejoría clínica. Así, Hall, Marshall, Mercado \& Tkachuk (2011) midieron el cambio clínico en personas que habían sufrido un accidente de tráfico después de ser sometidas a tratamiento y sus resultados revelaron que, tras la intervención, aquellos pacientes que adoptaban una afrontamiento activo hacia la rehabilitación (evitando el afrontamiento pasivo), informaron mayores beneficios tanto en las puntuaciones de calidad de vida como en su funcionalidad física, en comparación con aquellos que no lo hicieron.

En el ámbito de los trastornos de ansiedad las estrategias de afrontamiento han mostrado un comportamiento similar. En un estudio realizado con pacientes con trastorno de pánico que habían recibido una intervención cognitivo-conductual grupal, se observó posterior a la terapia un uso menos frecuente de estrategias como la confrontación, el escape y la evitación; además como resultado del tratamiento también incrementó el uso de estrategias adaptativas, aspecto que se relacionó con una disminución de la frecuencia de los ataques de pánico y de las puntuaciones de ansiedad anticipatoria (Wesner et al., 2014). Investigaciones recientes 
también han revelado que el afrontamiento cognitivo funciona como un mecanismo de cambio en pacientes con miedo a volar pues después de un tratamiento cognitivo-conductual se observó una reducción significativa en el uso del afrontamiento desadaptativo (auto-inculpación, rumiación, catastrofización y evitación) y un incremento significativo en las estrategias adaptativas (reenfoque positivo y reevaluación positiva). Además, ambos resultados fueron predictores de mejoras en el miedo a volar auto-informado tanto a corto como a mediano plazo (Busscher \& Spinhoven, 2016).

Por último, en lo referido a la investigación sobre el TA, se ha encontrado que contar con características personales como la extroversión, tener vínculos familiares fuertes y recibir apoyo y consuelo de parte de los miembros de la red social (amigos), constituyen factores que previenen el desarrollo de trastornos emocionales inducidos por estrés; de forma inversa el uso inapropiado de las estrategias de afrontamiento y de los recursos sociales incrementa el riesgo de su aparación (Kornblith et al., 2001). Finalmente, el estudio llevado a cabo por Ponizovsky, Levov, Schultz \& Radomislensky (2011), reveló que los participantes con TA tenían más probabilidad de usar un patrón de afrontamiento orientado hacia las emociones ante situaciones estresantes, mientras que la población no clínica tendía a utilizar estrategias centradas en tareas; también encontraron que los participantes con TA usaban significativamente menos el afrontamiento mediante búsqueda de apoyo social y tenían una percepción disminuída de la ayuda recibida de parte de familiares y pares. Un hallazago relevante derivado de este estudio fue la asociación predictiva encontrada entre un deficiente apoyo social y la intensidad de los síntomas depresivos.

Tomando como base la evidencia empírica que confirma que el afrontamiento constituye una variable tanto predictiva como de cambio clínico en un amplio espectro de trastornos y, atendiendo a la escasa investigación que existe en el campo de los TA, el presente estudio plantea la necesidad de explorar con mayor profundidad la manera en que el afrontamiento tanto adaptativo como desadaptativo opera en las variables clínicas asociadas a este trastorno. Así, el objetivo de este estudio es conocer la capacidad predicitiva de las estrategias de afrontamiento en la intensidad sintomatológica pre-tratamiento, por un lado, y en el cambio clínico en pacientes diagnosticados con TA tras recibir una intervención cognitivo conductual, por otro.

\section{Método}

\section{Participantes}

La muestra del estudio estuvo compuesta por 44 pacientes (33 mujeres y 11 hombres) con diagnóstico de TA (APA, 2013), cuya media de edad fue de 29,09 años (DT = 8,95). El 75 $\%$ de participantes contaba con estudios universitarios y el $25 \%$ restante tenían formación básica (primaria y/o secundaria). En cuanto a la distribución de los subtipos clínicos, el 70,5 $\%$ presentaban TA adaptativo mixto (con síntomas depresivos y ansiosos), el 15,9\% cumplían los criterios para el diagnóstico de TA con estado de ánimo depresivo, el 11,4 \% fue diagnosticado con TA con ansiedad y el 2,3 \% presentaba alteración mixta de emociones y comportamiento. 


\section{Medidas}

Medidas para las estrategias de afrontamiento

Escala Multidimensional de Estilos de Afrontamiento (Abreviado) (Brief COPE; Carver, 1997). Es un instrumento que evalúa las estrategias de afrontamiento, tanto efectivas como ineficaces. Consta de 28 preguntas que se responden en una escala Likert de 4 alternativas que van de 0 (»no lo hago nunca») a 3 (»lo hago con mucha frecuencia»). Se compone de 14 sub-escalas (de 2 ítems cada una) que pueden agruparse bajo 4 factores (Morán, Landero \& Gozález, 2010): 1) Afrontamiento cognitivo, que incluye las sub-escalas de afrontamiento activo, planificación, reinterpretación positiva, humor y desconexión (inverso); 2) Afrontamiento mediante apoyo social, que incluye las sub-escalas de apoyo (emocional y social) y desahogo; 3) Bloqueo del afrontamiento (evitación), que agrupa las sub-escalas de negación, auto-distracción, auto-inculpación y uso de sustancias; y 4) Afrontamiento espiritual compuesto únicamente por la sub-escala de religión. La versión española ha demostrado una buena consistencia interna ( $\alpha$ de Cronbach entre 0,60 y 0,90) (Crespo \& Cruzado, 1997).

\section{Medidas para determinar la intensidad sintomatológica}

Inventario de Depresión de Beck-II (BDI-II; Beck, Steer \& Brown, 1996). Es uno de los instrumentos más usados para medir la severidad de los síntomas y cogniciones relacionadas con la depresión. Consta de 21 ítems que se puntúan de 0 a 3, ofreciendo una evaluación sencilla del estado de ánimo deprimido. Es sensible a los cambios en los niveles de depresión, por lo que permite determinar la magnitud del cambio clínico. La versión española del instrumento presenta altos niveles de consistencia interna, tanto para la población general ( $\alpha$ de Cronbach de 0,87) (Sanz, Navarro \& Vázquez, 2003) como clínica (a de Cronbach de 0,89) (Sanz, García-Vera, Espinosa, Fortún \& Vázquez, 2005).

Inventario de Estrés y Pérdida (IEP; Quero, Molés, Mor, Baños \& Botella, 2014). Este instrumento de 17 ítems permite valorar la magnitud tanto de la afectación sintomática como de las alteraciones funcionales que aparecen como consecuencia de vivir una situación estresante. Se trata de una adaptación del Inventario de Duelo Complicado (Prigerson et al., 1995), en la que las expresiones referidas al fallecido fueron sustituidas por otras que aluden a la persona o situación relacionadas con el evento estresante experimentado (p.ej., la pérdida de un trabajo, la pérdida de una pareja, la pérdida de la salud, etc.). El análisis factorial llevado a cabo para el IEP demostró la existencia de un factor único y los resultados preliminares indican que cuenta con un buen coeficiente de consistencia interna en población general y clínica (0,92 y 0,79 , respectivamente), así como una excelentes fiabilidad test-retest $(0,90)$ (Mor, Molés, Rachyla \& Quero, 2015).

\section{Protocolo de intervención}

Todos los participantes recibieron un protocolo de intervención cognitivo-conductual (TCC) para TA (Botella, Baños \& Guillén, 2008), cuyo principal objetivo era reconstruir el significado de las dificultades y los eventos estresantes y aprender de la experiencia vivida. El tratamiento se componía de 6 sesiones (que podían ser ampliadas a 8 en función de las necesidades individuales de cada paciente) de frecuencia semanal y de 90 minutos de duración. En cuanto a los componentes terapéuticos de la intervención, fueron los siguientes: 1) psico- 
educación sobre las reacciones más comunes que se producen en respuesta a un evento estresante, así como sobre el origen y mantenimiento de los TA.; 2) exposición en vivo para superar el malestar vinculado a las situaciones, actividades, lugares o personas relacionadas con el acontecimiento estresante; 3) elaboración del evento estresante que consistía en la evocación y confrontación de las emociones negativas vinculadas a la situación problema con el objetivo de procesar el malestar y encontrarle un significado alternativo más positivo a la situación; 4) prevención de recaídas. Además, se incluyeron estrategias basadas en psicología positiva con el propósito de potenciar la capacidad de resistencia y crecimiento ante la adversidad. Como principal novedad de la intervención, cabe resaltar que se utilizó un sistema flexible de Realidad Virtual (El Mundo de EMMA) durante el procesamiento y elaboración del acontecimiento estresante. Dicho sistema permitió evocar significados y reacciones emocionales asociadas al evento estresante mediante la combinación de distintos elementos simbólicos dentro de un entorno 3D. Una explicación más amplia del protocolo de intervención y del entorno EMMA puede encontrarse en Quero et al. (2017).

\section{Procedimiento}

Todos los participantes fueron voluntarios y firmaron el consentimiento informado para participar en el estudio. La sintomatología clínica se evaluó en el pre y post-tratamiento, así como en seguimientos a los 3, 6 y 12 meses. En cuanto a las estrategias de afrontamiento, éstas sólo se evaluaron entes de la intervención.

\section{Resultados}

En las Tablas 1 y 2 se presentan respectivamente los estadísticos descriptivos de las diferentes escalas de Brief-COPE y de las puntuaciones totales del BDI-II e IEP obtenidas en cada uno de los momentos de evaluación.

Tabla 1

Medias y desviaciones típicas de las 4 escalas de Brief-COPE obtenidas en el pre-tratamiento

\begin{tabular}{lcc}
\hline Estrategias de afrontamiento & \multicolumn{2}{c}{ Pre-trat } \\
\hline Escala de afrontamiento cognitivo & 22,20 & 3,50 \\
Escala de afrontamiento mediante apoyo social & 15,95 & 4,09 \\
Escala de bloqueo & 16,77 & 3,26 \\
Escala espiritual & 3,13 & 1,53 \\
\hline
\end{tabular}


Tabla 2

Medias y desviaciones típicas del BDI-Il e IEP obtenidas en el pre, post y seguimientos de los 3, 6 y 12 meses

\begin{tabular}{ccccccccccc}
\hline & \multicolumn{2}{c}{ Pre-trat } & \multicolumn{2}{c}{ Post-trat } & \multicolumn{2}{c}{ Seg3m } & \multicolumn{2}{c}{ Seg6m } & \multicolumn{2}{c}{ Seg12m } \\
\cline { 2 - 13 } & M & DT & M & DT & M & DT & M & DT & M & DT \\
\hline BDI-II & 23,20 & 9,59 & 6,18 & 5,55 & 6,00 & 5,03 & 3,33 & 3,72 & 4,56 & 6,72 \\
IEP & 36,15 & 11,14 & 15,31 & 9,87 & 12,81 & 9,96 & 11,11 & 7,91 & 6,11 & 6,25 \\
\hline
\end{tabular}

Con el objetivo de evaluar si las estrategias de afrontamiento influían en la intensidad de la sintomatología clínica, se llevó a cabo un análisis de regresión lineal por pasos. Las cuatro escalas de Brief-COPE fueron incluidas como variables independientes (VI) y las puntuaciones del BDI-II e IEP obtenidas en el pre-tratamiento como variables dependientes (VD). Los resultados del análisis revelaron que ninguna de las escalas de Brief-COPE predijo la intensidad de la sintomatología depresiva en pacientes con TA. Sin embargo, en lo relacionado a los síntomas de estrés y pérdida, el análisis identificó las escalas de afrontamiento cognitivo activo y de bloqueo como variables predictoras de la gravedad sintomática $\left(\mathrm{R}^{2}=0,027 ; t=-2,57\right.$; $\rho<, 014$ y $t=3,32 ; \rho<, 001$ respectivamente).

Con el propósito de explorar en qué medida las estrategias de afrontamiento predecían el cambio clínico en los pacientes con TA, se volvió a realizar el análisis de regresión por pasos, utilizando esta vez como variables dependientes los índices de cambio fiable (ICF) de Jacobson y Truax (1991) calculados para el BDI-II y el IEP en cada uno de los momentos de evaluación (ver Tabla 3).

Tabla 3

Cambio clínicamente significativo observado en el BDI-Il y el IEP en el post-tratamiento y seguimientos a 3, 6 y 12 meses

\begin{tabular}{rrrrr}
\hline & \multicolumn{1}{c}{ Post } & Seg3m & Seg6m & Seg12m \\
\hline BDI-II & & & & \\
Recuperados & $61,4 \%$ & $62,5 \%$ & $85,2 \%$ & $77,8 \%$ \\
Mejorados & $2,3 \%$ & $0 \%$ & $0 \%$ & $0 \%$ \\
No cambio & $36,4 \%$ & $37,5 \%$ & $14,8 \%$ & $22,2 \%$ \\
Deteriorados & $0 \%$ & $0 \%$ & $0 \%$ & $0 \%$ \\
\hline IEP & & & & $88,9 \%$ \\
Recuperados & $71,4 \%$ & $81,3 \%$ & $78,6 \%$ & $0 \%$ \\
Mejorados & $2,4 \%$ & $3,1 \%$ & $17,1 \%$ & $0 \%$ \\
No cambio & $21,4 \%$ & $6,3 \%$ & $3,6 \%$ & \\
Deteriorados & $4,8 \%$ & $9,4 \%$ & & \\
\hline
\end{tabular}


En cuanto a la capacidad predictiva de las estrategias de afrontamiento para determinar la magnitud del cambio tras la intervención, en las puntuaciones del BDI-II no se encontró ninguna relación significativa entre los ICF calculados y las 4 escalas del Brief-COPE. Resultados similares fueron hallados para IEP en la evaluación post-tratamiento y en los seguimientos a 3 y 12 meses. No obstante, en el seguimiento de los 6 meses la estrategia de afrontamiento mediante apoyo social resultó ser la única variable predictora del cambio clínico, hallándose una asociación negativa entre este tipo de afrontamiento y la magnitud del cambio en los síntomas de estrés y pérdida $\left(\mathrm{R}^{2}=0,38 ; t=-4,20 ; \rho<, 000\right)$.

\section{Discusión y conclusiones}

El objetivo del presente trabajo fue determinar en qué medida diferentes estrategias de afrontamiento predecían tanto la intensidad de los síntomas como la mejoría post-tratamiento en pacientes con TA.

En lo referente a la gravedad clínica, los resultados mostraron la ausencia de relaciones significativas entre la sintomatología depresiva y las estrategias de afrontamiento. Sin embargo, sí que se observó que las estrategias de afrontamiento influían en la intensidad de la sintomatología de estrés y pérdida. Concretamente, se encontró que el uso de estrategias tales como el afrontamiento activo, la reinterpretación positiva, la planificación o el humor, funcionaba como factor protector ante la adversidad, por lo que los pacientes presentaban una sintomatología menos intensa al vivir una situación estresante. El efecto opuesto era observado al utilizar estrategias de afrontamiento caracterizadas por el uso de la auto-distracción, la autoinculpación o el uso de sustancias. Los resultados mostraron que la sintomatología clínica relacionada con el acontecimiento estresante fue más intensa en personas que con mayor frecuencia utilizaban estas estrategias de afrontamiento relacionadas con la evitación y el bloqueo. Estos resultados van en la misma línea que los hallados en la literatura en relación a los trastornos de estado de ánimo y ansiedad y que sugieren que el uso de estrategias de afrontamiento relacionadas con la autoinculpación, la catastrofización o la rumiación generalmente se asocia a mayor intensidad sintomática, mientras que el efecto contrario se observa al utilizar estrategias tales como la reinterpretación positiva o el crecimiento (Giammanco \& Gitto 2016; Potthoff et al., 2016).

Con respecto al cambio clínico significativo, los resultados mostraron que la mejora tanto de los síntomas depresivos como de los de estrés y pérdida era independiente de las estrategias de afrontamiento iniciales de los pacientes, tanto en las mediciones post-tratamiento como en los seguimientos de los 3 y 12 meses. Únicamente en el seguimiento a medio plazo (6 meses) se encontró que las personas que habían estado afrontando el estrés antes de recibir el TCC mediante la búsqueda de apoyo en su círculo social presentaban una mayor disminución del malestar. Estos resultados sugieren que el programa de tratamiento utilizado en este estudio es igual de eficaz para todos los pacientes, sin importar los recursos de afrontamiento de los que disponen. Estos hallazgos también van en la misma línea que los encontrados en la literatura. Así, Busscher \& Spinhoven (2016) encontraron que las estrategias de afrontamiento de los pacientes con fobia a volar registradas en la línea base no influían en su respuesta al tratamiento.

El papel predictor del uso de apoyo social en la evolución positiva del TA es un hallazgo interesante, sobre todo teniendo en cuenta los resultados encontrados por Ponizovsky, Levov, Schultz \& Radomislensky (2011). Estos autores observaron que los pacientes con TA presentaban dificultades para adoptar estrategias que implicaban buscar apoyo social y manifestaban una valoración deficiente del apoyo emocional que recibían de parte de familiares y pares. 
Sus resultados también arrojaron que un deficiente apoyo social era capaz de predecir mayor intensidad en determinados síntomas del trastorno. Los resultados conjuntos de ambos trabajos ponen de manifiesto que el entrenamiento en el uso y la explotación del apoyo social puede ser de crucial interés para la prevención y el tratamiento de los TA.

Algunas limitaciones de este trabajo deben tenerse en cuenta. En primer lugar, el tamaño de la muestra. En segundo lugar, no se debe olvidar que las estrategias de afrontamiento únicamente se midieron en la fase de pre-tratamiento, por lo que los resultados no aportan información en cuanto a si hubo o no cambio en el tipo de estrategias de afrontamiento utilizado después de recibir el TCC. Esta sin duda podría ser una línea de investigación futura.

En conclusión, los resultados encontrados confirman el carácter predictivo de las estrategias de afrontamiento en la clínica del TA, por lo que sería relevante promover el conocimiento y uso de estrategias adecuadas de afrontamiento a nivel preventivo. Por tanto, proponemos la creación de programas de prevención dirigidos a población no clínica que incluyan dichas estrategias con el propósito de reducir la vulnerabilidad al desarrollo de trastornos emocionales inducidos por el estrés.

\section{Referencias Bibliográficas}

APA. Asociación Americana de Psiquiatría (2013). Manual Diagnóstico y Estadístico de los Trastornos Mentales DSM-5 (5a Ed). Washington: American Psychiatric Association.

Beck, A. T., Steer, R. A. \& Brown, G. (1996). Manual for the Beck Depression Inventory-II. San Antonio, TX: Psychological Corp.

Botella, C., Baños, R. M. \& Guillen, V. (2008). Una propuesta de tratamiento para los trastornos adaptatios: creciendo en la adversidad. En C. Vázquez \& G. Hervás (dirs.), Psicología positiva aplicada (pp. 129-154). Bilbao: Desclee de Brouwer.

Burns, D. D. \& Nolen-Hoeksema, S. (1991). Coping styles, homework compliance, and the effectiveness of cognitive-behavioral therapy. Journal of Consulting and Clinical Psychology, 59(2), 305-311. http://doi.org/10.1037/0022-006X.59.2.305

Busscher, B. \& Spinhoven, P. (2016). Cognitive Coping as a Mechanism of Change in Cognitive-Behavioral Therapy for Fear of Flying: A Longitudinal Study With 3-Year Follow-Up. Journal of Clinical Psychology, 0, 1-12. http://doi.org/10.1002/jclp.22424

Carver, C. S. (1997). You want to measure coping but your protocol's too long: Consider the brief cope. International Journal of Behavioral Medicine, 4, 92-100. http://doi.org/10.1207/ s15327558ijbm0401_6

Crespo, M. \& Cruzado, J. A. (1997). La evaluación del afrontamiento: adaptación española del cuestionario COPE con una muestra de estudiantes universitarios. Análisis y Modificación de Conducta, 23, 797-830.

Folkman, S. (1984). Personal control and stress and coping processes: a theoretical analysis. Journal of Personality and Social Psychology, 46, 839-52. Retrieved from http://www. ncbi.nlm.nih.gov/pubmed/6737195

Giammanco, M. D. \& Gitto, L. (2016). Coping, uncertainty and health-related quality of life as determinants of anxiety and depression on a sample of hospitalized cardiac patients in Southern Italy. Quality of Life Research, 25, 2941-2956. http://doi.org/10.1007/s11136016-1323-5

Hall, P. A, Marshall, J., Mercado, A. \& Tkachuk, G. (2011). Changes in coping style and treatment outcome following motor vehicle accident. Rehabilitation Psychology, 56, 43-51. http://doi.org/10.1037/a0022443 
Holahan, C. J., Moos, R. H., Holahan, C. K. \& Brennan, P. L. (1995). Social support, coping, and depressive symptoms in a late-middle-aged sample of patients reporting cardiac illness. Health Psychology, 14, 152-163. http://doi.org/10.1037/0278-6133.14.2.152

Jacobson, N. S. \& Truax, P. (1991). Clinical significance: A statistical approach to defining meaningful change in psychotherapy research. Journal of Consulting and Clinical Psychology, 59, 12-19.

Kornblith, A. B., Herndon, J. E., Zuckerman, E., Viscoli, C. M., Horwitz, R. I., Cooper, M. R., ... Holland, J. C. (2001). Social support as a buffer to the psychological impact of stressful life events in women with breast cancer. Cancer, 91, 443-454. http://doi.org/10.1002/10970142(20010115)91:2<443::AID-CNCR1020>3.0.CO;2-Z

Lazarus, R. S., Delongis, A., Folkman, S. \& Gruen, R. (1985). Stress and Adaptional Outcomes, The Problem of Confounded Measures. American Psychologist, (7), 770-779. http://doi.org/10.1037/0003-066X.40.7.770

Mor, S., Molés, M., Rachyla, I. \& Quero, S. (2015). Validación española del inventario de estrés y pérdida adaptado del inventario de duelo complicado para los trastornos adaptativos. Póster presentado en las I Jornadas de Recerca per als estudiants de Psicologia de la Facultat de Ciències de la Salut. Universitat Jaume I. Castellón.

Morán, C., Landero, R. \& González, M. T. (2010). COPE-28: Un análisis psicométrico de la versión en Español del Brief COPE. Universitas Psychologica, 9, 543-552.

Moritz, S., Jahns, A. K., Schröder, J., Berger, T., Lincoln, T. M., Klein, J. P. \& Göritz, A. S. (2016). More adaptive versus less maladaptive coping: What is more predictive of symptom severity? Development of a new scale to investigate coping profiles across different psychopathological syndromes. Journal of Affective Disorders, 191, 300-307. http://doi. org/10.1016/j.jad.2015.11.027

Pérez-García, A. M., Oliván, S. \& Bover, R. (2013). Subjective Well-being in Heart Failure Patients: Influence of Coping and Depressive Symptoms. http://doi.org/10.1007/s12529-013 $-9311-4$

Ponizovsky, A. M., Levov, K., Schultz, Y. \& Radomislensky, I. (2011). Attachment Insecurity and Psychological Resources Associated With Adjustment Disorders. American Journal of Orthopsychiatry, 81, 265-276. http://doi.org/10.1111/j.1939-0025.2011.01095.x

Potthoff, S., Garnefski, N., Miklósi, M., Ubbiali, A., Domínguez-Sánchez, F. J., Martins, E. C., ... Kraaij, V. (2016). Cognitive emotion regulation and psychopathology across cultures: A comparison between six European countries. Personality and Individual Differences, 98, 218-224. http://doi.org/10.1016/j.paid.2016.04.022

Prigerson, H. G., Maciejewsku, P. K., Reynolds, C. F., Bierhals, A. J., Newsom, J. T., Fasiczka, A., ... Miller, M. (1995). Inventory of Complicated Grief: A scale to measure maladaptive symptoms of loss. Psychiatry Research, 59, 65-79.

Quero, S., Andreu-Mateu, S., Moragrega, I., Baños, R. M., Molés, M., Nebot, S., \& Botella, C. (2017). Un programa cognitivo-conductual que utiliza la realidad virtual para el tratamiento de los trastornos adaptativos: Una serie de casos. Revista Argentina de Clínica Psicológica, 36, 5-18.

Quero, S., Molés, M., Mor, S., Baños, R. \& Botella, C. (2014). Spanish Validation of the Complicated Grief Inventory adapted for Adjustment Disorders. Poster presentado en ABCT's 48th Annual Convention. Philadelphia.

Sanz, J., García-Vera, M-P., Espinosa, R., Fortún, M. \& Vázquez, C. (2005). Adaptación española del inventario para la depresión de Beck- II (BDI-II): Propiedades psicométricas en pacientes con trastornos psicológicos. Clínica Y Salud, 16, 121-142. 
Sanz, J., Navarro, M. E. \& Vázquez, C. (2003). Adaptación española del Inventario para la Depresión de Beck-II (BDI-II): Propiedades psicométricas en estudiantes universitarios. Análisis y Modificación de Conducta, 29, 239-288.

Savoia, M. G. \& Bernik, M. (2004). Adverse life events and coping skills in panic disorder, 59, 337-340. Retrieved from http://www.scielo.br/pdf/rhc/v59n6/a05v59n6.pdf

Wesner, A. C., Gomes, J. B., Detzel, T., Blaya, C., Manfro, G. G. \& Heldt, E. (2014). Effect of cognitive-behavioral group therapy for panic disorder in changing coping strategies. Comprehensive Psychiatry, 55, 87-92. http://doi.org/10.1016/j.comppsych.2013.06.008 



\title{
Estrategias de búsqueda de empleo en jóvenes: ¿existen diferencias por género?
}

\author{
AÍDA FERNÁNDEZ IZQUIERDO \\ al260801@uji.es \\ M. CARMEN PAstor VerchiLI \\ mpastor@uji.es \\ Eva CifRe GaLlego \\ cifre@uji.es
}

\section{Resumen}

La ruptura de la estabilidad laboral que se ha vivido en la última década ha producido un incremento del desempleo, sobretodo en la población joven, y del interés científico en el ámbito de la búsqueda de empleo. Sin embargo, las investigaciones actuales no han aplicado la perspectiva de género en este campo. Por ello, el objetivo del presente estudio es analizar si los y las jóvenes se enfrentan a la búsqueda de empleo de manera diferencial según su género. Para ello se ha llevado a cabo un estudio longitudinal cualitativo con 28 jóvenes que se encontraban en situación de desempleo desde hacía como mínimo un año. Mediante un estudio de diario, los sujetos describieron durante cinco días laborables consecutivos las actividades relacionadas con la búsqueda de empleo que habían llevado a cabo. Los resultados muestran que, aunque las mujeres han usado menos técnicas por día que los hombres, durante la semana han usado de media más técnicas que los hombres. Además, cabe destacar que varias mujeres llevaron a cabo actividades relacionadas con la formación mientras que ningún hombre lo hizo. En conclusión, los resultados sugieren que existen diferencias de género que han de tenerse en cuenta a la hora de abordar la orientación laboral en jóvenes.

Palabras clave: género, desempleo, jóvenes, estrategias de búsqueda de empleo.

\section{Abstract}

The breakdown of labor stability that has been experienced in the last decade has produced an increase in unemployment, especially in the young population, and of scientific interest in the field of job search. However, current research has not applied the gender perspective in this field. For this reason, the aim of the present study is to analyze if the young people face with the search of employment in a differential way according to their gender. A qualitative longitudinal study was carried out with 28 young people who had been unemployed for at least one year. Through a diary study, the subjects described for five working days in a row the activities related to the job search they had carried out. The results show that, although women have used fewer techniques per day than men, they have used more techniques on average during the week than men. In addition, it 
should be emphasized that several women carried out training-related activities while no men did. In conclusion, the results suggest that there are gender differences that need to be taken into account when tackling youth employment orientation.

Keywords: gender, unemployment, young people, job search strategies.

\section{Introducción}

En el año 2008 comenzó una crisis global que varió el rumbo de todo un país que había pasado varios años de bonanza económica y social. La Encuesta de Población Activa (EPA) muestra que, en cuestión de dos años, desde el segundo trimestre de 2007 al mismo trimestre de 2009, el número de personas paradas en España ascendió de 1.773.200 a 4.139.600, lo que supone un incremento del 233.45 \% (Instituto Nacional de Estadística, 2009). Todos estos cambios y la difícil situación que ha tocado vivir han provocado grandes tensiones en la sociedad y han convertido al empleo en la principal preocupación de los/as españoles/as. Según datos del Centro de Investigaciones Sociológicas (CIS), en diciembre de 2016 el paro preocupaba a un $74,7 \%$ de los/as ciudadanos/as, muy por encima de la siguiente preocupación registrada, la corrupción y el fraude, que puntuaba un 36,7 \%.

Por todos estos cambios en la sociedad, la búsqueda de empleo se ha convertido en un tema de interés tanto popular como científico, pues es más necesaria que nunca la correcta elección y ejecución de las estrategias de búsqueda de empleo debido a la gran cantidad de demandantes de empleo existentes en la actualidad. Debido a ello, el objetivo de nuestra investigación es analizar las técnicas de búsqueda de empleo (TBE) usadas por un grupo de jóvenes teniendo en cuenta la variable género.

A parte del drama personal de todas aquellas personas que perdieron su empleo por las circunstancias y de las inmensas consecuencias que ello conllevó, a nivel político se realizaron determinadas actuaciones que afectaron al país entero; entre ellas las más reseñables fueron los recortes en diferentes servicios públicos y una profunda reforma de la legislación laboral vigente que redujo las indemnizaciones por despido improcedente.

El colectivo más perjudicado por la falta de empleo ha sido el de las personas jóvenes, y así lo muestra la Tabla 1 (Instituto Nacional de Estadística, 2016), referente al último trimestre de 2016. Aunque se puede apreciar que conforme más edad tienen más disminuye la tasa de desempleo, en todas las franjas de edad las personas menores de 30 años presentan una tasa de desempleo mayor que la total.

Tabla 1

Tasas de paro por sexo y grupo de edad

\begin{tabular}{lccc}
\hline & Ambos sexos & Hombres & Mujeres \\
\hline Año/Trimestre & $2016 /$ T4 & $2016 /$ T4 & $2016 /$ T4 \\
Total & 18,63 & 17,22 & 20,25 \\
De 16 a 19 años & 58,67 & 54,62 & 64,02 \\
De 20 a 24 años & 39,83 & 40,29 & 39,31 \\
De 25 a 29 años & 24,05 & 23,16 & 24,99 \\
\hline
\end{tabular}


Teniendo en cuenta este contexto, cabe esperar que las personas jóvenes sientan emociones negativas tales como miedo o ansiedad, sobretodo en el caso de depender del trabajo como fuente principal de ingresos y, por lo tanto, sentir presión financiera. Cuando una persona presenta elevada ansiedad el funcionamiento cognitivo queda bastante obstruido debido a que hay parte de la capacidad mental anclada en sus preocupaciones, y dichas preocupaciones le restan capacidad para hacer otro tipo de actividades (Mestre \& Guil, 2012).

No se puede dejar de lado la variable género a la hora de abordar el desempleo, debido sobretodo a los estereotipos de género tradicionales. Históricamente, según estos estereotipos, se ha asociado a los hombres la figura "proveedora de pan» (breadwinner) y a las mujeres roles de cuidado, lo cual podría llevar a pensar que las emociones negativas derivadas del desempleo podrían ser menores para las mujeres que para los hombres. Sin embargo, en la sociedades modernas estos roles ya no se encuentran tan definidos. La incorporación de la mujer al mercado laboral ha hecho que la definición de feminidad también se asocie con el desarrollo profesional y el mantenimiento de unas condiciones de trabajo dignas. Estos cambios están asimismo asociados a las transformaciones en el modelo tradicional de división sexual del trabajo, que es también incompatible con las necesidades socioeconómicas actuales de las familias en las que ambos sueldos son necesarios y están cada vez más equilibrados.

Sin embargo, a pesar de que los avances sociales de las últimas décadas han dado cierta flexibilidad a los roles de género y han favorecido la consecución de cambios en la estructuración y definición de las funciones de hombres y mujeres en muchos ámbitos sociales, hombres y mujeres siguen siendo socializados en relación a la división sexual del trabajo con normas y expectativas distintas en lo que concierne a los roles profesionales, la presión hacia el éxito en las tareas académicas o laborales, la participación en los trabajos domésticos, el compromiso e interés por las relaciones y cuidado de los demás, la expresión de los sentimientos, etc. (Fineman, 2008).

Dado que es sobre técnicas de búsqueda de empleo en lo que se centra este trabajo, es necesario definir las diferentes clases que hay. Siguiendo a Puchol (2000), las dos principales categorías son la búsqueda activa y la búsqueda pasiva. La búsqueda pasiva se basa en responder a ofertas de trabajo que se encuentran publicadas en diferentes medios, tales como portales web, aplicaciones móviles, prensa diaria, prensa especializada y boletines y revistas de Colegios y Asociaciones profesionales. La búsqueda activa consiste en ofertarse a empresas que no han hecho pública ninguna oferta de empleo. Existen diferentes medios para llevarla a cabo, como por ejemplo:

a) Campaña de e-mailing. Elaborar una carta personalizada sobre uno mismo y enviarla junto con el curículum a un gran número de empresas seleccionadas según el propio criterio de la persona (proximidad a la vivienda, rama profesional, etc).

b) Candidatura espontánea. Investigar acerca de las empresas de nuestro interés que potencialmente puedan ofrecer un puesto de trabajo y enviar una carta personalizada para cada una de ellas junto con el currículum.

c) Promoción directa en la red social cercana. Consiste en preguntar a los conocidos acerca de ofertas de empleo que ellos puedan tener constancia.

d) Promoción on-line. Existen multitud de portales web, redes sociales y aplicaciones en las cuales promocionarse como empleado.

Por todos los indicios sobre un abordaje diferencial en la búsqueda de empleo entre hombres y mujeres, y por el interés de este tema en la actualidad, nuestro objetivo es analizar si los y las jóvenes se enfrentan a la búsqueda de empleo de manera diferencial según su género. 
Nuestra hipótesis es que así será, de modo suponemos que hallaremos diferencias entre las TBE escogidas por mujeres y las escogidas por hombres.

\section{Método}

\section{Muestra}

Los participantes fueron 15 mujeres y 13 hombres con una media de edad de 28 años $(D T=2,16)$, con un rango de edad de 23 a 31 años.

\section{Diseño y procedimiento}

Para este trabajo se ha llevado a cabo un estudio longitudinal cualitativo con jóvenes que se encontraban en situación de desempleo desde hacía como mínimo un año y que llevaban acumulado como mínimo un año de experiencia laboral. Este trabajo ha sido realizado dentro del marco del proyecto de investigación «Calidad de vida en los jóvenes: importancia de la regulación emocional en empleados y desempleados», financiado por la Universitat Jaume I (PI1A2013-06), del grupo de investigación MPAGER (Multidimensional Psychological Approach to Gender and Emotion Regulation).

La muestra se obtuvo gracias a la colaboración con el Servicio Valenciano de Empleo y Formación (SERVEF), que les citó en sus instalaciones, y les propuso su participación en el proyecto a cambio de una formación sobre regulación emocional en el proceso de búsqueda de empleo.

Mediante un estudio de diario, los sujetos describieron durante cinco días laborables consecutivos las actividades relacionadas con la búsqueda de empleo que habían llevado a cabo cada día. Ejemplos de ello serían: búsqueda mediante páginas web de empleo, visita de empresas para entregar $\mathrm{CV}$ y contacto con redes informales.

\section{Resultados}

Los resultados confirman la hipótesis inicial de la diferencia entre hombres y mujeres a la hora de buscar empleo. Hemos encontrado que de media las mujeres han utilizado más TBE que los hombres; concretamente, las mujeres han empleado una media de 5,8 TBE a lo largo de la semana del estudio mientras que los hombres han empleado una media de 5,38. Sin embargo, los días en los que los hombres afirmaban haber buscado empleo solían emplear más de una técnica el mismo día en un $17 \%$ más de ocasiones que las mujeres

Cabe señalar que existen diferencias entre las técnicas empleadas. Las mujeres han buscado ofertas a través de diferentes medios en 2,13 ocasiones como media; sin embargo, los hombres solo lo han hecho en 1,15 ocasiones. No obstante, los hombres han realizado una promoción en la red social cercana con mucha más frecuencia que las mujeres $(0,92$ veces en el caso de los hombres y 0,2 en el de las mujeres), siendo ésta la única técnica de búsqueda activa relatada por los sujetos. Respecto al resto de técnicas, de búsqueda pasiva, no se hallan resultados tan diferentes, aunque salvo en el caso previamente comentado las mujeres siempre han usado un mayor número de TBE. Otra diferencia hallada ha sido el hecho de que varias mujeres han llevado a cabo una o más técnicas de formación mientras que ningún hombre lo ha hecho. 


\section{Discusión y conclusiones}

Los resultados sugieren que las mujeres tienen más empeño y disciplina a la hora de buscar empleo, puesto que en general han empleado TBE en un mayor número de ocasiones que los hombres. Este dato que parece tan simple es muy relevante, dado que parece indicar que ellas están más concienciadas con la realidad de la situación actual y con la relación inversa que hay entre la duración del desempleo y la probabilidad de volver a encontrar trabajo. Además, el hecho de llevar a cabo actividades formativas implica un interés en la mejora del currículum que puede beneficiar a la búsqueda de empleo mediante dos vías: a) ampliando el abanico de ofertas a las que poder aspirar y b) siendo más competitivo que los demás demandantes de empleo que se encuentran en la misma situación.

Que los hombres hayan usado más estrategias por día que las mujeres es un dato que no apoya la hipótesis de partida. Es posible que sugiera que son menos constantes que las mujeres a la hora de la búsqueda pero que cuando deciden buscar se centran en ello y le dedican más tiempo, aunque sería necesario replicar el estudio indagando en los motivos diarios de las personas para buscar o no buscar empleo. Por otra parte, que la única técnica que los hombres han llevado a cabo más que las mujeres haya sido la promoción en la red social cercana también merece un análisis más profundo. Este dato es llamativo además porque estos hombres son los únicos que han realizado búsqueda activa, no hay otra técnica relatada ni por los sujetos hombres ni por las sujetos mujeres que pertenezca a la búsqueda activa. Sería interesante recabar información sobre las redes sociales de los/as sujetos por si hay algún motivo que lleve a los hombres a sentir mayor confianza que las mujeres para preguntar a sus conocidos/as por ofertas de empleo.

Por último, consideramos que habría que utilizar esta información para mejorar la orientación laboral que se ofrece a los y las jóvenes que se encuentran en situación de desempleo o buscando un cambio de trabajo. Nuestros resultados sugieren que es posible que no conozcan todas las técnicas que pueden emplear o que no sean conscientes de la importancia de realizar una buena búsqueda para tener éxito. La información que aporta nuestro estudio es especialmente útil para incidir en las carencias que cada sexo presenta y obtener buenos resultados en el menor tiempo posible.

\section{Referencias bibliográficas}

Barómetro de diciembre 2016. (2016). Centro de Investigaciones Sociológicas, Estudio no 3162. Recuperado de http://www.cis.es/cis/opencm/ES/11_barometros/depositados.jsp

Brody, L. R. \& Hall, J. A. (2000). Gender, emotion, and expression. Handbook of emotions, 2, 338-349.

Fineman, M. A. (2008). The Vulnerable Subject: Anchoring Equality in the Human Condition. Yale Journal of Law and Feminism, 20(1), 1-23. http://doi.org/10.4324/ 9780203848531

Instituto nacional de Estadística (2009). Parados por sexo y grupo de edad. Valores absolutos y porcentajes respecto del total de cada sexo. Recuperado de http://www.ine.es/jaxiT3/ Tabla.htm? $\mathrm{t}=4084 \& \mathrm{~L}=0$

Instituto Nacional de Estadística (2016). Tasas de paro por sexo y grupo de edad. Resultados nacionales. Recuperado de: http://www.ine.es/jaxiT3/Tabla.htm?t=4086

Puchol, L. (2000). La venta de sí mismo. Madrid: Díaz de Santos. 



\title{
Estructura factorial de la Escala de Actitudes hacia la Metodología
}

\author{
ROCIO VIEGAS GARCIA \\ al269450@uji.es \\ SIMONA ROMÁN \\ al260741@uji.es \\ Antonio Caballer Miedes \\ caballer@uji.es
}

\section{Resumen}

En el nuevo Plan de Estudios del Grado en Psicología destaca la incorporación de la asignatura obligatoria de «Métodos y Técnicas de Investigación» en el primer curso. Existen evidencias de la importancia que tiene la actitud en el proceso de enseñanzaaprendizaje de la metodología de investigación en el Grado de Psicología. Las actitudes que presenta el alumnado hacia la estadística impactan en el proceso de enseñanza y aprendizaje, dado que aquello que es congruente con nuestras propias actitudes se aprende mejor que aquello que no concuerda con éstas o que produce mayor desagrado. Por tanto, se considera adecuado diseñar un instrumento válido y fiable para medir las actitudes hacia la metodología en estudiantes del Grado de Psicología. El objetivo de esta investigación es analizar la estructura factorial de un instrumento de medición de actitudes hacia la metodología basado en otras escalas de actitudes hacia la estadística. Se ha aplicado una escala compuesta por 12 ítems a una muestra de 167 participantes de ambos sexos (22,8 \% hombres y $77,2 \%$ mujeres) de primer curso del Grado de Psicología de la Universitat Jaume I. Se ha realizado un Análisis Factorial Exploratorio para detectar la estructura latente de la escala y se han extraído 3 factores: respuesta fisiológica, predisposición positiva y percepción de utilidad, con una fiabilidad alfa de Cronbach de la totalidad de la escala igual a 0,80 . Los resultados muestran que la escala posee las propiedades psicométricas adecuadas para analizar la actitud del alumnado hacia la metodología.

Palabras clave: escala, actitudes, metodología, análisis factorial exploratorio, fiabilidad.

\section{Abstract}

In the Degree in Psychology Curriculum, we can highlight inclusion of compulsory subject «Research Methods» in the first year. There is evidence of the importance of attitude in the process of teaching and learning. Research Methodology Students with positive attitudes toward Methodology are likely to show strong academic performance in statistics courses. The students attitudes to statistics influence the teaching and learning process. What is congruent with our own attitudes is better learned than that which does not agree with them 
or that produces more displeasure. Therefore, we consider appropriate to design a valid and reliable instrument to measure student's attitudes towards Methodology in Psychology Students. The objective of this research is to analyze the dimensional structure of the Scale of Attitudes towards Methodology based on other scales of attitudes toward statistics. We employed a survey to observe student's attitude towards the Methodology with a sample of 167 participants of both sexes (22,8 \% men y $77,2 \%$ woman) from first year of the Degree in Psychology at the Universitat Jaume I. We used Exploratory Factor Analysis to detect the latent structure of the scale were extracted three factors: physiological response, positive bias and perception of usefulness, with a Cronbach's alpha reliability coefficient of 0.80. The results of this study have shown that the Scale has adequate psychometric properties for the study of the attitudes towards the Methodology.

Keywords: scale, attitudes, methodology, exploratory factor analysis, reliability.

\section{Introducción}

La importancia de la Estadística como herramienta de uso para el profesional de la Psicología es un hecho tradicionalmente defendido (Amón, 1980; Nunnally, 1967; Stevens, 1951) e irrefutable en la actualidad. La formación de cualquier profesional de la Psicología debe incluir un bagaje de conocimientos arraigado dentro del campo de la metodologia, para facilitar el acercamiento válido y fiable a la realidad psicológica de los individuos. Las creencias y actitudes del alumnado hacia la estadística podría condicionar la enseñanza y repercutir en el proceso de aprendizaje y rendimiento académico, por lo que se considera necesario profundizar en ciertos aspectos que permiten medir las actitudes hacia la metodología en estudiantes del Grado de Psicología.

Las actitudes son estimaciones generales que se hacen sobre uno mismo, sobre otras personas, objetos o conductas y que cumplen una función relevante para el desarrollo psicologico de los individuos. Para Chacón (2000), la actitud es uno de los descriptores básicos del dominio afectivo que se define como una predisposición evaluativa (positiva o negativa) que determina las intenciones personales e influye en el comportamiento.

Para ampliar brevemente este campo conceptual, las actitudes hacia las matemáticas y la estadística vienen determinadas por tres componentes pedagógicos (Auzmendi, 1992; Flores, 1999; Chacón, 2000): componente cognitivo, componente afectivo o emocional y componente conductual o tendencial. El componente cognitivo abarca las expresiones de pensamiento, concepciones y creencias, acerca de la estadística, incluyendo procesos perceptivos simples y cognitivos complejos. El componente afectivo o emocional queda reflejado por expresiones de sentimiento hacia el objeto actitudinal, recogiendo todas aquellas emociones, sentimientos o reacciones subjetivas positivas/negativas que despiertan la estadística. Por último, el componente conductual o tendencial comprende las expresiones de acción o intención conductual vinculadas con el objeto de referencia, en este caso la estadistica.

Los estudios acerca de las actitudes hacia la estadística recibieron muy poca atención hasta los años 80 cuando varios autores diseñaron algunos instrumentos específicos para medir dichas actitudes (Roberts \& Bilderback, 1980), entre los cuales señalamos el SAS -Statistics Attitude Survey- de Roberts \& Bilderback (1980), el ATS -Attitudes Toward Statistics scale- de Wise (1985), el SATS -Survey of Attitudes Toward Statistics- de Schau, Stevens, Dauphinee \& Del Vecchio (1995), el Students' Attitudes Toward Statistics de Sutarso (1992) y el Quantitative 
Attitudes Questionnaire de Chang (1996). Siguiendo la misma linea de razonamiento, encontramos dos instrumentos elaborados en español: la EAE -Escala de Actitudes hacia la Estadística- de Auzmendi (1991) y un cuestionario más reciente denominado Escala de Actitudes hacia la Estadística de Velandrino \& Parodi (1999).

Desde una perspectiva general, la visión generica de las actitudes hacia la estadistica es compartida por la mayoria de los autores aunque sin llegarse a un acuerdo de unanimidad respeto a las dimensiones más adecuada para describir la complejidad de este ámbito psicológico. No obstante, Wise (1985) y Schau et al. (1995) plantearon dos enfoques muy extendidos en la comunidad científica contemporanea, que desglosamos brevemente a continuación.

Según Wise (1985), cuando se trata de las actitudes del alumnado hacia la estadística se pueden perfilar dos dimensiones distintas: las actitudes hacia la asignatura de estadística en que están matriculados y las actitudes hacia el uso de la estadística en su campo de estudios.

Por otra parte, Schau et al. (1995) destacan cuatro dimensiones en las actitudes hacia la estadística: afectos positivos o negativos en relación a la estadística, competencia cognitiva acerca de los conocimientos y las habilidades intelectuales aplicadas, valores y actitudes sobre la utilidad, relevancia e idoneidad de la estadística en la vida personal y profesional, y por último, las actitudes acerca de la dificultad de la estadística como materia curricular.

Dichas propuestas teoricas han constituido la base referencial para elaborar uno de los cuestionarios de actitudes más usados y replicados, la Escala de Actitudes hacia la Estadística EAE de Auzmendi (1992), un instrumento válido y fiable compuesto por 25 ítems desglosados en cinco dimensiones: utilidad, ansiedad, confianza, agrado y motivación.

En estrecha relación con estos precedentes, esta investigación tiene como objetivo analizar la estructura factorial de un instrumento de medición de actitudes hacia la metodología basado en otras escalas de actitudes hacia la estadística.

\section{Método}

\section{Participantes}

La muestra estuvo formada por 167 estudiantes de ambos sexos de primer curso del Grado de Psicología de la Universitat Jaume I de Castellón. Del total de la muestra, el 22,8 \% son hombres y el 77,2 \% mujeres. La edad media fue de 19,84 años, desviación estándar = $3,93)$. El $63,5 \%$ del alumnado realizó la modalidad de bachillerato de Ciencias y Tecnología, el $27,5 \%$ la de Humanidades y Ciencias Sociales, el 0,6 \% la de Artes y el $8,4 \%$ no habían cursado el bachillerato. Respecto a la opción para estudiar el Grado de Psicología, el 75 \% la eligió como primera opción.

\section{Instrumento}

La escala de actitudes hacia la metodología es un instrumento que se desarrolló tomando como base otros cuestionarios que median actitudes hacía la estadística como la Escala de Actitudes hacia la Estadística de Auzmendi (1992) y la de Tejero-González \& CastroMorera (2011). Está formada por 19 ítems; los 7 primeros permiten recabar información sobre género, edad, grupo de matriculación (mañana o tarde), vía de acceso a la universidad, modalidad de bachillerato, asignaturas cursadas en bachillerato y opción de preferencia para estudiar Psicología. Los siguientes 12 ítems están relacionados con las actitudes hacia la metodología. Los primeros ítems del cuestionario eran de respuesta única y los 12 últimos 
estaban construidos con una escala tipo Likert dónde 1 significaba que se estaba en total desacuerdo con el ítem y 5 en total acuerdo.

La escala evalúa 3 factores compuestos por 4 ítems cada uno:

- Respuesta fisiológica: compuesta por los ítems 5, 6, 7 y 8.

- Predisposición positiva: compuesta por los ítems 1, 2, 3 y 4.

- Percepción de utilidad: compuesta por los ítems 9, 10, 11 y 12.

\section{Procedimiento}

El instrumento fue cumplimentado por los estudiantes de primer curso del Grado de Psicología de la Universitat Jaume I. El pase del cuestionario se realizó de forma colectiva durante las clases de laboratorio de la asignatura de Métodos y Técnicas de Investigación mediante la aplicación de google, Google Drive. Se explicó a los estudiantes cómo debían de cumplimentar el cuestionario a través de la aplicación, se les solicitaba que fueran complementamente sinceros y, se les informó que los datos recogidos serían totalmente confidenciales.

\section{Análisis de datos}

Una vez recogidos los datos, se realizó un análisis factorial exploratorio mediante el método de factorización de eje principal con rotación promax con normalización Kaiser. Además, se obtuvo la varianza total de la escala y las varianzas para cada uno de los tres factores. Para evaluar la pertinencia del análisis factorial se procedió a calcular el estadístico de adecuación de la muestra de Kaiser-Meyer-Olkin (KMO) además de la prueba de esfericidad de Bartlett.

La fiabilidad de la escala se comprobó a través del cáculo del coeficiente Alpha de Cronbach, obteniendo así la fiabilidad total de la escala y la fiabilidad de cada uno de los factores obtenidos.

\section{Resultados}

Se procedió a calcular la media, desviación estandar y la correlación item total o índice de homogeneidad de los ítems de la escala. En la tabla 1 podemos observar los estadísticos de los ítems de la escala. Los resultados indican unos valores adecuados en los índices de homogeneidad, siempre mayores de 0,30. 
Tabla 1

Estadísticos de los ítems de la escala

\begin{tabular}{cccc}
\hline Ítem & Media & Desviación Standar & $\mathrm{R}$ Ítem Total \\
\hline 1 & 3,30 &, 948 &, 515 \\
2 & 3,73 &, 960 &, 431 \\
3 & 3,34 & 1,004 &, 470 \\
4 & 4,05 &, 943 &, 488 \\
5 & 2,50 &, 891 &, 526 \\
6 & 2,81 &, 898 &, 537 \\
7 & 2,90 & 1,066 &, 499 \\
8 & 2,21 & 1,011 &, 353 \\
9 & 4,16 &, 816 &, 510 \\
10 & 4,04 &, 857 &, 373 \\
11 & 4,19 &, 903 &, 372 \\
12 & 3,93 & 1,009 &, 336 \\
\hline
\end{tabular}

Tras el cálculo de los estadísticos se procedió a calcular la pertinencia factorial de la Escala de Actitudes hacía la metodología mediante la prueba de Kaiser-Meyer-Olkin (KMO) $=, 790$ y la prueba de esfericidad de Bartlett $=618,275$ con una $p=, 000$. Posteriormente se realizó un Análisis Factorial Exploratorio (AFE) del cual se extrajeron 3 factores:

- Respuesta fisiológica

- Predisposición positiva

- Percepción de utilidad

La fiabilidad de las puntuaciones obtenidas por los sujetos en la escala queda determinada por el coeficiente Alpha de Cronbach, que nos indica que la escala es fiable tanto de forma global como en cada uno de los factores que se han obtenido (ver Tabla 2). La escala global mostró una alta consistencia interna con un coeficiente alfa de 0,80 , la consistencia de los tres factores osciló entre 0,67 y 0,80 .

Tabla 2

Alpha de Cronbach para cada factor y escala total

\begin{tabular}{ccc}
\hline Factor & Items & Alpha \\
\hline 1 & 4 & 0,80 \\
2 & 4 & 0,80 \\
3 & 4 & 0,67 \\
\hline TOTAL & 12 & 0,80 \\
\hline
\end{tabular}


El número de factores obtenidos en la escala es de tres, que explican el $47 \%$ de de la varianza. En la Tabla 3 podemos observar la saturación de los ítems en cada factor con su respectiva saturación.

Tabla 3

Saturación de los ítems en los factores encontrados

\begin{tabular}{llcl}
\hline & \multicolumn{3}{c}{ Factor } \\
Item & 1 & 2 & 3 \\
\hline 5 &, 779 & & \\
6 &, 699 & & \\
7 &, 692 & & \\
8 &, 659 & & \\
1 & &, 688 & \\
2 & &, 758 &, 559 \\
3 & &, 645 &, 613 \\
4 & &, 772 &, 628 \\
9 & & &, 561 \\
10 & & & \\
11 & & & \\
12 & & & \\
\hline
\end{tabular}

A modo de ejemplo tenemos que el factor 1 está compuesto por ítems como: «El utilizar la metodología es una diversión para mí» (ítem 5) o «Si tuviera oportunidad, me inscribiría en más cursos de metodología de los que son necesarios» (ítem 8).

Por otro lado el factor 2 lo forman ítems como: «La metodología es una de las materías que más temo» (ítem 1) o «Estoy calmado/a y tranquilo/a cuando me enfrento a un problema de metodología» (ítem 3).

Por último tenemos el factor 3, que está formado por ítems como: «La metodología es demasiado teórica como para ser de utilidad práctica para un/a Psicólogo/a» (ítem 10) o «Para el desarrollo profesional de un/a Graduado/a en Psicología considero que existen otras asignaturas más importantes que la metodología» (ítem 12).

\section{Discusión y conclusiones}

Los resultados obtenidos nos indican que la escala posee unas adecuadas propiedades psicométricas para el estudio de la actitud del alumnado hacía la metodología.

La formación previa en estadística y matemáticas parece ser un antecedente bastante consistente de las actitudes y la ansiedad hacia la estadística. Esta relación, sin embargo, tiende a ser más débil que la encontrada entre las actitudes o la ansiedad con indicadores de la percepción que tienen los alumnos acerca de sus capacidades en estas materias (Schutz 
et al., 1998). Por ello proponemos para futuros estudios realizar con una muestra diferente un Análisis Factorial Confirmatorio que permita la validación definitiva de la escala y la búsqueda de aquellos factores (género, edad, modalidad de bachillerato, opción de preferencia del Grado de Psicología y asignaturas cursadas en bachillerato) que puedan determinar la actitud hacía la metodología.

Así mismo, consideramos conveniente incorporar medidas específicas del autoconcepto académico y de autoeficacia en estadística, como las medidas desarrolladas por Finney \& Schraw (2003).

En conclusión, con la creación de esta escala se pretende tener una herramienta importante que permita un mejor desarrollo de la estructuración y planes de estudios de la metodología dentro del Grado de Psicología y que pueda favorecer la mejora en la enseñanza y aprendizaje de la misma.

\section{Referencias bibliográficas}

Amón, J. (1980). Estadística para psicólogos. I. Estadística descriptiva. Madrid: Pirámide.

Auzmendi, E. (1991). Evaluación de las actitudes hacia la estadística en estudiantes universitarios y factores que las determinan. Tesis doctoral no publicada, Universidad de Deusto, Bilbao, España.

Auzmendi, E. (1992). Las actitudes hacia la matemática-estadística en las enseñanzas media y universitaria.Características y medición. Bilbao: Mensajero.

Chacón, I. M. (2000). Matemática emocional: los afectos en el aprendizaje matemático. Madrid: Narcea.

Chang, L. (1996). Quantitative Attitudes Questionnaire: Instrument Development and Validation. Educational and Psychological Measurement, 56(6), 1037-1042.

Finney, S. J. \& Schraw, G. (2003). Self-efficacy beliefs in college statistics courses. Contemporary Educational Psychology, 28, 161-186.

Flores, J. G. (1999). Actitudes hacia la estadística. Incidencia de las variables sexo y formación previa. Revista española de pedagogía, 18(2), 567-589.

Méndez, D. \& Macía, F. (2007). Análisis factorial confirmatorio de la escala de actitudes hacia la estadística. Cuadernos de Neuropsicología,1(3), 337-345.

Nunnally, J. C. (1967). Psychometric theory. New York: McGraw-Hill.

Roberts, D. M. \& Bilderback, E.W. (1980). Reliability and validity of a statistics attitude survey. Educational and Psychological Measurement, 40, 235-238.

Schau, C., Stevens, J., Dauphinee, T. L. \& Del Vecchio, A. (1995). The development and validation of the Survey Attitudes Toward Statistics. Educational and Psychological Measurement, 55(5), 868-875

Schutz, P. A., Drogosz, L. M., White, V. E., \& Distefano, C. (1998). Prior knowledge, attitude, and strategy use in an introduction to statistics course. Learning and Individual Differences, 10(4), 291-308.

Stevens, S. S. (1951). Matemáticas y Medición. USA. Universidad de Harvard.

Sutarso, T (1992, noviembre). Students' Attitudes toward Statistics (STATS). Comunicación Presentada en el Annual Meeting of the Mid-South Educational Research Association, Knoxville, USA.

Tejero-González, C. M. \& Castro-Morera, M. (2011). Validación de la escala de actitudes hacia la estadística en estudiantes españoles deficiencias de la actividad física y del deporte. Revista Colombiana de Estadística,34, 1-14. 
Velandrino, A. P. \& Parodi, L. H. (1999). La escala de actitudes hacia la estadística (EAE): Desarrollo y propiedades psicométricas. Comunicación presentada a la Conferência Internacional Experiências e Expectativas do Ensino da Estatística: Desafios para o Século XXI, Florianópolis, Brasil. [Online: http://www. inf. ufsc. br/cee/comunica/EAE. html].

Wise, S. (1985). The development and validation of a scale measuring attitudes towars statistics. Educational and Psychological Measurement, 45, 401-405. 


\title{
Estudio de la especificidad de vías de insulina/IGF-1 en los patrones de arborización y señalización mediante el uso de virus asociados a adenovirus
}

\author{
ALBERTO RIBES-NAVARRO \\ alribes@uji.es \\ ANA SÁNCHEZ PÉREZ \\ sanchean@med.uji.es
}

\section{Resumen}

Objetivo: Las vías de señalización de insulina y del factor de crecimiento insulínico tipo I (IGF-1) están involucradas en el control de la arborización dendrítica, señalización y crecimiento celular. Varios estudios han demostrado que déficits en estas vías están relacionados con trastornos cognitivos, tales como autismo, y con un elevado riesgo de sufrir demencia. Con tal de elucidar el papel exacto que tiene la señalización de insulina cerebral en las funciones neuronales importantes para los procesos cognitivos, pretendemos silenciar la expresión de los substratos del receptor de insulina; IRS-1 e IRS-2, los cuales son dos componentes clave en la vía de señalización de Insulina-IGF-1. Diseño experimental y Métodos: Con tal de estudiar el papel de IRS-1 e IRS-2 en la arborización dendrítica y en la plasticidad neuronal, generaremos varios virus adeno asociados (AAV) que sean específicos de neurona. Además, estas partículas víricas contendrán específicos shRNA para poder silenciar la expresión de IRS-1 y/o IRS-2, junto con un gen chivato para comprobar la eficiencia de la infección del virus. La generación de estas partículas la hemos realizado siguiendo el método de recombinación Gateway, utilizando un promotor específico de neurona y un shRNA contra IRS-1/IRS-2 junto con EGFP como gen chivato. Resultados y conclusiones: Hemos sido capaces de generar una partícula vírica que consta de un promotor genérico potente (CMV) junto con el gen chivato EGFP. Hemos testado la eficiencia y actividad de esta partícula vírica in vivo en varias regiones del cerebro de rata.

Palabras clave: neurobiotecnología, virus adeno asociado, terapia génica, demencia, señalización de insulina en cerebro.

\section{Abstract}

Objective: The Insulin and insulin-like growth factor 1 (IGF-1) pathway are involved in the normal control of dendritic arborisation, cell signalling and development. Several studies have shown that deficits in these pathways are related to cognitive disorders, such as autism, and an increased risk of dementia. To elucidate the specific role of brain insulin signalling in neuronal functions that are relevant for cognitive processes we want to silence the 
gene expression of the Insulin Receptor Substrate 1, and 2, (IRS-1, IRS-2) two key components of the Insulin-IGF-1 pathway. Research Design and Methods: To study the role of IRS-1 and IRS-2 in dendritic arborisation and neural plasticity we want to generate several adeno-associated viruses (AAV) that are neuron-specific. Besides these virus will contain a specific shRNA to silence both IRS-1 or IRS-2 and a reporter gene in order to track their infection efficiency. To do so, we have followed the Gateway method for viral particles generation, with a neuron-specific promoter and a shRNA against IRS-1/IRS-2 along with the enhanced green fluorescent protein (EGFP) as a reporter gene. Results and conclusions: We have been able to generate a viral particle that contains a strong generic promoter (CMV) along with a reporter gene (EGFP). We have tested the efficiency and activity of this viral particle in vivo in several regions of the rat brain.

Keywords: neurobiotechnology, adeno associated virus, gene therapy, dementia, brain insulin signalling.

\section{Introducción}

Desde que en la década de los 70 se descubriera el receptor de insulina en cerebro (Havrankova, Schmechel, Roth, \& Brownstein, 1978) una gran cantidad de información ha demostrado que donde antes el cerebro era considerado un órgano independiente de la señalización por insulina y su homólogo, el factor de crecimiento insulínico de tipo I (IGF1), ahora se le reconoce como un centro diana de la acción de estos péptidos.

A nivel de sistema nervioso, las vías de señalización de Insulina e IGF-1 están involucradas en una gran variedad de procesos celulares, incluyendo la arborización dendrítica, crecimiento y reparación celular, regulación de las sinapsis y neuroprotección (Bedse, Di Domenico, Serviddio, \& Cassano, 2015; Craft \& Watson, 2004; Hoyer, 2004; Kleinridders, Ferris, Cai, \& Kahn, 2014; Van Dam \& Aleman, 2004). La insulina juega un papel fundamental en la memoria y el aprendizaje(Bedse et al., 2015) y niveles bajos de IGF-1 circulante y de tanto el receptor de Insulina como de IGF-1 pueden provocar problemas cognitivos y emocionales(Steinman \& Mankuta, 2013; Zhao et al., 2004).

Una de las principales enfermedades causadas por una resistencia a insulina es la diabetes tipo 2; se produce una alteración en el metabolismo de glucosa que resulta en hiperglicemia. Además de la diabetes tipo 2, varios estudios han demostrado que una resistencia a insulina en el cerebro está altamente relacionada con enfermedades neurodegenerativas tales como la enfermedad de Alzheimer (AD) (Talbot et al., 2012).

Los receptores de Insulina (IR) y del IGF-1 (IGF-1R) son glicoproteínas. Cada receptor consiste de dos subunidades a y dos subunidades $\beta$ (Duarte, Moreira, \& Oliveira, 2012; Moloney et al., 2010; Schlessinger, 2000; Wada, Yokoo, Yanagita, \& Kobayashi, 2005). Ambos receptores actúan mediante unión a su ligando, el cuál causa una fosforilación en tirosina del receptor. El receptor fosforilado es activo, une y fosforila el substrato del receptor de insulina (IRS) en residuos de tirosina, lo cual inicia varias cascadas de señalización intracelular que resultan en la activación y modificación de diversos procesos celulares (Duarte et al., 2012).

En cerebro hay dos isoformas de IRS mayormente expresadas: IRS-1 e IRS-2(Sesti et al., 2001). Aunque median las mismas vías y, aparentemente tienen la misma función, los IRS pueden controlar diferentes aspectos de la señalización de Insulina / IGF-1. Los modelos de ratones knockout para estas proteínas muestran que la ausencia de IRS-1 en ratones (IRS-1 - / -) causa 
un crecimiento corporal bajo y una diabetes(Tamemoto et al., 1994). Además, los ratones knockout de IRS-2 tienen una reducción del $50 \%$ en la proliferación neuronal, resultando en una disminución de hasta un $40 \%$ en el tamaño del cerebro. A diferencia de los IRS-1 - / -, los ratones IRS-2 - / - desarrollan diabetes temprana en tres meses de edad, debido a una combinación de resistencia a la insulina periférica y la muerte de las células $\beta$ pancreáticas(Lin et al., 2004; Schubert et al., 2003; Withers et al., 1999). Además, la ausencia de IRS-2 causa infertilidad en ratones hembra (Burks et al., 2000).

Hasta ahora, el uso de animales transgénicos ha sido el método principal para estudiar cómo las diferentes isoformas del sustrato del receptor de insulina pueden afectar las vías de señalización de la insulina y el IGF-1. El gran problema asociado al uso de animales transgénicos es que las alteraciones introducidas en el animal pueden afectar a su desarrollo e incluso pueden Ilegan a ser letales (Burks et al., 2000; Fantin, Wang, Lienhard, \& Keller, 2000; Schubert et al., 2003; Tamemoto et al., 1994). Por último, y muy preocupante es el hecho de que puede haber compensaciones durante el desarrollo que lleguen a enmascarar el efecto de las proteínas en estudio. Una alternativa a la generación de animales transgénicos es el uso de vectores virales que sirvan como vehículo para introducir nuevos genes o alterar la expresión de los genes endógenos en sujetos adultos vivos. Esta técnica abre una nueva gama de posibilidades en el campo de la investigación biomédica, debido a su alta especificidad y versatilidad. Varios estudios han demostrado la efectividad del uso de vectores virales en animales (Alonso et al., 2007; Cascallo et al., 2007; Fueyo et al., 2000; King et al., 2008).

\section{Diseño experimental y Métodos}

\section{Construcción y purificación de partículas víricas derivadas de AAV (rAAV)}

Para la generación de partículas víricas derivadas de AAV se utilizó el método Helper Free de CellBiolabs, INC. Este método permite la generación de AAV recombinantes sin la necesidad de utilizar un Adenovirus como ayudante (helper) para la transfección de nuestra partícula, tal y como se hacía en los métodos convencionales. En este sistema, la mayoría de genes (E2A, E4, y VA) necesarios para la generación de AAV vienen suministrados por un plásmido (que se denomina pHelper, el cual no es un Adenovirus sino un plásmido de DNA). Los genes que codifican para las proteínas de la cápside del AAV (cap, que determinará el serotipo del AAV) y para el ciclo de replicación del AAV (rep) son suministrados en el plásmido $p A A V-R C$. Finalmente, la propia célula empaquetadora HEK 293 expresa de forma constitutiva el gen $\mathrm{E} 1$ de adenovirus. El plásmido de expresión, el cual contiene el promotor genérico CMV y el gen EGFP, se co-transfectó junto con el pHelper y el $p A A V-R C$ en las células empaquetadoras HEK 293 utilizando el método de precipitación con fosfato de calcio, con el cual se obtienen altas eficiencias de transfección. Las células se incubaron duran 72 horas a $37^{\circ} \mathrm{C}$ y 5 $\%$ de $\mathrm{CO}_{2}$. Después de la transfección, las células se recogieron y se lisaron con tal de poder extraer la partícula vírica ya formada. La fracción viral se aisló mediante la precipitación con polietilenglicol (PEG) y cloruro de sodio ( $\mathrm{NaCl}$ ) (Guo et al., 2012; Xiaobing, Xiaoyan, Zhijian, Hong, \& Yunde, 2001). La subsiguiente purificación se llevó a cabo por extracción de cloroformo y diálisis en phosphate buffered saline (PBS) durante toda la noche a $4^{\circ} \mathrm{C}$. Las proteínas víricas se detectaron por tinción de nitrato de plata del gel de poliacrilamida al $12 \%$. La fracción vírica se desnaturaliza previamente durante 10 minutos a $75^{\circ} \mathrm{C}$ en SDS $0,1 \%$; posteriormente la muestra se carga en un gel de acrilamida al $12 \%$ y se detecta su peso molecular mediante tinción por nitrato de plata. 


\section{Estudio in vivo de la infectividad de la partícula vírica}

Para comprobar la actividad de la partícula vírica generada, se utilizaron dos ejemplares hembra de rata Wistar adulta entre 250-350 g. Ambas ratas se mantuvieron en un ciclo de $12 \mathrm{~h}$ de luz y con suministro de comida y agua ad libitum. La partícula vírica se introdujo en el hipocampo y el cuerpo estriado del cerebro de las ratas mediante cirugía esterotáctica, la cual utiliza coordenadas para poder localizar estas regiones en el cerebro. Ambas ratas se anestesiaron con isofluorano, previa cirugía. Se hicieron dos experimentos diferentes: En la primera rata se inyectó una cantidad de $0,5 \mu \mathrm{L}$ de rAAV en hipocampo y $2 \mu \mathrm{L}$ en estriado; esta rata se sacrificó a las 2 semanas de la intervención. A la segunda rata se le inyectó un volumen de $0,3 \mu \mathrm{L}$ de rAAV en hipocampo, $2 \mu \mathrm{L}$ en estriado posterior, y $2,5 \mu \mathrm{L}$ en estriado anterior; sacrificio a las 3 semanas de la intervención.

El sacrificio se realizó mediante inyección letal, posteriormente realizamos la perfusión; el animal se fija en paraformaldehído (PFA) al $4 \%$ y se procede a la extracción del cerebro. EI cerebro se crio-protege con una solución de sacarosa al $30 \%$ y se congela. Posteriormente se obtienen cortes de $40 \mu \mathrm{m}$ en el criostato. Estos cortes son posteriormente visualizados al microscopio de fluorescencia para comprobar que se produce señal del EGFP que contenía el virus.

\section{Resultados}

\section{Purificación y titulación del rAVV-CMV-EGFP}

Con tal de comprobar la eficiencia de la co-transfección de nuestros 3 plásmido en las células empaquetadoras HEK 293, éstas se visualizaron al microscopio de fluorescencia (Figura 1). Mediante la visualización al microscopio podemos observar todas aquellas células que hayan incorporado los plásmidos, ya que nuestro plásmido de expresión contiene una secuencia del gen chivato EGFP.

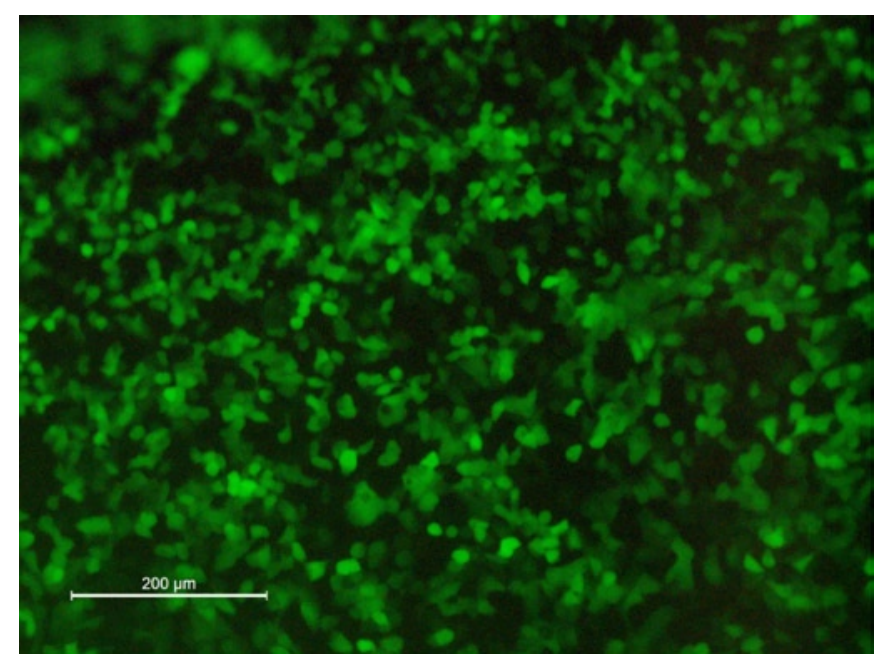

Figura 1. Eficiencia de la co-transfección en HEK 293. Mediante el método del fosfato de calcio se consiguen unas eficiencias de entre el 75 y $80 \%$. Todas aquellas células que presentan fluorescencia son aquellas que han incorporado los plásmido y, por tanto, podrán realizar la encapsulación del virus. Imagen tomada a 10x aumentos 
Una vez comprobada la eficiencia de la transfección, las células se incubaron durante 72 h y posteriormente, se realizó la extracción y purificación de la partícula vírica. La presencia de rAAV en nuestra muestra purificada se comprobó mediante tinción de nitrato de plata en un gel de acrilamida al $12 \%$ (Figura 2).

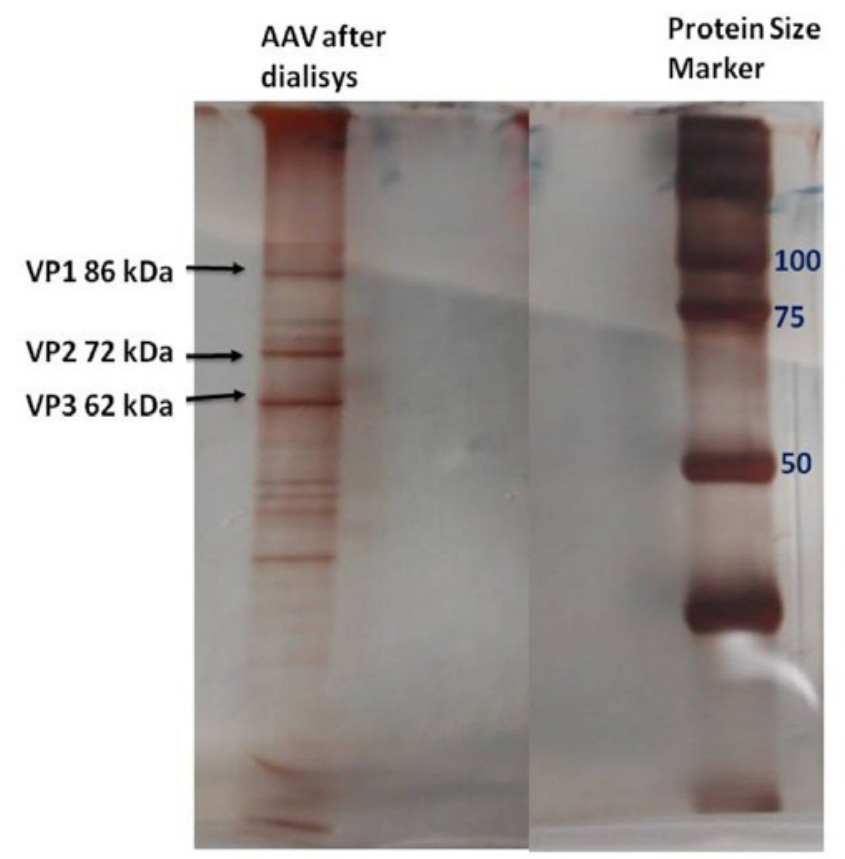

Figura 2. Tinción en nitrato de plata del gel de poliacrilamida al $12 \%$. Las muestras se cargaron en un gel de poliacrilamida para poder detectar el peso molecular de las proteínas características del AAV (VP1, VP2, VP3). El carril de la izquierda muestra nuestro rAAV purificado, mientras que el carril de la derecha es el marcador de peso molecular Precision Plus Protein ${ }^{\mathrm{TM}}$, Kaleidoscope ${ }^{\mathrm{TM}}$ (Bio-Rad)

\section{Test in vivo rAAV}

Una vez titulada nuestra partícula vírica, se introdujo en cerebro de rata mediante cirugía esterotáctica con tal de testar su eficiencia in vivo. Se realizaron dos experimentos diferentes (véase apartado 2 de Métodos). Hasta el momento sólo se han obtenido datos para el primer experimento, en el cual la rata se sacrificó dos semanas después de la intervención. En este experimento se hicieron dos inyecciones, una de $0,5 \mu \mathrm{L}$ de rAAV en hipocampo y otra de $2 \mu \mathrm{L}$ en estriado (Figura 3). 
A
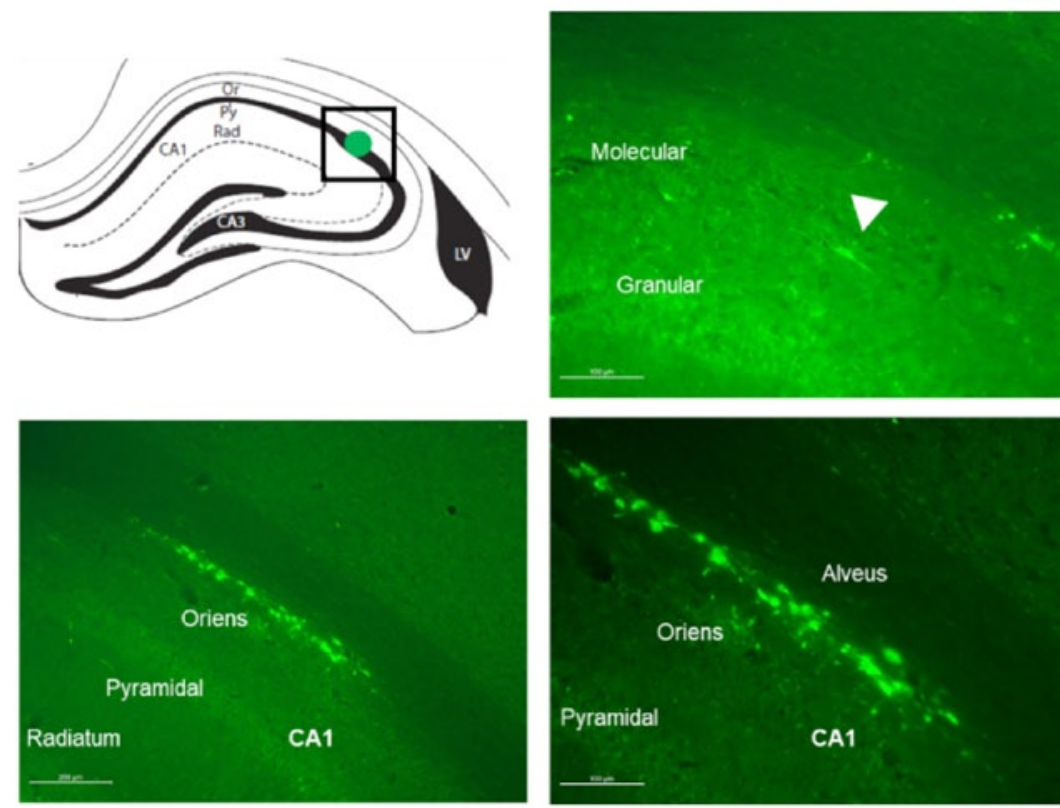

B
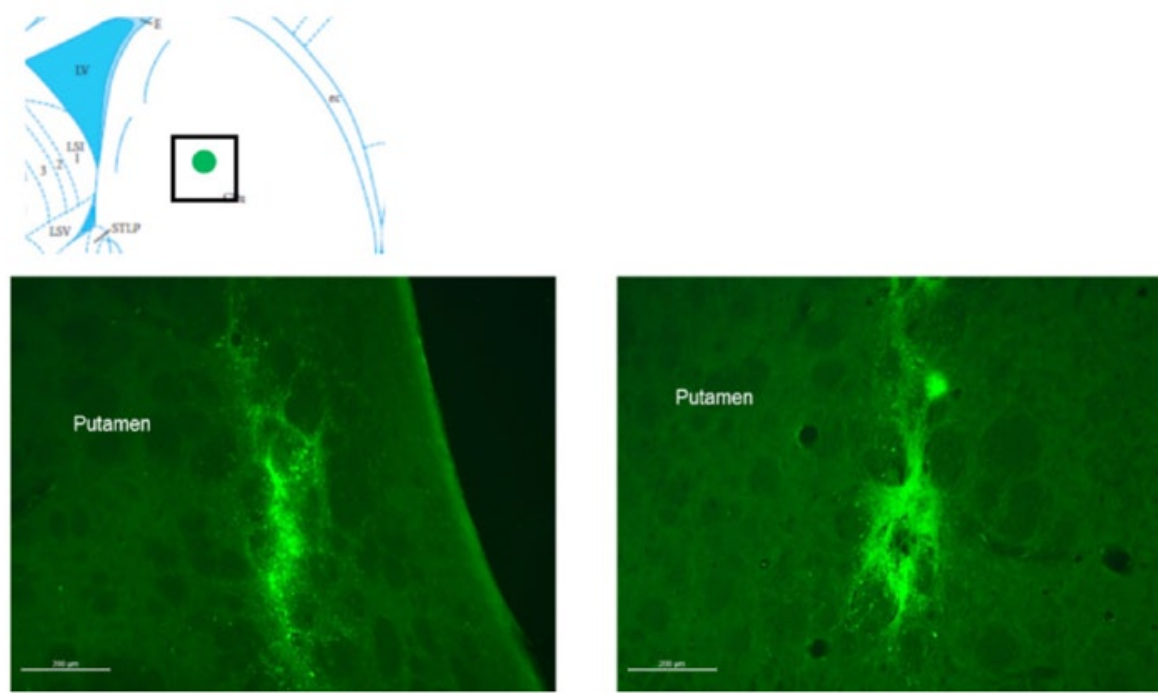

Figura 3. Actividad del rAAV-CMV-EGFP en Hipocampo (A) y Estriado de rata (B). 2 semanas post- inyección los cerebros fueron crio preservados. Posteriormente se hicieron cortes de $40 \mu \mathrm{m}$ para visualización en microscopio de fluorescencia

\section{Discusión y conclusiones}

En este proyecto se ha abordado la posibilidad de generar partículas víricas para el estudio de las vías de señalización de Insulina-IGF-1 como alternativa a la generación de animales transgénicos debido a los problemas que éstos pueden acarrear (Burks et al., 2000; Fantin et al., 2000; Schubert et al., 2003; Tamemoto et al., 1994).

Previa generación de las partículas víricas con las secuencias silenciadoras pertinentes para bloquear la expresión de IRS-1 e IRS-2 se decidió generar una partícula control para poder 
validar el método de generación y purificación de rAAV. Se utilizaron los plásmidos y las células facilitados por CellBiolabs, INC con tal de generar un rAAV control el cual produjera expresión de la proteína fluorescente EGFP bajo el control de un promotor constitutivo (CMV).

Mediante el método de co-transfección con fosfato de calcio y posterior precipitación y purificación del rAAV con PEG/NaCl y subsiguiente diálisis en PBS hemos conseguido generar y obtener la partícula vírica rAAV-CMV-EGFP, la cual es activa in vivo.

Este hallazgo abre una nueva ventana en nuestra investigación, ya que una vez hemos conseguido optimizar el método de generación y purificación de rAAV, podemos empezar a generar diversas partículas víricas bajo el control de promotores específicos de neurona y/o astrocito junto con secuencias silenciadoras tanto para IRS-1 como para IRS-2. De esta forma, podremos estudiar el papel específico que juega cada una de estas moléculas en la señalización de Insulina/IGF-1 en el cerebro.

\section{Referencias bibliográficas}

Alonso, M. M., Cascallo, M., Gomez-Manzano, C., Jiang, H., Bekele, B. N., Perez-Gimenez, A., ... Fueyo, J. (2007). ICOVIR-5 shows E2F1 addiction and potent antiglioma effect in vivo. Cancer Research, 67(17), 8255-8263. https://doi.org/10.1158/0008-5472.CAN-06-4675

Bedse, G., Di Domenico, F., Serviddio, G., \& Cassano, T. (2015). Aberrant insulin signaling in Alzheimer's disease: Current knowledge. Frontiers in Neuroscience, 9(MAY), 1-13. https:// doi.org/10.3389/fnins.2015.00204

Burks, D. J., Font de Mora, J., Schubert, M., Withers, D. J., Myers, M. G., Towery, H. H., ... White, M. F. (2000). IRS-2 pathways integrate female reproduction and energy homeostasis. Nature, 407(6802), 377-82. https://doi.org/10.1038/35030105

Cascallo, M., Alonso, M. M., Rojas, J. J., Perez-Gimenez, A., Fueyo, J., \& Alemany, R. (2007). Systemic toxicity-efficacy profile of ICOVIR-5, a potent and selective oncolytic adenovirus based on the pRB pathway. Molecular Therapy: The Journal of the American Society of Gene Therapy, 15(9), 1607-1615. https://doi.org/10.1038/sj.mt.6300239

Craft, S., \& Watson, G. S. (2004). Insulin and neurodegenerative disease: Shared and specific mechanisms. Lancet Neurology, 3(3), 169-178. https://doi.org/10.1016/S1474-4422(04)00681-7

Duarte, A. I., Moreira, P. I., \& Oliveira, C. R. (2012). Insulin in central nervous system: More than just a peripheral hormone. Journal of Aging Research, 2012. https://doi. org/10.1155/2012/384017

Fantin, V. R., Wang, Q., Lienhard, G. E., \& Keller, S. R. (2000). Mice lacking insulin receptor substrate 4 exhibit mild defects in growth, reproduction, and glucose homeostasis. American Journal of Physiology. Endocrinology and Metabolism, 278(1), E127-33.

Fueyo, J., Gomez-Manzano, C., Alemany, R., Lee, P. S., McDonnell, T. J., Mitlianga, P., ... Kyritsis, a P. (2000). A mutant oncolytic adenovirus targeting the Rb pathway produces antiglioma effect in vivo. Oncogene, 19(June 1999), 2-12. https://doi.org/10.1038/sj. onc. 1203251

Guo, P., El-Gohary, Y., Prasadan, K., Shiota, C., Xiao, X., Wiersch, J., ... Gittes, G. K. (2012). Rapid and simplified purification of recombinant adeno-associated virus. Journal of Virological Methods, 183(2), 139-146. https://doi.org/10.1016/j.jviromet.2012.04.004

Havrankova, J., Schmechel, D., Roth, J., \& Brownstein, M. (1978). Identification of insulin in rat brain. Proceedings of the National Academy of Sciences of the United States of America, 75(11), 5737-41.

Hoyer, S. (2004). Glucose metabolism and insulin receptor signal transduction in Alzheimer disease. European Journal of Pharmacology, 490(1-3), 115-125. https://doi.org/10.1016/j. ejphar.2004.02.049 
King, G. D., Muhammad, a K., Curtin, J. F., Barcia, C., Puntel, M., Liu, C., ... Castro, M. G. (2008). Flt3L and TK gene therapy eradicate multifocal glioma in a syngeneic glioblastoma model. Neuro Oncol, 10(1), 19-31. https://doi.org/10.1215/15228517-2007-045

Kleinridders, A., Ferris, H. a., Cai, W., \& Kahn, C. R. (2014). Insulin action in brain regulates systemic metabolism and brain function. Diabetes, 63(7), 2232-2243. https://doi. org/10.2337/db14-0568

Lin, X., Taguchi, A., Park, S., Kushner, J. a, Li, F., Li, Y., \& White, M. F. (2004). Dysregulation of insulin receptor substrate 2 in beta cells and brain causes obesity and diabetes. J Clin Invest, 114(7), 908-916. https://doi.org/10.1172/JCl200422217.908

Moloney, A. M., Griffin, R. J., Timmons, S., O'Connor, R., Ravid, R., \& O'Neill, C. (2010). Defects in IGF-1 receptor, insulin receptor and IRS-1/2 in Alzheimer's disease indicate possible resistance to IGF-1 and insulin signalling. Neurobiology of Aging, 31(2), 224-243. https:// doi.org/10.1016/j.neurobiolaging.2008.04.002

Schlessinger, J. (2000). Cell Signaling by Receptor Tyrosine Kinases A large group of genes in all eukaryotes encode for. October, 103(2), 211-225. https://doi.org/10.1016/j. cell.2010.06.011

Schubert, M., Brazil, D. P., Burks, D. J., Kushner, J. a, Ye, J., Flint, C. L., ... White, M. F. (2003). Insulin receptor substrate-2 deficiency impairs brain growth and promotes tau phosphorylation. The Journal of Neuroscience: The Official Journal of the Society for Neuroscience, 23(18), 7084-7092. https://doi.org/23/18/7084 [pii]

Sesti, G., Federici, M., Hribal, M. L., Lauro, D., Sbraccia, P., \& Lauro, R. (2001). Defects of the insulin receptor substrate (IRS) system in human metabolic disorders. FASEB Journal, 15, 2099-111. https://doi.org/10.1096/fj.01-0009rev

Steinman, G., \& Mankuta, D. (2013). Insulin-like growth factor and the etiology of autism. Medical Hypotheses, 80(4), 475-480. https://doi.org/10.1016/j.mehy.2013.01.010

Talbot, K., Wang, H., Kazi, H., Han, L., Bakshi, K. P., Stucky, A., ... Arnold, S. E. (2012). Demonstrated brain insulin resistance in alzheimer's disease patients is assocaited with IGF-1 resisitance, IRS-1 dysregulation, and cogntive decline. Journal of Clinical Investigation, 122(4). https://doi.org/10.1172/JCI59903DS1

Tamemoto, H., Kadowaki, T., Tobe, K., Yagi, T., Sakura, H., Hayakawa, T., ... Aizawa, S. (1994). Insulin resistance and growth retardation in mice lacking insulin receptor substrate-1. Nature, 372(6502), 182-186.

Van Dam, P. S., \& Aleman, A. (2004). Insulin-like growth factor-I, cognition and brain aging. European Journal of Pharmacology, 490(1-3), 87-95. https://doi.org/10.1016/j. ejphar.2004.02.047

Wada, A., Yokoo, H., Yanagita, T., \& Kobayashi, H. (2005). New twist on neuronal insulin receptor signaling in health, disease, and therapeutics. Journal of Pharmacological Sciences, 99(2), 128-143. https://doi.org/10.1254/jphs.CRJ05006X

Withers, D. J., Burks, D. J., Towery, H. H., Altamuro, S. L., Flint, C. L., \& White, M. F. (1999). Irs-2 coordinates Igf-1 receptor-mediated beta-cell development and peripheral insulin signalling. Nature Genetics, 23(1), 32-40. https://doi.org/10.1038/12631

Xiaobing, W. U., Xiaoyan, D., Zhijian, W. U., Hong, W., \& Yunde, H. O. U. (2001). NOTES A novel method for purifica- tion of recombinant adeno- associated virus vectors on a large scale. Chinese Science Bulletin, 46(6), 3-6.

Zhao, L., Teter, B., Morihara, T., Lim, G. P., Ambegaokar, S. S., Ubeda, O. J., ... Cole, G. M. (2004). Insulin-Degrading Enzyme as a Downstream Target of Insulin Receptor Signaling Cascade : Implications for Alzheimer 's Disease Intervention. Analyst, The, 24(49), 1112011126. https://doi.org/10.1523/JNEUROSCI.2860-04.2004 


\title{
Estudio de la influencia de la pericial en los procesos de familia
}

\author{
AINHOA RODRÍGUEZ ZAFRA \\ al225863@uji.es \\ LIDÓN VILLANUEVA BADENES \\ bvillanu@uji.es
}

\section{Resumen}

El propósito del presente estudio es comprobar el porcentaje de acuerdo entre las propuestas del Equipo Técnico en materia de Guarda y Custodia y las sentencias emitidas por los Jueces del Juzgado de Primera Instancia, Juzgado de Violencia sobre la Mujer y Audiencia Provincial de una provincia española. Para la elaboración de este estudio se tuvieron en cuenta los expedientes tramitados por parte del Equipo Técnico entre 2014 y 2015 ( $N=100)$ que cumplían con los requisitos previstos para el mismo. Los resultados obtenidos determinan un bajo índice de acuerdo. La propuesta mayoritaria del Equipo Técnico es la Guarda y Custodia Exclusiva, en un $40 \%$, frente a un $55 \%$ de las ocasiones en que las sentencias establecían la Guarda y Custodia Compartida. La guarda y custodia que mayor acuerdo suscita es la repartida (100\%), seguido de la exclusiva (95\%) y por último la compartida (35\%).

Palabras clave: custodia compartida, custodia exclusiva, equipo técnico, pericial.

\section{Abstract}

The purpose of the present study was to check the percentage of agreement between the proposals of the Psychosocial Team in matters of custody and sentences issued by the judges of the Court of first instance, Court of violence on women and Provincial Court of a Spanish province. The files kept by the Psychosocial Team between 2014 and 2015 were considered for the elaboration of this study $(N=100)$, which met the requirements laid down for it. The results determined a low rate of agreement by alpha coefficient. The majority proposal of the Psychosocial Team is the sole custody (40\%), compared to shared custody (55\%). The highest agreement reaches in separated custody (100\%), followed by sole custody, and finally, shared custody (35\%).

Keywords: shared custody, sole custody, psychosocial team, report. 


\section{Introducción}

En España, los divorcios en los que se ven involucrados menores han supuesto un incremento de demandas de informes periciales. Aunque datos del Consejo General del Poder Judicial (CGPJ), indican que en España se ha producido un descenso de los divorcios de un $7,8 \%$ en 2016, la Comunidad Valenciana es una de las dos comunidades con mayor demanda de disolución matrimonial por número de habitantes. Por lo que, en las últimas décadas juristas y psicólogos, han colaborado en mayor medida, integrando ambas ramas del conocimiento procurando el cumplimiento del principio «bonum filii» o «interés superior del menor».

La función pericial en nuestro país, está regulada por el Derecho Civil, en concreto por la Ley de Enjuiciamiento Civil (de ahora en adelante LEC). Tal y como recoge el Art. 335 de la LEC, el informe pericial se realiza durante la fase de obtención de la prueba, siendo un procedimiento legal a disposición del Juez, cuando son requeridos conocimientos especializados o técnicos de los que no tiene por qué poseer. Estos conocimientos técnicos son necesarios en estos supuestos para valorar hechos que no podrían lograrse sin esta figura (Rodríguez-Domínguez \& Jarne-Esparcia, 2015)

La estructura que debe seguir el informe pericial debe ceñirse a las recomendaciones genéricas del American Psychological Association (APA), AACAP (1997) y AFCC (2006) (ArchMarín \& Jarne-Esparcia, 2010), así como de las orientaciones éticas de los colegios profesionales de psicólogos y trabajadores sociales, ya que serán estos los encargados de elaborar el informe psicosocial o pericial.

Para efectuar el informe, en primer lugar, deberá extraer del expediente judicial toda aquella información que considere relevante para tener una primera aproximación a la unidad familiar que debe valorar, obtenido de éste, informes previos de distintas áreas como puede ser Servicios Sociales, Sanidad, etc. Una vez extraída toda esta información, el perito deberá realizar una evaluación individual de cada uno de los cónyuges, una evaluación individual de cada uno de los hijos menores del matrimonio (incluyendo si considera relevante entrevistarse con alguno de los hijos mayores de edad, en el caso de haberlos), evaluar las pautas o patrones filio-parentales observadas o referidas en las entrevistas, así como realizar un análisis de la influencia que puedan estar ejerciendo terceras personas, como pueden ser nuevas parejas de los progenitores en el desarrollo de la dinámica familiar (Ibáñez \& López, 1984).

Estos informes son considerados un medio probatorio. Por ello, en la metodología se deben especificar las fuentes de información a través de las cuales se ha llegado a las conclusiones que se determinan en el informe, así como los argumentos científicos que garanticen esos datos. Además, se deben especificar los instrumentos utilizados y los resultados de las pruebas administradas a cada una de las partes que han sido valoradas durante el proceso.

Hay que tener en cuenta que, el informe psicosocial, exclusivamente es válido para el momento de la exploración, puesto que las circunstancias o contextos de los progenitores, así como del menor pueden variar (Rodríguez-Domínguez \& Jarne-Esparcia, 2015)

Toda la información recogida en el informe, así como lo expuesto en sala, en caso de requerir ratificación, será valorado por el Juez en su toma de decisión a la hora de dictar la sentencia, ya que, será decisión suya el valor o importancia que le otorgue a dicho informe, ya que, como indica el Artículo 348 de la LEC «el tribunal valorará los dictámenes periciales según las reglas de la sana crítica».

En este sentido, un estudio realizado en 2003 por Aguilera \& Zaldívar, señaló que, según los Jueces y Magistrados, la pericial tenía un papel decisivo, e incluso, solo en algunas ocasiones la toma de decisiones difiere entre las recomendaciones del informe y la sentencia emitida. En este sentido, cabe señalar que, estudios realizados con anterioridad sobre acuerdos en decisiones judiciales, destacan los trabajos realizados por Arce, en los que se analiza- 
ba la disparidad de acuerdo entre la decisión del Juez y del jurado popular en procedimientos penales en casos ficticios; oscilando entre el $30 \%$ y el $58 \%$ en unos estudios y entre un 65 $\%$ y un $80 \%$ en otros (Arce, Tortosa \& Alfaro, 2003)

Como recogen en su estudio Arch-Marín \& Jarne-Esparcia (2010), estos informes no están libres de críticas, ya que, si bien es cierto que los test psicológicos aportan objetividad científica para los juristas, los profesionales de la psicología le dotan de un valor moderado, puesto que se está dando uso a instrumentos diseñados para el ámbito clínico en el ámbito judicial.

Los informes psicosociales elaborados en los Juzgados de Familia, así como en los Juzgados de Violencia sobre la Mujer, en procesos de separación, divorcio, modificación de medidas o relaciones y alimentos de hijos extramatrimoniales, responden a una pregunta realizada por el Juez que en resumen consistiría en determinar la idoneidad o mejor alternativa de custodia según el caso y haciendo prevalecer el mayor interés del menor. Lo cual se recoge al final del documento como propuesta de régimen de convivencia.

Los tipos de custodia que recoge la legislación española son exclusiva y compartida, pero, si el Juez considera oportuno, puede establecer para cada uno de los menores un guardador, estableciendo así, una guarda y custodia repartida. Como recogen Fariña \& Arce (2006) en su estudio se trataría de:

La custodia exclusiva (custodia simple en solitario) es la custodia en la que uno de los progenitores (custodio) se hace cargo del/los menores, y el otro progenitor (no custodio) dispone de un régimen de visitas. Por otro lado, la custodia compartida, que supone que ambos progenitores van a responsabilizarse del mismo modo de los menores y ambos son custodios; siendo esta modalidad considerada como la forma ideal tanto para los menores como para los padres.

Además, como recogen diversos estudios (Alameda et al., 1982; Catalán, Andreu, García \& Soler, 2009; Fariña \& Arce, 2006) la imposibilidad de realizar un control o seguimiento de desarrollo de las relaciones en la unidad familiar evaluada cuando ya se ha dictado sentencia, considerándolo un aspecto que preocupa a los profesionales, ya que, la elaboración del informe supone en la mayoría, si no en todos los casos, una modificación de las relaciones intrafamiliares. Además, este seguimiento permitiría la comprobación o constatación del cumplimiento de la sentencia, para así poder adaptarla a las necesidades particulares de cada familia, garantizando así, el interés superior del menor.

Como puede comprobarse en la revisión realizada, el objetivo de este trabajo era determinar el coeficiente de acuerdo entre el Equipo Técnico y el Juez, estableciendo a su vez en qué tipo de guarda y custodia se produce mayor acuerdo y comprobar el porcentaje de custodia propuestas por el Equipo Técnico y las emitidas por el Juez en los procedimientos de separación, divorcio, modificación de medidas y guarda y custodia de hijos no matrimoniales.

Se espera encontrar un alto grado de acuerdo entre el Equipo Técnico y la sentencia judicial. Se cree que la guarda y custodia que más va a proponer el Equipo Técnico es la Guarda y Custodia Exclusiva, y que va a ser esta la que mayor acuerdo suscite entre el Equipo Técnico y la Sentencia.

\section{Método}

En el presente trabajo se analizan los expedientes sentenciados de procedimiento de separación, divorcio contencioso (37\%), modificación de medidas $(47 \%)$ y relaciones y alimentos de hijos e hijas extramatrimoniales (16\%), de los años 2014 y 2015 del Juzgado de Familia y de Violencia sobre la Mujer de una provincia española, de los que el Juez encargado 
solicitaba la realización de un peritaje por parte del Equipo Psicosocial. El total de los expedientes revisados para el presente trabajo fueron 100, de los cuales un $46 \%$ pertenecen a 2014 y un $60 \%$ a 2015. Por lo tanto, para la realización de este trabajo se contó con el informe del Equipo Técnico y con la sentencia definitiva.

De los expedientes seleccionados, se extrajeron datos correspondientes a los progenitores como edad en fecha de la realización del informe, asistencia a unidades de salud mental (si/no), relaciones de pareja actuales sin tener en cuenta si convivían o no en ese momento (si/no), y asistencia a recursos sociales (si/no). Además, se tuvieron en cuenta aspectos sociodemográficos como red de apoyo familiar y social, codificado en número de personas según datos de la entrevista realizada para el informe; distancia geográfica que fue codificado mediante 4 categorías (misma población, distinta población cercana/lejana, distinta comunidad autónoma y distinto país) y cobro de subsidios por desempleo (si/no). En cuanto a los menores se han tenido en cuenta factores como la edad a fecha de la realización del informe teniendo en cuenta años y meses, sexo (masculino/femenino) y deseo respecto al tipo de guarda y custodia (exclusiva/compartida/neutro o indiferente).

\section{Resultados}

Este apartado se encuentra dividido en dos partes. Por un lado, se exponen los resultados descriptivos referentes a los progenitores y a los menores comentados anteriormente. Por otro lado, se ilustran los resultados obtenidos referentes al acuerdo entre el Equipo Técnico y la sentencia emitida por el Juez mediante coeficiente kappa, así como la propuesta mayoritaria por parte del Equipo Técnico y la decisión judicial a través de las pruebas $\square 2$ y proporciones de distribución. Para finalizar el apartado se exponen los porcentajes de guarda y custodia en sentencia de 2014 y 2015.

En la Tabla 1 se representan los datos referidos a los progenitores evaluados para los informes periciales en los procesos en los años 2014 y 2015. La muestra de progenitores estaba compuesta por un total de 89 progenitores con una media de edad de 43,13 años y 89 progenitoras con una media de edad de 38,97 años.

Tabla 1

Características de los progenitores $(N=89)$ y progenitoras $(N=89)$

\begin{tabular}{cccccccc}
\hline & $\begin{array}{c}\text { Edad } \\
\text { media }\end{array}$ & $\begin{array}{c}\text { Unidad } \\
\text { de Salud } \\
\text { Mental }\end{array}$ & $\begin{array}{c}\text { Red } \\
\text { apoyo } \\
\text { familiar }\end{array}$ & $\begin{array}{c}\text { Red } \\
\text { apoyo } \\
\text { social }\end{array}$ & $\begin{array}{c}\text { Nueva } \\
\text { pareja }\end{array}$ & $\begin{array}{c}\text { Prestación o } \\
\text { ayuda social }\end{array}$ & $\begin{array}{c}\text { Recurso } \\
\text { social: } \\
\text { Mujer 24H }\end{array}$ \\
\hline Progenitor & 43,13 & $11,44 \%$ & 4,41 & 4,77 & $60,32 \%$ & $32,40 \%$ & - \\
Progenitora & 38,97 & $14,56 \%$ & 6,52 & 5,32 & $37,44 \%$ & $30,16 \%$ & $30,16 \%$ \\
\hline
\end{tabular}

Como muestra la Tabla 1, las progenitoras asisten en mayor medida a Unidades de Salud mental y disponen de mayor red de apoyo social y familiar, pese a que son más los progenitores que disponen de una nueva pareja. En cuanto a la prestación de subsidio o ayuda social, los porcentajes son muy similares entre ambos. Cerca de un tercio de la población femenina entrevistada acude al Servicio Mujer 24 horas, dado que había informes que derivaban del Juzgado de Violencia sobre la Mujer. 
Por lo que respecta a la proximidad geográfica entre los domicilios en los que residen ambos progenitores, se agruparon en cuatro categorías. Por un lado, los progenitores que residían en la misma localidad (40,56 \%), una segunda categoría que se subdivide en dos, diferenciando localidades cercanas, es decir, a menos de 30 kilómetros $(36,58 \%)$ y localidades lejanas con una distancia superior a 30 kilómetros $(13,72 \%)$. Una tercera división se generó para los progenitores que residían en diferentes comunidades autónomas $(6,24 \%)$ y, por último, una categoría para aquellos progenitores que residían en diferentes países (3\%).

El total de los menores entrevistados para la elaboración del informe contaba con un total de 141 menores, una media de 1,35 hijos por pareja, de los cuales 78 son varones y 63 son mujeres. Presentan una edad media de 9,44 años. En cuanto al deseo del menor, solo se pudo obtener en los casos en los que las edades eran superiores a los 6 años, resultando un total de 85 niños. La opción preferente de guarda y custodia por parte de los menores es la exclusiva $(72,94 \%)$, seguido de la custodia compartida $(12,75 \%)$ y, por último, los menores que se mostraron indiferentes o neutros $(6,84 \%)$.

Por lo que respecta al porcentaje de acuerdo entre la propuesta del Equipo Técnico y la sentencia emitida por el Juez, se llevó a cabo mediante el coeficiente kappa resultando un valor de, 57 con una elevada significación estadística $(p=, 000)$.

En cuanto al análisis de las custodias, como se observa en la Tabla 2, existen diferencias significativas entre la propuesta mayoritaria del Equipo Técnico, que es la custodia Exclusiva $(60 \%)$, frente a la decisión judicial predominante que consiste en la Custodia Compartida (55 \%).

Tabla 2

Distribución en porcentaje y proporción de Guarda y Custodia en Sentencia y propuesta del Equipo Técnico

\begin{tabular}{|c|c|c|c|c|c|c|}
\hline & \multicolumn{2}{|c|}{ Sentencia } & \multicolumn{2}{|c|}{$\begin{array}{c}\text { Propuesta } \\
\text { Equipo Técnico }\end{array}$} & \multirow[t]{2}{*}{ Chi2 } & \multirow[t]{2}{*}{$p$} \\
\hline & Porcentaje & Proporción & Porcentaje & Proporción & & \\
\hline Custodia Exclusiva & $\begin{array}{c}40 \% \\
(N=40)\end{array}$ & 0,4 & $\begin{array}{c}60 \% \\
(N=60)\end{array}$ & 0,6 & & \\
\hline Custodia Compartida & $\begin{array}{c}55 \% \\
(N=55)\end{array}$ & 0,6 & $\begin{array}{c}35 \% \\
(N=35)\end{array}$ & 0,4 & 131,69 & 000 \\
\hline Custodia Repartida & $\begin{array}{c}5 \% \\
(N=5)\end{array}$ & 0,1 & $\begin{array}{c}5 \% \\
(N=5)\end{array}$ & 0,1 & & \\
\hline
\end{tabular}

Además, mediante las proporciones de distribución, se observa un patrón opuesto entre lo que propone el Equipo Técnico de Familia y la custodia que establece el Juez.

Por lo tanto, como podemos observar, la custodia que mayor acuerdo suscita es la custodia repartida, con un porcentaje de acuerdo del $100 \%(\mathrm{~N}=5)$, en segundo lugar, la custodia exclusiva con un $95 \%(\mathrm{~N}=60)$, y por último la custodia compartida con un $60 \%$ de acuerdo $(\mathrm{N}=35)$.

En una distribución de porcentajes, por lo que respecta a 2014 , en un $39,58 \%$ de las ocasiones la custodia fue otorgada a la madre, frente a un $8,33 \%$ de las ocasiones que le fue otorgada al progenitor y un $52,08 \%$ de las ocasiones se falló a favor de la custodia compartida. En cambio, en 2015 , se falló a favor de la madre, estableciendo la custodia exclusiva materna en un $51,5 \%$ de las ocasiones, un $12,5 \%$ la custodia fue otorgada al padre y un $46 \%$ se falló a favor de la custodia compartida. 


\section{Discusión y conclusiones}

El objetivo de este trabajo era el de comprobar el porcentaje de custodia propuestas por el Equipo Técnico y las emitidas por el Juez en los procedimientos de separación, divorcio, modificación de medidas y guarda y custodia de hijos no matrimoniales, establecer en qué tipo de guarda y custodia se produce mayor acuerdo y determinar el coeficiente de acuerdo entre ambos.

La primera de las hipótesis planteadas menciona el hecho de que se espera que la propuesta mayoritaria del Equipo Técnico sea la custodia exclusiva. Esta hipótesis es respaldada por los datos, ya que, es propuesta un $60 \%$, frente a un $40 \%$ de las ocasiones en que lo sentencia el Juez competente. Estos resultados parecen corroborar las conclusiones de Briones \& Villanueva (2014), ya que, los Jueces están sentenciando en mayor medida a favor de la custodia compartida.

En segundo lugar, se hipotetiza que la guarda y custodia que mayor acuerdo suscita es la custodia exclusiva, hipótesis que no respaldan los datos, ya que, es realmente, la guarda y custodia repartida la que supone un acuerdo del $100 \%$ entre la propuesta y la sentencia; quedando en segundo lugar la custodia exclusiva con un $95 \%$ y, por último, la custodia compartida con un $60 \%$.

Por último, se esperaba elevado grado de acuerdo, hipótesis que se desestima, dado que el coeficiente kappa arroja unos resultados de ,57, por lo que, el índice de acuerdo entre ambos es bajo. Por lo tanto, estos resultados no coinciden con la literatura revisada (Arce, Fariña \& Seijo, 2003; Arce, Tortosa \& Alfaro, 2005).

Pese a que la intervención del Equipo Técnico y la sentencia del Juez deben estar encaminadas a defender el mejor interés del menor (Fariña \& Arce, 2006), la falta de acuerdo puede estar producida por la necesidad de mejorar la integración entre los aspectos que motivan la propuesta y la sentencia. El Equipo Técnico se basa mayoritariamente variables psicológicas y sociales, en cambio, la sentencia debe estar motivada fundamentalmente por la legislación vigente, que en ese momento en la Comunidad Valenciana era la Ley 5/2000, actualmente derogada, que establecía como preferente el modelo de convivencia compartida, dado que en el apartado de fundamentos de derecho debe establecer en que artículos se basa para determinar una custodia u otra.

Entre las limitaciones de este estudio, debemos comentar que se limita a un área geográfica concreta y no se centra en unos juzgados especializados en familia, sino que también en el Juzgado de Violencia sobre la Mujer.

Dado el bajo nivel de acuerdo entre el Equipo Técnico y la sentencia judicial, se considera oportuno para futuros estudios realizar una revisión de los casos para comprobar si el establecimiento de un tipo u otro de guarda y custodia sentenciado ha sido favorable o si se ha tenido que solicitar por parte de alguno de los progenitores una modificación de medidas.

\section{Referencias bibliográficas}

Aguilera, G. \& Zaldívar, F. (2003). Opinión de los jueces (derecho penal y de familia) sobre el informe psicológico forense. Anuario de Psicología Jurídica, 13, 95-122.

Alameda, I., González de Lario, B., Ibáñez, V., Jiménez, V., Lillo, J., López, M., \& Salcedo, C. (1982). Los Equipos Técnicos en los Tribunales de Familia. Anuario de Sociología y Psicología Jurídicas, 9, 221-229.

Arce, R., Fariña, F. \& Seijo, D. (2005). Razonamientos judiciales en procesos de separación. Psicothema, 17(1), 57-63. 
Arce, R., Tortosa, F. \& Alfaro, E. (2003). Veredictos y análisis del contenido de las deliberaciones de los Tribunales de Jueces y Jurados en el contexto jurídico español. Psicothema, 15 (1),127-135.

Arch-Marín, M. \& Jarne-Esparcia, A. (2010). Evaluación psicológica en peritaciones de guarda y custodia de los niños. Anuario de Psicología Jurídica, 20, 59-70.

Briones, J. \& Villanueva, L. (2014). Impacto de la ley de custodia compartida de la Comunidad Valenciana en las modificaciones de medida. Anuario de Psicología Jurídica, 24, 43-48.

Catalán, Mª J., Andreu, P., Soler, C., \& García, Mª B. (2009). Motivos alegados por los progenitores varones al solicitar la custodia de sus hijos en los procedimientos contenciosos. Anuario de Psicología Jurídica, 19, 27-41.

Fariña, F. \& Arce, R. (2006). El papel del psicólogo en casos de separación o divorcio. En J. C. sierra, E., M. Jiménez \& G. Buela-Casal. (Ed.), Psicología forense: Manual de técnicas y aplicaciones (pp. 246-271). Madrid, España: Biblioteca Nueva.

Ibáñez, V. \& López R., (1984). La función del psicólogo en los juzgados de familia. Papeles del psicólogo, 16. Recuperado el 22 de mayo, 2017, de: http://www.papelesdelpsicologo.es/ resumen?pii=183

Ley de enjuiciamiento Civil capítulo VI Sección $5^{a}$. Reforma de 2000-vigente desde enero de 2001-Libroll. Título I. Capítulo VI. Sección $5^{\mathrm{a}}$ (artículos 335-352). Recuperado el 22 de mayo, 2017, de: http://noticias.juridicas.com/base_datos/Privado/l1-2000.I2t1.html

Ortuño, P. (1998). Valoración Judicial de la intervención psicológica en procedimientos de familia. En Marrero, J. L. (Ed.), Psicología Jurídica de la Familia (pp. 287-313). Madrid, España: Fundación Universidad-Empresa.

Rodríguez-Domínguez, C. \& Jarne-Esparcia, A. (2015). Valoración del Informe pericial sobre la custodia de menores en sentencias judiciales: Estudio comparativo entre informes privados y oficiales. Escritos de Psicología, 8(3), 11-19. 



\title{
Evaluación de la competencia emocional en niñas/os con trastorno del espectro autista a través de una APP novedosa
}

\author{
LAURA GARCÍA ARNANZ \\ al261148@uji.es \\ Melisa HeRRÁEz Aón \\ al088154@uji.es \\ ESTEFANÍA OLIVARES ROMERO \\ al260343@uji.es \\ Mari Carmen Selma SÁnchez \\ al313090@uji.es \\ CLARA ANDRÉS-ROQUETA \\ candres@uji.es
}

\section{Resumen}

Los niños con Trastornos del Espectro Autista (TEA) tienen dificultades en el área de competencia emocional. Existen distintos instrumentos no estandarizados para evaluar las habilidades emocionales de los niños/as, sin embargo, se suelen centrar en aspectos parciales de esta competencia, descuidan el componente motivador y no suelen estar adaptados a las características específicas de los niños/as con TEA. EI presente estudio pretende demostrar cómo es posible evaluar la competencia emocional en niños/as con TEA mediante una app novedosa de reciente creación por parte de investigadores de la Universitat Jaume I de Castellón: Emocionatest. Esta APP tiene cinco niveles de dificultad basados en hitos de desarrollo emocional típico de 3 a 12 años. Para ello, 33 niños/as con TEA fueron evaluados con la app. Los resultados muestran que los participantes presentan dificultades en la mayoría de niveles que a su edad deberían superar, teniendo mayor dificultad los niños/as más pequeños/as. Además, la app ha permitido conocer el tipo de error cometido, por ejemplo: confusión de emociones con valencias distintas ( $p$. ej. felicidad y enfado) y valencias similares (p. ej. miedo y tristeza). Se concluye que la app Emocionatest es una herramienta que válida para evaluar de una manera efectiva y comprensiva la competencia emocional en niños y niñas con TEA. En futuros trabajos, se validará la herramienta en población infantil con desarrollo típico para ser comparada con la ejecución de niños con TEA, y así poder ser usada por los profesionales del campo psicoeducativo.

Palabras clave: competencia emocional, App, evaluación, trastornos del espectro autista. 


\begin{abstract}
Children with Autism Spectrum Disorders (ASD) have difficulties in the emotional competence area. There are different non-standardized tools for evaluating the emotional abilities of children, however they are usually focused on partial aspects of this competence, they use to forget the motivating component, and they are not usually adapted to the specific characteristics of children with ASD. The present study aims to show how it is possible to evaluate emotional competence in children with ASD through a novel app created by researchers from the Jaume I Unviersity of Castellón: Emocionatest. This APP has five difficulty levels based on typical emotional development milestones from 3 to 12 years. To reach that aim, 33 children with ASD were assessed with the app. Results show that the participants present difficulties at most levels that they are expected to perform successfully according to their age, with smaller children having more difficulty. In addition, the app has made it possible to know the type of mistake committed, for example: confusion of emotions of different valence (e.g., happiness and anger) and similar valence (e.g., fear and sadness). It is concluded that the app Emocionatest is a good tool to make an effective and comprehensive assessment of the emotional competence in children with ASD. In the future, the app will be validated in children with typically development to be compared to the performance of children with ASD, and therefore it could be used by professionals in the psychoeducational field.
\end{abstract}

Keywords: emotional competence, APP, assessment, autistic spectrum disorder.

\title{
Introducción
}

Las emociones son la vía principal de comunicación en la infancia y las relaciones de los niños están vinculadas con la interacción con los demás (Dunn, 2003). Durante la vida, la mayoría de las experiencias y respuestas emocionales están contextualmente conectadas en las relaciones sociales, y las emociones se vuelven significativas gracias a la interacción social con otras personas (Saarni, 1999). Así pues, las emociones son procesos dinámicos que crean y son creados por las relaciones con los demás (Halberstadt, Denham \& Dunsmore, 2001). Por lo tanto, la definición de competencia emocional implica la conciencia de que las emociones están contextualmente insertadas en las interacciones sociales, y la capacidad de regular espontáneamente estas interacciones intercambiando emociones de acuerdo con las necesidades de la situación (Saarni, 1999).

\section{Competencia emocional en niños/as con TEA}

La socialización de las emociones empieza en los primeros tres años de vida, cuando los niños son capaces de enmascarar o reprimir sus emociones. Aproximadamente, se pueden distinguir los siguientes hitos evolutivos (Pons, Harris \& de Rosnay, 2004):

- Entre los 3 y 4 años, los niños son capaces de reconocer y nombrar de las emociones básicas (felicidad, tristeza, miedo y enfado) y empiezan a entender cómo las causas externas afectan las emociones de otros niños. 
- Entre los 3 y 5 años, los niños empiezan a apreciar que las reacciones emocionales de las personas dependen de sus deseos entendiendo, por ejemplo, que dos personas puedan tener sentimientos diferentes en una misma situación porque tienen deseos diferentes.

- Entre los 4 y los 6 años, empiezan a entender las creencias de las personas, si son verdaderas o falsas que determinarán su reacción emocional frente a una situación.

- Entre los 3 y los 6 años, los niños empiezan a entender la relación que existe entre la memoria y las emociones.

- Entre los 6 y 7 años serán capaces de utilizar estrategias para controlar las emociones.

- Finalmente, a los 8 años, los niños empiezan a entender que una persona puede tener múltiples o incluso contradicen las respuestas emocionales de una situación dada. a esta misma edad, éstos empezarán a entender que los sentimientos negativos resultan de una acción moralmente reprensible y que los sentimientos positivos se forman con una acción moralmente loable.

Según el manual diagnóstico y estadístico de los trastornos mentales (DSM-5, American Psychiatric Association, APA, 2013), las personas con Trastorno del Espectro Autista (TEA), se caracterizan por presentar déficits persistentes en comunicación social e interacción social (Criterio A), a lo largo de múltiples contextos que pueden ser actuales o pasados (déficits en reciprocidad socioemocional, déficits en conductas comunicativas no verbales usadas en la interacción social y déficits para desarrollar, mantener y comprender relaciones). Asimismo, también se caracterizan por presentar patrones repetitivos y restringidos de conductas, actividades e intereses (Criterio B), caracterizados por: movimientos motores, uso de objetos o habla estereotipados o repetitivos; insistencia en la igualdad, adherencia inflexible a rutinas o patrones de comportamiento verbal o no verbal ritualizado; intereses altamente restringidos $u$ obsesivos; y hiper- o hipo-reactividad sensorial o interés inusual en aspectos sensoriales del entorno.

En relación a la competencia emocional de los niños con TEA, actualmente existen distintas teorías que podrían explicar la incompetencia en este área: en primer lugar, podría deberse a déficits en Teoría de la Mente (Baron-Cohen, Tager-Flusberg \& Cohen, 1993), a la escasa motivación social (Chevallier, Kohls, Troiani, Brodkin \& Schultz, 2012), o debido a un procesamiento de la información distinto, de manera que son capaces de percibir mejor los detalles y no la globalidad en la Teoría de Coherencia Central (Happé \& Frith, 2006).

A nivel empírico, se sabe que durante la infancia estos niños/as presentan dificultades en el reconocimiento de algunas expresiones faciales, como el miedo o el enfado, así como en el reconocimiento de caras porque son menos atractivas para ellos que para otros niños, y no son capaces de integrar las emociones faciales en una entidad coherente. Además, también se ha demostrado que tienen una limitada capacidad para percibir las emociones ajenas (Begeer, Koot, Rieffe, Terwogt \& Stegge, 2008).

Más tarde en el desarrollo, también se ha demostrado que tienen dificultades en entender y procesar las emociones secundarias o complejas como, por ejemplo: sorpresa, orgullo, culpa y vergüenza, y también para entender las causas externas e internas de estas situaciones emocionales (Golan \& Baren-Cohen, 2006).

Por otro lado, a nivel no verbal, también se ha demostrado que estos niños tienen dificultades para mantener el contacto visual y en expresar facialmente las emociones que sienten, y a nivel verbal, tienen problemas para expresar deseos y ser empáticos (Grossman, Klin, Carter \& Volkmar, 2000). 
La competencia emocional requiere ser consciente de que las emociones están contextualmente añadidas en las interacciones sociales y, a su vez, implica la capacidad de regular espontáneamente estas interacciones intercambiando emociones en conformidad con los requisitos de cada situación (Saarni, 1999). Los niños y niñas, durante su proceso de desarrollo, se ven envueltos en situaciones emocionales más complejas, y por tanto, es importante detectar las causas que produce la pobreza de las interacciones sociales de éstos, para poder prevenir futuras exclusiones del grupo de iguales. Según estudios longitudinales en niños y niñas con TEA, la competencia emocional progresa con el tiempo (p. ej., Dissanayake, Sigman, \& Kasari, 1996).

\section{Evaluación de la competencia emocional mediante nuevas tecnologías}

Durante los últimos años, se han generado diferentes herramientas des del ámbito de las Tecnologías de la Información y la Comunicación (TIC) para niños y niñas con TEA debido a su mayor adaptación a la hora de procesar la información (Andrés-Roqueta, Benedito \& Soria, 2017).

Por ello, un grupo de investigación de la UJI ha diseñado una nueva herramienta digital que permite la evaluación de la competencia emocional, dirigida especialmente a niños y niñas de entre edad comprendidas entre 6 y 12 años con TEA, llamada Emocionatest. Su diseño está basado en el análisis de estudios evolutivos sobre el desarrollo de emociones en población con desarrollo típico y TEA. De esta manera, la intervención permite ser más lúdica y agradable para los niños y las niñas (Andrés-Roqueta et al., 2017).

En la actualidad, la comunidad psico-educativa carece de materiales completos y efectivos para evaluar problemas en el área emocional y los que ya existen no están basados en estudios evolutivos ni adaptados a los niños con TEA.

Por este motivo, se precisa de herramientas que detecten las posibles dificultades de manera cuantitativa (en relación a su edad) y cualitativa (según el tipo de confusiones).

\section{Objetivo e hipótesis}

Por todo ello, en este estudio se pretende probar la APP Emocionatest como medida de evaluación de la competencia emocional en niños con TEA de edad escolar.

En relación con este objetivo, se espera que los participantes con TEA demuestren dificultades en los diferentes niveles de la app, siendo su competencia no típica para su edad. Asimismo, se espera encontrar un patrón en los errores que cometen los participantes, es decir, hallar si se dan o no confusión entre valencias.

\section{Método}

\section{Participantes}

En el presente estudio participaron 33 niños y niñas diagnosticados con TEA (nivel 1 o 2, según el DSM-5, APA, 2013), pertenecientes a centros públicos escolares ordinarios de la provincia de Castellón con Aulas de Comunicación y Lenguaje. 
Los niños y niñas fueron seleccionados con la ayuda de la orientadora y los maestros especialistas de Educación Especial del centro, con edades comprendidas entre los 4 y los 12 años.

\section{Instrumentos}

Como medida de la competencia emocional de los participantes, se empleó la novedosa aplicación móvil Emocionatest (APP nativa), diseñada por profesores de la Universidad Jaume I de Castellón Andrés-Roqueta, Bresó \& Ramos (2015). La app está compuesta de cinco niveles de dificultad (con 12 ítems cada uno) basados en los estudios destacados en el área de desarrollo de la competencia emocional entre los 3 a 12 años (Pons et al., 2004). En cada nivel, los niños y niñas (con la compañía de un adulto que les guía), interactúan con 12 pantallas (ítems) encontrándose con episodios emocionales donde deben decidir qué emoción (o emociones) sienten los protagonistas. Los niveles son los siguientes:

- Nivel 1. Reconocimiento de la expresión facial. El participante debe identificar la emoción correcta, entre seis expresiones faciales presentadas.

- Nivel 2. Construcción de expresiones faciales. El participante debe construir la expresión emocional correcta, indicada mediante una etiqueta de texto, a partir de dos regiones: zona ocular y zona de la boca.

- Nivel 3. Identificación de las emociones en situaciones simples. El participante debe identificar la emoción que siente el personaje principal a partir de la comprensión de la causa de la emoción.

- Nivel 4. Reconocimiento de emociones basadas en las experiencias cognitivas. El participante debe comprender la emoción del protagonista en relación con sus distintas experiencias cognitivas (falsas creencias, olvidos, equivocaciones, etc.). En el 50 $\%$ de las historias, la emoción previa es negativa, y la posterior positiva; y en el $50 \%$ restante, la emoción previa es positiva, y la posterior negativa.

- Nivel 5. Reconocimiento de emociones reales y fingidas. El participante debe entender que puede haber una discrepancia entre las emociones fingidas del protagonista (emoción externa), y lo que realmente se siente (emoción interna). En el $50 \%$ de las historias, la emoción interna es negativa, y la externa positiva o neutra; y en el $50 \%$ restante, la emoción interna es positiva, y la externa negativa.

\section{Procedimiento}

Para llevar a cabo el trabajo, que forma parte de un proyecto de mayor envergadura, se solicitaron los permisos necesarios a Conselleria de Educación de la Comunidad Valenciana. Posteriormente, se presentó el proyecto al centro educativo, y se pidió permiso individual a los padres y madres de los niños/as con TEA.

Finalmente, la app fue administrada individualmente a cada participante en su centro escolar, respetando sus horarios.

Una vez evaluados todos los niños, se accedió a la base de datos donde quedaron registradas las respuestas, y se procedió a su análisis mediante el estadístico SPSS. 


\section{Resultados}

A partir de los datos recogidos se obtuvieron resultados no solo a nivel cuantitativo (número de emociones bien identificadas en cada nivel), sino también a nivel cualitativo (análisis de las confusiones).

\section{Datos cuantitativos: número de errores en cada nivel}

Los datos obtenidos por los participantes en cada nivel, se muestran en la Figura 1. En primer lugar, se puede observar un mayor número de aciertos en el nivel 1 reconocimiento de expresión facial (88 \% de aciertos), posteriormente por el nivel 3 identificación de emociones a partir de situaciones (60\% de aciertos); seguido por el nivel 4, identificación de emociones basadas en experiencias cognitivas ( $46 \%$ de aciertos); seguido por el nivel 2 , construcción de emociones faciales (44 \%); y por último, y con peores resultados, el nivel 5 reconocimiento de emociones escondidas ( $9 \%$ de aciertos).

\section{\% acierto}

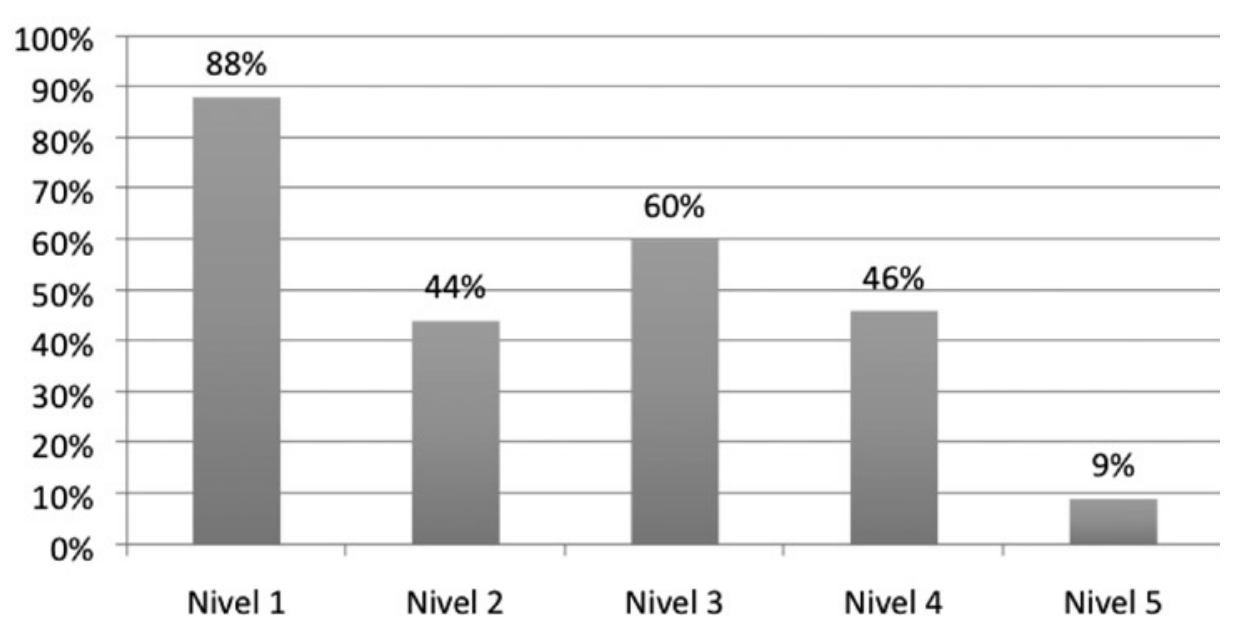

Figura 1. Porcentaje de acierto del grupo TEA en cada uno de los niveles de la APP Emocionatest

\section{Datos cualitativos: tipo de errores en cada nivel}

En los resultados a nivel cualitativo se observó que en el nivel 1 (reconocimiento de la expresión facial), el $57,57 \%$ de los errores se hallan a la hora de identificar correctamente la expresión facial de «miedo». En este ítem se encuentran un $24,24 \%$ de errores frente aciertos, confundiendo, miedo con sorpresa. En el resto de ítems encontramos un porcentaje de error entre el $1,51 \%$ y el $7,57 \%$. No hay diferencias entre los ítems de diferentes géneros.

En el nivel 2, construcción de expresiones faciales, se observó que la mayoría de participantes tuvieron más dificultades para identificar la parte de los ojos $(32,55 \%)$ que las de las bocas en cada emoción (18,48 \%). Concretamente, se halló más dificultad para identificar los 
ojos de "miedo", con un 53,15\% de errores frente aciertos, de ellos el 47,05\% de los errores se confunde con los ojos de «sorpresa». También mostraron dificultad en los ojos de «felicidad» con un $43,75 \%$ de errores; en los ojos de "sorpresa» $37,5 \%$, y en los ojos de "asco» $35,93 \%$. Respecto a las bocas, se encontró más dificultad para identificar la zona de la boca en las emociones de «miedo» $37,5 \%$; y en la boca de «enfado» $31 \%$.

En el nivel 3, identificación de emociones a partir de situaciones simples, se observaron mayor cantidad de errores en las historias donde el protagonista sentía "sorpresa» 33,87 \%; «enfado» 30,64 \%; «miedo» y «asco» $29 \%$ (\% errores frente aciertos). En cuanto al tipo de confusiones, se observa la confusión «sorpresa» con «felicidad» $(20,96 \%$ de las veces); «asco» con «tristeza» $(20,96 \%)$; «enfado» con «tristeza» $(19,35 \%)$; «felicidad» con "sorpresa» $(14.51 \%)$, y «miedo» con «sorpresa» $(12,9 \%)$. Asimismo, como existen dos ítems por cada emoción, se puede observar un efecto de la historia en los ítems de felicidad y de asco, habiendo diferencias en función de la historia: felicidad - patio $(45,16 \%)$ y felicidad-cumpleaños $(35,48 \%)$; así como en las historias de asco, asco-caca $(30,64 \%)$ y asco-chile $(40,32$ $\%)$.

En el nivel 4, identificación de emociones basadas en experiencias cognitivas, se observó un sesgo según si la emoción positiva aparece antes o después. Es decir, en las viñetas que aparece antes una emoción negativa, se hallan un 67,14 \% de aciertos, y por contra, en las que la emoción negativa aparece después, un $60 \%$ de aciertos. Por tanto, se observa que se obtiene menos tasa de error en las emociones positivas que en las negativas. También se observa que en estas historias que implican elementos cognitivos, se confunde "enfado» con «tristeza» en un $41,67 \%$ de las veces, y «tristeza» con "sorpresa» en un $14,76 \%$ de las veces, $\mathrm{y}$ "felicidad» con «sorpresa» en un $11 \%$ de las veces.

Por último, en el nivel 5, reconocimiento de emociones reales y fingidas, se encontró en los participantes bastante dificultad a la hora de encontrar la emoción externa (fingida) de los protagonistas, con solo un $11,96 \%$ de aciertos, la cual se confunde en su mayoría con la interna (es decir, no son capaces de discernir entre emoción real y fingida). Además, respecto la interna (real), también se encontró un índice de aciertos bajo (17,74 \%). En concreto, se encuentra mayor dificultad en historias donde los protagonistas sienten realmente emociones positivas, donde se halló únicamente un $16,93 \%$ de aciertos en emociones internas y un 7,66 $\%$ de emociones externas. En historias donde se aparentan emociones negativas, se encontró un $18,14 \%$ de aciertos en emociones internas y un $14,11 \%$ en emociones externas.

A rasgos generales, no se observan diferencias entre los ítems de diferentes géneros.

\section{Discusión y conclusiones}

En este estudio se pretendía probar la app Emocionatest como medida de evaluación de la competencia emocional en niños con TEA. En este sentido, se esperaba que los participantes con TEA demostrasen dificultades en los diferentes niveles de la app de acuerdo a su edad. Además, se esperaba encontrar tipos de errores que incluyeran la confusión entre valencias.

En primer lugar, cabe decir que se cumple la primera hipótesis, pues la mayoría de participantes han demostrado dificultades de acuerdo a su edad en los distintos niveles. En este sentido, cabe señalar que los datos obtenidos de las frecuencias de respuesta de los 33 participantes con TEA, demuestran que no todos los niveles de la app no se corresponden con el nivel de dificultad esperado, es decir, no se presentan en orden progresivo. Concretamente, se encontró que el nivel 2, componer expresiones faciales, resultó ser más difícil para los/as niños/as TEA de lo estipulado en un principio, quedando en la cuarta posición, justo por delante del último nivel. 
En segundo lugar, sobre el tipo de error cometido en cada nivel, se concluyen distintos puntos. A partir de los resultados cualitativos obtenidos en el nivel 1, se concluye que el reconocimiento de la expresión facial de miedo es la que más dificultad genera, confundiéndose con la expresión de sorpresa. Mediante los resultados obtenidos en el nivel 2, construcción de expresiones faciales, se puede llegar a una conclusión similar, el reconocimiento de la región ocular apropiada para expresar miedo se confunde nuevamente con la de sorpresa, y la región de la boca para la expresión de miedo muestra alta dificultad para identificarse correctamente. A su vez, los resultados del nivel 2 también presentan quela expresión de sorpresa vuelve a verse comprometida, en esta ocasión, con la expresión de felicidad.

De forma general, en el nivel 2 se observó que los/as niños/as TEA tienen dificultad para formar una expresión facial, sobre todo a la hora de reconocer la parte de la expresión emocional correspondiente a la región ocular. Este resultado es congruente con las investigaciones que apoyan la idea de que los/as niños/as con TEA perciben de forma fraccionada y muestran déficit en la integración de esas partes para concebirlas como un todo (Happé \& Frith, 2006).

En cuanto a la identificación de emociones a partir de situaciones simples, los datos han demostrado que existe bastante dificultad para distinguir cuando un protagonista siente la emoción de enfado de la de tristeza a partir de la comprensión de la historia (causas). Esta confusión también se da en las historias de felicidad (confundida con sorpresa) y sorpresa (confundida de el miedo). Estos datos probablemente estén revelando aspectos vivenciales de estos niños, puesto que en las situaciones donde un niño debe estar enfadado (como por ejemplo en la APP, cuando estás haciendo una fila y se cuelan), estos niños eligen "triste», demostrando una carencia de asertividad para hacer frente a la situación (enfadarse con esa persona), y optando por una opción mucho más infantil (llorar, estar triste).

Además, en este nivel, también ha podido verse un efecto derivado de la historia, que revela que existe más facilidad para responder correctamente ante la presencia de las emociones de felicidad y asco.

Según los resultados obtenidos del nivel de identificación de emociones basadas en experiencias cognitivas (olvidos, falsas creencias, etc.), demuestran que detectar la transición de una emoción a otra depende tanto de la situación como del contexto, pero sobre todo de la valencia de la emoción (positiva-negativa). Concretamente, se ha demostrado que el hecho de que la primera emoción sea positiva y la que acaece después sea negativa, es un elemento facilitador. Además, se observó que las emociones positivas se identifican más exitosamente que las negativas, y que las confusiones entre una emoción y otra suceden mayoritariamente con las emociones de enfado y tristeza.

En relación con el nivel más complejo, se detecta una gran dificultad en la tarea de reconocer cuando el protagonista de la historia debe fingir una emoción (emoción externa), distinta de la que se siente realmente (emoción interna). Así, en el nivel 5 , reconocimiento de emociones reales y fingidas, se observa que los/as niños/as no comprenden esta incongruencia, por ello les resulta muy difícil distinguir entre una y otra.

Finalmente, cabe destacar que no se apreció diferencia significativa entre el género del personaje de los diferentes ítems en ningún nivel.

Una vez comentados los resultados, se puede decir que se cumplen las hipótesis planteadas al inicio, encontrándose un gran número de errores entre los participantes, y distintas confusiones entre emociones de la misma valencia, pero también de distinta.

Con todo esto presente, actualmente se trabaja para validar la aplicación Emocionatest en niños y niñas con otras dificultades del desarrollo (Trastornos de la Comunicación, Trastornos por Déficit de Atención e Hiperactividad, entre otros), siendo los datos recogidos una guía sólida que dar pistas de las directrices por las que los profesionales deben orientarse para diseñar la intervención educativa. La ampliación de la muestra clínica, tanto con niños y niñas 
con dificultades como con desarrollo típico, darán como resultado la validación de la app, dotando a toda la red de profesionales tanto del ámbito educativo como sanitario, de una nueva herramienta útil y actual, adaptada a los nuevos tiempos de la tecnología y de fácil administración, para la evaluación de la competencia emocional en niñas/os con TEA.

\section{Agradecimientos}

Las autoras de este artículo quieren agradecer su participación a los Centros Educativos que participaron de este trabajo, así como la ayuda financiada otorgada por el proyecto Herramienta para la Evaluación en la competencia emocional de niños y niñas con Trastorno del Espectro Autista (Código: VAL-2004-04), subvencionado por la Acción 4.1. del Plan de Promoción de la Investigación 2014 - Convocatoria StartUJI de Valorización de Resultados de Investigación.

\section{Referencias bibliográficas}

American Psychiatric Association (2013). Diagnostic and statistical manual of mental disorders (5th ed., TR). Washington, DC: American Psychiatric Association.

Andrés-Roqueta, C., Bresó, E., \& Ramos, F. (2015). Emotional competence assessment in children with ASD by using a mobile app. EDULEARN15, Proceedings, 6180-6187.

Andrés-Roqueta, C., Benedito, I. \& Soria-Izquierdo, E. (2017). Uso de aplicaciones móviles para la evaluación de la comprensión emocional en niños y niñas con dificultades del desarrollo. Revista de Psicología y Educación, 12(1), 7-18

Baron-Cohen, S., Tager-Flusberg, H., \& Cohen, D. J. (1993). Understanding other minds: Perspectives from autism. Oxford: Oxford University Press.

Begeer, S., Koot, H. M., Rieffe, C., Terwogt, M. M. \& Stegge, H. (2008). Emotional competence in children with autism: Diagnostic criteria and empirical evidence. Developmental Review, 28(3), 342-369.

Chevallier, C., Kohls, G., Troiani, V., Brodkin, E. S. \& Schultz, R. T. (2012). The social motivation theory of autism. Trends in Cognitive Sciences, 16(4), 231-239. doi: 10.1016/j. tics.2012.02.007

Dissanayake, C., Sigman, M. \& Kasari, C. (1996). Long-term stability of individual differences in the emotional responsiveness of children with autism. Journal of Child Psychology and Psychiatry, 37, 461-467

Dunn, J. (2003). Emotional development in early childhood: A social relationship perspective. In R. Davidson, H. H. Goldsmith \& K. Scherer (Eds.), The handbook of affective science (pp. 332-346). Oxford, UK: Oxford University Press

Golan, O. \& Baren-Cohen, S. (2006). Systemizing empathy: teaching adults with Asperger syndrome and high functioning autism to recognise complex emotions using interactive media. Developmental Psychopathology 18, 589-615.

Grossman, J. B., Klin, A., Carter, A. S., \& Volkmar, F. R. (2000). Verbal bias in recognition of facial emotions in children with Asperger syndrome. Journal of Child Psychology and Psychiatry, 41, 369-379.

Halberstadt, A. G., Denham, S. A.,\& Dunsmore, J. C. (2001). Affective social competence. Social Development, 10, 79-119. 
Happé, F. \& Frith, U. (2006). The weak coherence account: detail-focused cognitive style in autism spectrum disorders. Journal of Autism and Developmental Disorders, 36(1), 5-25.

Pons, F., Harris, P., \& de Rosnay, M. (2004). Emotion comprehension between 3 and 11 years: Developmental periods and hierarchical organizations. European Journal of Developmental Psychology,1(2),127-152.

Saarni, C. (1999). The development of emotional competence. New York: Guilford Press. 


\title{
Experiencia, percepción y expectativas de adolescentes absentistas gitanos
}

\author{
LAURA BITRIÁN FERRER \\ al363204@uji.es \\ Ma RaQuel Agost FeliP \\ ragost@uji.es
}

\section{Resumen}

El abandono escolar temprano entre los jóvenes de etnia gitana se sitúa en el $63,7 \%$ frente al $25 \%$ de la población general (FSG, 2013), dándose habitualmente en jóvenes de entre 15 y 16 años. El presente trabajo surge ante dicha problemática y tiene como objetivo conocer las experiencias, percepciones y expectativas de los adolescentes absentistas gitanos ante la escolarización Secundaria Obligatoria. Para ello, se ha utilizado una metodología cualitativa, mediante la técnica de grupos de discusión, con una muestra de 7 adolescentes absentistas gitanos de entre 12 y 15 años. Se han diseñado dos grupos homogéneos (chicas y chicos) porque siguiendo las recomendaciones de la OMS (2006) para grupos de discusión, se obtienen resultados más fiables. Para el análisis se ha utilizado el programa MAXQDA 12: Qualitative Data Analysis Software. El guión de la entrevista, se ha realizado a partir de estudios precedentes (Bhopal, 2008 \& 2011; FSG, 2002) y recoge las siguientes variables: acceso a la escuela, adquisición de normas, rutinas y ritmos escolares, interacción social en el aula, logros escolares y relación familia-escuela. Los resultados obtenidos nos indican cuales son los factores que inciden en la ausencia reiterada y abandono de la escolarización obligatoria de los adolescentes de etnia gitana. En el caso de la muestra estudiada estos factores son: el racismo y la discriminación percibida, la desmotivación por seguir estudiando y la idea de seguir con los roles familiares tradicionales.

Palabras clave: absentismo, gitanos, escolarización, adolescentes, familia.

\section{Abstract}

Early school dropout among young roma is $63.7 \%$ whereas $25 \%$ of those who are considered as a "general population» (FSG, 2013) in young people aged 15 to 16 years. The present study face this problem and aims to know the experiences, perceptions and expectations of roma-travellers absentee adolescents in the face of secondary schooling. For this purpose, a qualitative methodology has been used, through the technique of discussion groups, with a sample of 7 abstainers's gypsies between 12 and 15 years old. Two homogeneous groups (boy's group and girl's group) have been designed, following the recommendations of OMS (2006) for discussion groups, which seems to find more reliable results. The analysis has been done with the MAXQDA 12 
program: Software of analysis of qualitative data. The interview script is based on previous studies (Bhopal, 2008 \& 2011, FSG, 2002) and includes the following variables: access to school, adquisition of rules, school's routines and rhythms, social interaction in the classroom, school achievement and family-school relationship. The results obtained indicate which ones are the factors that influence the repeated absence and abandonment of compulsory schooling of Roma teenagers. In the sample studied these factors are: racism and perceived discrimination, the lack of motivation to continue studying and the idea of continuing with traditional family roles.

Keywords: absenteims, gypsy-roma, schooling, teenagers, family.

\section{Introducción}

Según la Fundación Secretariado Gitano (FSG, 2013) existe una gran brecha educativa en los jóvenes gitanos que dificulta la posibilidad de completar los estudios obligatorios. El fenómeno del absentismo, se ha convertido en una preocupación compartida por las administraciones e instituciones con responsabilidad en esta materia, de allí que la Estrategia Nacional para la Inclusión Social de la Población Gitana 2010-2020 pretenda «incrementar la finalización de la educación secundaria obligatoria y éxito académico del alumnado gitano en esta etapa» (Ministerio de Sanidad, Servicios Sociales e Igualdad, 2014, p. 25).

Se podría definir absentismo escolar como «la no asistencia regular e injustificada a los centros educativos del alumnado escolarizado en la etapa de escolarización obligatoria» (Vázquez, 2013, p. 3). Martinez, Jimenez \& Alfageme (2011a) señalan que un factor que incide en el absentismo escolar es la falta de recursos socioeconómicos de las familias (como se cita en Grañeras, 2012), que obliga a los hijos e hijas a ayudar a sus padres, ya sea cuidando a sus hermanos, en el caso de las chicas o participando en el desarrollo de la economía familiar. Además, el racismo, las actitudes de los profesores y las experiencias de familiares (Bhopal, 2011b) son factores que influyen igualmente en la falta de asistencia de este colectivo. De hecho, las investigaciones han demostrado que los gitanos experimentan racismo en las escuelas (Bhopal 2009, 2011; Derrington \& Kendall, 2004) y en gran medida, ejercida por los profesores.

En España, son numerosos los autores (García 2003; Llevot \& Bernad 2015; Garreta 2015) que defienden la participación e implicación de las familias en la escuela. García (2003) habla de que los esfuerzos compartidos entre familia-escuela y una buena comunicación pueden llegar a prevenir y reducir el abandono escolar temprano. En este sentido, para poder abordar medidas efectivas para la erradicación del absentismo escolar, el Plan de Inclusión y Cohesión Social de la Comunitat Valenciana (2016) habla de la necesidad de "establecer acciones preventivas y de apoyo dirigidas a evitar el abandono escolar temprano en las poblaciones más vulnerables o desfavorecidas, como es el caso de la población gitana» (p.139), por ello, el sistema educativo debe actuar como elemento compensador de las desigualdades, garantizar oportunidades y la inclusión educativa.

Mediante este estudio, se pretende aportar un nuevo enfoque metodológico, ya que todos los estudios revisados abordan el tema del absentismo escolar en alumnos y alumnas de etnia gitana desde una perspectiva cuantitativa. Para ello, este trabajo se ha diseñado desde una metodología cualitativa que permita recoger el discurso de los adolescentes objeto de estudio. Ante el fenómeno del absentismo, se trata de conocer la percepción, experiencia y 
expectativas de adolescentes absentistas gitanos con el fin de proyectar las razones que les llevan a abandonar, de forma temprana, la Educación Secundaria Obligatoria.

\section{Método}

La investigación se ha llevado a cabo desde una perspectiva cualitativa, ya que los estudios encontrados hasta el momento, abordan el tema del absentismo escolar desde la perspectiva de la familia y están basados fundamentalmente en el análisis cuantitativo. El estudio se ha desarrollado mediante la técnica grupos de discusión, cuyo objetivo es conocer la opinión de los adolescentes gitanos en relación a la escolarización en secundaria. «El grupo de discusión consiste en una reunión de personas animadas a discutir un tema guiado por un moderador» (Corbetta, 2003, p. 90) cuyo proceso consiste en grabar, transcribir y analizar los resultados de las experiencias tratadas.

En el desarrollo de los grupos de discusión, se ha diseñado un guión a partir de las dimensiones contempladas en los trabajos existentes de la FSG (2010) Evaluación de la normalización educativa de las alumnas y los alumnos gitanos en la etapa de Educación Primaria. Las categorías a estudiar han sido las siguientes: acceso a la escuela, adquisición de normas, rutinas y ritmos escolares, interacción social en el aula, logros escolares y relación familia-escuela. Cada variable consta de un -conjunto de indicadores que han servido para elaborar los temas a tratar en los grupos de discusión y ofrecer una estructura más clarificada del proceso.

La investigación se ha llevado a cabo con 7 adolescentes, 3 chicas y 4 chicos de entre 12 y 16 años, todos ellos son alumnos absentistas en edad de cursar la Educación Secundaria Obligatoria. Se han formado dos grupos de discusión, el primero formado por 3 chicas de etnia gitana y el segundo grupo formado por 4 chicos de etnia gitana. Se ha decidido formar grupos homogéneos (sexo, edad y clase social) porque siguiendo las recomendaciones de Corbetta (2003) permite obtener resultados más fiables y trabajar intereses comunes que han experimentado los participantes. El grupo de discusión ha seguido el siguiente proceso: se ha informado a los participantes del día en el que se iba a llevar a cabo el grupo de discusión, el objetivo, la confidencialidad y el carácter voluntario de la actividad. Los grupos se han realizado durante los meses de enero y febrero de 2017 a las 11:00 de la mañana y han tenido una duración de 45 minutos aproximadamente.

Para el proceso de análisis de datos, se han transcrito los grupos de discusión y se ha utilizado el programa MAXQDA 12 (Software for Qualitative, Quantitative and Mixed Methods Research), que se utiliza en el ámbito de la investigación social para el análisis de entrevistas y grupos de discusión. En esta investigación se ha hecho un análisis conjunto de cada grupo, por un lado, se ha analizado el grupo de las chicas y por otro el de los chicos, y finalmente se ha realizado una comparación de los resultados de ambos grupos. Una vez transcritas las entrevistas, se ha procedido a la categorización de la información que se ha tratado en las entrevistas con el fin de realizar el posterior análisis.

\section{Resultados}

Para la obtención de resultados, el proceso se ha dividido en dos partes, la primera es descriptiva y analiza las frecuencias de palabras que aparecen en el discurso, y la segunda es de contenido para conocer el discurso de las personas en cada una de las categorías en los que se ha diseñado el instrumento. 


\section{Resultados del análisis descriptivo}

En primer lugar, se ha realizado una revisión de las categorías iniciales y se han recategorizado las variables a través de un proceso de triangulación entre la autora y tutora del trabajo, con el objetivo de dar una respuesta a las cuestiones iniciales. Las nuevas categorías establecidas son: sentido de comunidad, escuela, instituto, comunicación padre e hijos y actitud familia educación. Dentro de algunas categorías se han incorporado subcódigos, para un mismo código, que han permitido realizar un análisis más detallado para dar respuesta al objetivo de la investigación.

\begin{tabular}{|c|c|c|c|}
\hline \multicolumn{2}{|c|}{ Sistema de códigos } & \multirow[t]{2}{*}{ CHICAS } & \multirow[t]{2}{*}{ CHICOS } \\
\hline \multirow[t]{4}{*}{$\vee$} & $\because$ SENTIDO DE COMUNIDAD & & \\
\hline & Cultura gitana & - & - \\
\hline & Familia & - & - \\
\hline & Barrio & - & - \\
\hline \multirow[t]{4}{*}{$\checkmark$} & $\bullet$ ESCUELA & घ & - \\
\hline & ¿Hábitos de estudio & $\square$ & - \\
\hline & Dificultades & - & - \\
\hline & Asistencia & $\cdot$ & . \\
\hline \multirow[t]{10}{*}{$\checkmark$} & • INSTITUTO & . & . \\
\hline & CHábitos de estudio & - & . \\
\hline & Dificultades & - & - \\
\hline & Curriculum & 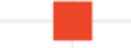 & 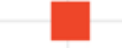 \\
\hline & Apoyos maestros & $\mathbf{a}$ & - \\
\hline & Actitudes maestros & घ & 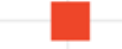 \\
\hline & Transición & $=$ & - \\
\hline & Percepciones & $\mathbf{\square}$ & $\square$ \\
\hline & COMUNICACIÓN PADRES E HIJAS & 口 & $\mathbf{\square}$ \\
\hline & - ACTITUD FAMILIA-EDUCACIÓN & 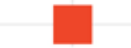 & $\square$ \\
\hline
\end{tabular}

Figura 1. Categorías analizadas

El sistema de códigos nos indica el total de segmentos analizados durante las entrevistas en los grupos de discusión, en total 256 segmentos. Según los resultados presentados, (Figura 1) los cuadros más grandes indican una mayor cantidad de opiniones, por lo que han sido los subcódigos más resaltados en las entrevistas.

\section{Resultados del análisis de contenido}

En la segunda fase, se ha procedido a realizar un análisis cualitativo de los resultados, por lo que, en este punto, se presentan los resultados del análisis de la información obtenida en los grupos de discusión. Para una mejor organización de la información, se han subdividido los resultados en función de los bloques que se van a tratar en el presente artículo: instituto y actitud familia-educación ya que son las categorías más destacadas en el análisis descriptivo. 
Respecto al instituto, si tratamos de analizar las percepciones de los adolescentes entrevistados, observamos que existe una clara coincidencia en los dos grupos de adolescentes, que perciben una diferencia de trato entre alumnos gitanos y no gitanos. Tras las entrevistas, se ha comprobado que se sienten discriminados porque no les atienden en igualdad y les ponen tareas y castigos diferentes.

«Sí mira, (...) pues yo he visto a payos salir de clase to amontonaos haciendo el loco y no les dicen nada, a nosotros nos ven cantando y parte ya» (chico 3 )

«Si, por ejemplo, que todos los payos estén hablando y todo y que hablemos nosotras y que nos manden a callar, que nos riñan, nos echen...» (chica 2)

Sienten que los profesores les ayudan menos porque reconocen estar desmotivados y no querer trabajar. Aun así, las chicas, hablan de que hay profesores que se preocupan y tratan de aconsejarles y motivarles en los estudios, hecho que valoran positivamente. También es cierto, que cuando se habló de si se sentían ayudadas por el profesorado, las tres confundieron ayuda con «beneficios» del siguiente tipo:

«Yo el otro día no quería entrar a clase y me dijo mira no pasa nada no te voy a poner falta... eso sí que es ayudar» (chica 1)

«Depende que maestra, hay una que nos dice que si no queremos hacer nada nos deja» (chica 2)

Por lo contrario, los chicos, no se sienten ayudados porque refieren no trabajar y no querer estudiar. Según los relatos de los dos grupos, la actitud de los maestros es muy pasiva, han adoptado un estilo educativo bastante permisivo que tolera el no trabajar y dedicarse a otras actividades.

«Nada, nos dicen que nos echemos a dormir» (chico 4)

«Es que alguno nada más entrar nos tira (echa de clase) y ya no hacemos na» (chica 1)

Cuando tienen un mal comportamiento, los profesores toman las medidas que ellos consideran adecuadas para solventar la situación, circunstancias que también les hace sentirse discriminados, sobre todo a los chicos. Durante la entrevista, los chicos tienden a generalizar la mayor parte del tiempo y refieren que todos los profesores son racistas y ponen castigos muy diferentes que a los payos.

«(...) a los gitanos nos expulsan y a los payos les riñen les ponen un parte... siempre la culpa es para nosotros...» (chico 2)

«(...) a los payos no les expulsan...» (chico 1)

Por el contrario, las chicas no generalizan y hablan de que hay profesores que, si tratan por igual a los alumnos, aunque hacen uso de «depende de que maestro» para referirse a la situación.

Cabe destacar, que los grupos también coinciden en que no quieren avanzar ni seguir estudiando, están desmotivados y tienen la sensación de desaprovechar el tiempo. Son conscientes de las capacidades que tienen e incluso refieren que si quisieran podrían llegar a obtener el graduado en educación secundaria.

\footnotetext{
«Que nos expulsaran para siempre que nos dijeran no volváis más a ningún instituto de Castellón, no quiero estudiar no necesito nada» (chico 3)

«Sí sí, que nos dejen en paz ya, tu sabes maestra que es madrugar, aguantar que te chillen... puff» (chico 4)
}

Alcanzar el éxito académico no es tan importante para los adolescentes, y tampoco se plantean obtener el graduado. Ambos sexos tienen muy claro que quieren hacer en un futuro 
y coinciden en seguir con los patrones familiares. Por lo que corresponde, las chicas si tienen una idea más construida sobre lo que les gustaría estudiar, como peluquería y jardinería, aunque son conscientes que deben seguir con los roles de género y consideran que no necesitan tener estudios para dedicarse al cuidado de la familia y del hogar

«Para mí no. Si vamos a acabar haciendo lo mismo de siempre, fregar en casa y luego cuando te cases fregar con tu marido también y cuidar a los niños» (chica 1)

«Para mí no, yo no lo quiero.Yo quiero casarme y el día que me case sé que me van a mantener» (chica 3)

Sobre los chicos, cabe resaltar el interés que tienen de incorporarse al mundo laboral. Los trabajos temporales y la venta ambulante son los que predominan entre sus familias, desde pequeños han visto que sus familias han salido adelante y por ello no ven necesario tener estudios para tener una vida estable y cómoda.

«No, ni me va ni me importa porque yo o me hago chatarrero o al mercao» (chico 1)

«No, porque yo quiero ser como mi padre, ir al mercao a trabajar con él» (chico 2)

En cuanto a la actitud de las familias, cabe destacar que éstas no dan tanta importancia a la educación como el grupo mayoritario, entienden que la educación se transmite en la familia y piensan que en la escuela o en el instituto no les van a transmitir los valores propios de los gitanos. Sin embargo, las familias valoran positivamente que sus hijos tengan estudios y tengan una vida mejor que ellos.

Por un lado, quieren que sus hijos e hijas aprovechen la oportunidad, pero al mismo tiempo, coexiste la necesidad de contar con la ayuda éstos para colaborar en el hogar o en el trabajo familiar.

Las relaciones entre familia-instituto son escasas o deficitarias porque cuando existe comunicación entre ellos, es para trasladar aspectos negativos de los y las adolescentes, que hace consolidar más la idea de racismo que sufren sus hijos e hijas en el centro.

Las familias reconocen que tener estudios les abriría posibilidades para el futuro, pero afirman que sufren una desventaja que hace que sus hijos prefieran integrarse a los 16 años al mundo laboral y contribuir en el cuidado de la familia.

«Mi madre (...) dice que es bueno estudiar y quieren que estudiemos y que tengamos nuestros estudios, pero sabiendo que no queremos, qué van a hacer» (chico 3)

«No quieren que vaya (...) y prefieren que me haga mis faenas que no que tire el tiempo iendo alli pa no hacer na» (chica 1)

«Les da igual (...) dicen que, si vamos que hagamos el esfuerzo, pero como ven que paso pues ellos también quieren que acabe... por lo menos ayudo en casa» (chica 3 )

\section{Discusión y conclusiones}

Conocer la percepción de adolescentes absentistas de etnia gitana ha tenido como finalidad poder interpretar cuales son las razones que llevan al colectivo gitano a abandonar la Educación Secundaria Obligatoria. Ha sido muy importante conocer el discurso de los y las adolescentes para poder alcanzar el objetivo planteado y llegar a unas conclusiones definidas, que den respuesta al fenómeno del absentismo, en relación a los temas estudiados, como son la escuela-instituto y el papel de la familia.

El absentismo escolar en los y las adolescentes entrevistados surge debido a la idea que tienen de empezar a trabajar de forma temprana y seguir con los roles tradicionales de sus familias, hecho que ya se constató en los estudios de Bhopal (2011). 
Los estudios de Bophal $(2010,2011)$, señalan al racismo y las actitudes de los profesores como la principal causa de no asistencia al centro escolar. En este estudio, los relatos de algunos chicos y chicas entrevistados, demuestran que hay profesores que manifiestan actitudes prejuiciosas, estereotipadas y claramente racistas que hace que las familias de éstos aprueben la ausencia reiterada de sus hijos e hijas al instituto. Aunque los chicos y chicas confirman que en el instituto hay profesores que se preocupan por su formación, siguen teniendo una visión muy negativa del centro escolar. Por sus relatos, valoran muy positivo que los profesores demuestren justicia con ellos, de hecho, dicha actitud, tiene efectos beneficiosos en la voluntad y esfuerzo por trabajar en las clases que imparten estos profesores.

Los y las adolescentes entrevistados, explican que tienen una conducta pasiva porque no hay una estimulación profesional directa que motive el aprendizaje dentro del aula. Además, su discurso, hace entrever que las expectativas de sus padres son que alcancen una vida mejor, con mayores oportunidades, aunque sin dejar de lado las obligaciones y los roles tradicionales de género, sobre todo en el caso de las chicas, tal y como afirman los estudios de Myers, McGhee \& Bhopal, 2010.

Es importante motivar a estos adolescentes y a sus familias para que vean que el instituto también puede ser un espacio de encuentro y apoyo. Consideramos importante trabajar desde la base para conseguir chicos y chicas gitanos motivados con ambiciones educativas futuras.

Con este estudio, pensamos que se abre una vía de investigación para recuperar percepciones, experiencias y expectativas de adolescentes de etnia gitana en relación a la Educación Secundaria Obligatoria e incidir en los aspectos más relevantes, que permitan crear proyectos dirigidos a prevenir y reducir el absentismo escolar y aumentar el éxito escolar entre los y las adolescentes gitanos.

Por ello, consideramos de interés profundizar en el estudio de esta situación desde la perspectiva cualitativa y poder contrastar los datos obtenidos en futuras investigaciones.

\section{Referencias bibliográficas}

Bhopal, K. (2011a). "This is a school, it»s not a site': teachers' attitudes towards Gypsy and Traveller pupils in schools in England, UK. British Educational Research Journal, 37(3), 465-483. https://doi.org/10.1080/01411921003786561

Bhopal, K. (2011b). «What about us?» Gypsies, Travellers and «White racism» in secondary schools in England. International Studies in Sociology of Education, 21(4), 315-329. https://doi.org/10.1080/09620214.2011.640520

Corbetta, P. (2003). Métodos y técnicas de investigación social. Madrid: McGraw-Hill.

Derrington, C. \& Kendall, S. 2004. Gypsy Traveller students in secondary schools, Stoke on Trent, UK: Trentham.

Fundación Secretariado Gitano. (2002). Evaluación de la normalización educativa del alumnado gitano en educación primaria. Madrid.

Fundación Secretariado Gitano. (2003). Enseñar y aprender en clave de diversidad cultural. Orientaciones y estrategias para los centros educativos. Madrid.

Fundación Secretariado Gitano. (2013). El alumnado gitano en secundaria: un estudio comparado. Madrid.

García, F. J. (2003). Las relaciones escuela-familia: un reto educativo. Infancia y aprendizaje, $26(4), 425-437$.

Garreta, J. (2015). "La comunicación familia-escuela en educación infantil y primaria». Revista de la Asociación de Sociología de la Educación (RASE), vol. 8, núm. 1, pp. 71-85. 
Grañeras, M. (2012). Gitanos: de los mercadillos a la escuela y del instituto al futuro (Vol. 6). Ministerio de Educación.

Llevot, N. \& Bernad, O. (2015). La participación de las familias en la escuela: factores clave. Revista de la Asociación de Sociologia de la Educación (RASE), vol. 8 (1), 57-70.

Martínez, M., Jiménez-Adelantado, A. \& Alfageme, A. (2001). La situación escolar de la infancia gitana y el absentismo. Comunicación VII Congreso Español de Sociología. Sesión Educación y desigualdad social.

Márquez, M. J. \& Padua, D. (n.d.). Comunidad Gitana y Educación Pública. La necesidad de construir un proyecto social y educativo compartido. Retrieved from http://aufop.com/ aufop/uploaded_files/revistas/14642744378.pdf\#page=92.

Ministerio de Sanidad, Servicios Sociales e Igualdad. (2012). Estrategia Nacional para la Inclusión Social de la Población Gitana en España 2012-2020. Madrid.

Myers, M., McGhee, D. \& Bhopal, K. (2010). At the crossroads: Gypsy and Traveller parents' perceptions of education, protection and social change. Race Ethnicity and Education, 13(4), 533-548. https://doi.org/10.1080/13613324.2010.492138.

O'Hanlon, C. (2010). Whose education? The inclusion of Gypsy/Travellers: continuing culture and tradition through the right to choose educational opportunities to support their social and economic mobility. Compare: A Journal of Comparative and International Education, 40(2), 239-254. https://doi.org/10.1080/03057920903546104.

Relinque, C. S., Moral, G., \& González, M. T. (2013). Consejos prácticos para escribir un artículo cualitativo publicable en Psicología. Psychosocial Intervention, 22(1), 71-79. https:// doi.org/10.5093/in2013a9.

Vázquez, C. (2013). Consecuencias Jurídicas del Absentismo Escolar. Avances en Supervisión Educativa, 18, 1-25.

Vicepresidència y Conselleria d'Igualtat y Polítiques Inclusives (2016). Plan Valenciano de Inclusión y Cohesión Social 2017-2022. Generalitat Valenciana 


\title{
Familia y diversidad funcional: Bienvenido a Holanda
}

\section{La primera noticia}

\author{
GuAdALUPE PAVÓN RodRíguez \\ liyupe@icloud.com \\ Ma RAQUEL Agost-FELIP \\ ragost@uji.es
}

\section{Resumen}

Introducción: Las familias que esperan descendencia, se encuentran en algunos casos ante la primera noticia de tener un hijo o hija con diversidad funcional. Esta situación, puede producirse durante el embarazo, en el nacimiento o en los primeros años de vida, y modifica su equilibrio. Desde una perspectiva de prevención secundaria, se debería intervenir, con el fin de disminuir los efectos del estrés, frustración, sintomatología ansioso-depresiva y decremento en la calidad de vida (Caplan, 1980). Por ello, primero nos planteamos revisar los recursos disponibles en la red social para atención a familias ante la primera noticia; segundo, diseñar un programa de intervención dirigido a familias después de esta noticia. Metodología: se realiza una revisión del tema, a partir del estudio del EDIS (1999). Se ha diseñado el programa de intervención según el modelo lógico (Kellogg, 2001), además, se ha utilizado una metodología de triangulación entre: profesionales, madres y padres, y personal investigador. Resultados: identificación de la red social en el trabajo con familias; diseño de un programa de intervención con familias de menores con diversidad funcional, en el momento de la primera noticia. Conclusiones: el programa propuesto «Bienvenido a Holanda», nace de la necesidad de rellenar las lagunas que se han identificado, tras una revisión teórica y el conocimiento de los servicios dentro del sistema de protección social (Atención temprana y programa «De padres a padres»). Este programa, pretende mejorar la calidad de vida desde una atención individual y familiar, así como formar a los y las profesionales en dar la primera noticia.

Palabras clave: primera noticia, familia, diversidad funcional, prevención, programa de intervención.

\section{Abstract}

Introduction: Families expecting offspring find themselves in some cases, with the first news of having a child with functional diversity. This situation can occur during pregnancy, at birth or in the first years of life, and modifies their harmony. From a secondary prevention perspective, should intervene in order to reduce the effects of stress, frustration, anxiety-depressive symptomatology and decrease in quality of life (Caplan, 
1980). Therefore, firstly we consider reviewing the resources available in the social network for care of families faced with the first news of the functional diversity of his son or daughter; secondly, to design a program of intervention directed to families after this news. Method: a review of the topic is carried out based on the study of the EDIS (1999). The intervention program has been designed according to the logical model (Kellogg, 2001); in addition, a triangulation methodology has been used among professionals, parents and researchers. Results: identification of the social network in the work with families; Design of an intervention program with families of children with functional diversity at the time of first news. Conclusions: The proposed program «Welcome to Holland» was born from the need to fill in the gaps that have been identify, following a theoretical review and knowledge of the services within the social protection system (Early Care and Parent to Parent Program). This program aims to improve the quality of life from an individual and family care, as well as to train the professionals involved in the situation of giving the first news.

Keywords: first news, family, functional diversity, prevention, intervention program

\section{Introducción}

\section{La primera noticia}

Según Minuchin, Simon \& Lee (1998), el nacimiento de una hija o un hijo representa un cambio en la organización y dinámica familiar, no solo emocional sino inclusive física. Los padres y madres se preparan para brindar amor, protección, apoyo y darles a sus hijos o hijas todo lo que ellos no pudieron tener. Sin embargo, cuando nace un niño o niña con Diversidad Funcional (DF), nacen también situaciones estresantes, diferentes, emocionalmente fuertes, búsqueda de respuesta y alternativas de solución.

El tener una hija o un hijo con DF puede generar rechazo en los padres y las madres, ante la ruptura de los esquemas y expectativas, que pueden desarrollar sentimientos de rabia, miedo e impotencia, preguntándose «¿por qué a mí?, ¿y ahora qué hago?». Así, la llegada de un niño o una niña con diversidad funcional, suele traer tristeza, también desafíos, expectativas y muchas veces frustración. A esto se refiere Giberti (1999) cuando habla de la frustración de los padres y las madres que pensaron en el «hijo o hija ideal» y que reaccionan con sentimientos contradictorios frente a ese bebé, con una herida que tarda mucho en cicatrizar.

Se dan distintas reacciones de los padres y las madres ante la primera noticia del nacimiento de un hijo o una hija con DF según el estudio sobre La Primera Noticia de la Federación Estatal de Asociaciones de Profesionales de Atención Temprana (GAT-Federación Estatal de Asociaciones de Profesionales de la Atención Temprana, 2011), el 93,17\% de las personas entrevistadas en este estudio valoran sus vivencias ante la primera noticia de forma negativa, el 4,55 \% haría una valoración neutra y sólo un 2,28 \% valoraría la primera noticia de forma positiva, Es destacable que las reacciones más frecuentes son las de rabia, impotencia y frustración $(20,50 \%)$ y la soledad $(20,25 \%)$. 


\section{Reacciones emocionales y fases ante la primera noticia}

Una vez recibida la noticia los padres y las madres, pasan por distintas fases y reaccionan de diferentes maneras, que se aproximan a un duelo. Algunos autores describen las reacciones emocionales por las que suelen pasar, y otros las clasifican en etapas. Así, Hutt \& Gwyn (1988) refieren tres reacciones emocionales de los padres y madres con niños o niñas con DF: a) Padres y madres que aceptan: son lo suficientemente maduros para optar por soluciones prácticas y bien pensadas, que no hacen de sus hijos e hijas el centro de su vida, pero cuya conducta involucra buscar ayuda para ir resolviendo los problemas que se van presentado; b) Padres y madres que ocultan: familias que se abocan a aprenden que nadie se entere que el niño o la niña tiene un problema y que van de médico en médico buscando una respuesta que ellos y ellas no quieren escuchar; c) Madres y padres que niegan: que se sienten incapaces de dar ayuda a sus hijos e hijas debido a la reacción emocional más grave, como es la negación.

Por su parte Muñoz (2003) describe tres etapas de las actitudes presentadas por padres y madres de hijos e hijas con DF: a) Fase de shock: en la que hay conmoción, bloqueo, desorientación, ansiedad y culpa ante lo desconocido y que muchas veces se asume como culpa de cada uno de los padres y las madres; b) Fase de reacción: o de enfado, rabia contra la vida, contra Dios, rechazo, sensación de pérdida, un verdadero «duelo»; c)Fase de adaptación: en la que ya se empieza a ver la luz al final de túnel y se preguntan ¿qué debo hacer con él? ¿qué necesita?

Hasta que se llega a la fase de adaptación, los padres y las madres pueden presentar mayor vulnerabilidad para la aparición de distintas patologías. Así, estas personas tienen más riesgo de experimentar estrés parental, síntomas ansiosos/depresivos, disminución del bienestar psicológico y disminución de la salud, pasando por un estado de duelo (Gupta, 2005).

Por otro lado, la aparición o no de todas y cada una de estas fases, así como su duración, depende de diversas variables. Scorgie \& Wilgosh (2008) realizan un resumen de la literatura científica en este sentido, clasificando estas variables en cuatro grupos: a) variables familiares: estatus socioeconómico, cohesión, ánimo, habilidades y creatividad para resolución de problemas, roles, responsabilidades y composición; b) variables de las madres y los padres: calidad de relación de pareja, locus de control de la madre (en qué se fija, a qué le da importancia), estima, tiempo y horario; c) variables del niño y la niña: grado de DF, edad, género y temperamento; d)Variables externas: actitudes sociales estigmatizantes, apoyos de la red social, colaboración con los y las profesionales.

Dado que una de estas variables es la colaboración con profesionales (que lleva implícita la forma de recibir esta primera noticia), es fundamental formar a los y las profesionales para que la comunicación del diagnóstico se realice de una forma adecuada, ya que de ello depende en gran medida la reacción posterior de la familia, pudiendo amortiguar, en parte, el impacto negativo de esta nueva realidad. Según los estudios anteriores, se puede constatar que las reacciones emocionales, y las fases por las que pasan los padres y madres después de la primera noticia, podría influir en la disminución de su calidad de vida, es en este sentido que Schalock \& Verdugo (2007) definen algunas dimensiones que pueden influir y deberían ser evaluadas para medir la calidad de vida en la familia.

\section{Necesidades observadas y expresadas por las familias}

Tal y como se recoge en el informe La Primera Noticia (GAT, 2011), las familias muestran su malestar en cuanto al tipo de apoyo psicológico recibido en el momento de recibir la prime- 
ra noticia sobre la DF de su hija o hijo. Por este motivo, se hace necesario mejorar la atención psicológica desde ese primer momento en el hospital, aun cuando la familia no percibe la necesidad inmediata, es importante que las madres y los padres conozcan de su existencia para acceder a ella de forma directa, en caso de necesitarlo. Otras necesidades que las madres y los padres entrevistados citan textualmente como las más importantes son: rapidez del diagnóstico, sinceridad, confianza, trato más humano, ayuda psicológica, amabilidad, apoyo permanente, e información fiable y veraz.

Por otro lado, en el ámbito hospitalario, existe un amplio rango de profesionales y especialistas en diferentes disciplinas (ginecología, neonatología, pediatría, psicología, etc.), las y los profesionales en un momento dado de su actividad cotidiana, pueden tener que encargarse de dar una 'primera noticia' y necesitarían una formación y preparación específica, para afrontar este momento de la forma más adecuada, conocer su alcance social, así como contar con recursos para documentarse y asesorarse (GAT, 2011).

A la partir de lo anteriormente expuesto, consideramos necesaria la implementación de programas de intervención dirigidos a la prevención secundaria, para reducir la prevalencia, acortar el problema e intervenir en las primeras fases para que este no se agrave Caplan (1980), que en nuestro caso será cuando las familias reciben la primera noticia.

Este acompañamiento planteado como «intervención en crisis», se espera que reduzca el tiempo de adaptación a la nueva realidad de los padres y las madres, y con ello el riesgo para el desarrollo de patología asociada.

Así pues, el objetivo de este trabajo es conocer los recursos existentes en la actualidad para abordar esta situación, y proponer un proyecto de intervención dirigido a minimizar el impacto negativo que pueda generar esta realidad en la familia, por medio de un acompañamiento terapéutico por parte de los y las profesionales, para evitar la disminución de la calidad de vida de los padres y las madres después de recibir esta noticia.

\section{Método}

En la primera parte, se ha realizado una revisión de la documentación especializada en el tema, identificando diferentes programas de atención a las familias (EDIS, 1999). En la segunda parte, se ha diseñado el programa de intervención según el modelo lógico (Kellogg, 2001), además, se ha utilizado una metodología de triangulación entre: profesionales, padres y madres, y personal investigador, para validar la propuesta.

\section{Resultados}

En los siguientes epígrafes, en primer lugar, se presentan dos ejemplos de recursos existentes en el apoyo a padres y madres, que se aplican en la actualidad y cubren alguna de las necesidades expuestas anteriormente: el programa de Atención temprana donde llegan las familias derivadas de los servicios sanitarios, y el programa de Padres a Padres impulsado por algunas asociaciones de madres y padres. En segundo lugar, se presenta el proyecto Bienvenido a Holanda como propuesta de intervención. 


\section{Recursos disponibles en el sistema de protección social para las familias}

La DF entra en las familias como un elemento que desmonta el equilibrio y afecta a su calidad de vida, en apoyo a estas familias y a la persona con DF existen diversos recursos dentro del sistema de protección social en la red de los Servicios Sociales generales y específicos a los que se refiere la LEY 5/1997, de 25 de junio, de la Generalitat Valenciana (1997), por la que se regula el Sistema de Servicios Sociales en el Ámbito de la Comunidad Valenciana.

"Los servicios sociales comprenden aquellos recursos, actuaciones y prestaciones que tienden a cumplir las finalidades establecidas en el artículo 1 de la presente ley, a fin de ayudar a las personas y grupos sociales a resolver sus problemas, superando sus dificultades, y a crear y conseguir recursos adecuados para mejorar su calidad de vida y la integración en la comunidad o entorno social al que pertenecen» (Título II, art 9).

\section{Atención temprana}

Según el libro blanco de Atención Temprana «se entiende por atención temprana el conjunto de intervenciones dirigidas a la población infantil de 0-6 años, a la familia y al medio, que tiene por objetivo atender lo más rápidamente posible las necesidades transitorias o permanentes que presentan las niñas y los niños con trastornos en su desarrollo o que tienen el riesgo de padecerlos. Estas intervenciones, que deben considerar la globalidad del niño, han de ser planificadas por un equipo de profesionales de orientación interdisciplinar o transdisciplinar». (Libro Blanco de atención Temprana 2005, p. 12).

Corral (2013), resume y destaca de este modelo la importancia de la figura profesional con funciones terapéuticas y de tutoría, y lo positivo de implicar a la familia en el desarrollo del Programa de Intervención, no sustituyendo al o a la terapeuta sino desarrollando una serie de roles: como cliente del servicio, como responsable del niño o de la niña (elemento estable y permanente del niño o de la niña), como recurso (para el buen desarrollo de los vínculos afectivos), y como agente de la Atención Temprana, siendo el objetivo crear «entornos competentes» para la niña o el niño.

Los ámbitos de actuación de la Atención Temprana se centran en: servicios sanitarios, sociales y educativos y en los Centros de Desarrollo Infantil y Atención Temprana (CIDAT), de estos últimos existen 17 en la Comunidad Valenciana, 13 corresponden a la provincia de Valencia, 8 se encuentran en la de Alicante, y 5 se encuentran en la de Castellón (destacar que cuatro están localizados en la capital), según datos de la Conselleria de Bienestar Social de la Comunidad Valenciana en diciembre de 2012 (AVAP, 2012).

\section{Programa «De padres a Padres»}

FEAPS impulsó el Programa de Padres a Padres (Ponce, 2008), que se redactó a partir de las experiencia y materiales aportados por diferentes programas que tenían éxito en Estados Unidos y Europa, también se tuvo en cuenta el desarrollo del mismo en las Comunidades Autónomas de nuestro país, como por ejemplo Cataluña, que lo iniciaron dentro del Programa de Apoyo y Respiro Familiar (PARF), dirigido a proveer de apoyo emocional e información a padres y madres, cuyas hijas e hijos tienen necesidades especiales a través del encuentro uno-a-uno, entre un padre o madre veteranos y un padre o madre nuevos.

Este Programa consiste en la relación entre padre o madre de apoyo previamente entrenado, y madre o padre que busca tanto ese apoyo emocional, así como conocer la experiencia 
en familias con vivencias parecidas en el mundo de la Diversidad Funcional. Es el programa el que provee apoyo y seguimiento para los encuentros.

La creencia básica de este Programa se define como: "El apoyo que se ofrece a la familia en conjunto, en lugar del que se ofrece a la persona con discapacidad de manera individual, y está basado en las prioridades y preocupaciones que han sido identificadas por la familia, no por los profesionales» (Ribas, 2008, p.27).

\section{Proyecto «Bienvenido a Holanda»}

La atención a las familias (como individuos) es el objetivo de la intervención, ya que en la mayoría de las ocasiones el niño o niña es el epicentro de la vida de sus progenitores, pasando sus propias necesidades a su segundo plano y provocando un desajuste emocional difícil de resolver. Según McCubbin y Patterson (1982) el estrés generado en la familia producto del impacto de la primera noticia de la DF de uno de sus miembros, provoca una presión que puede perturbar o cambiar el sistema familiar.

Esta atención a las familias, necesariamente ha de contribuir a la mejora de su calidad de vida, definida por la OMS (1993) como «la percepción que una persona tiene de su lugar en la existencia, en el contexto de la cultura y del sistema de valores en los que vive y en relación con sus objetivos, sus expectativas, sus normas, sus inquietudes. Se trata de un concepto que está influido por la salud física de la persona, su estado psicológico, su nivel de independencia, sus relaciones sociales, así como su relación con su entorno «.

Para el diseño de programas de intervención dirigidos a la mejora de la calidad de vida de estos padres y madres puede ser de utilidad tener en cuenta las dimensiones planteadas por Schalock \& Verdugo (2007), para ayudar a la elección de tareas y actividades específicas para cada uno de los ámbitos afectados.

Bienvenido a Holanda es un proyecto diseñado a partir del modelo lógico (Kellogg, 2001) que permite integrar, planificar y priorizar en primera instancia los objetivos generales, desde los que se deducirán los objetivos específicos. Este proyecto va dirigido a padres y madres, que acaban de recibir la noticia de que tienen un hijo o una hija con Diversidad Funcional de entre 0 y 16 años, independientemente del tipo de Diversidad, física, intelectual, condiciones médicas y otras necesidades especiales de cuidado, así como, a los profesionales implicados en el nacimiento, diagnóstico y tratamiento. El rango de edad escogido es amplio, porque la detección de la diversidad funcional no tiene porqué darse necesariamente en los primeros años de vida, debido a que hay déficits funcionales que se detectan en procesos más tardíos del desarrollo evolutivo del niño o de la niña. A falta de datos más actuales, según la encuesta sobre Discapacidad, Autonomía personal y situaciones de Dependencia (GAT, 2011) en la Comunidad Valenciana, existe una población con discapacidad o limitaciones de 462.303 personas, de las cuales un 6,4 \% (16.508) se encuentran entre los 0 y 15 años.

El proyecto tiene como objetivo general la intervención en padres y madres después de la primera noticia, y se propone como objetivos específicos mejorar la relación de la red sanitaria en la situación de dar la primera noticia, así como mejorar la calidad de vida de los padres y madres a partir de esa situación (Pavón, 2016).

Bienvenido a Holanda, busca ayudar y acompañar a la familia en esos momentos de desorientación, para prevenir la aparición de alteraciones psicológicas posteriores (dada su especial vulnerabilidad), creando condiciones que promuevan la calidad de vida de las personas y ayudándoles a generar habilidades para que consigan dicha calidad de vida. Este proyecto se fundamenta en la promoción de la salud psico-social, concretamente en las áreas de inclusión social, auto-determinación, bienestar físico, desarrollo personal, bienestar material, relaciones 
interpersonales y bienestar emocional (Schalock \& Verdugo, 2007). Para ello su contenido se articula en seis fases: primera noticia (detección del problema), derivación (identificación del problema), bienvenida al centro (examinar efectos del problema), atención personalizada (identificar causas del problema), acompañamiento (recursos para la solución del problema), seguimiento de la intervención (evaluación y acompañamiento). Cada una de estas fases cuenta con un protocolo de actuación con las actividades a desarrollar (Pavón, 2016).

\section{Discusión y conclusiones}

Bienvenido a Holanda se diseña con el propósito de cubrir un pequeño espacio dentro de la atención de la DF, centrándonos en los padres y madres que en el momento de la primera noticia son junto con su hijo o hija los más vulnerables.

Una buena coordinación con los Centros Sanitarios, en cuanto a la formación de su personal, puede hacer que las familias reciban la noticia de forma más amortiguada y clara. Aunque no desaparecerán los sentimientos negativos en un primer momento, es importante la forma de recibirla.

El acompañamiento a los padres y madres, persigue acortar este proceso proporcionando un espacio en el que, por un momento, puedan exponer su rabia, miedo y preocupación, sin sentirse culpables, mejorando de esta manera su bienestar emocional y muy posiblemente la relación con su hijo o hija.

Merecen una mención especial, los servicios de Atención Temprana que realizan una labor encomiable, y está en el ánimo de esta propuesta aprender de su experiencia y ser un recurso/servicio con el que puedan colaborar, tomamos también en consideración todo lo positivo que tiene el programa de Padres a Padres.

Este proyecto no se crea con fecha de caducidad, ya que el acompañamiento a padres y madres puede ser necesario en distintas etapas de la vida evolutiva de su hijo o hija, como son la escolarización, adolescencia, incorporación al mundo laboral, vida independiente, todas estas etapas que irán surgiendo de forma natural, pueden generar inseguridad en los padres y las madres.

Tomando como propias las siguientes palabras del Colegio oficial de psicólogos, «El profesional de este ámbito asume un compromiso muy especial en la consecución de una mayor calidad de vida de las personas y del bienestar de las comunidades y ha de integrarse en la concepción de una ética global que contemple el respeto estricto por los derechos humanos y libertades de los individuos y de los pueblos» (COP, 1997), afrontamos la puesta en marcha del proyecto Bienvenido a Holanda.

\section{Referencias bibliográficas}

AVAP. Asociación Valenciana de Atención Precoz (2012). CENTRES I SERVICIS D’ATENCIÓ TEMPRANA DE LA COMUNITAT VALENCIANA. Recuperado el 10 marzo,2017de:http:// www.avapcv.com/images/direcciones/CentrosdeA\%20P\%20Nov\%2012.pdf Caplan, G. (1980). Principios de Psiquiatría Preventiva. Buenos Aires: Paidós.

Caplan, G. (1980). Principios de psiquiatría preventiva. Buenos Aires: Paidós.

Corral, P. (2014). La familia soporte básico para el niño en Atención Temprana a personas con Discapacidad. Madrid: CERMI. 
EDIS. Equipo de Investigaciones Sociológicas, E. (1999). Necesidades, demandas y situación de las familias con menores (0-6 años) discapacitados. Documentos 55/2005. Madrid: Real Patronato sobre Discapacidad.

Federación Estatal de Asociaciones de Profesionales de Atención Temprana (2005). Libro Blanco de la Atención Temprana. Madrid: Real Patronato sobre Discapacidad.

GAT-Federación Estatal de Asociaciones de Profesionales de Atención Temprana (2011). La primera noticia. Estudio sobre los procedimientos profesionales, las vivencias y las necesidades de los padres cuando se les informa de que su hijo tiene una discapacidad o un trastorno del desarrollo. Recuperado el 10 marzo, 2017de: http://ccsegarra.cat/observatori_social/admin/uploads_doc/biblioteca_doc_01082012110038_5._PRIMERANOTICIA.pdf

Generalitat Valenciana. (1997). LEY 5/1997, de 25 de junio, de la Generalitat Valenciana, por la que se regula el Sistema de Servicios Sociales en el Ámbito de la Comunidad Valenciana. (DOCV núm. 3028 de 04.07.1997) Ref. Base Datos 1755/1997.

Giberti, E. (1999). Escuela para Padres. Fascículo No 20. Página 12.

Gupta, A. \& Singhal, N. (2005). Psychosocial Support for Families of Children with Autism. Asia Pacific Disability Rehabilitation Journal, 16(2), 62-83.

Hutt M. \& Gwyn G. (1988). Los niños con retrasos mentales. Desarrollo, aprendizaje y educación. México: Fondo de Cultura Económica.

Kellogg Foundation (2001). Uso de modelos lógicos para integrar la planificación, evaluación y acción. Guía de Desarrollo de Modelos Lógicos. Michigan: Kellogg Foundation.

McCubbin, H. I. \& Patterson, J. (1982). Family adaptation to crisis. En H. McCubbin, A. Cauble, \& J. Patterson (Eds.), Family stress, coping and social support. Springfield-Illinois: Thomas Publishers.

Minuchin, S., Lee, W. Y. \& Simon, G. M. (1998). Supervision and familien therapeutisches Können. Friburgo: Lambertus-Verlag.

Muñoz B. (2003) La familia con un hijo con discapacidad: sus conflictos vinculares Archivos Argentinos de Pediatría, 10(2), 133-142.

OMS (1993). Informe de la OMS/Fundación IPSEN sobre calidad de Vida. Ginebra: OMS (MNH/ PSF/93.4).

Ponce, A. (2008). De padres a padres. Madrid: FEAPS, Cuadernos de Buenas Prácticas.

Pavón, G. (2016). Bienvenido a Holanda: Intervención en familias después de la primera noticia. Trabajo de Fin de Grado. Trabajo no publicado.

Ponce i Ribas, A. (2008). De Padres a Padres. Madrid: FEAPS

Scorgie, K. \& Wilgosh, L. (2008). Reflections on an uncommon journey: A follow-up study of life management of six mothers of children with diverse disabilities. International Journal of Special Education, 23(1), 103-114.

Schalock, R. L. \& Verdugo, M. A. (2007). El concepto de calidad de vida en los servicios y apoyos para personas con discapacidad intelectual. Siglo Cero, 38, 21- 36. 


\title{
Identificación de variantes genéticas asociadas a la sensibilidad solar
}

\author{
Julio Alberto Deserio-Cuesta \\ al224979@uji.es \\ RAQUEL SORIA-NAVARRO \\ al224942@uji.es \\ INCA VILAR-SASTRE \\ al224960@uji.es \\ BÁRBARA HERNANDO \\ hernandb@uji.es \\ ConRado Martínez-Cadenas \\ ccadenas@uji.es
}

\section{Resumen}

Introducción: La sensibilidad a la radiación ultravioleta está determinada por características pigmentarias influenciadas por varios genes. Ciertos rasgos de la pigmentación, como tener un color de piel claro, tener muchas efélides y/o nevus y una dificultad de bronceado, son indicadores de una mayor susceptibilidad a esta radiación solar y, por tanto, al cáncer de piel. Sin embargo, poco se conoce sobre los determinantes genéticos asociados a la sensibilidad solar, a excepción del gen MC1R. Este estudio analiza las bases genéticas de la sensibilidad solar y la predisposición al cáncer cutáneo en una población española. Metodología: En el estudio participaron 300 voluntarios. Mediante un cuestionario estandarizado, se recogieron características fenotípicas de pigmentación, historia de quemaduras solares y hábitos de exposición solar. Para cada individuo, se determinó el genotipo de genes involucrados en la ruta de la pigmentación humana - MC1R, ASIP, TYR, OCA2, HERC2, SLC24A4, BNC2, IRF4, KITLG, y SLC45A2. El análisis de asociación entre las características fenotípicas y el genotipo se realizó con una regresión logística, utilizando el programa SPSS v24. Resultados: El mayor determinante genético de los rasgos de pigmentación y sensibilidad solar es el gen MC1R. Polimorfismos en IRF4, ASP y SLC45A2 también parecen influir en la pigmentación cutánea basal, así como en la aparición de lesiones hiperpigmentadas benignas. Conclusión: Los individuos con fenotipo de riesgo tienen significativamente mayor número de polimorfismos asociados con una peor tolerancia al sol. Individuos portadores de estos polimorfismos tendrían una mayor sensibilidad a la radiación solar y, por tanto, a padecer cáncer cutáneo.

Palabras clave: Pigmentación humana, Sensibilidad solar, Lesiones hiperpigmentarias benignas, Polimorfismos, MC1R 


\section{Abstract}

Introduction: Sensitivity to ultraviolet radiation is determined by pigmentation traits, which are influenced by several genes. Particular pigmentation characteristics, such as having fair skin, having ephelides and/or naevi, and the inability to tan, are associated with a high sensitivity to sunlight and, therefore, a predisposition to skin cancer. However, little is known about the genetic determinants associated with sunlight sensitivity, apart from $M C 1 R$ gene. This study analyses the genetic basisof sunlight sensitivity and skin cancer susceptibility in a Spanish population. Methodology: Three-hundred volunteers participated in the study. Phenotypic characteristics of pigmentation, history of sunburn and sun exposure behaviour were collectedby using a standardized questionnaire. For each participant, we examined the genotype of the following genes involved in the human pigmentation pathway: MC1R, ASIP, TYR, OCA2, HERC2, SLC24A4, BNC2, IRF4, KITLG, and SLC45A2. To determine the association with phenotypic characteristics, a logistic regression was performed for each polymorfism. Statistical analysis were perfomed by using SPSS v24 software. Results: The major genetic determinant of pigmentation and sunlight sensitivity traits is the MC1R gene. Polymorphisms in IRF4, ASIP and SLC45A4 also seems to impacton basal skin pigmentation, as well as on the appearance of benign hyperpigmented lesions. Conclusion: Individuals having a risk phenotype carry significantly a higher number of genetic variants associated with reduced tolerance to sun exposure. Individuals carrying these polymorphisms would have a higher sensitivity to UV radiation and, therefore, an increased susceptibility todevelop skin cancer.

Keywords: Human pigmentation, Sunlight sensitivity, Benign hyperpigmented lesions, Polymorphisms, MC1R.

\section{Introducción}

Los rasgos de pigmentación humana, como el color de ojos, piel y pelo, son los rasgos fenotípicos más diferenciables entre humanos. La pigmentación humana está principalmente determinada por la cantidad y el tipo de melanina en la epidermis, iris y pelo (Praetorius, Sturm, y Steingrimsson, 2014; Ryung Roh, Eliades, Gupta, Grant-Kels, y Tsao, 2015). La melanina de la piel, producida como respuesta a la exposición a los rayos ultravioleta procedentes del sol, protege al ADN del núcleo de las células impidiendo que esta radiación produzca daño celular (Praetorius y cols., 2014; Scherer y Kumar, 2010). Existen dos tipos de melanina: la eumelanina, de color marrón-negruzca con elevada capacidad de absorber la radiación ultravioleta; y la feomelanina, de color rojizo-amarillento compuesta de unidades de benzotiazina que en gran medida es responsable del pelo rojo y las pecas (Scherer y Kumar, 2010).

La sensibilidad solar es el término referido a la capacidad de la piel de responder a la exposición solar. La aparición de quemaduras y la imposibilidad de bronceado son rasgos característicos de una mala respuesta al sol, siendo también indicadores de una mayor susceptibilidad a aparición de lesiones hiperpigmentadas benignas así como a desarrollar un cáncer cutáneo (Hernando, Ibarrola-Villava, Peña-Chilet, y cols., 2016; Scherer y Kumar, 2010; Sulem y cols., 2007). El grado de sensibilidad cutánea a la exposición solar está definido por rasgos de pigmentación determinados genéticamente, como tener el color de piel clara, 
los ojos azules o verdes, el pelo rubio o rojo, así como tener muchas pecas o lunares (Jacobs y cols., 2015).

Los rasgos de pigmentación son de carácter poligénico, es decir, están influenciados por muchísimos genes con efectos relativamente pequeños. Son muchos los estudios que han descrito variantes genéticas localizadas en genes relacionados con la pigmentación humana asociadas a fenotipos pigmentarios de riesgo y de sensibilidad solar, así como con el riesgo a cáncer de piel (Avilés y cols., 2012; Bastiaens y cols., 2001; Córdoba-Lanús y cols., 2014; Fernandez y cols., 2007; Law, MacGregor, y Hayward, 2012; Matichard y cols., 2004). Uno de los genes más estudiados, debido a su clara y directa asociación con fenotipos de sensibilidad solar, es el receptor de melanocortina $1(M C 1 R)$. La secuenciación de este gen ha permitido identificar la existencia de más de 100 variantes alélicas no sinónimas en poblaciones Caucásicas. Seis variantes han sido relacionadas con el color rojo de pelo, piel clara y la aparición de efélides (variantes RHC, red haircolour): D84E, R142H, R151C, I155T, R160W y D294H (Fernandez y cols., 2007; Ibarrola-Villava y cols., 2014). Asimismo, se han descrito otros genes que también parecen estar involucrados en la pigmentación y en la capacidad de respuesta a la exposición solar, como BNC2, IRF4, TYR, ASP o SLC45A2 (Eriksson y cols., 2010; Jacobs y cols., 2015; Scherer y Kumar, 2010).

Sin embargo, poco se conoce de su implicación de estos genes en el riesgo de aparición de lesiones hiperpigmentarias benignas y la predisposición a los diferentes cánceres de piel en la población española. Por ello, este estudio intentará esclarecer cuáles son las variantes genéticas que determinan la sensibilidad solar cutánea en la población española.

\section{Métodos}

\section{Sujetos y recogida de datos}

Se incluyeron un total de 300 individuos de origen español (150 hombres y 150 mujeres). Este estudio se engloba dentro de un proyecto de investigación el cual ha sido aprobado por la Comisión Deontológica de la Universitat Jaume I de Castellón. Todos los participantes firmaron un consentimiento informado.

Se utilizó un cuestionario estandarizado para recoger datos de filiación (edad, sexo y lugar de nacimiento), hábitos de exposición solar y características de sensibilidad solar cutánea. Cada rasgo fenotípico de sensibilidad solar fue clasificado en dos categorías: fototipo cutáneo I-II o III-IV, presencia o ausencia de lentigos solares, número de nevus menor o mayor de 25, presencia o ausencia de efélides, y presencia o ausencia de quemaduras solares en la infancia.

EI DNA genómico de cada individuo se obtuvo de una muestra de saliva. La extracción del DNA se realizó utilizando QIAamp DNA Mini Kit (Qiagen), siguiendo las recomendaciones del fabricante.

\section{Genotipado de variantes genéticas}

Se analizó un total de 10 polimorfismos (SNPs) localizados en genes previamente asociados a rasgos de pigmentación humana y sensibilidad solar (HERC2, ASP, OCA2, TYR, SLC45A2, BNC2, IRF4, SLC24A4 y KITLG). Todas las reacciones de genotipado se realizaron utilizando KASP SNP Genotyping Chemistry (LGC, Hoddesdon, Reino Unido) y TaqMan SNP Genotyping Assays (Applied Biosystems, California, EEUU). El análisis de la genotipación se 
Ilevó a cabo utilizando el equipo de PCR a tiempo real StepOnePlusTM (AppliedBiosystems, Foster City, CA, EE.UU.), y utilizando el software SDS 2.1 para el análisis de discriminación alélica (AppliedBiosystems)

Como medida de control de calidad, se incluyeron tres controles positivos (un heterocigoto, un homocigoto del alelo ancestral y un homocigoto del alelo derivado) y un control negativo por placa de 96 pocillos.

\section{Secuenciación del gen MC1R}

El ensayo genotípico del gen $M C 1 R$ se realizó mediante la secuenciación completa de la región codificante del gen, ya que se trata de un gen altamente polimórfico. Una vez amplificada la región codificante del gen, los productos de la PCR fueron purificados utilizando exonucleasa I y fosfatasa alcalina (Roche Molecular Bioquímicos AQ2, Mannheim, Alemania). El análisis de secuenciación se realizó utilizando la tecnología Sanger Sequencing. Los individuos fueron clasificados según eran portadores o no de variantes RHC del gen.

\section{Análisis estadístico}

Inicialmente, se realizó un test Chi-cuadrado tanto para comprobar el cumplimiento del equilibrio de Hardy-Weinberg (HWE) como para comparar la distribución de la frecuencia del alelo menor (MAF) de la población española y las poblaciones europeas de referencia: Utah residents with Northern and Western European ancestry(CEU) y Toscani in Italy (TSI). Los datos de estas poblaciones fueron extraídos de la base de datos ensembl (http://www.ensembl.org/).

Posteriormente, para determinar si existe una asociación entre las diferentes características fenotípicas y las variables genéticas estudiadas se llevó a cabo una regresión logística binaria (considerando el modelo genético de herencia aditivo). Para cada asociación se obtuvo el valor $p$ bilateral ( $P$-value), el odd ratio $(\mathrm{OR})$ y el correspondiente intervalo de confianza (IC).

Todos los análisis estadísticos se realizaron mediante el programa estadístico informático SPSS v24 y el Excel 2013.

\section{Resultados}

Antes de realizar los análisis genéticos, se llevó a cabo un análisis descriptivo para observar la distribución de las características de sensibilidad solar en nuestra población (número de nevus, historia de quemaduras solares, lentigos solares, fototipo cutáneo y efélides), formada por 150 hombres y 150 mujeres de origen español (Figura 1). 


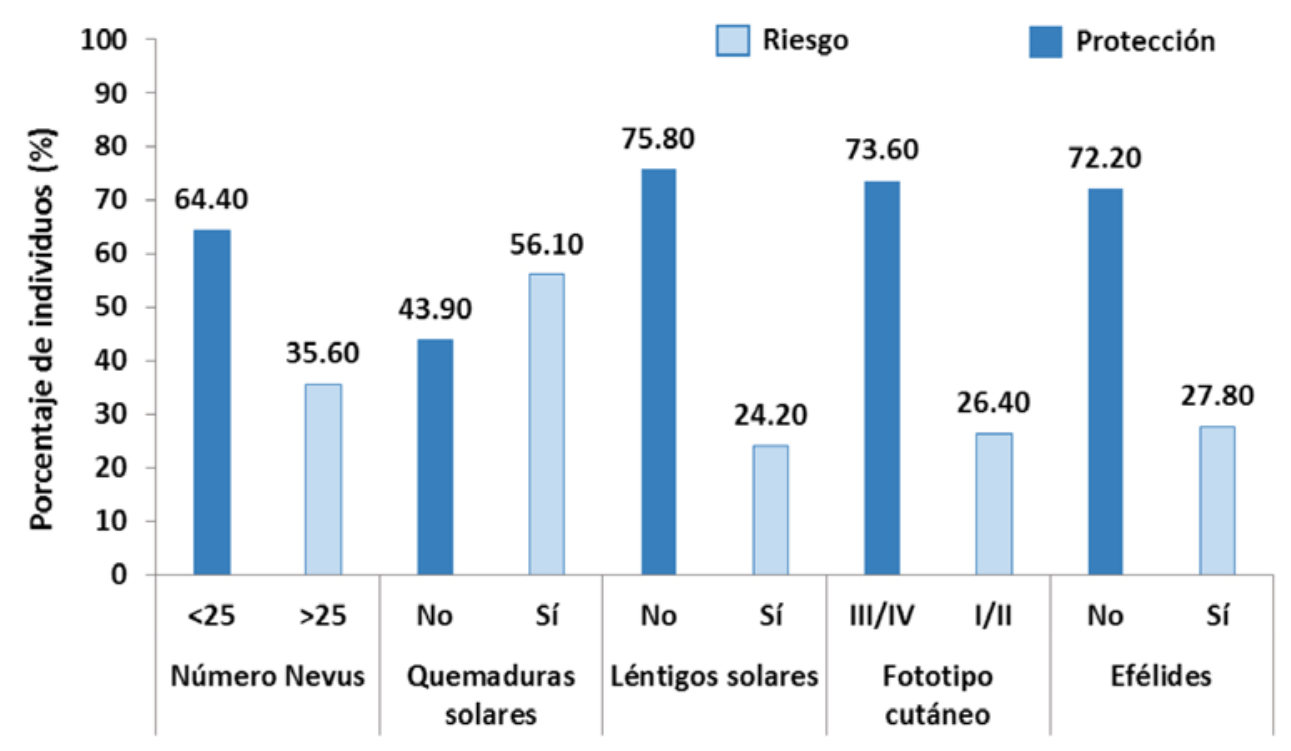

Figura 1.Distribución de características pigmentarias de sensibilidad solar en el total de individuos de la población española. Las barras representan el porcentaje de individuos del total que presenta cada característica según indica la leyenda

Tabla 1

Distribución de la frecuencia alélica en las diferentes poblaciones europeas

\begin{tabular}{|c|c|c|c|c|c|c|c|c|}
\hline \multirow{2}{*}{ Gen } & \multirow{2}{*}{ SNP } & \multirow{2}{*}{ Alelo Menor ${ }^{a}$} & \multirow{2}{*}{ MAF CEU } & \multirow{2}{*}{ MAF TSI } & \multicolumn{2}{|c|}{ Población España } & \multirow{2}{*}{$P$-value $\mathrm{CEU}^{e}$} & \multirow{2}{*}{$P$-value TSI } \\
\hline & & & & & MAF España & $\mathrm{pHWE}^{\mathrm{d}}$ & & \\
\hline OCA2 & rs1800407 & $\mathrm{T}$ & 0,081 & 0,098 & 0,078 & 0,402 & 0,896 & 0,390 \\
\hline HERC2 & rs12913832 & $T^{b}$ & 0,232 & 0,579 & 0,576 & 0,477 & $1,00 \mathrm{E}-05$ & 0,926 \\
\hline$A S P$ & rs4911442 & G & 0,121 & 0,056 & 0,081 & 0.107 & 0,087 & 0,237 \\
\hline BNC2 & rs2153271 & $\mathrm{C}$ & 0.399 & 0,435 & 0,457 & 0,054 & 0,153 & 0,569 \\
\hline IRF4 & rs12203592 & $A$ & 0,162 & 0,093 & 0,140 & 0,866 & 0,449 & 0,083 \\
\hline TYR1 & rs1393350 & A & 0,242 & 0,248 & 0,230 & 0,486 & 0,715 & 0,597 \\
\hline TYR2 & rs1042602 & A & 0,399 & 0,486 & 0,460 & 0,638 & 0,140 & 0,173 \\
\hline SLC24A4 & rs12896399 & $G^{c}$ & 0,439 & 0,617 & 0,437 & $4,00 E-03$ & 0,946 & $1,00 \mathrm{E}-05$ \\
\hline SLC45A2 & rs16891982 & $\mathrm{C}$ & 0,020 & 0,033 & 0,113 & 0,161 & $1,00 \mathrm{E}-04$ & $5,00 \mathrm{E}-04$ \\
\hline KITLG & rs 12821256 & C & 0,131 & 0,037 & 0,041 & 0,483 & $1,00 \mathrm{E}-05$ & 0,817 \\
\hline
\end{tabular}

Los valores resaltados en negrita son estadisticamente significativos $(P$-value $<0,05)$.

${ }^{a}$ Alelo menor de la población caucásica de referencia CEU

${ }^{b}$ Alelo con mayor frecuencia en la población italiana y española, que representa el mayoritario en estas poblaciones sur-europeas

${ }^{\mathrm{c}}$ Alelo con mayor frecuencia en la población italiana, que representa el alelo mayoritario en la población TSI

${ }^{d}$ pHWE es el $P$-value obtenido al analizar el cumplimiento del equilibrio de Hardy-Weinberg mediante un test Chi-cuadrado

${ }^{e} P$-value obtenido al compara las MAF de la población española con las MAF de CEU y TSI mediante un test Chi-cuadrado

Todos los SNPs estudiados cumplieron el equilibrio de Hardy-Weinberg, a excepción de SLC24A4 rs12896399 que fue descartado en los análisis de asociación posteriores (Tabla 1). La distribución alélica de HERC2 rs12913832, SLC45A2 rs16891982 y KITLG rs12821256 en la población española es significativamente diferente a la distribución observada en la población de referencia del norte de Europa (CEU). Asimismo, SLC24A4 rs12896399 y SLC45A2 
rs16891982 presentan una frecuencia del alelo menor diferente en nuestra población de origen español respecto a la descrita en la población de referencia del sur de Europa (TSI) (Tabla 1).

Posteriormente, se realizó un análisis para determinar si existe una asociación entre el genotipo y las características fenotípicas de sensibilidad solar. Para llevar a cabo este análisis de asociación se utilizó una regresión logística binaria entre cada variante genética y cada uno de los rasgos fenotípicos incluidos en el estudio (Tabla 2). Tres polimorfismos presentan una asociación significativa con la presencia de efélides (OR>1): rs12203592*A del gen IRF4 ( $P$ value $=0.026)$, rs $4911442^{*} \mathrm{G}$ del gen $A S P(P$-value $=0.048)$ y las variantes $\mathrm{RHC}$ del gen $M C 1 R$ $\left(P\right.$-value $\left.=5.00 \times 10^{-6}\right)$. Únicamente IRF4 rs12203592 está significativamente correlacionado con la presencia de léntigos solares $(O R>1, P$-value $=0.029)$. Nuestros resultados revelan que las variantes RHC del gen $M C 1 R$ predisponen a tener un fototipo cutáneo bajo $(P$-value $=$ $\left.1.00 \times 10^{-3}\right)$, y por consiguiente incrementan el riesgo a quemaduras solares cutáneas tras la exposición solar $(P$-value $=0.026)$. Sin embargo, el alelo C de SLC45A2 rs16891982 predispone a tener un fototipo alto $(\mathrm{OR}<1, P$-value $=0.016)$.

Tabla 2

Asociación del genotipo con cada una de las características pigmentarias de sensibilidad solar

\begin{tabular}{|c|c|c|c|c|c|c|c|c|}
\hline \multirow{2}{*}{ Gen } & \multirow{2}{*}{ SNP } & \multirow{2}{*}{ Alelo } & \multicolumn{2}{|c|}{ Efélides } & \multicolumn{2}{|c|}{ Lentigos solares } & \multicolumn{2}{|c|}{ Quemaduras solares } \\
\hline & & & P-value & OR $(95 \%$ IC) & P-value & OR $(95 \%$ IC) & P-value & OR $(95 \%$ IC) \\
\hline TYR & rs1042602 & A & 0,747 & $0,94(0,65-1,36)$ & 0,35 & $0,83(0,56-1,23)$ & 0,055 & $0,71(0,50-1,01)$ \\
\hline$T Y R$ & rs1393350 & A & 0,263 & $1,28(0,83-1,95)$ & 0,783 & $0,94(0,59-1,48)$ & 0,744 & $0,94(0,63-1,34)$ \\
\hline SLC45A2 & rs16891982 & $\mathrm{C}$ & 0,66 & $0,88(0,50-1,56)$ & 0,12 & $0,58(0,29-1,15)$ & 0,869 & $0,96(0,58-1,59)$ \\
\hline IRF4 & rs 12203592 & A & 0,026 & $1,76(1,07-2,89)$ & 0,029 & $1,77(1,06-2,96)$ & 0,829 & $1,05(0,66-1,70)$ \\
\hline$A S P$ & rs4911442 & G & 0.048 & $1,80(1,01-3,24)$ & 0,155 & $1,55(0,85-2,84)$ & 0,309 & $1,36(0,75-2,47)$ \\
\hline HERC2 & rs12913832 & $\mathrm{T}$ & 0,118 & $0,69(0,43-1,10)$ & 0,127 & $0,72(0,47-1,10)$ & 0,178 & $0,76(0,51-1,14)$ \\
\hline OCA2 & rs1800407 & $\mathrm{T}$ & 0,685 & $1,19(0,52-2,70)$ & 0,519 & $1,28(0,60-2,73)$ & 0,789 & $0,91(0.44-1,87)$ \\
\hline KITLG & rs12821256 & C & 0,494 & $0,70(0,25-1,96)$ & 0,343 & $0,55(0,16-1,91)$ & 0,576 & $0,78(0,33-1,87)$ \\
\hline$M C 1 R$ & $\mathrm{RHC}$ variants & $\mathrm{RHC}$ & $5,00 \mathrm{E}-06$ & $3,79(2,14-6,71)$ & 0,92 & $0,97(0,53-1,77)$ & 0,026 & $1,94(1,08-3,47)$ \\
\hline \multirow{2}{*}{ Gen } & \multirow{2}{*}{ SNP } & \multirow{2}{*}{ Alelo- } & \multicolumn{2}{|c|}{ Fototipo cutáneo } & \multicolumn{2}{|c|}{ Número de nevus } & & \\
\hline & & & P-value & OR (95\% IC) & P-value & OR (95\% IC) & & \\
\hline$T Y R$ & rs1042602 & $A$ & 0,976 & $1,01(0,69-1,47)$ & 0,084 & $0,73(0,51-1,04)$ & & \\
\hline$T Y R$ & rs1393350 & A & 0,917 & $1,02(0,66-1,59)$ & 0,147 & $1,34(0,90-1,99)$ & & \\
\hline$S L C 45 A 2$ & rs16891982 & $\mathrm{C}$ & 0,016 & $0,34(0,19-0,84)$ & 0,438 & $0,81(0,47-1,39)$ & & \\
\hline IRF4 & rs 12203592 & $A$ & 0,419 & $1,24(0,74-2,07)$ & 0,829 & $0,95(0,58-1,55)$ & & \\
\hline$A S P$ & rs4911442 & G & 0,512 & $1,23(0,67-2,26)$ & 0,955 & $0,98(0,55-1,77)$ & & \\
\hline HERC2 & rs12913832 & $\mathrm{T}$ & 0,346 & $0,79(0,48-1,29)$ & 0,57 & $0,89(0,59-1,34)$ & & \\
\hline OCA2 & rs1800407 & $\mathrm{T}$ & 0,977 & $1,01(0,41-2,51)$ & 0,242 & $0,61(0,27-1,39)$ & & \\
\hline KITLG & rs 12821256 & C & 0.621 & $0,77(2,73-2,17)$ & 0,447 & $0,69(0,26-1,82)$ & & \\
\hline$M C 1 R$ & $\mathrm{RHC}$ variants & $\mathrm{RHC}$ & $1.00 \mathrm{E}-03$ & $2,53(1,46-4,41)$ & 0,508 & $1,20(0,70-2,04)$ & & \\
\hline
\end{tabular}

Los valores resaltados en negrita son estadísticamente significativos $(P$-value $<0.05)$

\section{Discusión y conclusiones}

En este estudio, se ha recogido información de varias características pigmentarias de sensibilidad solar cutánea (fototipo cutáneo, lentigos solares, número de nevus, efelides, e historia de quemaduras solares) y determinado el genotipo de diferentes genes relacionados 
con la pigmentación humana de 300 individuos de origen español. El objetivo del era analizar si existen variantes genéticas específicas que incrementen la sensibilidad solar cutánea.

Inicialmente se realizó una descripción de nuestra población de acuerdo a las variables fenotípicas incluidas en el análisis. La distribución de las características fenotípicas en nuestra población española son concordantes con otros estudios realizados en poblaciones mediterráneas (Candille y cols., 2012; Ibarrola-Villava y cols., 2011; Martinez-Cadenas, Peña-Chilet, Ibarrola-Villava, y Ribas, 2013), donde los individuos suelen presentar fototipos cutáneos altos (III/IV) y la prevalencia de efélides es baja (Figura 1). Destacar el bajo número de individuos que presentan lentigos solares $(24.20 \%)$, seguramente debido a que la mayoría de individuos incluidos en el estudio tiene menos de 35 años y los lentigos solares son lesiones hiperpigmentadas benignas relacionadas principalmente con el fotoenvejecimiento (Ezzedine y cols., 2013). Por otro lado, es interesante que, aunque la mayoría de individuos tengan una buena capacidad de respuesta a la exposición solar (fototipos III/IV), existe un elevado porcentaje de la población que ha sufrido quemaduras solares en la infancia (56.10\%). Una causa que podría explicar estos resultados es que los individuos incluidos en el estudio residen en la zona del Levante donde, debido a las buenas condiciones climáticas, la gente podría estar más expuesta a las radiaciones solares que en otras regiones de España.

A continuación, se realizó una comparación entre la distribución de la frecuencia alélica entre nuestra población y las dos poblaciones europeas de referencia (CEU y TSI). Este análisis demuestra que existen diferencias en las frecuencias alélicas de genes relacionados con la pigmentación entre poblaciones europeas. Estas diferencias son las que determinan que poblaciones norte-europeas tengan un color de piel, ojos y pelo más claro, y mayor número de efélides, que las poblaciones del sur de Europa. En concordancia con nuestros resultados, estudios recientes han detectado cambios en la frecuencia alélica de variantes localizadas en genes de pigmentación (SLC45A2, SLC24A5 y HERC2) en el proceso de evolución de las diferentes poblaciones de la especie humana, poniendo de manifiesto que la pigmentación cutánea basal y la respuesta al sol por bronceamiento son rasgos hereditarios que responden a una selección natural vía adaptación genética a la radiación solar (Mathieson y cols., 2015). Así pues, los africanos ancestrales tienen fijados alelos asociados a pigmentación oscura y, mediante un proceso de adaptación genética, la frecuencia de dichos alelos disminuye progresivamente en gradiente sur-norte con el objetivo de aclarar el color de la piel en zonas geográficas donde los niveles de radiación solar son menores. Un ejemplo claro es el gen SLC45A2, ya que la frecuencia del alelo ancestral de rs16891982 (asociado a pigmentación oscura) en la población española es mayor que en el resto de poblaciones europeas, seguramente debido a un proceso de selección a la mayor exposición solar que existe en España (Ibarrola-Villava y cols., 2011). Estas diferencias genotípicas explicarían el hecho de que la pigmentación cutánea basal en individuos de poblaciones Mediterráneas sea más oscura (Martinez-Cadenas y cols., 2013).

\section{Asociación de variantes genéticas con rasgos fenotípicos de sensibilidad solar}

Nuestros resultados confirman estudios previos que definen las variantes $\mathrm{RHC}$ del gen $M C 1 R$ como el mayor determinante del fenotipo pigmentario de riesgo característico de tener la piel clara que tras la exposición solar siempre se quema y nunca se broncea (fototipo cutáneo I/II), así como tener efélides (Jacobs y cols., 2015; Praetorius y cols., 2014; Scherer y Kumar, 2010). 
Por otro lado, nuestros resultados muestran una relación entre el polimorfismo rs12203592 localizado en el gen que codifica para el factor regulador de interferón 4 (IRF4) y la aparición de lesiones hiperpigmentarias benignas como efélides y lentigos solares. Por ejemplo, ser portador del alelo derivado $(T)$ de este polimorfismo incrementa casi el doble el riesgo relativo de tener efélides respecto a ser portador del alelo ancestral $(G)$. Este resultado parece concordante con estudios previos dónde determinadas variantes genéticas de IRF4 han sido asociadas a ciertos rasgos relacionados con la pigmentación cutánea basal, la sensibilidad cutánea a la exposición solar, la aparición prematura de canas, la aparición de pecas, y también con el riesgo a melanoma (Jacobs y cols., 2015; Peña-Chilet y cols., 2013; Praetorius y cols., 2013, 2014). Además de expresarse en células del sistema inmunitario y mediar en la respuesta inmunológica frente a infecciones víricas, este gen también se expresa en los melanocitos de la epidermis. La expresión de IRF4 tiene un efecto inductor en la síntesis de melanina, al incrementar los niveles de la tirosinasa (encima clave en la melanogéneis) en el interior del melanocito (Praetorius y cols., 2013). Asimismo, IRF4 coopera con MITF en la regulación de la expresión de $M C 1 R$ en el melanocito - gen clave en la activación de la vía de la pigmentación (Praetorius y cols., 2013).

Otro de los genes relacionados previamente con la pigmentación que ha sido incluido en el estudio esSLC45A2 - gen que codifica un transportador de solutos localizado en el melanosoma involucrado en la maduración del mismo (Ibarrola-Villava y cols., 2011; Scherer y Kumar, 2010). Son varios los estudios que han descrito variantes genéticas en este gen relacionadas con cambios en la pigmentación cutánea basal, así como con el riego a melanoma. Tal y como se explica anteriormente, el alelo ancestral del polimorfismo rs16891982 se asocia con color de piel, pelo y ojos oscuros, capacidad de responder a la exposición solar por bronceamiento y un menor riesgo de cáncer cutáneo (Ibarrola-Villava y cols., 2011; Scherer y Kumar, 2010). Los resultados obtenidos en nuestra población respaldan dichas observaciones previas, ya que la mayoría de individuos que presentan una mejor tolerancia a la exposición solar (fototipo cutáneo III/IV) son portadores del alelo ancestral C.

El gen que codifica para la proteína de señalización agouti $(A S P)$, ligando de $M C 1 R$ que antagoniza la función del receptor transmembrana, también ha sido intensamente estudiado debido a su importancia en el ratio eumelanina/feomelanina sintetizado en el interior del melanocito (Liu, Wen, y Kayser, 2013; Scherer y Kumar, 2010). En nuestra población española, rs4911442 parece estar implicada en la aparición de efélides vía alteración de los niveles de expresión del gen. Concretamente, el alelo $G$ de esta variante genética incrementa la posibilidad de presentar efélides, seguramente debido a que este alelo activa la expresión de ASP incrementando los niveles de agouti que, tras su unión con MC1R, inhibe la vía de la pigmentación favoreciendo la síntesis de feomelanina en detrimento de la síntesis de eumelanina (Jacobs y cols., 2015; Praetorius y cols., 2014).

Tener un elevado número de nevus no parece estar determinado por ninguna de las variantes genéticas incluidas en este estudio. Los nevus adquiridos son tumores benignos que surgen como consecuencia directa del daño causado por la radiación ultravioleta, favoreciendo la transformación de los melanocitos de la epidermis. Así pues, la presencia de mayor número de nevus vendría determinada por mutaciones somáticas adquiridas y no tanto por las mutaciones en línea germinal analizadas en este estudio (Baron y cols., 2014; Hernando, Ibarrola-Villava, Fernandez, y cols., 2016).

En conclusión, este estudio revela variantes genéticas que determinan rasgos de sensibilidad solar en individuos de origen español. Debido a que la pigmentación depende de la interacción entre varios genes, es interesante conocer si existe un efecto acumulativo en individuos portadores de varios polimorfismos asociados a fenotipo de riesgo, es decir, a tener una mayor susceptibilidad a la radiación solar y, por tanto, a padecer cáncer cutáneo. La 
identificación de variantes asociadas con rasgos fenotípicos que predisponen a cáncer de piel ofrece la oportunidad de estudiar su asociación con el riesgo de cáncer cutáneo, ya que la forma esporádica de cáncer de piel se desarrolla a través de la interacción con el medio ambiente y con factores de predisposición genética.

\section{Referencias bibliográficas}

Avilés, J. A., Lázaro, P., Fernández, L. P., Benítez, J., Ibarrola-Villava, M., y Ribas, G. (2012). Características fenotípicas e histológicas de los pacientes con melanoma cutáneo en función de los polimorfismos del MC1R. Actas Dermo-Sifiliograficas, 103(1), 44-50. https:// doi.org/10.1016/j.ad.2011.04.009

Baron, A. E., Asdigian, N. L., Gonzalez, V., Aalborg, J., Terzian, T., Stiegmann, R. A., Box, N. F. (2014). Interactions between ultraviolet light and MC1R and OCA2 variants are determinants of childhood nevus and freckle phenotypes. Cancer Epidemiol Biomarkers Prev, 23(12), 2829-2839. https://doi.org/10.1158/1055-9965.EPI-14-0633

Bastiaens, M., Huurne, J., Gruis, N., Bergman, W., Westendorp, R., Vermeer, B. J., y Bavinck, J. (2001). The melanocortin-1-receptor gene is the major freckle gene. Hum Mol Genet, 10(16), 1701-1708. https://doi.org/10.1093/hmg/10.16.1701

Candille, S. I., Absher, D. M., Beleza, S., Bauchet, M., McEvoy, B., Garrison, N. A., Shriver, M. D. (2012). Genome-Wide Association Studies of Quantitatively Measured Skin, Hair, and Eye Pigmentation in Four European Populations. PLoS ONE, 7(10), e48294. https://doi. org/10.1371/journal.pone.0048294

Córdoba-Lanús, E., Hernández-Jiménez, J. G., Medina-Coello, C., Espinoza-Jiménez, A., González, A., Rodríguez-Pérez, M. D. C., Fernández-De-Misa, R. (2014). MC1R gene variants and sporadic malignant melanoma susceptibility in the Canary Islands population. Archives of Dermatological Research, 306(1), 51-58. https://doi.org/10.1007/s00403-013-1420-z

Eriksson, N., Macpherson, J. M., Tung, J. Y., Hon, L. S., Naughton, B., Saxonov, S., Mountain, J. (2010). Web-based, participant-driven studies yield novel genetic associations for common traits. PLoS Genetics, 6(6), e1000993. https://doi.org/10.1371/journal.pgen.1000993

Ezzedine, K., Mauger, E., Latreille, J., Jdid, R., Malvy, D., Gruber, F., Guinot, C. (2013). Freckles and solar lentigines have different risk factors in Caucasian women. Journal of the European Academy of Dermatology and Venereology, 27(3), 345-56. https://doi. org/10.1111/j.1468-3083.2012.04685.x

Fernandez, L. P., Milne, R. L., Bravo, J., Lopez, J. M., Avilés, J. A., Longo, M. I., Ribas, G. (2007). MC1R: Three novel variants identified in a malignant melanoma association study in the Spanish population. Carcinogenesis, 28(8), 1659-1664. https://doi.org/10.1093/carcin/ bgm084

Hernando, B., Ibarrola-Villava, M., Fernandez, L. P., Peña-Chilet, M., Llorca-Cardeñosa, M., Oltra, S. S., Ribas, G. (2016). Sex-specific genetic effects associated with pigmentation, sensitivity to sunlight, and melanoma in a population of Spanish origin. Biology of Sex Differences, 7(17), 1-9. https://doi.org/10.1186/s13293-016-0070-1

Hernando, B., Ibarrola-Villava, M., Peña-Chilet, M., Alonso, S., Ribas, G., y Martinez-Cadenas, C. (2016). Sex and MC1R variants in human pigmentation: Differences in tanning ability and sensitivity to sunlight between sexes. Journal of Dermatological Science, 84(3), 346348. https://doi.org/10.1016/j.jdermsci.2016.09.004

Ibarrola-Villava, M., Fernandez, L. P., Alonso, S., Boyano, M. D., Peña-Chilet, M., Pita, G., Ribas, G. (2011). A customized pigmentation SNP array identifies a novel SNP associated with 
melanoma predisposition in the SLC45A2 gene. PLoS ONE, 64(4), e19271. https://doi. org/10.1371/journal.pone.0019271

Ibarrola-Villava, M., Pe, M., Llorca-Carde, M. J., Oltra, S., Cadenas, C.-M., Bravo, J., y Ribas, G. (2014). Modeling MC1R Rare Variants: A Structural Evaluation of Variants Detected in a Mediterranean Case-Control Study. Journal of Investigative Dermatology, 134(4), 11461149. https://doi.org/10.1038/jid.2013.469

Jacobs, L. C., Hamer, M. A., Gunn, D. A., Deelen, J., Lall, J. S., Van Heemst, D., Nijsten, T. (2015). A Genome-Wide Association Study Identifies the Skin Color Genes IRF4, MC1R, ASIP, and BNC2 Influencing Facial Pigmented Spots. Journal of Investigative Dermatology, 135(7), 1735-1742. https://doi.org/10.1038/jid.2015.62

Law, M. H., MacGregor, S., y Hayward, N. K. (2012). Melanoma Genetics: Recent Findings Take Us Beyond Well-Traveled Pathways. Journal of Investigative Dermatology, 132(7), 17631774. https://doi.org/10.1038/jid.2012.75

Liu, F., Wen, B., y Kayser, M. (2013). Colorful DNA polymorphisms in humans. Seminars in Cell and Developmental Biology, 24(6-7), 562-575. https://doi.org/10.1016/j. semcdb.2013.03.013

Martinez-Cadenas, C., Penãa-Chilet, M., Ibarrola-Villava, M., y Ribas, G. (2013). Gender is a major factor explaining discrepancies in eye colour prediction based on HERC2/OCA2 genotype and the IrisPlex model. Forensic Science International: Genetics, 7(4), 453-460. https://doi.org/10.1016/j.fsigen.2013.03.007

Mathieson, I., Lazaridis, I., Rohland, N., Mallick, S., Patterson, N., Roodenberg, S. A., Reich, D. (2015). Genome-wide patterns of selection in 230 ancient Eurasians. Nature, 528(7583), 499-503. https://doi.org/10.1038/nature16152

Matichard, E., Verpillat, P., Meziani, R., Gérard, B., Descamps, V., Legroux, E., Soufir, N. (2004). Melanocortin 1 receptor (MC1R) gene variants may increase the risk of melanoma in France independently of clinical risk factors and UV exposure. J Med Genet, 41(2), e13. https:// doi.org/10.1136/jmg.2003.011536

Peña-Chilet, M., Blanquer-Maceiras, M., Ibarrola-Villava, M., Martinez-Cadenas, C., MartinGonzalez, M., Gomez-Fernandez, C., Ribas, G. (2013). Genetic variants in PARP1 (rs3219090) and IRF4 (rs12203592) genes associated with melanoma susceptibility in a Spanish population. BMC Cancer, 13(1), 160. https://doi.org/10.1186/1471-2407-13-160

Praetorius, C., Grill, C., Stacey, S. N., Metcalf, A. M., Gorkin, D. U., Robinson, K. C., Steingrimsson, E. (2013). A polymorphism in IRF4 affects human pigmentation through a tyrosinasedependent MITF/TFAP2A pathway. Cell, 155(5), 1022-1033. https://doi.org/10.1016/j. cell.2013.10.022

Praetorius, C., Sturm, R. A., y Steingrimsson, E. (2014). Sun-induced freckling: Ephelides and solar lentigines. Pigment Cell and Melanoma Research, 27(3), 339-350. https://doi. org/10.1111/pcmr.12232

Ryung Roh, M., Eliades, P., Gupta, S., Grant-Kels, J. M., y Tsao, H. (2015). Cutaneous melanoma in women. Int $J$ Womens Dermatol, 1(1), 21-25. https://doi.org/10.1016/j. ijwd.2015.01.001

Scherer, D., y Kumar, R. (2010). Genetics of pigmentation in skin cancer - A review. Mutation Research - Reviews in Mutation Research, 705(2), 141-153. https://doi.org/10.1016/j. mrrev.2010.06.002

Sulem, P., Gudbjartsson, D. F., Stacey, S. N., Helgason, A., Rafnar, T., Magnusson, K. P., Stefansson, K. (2007). Genetic determinants of hair, eye and skin pigmentation in Europeans. Nature Genetics, 39(12), 1443-52. https://doi.org/10.1038/ng.2007.13 


\title{
Influencia de la autoestima e imagen corporal en la satisfacción sexual de jóvenes universitarios
}

\author{
VERÓNICA MARTÍNEZ-BORBA \\ al189588@uji.es \\ LARA SALVADOR-BOIX \\ al189590@uji.es \\ BEATRIZ GIL-JULIÀ \\ bgil@uji.es \\ Jesús CAstro-CaLvo \\ castroj@uji.es \\ RAFAEL BALLESTER-ARNAL \\ rballest@uji.es
}

\section{Resumen}

Introducción: Recientemente, las investigaciones sobre sexualidad han tratado de dilucidar la importancia de factores psicológicos, como la autoestima o la imagen corporal, en la satisfacción sexual. Algunos estudios señalan la importancia del género en este campo, con resultados incongruentes. El objetivo del presente trabajo es explorar la influencia de la autoestima e imagen corporal en la satisfacción sexual y si esta influencia difiere en función del género en jóvenes universitarios. Método: La muestra está formada por 367 sujetos ( $58 \%$ mujeres) con edades entre los 18 y 28 años (Media=21,23; $D T=2,65$ ). Todos respondieron la Nueva Escala de Satisfacción Sexual (NSSS), la Escala de Autoestima de Rosenberg (RSES) y el Cuestionario de la Forma Corporal (BSQ). Resultados: No se han encontrado diferencias de género estadísticamente significativas en satisfacción sexual $(t=-0,80, p=, 422)$ pero sí en autoestima $(t=4,56, p \leq, 001)$ con una media superior en hombres, e insatisfacción con la imagen corporal $(t=-10,31, p \leq, 001)$ con una media mayor en las mujeres. Tras controlar el efecto de la edad, la varianza en satisfacción sexual explicada por la autoestima era del $9,7 \%$ en hombres y del $4,1 \%$ en mujeres. La imagen corporal no explicó la satisfacción sexual en ninguno de los sexos. Conclusiones: Entre los jóvenes, no hay diferencias de género en satisfacción sexual, pero las mujeres presentan menor autoestima y mayor insatisfacción con su imagen corporal. La autoestima juega un papel relevante en la satisfacción sexual, sobre todo de los hombres. En la práctica clínica, es importante atender a las diferencias de género en los factores asociados a la satisfacción sexual dado que éstas nos pueden guiar en la prevención y tratamiento de problemas sexuales.

Palabras clave: satisfacción sexual, autoestima, imagen corporal, diferencias de género. 


\section{Abstract}

Introduction: Recently, research on sexuality has focused on the importance of psychological factors, such as self-esteem or body image, in sexual satisfaction. Some studies highlight the importance of gender in this field. However, this topic remains unclear. The aim of this study is to explore whether the contribution of self-esteem and body imagen on sexual satisfaction outcomes is also sensitive to sex. Method: The sample was composed of 367 university students (58\% female) aged 18 to 28 years $(M=21.23, S D= \pm 2.65)$. They responded the New Sexual Satisfaction Scale (NSSS), the Rosenberg Self-esteem Scale (RSES) and the Body Shape Questionnaire (BSQ). Results: No gender differences in sexual satisfaction were found $(t=-0.80, p=422)$ but in self-esteem $(t=4.56, p \leq, 001)$ with a higher mean in men, and dissatisfaction with body image $(t=-10.31, p \leq .001)$ with a higher mean in women. After controlling for age, the variance of sexual satisfaction explained by self-esteem was $9.7 \%$ for men and $4.1 \%$ for women. Body image did not contributed to sexual satisfaction regardless of gender. Conclusions: Among young people, there are no gender differences in sexual satisfaction, but women have lower self-esteem and greater dissatisfaction with their body image. Self-esteem plays an important role in sexual satisfaction, especially in men. In clinical practice, gender differences in the factors associated with sexual satisfaction could guide sexual problem's prevention and treatment.

Key Words: sexual satisfaction, self-esteem, body image, gender differences.

\section{Introducción}

El concepto de sexualidad se ha transformado en las últimas décadas de forma paralela a los avances y cambios en la sociedad. Durante siglos, se pensó que la única finalidad de la sexualidad era la reproducción, por lo que se veía relacionada con el instinto que surge de forma natural en todos los animales. Más tarde se aceptó la idea de que la sexualidad no podía definirse por una única función, sino que implica un conjunto de fenómenos emocionales y conductuales asociados a la búsqueda de placer sexual. Actualmente, se defiende que la sexualidad constituye una función básica del ser humano que implica factores fisiológicos, emocionales y cognitivos, relacionándose con otros aspectos personales y psicológicos tales como el bienestar, la salud o la calidad de vida. Desde el presente trabajo entendemos la satisfacción sexual como el nivel de agrado, bienestar y ajuste presentado frente a una interacción sexual (Rodríguez, 2010).

La satisfacción sexual constituye un derecho humano y un elemento clave en la calidad de vida de las personas, asociándose a un mejor estado de salud física y mental (Scott, Sandberg, Harper y Miller, 2012). Se han encontrado relaciones entre satisfacción sexual, salud física, psicológica, bienestar general (Scott y cols., 2012) y calidad de vida (Davidson, Bell, LaChina, Holden y Davis, 2009). Recientemente, se ha estudiado la influencia de los factores sociodemográficos, tales como el género y el nivel educativo, en la satisfacción sexual. Los resultados sobre género son incongruentes: algunos postulan que las mujeres tienen mayor satisfacción sexual que los hombres (Rehman, Rellini y Fallis, 2011); otros sitúan a los hombres como más satisfechos sexualmente (Carpenter, Nathanson y Kim, 2009; Ji y Norling, 2004) y con una actitud ante la sexualidad más positiva (Peris, Maganto y Kortabarria, 2013); mientras que hay quien no ha encontrado diferencias entre hombres y mujeres (McClelland, 
2011; Santos-Iglesias, Sierra, García, Martínez, Sánchez y Tapia, 2009). En cuanto al nivel educativo, se ha encontrado relación entre satisfacción sexual y nivel académico, de manera que una mayor satisfacción sexual parece que se relaciona con altos niveles educativos (Acuña y Ceballos, 2005; Carpenter y cols., 2009).

Además, la satisfacción sexual ha sido ampliamente estudiada en relación con variables psicológicas, entre las que destacan la imagen corporal y la autoestima. En este sentido, se ha encontrado que una mayor autoestima se asocia con una menor insatisfacción corporal (Mellor, Fuller, McCabe y Ricciardelli, 2010; Salvador, García-Gálvez y de la Fuente, 2010). En cuanto a las diferencias de género, se ha encontrado que las mujeres tienen menor autoestima (Salvador y cols., 2010) y están más insatisfechas con su cuerpo (Mellor y cols., 2010) mientras que los hombres presentan una mayor autoestima tanto física y social como erótica (Peris y cols., 2013). Cuando se ha explorado la relación entre satisfacción sexual y autoestima se han encontrado relaciones positivas entre estas variables (Calado, Lameiras y Rodríguez, 2004).

Desde hace décadas, se ha venido explorando el papel de la imagen corporal en la sexualidad. Faith, Mitchell y Schare (1993) encontraron que la imagen corporal predecía la frecuencia de los encuentros sexuales tanto en hombres como en mujeres. De manera que, la imagen corporal (apreciación positiva o negativa) influye significativamente en la frecuencia sexual. Más tarde, Pujols, Meston y Seal (2010) han hallado relaciones positivas entre el funcionamiento sexual, satisfacción sexual e imagen corporal. Una mayor satisfacción sexual se relacionó con una mejor imagen corporal. En este sentido, una buena valoración de la imagen corporal así como una baja frecuencia de pensamientos sobre la apariencia corporal predijeron la satisfacción sexual (Pujols y cols., 2010). Esta relación entre la insatisfacción corporal y la insatisfacción sexual también se ha encontrado en población homosexual (Cedillo, 2015). En conclusión, las investigaciones sobre la relación entre la satisfacción sexual e imagen corporal demuestran que la autopercepción del atractivo físico puede tener una influencia importante sobre la actividad sexual y, con ello, brinda la oportunidad de modelar dichas percepciones para mejorar la calidad de la actividad sexual (Weaver y Byers, 2006).

En nuestro país se llevó a cabo un estudio en población no clínica, donde se exploraba la influencia de la imagen corporal y la autoestima en la experiencia sexual de las mujeres. La media de edad de las jóvenes fue de 19,5 años y un nivel socio-económico medio. Se encontró que las chicas que tenían miedo a ganar peso tenían menos experiencias sexuales. Aquellas chicas con distorsión de la imagen corporal estaban más insatisfechas con su primera relación coital, y mayor insatisfacción corporal en el momento de la evaluación se relacionó con una menor actividad sexual. Parece que las chicas que se autoperciben como menos atractivas han mantenido y mantienen menos actividades sexuales (Calado y cols., 2004).

Sin embargo, la importancia de estas tres variables en conjunto se ha explorado poco. Cuando se ha hecho, el aspecto evaluado ha sido la frecuencia de las relaciones sexuales, aunque sabemos que la satisfacción sexual engloba mucho más que eso. Además, las investigaciones en las que se ha tenido en cuenta estas tres variables suelen centrarse en población clínica (Pintado, 2013). Finalmente, la literatura se focaliza en mujeres, pasando por alto las diferencias de género en sexualidad. Por lo tanto, el objetivo del presente trabajo es analizar la relación y diferencias de género en la satisfacción sexual, la autoestima y la imagen corporal, así como analizar la influencia de la imagen corporal y la autoestima en el desarrollo de la satisfacción sexual en una muestra de jóvenes universitarios. En relación a la literatura descrita, planteamos como hipótesis que los hombres mostrarán mayor satisfacción sexual, autoestima y menor insatisfacción con la imagen corporal que las mujeres. Además, encontraremos relaciones negativas entre la insatisfacción corporal y la autoestima. Estas variables a su vez se relacionaran con la satisfacción sexual. Finalmente, esperamos que la autoestima e imagen corporal tengan un papel predictor de la satisfacción sexual. 


\section{Método}

\section{Participantes}

En la recogida inicial de muestra se contó con 420 participantes. El cribado de la muestra se hizo en función a dos criterios. En primer lugar, se eliminaron los participantes que no habían cumplimentado adecuadamente los cuestionarios, quedando la muestra reducida a 400 sujetos. En segundo lugar, se acotó la edad de 18 a 28 años, puesto que constituían el rango más representativo de participantes. Por lo tanto, la muestra final estuvo formada por 367 jóvenes universitarios de la localidad de Castellón de la Plana y Valencia (España). De ellos 213 eran mujeres (58\%) y 154 hombres (42\%). La edad media fue de 21,23 años (DT $=2,65$ ). Respecto al nivel educativo, la mayoría tenían estudios universitarios $(84,2 \%$ de grado o licenciatura y $5,4 \%$ de postgrado), y el resto de bachiller $(9,3 \%)$. En cuanto a la orientación sexual el $93,5 \%$ de los participantes son heterosexuales, el $3,3 \%$ son bisexuales, el $3 \%$ son homosexuales y $0,3 \%$ asexuales.

\section{Instrumentos}

- New Sexual Satisfaction Scale (NSSS; Pérez, 2013): cuestionario diseñado para medir la satisfacción sexual independientemente del género, orientación sexual o estatus de relación de pareja. Se evalúan aspectos de las relaciones sexuales como las sensaciones físicas, conciencia sexual, intercambio sexual, apego emocional y actividad sexual. No está asociado a muestras clínicas por lo que se puede aplicar en cualquier población. Consta de 20 ítems con 5 alternativas de respuesta tipo Likert (1= nada satisfecho / $5=$ muy satisfecho). La puntuación total oscila entre 20 y 100 . La consistencia interna en nuestra muestra fue de 0,91.

- Escala de autoestima de Rosenberg (RSES; Rosenberg, 1965): escala que explora la autoestima general, entendida como los sentimientos de valía personal, aceptación y respeto a sí mismo. Está compuesta por 10 ítems, 5 están redactados en sentido positivo y los 5 restantes en sentido negativo. Se responde mediante una escala Likert de 4 grados, los ítems positivos están codificados de manera que 1=muy en desacuerdo y 4=muy de acuerdo. Los ítems negativos se codifican a la inversa (4=muy en desacuerdo / 1=muy de acuerdo). La puntuación total se encuentra entre 10 y 40 . La fiabilidad obtenida en nuestro estudio ha sido buena $(\alpha=0,87)$.

- Cuestionario de la forma corporal (BSQ; Raich, Mora, Soler, Ávila, Clos y Zapater, 1996): instrumento diseñado para medir la preocupación por el peso y la imagen corporal, la insatisfacción producida por el propio cuerpo, el miedo a engordar, la autodesvalorización por la apariencia física, el deseo de perder peso y la evitación de situaciones en las que la apariencia física pueda atraer la atención. Está formado por 34 ítems de respuesta según escala Likert de 6 alternativas ( $1=$ nunca / $6=$ =siempre). La puntuación total oscila entre 34 y 204 puntos. La versión española del cuestionario permite dividirlo en un único factor de insatisfacción corporal general o en 5 factores (preocupación por el peso en relación con la ingesta, preocupación por los aspectos antiestéticos de la obesidad, insatisfacción y preocupación general, insatisfacción corporal respecto a la parte inferior del cuerpo y empleo del vómito o laxantes para reducir la insatisfacción corporal). La fiabilidad ha sido buena para todos los factores $(0,56<\alpha<0,88)$. 


\section{Procedimiento}

En primer lugar se expusieron los objetivos de la investigación, haciendo hincapié en la confidencialidad y el anonimato. Una vez obtenida la aprobación de las personas participantes se procedió a administrarles la batería de cuestionarios en formato papel y lápiz. Se empleó el programa estadístico IBM SPSS Statistics versión 22 para realizar el análisis de datos. En primer lugar, se realizaron análisis descriptivos de cada una de las variables del estudio diferenciadas por género y se llevó a cabo una prueba $t$ de Student de muestras independientes para analizar las diferencias de género. También se ha realizado análisis de ítems con la finalidad de profundizar en el estudio de la satisfacción sexual, la autoestima y la imagen corporal. En segundo lugar, se analizaron las relaciones entre las variables estudiadas mediante el coeficiente de correlación $r$ de Pearson. Por último, realizamos análisis de regresión lineal para explorar las relaciones de dependencia de estas variables.

\section{Resultados}

\section{Diferencias de género en las puntuaciones totales}

Los datos de la prueba $t$ student para analizar las diferencias entre hombres y mujeres en la satisfacción sexual, autoestima e insatisfacción corporal se muestran en la tabla 1.

Estos resultados indican que existen diferencias estadísticamente significativas entre ambos sexos en autoestima, insatisfacción corporal, y todos sus factores (preocupación por el peso en relación a la ingesta, preocupación por los aspectos antiestéticos de obesidad, insatisfacción y preocupación corporal general e insatisfacción corporal respecto a la parte inferior del cuerpo) excepto en el factor referente a la inducción del vómito y uso de laxantes. Así, los hombres tienen una mayor autoestima mientras que las mujeres están más insatisfechas con su imagen corporal y con todos los factores relacionados con la imagen. No se encuentran diferencias de género en las puntuaciones en satisfacción sexual.

Tabla 1

Diferencias de género en satisfacción sexual, autoestima e insatisfacción corporal

\begin{tabular}{lcccc}
\hline & Hombres $M(D T)$ & Mujeres $M(D T)$ & $\mathrm{t}$ & $\mathrm{p}$ \\
\hline Satisfacción sexual & $72,47(10,58)$ & $73,38(10,78)$ & $-0,80$ &, 422 \\
Autoestima & $33,04(4,80)$ & $30,77(4,65)$ & 4,56 & $<, 001$ \\
Insatisfacción corporal & $59,17(18,83)$ & $84,50(28,21)$ & $-10,31$ & $<, 001$ \\
Factor 1 BSQ & $13,52(5,40)$ & $18,75(7,70)$ & $-7,64$ & $<, 001$ \\
Factor 2 BSQ & $7,04(2,73)$ & $10,85(3,84)$ & $-11,13$ & $<, 001$ \\
Factor 3 BSQ & $3,85(1,66)$ & $5,29(2,59)$ & $-6,47$ & $<, 001$ \\
Factor 4 BSQ & $3,47(1,77)$ & $5,90(2,60)$ & $-10,65$ & $<, 001$ \\
Factor 5 BSQ & $2,23(0,99)$ & $2,34(0,96)$ & $-1,02$ &, 310 \\
Factor General BSQ & $35,65(11,64)$ & $47,90(17,39)$ & $-10,06$ & $<, 001$ \\
\hline
\end{tabular}

Factor $1 \mathrm{BSQ}=$ preocupación por el peso en relación a la ingesta; Factor $2 \mathrm{BSQ}=$ preocupación por los aspectos antiestéticos de obesidad; Factor $3 \mathrm{BSQ}=$ insatisfacción y preocupación corporal general; Factor $4 \mathrm{BSQ}=$ insatisfacción corporal respecto a la parte inferior del cuerpo; Factor $5 \mathrm{BSQ}=$ empleo del vómito o laxantes para reducir la insatisfacción corporal. 


\section{Análisis de ítems en función del género}

Vemos que hombres y mujeres no difieren en la satisfacción sexual de manera significativa. Sin embargo, realizando un análisis descriptivo de los ítems del cuestionario de satisfacción sexual, observamos algunas diferencias interesantes en función del género. Los hombres parecen estar más insatisfechos con cuestiones relacionadas con la pareja. Así, el $21 \%$ de hombres, frente al $4,7 \%$ de mujeres se muestra insatisfecho con la iniciativa de la pareja. Además el $23,4 \%$ de los hombres y el $10,4 \%$ de las mujeres valora como poco satisfactoria la creatividad sexual de su pareja. Las mujeres, en cambio, parecen estar más insatisfechas con aspectos relacionados con las sensaciones físicas y el placer. El porcentaje de mujeres y hombres insatisfechos con la calidad de sus orgasmos fue de 7,5\% y $2,5 \%$ respectivamente. La insatisfacción con la frecuencia del orgasmo fue del $13,8 \%$ en las mujeres y $7,1 \%$ en hombres.

En cuanto a la autoestima, las diferencias de género sí han resultado ser significativas. Estos resultados, también han resultado visibles en el análisis de las respuestas al cuestionario de Rosenberg. Los datos más llamativos son aquellos que tienen que ver con el sentimiento de valía y respeto. Un porcentaje elevado de jóvenes siente que no es bueno en nada $(20,1 \%$ hombres; $33,8 \%$ de mujeres) y otros tantos desearían respetarse más a sí mismo $(28,9 \%$ hombres; $41,8 \%$ de mujeres). En ambos casos el porcentaje de mujeres es superior al de los hombres.

Finalmente, las diferencias de género en satisfacción con la imagen corporal han resultado ser estadísticamente significativas. A pesar de que la media de insatisfacción corporal de hombres y mujeres se encuentra dentro de la normalidad, el análisis de los ítems del cuestionario $B S Q$ muestra que el $4,5 \%$ de hombres y el $12,7 \%$ de las mujeres han vomitado en alguna ocasión para sentirse más delgados. Además, un pequeño porcentaje de hombres $(1,95 \%)$ y un porcentaje muy superior de mujeres $(20,19 \%)$ obtienen una puntuación total en el BSQ superior a 110, lo que se traduce en insatisfacción con la imagen corporal. Sin embargo, el $77,4 \%$ de estos jóvenes tenían un Índice de Masa Corporal (IMC) inferior a 24,50 (rango considerado como normopeso).

\section{Relación entre las variables}

En las tablas 2 y 3 se presentan las correlaciones entre las variables de satisfacción sexual, autoestima e imagen corporal diferenciadas por género. Tanto en hombres como en mujeres, se ha hallado correlación positiva entre la satisfacción sexual y la autoestima. Este resultado indica que una mayor satisfacción sexual se asoció a mayor autoestima, aunque en hombres la relación fue moderada y en las mujeres débil. Además, una mayor autoestima se asoció a menores niveles de insatisfacción corporal. Ahora bien, existen diferencias entre hombres y mujeres. Mientras en las chicas la autoestima correlacionó con todos los factores de insatisfacción corporal, en los chicos no se asoció con el factor de insatisfacción corporal general ni con el uso de vómitos y laxantes. Además, las asociaciones fueron, en términos generales, más fuertes en mujeres. 
Tabla 2

Intercorrelaciones entre las variables de estudio en hombres

\begin{tabular}{|c|c|c|c|c|c|c|c|c|}
\hline & 2 & 3 & 4 & 5 & 6 & 7 & 8 & 9 \\
\hline $\begin{array}{l}\text { 1.Satisfacción } \\
\text { sexual }\end{array}$ &, $33^{* *}$ &,- 11 &,- 11 &,- 03 &,- 03 &,- 12 &, 04 &,- 13 \\
\hline 2.Autoestima & &,$- 21^{\text {** }}$ &,$- 22^{* *}$ &,$- 17^{*}$ &,- 14 &,$- 25^{* *}$ &,- 07 &,$- 22^{* *}$ \\
\hline $\begin{array}{l}\text { 3.Insatisfacción } \\
\text { corporal }\end{array}$ & & &, $91^{* *}$ &, $76^{* *}$ &, $73^{\text {** }}$ &, $70^{* *}$ &, $39^{* *}$ &, $96^{* *}$ \\
\hline 4.BSQ_1 & & & &, $58^{* *}$ &, $53^{\star *}$ &, $64^{* *}$ &, $23^{* *}$ &, $96^{* *}$ \\
\hline 5.BSQ_2 & & & & &, $59^{* *}$ &, $49^{* *}$ &, $34^{* *}$ &, $63^{* *}$ \\
\hline 6.BSQ_3 & & & & & &, $43^{* *}$ &, $53^{* *}$ &, $59^{* *}$ \\
\hline 7.BSQ_4 & & & & & & &, $18^{*}$ &, $71^{* *}$ \\
\hline 8.BSQ_5 & & & & & & & &, $25^{* *}$ \\
\hline 9.BSQ_GENERAL & & & & & & & & \\
\hline
\end{tabular}

BSQ_1=preocupación por el peso en relación a la ingesta; BSQ_2=preocupación por los aspectos antiestéticos de obesidad; BSQ_3 = insatisfacción y preocupación corporal general; BSQ_4= insatisfacción corporal respecto a la parte inferior del cuerpo; BSQ_5= empleo del vómito o laxantes para reducir la insatisfacción corporal.

Tabla 3

Intercorrelaciones entre las variables de estudio en mujeres

\begin{tabular}{|c|c|c|c|c|c|c|c|c|}
\hline & 2 & 3 & 4 & 5 & 6 & 7 & 8 & 9 \\
\hline $\begin{array}{l}\text { 1.Satisfacción } \\
\text { sexual }\end{array}$ & ,20** &,- 07 &,- 01 &,- 02 &,- 07 &,- 03 &,- 03 &,- 06 \\
\hline 2.Autoestima & &,$- 47^{* *}$ &,$- 38^{* *}$ &,$- 27^{* *}$ &,$- 46^{* *}$ &,$- 36^{* *}$ &,$- 25^{* *}$ &,$- 44^{* *}$ \\
\hline $\begin{array}{l}\text { 3.Insatisfacción } \\
\text { corporal }\end{array}$ & & &, $93^{* *}$ &, $75^{\star *}$ &, $78^{* *}$ &, $83^{* *}$ &, $41^{* *}$ &, $98^{* *}$ \\
\hline 4.BSQ_1 & & & &, $64^{* \star}$ &, $69^{* *}$ &, $74^{* *}$ &, $33^{* *}$ &, $95^{* *}$ \\
\hline 5.BSQ_2 & & & & &, $51^{* *}$ &, $62^{* *}$ &, $22^{* *}$ &, $68^{* *}$ \\
\hline 6.BSQ_3 & & & & & &, $59^{* *}$ &, $49^{* *}$ &, $71^{* *}$ \\
\hline 7.BSQ_4 & & & & & & &, $22^{* *}$ &, $85^{* *}$ \\
\hline 8.BSQ_5 & & & & & & & &, $33^{* *}$ \\
\hline 9.BSQ_GENERAL & & & & & & & & \\
\hline
\end{tabular}

BSQ_1=preocupación por el peso en relación a la ingesta; BSQ_2=preocupación por los aspectos antiestéticos de obesidad; BSQ_3= insatisfacción y preocupación corporal general; BSQ_4= insatisfacción corporal respecto a la parte inferior del cuerpo; BSQ_5= empleo del vómito o laxantes para reducir la insatisfacción corporal. 


\section{Capacidad predictiva de la autoestima y la insatisfacción corporal sobre} la satisfacción sexual

Se ha realizado análisis de regresión diferenciando por género y se ha encontrado que, tras controlar el efecto de la edad, la autoestima predijo la satisfacción sexual en ambos sexos. En los hombres la varianza en satisfacción sexual explicada por la autoestima fue del 9,7\% $(\beta=, 32)$ mientras que en las mujeres fue del $4,1 \%(\beta=, 21)$. La insatisfacción con la imagen corporal no predijo la satisfacción sexual en ninguno de los sexos.

\section{Discusión y conclusiones}

Respecto a los resultados sobre las diferencias de género en las variables de satisfacción sexual, autoestima e imagen corporal, nuestra hipótesis no se ha confirmado totalmente. No se han encontrado diferencias en satisfacción sexual, lo que apoyaría los hallazgos de trabajos anteriores (McClelland, 2011; Santos-Iglesias y cols., 2009). No obstante, las diferencias desde un punto de vista cualitativo son interesantes. Parece que las mujeres están más insatisfechas con los aspectos relacionados con las sensaciones físicas durante las relaciones sexuales mientras que los hombres valoran peor aspectos relacionados con la pareja sexual. Vemos que hombres y mujeres jóvenes siguen sin estar completamente satisfechos con sus relaciones sexuales, quizás por desconfianza, falta de información o comunicación, vergüenza o tabúes.

Por otra parte, y según lo hipotetizado, sí encontramos diferencias de género en autoestima, en consonancia con el trabajo de Salvador y cols. (2010), y en la imagen corporal (Acosta y Gómez, 2003; Baile, Guillén y Garrido, 2002; Lameiras, Calado, Rodríguez y Fernández, 2003). Las mujeres se encuentran más preocupadas e insatisfechas con su imagen corporal que los hombres. Esto no deja de ser un reflejo de la tiranía de la presión cultural y social sobre las mujeres que todavía hoy hace que muchas se obsesionen por el cumplimiento de unos cánones que les han sido impuestos. Además, las mujeres también tienen menor autoestima, y en ese sentido los datos son preocupantes pues revelan que nuestros jóvenes no se sienten válidos, útiles ni se respetan a sí mismos. Nos sorprende especialmente al tratarse de muestra universitaria. Estamos ante una población joven y con estudios que se siente fracasada. Esta falta de respeto a uno mismo se puede traducir en conductas de riesgo tanto en el ámbito sexual como relacionadas con la imagen corporal. Esto demuestra que tenemos mucho que hacer en cuanto a intervenciones para mejorar la autoestima de los jóvenes y potenciar el sentimiento de éxito.

El segundo de nuestros objetivos tenía que ver con la relación entre las tres variables de estudio. Esperábamos encontrar relaciones negativas entre la insatisfacción corporal y la autoestima. Nuestros resultados permiten confirmar esta hipótesis tanto en hombres como en mujeres, y van en consonancia con lo planteado en la literatura (Mellor y cols., 2010; Salvador y cols., 2010). Parece que la autoestima en muchas ocasiones queda supeditada a algo tan externo, variable y en gran medida ajeno a nuestro control como la imagen corporal, a su vez determinada por patrones culturales y sociales.

También planteábamos que la satisfacción sexual se relacionaría con la autoestima de forma positiva. Esto se ha confirmado en nuestros análisis y es congruente con lo planteado en la literatura (Calado y cols., 2004). Finalmente, postulamos que la satisfacción sexual se asociaría de manera inversa con la insatisfacción corporal. Esta hipótesis no se ha podido confirmar en este estudio, en contra de lo planteado por otros trabajos (Calado y cols, 2004; Faith y cols., 1993; Pujols y cols., 2010). Estos resultados se pueden discutir atendiendo a 
las características de nuestra muestra. Es posible que la relación entre la imagen corporal y la satisfacción sexual sea más evidente cuando la imagen corporal se encuentra muy dañada (como por ejemplo ante una mastectomía).

En relación a esto, el último objetivo perseguido en este trabajo era analizar la influencia de la autoestima e imagen corporal en la satisfacción sexual. La hipótesis de que la autoestima e imagen corporal explicarían parte de la varianza en satisfacción sexual no ha quedado confirmada. La única variable predictora de la satisfacción sexual, tanto en hombres como mujeres, ha sido la autoestima. Además, la autoestima de los hombres influye más en la satisfacción sexual que en las mujeres. Quizá la satisfacción sexual de las mujeres se explica mejor por otras variables como la satisfacción con la relación de pareja o duración de la misma, las expectativas, la asertividad sexual o creencias sobre la sexualidad, por lo que queda abierto un gran campo de investigación.

Con el fin de contextualizar y comprender mejor los resultados hallados, es necesario destacar algunas limitaciones de este trabajo. Una de ellas hace referencia al hecho de que el instrumento sobre la insatisfacción corporal se centra en la insatisfacción con el peso. Se considera que el hecho de estar grueso es motivo de insatisfacción con la imagen corporal, sin tener en cuenta que la insatisfacción puede deberse a un motivo totalmente opuesto (e.g. sentirse excesivamente delgado). Además, el instrumento se plantea como una herramienta de evaluación de trastornos alimentarios en población clínica, siendo nuestro estudio dirigido a población no clínica. Esto podría explicar la nula relación entre la satisfacción sexual e insatisfacción corporal en nuestro estudio. Por lo tanto, estos resultados deben tratarse con precaución.

Otra de las limitaciones está relacionada con el rango de edades de la muestra. Nuestros participantes tenían entre 18 y 28 años de edad, por lo que los resultados no son generalizables a toda la población. No podemos asumir que personas que se encuentran en diferentes momentos vitales tienen las mismas preocupaciones y necesidades en cuanto a sexualidad, imagen corporal y autoestima. Por otra parte, y pensando en investigaciones futuras, sería conveniente incluir datos acerca de si los participantes tienen relación de pareja estable o no, y qué variables de la misma pueden estar mediando en la satisfacción sexual. En este estudio únicamente se ha valorado que los participantes tuvieran relaciones sexuales, no sabemos cómo la relación de pareja puede estar influyendo, positiva o negativamente, en la satisfacción sexual. Sería conveniente incluir esta variable en futuras investigaciones.

Pese a las limitaciones encontradas, los resultados obtenidos en el presente trabajo ofrecen nuevas evidencias sobre la relación entre la satisfacción sexual, la autoestima y la imagen corporal teniendo en cuenta también las diferencias de género. También se plantean líneas de investigación futura, puesto que aunque a lo largo de la literatura se ha demostrado la relación entre la satisfacción sexual y la imagen corporal, este trabajo refleja que esta realidad no siempre se cumple, especialmente cuando se incluye a la población masculina. Estas conclusiones señalan, por lo tanto, la necesidad de profundizar en el estudio de la satisfacción sexual y su relación con otras variables significativas en el bienestar psicológico y físico, entre ellas el género. Estos datos resultan de gran relevancia en la práctica clínica, ya que debemos atender a las diferencias de género en sexualidad para que nos puedan guiar en el diseño de programas de prevención y tratamiento de problemas sexuales. 


\section{Referencias bibliográficas}

Acosta, M.V. y Gómez, G. (2003). Insatisfacción corporal y seguimiento de dieta. Una comparación transcultural entre adolescentes de España y México. Revista Internacional de Psicología Clínica y de la Salud/International Journal of Clinical and Health Psychology, 3, 9-21.

Acuña, A. y Ceballos, M. P. (2005). Estudios sobre algunos aspectos del comportamiento sexual masculino. Revista Urología Colombiana, 14, 93-100.

Baile, J.I., Guillén, F. y Garrido, E. (2002). Insatisfacción corporal en adolescentes medida con el Body Shape Questionnaire (BSQ): efecto del anonimato, el sexo y la edad. Revista Clínica Internacional de Psicología Clínica y de la Salud/International Journal of Clinical and Health Psychology, 2, 439-450.

Calado, M., Lameiras, M. y Rodríguez, Y. (2004). Influencia de la imagen corporal y la autoestima en la experiencia sexual de estudiantes universitarias sin trastornos alimentarios. International Journal of Clinical and Health Psychology, 4(2), 357-370.

Carpenter, L. M., Nathanson, C. A. y Kim, Y. J. (2009). Physical women, emotional men: Gender and sexual satisfaction in midlife. Archives of Sexual Behavior, 38, 87-107.

Cedillo, C. (2015). Imagen corporal y satisfacción sexual de homosexuales masculinos usuarios y no usuarios de gimnasio. Archivos hispanoamericanos de Sexología, 20(1), 60-72.

Davidson, S., Bell, R., LaChina, M., Holden, S. y Davis, S. (2009). The relationship between self-reported sexual satisfaction and general well-being in women. Journal of sex medicine, 6(10), 2690-2697.

Ji, J. y Norling, A. M. (2004). Sexual satisfaction of married urban Chinese. Journal of Developing Societies, 20, 21-38.

Faith, M. S., Mitchell, L. y Schare, M. L. (1993). The role of body image in sexually avoidant behavior. Archives of Sexual Behavior, 22(4), 345-356.

Lameiras, M., Calado, M., Rodríguez, Y. y Fernández, M. (2003). Hábitos alimentarios e imagen corporal en estudiantes universitarios sin trastornos alimentarios. Revista Internacional de Psicología Clínica y de la Salud/International Journal of Clinical and Health Psychology, 3, 23-33.

McClelland, S. I. (2011). Who is the "Self» in self reports of sexual satisfaction? Research and policy implications. Sexuality Research and Social Policy, 8, 304-320.

Mellor, D., Fuller, M., McCabe, M. y Ricciardelli, L. (2010). Body image and self-esteem across age and gender: a short-term longitudinal study. Sex roles, 63(9), 672-681.

Pérez, F. (2013). Nueva escala de satisfacción sexual (NSSS) en usuarios de redes sociales. Tesina de Master en Sexología, Ciencias de la Educación, Enfermería y Fisioterapia. Universidad de Almería, España.

Peris, M., Maganto, C. y Kortabarria, L. (2013). Autoestima corporal, publicaciones virtuales en las redes sociales y sexualidad en adolescentes. European Journal of Investigation in Health, Psychology and Education, 3(2), 171-180.

Pintado, Ma . S. (2013). Bienestar emocional, imagen corporal, autoestima y sexualidad en mujeres con cáncer de mama. Tesis doctoral. Universidad de Valencia, Valencia, España.

Pujols, Y., Meston, C. M. y Seal, B. N. (2010). The association between sexual satisfaction and body image in women. Journal of Sexual Medicine, 7, 905-916.

Raich, R.Ma ., Mora, M., Soler, A., Ávila, C., Clos, I. y Zapater, I. (1996). Adaptación de un instrumento de evaluación de la insatisfacción corporal. Clínica y salud, 7(1), 51-66. 
Rehman, U. S., Rellini, A. H. y Fallis, E. (2011). The importance of sexual self-disclosure to sexual satisfaction and functioning in committed relationships. Journal of Sexual Medicine, 8, 3108-3115.

Rodríguez, O.R. (2010). Relación entre satisfacción sexual, ansiedad y prácticas sexuales. Pensamiento Psicológico, 7(14), 41-52.

Rosenberg, M. (1965). Society and the adolescent self-image. Princeton, NJ: Princeton University Press.

Salvador, M., García-Gálvez, C. y De la Fuente, M. (2010). Creencias y estrategias para el control del peso, satisfacción con la imagen corporal y autoestima. European Journal of Education and Psychology, 3(2), 257-273.

Santos-Iglesias, P., Sierra, J. C., García, M., Martínez, A., Sánchez, A. y Tapia, M. I. (2009). Índice de Satisfacción Sexual (ISS): Un estudio sobre su fiabilidad y validez. International Journal of Psychology and Psychological Therapy, 9, 259-273.

Scott, V., Sandberg, G., Harper, M. y Miller, R. (2012). The impact of depressive symptoms and health on sexual satisfaction for older couples: implications for clinicians. Contemporary Family Therapy, 34(3), 376-390.

Weaver A. y Byers S. (2006). The relationships among body Image, body mass index, exercise, and sexual functioning in heterosexual women. Psychology of Women Quarterly, 30(4), 333-339. 



\title{
Influencia del apoyo por parte del terapeuta en la satisfacción de un programa auto-aplicado a través de Internet para la depresión
}

\author{
Clara Miguel Sanz \\ al189588@uji.es \\ LAURA DÍAZ SANAHUJA \\ al189588@uji.es \\ AdRIANA MIRA PASTOR \\ al189588@uji.es \\ JuANA MARÍA BRETÓN LÓPEZ \\ al189588@uji.es \\ CRISTINA Botella ARBona \\ al189588@uji.es
}

\section{Resumen}

Introducción: Las intervenciones auto-aplicadas a través de Internet cuentan con resultados consistentes respecto a su eficacia como tratamiento psicológico. Sin embargo, las altas tasas de abandono siguen suponiendo un reto. El apoyo recibido por parte del terapeuta a lo largo de la intervención es una de las variables que pueden influir en estas tasas (Karyotaki et al., 2017). Objetivo: Este estudio pretende analizar las diferencias en satisfacción, agrado y utilidad respecto a recibir o no apoyo telefónico en una intervención auto-aplicada a través de Internet para la depresión. Método: 80 participantes con síntomas depresivos fueron aleatorizados en dos condiciones experimentales: Intervención auto-aplicada con apoyo $(\mathrm{N}=44)$ y sin apoyo telefónico $(\mathrm{N}=$ 36). En el post-tratamiento se evaluó el grado de satisfacción con la intervención, así como el agrado y utilidad de las llamadas. Resultados: Ambos grupos valoraron, sin diferencias significativas entre ellos, que estaban satisfechos con el tratamiento. Únicamente se observaron diferencias significativas $(\mathrm{F}=4,67 ; p=0,035)$ en relación a la aversividad del mismo, valorándolo como más aversivo el grupo sin apoyo telefónico. El grupo que contaba con el contacto telefónico lo evaluó con un alto porcentaje de agrado y utilidad, mientras que el grupo sin apoyo no valoró tan positivamente la posibilidad de haber dispuesto de éste. Conclusiones: Los resultados obtenidos sugieren la importancia de ofrecer apoyo telefónico durante la intervención auto-aplicada, sin embargo, también plantean que, en los programas con los que el usuario se siente satisfecho, el apoyo explícito se vuelve menos necesario.

Palabras clave: intervención auto-aplicada, Internet, depresión, apoyo telefónico. 


\section{Abstract}

Introduction: Self-applied interventions via the Internet have shown consistent results regarding their efficacy as psychological treatment. However, they are characterized by a high dropout rate. This issue can be influenced by the support the therapist offers throughout the intervention (Karyotaki et al., 2017). Objective: This study intends to analyse whether "satisfaction», liking and "utility» indexes are different between patients receiving or not this telephone support during a self-applied intervention for depression via the Internet. Methods: 80 participants presenting depressive symptoms were randomized in two experimental conditions: Self-applied interventions via the Internet with and without telephone support ( $\mathrm{N}=44$ and $\mathrm{N}=36$, respectively). When the treatment was finished, satisfaction with the intervention, and liking and utility degree of these calls were evaluated. Results: No significant differences were observed between groups in terms of satisfaction, being both groups satisfied with the treatment. Significant differences were only found on treatment aversion $(F=4.67 ; p=0.035)$, being considered more aversive by the group without telephone support. The group that received telephone support assessed this human intervention with a high percentage of satisfaction and utility, while the group without this kind of support did not appreciate the possibility of having this contact. Conclusions: Present results suggest the importance of offering support during the self-applied intervention. However, they also point out that in programs in which participants feel satisfied, explicit support becomes less necessary.

Keywords: self-applied intervention, Internet, depression, human support.

\section{Introducción}

La depresión constituye uno de los problemas más importantes para la salud mundial e interfiere de manera significativa en distintas áreas de funcionamiento del individuo (Haro et al., 2013). El número total de personas con depresión a nivel mundial incrementó en un 18,4\% entre 2005 y 2015, estimándose una prevalencia total del 4.4\% (OMS, 2017). Asimismo, supone un coste económico muy elevado a nivel de salud pública (Buntrock et al., 2016) y tiene un impacto muy significativo en el índice de calidad de vida ajustada por años de vida (YLD), siendo éste de 8,1\% en Europa y de 8,7\% en España (OMS, 2017).

Actualmente, contamos con tratamientos psicológicos eficaces y empíricamente validados para la depresión como la terapia cognitivo-conductual, la terapia conductual y la terapia interpersonal (Nathan \& Gorman, 2016). Sin embargo, estas intervenciones tienen una importante limitación: los servicios de salud mental con los que contamos no son adecuados en términos de accesibilidad y calidad. Menos del $50 \%$ de las personas con depresión son tratadas por un profesional de la salud y sólo un cuarto recibe el tratamiento adecuado, bien sea por los costes y las demandas de la terapia cara a cara, el tiempo requerido en su aplicación o la falta de profesionales bien entrenados (Titov, 2011). A esto se suma que, aquellos que reciben el tratamiento, por lo general, lo hacen después de mucho tiempo, una vez el problema ha generado efectos adversos en sus vidas, por lo que el éxito de la intervención es mucho más difícil que si la ayuda se hubiera ofertado en el momento oportuno (Kessler \& Greenberg, 2002). 
Los datos anteriores ponen de manifiesto que el modelo dominante de terapia con el que contamos, la terapia cara a cara, no soluciona estas necesidades (Kazdin \& Blase, 2011). Con el fin de potenciar la accesibilidad a aquellas personas que lo necesitan y que debido a la distancia o coste no recibirían tratamiento de otro modo, se plantea como estrategia fundamental la inclusión de las Tecnologías de la Información y la Comunicación (TICs) (Kazdin \& Rabbitt, 2013). Especialmente el uso de Internet en la aplicación de los tratamientos psicológicos ha mostrado ser una estrategia efectiva (Cuijpers, Donker, van Straten \& Andersson, 2010; Karyotaki et al., 2017). Los estudios de meta-análisis ponen de manifiesto que estos tratamientos tienen tamaños del efecto comparables a los de los tratamientos cara a cara (Bee et al., 2008; Cuijpers et al., 2010), mostrando la utilidad de numerosas intervenciones autoaplicadas a través de Internet para la depresión sin que pierdan su eficacia (Karyotaki et al., 2017) y siendo intervenciones costo-efectivas (Donker et al., 2015).

Asimismo, la actitud de los pacientes hacia este tipo de tratamientos es similar a la que muestran ante las terapias cara a cara (Moritz, Schröder, Meyer, \& Hauschildt, 2013). A pesar de todas estas ventajas, todavía se encuentran importantes problemas que afrontar ante este tipo de tratamientos, como es la elevada tasa de abandonos. Estudios de meta-análisis sobre programas auto-aplicados a través de Internet para la depresión muestran una tasa de abandonos de alrededor del 32\% (Melville, Casey, \& Kavanagh, 2010). Esto puede deberse a múltiples causas, siendo posiblemente una de ellas el apoyo proporcionado por parte del terapeuta a lo largo de la intervención auto-aplicada). Recientemente un número importante de investigaciones se han llevado a cabo para determinar el papel del apoyo humano en estas intervenciones auto-aplicadas.Los estudios de meta-análisis consideran que los tratamientos más eficaces y con menos abandonos son los que cursan con apoyo por parte del terapeuta, en comparación con los programas totalmente auto-aplicados (Karyotaki et al., 2017). No obstante, existe evidencia de que las intervenciones totalmente auto-aplicadas también son eficaces en el tratamiento de la depresión y son mucho más fáciles de implementar y menos costosas que las intervenciones auto-aplicadas con apoyo (Karyotaki et al., 2015). Por todo ello es interesante conocer la opinión de las personas que utilizan los programas auto-aplicados en cuanto a recibir o no dicho apoyo a lo largo de la intervención.

Con el objetivo de conocer más específicamente el papel que tiene el apoyo del terapeuta en los tratamientos auto-aplicados, en este estudio se plantean las siguientes cuestiones: ¿Es necesario el apoyo semanal por parte de un terapeuta durante la realización de un programa de intervención auto-aplicado a través de Internet para que los usuarios estén satisfechos y valoren positivamente la intervención? ¿Cómo valoran el apoyo y qué utilidad tiene para ellos?

El objetivo del presente estudio es analizar las diferencias en satisfacción, agrado y utilidad respecto a recibir o no apoyo telefónico por parte del terapeuta en una intervención autoaplicada a través de Internet para la depresión.

\section{Método}

\section{Participantes}

La muestra está compuesta por 80 participantes con síntomas de depresión leve a moderada, con puntuación igual o inferior a 28 en el Inventario de Depresión de Beck (Beck, Steer \& Brown, 1996). La media de edad de la muestra fue de 35,15 años, con una desviación típica de 9,45. Para poder participar en el estudio se debía tener entre 18 y 65 años, posibilidad de utilizar ordenador con Internet en casa y presentar síntomas de depresión leve o moderada. 
Estar recibiendo tratamiento psicológico o haber recibido en el último año fueron criterios de exclusión, además de padecer un trastorno mental grave en el Eje I o la presencia de planes o ideación suicida.

\section{Tratamiento}

Los participantes recibieron un programa totalmente auto-aplicado a través de Internet: Sonreír es Divertido (www.sonreiresdivertido.com). Este programa tiene dos objetivos fundamentales, la prevención y el tratamiento de la depresión, ya que ofrece asistencia tanto a personas con alto riesgo de padecer depresión como a personas que ya presentan la sintomatología. El programa de intervención es de corte cognitivo-conductual. Incorpora estrategias para mejorar el estado de ánimo positivo, así como los enfoques más tradicionales para prevenir el estrés y la depresión, como la activación conductual. Combina los procedimientos existentes más efectivos para promocionar la regulación emocional, la capacidad de afrontamiento y la resiliencia.

Sonreír es Divertido está diseñado para que se lo pueda aplicar uno mismo, desde casa o desde cualquier lugar que disponga de acceso a Internet. El programa está formado por los siguientes componentes terapéuticos: motivación para el cambio, psicoeducación, terapia cognitiva, activación comportamental, psicología positiva y prevención de recaídas. Estos componentes son trabajados por el paciente a lo largo de los 8 módulos que conforman el protocolo de tratamiento. Para más detalle, ver Figura 1. Además de los componentes de la TCC, se incluyen ejercicios prácticos y estrategias para mejorar el afecto positivo. El propio programa también ofrece apoyo e información a los usuarios para que realicen un seguimiento de su estado dentro del tratamiento. Para ello utilizan tres herramientas transversales: ¿Cómo estoy?, donde se ofrecen gráficas, para ver la evolución de sus puntuaciones después de haber cumplimentado cada módulo (afecto positivo y negativo, ansiedad y depresión); el Calendario, donde se muestra la frecuencia de acceso al sistema y las tareas realizadas o pendientes; y el Diario de actividad, que muestra la relación entre el estado de ánimo y las actividades realizadas durante la semana.
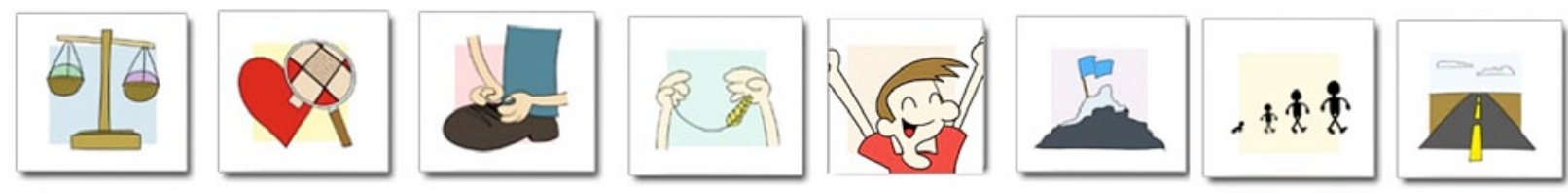

1. Motivación para el cambio

2. Entendiendo los problemas emocionales

3. Aprendiendo a ponerse en marcha

4. Aprendiendo a ser flexibles

5. Aprendiendo a disfrutar: importancia de las experiencias positivas

6. Aprendiendo a vivir: importancia de los valores y las metas

7. Viviendo y aprendiendo

8. ¿Y a partir de ahora...qué?

Figura 1. Módulos del programa Sonreír es Divertido 


\section{Diseño}

Se utilizó un estudio controlado aleatorizado de simple ciego en el que los 80 participantes fueron asignados al azar en dos condiciones experimentales:

1) Intervención auto-aplicada con apoyo telefónico (SCA, $N=44)$. En esta condición los participantes realizaban el programa de tratamiento Sonreír es Divertido de forma totalmente auto-aplicada a través de Internet. A lo largo de la intervención, los participantes de esta condición recibían una llamada semanal por parte de un terapeuta de una duración máxima de dos minutos. El objetivo de estas llamadas era valorar si el uso del programa se realizaba correctamente, recomendarles avanzar a un ritmo adecuado y fomentar la importancia de practicar las tareas que se presentan en los diferentes módulos (Figura 2).

El contenido de la llamada cambiaba en función del progreso:

1. Si el participante no ha finalizado el módulo (Motivarlo para hacerlo)

2. Si el participante ha finalizado uno de los módulos (Refuerzo).

3. Si el participante ha finalizado dos módulos (Refuerzo y recomendación de ralentizar la ejecución).

4. Si el participante finaliza más de dos módulos (Recomendación de ralentizar la ejecución)

Recordarle realizar las tareas que se piden en cada uno de los módulos

Figura 2. Protocolo de apoyo telefónico

2) Intervención auto-aplicada sin apoyo telefónico (SSA, $N=36$ ). En esta condición, los participantes recibían el mismo programa de intervención, Sonreír es Divertido, aunque sin la llamada de apoyo semanal por parte del terapeuta.

Ambas condiciones de intervención cuentan con las tres herramientas transversales descritas anteriormente.

\section{Medidas}

Escala de Satisfacción sobre el Tratamiento (Adaptación Borkovec \& Nau, 1972): Los aspectos que se abordan en esta escala son: 1) La lógica del tratamiento; 2) La satisfacción con el mismo; 3) El grado en que lo recomendarían a un amigo con el mismo problema; 4) El grado en el que consideran que le ha ayudado en otros problemas; 5) El grado en que les ha sido útil en su caso; 6) El grado en que consideran que el tratamiento ha sido aversivo.

Entrevista cualitativa (Utilizada en el estudio de Mira, 2014): Se elaboró una entrevista cualitativa para valorar la opinión de los participantes acerca de la utilidad y agrado de las llamadas de apoyo semanal. Estas preguntas se contestaban en una escala tipo likert de 1 «poquísimo» a 5 «muchísimo». 


\section{Procedimiento}

En primer lugar, se realizó un muestreo telefónico para comprobar que los participantes cumplieran los criterios de inclusión del estudio. Posteriormente, en una entrevista presencial, se evaluaron los criterios de inclusión, se administró el BDI-II para evaluar el nivel de depresión y se realizó una entrevista diagnóstica para descartar la presencia de otros trastornos psicológicos graves. Una vez pasaron a formar parte del estudio, los participantes fueron asignados aleatoriamente a las dos condiciones experimentales. Después, un terapeuta contactó con ellos para informarles acerca de la condición a la que habían sido asignados y de las fases posteriores. Una vez tenían una cuenta y una contraseña, podían acceder a la plataforma y realizar la evaluación pre-tratamiento. Posteriormente realizaban cada uno de los módulos de intervención. Se realizaba una evaluación continua tras finalizar cada módulo en la que se evaluaba sintomatología ansiosa, depresiva y se rastreaba la presencia de ideación suicida. Después del módulo 2, los participantes cumplimentaban la Escala de Expectativas sobre el tratamiento.

Al finalizar los 8 módulos del programa los participantes realizaron la evaluación posttratamiento y se evaluó en ambos grupos el grado de satisfacción con la intervención a través de la Escala de Satisfacción sobre el Tratamiento. Adicionalmente, mediante la entrevista cualitativa, al grupo SCA se le preguntó en qué medida había sido de agrado la llamada de apoyo telefónico por parte del terapeuta y cómo de útil la consideraban. Al grupo SSA se le preguntó en qué medida le hubiera resultado de agrado una llamada de apoyo telefónico por parte del terapeuta y cómo de útil la hubieran considerado.

\section{Resultados}

\section{Satisfacción}

Para estos análisis se cuenta con las puntuaciones en satisfacción de 28 de los participantes de la condición sin apoyo y de 36 de los participantes de la condición con apoyo. Son los datos de los participantes que realizaron la evaluación post-tratamiento en la que se administraba la Escala de Satisfacción sobre el Tratamiento (Adaptación Borkovec \& Nau, 1972). En general, los resultados obtenidos en satisfacción con el tratamiento fueron muy elevados en todas las variables evaluadas en la escala, con un valor de media en el post-tratamiento entre 7 y 8 puntos sobre 10. Los análisis ANOVA de un factor (ver Tabla 1) indicaron que ambos grupos valoraron, sin diferencias significativas entre ellos, que estaban satisfechos con el tratamiento, que fue lógico, útil y que lo recomendarían a un amigo. Únicamente se encontraron diferencias significativas $(F=4,67 ; p=0,035)$ en relación a la aversividad del tratamiento, valorándolo como más aversivo el grupo sin apoyo. No obstante, las puntuaciones medias en dicho ítem (SCA $=1,67$; SSA $=2,75$ ) indican que los participantes valoraron el tratamiento como poco aversivo en ambas condiciones. 
Tabla 1

Medidas de la satisfacción con el tratamiento de las dos condiciones de intervención analizadas utilizando ANOVAs de un factor

\begin{tabular}{lccccc}
\hline VD & Condición & $M$ & DT & $F$ & $p$ \\
\hline Lógico & SSA & 8,21 & 1,77 & 0,109 & 0,742 \\
& SCA & 8,08 & 1,40 & & \\
Sotal & 8,14 & 1,56 & & 0,830 \\
& SSA & 7,93 & 1,92 & 0,046 & \\
Recomendacción & SCA & 7,83 & 1,61 & & 0,761 \\
& Total & 7,88 & 1,74 & & \\
Útil otros problemas & SSA & 8,25 & 1,96 & 0,093 & 0,818 \\
& SCA & 8,39 & 1,68 & & \\
\multirow{4}{*}{ Útil en su caso } & Total & 8,33 & 1,79 & & \\
& SSA & 8,04 & 1,92 & 0,053 & \\
Aversivo & SCA & 8,14 & 1,66 & & \\
& Total & 8,09 & 1,76 & & 0,035 \\
& SSA & 7,46 & 2,03 & 0,137 & \\
\hline
\end{tabular}

Nota. $\mathrm{VD}=$ Variable dependiente $; \mathrm{M}=$ Media; $\mathrm{DT}=$ Desviación típica; $\mathrm{F}=$ valores de $\mathrm{F} ; p=$ grado de significación; $\mathrm{SSA}=\mathrm{Condición}$ experimental sin apoyo por parte del terapeuta $(n=28)$; SCA = Condición experimental con apoyo por parte del terapeuta $(n=36)$.

\section{Utilidad}

A los participantes de la condición con apoyo por parte del terapeuta se les preguntó en qué medida habían considerado útil la llamada de apoyo semanal. La mayoría de los participantes de esta condición (SCA, $\mathrm{N}=48$ ) consideraron que la llamada les había sido útil («muchísimo» $=50 \%$ y «mucho» $=27,08 \%$ ). Al mismo porcentaje de los participantes les resultó «algo» útil y «muy poco útil» la llamada (8,33 \%) y el 6,23\% la valoraron con «poquísima» utilidad (ver Figura 3).

En cuanto a los participantes de la condición experimental sin apoyo por parte del terapeuta, se les preguntó en qué medida habrían considerado útil dicho apoyo. La mayoría de estos participantes (SSA, $\mathrm{N}=34$ ) consideraron que les habría resultado útil («muchísimo» = $23,52 \%$ y «mucho» $=23,52 \%)$. Un $17,65 \%$ consideraron que les habría resultado «algo» útil y un $26,47 \%$ consideró que les habría sido «poco» útil. Sólo tres un $8,82 \%$ la valoraron con «poquísima» utilidad (ver Figura 4).

\section{Agrado}

A los participantes de la condición experimental con apoyo (SCA, $N=48$ ) se les preguntó en qué medida les había gustado recibir la breve llamada de apoyo semanal. La mayoría 
contestó que les gustó ( «muchísimo» $=47,92 \%$, «mucho» $=29,17 \%$ ), el 18,75 \% valoraron que les gustó «algo» recibir la breve llamada de apoyo, sólo a dos participantes les gusto «poco» $(2,08 \%)$ y a otros dos «poquísimo» $(2,08 \%)$ (Figura 5$)$.

A los participantes de la condición experimental sin apoyo (SSA, $N=34$ ) se les preguntó en qué medida les habría gustado recibir la llamada telefónica. El 29,41\% de los participantes de esta condición indicó que les habría gustado «muchísimo» recibirla y un $14,71 \%$ que les habría gustado «mucho». A un 20,59 \% le habría gustado «algo» y a un 29,41 \% les habría gustado «poco» recibirla. Sólo a dos participantes (5,88 \%) les habría gustado "poquísimo» que les hicieran una breve llamada semanal (ver Figura 6).

Utilidad SCA

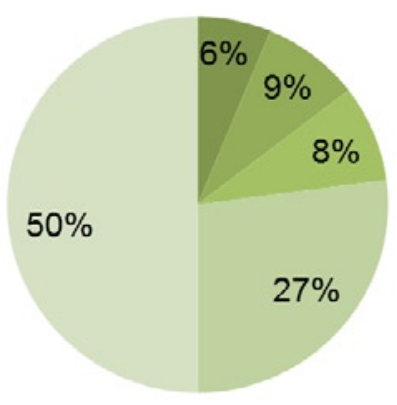

Figura 3. Porcentajes de valoración de la utilidad de la llamada de apoyo de los participantes de la condición SCA

Agrado SCA

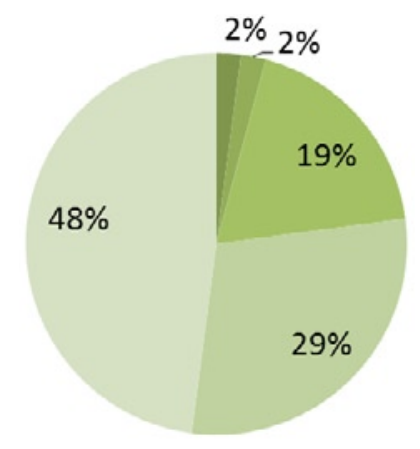

Figura 5. Porcentajes de agrado de las llamadas de apoyo de los participantes de la condición SCA.
Utilidad SSA

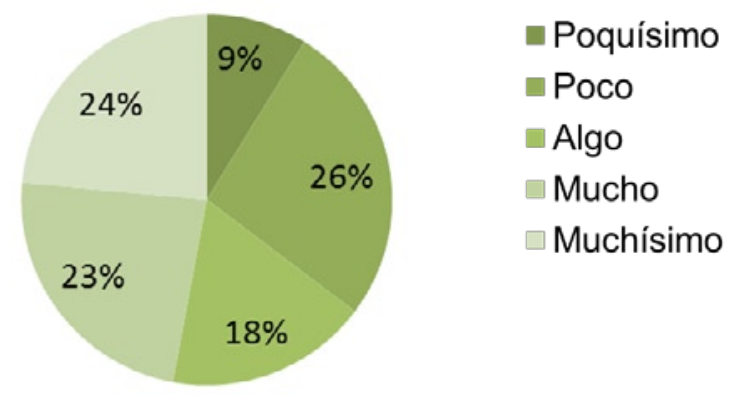

Figura 4. Porcentajes de valoración de la utilidad de la llamada de apoyo de los participantes de la condición SSA.

Agrado SSA

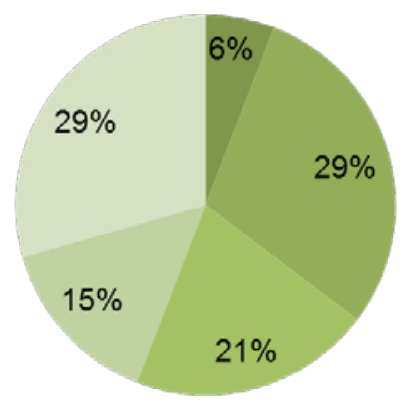

Figura 6. Porcentajes de agrado de las llamadas de apoyo de los participantes de la condición SSA.

\section{Discusión y conclusiones}

El objetivo de este estudio era analizar las diferencias en satisfacción, agrado y utilidad respecto a recibir o no apoyo telefónico por parte del terapeuta en una intervención autoaplicada a través de Internet para la depresión. 
Los resultados obtenidos en cuanto a satisfacción muestran que los participantes de ambas condiciones experimentales se sintieron muy satisfechos con el tratamiento, no evidenciándose diferencias significativas entre ambos grupos a excepción de la aversividad del tratamiento. En este ítem, el grupo sin apoyo lo consideró más aversivo, aunque las puntuaciones en esta variable fueron muy bajas para ambos grupos. Esta falta de diferencias significativas en satisfacción entre una condición que recibe apoyo humano y otra que sólo cuenta con el apoyo automatizado que ofrece el programa se ha obtenido también en un estudio reciente (Kelders, Bohlmeijer, Pots \& van Gemert-Pijnen, 2015). Una posible explicación de la falta de diferencias entre los grupos puede ser la riqueza y calidad del apoyo ofrecido por Sonreír es Divertido a través de sus herramientas transversales de apoyo (¿Cómo estoy?, Calendario y Diario de Actividad). El programa ofrece una retroalimentación personalizada y continua a los usuarios a través de dichas herramientas.

En cuanto a la opinión de los participantes acerca de la utilidad y agrado de las llamadas de apoyo, los resultados obtenidos muestran que, a la gran mayoría de los participantes de la condición con apoyo, que sí habían recibido la llamada, les gustó y la consideraron útil. Sin embargo, aquellos de la condición sin apoyo, en la que no se realizó la llamada telefónica semanal, no la consideraron esencial. Detrás del hecho de que el grupo de participantes que no recibieron apoyo no valoraran tan positivamente el haber podido recibir una llamada, podría estar que consideraban que el programa ya les indicaba el ritmo que tenían que seguir, les animaba y les apoyaba, por lo que no la consideraron tan necesaria.

A la vista de estos resultados es importante tener en cuenta la necesidad de desarrollar no solamente intervenciones eficaces, sino que cuenten con aspectos que mejoren la satisfacción con la intervención (Wallin, Mattsson \& Olsson, 2016). En este sentido nos pueden ayudar estrategias que den apoyo a través de las TICs como aquellas con las que cuenta Sonreír es Divertido. La satisfacción y aceptación de los programas de intervención auto-aplicados es una variable fundamental a tener en cuenta en este tipo de investigaciones, ya que informa acerca de la viabilidad de las intervenciones y ayuda a optimizar la eficacia de las mismas (Wallin et al., 2016). Considerando las numerosas posibilidades de las TICs, es importante seguir estudiando estos aspectos. El apoyo automatizado a través de las TICs puede tener beneficios significativos e influir en los resultados, desempeñando una función similar al apoyo humano. La literatura muestra que los tratamientos auto-aplicados basados en Internet ahorran tiempo al terapeuta en comparación con los tratamientos tradicionales cara a cara. Por lo tanto, es posible que, al utilizar diferentes estrategias basadas en las TICs para proporcionar apoyo, el tiempo del terapeuta pueda reducirse aún más. Esto representa un progreso en la línea de la propuesta de Kazdin \& Blase (2011):Ia investigación en psicoterapia necesita desarrollar intervenciones que puedan aplicarse a más pacientes de una manera más simple y rentable.

Por tanto, respondiendo a la pregunta que se planteaba al inicio del estudio, se puede concluir que los resultados obtenidos en esta investigación sugieren la importancia de ofrecer apoyo durante la intervención auto-aplicada, aunque, también plantean que, en los programas con los que el usuario se siente satisfecho, el apoyo explícito se vuelve menos necesario.

\section{Referencias}

Bee, P. E., Bower, P., Lovell, K., Gilbody, S., Richards, D., Gask, L., \& Roach, P. (2008). Psychotherapy mediated by remote communication technologies: a meta-analytic review. BMC Psychiatry, 8, 60.

Beck, A. T., Steer, R.A., \& Brown, G.K. (1996). Manual for the Beck Depression Inventory-II. San Antonio, TX: Psychological Corp. 
Buntrock, C., Ebert, D. D., Lehr, D., Smit, F., Riper, H., Berking, M., \& Cuijpers, P. (2016). Effect of a web-based guided self-help intervention for prevention of major depression in adults with subthreshold depression: a randomized clinical trial. Jama, 315(17), 1854-1863.

Cuijpers, P., Donker, T., van Straten, A., Li, J., \& Andersson, G. (2010). Is guided self-help as effective as face-to-face psychotherapy for depression and anxiety disorders? A systematic review and meta-analysis of comparative outcome studies. Psychological Medicine, 40 (12), 1943-1957.

Donker, T., Blankers, M., Hedman, E., Ljotsson, B., Petrie, K., \& Christensen, H. (2015). Economic evaluations of Internet interventions for mental health: a systematic review. Psychological medicine, 45(16), 3357-3376.

Haro, J. M., Ayuso-Mateos, J. L., Bitter, I., Demotes-Mainard, J., Leboyer, M., Lewis, S. W., ... \& Robbins, T. W. (2013). ROAMER: roadmap for mental health research in Europe. International journal of methods in psychiatric research, 23(S1), 1-14.

Karyotaki, E., Riper, H., Twisk, J., Hoogendoorn, A., Kleiboer, A., Mira, A., ... \& Andersson, G. (2017). Efficacy of Self-guided Internet-Based Cognitive Behavioral Therapy in the Treatment of Depressive Symptoms: A Meta-analysis of Individual Participant Data. JAMA psychiatry, 74(4), 351-359.

Karyotaki, E., Kleiboer, A., Smit, F., Turner, D. T., Pastor, A. M., Andersson, G., ... \& Christensen, $\mathrm{H}$. (2015). Predictors of treatment dropout in self-guided web-based interventions for depression: an 'individual patient data'meta-analysis. Psychological medicine, 45(13), 2717-2726.

Kazdin, A. E., \& Blase, S. L. (2011). Rebooting Psychotherapy Research and Practice to Reduce the Burden of Mental Illness. Perspectives on Psychological Science, 6 (1), 21-37.

Kazdin, A. E., \& Rabbitt, S. M. (2013). Novel Models for Delivering Mental Health Services and Reducing the Burdens of Mental Illness. Clinical Psychological Science, 1 (2), 170-191.

Kelders, S. M., Bohlmeijer, E. T., Pots, W. T., \& van Gemert-Pijnen, J. E. (2015). Comparing human and automated support for depression: Fractional factorial randomized controlled trial. Behaviour research and therapy, 72, 72-80.

Kessler, R. C. \& Greenberg. P. (2002). The economic burden of anxiety of anxiety and stress disorders, En L.D. Kennet, D. Charney, J. T. Coyle C. H. y Nemer- off (Eds.), Neuropsychopharmacology: the fifth generation of progress (pp. 981-991). Philadelphia: Lippincott Williams y Wilkins.

Melville, K. M., Casey, L. M., \& Kavanagh, D. J. (2010). Dropout from internet-based treatment for psychological disorders. British Journal of Clinical Psychology, 49, 455-471.

Mira, A. (2014). Eficacia diferencial de un programa de intervención auto-aplicado a través de Internet para la prevención y el tratamiento de la depresión leve o moderada con apoyo y sin apoyo por parte del terapeuta. Tesis Doctoral, Universitat Jaume I, Castellón, España.

Moritz, S., Schröder, J., Meyer, B., \& Hauschildt, M. (2013). The more it is needed, the less it is wanted: Attitudes toward face-to-face intervention among depressed patients undergoing online treatment. Depression and Anxiety, 30, 157-167.

Nathan, P. E., y Gorman, J. M. (Eds.). (2016). A Guide to Treatments That Work 4th Edition. New York: Oxford University Press.

Titov, N. (2011). Internet-delivered psychotherapy for depression in adults. Current opinion in psychiatry, 24(1), 18-23.

Wallin, E. E. K., Mattsson, S., \& Olsson, E. M. G. (2016). The Preference for internet-based psychological interventions by individuals without past or current use of mental health treatment delivered online: a survey study with mixed-methods analysis. JMIR mental health, 3(2), e25

World Health Organization (2017). Depression and Other Common Mental Disorders: Global Health Estimates. Geneva, Switzerland: WHO Document Production Services. 


\title{
Inteligencia emocional para frenar el rechazo en las aulas
}

\author{
MARTÍN SÁNCHEZ GÓMEZ \\ martin.sanchez@uji.es \\ EDGAR BREsó ESTEVE \\ breso@uji.es
}

\section{Resumen}

En los últimos años, una de las líneas de investigación que más interés ha generado dentro del contexto educativo ha sido el análisis del papel que juegan las emociones en el aula y, sobre todo, su relación con la adaptación escolar y el bienestar de los estudiantes. El estudio aquí presentado continúa la línea de las investigaciones realizadas previamente con el propósito de analizar la relación de la inteligencia emocional (IE) con el rechazo recibido por parte del grupo de iguales. La muestra de esta investigación está compuesta por 243 alumnos (120 chicos y 123 chicas) de educación primaria con edades comprendidas entre los 8 y 12 años que fueron evaluados a través de dos cuestionarios: el Mobile Emotional Intelligence Test (MEIT) (Bresó, Ferrer \& Giorgi, 2013) y el Cuestionario sociométrico de nominaciones (García-Bacete \& González, 2006). Tras analizar los resultados obtenidos podemos afirmar que están en la línea de las investigaciones previas y defienden la relación de la IE con la aceptación grupal. En concreto, existe una relación significativa negativa entre la variable de IE Gestión y las nominaciones negativas recibidas En la parte final se discuten las implicaciones prácticas de los resultados obtenidos.

Palabras clave: Inteligencia emocional, rechazo, adaptabilidad, manejo del estrés.

\section{Abstract}

In recent years, one of the lines of research that has generated the greatest interest in the educational context has been the analysis of the role of emotions in the classroom and, above all, their relationship with school adaptation and student well-being. The study presented here continues the line of research previously done with the purpose of analyzing the relationship between emotional intelligence (EI) and the rejection received by the peer groups. The sample of this research is composed of 243 students (120 and 123 girls) of primary education aged between 8 and 12 years who were evaluated through two questionnaires: the Mobile Emotional Intelligence Test (MEIT) and the Sociometric Questionnaire of Nominations (García-Bacete \& González, 2006). After analyzing the obtained results we can affirm that they are in the line of the previous investigations and defend the relation of the El with the group acceptance. Specifically, there is a significant negative relationship between the variable EI Management and the 
negative nominations received. The final part discusses the practical implications of the results obtained.

Keywords: Emotional intelligence, rejection, adaptability, stress management.

\section{Introducción}

La inteligencia emocional (IE), definida como la habilidad para percibir, usar, comprender y regular las emociones, ha demostrado ser una variable fundamental a la hora de entender el ajuste social. Pese a ello, son escasos los trabajos que exploren su papel en la infancia, ya que la mayor parte de la investigación en torno a la IE ha sido realizada con muestras de población adulta.

El término IE es un constructo psicológico tan interesante como controvertido, que aun siendo conceptualizado de modos muy diferentes, se refiere a la interacción entre emoción y cognición, que permite al individuo, un funcionamiento adaptado a su medio (Salovey \& Grewal, 2005). La literatura científica sobre IE ha mostrado de forma amplia la influencia que la percepción emocional, el conocimiento de las emociones y la regulación de nuestros estados de ánimo tienen sobre nuestras vidas (Fernández-Berrocal, Ramos \& Extremera, 2001). Este reconocimiento de los aspectos emocionales como factores determinantes de la adaptación de los individuos a su entorno, ha contribuido al surgimiento de un interés renovado por el estudio de la influencia de la IE en entornos académicos.

En los últimos años se ha incrementado el interés por analizar la relación existente entre la IE y otras variables como el ajuste socio-emocional o el rendimiento académico de los estudiantes. Lopes et al. (2004) encontraron una relación positiva entre la capacidad de manejar las emociones y la calidad de las interacciones sociales entre iguales. Atendiendo a las investigaciones más destacadas, los resultados demuestran que las habilidades emocionales se relacionan con aspectos como la felicidad, el funcionamiento social y el bienestar en niños y pre-adolescentes (Fernández-Berrocal \& Extremera, 2009). Es cada vez más evidente que el éxito general y el bienestar en la adultez puede ser una consecuencia del aprendizaje temprano en la utilización de estas habilidades sociales y emocionales para afrontar de manera productiva los cambios vitales (Fernández-Berrocal \& Ruiz, 2008). Los resultados obtenidos han aportado evidencias de que la IE autoinformada se relaciona significativamente con un elevado autoconcepto y con el nivel de adaptación social de los estudiantes (Jiménez \& López-Zafra, 2011). Por tanto, su valor en el ámbito escolar es ya indudable y su implicación futura una tarea inevitable (Fernández-Berrocal \& Ruiz, 2008).

Además de esto, se ha observado que los adolescentes con más habilidad para reconocer los estados emocionales informaban de mejores relaciones sociales con el grupo de iguales y sus padres, así como una menor conflictividad en sus relaciones sociales con otras personas (Brackett, Rivers, Shiffman \& Salovey, 2006; Garaigordobil \& Oñederra, 2010; Salguero, Fernández-Berrocal \& Ruiz-Aranda, 2011).

Sin embargo, no todos los resultados se muestran consistentes debido a la falta de consenso en cuanto a la definición del constructo IE y a la metodología tan diversa que hasta ahora han presentado los estudios. Tanto los resultados de investigaciones que recurren a autoinformes como las que utilizan medidas de ejecución para evaluar IE, señalan la existencia de relaciones moderadas aunque significativas de los factores emocionales con el rendimiento 
académico (López \& Jiménez, 2009; Martín, Berrocal \& Brackett, 2008; Petrides, Frederickson \& Furnham, 2004; Schutte et al., 1998).

La IE es un constructo que se ha incorporado en los últimos años al campo de la psicología de la educación. Hasta la fecha, pocas investigaciones han abordado la influencia de la misma en el juego de roles que se despliega y caracteriza la dinámica social de las aulas escolares. No obstante, nuestro trabajo pretende aportar una mayor claridad a los datos ya recogidos acerca del estudio de la relación entre IE y diferentes variables como el rechazo, de vital importancia en el contexto académico. Los estudios realizados ponen de manifiesto que las competencias emocionales son un elemento diferencial en la forma en que los alumnos se agrupan socialmente (Elipe, Ortega, Hunter \& Del Rey, 2012). Las relaciones entre iguales suponen una pieza fundamental en el desarrollo de los niños y el rechazo supone un proceso interpersonal en el que hay que considerar tanto las características del alumno rechazado como las del contexto en el que tiene lugar el rechazo (García-Bacete, Sureda-García \& Monjas-Casares, 2010). Desde una perspectiva contextual, y teniendo en cuenta los diferentes escenarios en los que se desarrollan las relaciones sociales, los principales resultados indican que la preferencia y el rechazo están mediatizados por los contextos interpersonales (Ortega \& Mora-Merchán, 2008). Los tipos sociométricos pueden ser considerados como un indicador de la competencia social aunque está muy determinado por las características del aula, lo cual no significa que fuera de ella se de la misma situación. Por tanto, es fundamental atender a otros indicadores como las nominaciones positivas y negativas recibidas por los compañeros de aula. Se ha descubierto que la inteligencia emocional correlaciona con una menor propensión a acosar y ser acosado durante la etapa escolar (Kokkinos \& Kipritsi, 2012). Diferentes estudios han intentado conocer qué dimensiones de la IE tienen mayor correlación con la propensión de los adolescentes a ser sometidos a la victimización por pares (Baroncelli \& Ciucci, 2014; Lomas, Stough, Hansen \& Downey, 2012). En lo relativo a diferencias de género en procesos de rechazo, ellos son más rechazados y controvertidos y ellas más ignoradas y promedio (García-Bacete, Sureda \& Monjas, 2008). El estudio de Gutiérrez y Lehalle (2012) encontró que los adolescentes varones con puntuaciones de alta IE recibieron más nominaciones positivas de sus compañeros de clase y las niñas dieron significativamente más nominaciones a los compañeros de clase con puntuaciones de IE alta. El estudio de Andrei, Mancini, Mazzoni, Russo \& Baldaro (2015) descubrió que la IE se relaciona con el estatus social real y percibido, y que el estatus social ejerce influencia en el rendimiento escolar.

Como hemos visto, las relaciones con los iguales en la escuela están en relación directa con las capacidades emocionales. Por ello, en el presente artículo profundizamos en estas asociaciones y buscamos ampliar los conocimientos existentes en este terreno de la psicología educativa.

El objetivo de este trabajo es analizar si existe relación entre la IE y las nominaciones negativas recibidas por parte de compañeros del aula. Hipotetizamos que los alumnos con alta puntuación IE recibirán menos nominaciones negativas.

\section{Método}

\section{Muestra}

La recogida de datos original nos dejó una muestra de 261 sujetos, pero tras eliminar del estudio a todos aquellos alumnos que no habían realizado correctamente el cuestionario se obtuvo una muestra final de 243 alumnos (120 chicos y 123 chicas) con un rango de edad comprendido entre 8 y 12 años y una media de 10,11 años (DT = 0,54). 


\section{Instrumentos}

MEIT: el Mobile Emotional Intelligence Test (Bresó, Ferrer \& Giorgi, 2013), en su versión para niños, evalua la IE a través de diferentes pruebas de habilidad que permiten conocer la capacidad de percibir, comprender y gestionar emociones. Diseñado ex profeso por Bresó \& Sánchez-Gómez, está basado en el modelo de habilidad propuesto por Salovey \& Mayer (1990) y se compone de 38 ítems divididos en 7 tipos de tareas. En las pruebas de percepción el usuario debe identificar y reconocer expresiones emocionales; en las de comprensión se pide al usuario que constuya emociones complejas y que deduzca que situaciones conducen a ciertos estados emocionales; mientras que en el apartado de gestión se pregunta sobre la mejor forma de actuar para resolver un conflicto emocional en una determinada situación. El cuestionario cuenta con propiedades psicométricas satisfactorias, ya que sus escalas para el grupo de edad de 9 a 11 años tienen índices de consistencia interna entre ,78 y ,88.

Cuestionario sociométrico: el rechazo ha sido evaluado a través del Cuestionario sociométrico de nominaciones (García-Bacete \& González, 2006). El Sociomet (González \& GarcíaBacete, 2010), un software que utiliza los datos del cuestionario sociométrico, nos ha permitido clasificar a los alumnos en función de las nominaciones positivas y negativas que el resto de compañeros han dado acerca suya.

\section{Procedimiento}

Las respuestas a los instrumentos de los 243 sujetos fueron recogidas de distintos centros de educación primaria de la Comunidad Valenciana. Todos los participantes aceptaron colaborar voluntariamente en el estudio y los padres o turores firmaron una hoja de consentimiento antes de proceder a la realización del estudio. Los datos obtenidos han sido tratados con total confidencialidad y únicamente con fines de investigación.

\section{Análisis de datos}

Una vez obtenidas las respuestas se almacenaron los datos para su posterior análisis mediante el programa estadístico SPSS (versión 24,0). En primer lugar se trabajó con los datos descriptivos de la muestra para conocer sus características y considerar si resultaba adecuada la generalización de los datos aquí extraídos. Más tarde se obtuvieron correlaciones bivariadas mediante la $r$ de Pearson para conocer la posible relación entre las variables objeto de estudio. El nivel de significación estadística fue del $5 \%$ en todos los casos $(p<0,05)$.

\section{Resultados}

Antes de analizar si existe relación entre la IE y el rechazo, medido a través de nominaciones negativas, se presenta la tabla 1 donde se muestra el análisis de correlación entre la dimensiones de IE evaluadas por el MEIT. 
Tabla 1

Correlación entre las dimensiones de IE (Pearson)

\begin{tabular}{lccc}
\hline Variable & IE Percepción & IE Comprensión & IE Gestión \\
\hline IE Percepción & 1 & & \\
IE Comprensión &, $27^{*}$ & 1 & \\
IE Gestión &, $37^{*}$ &, $26^{*}$ & 1 \\
\hline
\end{tabular}

* La correlación es significativa en el nivel 0,01

Como se puede observar, los resultados indican que los constructos que componen la IE percibida están relacionados de forma significativa y moderada, demostrando así que miden aspectos que tienen relación pero no son idénticos.

Relación entre IE y rechazo

Tras analizar los resultados obtenidos en este estudio podemos afirmar que están en la línea de las investigaciones previas y defienden la relación de la IE con el rechazo grupal. En concreto, existe una relación significativa negativa entre la variable de IE gestión y las nominaciones negativas recibidas.

En la Tabla 2 podemos observar los resultados arrojados por el análisis de correlaciones entre las tres dimensiones de IE (eje $\mathrm{X}$ ) y el rechazo (eje $\mathrm{Y}$ ).

Tabla 2

Correlación de las variables de estudio (Pearson)

\begin{tabular}{lccc}
\hline Variable & IE Percepción & IE Comprensión & IE Gestión \\
\hline Rechazo &,- 17 &,- 19 &,$- 34^{*}$ \\
\hline
\end{tabular}

${ }^{*}$ La correlación es significativa en el nivel 0,01

Atendiendo a la variable que evalúa el rechazo (Nominaciones negativas), los resultados nos indican la existencia de una relación significativa negativa $(,-34)$ entre el número de nominaciones negativas y la puntuación en la variable de IE gestión emocional. Sin embargo, no encontramos una relación significativa entre las nominaciones negativas y el resto de constructos de la IE.

\section{Discusión y conclusiones}

Como ha quedado demostrado en la introducción teórica, la calidad de las relaciones con los iguales en la escuela es un aspecto clave para el ajuste psicosocial en esta etapa de la vida. 
El presente estudio partió del interés por conocer la relación entre la inteligencia emocional y el rechazo en alumnos de primaria, todo ello con el objetivo de obtener nuevos datos que aporten valor a este campo de la investigación. A partir de la muestra de 243 alumnos, ha sido posible conocer cuál es la relación entre las variables de estudio en este grupo poblacional, además de indagar qué factores afectan significativamente sobre estas variables y en qué medida lo hacen. Para ello examinamos la relación entre IE y rechazo medido a través de nominaciones negativas recibidas. Siguiendo la línea de investigaciones previas (Baroncelli \& Ciucci, 2014; Lomas, Stough, Hansen \& Downey, 2012) observamos que existe una relación significativa negativa entre la variable de IE gestión emocional y el rechazo recibido por los compañeros de aula. Cuanto mayor es la capacidad para gestionar emociones menor es la probabilidad de ser rechazados por el resto de compañeros. La gestión emocional supone la capacidad para regular las emociones en situaciones concretas con el objetivo de llevar a cabo respuestas lo más adaptativas posibles, así como la capacidad para resolver problemas personales e interpersonales de manera efectiva, por tanto, es frecuente hallar esta relación la aceptación de los compañeros y la adaptabilidad al contexto. Esta dimensión también está relacionada con la tolerancia al estrés y el control de impulsos, por tanto, asumimos que un buen control de estas emociones permite regularse de manera constructiva y efectiva, lo cual, según muestran los resultados, parece actuar como un factor de protección ante el rechazo (Salovey \& Grewal, 2005).

Tras haber analizado los resultados podemos afirmar que se encuentran en consonancia con las hipótesis planteadas al principio del trabajo. Sin embargo, no todas las dimensiones de IE han demnostradeo estar relacionadas significativamente con el rechazo recibido, ya que solo la dimensión de gestión emocional ha resultado significativa. Por tanto, aquellos alumnos con mayores puntuaciones en gestión emocional presentan puntuaciones menos nominaciones negativas por parte de sus compañeros de aula.Los resultados aquí obtenidos esperan formar parte de la base de conocimientos que sirva para consolidar futuras investigaciones que desarrollen la presente y fortifiquen este campo de la Psicología educativa. De cualquier modo, estos datos deben ser tomados con cautela y su generalización debe realizarse con precaución y sólo en muestras similares a la presentada en este trabajo.

Creemos útil y necesario que los hallazgos encontrados en la investigación sirvan en su utilización como guía durante el diseño de programas para la formación en esta capacidad. En 1990 Salovey \& Mayer iniciaron el estudio del papel de las habilidades emocionales en el aprendizaje con la esperanza de integrar la educación emocional en los currículos académicos (Extremera \& Fernández-Berrocal, 2006). Con el paso del tiempo los programas de educación emocional en niños han demostrado resultados muy positivos (Havighurst, Harley \& Prior, 2004; Vadebencoeur \& Bégin, 2005), ya que la IE se ha relacionado de forma evidente con el ajuste social y emocional, así como con la calidad de las relaciones interpersonales.

En futuras investigaciones es importante aumentar el tamaño muestral del presente estudio, ya que consideramos que una muestra de 243 participantes no es un tamaño pequeño pero dificulta el análisis de resultados y puede restar cierta fuerza a los resultados extraídos. También creemos que estudios futuros deben tratar de realizar análisis causales para poder observar si existen relaciones de causalidad entre las variables objeto de estudio.

Para finalizar solamente queremos resaltar que, a pesar de la aparición de múltiples libros, revistas y manuales sobre la importancia de la promoción de la IE, aún resulta necesario una mayor cantidad de datos científicos que permitan conocer cómo aplicar la enseñanza en el aula para multiplicar sus efectos beneficiosos. Es cierto que cada vez existe más literatura científica sobre la IE en contextos académicos, pero la aplicación de programas para desarrollar esta capacidad en centros educativos debe seguir mejorando (Extremera \& FernándezBerrocal, 2006). Esperamos que este trabajo permita ahondar un poco más en este campo de conocimiento y forme parte del grueso de investigaciones que defienden la importancia de la 
IE en contextos académicos. Al fin y al cabo, como hemos observado durante la investigación, para evitar el rechazo resulta importante no dejar de prestar atención a los aspectos emocionales de las personas.

\section{Referencias bibliográficas}

Andrei, F., Mancini, G., Mazzoni, E., Russo, P. \& Baldaro, B. (2015). Social status and its link with personality dimensions, trait emotional intelligence, and scholastic achievement in children and early adolescents. Learning and Individual Differences, 42, 97-105.

Baroncelli, A. \& Ciucci, E. (2014). Unique effects of different components of trait emotional intelligence in traditional bullying and cyberbullying. Journal of Adolescence, 37(6), 807815.

Brackett, M., Rivers, S., Shiffman, S., Lerner, N. \& Salovey, P. (2006). Relating emotional abilities to social functioning: a comparison of self-report and performance measures of emotional intelligence. Journal of Personality and Social psychology, 91(4), 780.

Bresó, E., Ferrer, A. \& Giorgi, G. (2013). MEIT (Mobile Emotional Intelligence Test): Una novedosa metodología para evaluar la percepción de emociones haciendo uso de dispositivos móviles. Ansiedad y Estrés, 19, 185-200.

Elipe, P., Ortega, R., Hunter, S. C. \& Del Rey, R. (2012). Inteligencia emocional percibida e implicación en diversos tipos de acoso escolar. Psicología Conductual, 20(1), 169-181.

Extremera, N. \& Fernández-Berrocal, P. (2006). Emotional intelligence as predictor of mental, social, and physical health in university students. The Spanish Journal of Psychology, $9(1), 45-51$.

Fernández-Berrocal, P., Ramos, N. \& Extremera, N. (2001). Inteligencia emocional, supresión crónica de pensamientos y ajuste psicológico. Boletín de Psicología, 70, 79-95.

Fernández-Berrocal, P. \& Ruiz, D. (2008). La inteligencia emocional en la educación. Revista Electrónica de Investigación Psicoeducativa, 6(2), 421-436.

Fernández-Berrocal, P. \& Extremera, N. (2009). La Inteligencia Emocional y el estudio de la felicidad. Revista Interuniversitaria de Formación del Profesorado, (66), 85-108.

Garaigordobil, M. \& Oñederra, J. A. (2010). Inteligencia emocional en las víctimas de acoso escolar y en los agresores. European Journal of Education and Psychology, 3(2), 243256.

García-Bacete, F. \& González, J. (2006). La identificación de los alumnos rechazados. Comparación de métodos sociométricos de nominaciones bidimensionales. Infancia y Aprendizaje, 29(4), 437-451.

García-Bacete, F., Sureda, I. \& Monjas, I. (2008). Distribución sociométrica en las aulas de chicos y chicas a lo largo de la escolaridad. Revista de Psicología Social, 23(1), 63-74.

García-Bacete, F., García, I. S. \& Casares, M. I. M. (2010). El rechazo entre iguales en la educación primaria: Una panorámica general. Anales de psicología, 26(1), 123-136.

González, J. \& García-Bacete, F. (2010). SOCIOMET. Evaluación de la competencia social entre iguales. La sociometría y otras medidas. Madrid: TEA Ediciones.

Gutiérrez, J. \& Lehalle, H. (2012). La violencia escolar entre iguales en alumnos populares y rechazados. Psychosocial Intervention, 21(1), 77-89.

Havighurst, S., Harley, A. \& Prior, M. (2004). Building Preschool Children's Emotional Competence: A parenting Program. Early Education and Development. Special Issue: Prevention Interventions with Young Children, 15(4), 423-447. 
Jiménez, M. I. \& López-Zafra, E. (2011). Actitudes sociales y adaptación social en adolescentes españoles: el papel de la inteligencia emocional percibida. Revista de Psicología Social, 26(1), 105-117.

Kokkinos, C. M. \& Kipritsi, E. (2012). The relationship between bullying, victimization, trait emotional intelligence, self-efficacy and empathy among preadolescents. Social Psychology of Education, 15(1), 41-58.

Lomas, J., Stough, C., Hansen, K. \& Downey, L. A. (2012). Brief report: Emotional intelligence, victimisation and bullying in adolescents. Journal of Adolescence, 35(1), 207-211.

Lopes, P. N., Brackett, M. A., Nezlek, J. B., Schütz, A., Sellin, I. \& Salovey, P. (2004). Emotional Intelligence and Social Interaction. Personality and Social Psychology Bulletin, 30(8), 1018-1034.

López, E. \& Jiménez, M., (2009). Inteligencia emocional y rendimiento escolar: estado actual de la cuestión. Revista Latinoamericana de Psicología, 41(1), 69-79.

Martín, R., Berrocal, P. F. \& Brackett, M. A. (2008). La inteligencia emocional como una competencia básica en la formación inicial de los docentes: algunas evidencias. Electronic Journal of Research in Educational Psychology, 6(15), 437-454.

Ortega, R. \& Mora Merchán, J. (2008). Las redes de iguales y el fenómeno del acoso escolar: explorando el esquema dominio-sumisión. Infancia y Aprendizaje, 31, 515-528.

Petrides, K., Frederickson, N. \& Furnham, A. (2004). The role of trait emotional intelligence in academic performance and deviant behavior at school. Personality and Individual Differences, 36(2), 277-293.

Salguero, J. M, Fernández-Berrocal, P. \& Ruiz-Aranda, D. (2011). Emotional intelligence and acute pain: The mediating effect of negative affect. The Journal of pain, 12(11), 11901196.

Salovey, P. \& Mayer, J. D. (1990). Emotional intelligence. Imagination, Cognition and Personality, 9(3), 185-211.

Salovey, P. \& Grewal, D. (2005). The science of emotional intelligence. Current Directions in Psychological Science, 14(6), 281-285.

Schutte, N. S., Malouff, J. M., Hall, L. E., Haggerty, D. J., Cooper, J. T., Golden, C. J. \& Dornheim, L. (1998). Development and validation of a measure of emotional intelligence. Personality and Individual Differences, 25(2), 167-177.

Vadebencoeur, J. \& Bégin, H. (2005). The efficacy of social skills promotion programs designed for 5-12 years old children: a critical anlysis. Revue Québécoise de Psychologie, 26(1), 183-201. 


\title{
La diabetes mellitus
}

\section{Herramienta para la toma de decisiones compartidas en la diabetes mellitus tipo II}

\author{
Leticia Gimeno PITARCH \\ al337848@uji.es \\ Rosa ÁlVARO BALLESTER \\ al318269@uji.es \\ GLORIA DE LA TORRE MONFORT \\ al319535@uji.es \\ Mariana Claudia Matel \\ al317225@uji.es \\ LUIS VICENTE LIZÁN TUDELA \\ lizan@med.uji.es
}

\section{Resumen}

La Diabetes es una enfermedad crónica y prevalente, que tiene un desarrollo gradual y para cuyo control son esenciales el consejo y la guía del personal sanitario, junto con la atención del paciente. Por lo tanto, resulta imprescindible que el paciente conozca y entienda su patología junto con las opciones para su tratamiento, cómo afecta a su calidad de vida, así como que pueda valorar sus propias preferencias y sepa dónde ha de buscar información. Se ha elaborado una herramienta de ayuda con el objetivo de proporcionar información sobre las diferentes opciones de tratamiento, de manera que facilite la reflexión y la discusión conjunta con el profesional. El resultado ha sido la creación de un tríptico. En conclusión, se ha conseguido implementar un instrumento de ayuda para que los pacientes conozcan más detalladamente acerca de su patología y puedan tomar decisiones compartidas con el profesional sanitario según sus preferencias, aumentando la confianza en el sistema de salud y la adherencia al tratamiento.

Palabras claves: diabetes, tratamiento, preferencias, información, herramienta de ayuda.

\section{Abstract}

Diabetes is a chronic and prevalent disease, which has a gradual development and for its control are essential advice and guidance of health personal, together with the patient's attention. Therefore, it is imperative that the patient knows and understands 
their pathology along with the options for their treatment, how it affects their quality of life, as well as being able to value their own preferences and look for where to look for information. An aid tool has been developed with the objective of providing information on the different treatment options, so as to facilitate reflection and joint discussion with the professional. The result has been the creation of a triptych. In conclusion, an instrument has been implemented to help patients to know more about their pathology and to make decisions that are shared with the healthcare professional according to their preferences, increasing confidence in the health system and adherence to treatment.

Keywords: diabetes, treatment, preferences, information, help tool.

\section{Introducción}

La prevalencia de la diabetes tipo 2 se ha convertido en uno de los problemas sanitarios más graves de nuestro tiempo. Según un estudio llevado a cabo por el Centro de Investigación Biomédica en Red de Diabetes y Enfermedades Metabólicas Asociadas, y la Sociedad Española de Diabetes, existen 246 millones de personas afectadas en todo el mundo, una cifra que sigue amentando y que va a suponer uno de los principales motivos de consulta en atención primaria.

La Diabetes Mellitus aparece cuando el páncreas no produce suficiente insulina o cuando el organismo no utiliza eficazmente la que produce. Se trata de una enfermedad crónica, con la que el paciente tendrá que aprender a convivir, adaptando su estilo de vida a las nuevas necesidades.

Cabe mencionar, que el buen control de la diabetes es clave, no solo para asegurar la calidad de vida de los pacientes según afirma Pablos-Velasco, Pedro, Emilio Salguero-Chaves, Julio Mata-Poyo, Beatriz Derivas-Otero, Ricardo García-Sánchez y Pablo Viguera-Ester en su artículo Quality of Life and Satisfaction with Treatment in Subjects with Type 2 Diabetes (2014), sino también para evitar posibles complicaciones como la afectación microvascular (retinopatía diabética, nefropatía diabética, neuropatía periférica...), o bien, la macrovascular; ya que la Diabetes Mellitus está considerada como una enfermedad asociada al riesgo cardiovascular, siendo ésta la primera causa de muerte entre los diabéticos. Tal y como se determinó en un estudio realizado sobre Estadísticas y Causas de Mortalidad por parte de M. Salgado Pineda, J. Franch Nadal, M. Pallas Ellacuria, C. Oriol Zerbe, J. Grau Bartomeu y J. Castellà García (2001), «La principal causa de muerte en diabéticos tipo 2 fue la enfermedad cardiovascular $(47,7 \%)$, mientras que en el Registro Civil la mortalidad por esta razón es claramente menor (...). Esto sugiere que debemos insistir aún más en la importancia de monitorear los factores de riesgo cardiovascular.»

Todo ello ha conllevado un gran impulso en el desarrollo de nuevas terapias antidiabéticas, lo que puede causar cierta incertidumbre a la hora de prescribir el mejor tratamiento, ya que cada uno de ellos presenta una serie de ventajas y desventajas que tanto paciente como médico deberán valorar. Como estudiantes de $3^{\circ}$ Medicina hemos sido testigos, durante nuestras prácticas externas, de la gran cantidad de pacientes con Diabetes Mellitus tipo II mal controlada y por lo tanto, con necesidad de modificar su tratamiento.

Definido el origen del estudio, nuestro objetivo principal ha sido elaborar una herramienta de autoayuda dirigida a los pacientes con Diabetes Mellitus tipo II, con necesidad de modificar y adaptar el tratamiento, teniendo en cuenta sus preferencias. 
Según Bosch J.M., (2012), en La toma de decisiones conjuntas en medicina, "La participación del paciente en la toma de decisiones (PPTD) precisa un cambio en la forma tradicional de la atención sanitaria, pasando de un modelo paternalista a una relación más colaborativa, donde la opinión del paciente (y sus familiares) comporta ceder parte del control de la consulta, un trabajo de negociación continuado, y si nos atenemos a respetar las decisiones del paciente, un claro ejercicio que le permita ejercer su autonomía, lo que constituye un imperativo ético». Además, según Ruiz Moral R., Peralta Munguia L., Pérula de Torres LA., Olloqui Mundet J, Carrión de la Fuente T, Sobrino López A y cols. (2012), la mayoría de los pacientes tras una consulta concreta desean poder dar su opinión a las propuestas de tratamiento que surgen, sin embargo perciben que sus médicos raramente les ofrecen estas oportunidades de participación. Por lo tanto, partiendo de la evidencia encontrada, la posibilidad de crear un instrumento que logre y asegure la toma de decisiones compartidas médico-paciente, supone un gran objetivo a conseguir.

\section{Método}

Según The BMJ (2013), una plataforma involucrada en el debate sobre la salud, cada vez más pacientes manifiestan su deseo de participar activamente en las decisiones relacionadas con su tratamiento. Siendo la cifra cada vez mayor, aparecen nuevas necesidades a la hora de afrontar una decisión compartida médico-paciente, por lo que el objetivo de nuestro estudio se basa en proporcionar la información necesaria a los pacientes sobre las diferentes opciones de tratamiento de manera que facilite la reflexión y discusión con el profesional sanitario a la hora de tomar decisiones compartidas.

El método utilizado ha sido la creación de una herramienta de autoayuda, que es un instrumento para facilitar la toma de decisiones compartidas sobre el tratamiento de la Diabetes Mellitus, lo cual se consigue con la aportación de información a los pacientes sobre su enfermedad. Según Coulter A., Parsons S. y Askham J (2008), la alfabetización en salud es fundamental para mejorar la participación de los pacientes en su atención, y por lo tanto todas las estrategias para fortalecer la participación de los pacientes deben tener como objetivo mejorarla.

Esta herramienta ha de ser clara, concisa, sencilla, visual, breve, divulgativa y sobre todo accesible para aquellos a los que estaba dirigida, es decir, pacientes con Diabetes Mellitus Tipo 2 mal controlada, que acuden al centro de atención con el objetivo de modificar y mejorar su tratamiento. De la misma forma, tal y como afirman Jiménez De Gracia L., Ruiz Moral R., Gavilán Moral E., Hueso Montoro C., Cano Caballero Gálvez D., y Alba Dios MA (2012), ha de ser un instrumento práctico que pueda incorporarse fácilmente en la consulta, y en la rutina del día a día de los médicos, en este caso, de atención primaria.

\section{Resultados}

El resultado obtenido ha sido la elaboración de un tríptico que contiene una portada en la que se presenta la diabetes como patología de forma breve, clara y sencilla. En su interior, se define la enfermedad junto a los niveles de glucosa plasmática en ayunas que la determinan. Al mismo tiempo, se especifican los diferentes tipos de diabetes y cómo puede llegar esta a repercutir en la calidad de vida de los pacientes, con el objetivo de que sean conocedores de los posibles síntomas que se pueden presentar a lo largo del tiempo. 
La información encontrada en el tríptico se extrae de una serie de asociaciones internacionales sobre la diabetes como es el caso de American Association of Clinical Endocrinologists (AACE), American Diabetes Association (ADA), Canadian Diabetes Association (CDA).

Además, se ha incluido un apartado de opciones terapeuticas para proporcionar información al paciente acerca de los distintos tratamientos disponibles. El apartado más característico de la herramienta, ha sido el de preferencias del paciente, en el cual, se han incluido una serie de cuestiones para que este valore los diferentes tratamientos de acuerdo a sus características, necesidades e intereses y pueda tomar una decisión conjunta con su médico. Al mismo tiempo se ha incluido una check list basada en los criterios de la International Patient Decision Aid. Standards. Por último, se ha considerado de gran importancia proporcionar al paciente páginas web dónde pueda acceder y ampliar sus conocimientos acerca de la patología y les pueda servir como guía.

El conocimiento sobre la farmacología de la diabetes se basa en el Manual de Farmacología y terapéutica, Brunton, L., Parker, K., Blumenthal, D. y Buxton, I. (2009). Goodman y Gilman. Sección XII, Hormonas y sus antagonistas, insulina, hipoglucemiantes orales y la farmacología del páncreas endocrino (páginas 1037-1059). Mc Graw Hill, y en el libro Farmacología Humana ( $5^{\mathrm{a}}$ Edicicón), J.C. Flórez, K. Freijanes y J. Flórez. Insulina y Hormonas antidiabéticas (pàgines 1051-1073).

A continuación se incluye el resultado de este trabajo:

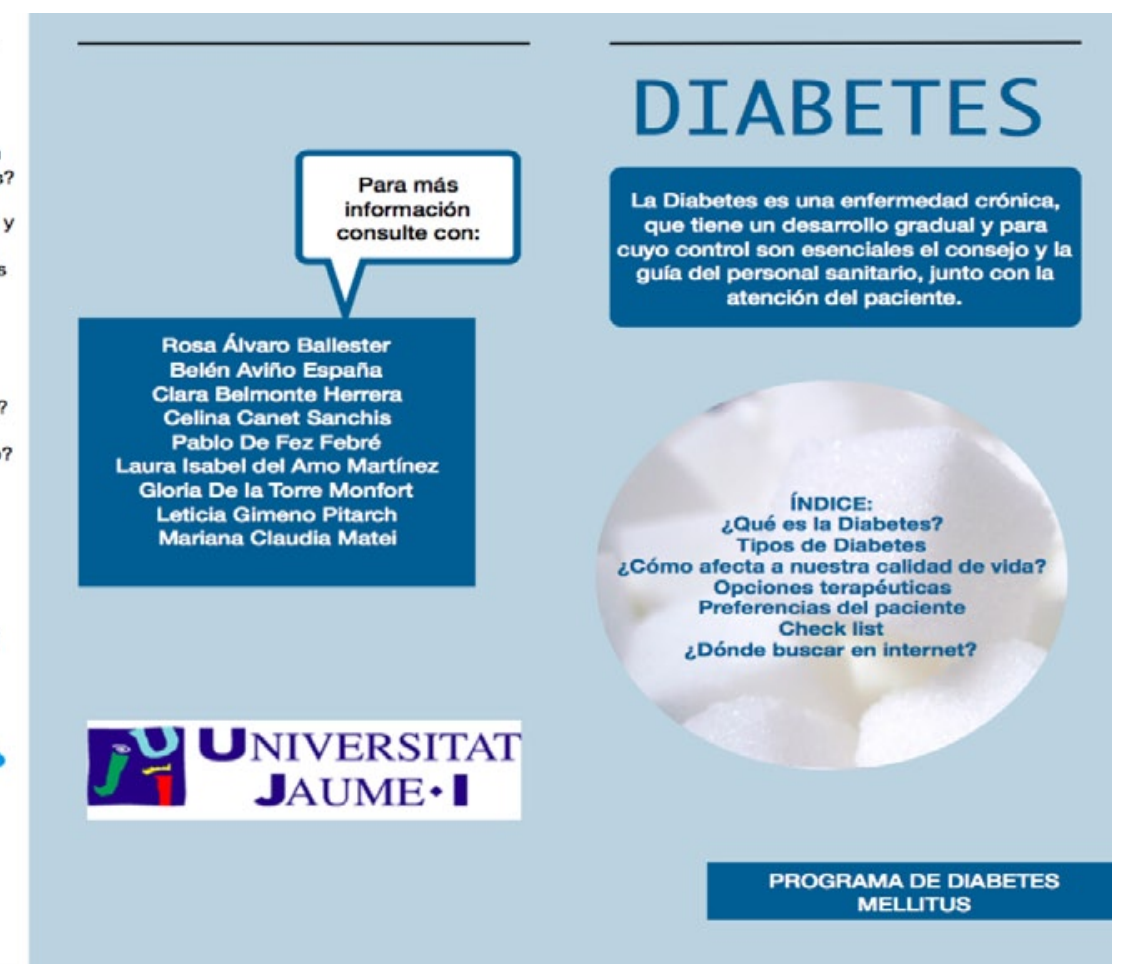



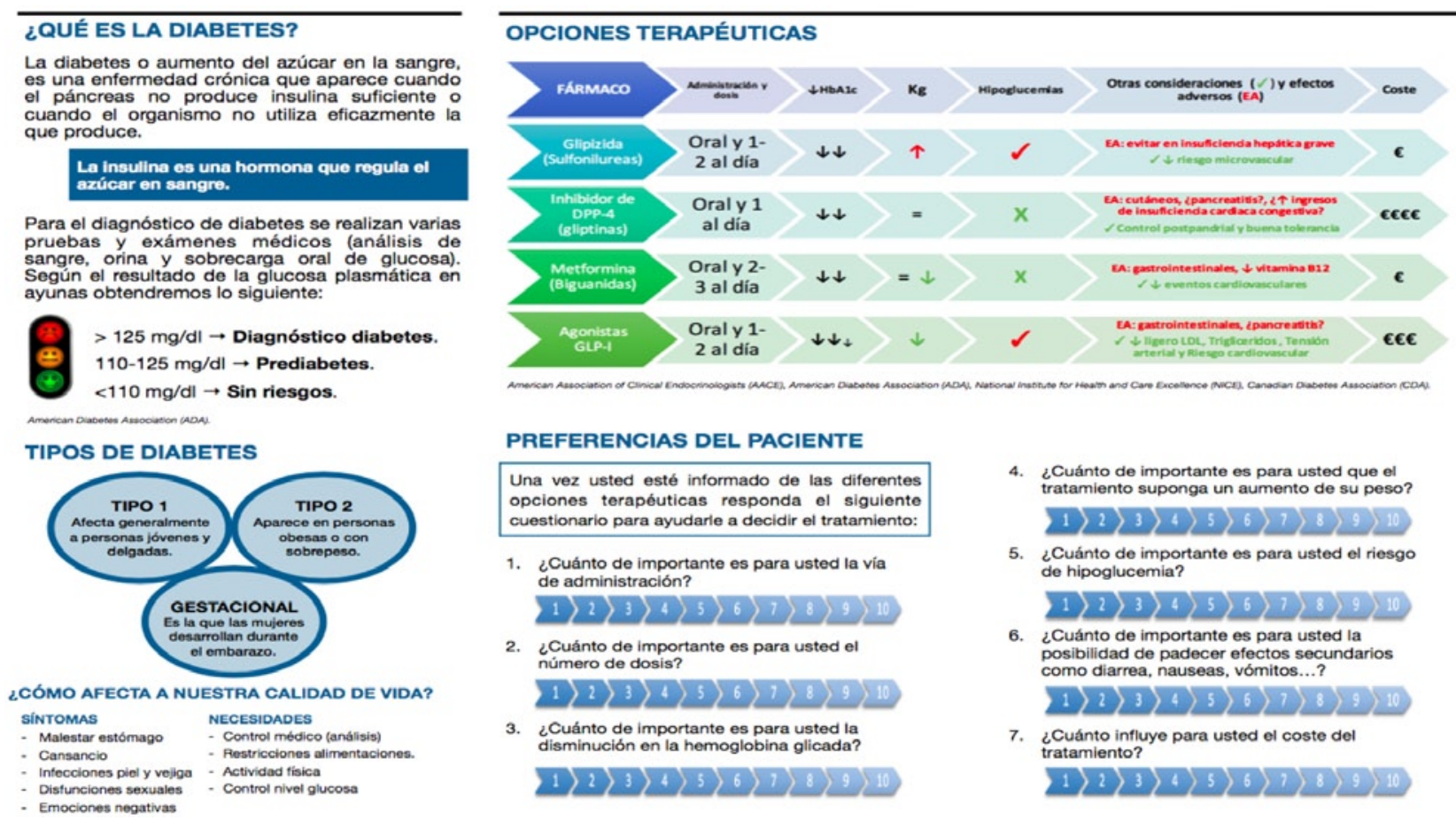

\section{Discusión y conclusiones}

Se han elaborado muchas herramientas a lo largo del tiempo para abordar y ofrecer información de la diabetes a los pacientes, pero no todas han resultado ser utiles. Por eso se ha considerado de vital importancia poner a prueba nuestro resultado. Primero se ha realizado una autoevaluación en la que se ha estudiado si esta herramienta es realmente un instrumento de autoayuda, supone una mejora de la corresponsabilidad médico-paciente a la hora de tomar decisiónes terapéuticas, y además fomenta el principio de autonomía, aumentando la confianza del paciente y sobre todo mejorando su adherencia al tratamiento.

Además, la herramienta ha sido validada según los criterios de evaluación y validación de las herramientas de ayuda para la toma de decisiones, basado en los criterios de The International Patient Decision Aid Standards (IPDAS) Collaboration Quality Dimensions: checklist y manual. El único criterio no cumplido ha sido el de conflicto de intereses. Sin embargo, no consta de este apartado dado que no es valorable que se presente un conflicto de interés en herramientas de este tipo.

Por último, los meses de abril y mayo se ha evaluado esta herramienta en los centros de atención primaria a aquellos pacientes con diabetes de tipo 2 que acudían a consulta con el objetivo de cambiar su tratamiento. El resultado ha sido muy positivo y favorable, ya que los pacientes han afirmado entender claramente la información proporcionada y aumentar su nivel de interés frente a su patología, al haberles dado un papel fundamental en la toma de decisiones frente a la misma.

Con todo esto, la finalidad del trabajo ha sido la elaboración de un instrumento de ayuda para que los pacientes conozcan más acerca de su patología y puedan tomar decisiones según sus preferencias, aumentando su confianza en el sistema de salud y la adherencia al tratamiento.

Concluyendo como frase final, «el médico proporciona la información, el paciente valora la opción y ambos toman la decisión». 


\section{Referencias bibliográficas}

American Association of Clinical Endocrinologists |. (s. f.). Recuperado el 8 de noviembre de 2017, a partir de https://www.aace.com/

American Diabetes Association $®$. (s. f.). Recuperado 8 de noviembre de 2017, a partir de http://www.diabetes.org/es/

Brunton, L., Parker, K., Blumenthal, D. y Buxton, I. (2009). Manual de farmacología y terapéutica. Goodman y Gilman: Mc Graw Hill.

Bosch J.M., (2012). La toma de decisiones conjuntas en medicina: una difícil asignatura. Aten Primaria: 44: 385-6.

Coulter A., Parsons S. y Askham J (2008). Where are the patients in decision-making about their own care? World Health Organization 2008 and World Health Organization, on behalf of the European Observatory on Health Systems and Policies.

Depablos, P., Salguero, E., Mata, J., Derivas, B., García, R. y Viguera, P. (2014). Quality of Life and Satisfaction with Treatment in Subjects with Type 2 Diabetes: Results in Spain of the Panorama Study. Endocrinología Y Nutrición: Órgano De La Sociedad Espanola De Endocrinologia Y Nutricion 61, no. 1: 18-26.

Drug and Therapeutics Bulletin. (2013). An introduction to patient decision aids. BMJ (Clinical Research Ed.), 347, f4147.

Flores, J., Armijo, J.A., y Mediavilla, A. (2008). Farmacología Humana. Masson-Salvat: $5^{\circ}$ Edición.

Jiménez De Gracia L., Ruiz R., Gavilán E., Hueso C., Cano Caballero D. y Alba Dios MA (2012). Opiniones de los médicos de familia acerca de la implicación de los pacientes en la toma de decisiones: un estudio con grupos focales. Aten Primaria. 44(7): 379-386.

Ministerio de sanidad, servicios sociales e igualdad. (s. f.). Manual con criterios de evaluación y validación de las Herramientas de Ayuda para la Toma de Decisiones (Basado en los criterios de The International Patient Decision Aid Standards (IPDAS) Collaboration Quality Dimensions: checklist y manual).

Centro de investigación biomédica en Red de Diabetes y Enfermedades Metabólicas asociadas. (s. f.). Prevalencia de la Diabetes en España. Estudio Di@bet.es.

Risk Factors. (s. f.). Recuperado el 8 de noviembre de 2017, a partir de http://www.diabetes. ca/about-diabetes/risk-factors

Ruiz, R., Peralta, L., Pérula, L.A., Olloqui, J., Carrión T., Sobrino, A., y cols. (2012). Opiniones y percepciones de los pacientes sobre su participación en la toma de decisiones en las consultas de medicina de familia. Aten Primaria. 44: 5-12.

Salgado, M., Franch, J., Pallas, M., Oriol, C., Grau, J. y Castellà, J. (s. f.). Estadísticas y causas de mortalidad en la diabetes tipo 2 | Atención Primaria. Recuperado el 8 de noviembre de 2017, a partir de http://www.elsevier.es/pt-revista-atencion-primaria-27-articuloestadisticas-causas-mortalidad-diabetes-tipo-S0212656701788750

Signs y Symptoms. (s. f.). Recuperado el 8 de noviembre de 2017, a partir de http://www.diabetes.ca/about-diabetes/signs-and-symptoms

Types of Diabetes. (s. f.). Recuperado 8 de noviembre de 2017, a partir de http://www.diabetes.ca/about-diabetes/types-of-diabetes 


\title{
Parto acuático: complicaciones y beneficios más relevantes respecto al parto vaginal convencional
}

\author{
Revisión Integradora \\ Sergio Pascual Romero Lecha \\ al286989@uji.es \\ MARIA ORIOLA ALBA \\ al205257@uji.es \\ SOLEDAD CARREGUI VILAR \\ solecarregui@gmail.com \\ ELADIO JOAQUIN COLLADO BOIRA \\ colladoe@uji.es
}

\section{Resumen}

La inmersión en el agua durante el parto se viene dando desde hace siglos, siendo esta en la actualidad, una técnica cada vez más demandada por la sociedad. Sus principales defensores abogan que proporciona mayor control del dolor, añadiendo una opción más para ampliar la autonomía de la mujer en la toma de decisiones. No obstante, como en cualquier otro parto no está exenta de riesgos. El propósito del presente estudio es conocer aquellas complicaciones más frecuentes que se dan relacionadas con el parto acuático comparándolas con las del parto vaginal convencional. Se realizó una revisión integradora de la literatura través de las bases de datos PubMed, CINAHL, ProQuest, LILACS, y SCOPUS, limitándose la búsqueda a publicaciones con rigor científico de los últimos diez años, en inglés o español y acceso a texto completo. De los 147 artículos encontrados en la búsqueda inicial, 135 estaban fuera de las limitaciones de búsqueda, o no cumplían con los requisitos de calidad CASPE o STROBE, quedando 15 artículos. El parto en el agua reduce el tiempo de dilatación y el grado de trauma perineal con respecto al parto convencional, asociado a un mayor grado de satisfacción de la mujer al final del proceso. Entre los riesgos relacionados con el neonato existe controversia entre los distintos estudios, aludiéndosele riesgo de rotura de cordón, y la broncoaspiración de agua como las principales complicaciones asociadas. No obstante, son datos que deben tomarse con cautela, requiriéndose estudios más sólidos que evidencien diferencias sustanciales en comparación al parto normal.

Palabras clave: nacimiento bajo el agua, nacimiento subacuático, complicaciones, beneficios. 


\section{Abstract}

The immersion in water during childbirth has been taking place for centuries and is being increasingly demanded by today's society. Its main advocates argue that it provides greater pain control, adding one more option to expand women's autonomy in decisionmaking. However, as in any other birth, it is not without risks. The purpose of the present study is to know the most frequent complications related to water birth compared to those of conventional vaginal delivery. An integrative review of the literature was carried out through the PubMed, CINAHL, ProQuest, LILACS, and SCOPUS databases, limiting the search to publications with scientific rigor of the last ten years, in English or Spanish and full text access. Of the 147 articles found in the initial search, 135 were outside the search limitations, or did not meet the requirements of the CASPE quality scale, leaving 15 articles. Water delivery reduces the time of dilation and the degree of perineal trauma with respect to conventional delivery, associated to a higher degree of satisfaction of the woman at the end of the process. Among the risks related to the neonate, there is controversy among the different studies, mentioning the risk of cord rupture and water broncho aspiration as the main associated complications. However, these data should be taken with caution, requiring more robust studies that show substantial differences compared to normal delivery.

Keywords: waterbirth, underwaterbirth, complications, benefits.

\section{Introducción}

El parto en el agua y la inmersión en el agua durante el proceso del parto son dos fenómenos diferentes, sin embargo, a menudo se confunden. La inmersión en el agua se utiliza durante el trabajo de parto como estrategia para manejar el dolor, pero se abandona el medio acuático antes del periodo expulsivo. Sin embargo, el parto en el agua se produce cuando el neonato nace bajo el agua, esto puede ocurrir intencional o no deliberadamente, por ejemplo, cuando una mujer usa la inmersión en el agua durante el trabajo de parto y se dan las circunstancias adecuadas para permanecer en la misma durante el expulsivo. Por ello, aunque ambas definiciones sean fáciles de discriminar, las descripciones de su uso durante la investigación a menudo pueden llegar a fusionarse. Teniendo en cuenta esto, queda justificado que, al intentar describir los beneficios y los riesgos del trabajo de parto en el agua, se considere esencial definir estas dos cuestiones por separado (Davies, Davis, Pearce \& Wong, 2015). Contemporáneamente el parto en el agua empieza a conocerse como un nuevo método de atención al parto sin embargo el medio acuático ya ha sido utilizado desde las antiguas civilizaciones como herramienta terapéutica (Cortes, Basra \& Kelleher, 2011). No es hasta 1805 cuando en Francia se menciona por primera vez el parto acuático como método utilizado para fomentar la relajación materna durante el proceso trabajo de parto. Un siglo después en la década de los 60 , los obstetras rusos Tjarkovsky \& Leboyer estudian este concepto con un enfoque orientado a la mejora de los resultados neonatales. Abanderaron la defensa del parto en el agua y todavía hoy sus teorías mantienen su influencia entre los impulsores del parto acuático (Lim, Tong \& Chong, 2016). En 1975 esta técnica comenzó a ganar popularidad gracias a la publicación del obstetra francés, Frederick Leboyer, pionero con su divulgación del «Birth Without Violence», "nacimiento sin violencia». A finales de los años 70 se incorporó por primera vez 
en la historia la bañera en la maternidad del hospital de Pihiviers en Francia, con el fin de favorecer un parto más cómodo y agradable. Esta importante revolución, fue liderada por el también obstetra francés Michel Odent, autor de la publicación " Nacimiento bajo el agua» (Odent, 1983). Desde entonces ha ido aumentando su aceptación y demanda en la mayoría de los países con ingresos altos (Henderson et al., 2014; Schafer, 2014). Bárbara Harper fundó la organización Waterbirth Internacional en Santa Bárbara, California (1988). Desde entonces ha sido líder en su misión por dar alcance internacional a este movimiento, diseñando programas de educación basados en su modelo «Gentle Birth of maternity care» que busca la mayor evidencia hacia la atención materna.(«Waterbirth International - Dedicated to making waterbirth an available option for all women,» 2017). Todos estos iniciales divulgadores, defendieron que la inmersión en el agua a temperatura corporal durante el trabajo de parto, contribuía a un inmediato alivio del dolor, facilitando la relajación y la movilización libre de la madre, observándose una mejor progresión de la dilatación, atribuyéndose a una mayor liberación de oxitocina al reducirse la ansiedad y el estrés como consecuencia de la inmersión en el agua caliente ( Grupo de trabajo de la Guía de Práctica Clínica sobre Atención al Parto Normal, 2010). En la actualidad, la importancia de la humanización del parto, la autonomía en las decisiones durante el proceso, el interés por reducir la intervención instrumental y la analgesia natural, han contribuido a considerar este método físico como una alternativa eficaz en muchos paritorios del mundo. En España, en el año 2010 se publica por parte del Ministerio de Sanidad y Política Social la guía de Práctica Clínica sobre la atención al parto normal. Grupo de trabajo de la Guía de Práctica Clínica sobre Atención al Parto Normal, 2010) . En dicha guía se recomienda con un nivel de evidencia, la inmersión en el agua templada como un método eficaz de alivio del dolor durante la fase tardía de la primera etapa del parto. La Asociación Española de Pediatría (AEP) (Iriondo et al., 2015) publica en el año 2014 un informe en el que hace alusión al parto acuático, con indicación en gestaciones no complicadas y a término. En los Estados Unidos, la American Academy of Pediatrics (AAP) y The American College of Obstetricians and Gynecologist (ACOG)(American Academy of Pediatrics Committee on Fetus and Newborn y American College of Obstetricians and Gynecologists Committee on Obstetric Practice, 2014), publicaron un informe en la primavera del 2014 señalando lo potenciales beneficios maternos durante la primera fase de parto. A pesar de todo lo que se ha escrito en la literatura por expertos en relación a la conveniencia, virtudes y ventajas de este método, existe una falta de consenso entre la comunidad científica en relación a cuál es el mejor enfoque. No obstante, la mayoría coincide en la necesidad de apoyar los deseos de la mujer durante el parto, así como la necesidad de ser informada acerca de sus opciones desde la perspectiva de la máxima seguridad hacia la paciente y el recién nacido (Simpson, 2013). El objetivo del presente estudio pretende recuperar las evidencias científicas disponibles que nos permitan conocer las complicaciones y beneficios más frecuentes que se dan relacionadas con el parto acuático y comparándolos con los resultados del parto vaginal convencional.

\section{Metodología}

La metodología empleada para la realización de este estudio se ha basado en una revisión integradora de la literatura con el fin de elaborar un análisis sobre las evidencias científicas acerca de los beneficios y complicaciones del parto acuático frente al parto convencional. Uno de los primeros pasos para realizar un estudio de cualquier índole consiste en la formulación clara y concisa de la pregunta de investigación de acuerdo a unos criterios explícitos que definan el problema que se pretende evaluar (Sierra et al., 2013). La pregunta de determina la estructura y el alcance de la revisión. Centra, ubica el tema, el problema acerca 
del cual queremos llamar la atención. Para realizar la búsqueda inicial se realizó una pregunta clínica en base a la estrategia PICO (Tabla 1), para conocer y comparar los resultados ante una intervención realizada en la población elegida en el objeto del estudio. En el que se estudia a la mujer embarazada en condiciones de bajo riesgo que durante el proceso de parto $(P)$ decide utilizar el medio acuático (I), con el objetivo de conocer y comparar sus complicaciones y/o beneficios $(\mathrm{O})$ respecto al parto natural(C). En base a esta duda elaboramos la pregunta clínica ¿qué beneficios y/o complicaciones ofrece la utilización del medio acuático durante el proceso de parto respecto al parto natural normal? Para ello utilizamos en la estrategia de búsqueda las palabras clave «waterbirth», "underwaterbirth», "complications» y «benefits» en base al lenguaje natural parto en el agua, parto natural, complicaciones y beneficios.

Tabla 1

Pregunta PICO

\begin{tabular}{llll}
\hline & Lenguaje natural & DeCs & MeSH \\
\hline $\mathrm{P}$ & Proceso de parto & nacimiento & birth \\
$\mathrm{I}$ & Parto en el agua & $*$ & Waterbirth/underwaterbirth \\
$\mathrm{C}$ & Parto normal & Parto normal & Childbirth \\
$\mathrm{O}$ & Complicaciones/beneficios & Complicaciones ${ }^{*}$ & Complications/Benefits \\
\hline
\end{tabular}

Se realiza una selección de las palabras clave que más concreten el tema a tratar, estas palabras clave se comprueban en la base Descriptores en Ciencias de la Salud (DeSC) y en el Medical Subjects Heading (MeSH), para encontrar los descriptores que orientaran la búsqueda bibliográfica mediante la aplicación de una terminología común. Las palabras clave seleccionadas y sus correspondientes descriptores son: Nacimiento (Birth), parto acuático (waterbirth o underwaterbirth), parto normal (child birth), complicaciones/beneficios (complicactions/benefits).

Utilizando los descriptores previamente indicados y conectados entre sí mediante los operadores booleanos «AND» y «OR». De tal modo que la estrategia de búsqueda seleccionada fue «(waterbirth OR underwaterbirth) AND (complications OR benefits)»

Se realiza la búsqueda de información en las siguientes bases de datos: CINHAL, LILACS, ProQuest, PubMed y SCOPUS. También se ha utilizado en la búsqueda páginas web como la Organización Mundial de la Salud (OMS) y el Sistema Nacional de Salud.

Se aplican a la búsqueda los limitadores tiempo e idioma. Para el limitador tiempo se seleccionan los últimos diez años, mientras que para el limitador del idioma se seleccionan únicamente aquellos artículos en inglés y en español que además incluyeran texto completo, fueran revisiones, estudios cuantitativos o cualitativos recuperados en la búsqueda.

Para el análisis de calidad de los estudios obtenidos tras la estrategia de búsqueda se utilizó la herramienta metodológica CASP-e para las distintas revisiones obtenidas en los resultados iniciales, así como aquellos estudios experimentales obtenidos. La herramienta de calidad metodológica STROBE se utilizó para evaluar aquellos estudios observacionales descriptivos transversales. Para la inclusión de gráficos y tablas incluidos en el estudio y con el fin de facilitar un análisis de las características de los artículos recuperados fue utilizado el programa informático Microsoft EXCEL. 


\section{Resultados}

Una vez realizada la pregunta clínica utilizamos las palabras clave «waterbirth», «underwaterbirth», "complications» y "benefits» se inició la búsqueda en la bases de datos CINAHL, LILACS, ProQuest, PubMed y SCOPUS filtrando sus resultados a artículos con disponibilidad de resumen y texto completo, en idioma inglés con fecha de publicación posterior a 2007(Ver tabla 2). Tras el filtro inicial se pasó de los 147 resultados iniciales obtenidos en la búsqueda a los 58 tras los filtros utilizados en las distintas bases de datos empleadas.

Tabla 2

Detalles de la búsqueda bibliográfica

\begin{tabular}{|c|c|c|c|}
\hline BBDD & Detalles de la búsqueda & limitadores & Art. \\
\hline CINAHL & $\begin{array}{l}\text { AB (waterbirth OR underwater- } \\
\text { birth) AND (complications OR } \\
\text { benefits) } 8 \text { docs. }\end{array}$ & texto completo, inglés, 2007 & 5 \\
\hline LILACS & $\begin{array}{l}\text { (tw:(waterbirth OR underwater- } \\
\text { birth)) AND (tw:(complications } \\
\text { OR benefits)) } 22 \text { doc. }\end{array}$ & Inglés, texto completo, 2007 & 10 \\
\hline $\begin{array}{l}\text { ProQuest Cen- } \\
\text { tral }\end{array}$ & $\begin{array}{l}\text { ab (waterbirth OR underwater- } \\
\text { birth) AND (complications OR } \\
\text { benefits) } 66 \text { docs. }\end{array}$ & Fulltext, 2007, inglés, & 21 \\
\hline PubMed & $\begin{array}{l}\text { ((waterbirth[Title/Abstract] OR } \\
\text { underwater birth[Title/Abstract])) } \\
\text { AND (complications or benefits) } \\
25 \text { art. }\end{array}$ & $\begin{array}{l}\text { («loattrfull text»[sb] AND } \\
\text { «2012/03/04»[PDat]: «2017/03/02»[PDat] } \\
\text { AND «humans»[MeSH Terms] AND } \\
\text { (English[lang] OR Spanish[lang])) }\end{array}$ & 10 \\
\hline SCOPUS & $\begin{array}{l}\text { TITLE-ABS-KEY (waterbirth OR } \\
\text { underwaterbirth AND complica- } \\
\text { tions OR benefits) } 26 \text { DOCS. }\end{array}$ & $\begin{array}{l}\text { (limit-to (pubyear, 2016) or limit-to (pub- } \\
\text { year , 2015) or limit-to (pubyear, 2014) or } \\
\text { limit-to (pubyear , 2013)) and (limit-to (lan- } \\
\text { guage, "english») or limit-to (language } \\
\text { «spanish»)) }\end{array}$ & 12 \\
\hline
\end{tabular}

Se recogieron los datos del Hospital Universitario de la Plana desde el año 2011 (Tabla 3) hasta diciembre del año de 2016. Estos datos fueron analizados a través de la plataforma digital Microsoft EXCEL con el fin de comparar sus resultados estadísticamente con respecto a los resultados obtenidos en la literatura encontrada en las búsquedas digitales de la presente revisión. En la estrategia de búsqueda inicial se obtuvo como resultado inicial un total de 147 artículos. Tras aplicar los limitadores de búsqueda se redujo la búsqueda a 65 artículos, de los cuales un $19 \%$ estaban repetidos $(n=27)$ en las diferentes bases de datos utilizadas. Se desecharon un $12 \%(n=17)$ de los que no cumplían los requisitos mínimos de calidad el $2 \%$, de descarto por no tener disponible el resumen $(n=3)$ finalmente tras leer el resumen el $1 \%$ se desviaban del tema de estudio por lo que fueron descartados $(n=2)$ recuperándose un $10 \%$ de los artículos $(n=15)$ incluidos para la revisión del estudio (Figura 1). 


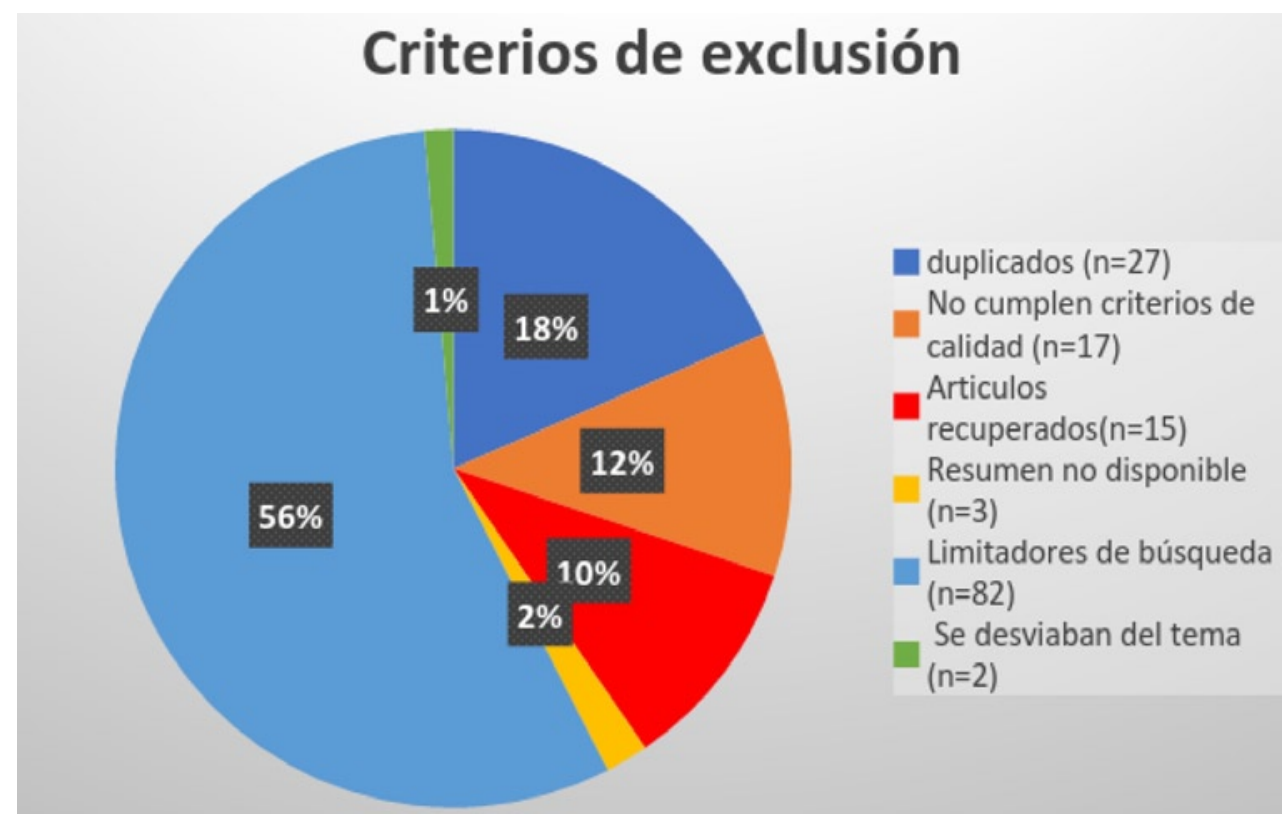

Figura 1.Porcentaje de artículos recuperados

Se establecieron una serie de requisitos para la selección de los estudios con el objeto de aplicar los criterios de inclusión y de exclusión previamente establecidos (Figura 2). Para evaluar la calidad metodológica se utilizaron las herramientas de calidad CASP-e para las revisiones y ensayos controlados. Con dicha herramienta, los artículos recuperados cual debían de responder afirmativamente en al menos dos terceras partes de los ítems que ofrece para ser admitidos en el análisis de este estudio (Manterola, Astudillo, Arias \& Claros, 2013). Entre las revisiones evaluadas el $100 \%$ de los artículos superaba el $80 \%$ de los ítems relacionado mientras que en el ensayo clínico aleatorizado que recuperamos no se pudo superar el 4 ítem debido a las características del estudio. Se utilizó el cuestionario STROBE (da Costa, Cevallos, Altman, Rutjes \& Egger, 2011) del mismo modo se admitieron todos aquellos estudios que respondieran afirmativamente al menos a $2 / 3$ partes de los 22 ítems del cuestionario.

Tabla 3

Tabla de registros en relación a los últimos 6 años en la unidad de partos del hospital la plana

\begin{tabular}{lrlcc}
\hline Número total de partos & & Integridad perineal & $\begin{array}{c}\text { Expulsivo } \\
\text { en el agua }\end{array}$ & $\begin{array}{c}\text { Dilatación } \\
\text { en el agua }\end{array}$ \\
\hline Media de partos anuales & 1600 & Periné intacto & 55 & 187 \\
Tasa de cesáreas & $1,4 \%$ & Tipo I & 37 & 143 \\
Tasa de partos espontáneos & $69 \%$ & Tipo II & 56 & 189 \\
Tasa de episiotomías & $7 \%$ & Tipo IIla & 3 & 13 \\
Tasa de analgesia epidural & $52 \%$ & Tipo IIlb & 2 & 4 \\
Tasa de inducciones & $24 \%$ & Tipo IIIc & 1 & 2 \\
& & Tipo IV & $*$ & 1 \\
& & Total & 154 & 537 \\
\hline
\end{tabular}




\begin{tabular}{lclc}
\hline Utilización del medio acuático & & Diagnóstico sobre RN & N. ${ }^{\circ}$ casos \\
\hline Número total de intervenciones & 691 & Ictericia & 15 \\
media anual & 115 & Alteración anatómica & 9 \\
Dilataciones en el agua & 537 & $\begin{array}{l}\text { Dificultad en la alimen- } \\
\text { tación }\end{array}$ & 7 \\
N. ${ }^{\circ}$ cesáreas & 18 & Riesgo infeccioso & 8 \\
N..$^{\circ}$ instrumentaciones & 62 & $\begin{array}{l}\text { Distrés respiratorio } \\
\text { leve }\end{array}$ & 1 \\
N. ${ }^{\circ}$ eutócico & 457 & Sin complicaciones & 114 \\
N.o expulsivo en el agua & 154 & Total & 154 \\
\hline
\end{tabular}

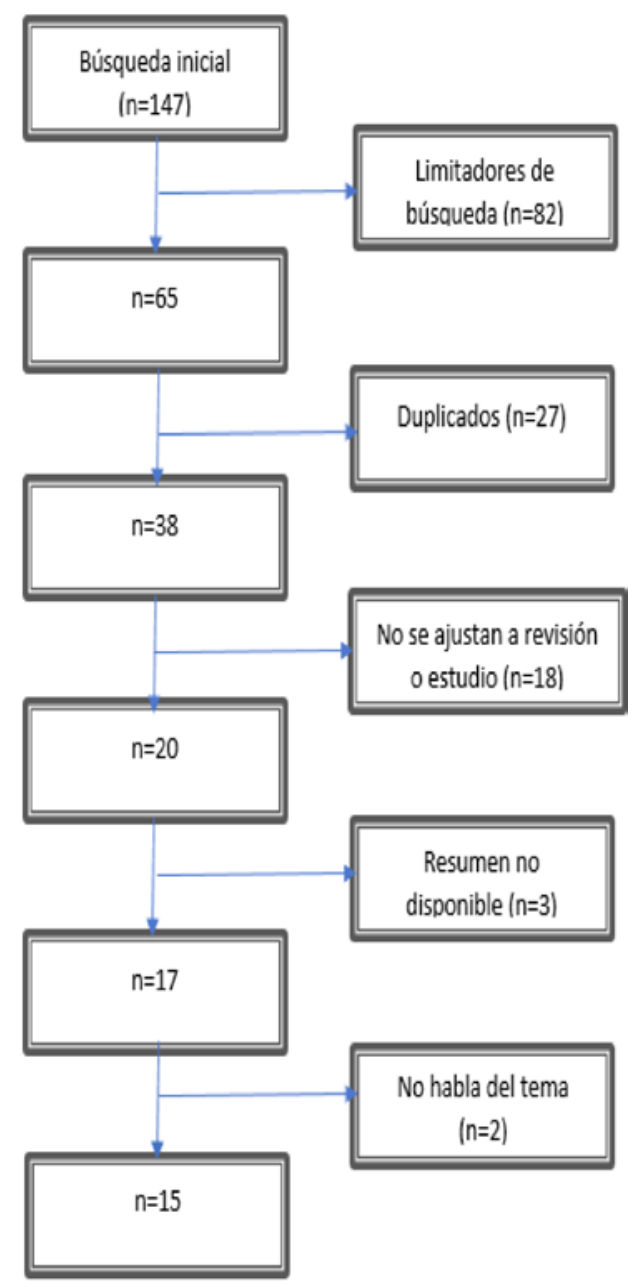

Figura 2. Diagrama de flujo de la revisión 


\section{Discusión y conclusiones}

La mayor parte de la literatura hallada es de tipo descriptiva, observacional. Entre los estudios revisados, el $33 \%(n=5)$ coinciden afirmando que el parto en el agua produce una reducción del dolor, aumentando la satisfacción de la mujer como consecuencia de aportarle mayor autonomía y movilidad durante todo el proceso de dilatación, siendo una consecuencia de ello la reducción de la tasa de epidural (Cortes et al., 2011; Davies et al., 2015; Maude \& Foureur, 2007; Salazar-Herrera et al., 2016; Schafer, 2014) Davies et al., (2015) y Henderson et al. (2014) afirman que este tipo de parto supone un descenso de la tasa de intervenciones respecto al parto vaginal convencional en consecuencia reduciéndose considerablemente el número de episiotomías, el tiempo de duración del parto se reduce considerablemente. En contraposición, otros autores como Bovbjerg, Cheyney \& Everson (2016), lo correlacionan con una mayor tasa de desgarros, justificándolo por un acortamiento de la segunda fase de la dilatación y el menor tiempo de adaptación a la presión de los tejidos musculares perianales. Son los riesgos perinatales los que más que preocupan a la comunidad científica, destacando en primer lugar la rotura de cordón accidental y la aspiración del agua de la inmersión en segundo lugar, según afirman Veltman \& Doherty (2013). Estos autores consideran y coinciden en que resulta de transcendental importancia la formación de los profesionales asistentes al parto con el fin de evitar las complicaciones relacionadas con el mismo. Salazar-Herrera et al., (2016) y Taylor, Kleine, Bewley, Loucaides \& Sutcliffe (2016) realizan una revisión en la que incluyen en su estudio el riesgo de infección, el distrés respiratorio, la tasa de mortalidad, y el pH obtenido en el cordón umbilical, Apgar en el primer minuto de vida y a los 5 minutos, así como los ingresos en una Unidad de Cuidados Intensivos Neonatales (UCIN) comparando sus resultados con el parto convencional de bajo riesgo, no encontrando en ninguno de los casos diferencias significativas (Salazar-Herrera et al., 2016; Taylor et al., 2016). En el ensayo controlado incluido en el estudio (da Silva et al., 2009), fueron evaluados los resultados maternos comparándolos con respecto al parto convencional normal. La incidencia de casos de perdida de la integridad perineal se situó en un 24,1\% del grupo experimental (parto acuático) frente al 20,4 que se registró en el grupo control (parto normal). El grado de episiotomías tipo 1 se situó en un $13 \%$ respecto al $20,4 \%$ del grupo control. Se evaluó el dolor percibido mediante la escala numérica mencionada en ambos grupos obteniendo una puntuación de 8,1 en el grupo experimental mientras que el grupo control obtuvo una puntuación de 8,9. La incidencia de líquido amniótico con meconio fue de seis casos para el grupo control frente a 1 solo caso del grupo experimental. Este estudio indica que existe una menor incidencia de cesáreas, no obstante, no alude a datos estadísticos en sus resultados. La tasa de inducción por oxitocina también se vio reducida a un 35,2\% frente al 42,6\% del grupo control. Por otro lado, en referencia a los datos recogidos en la unidad de partos del hospital universitario de la Plana entre los años 2011 y 2016, se registraron una media de 1600 partos anuales con una tasa del 14 $\%$ de mujeres que finalizaron el parto por cesárea, un $52 \%$ hicieron uso de la analgesia epidural para el control de dolor y en un $31 \%$ fue necesario algún tipo de intervención instrumentalizada. En base a estos datos se analizaron aquellos partos que se produjeron dentro del agua en la bañera de dilatación de dicha unidad obteniendo como resultados de interés para el presente estudio los siguientes datos: una tasa del $3 \%$ de mujeres que requirieron cesárea, un $14 \%$ decidió solicitar analgesia epidural durante el proceso de dilatación y el $15 \%$ necesito algún tipo de intervención instrumentalizada. En la revisión publicada en 2009 (Cluett y Burns, 2009) describe los resultados en referencia a la duración de la primera etapa de parto en el agua comparados con el parto convencional en el que hubo una reducción significativa en la tasa de analgesia epidural, una reducción en la duración de tiempo de la primera etapa del parto en el agua situándose en 32,4 minutos menos que el parto convencional de bajo 
riesgo. El estudio recoge los resultados neonatales en el cual tampoco se obtuvieron diferencias significativas, no obstante, este estudio encontró un alto nivel de heterogeneidad en algunos de sus resultados por lo que estos, describe, que deberían ser examinados con cautela. En la revisión de (Nutter et al., 2014) concluye que los principales beneficios están relacionados con el alto grado de satisfacción materna asociados con el parto en el agua, considerando un posible aumento de tasas de integridad perineal, una disminución en la tasa de episiotomías pudiendo contribuir a una reducción significativa de hemorragias post-parto. Esta revisión recoge una tasa de rotura de cordón accidental de 2,4/1000 relacionado con el parto en el agua desconociendo su comparación directa con el parto espontaneo convencional de bajo riesgo.

La evidencia científica disponible nos muestra que el parto en el agua se asocia a numerosos beneficios maternos, destacando el incremento de la satisfacción materna durante el proceso del parto y la reducción significativa en la percepción del dolor con una disminución del uso de analgesia farmacológica. Entre los pocos riesgos asociados a la mujer descritos en las evidencias recuperadas destaca el incremento en el número de desgarros perianales tipo II relacionado con un acortamiento en los tiempos de dilatación y expulsivo con respecto al parto vaginal convencional.

No se describe ningún beneficio sobre el neonato, sin embargo, se alude a ciertas complicaciones recogidos en casos aislados. Por tanto, los resultados obtenidos, deberían ser tomados con cautela ya que sería conveniente realizar estudios de investigación con mayor rigor científico que evidencien los riesgos y beneficios en la utilización de este medio con respecto al parto convencional. En lo que sí coinciden todos los expertos es en la necesidad de que el parto en el agua sea un método dirigido siempre por profesionales formados y acreditados en la materia, así como poseer de unas instalaciones para tal fin que ofrezca unas garantías mínimas sobre la madre y el neonato con el objeto de conseguir un parto en el agua seguro.

\section{Referencias bibliográficas}

American Academy of Pediatrics Committee on Fetus and Newborn, y American College of Obstetricians and Gynecologists Committee on Obstetric Practice. (2014). Immersion in Water During Labor and Delivery. PEDIATRICS, 133(4), 758-761.

Bovbjerg, M. L., Cheyney, M. \& Everson, C. (2016). Maternal and Newborn Outcomes Following Waterbirth: The Midwives Alliance of North America Statistics Project, 2004 to 2009 Cohort. Journal of Midwifery \& Women's Health, 61(1), 11-20.

Cluett, E. R. \& Burns, E. (2009). Immersion in water in labour and birth. The Cochrane Database of Systematic Reviews, (2), CD000111.

Cortes, E., Basra, R. \& Kelleher, C. J. (2011). Waterbirth and pelvic floor injury: a retrospective study and postal survey using ICIQ modular long form questionnaires. European Journal of Obstetrics \& Gynecology and Reproductive Biology, 155(1), 27-30.

da Costa, B. R., Cevallos, M., Altman, D. G., Rutjes, A. W. \& Egger, M. (2011). Uses and misuses of the STROBE statement: bibliographic study. BMJ Open, 1(1), e000048.

da Silva, F. M., de Oliveira, S. M. \& Nobre, M. R. (2009). A randomised controlled trial evaluating the effect of immersion bath on labour pain. Midwifery, 25(3), 286-294.

Davies, R., Davis, D., Pearce, M. \& Wong, N. (2015). The effect of waterbirth on neonatal mortality and morbidity: a systematic review and meta-analysis. JBI Database of Systematic Reviews and Implementation Reports, 13(10), 180-231. 
Grupo de trabajo de la Guía de Práctica Clínica sobre Atención al Parto Normal (2010). Guía de Práctica Clínica sobre la Atención al Parto Normal. Disponible en http://www.guiasalud.es/GPC/GPC_472_Parto_Normal_Osteba_compl.pdf (consultado el 24 de marzo de 2017).

Henderson, J., Burns, E. E., Regalia, A. L., Casarico, G., Boulton, M. G. \& Smith, L. A. (2014). Labouring women who used a birthing pool in obstetric units in Italy: prospective observational study. BMC Pregnancy and Childbirth, 14(1), 17.

Iriondo, M., Sánchez, M., Botet, F., Martínez-Astorquiza, T., Lailla, J. M. \& Figueras, J. (2015). Atención del parto en el agua. Consenso de la Sociedad Española de Neonatología y de la Sección de Medicina Perinatal de la Sociedad Española de Obstetricia y Ginecología. Anales de Pediatría, 82(2), 108.e1-108.e3.

Lim, K. M., Tong, P. S. \& Chong, Y. S. (2016). A comparative study between the pioneer cohort of waterbirths and conventional vaginal deliveries in an obstetrician-led unit in Singapore. Taiwanese Journal of Obstetrics and Gynecology, 55(3), 363-367.

Manterola, C., Astudillo, P., Arias, E. \& Claros, N. (2013). Revisiones sistemáticas de la literatura. Qué se debe saber acerca de ellas. Cirugía Española, 91(3), 149-155.

Maude, R. M. \& Foureur, M. J. (2007). It's beyond water: Stories of women's experience of using water for labour and birth. Women and Birth, 20(1), 17-24.

Salazar-Herrera, D., Ferreira-Jaime, T. F. \& Márquez-González, H. (2016). Diferencia en la presentación de complicaciones en neonatos recibidos por parto convencional y parto en agua en un hospital privado de la Ciudad de México. Revista Mexicana De Pediatría, 83(5), 154-157.

Nutter, E., Meyer, S., Shaw-Battista, J. \& Marowitz, A. (2014). Waterbirth: an integrative analysis of peer-reviewed literature. Journal of Midwifery \& Women's Health, 59(3), 286-319.

Odent M. (1983). Birth under water. Lancet, 2(8365-66), 1476-1477.

Schafer, R. (2014). Umbilical cord avulsion in waterbirth. Journal of Midwifery \& Women's Health, 59(1), 91-94.

Sierra, J. C., Haynes, S. N., Eysenck, M. W., Buela, G. \& Perestelo-Pérez, L. (2013). Standards on how to develop and report systematic reviews in Psychology and Health. International Journal of Clinical and Health Psychology International Journal of Clinical and Health Psychology, 13(1), 49-57.

Simpson, K. R. (2013). Underwater birth. Journal of Obstetric, Gynecologic, and Neonatal Nursing : JOGNN, 42(5), 588-594.

Taylor, H., Kleine, I., Bewley, S., Loucaides, E. \& Sutcliffe, A. (2016). Neonatal outcomes of waterbirth: a systematic review and meta-analysis. Archives of Disease in Childhood. Fetal and Neonatal Edition, 101(4), 357-365.

Veltman, L. \& Doherty, D. (2013). Safety and underwater birth-what every risk manager should know. Journal of Healthcare Risk Management : The Journal of the American Society for Healthcare Risk Management, 32(4), 16-24.

Waterbirth International (2017). Dedicated to making waterbirth an available option for all women. disponible en https://waterbirth.org/ (consultado el 24 de marzo de 2017). 


\title{
Percepción sobre el trastorno del espectro autista
}

\author{
¿Estamos preparados para la realidad de las aulas inclusivas?
}

\author{
IRENE GARCIA MOLINA \\ imolina@uji.es \\ Raquel Nieto Garoz \\ raquel.nieto@uji.es \\ AIDA SANAHUJA RIBÉS \\ asanahuj@uji.es \\ Alicia Benet GIL \\ abenet@uji.es
}

\section{Resumen}

Introducción: Resulta de suma importancia el hecho de que profesionales de la educación y la psicología así como los estudiantes sobre estas disciplinas, se formen y entiendan uno de los trastornos cuya prevalencia crece de año en año, como es el Trastorno del Espectro Autista (TEA). Partiendo de esta premisa, nuestro objetivo como investigadores y especialistas fue conocer si los participantes de un curso on-line sobre TEA tenían claros los conceptos básicos sobre el trastorno, la percepción de su formación acerca del TEA y la inclusión de estos niños en la escuela ordinaria. Método: El diseño metodológico utilizado consistía en un diseño de tipo descriptivo, que utiliza el método de encuesta y como instrumento el cuestionario. La muestra fue de 241 informantes, concretamente $201(83,40 \%)$ eran mujeres y $40(16,60 \%)$ hombres. Por lo que respecta a su formación, $87(36,1 \%)$ eran estudiantes y $154(63,9 \%)$ profesionales de la educación o psicología educativa. Resultados: Los resultados evidencian que existe un alto porcentaje de los participantes que han tenido contacto con personas con TEA. Sin embargo, sienten que no se encuentran lo suficientemente preparados para poder trabajar con este colectivo, hecho que cualitativamente se ha denotado durante el transcurso del propio curso online con sus preguntas y sus dudas. Por otro lado, se apuesta por la inclusión del alumnado en el aula, independientemente de su trastorno, hecho que arroja un poco de luz a la necesidad actual de transformar el aula para que todos los alumnos sean valorados y tomados en cuenta, y de esta manera propiciar la participación y el aprendizaje. Conclusión: Como conclusión, se destaca la necesidad permanente de formación por parte del profesional y del estudiantado, para dar cabida a la diversidad en el aula desde una perspectiva inclusiva.

Palabras clave: educación inclusiva, Trastorno del Espectro Autista, MOOC, percepción, formación. 


\section{Abstract}

Introduction: It is extremely important that education and psychology professionals, as well as students about these disciplines, can train and understand one of the disorders whose prevalence grows from year to year, such as Autism Spectrum Disorder (ASD). Based on this premise, our objective as researchers and specialists was to know if the participants of an on-line course (MOOC) on ASD had clear the basic concepts about the disorder, the perception of their knowledge about ASD and the inclusion of these children in the school. Method: The design used was descriptive, which used the survey as method and a questionnaire as instrument. The sample was of 241 informants, specifically $201(83.40 \%)$ were women and $40(16.60 \%)$ were men. With regard to their training, 87 (36.1\%) were students and 154 (63.9\%) professionals in education or educational psychology. Results: The results show that there was a high percentage of participants who have had contact with people with ASD. However, they feel that they are not sufficiently prepared to be able to work with this group, a fact that has been qualitatively denoted during the MOOC with their questions and their doubts. On the other hand, it is committed to the inclusion of students in the classroom, regardless of their disorder, a fact that sheds some light on the current need to transform the classroom. All the students should be valued and taken into account for their participation and learning. Conclusion: In conclusion, the permanent need for training of the professional and the students is emphasized, in order to know the diversity in the classroom from an inclusive perspective.

Key Words: inclusive education, Autism Spectrum Disorder, MOOC, perception, training.

\section{Introducción}

El Trastorno del Espectro Autista (TEA) es uno de los trastornos del neurodesarrollo con más prevalencia hoy en día (1/160 según la OMS, 2016). Es por esto que resulta de suma importancia que los profesionales estén formados y entiendan la importancia de incluir a todo el alumnado en el aula, sea cual sea su circunstancia.

Actualmente, aunque están surgiendo nuevos materiales específicos para niños y niñas con TEA, la realidad escolar es que existe poca información en torno a cómo actuar o de qué forma incluir a estos niños en su grupo clase. Los profesionales, maestros y estudiantes del campo de la educación pueden encontrar fácilmente materiales nuevos en internet, en blogs, o en plataformas específicas, pero la mayoría de las veces están destinados a los más pequeños, como en los casos de la Teoría de la Mente: prueba de cambio de ubicación, como el de Sally y Anne (Baron-Cohen, Leslie y Frith, 1985; Wimmer y Perner, 1983) y de contenido inesperado, como la prueba de los Lacasitos (Hogrefe, Wimmer y Perner, 1986); a la comunicación, como los Sistemas Alternativos y/o Aumentativos de la Comunicación (SAAC) o a niveles más afectados, como los PECS (Picture Exchange Communication System) (Bondy y Frost, 1985). Y esto implica que se le dé menor importancia al hecho de aplicar dichos materiales, intervenciones o prácticas con todo el grupo clase, para que los demás alumnos se beneficien, viendo el conjunto de la clase como un conjunto social y de comunicación que pueda beneficiar a los niños con autismo. Por esta razón, es necesario entender la práctica inclusiva y a 
las personas con autismo; y con esto entender la percepción sobre estos niños y niñas en la escuela ordinaria. Desde la Ley Orgánica de Ordenación General del Sistema Educativo 2/2006 (LOGSE) los principios de normalidad e inclusión se conciben por ley en nuestras escuelas, pero es bien cierto que en la práctica real la percepción del profesorado dista mucho del papel, sobre todo cuando se trata de alumnos que presentan algún tipo de dificultad o se encuentran en riesgo de exclusión. Es decir, si partimos de que en nuestra realidad escolar el alumno cada vez es más diverso, las escuelas deberían atender mejor las necesidades e intereses de cada alumno. Para cumplir con ello, resulta primordal el papel del profesor (o futuros profesionales), su actitud y predisposición hacia la inclusión debería ser uno de los objetivos principales a indagar en el Sistema Educativo. De hecho estos últimos años ésta ha sido una de las mayores preocupaciones dentro de la investigación educativa (Chiner, 2011).

Desde un carácter más general dentro de las necesidades de los alumnos, Scruggs y Mastropieri (1996), informaron en su investigación que, a pesar de que dos tercios de profesorado apoyaba la idea de la inclusión (casi 11.000 participantes en total) sólo unos pocos deseaban tener alumnos con algún tipo de necesidades educativa especial en sus propias clases. En la misma línea, Avramidis, Bayliss y Burden (2000) hallaron en su estudio que los profesores demandaban más formación inicial y continua para responder a las necesidades de sus alumnos. También relativo al tema de la formación merece atención el hecho de la percepción negativa que pueden tener los profesores sobre dicho alumnado. Y es que, aquellos docentes que en el estudio de Van Reusen, Shoho y Barker (2001) tenían una actitud más negativa hacia la inclusión eran aquellos que tenían menos conocimientos y formación en educación especial.

La investigación en España muestra resultados similares a los internacionales, observando que los docentes mostraron cierto rechazo e indecisión en cuanto a su práctica educativa inclusiva (Fernandez-González, 1999). Más concretamente, en nuestra comunidad (Comunidad Valenciana) Cardona (2000) encontró resultados parecidos a los nacionales, sintiéndose los participantes reticentes a aceptar nuevas responsabilidades que pudieran conllevar los alumnos con necesidades educativas especiales. Además, nuevamente en lo relativo a la formación, en un estudio de 2006 realizado por Jiménez Trens, Díaz Allué y Carballo, se observó que una amplia mayoría de los encuestados reconocían no haber sido suficientemente formados, y tampoco se sentían preparados para atender a la diversidad. En particular, dicho grupo demandaba mejor formación en estrategias de enseñanza y aprendizaje para ofrecer una mejor respuesta a las necesidades de cada alumno. También se destacó el mayor apoyo por parte de la administración educativa, y más recursos tanto materiales como personales para una atención adaptada (Alemany y Villuendas, 2004).

Por todo esto, y debido a la oportunidad de preguntar e indagar con una muestra de estudiantes y profesionales de habla hispana preocupados por el TEA, se decidió conocer su percepción sobre la inclusión de, concretamente, el autismo en las aulas. Partiendo de esta premisa pues, el objetivo de este estudio es averiguar si los participantes de un curso on-line sobre TEA tenían claros los conceptos básicos sobre el trastorno, su percepción sobre la preparación recibida, y la percepción de su formación acerca del TEA y la inclusión de estos niños en la escuela ordinaria. 


\section{Método}

\section{Participantes}

En este estudio participaron un total de 241 informantes, concretamente $201(83,40 \%)$ eran mujeres y $40(16,60 \%)$ hombres. Por lo que respecta a la edad decir que: $9(3,73 \%)$ participantes tenían menos de 20 años, $71(29,46 \%)$ tenían una edad comprendida entre los 20-25 años, 40 (16,60\%) entre los $26-30$ años y $121(50,21 \%)$ tenían más de 31 años. Por lo que respecta a su formación, $87(36,1 \%)$ eran estudiantes y $154(63,9 \%)$ profesionales de la educación o psicología educativa. Más específicamente, $56(23,24 \%)$ eran estudiantes de magisterio, $3(1,24 \%)$ estudiantes de pedagogía, $6(2,49 \%)$ estudiante de psicología, 19 $(7,89 \%)$ estudiantes de algún máster relacionado con la educación o la psicología, $3(1,24 \%)$ de doctorado, $88(36,51 \%)$ maestros, $18(7,47 \%)$ maestros y pedagogos o maestros y psicopedagogos, $13(5,40 \%)$ máster en secundaria, 10 (4,14\%) pedagogos, 18 (7,47\%) psicólogos y $7(2,90 \%)$ psicopedagogos. Había $85(35,27 \%)$ participantes que no estaban trabajando en el campo de la educación o la psicología y 156 (64,73\%) sí que estaban ejerciendo. Por último, aludir a los años de experiencia: 57 (23,65\%) participantes no tenían ninguna experiencia profesional en este campo, $42(17,43 \%)$ menos de 1 año, $39(16,18 \%)$ tenían entre 1 y 3 años de experiencia y $103(42,74 \%)$ más de 4 años de experiencia.

\section{Instrumento}

El diseño metodológico utilizado consistía en un diseño de tipo descriptivo, que utiliza el método de encuesta y como instrumento el cuestionario. Para la recogida de datos se elaboró un cuestionario expresamente para este estudio. El cuestionario está formado por una primera parte de datos contextuales y una segunda parte constituida por 6 cuestiones de elección múltiple con el objetivo de indagar acerca de la percepción de los participantes sobre el trastorno del espectro autista y sobre su escolarización. En esta segunda parte se han preguntado aspectos relacionados con: si los informantes conocían alguna persona con autismo en su entorno, su formación en relación a trabajar con personas autistas, si el alumnado TEA aporta beneficios al grupo-clase, la modalidad de escolarización del alumnado TEA, las habilidades sociales de las personas con autismo y sobre sus conocimientos en torno al espectro autista.

\section{Procedimiento}

Primeramente se confeccionó el instrumento para la recogida de datos, esto es, el cuestionario. Posteriormente se recogieron los datos a través de un google formulario, los participantes estaban cursando un MOOC sobre TEA y se pretendía conocer su formación acerca del TEA y la inclusión de estos niños en la escuela ordinaria. El cuestionario fue administrado previamente al inicio de susodicho curso. El análisis de datos se ha realizado mediante Excel.

\section{Resultados}

La primera pregunta del cuestionario hace referencia a si los participantes conocen o han conocido personas con autismo. Podemos observar, en la Figura 1., como la gran mayoría 
responden afirmativamente a la cuestión, siendo el ámbito profesional el contexto donde más tienen contacto con este colectivo $(60 \%)$, posteriormente se encuentran los que tienen conocidos $(10 \%)$, los que tienen un familiar $(6 \%)$ y otros motivos que no se especifican en el cuestionario (6\%). Por otro lado, sólo un $18 \%$ de los participantes responden que nunca han tenido contacto con personas con autismo.

\section{En mi entorno, he conocido personas con autismo}

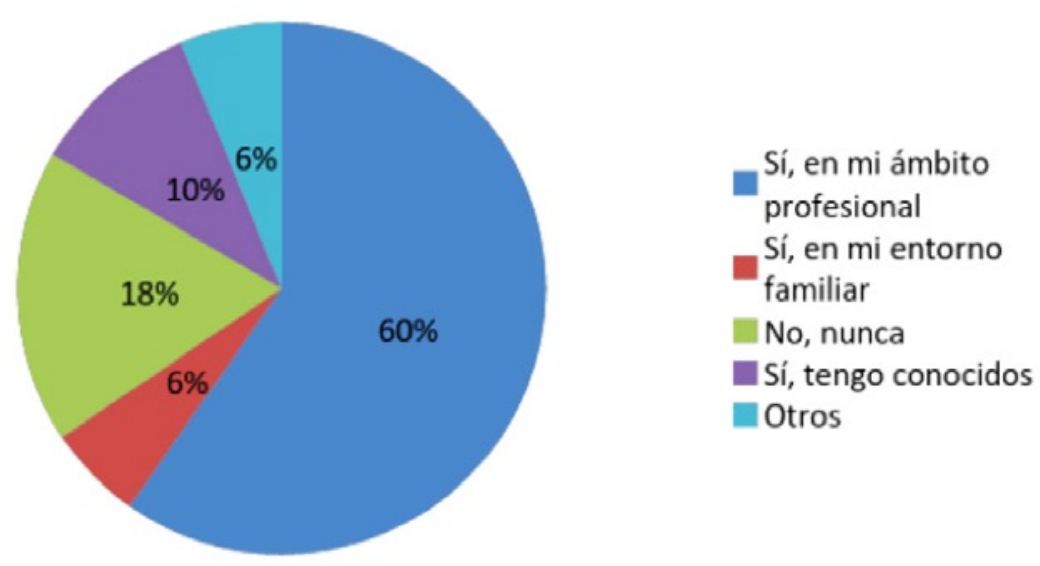

Figura 1. Contacto con personas con autismo

La siguiente cuestión, representada en la Figura 2., versa sobre la formación de los participantes respecto al TEA. Aquí podemos observar como la amplia mayoría considera que no tiene la suficiente formación $(90,46 \%)$ frente a una minoría que considera que sí la tiene $(9,54 \%)$.

\section{Como futuro o profesional vinculado a la educación, ¿crees que has recibido suficiente formación para trabajar adecuadamente con alumnado con autismo?}

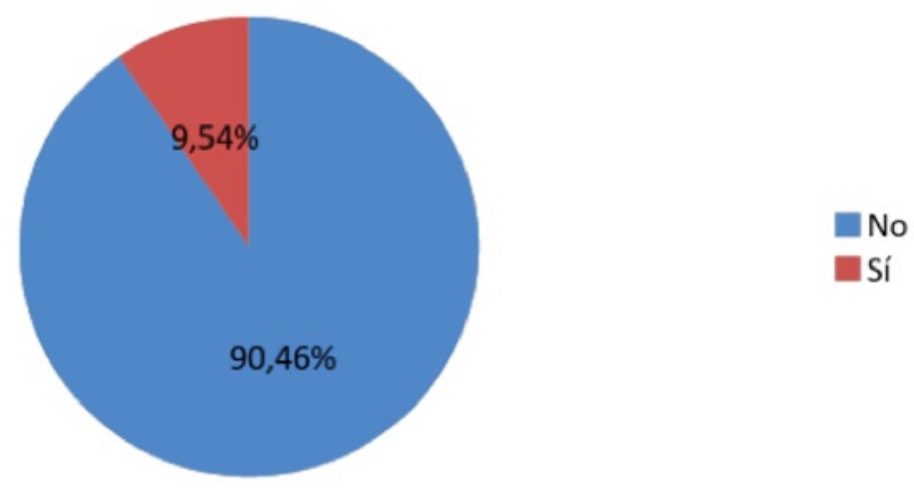

Figura 2. Formación de los participantes sobre el TEA 
La tercera pregunta (Ver Figura 3.) hace referencia a los beneficios que puede aportar el alumno con TEA al aula o clase donde se encuentra inmerso. En esta cuestión encontramos como ninguno de los encuestados considera que este alumnado perjudica el aprendizaje de los demás $(0 \%)$. La mayoría contesta afirmativamente la cuestión $(84,23 \%)$ y el resto responde que depende del nivel $(15,77 \%)$.

\section{3.¿Crees que un alumno con TEA puede aportar beneficios al grupo-clase?}

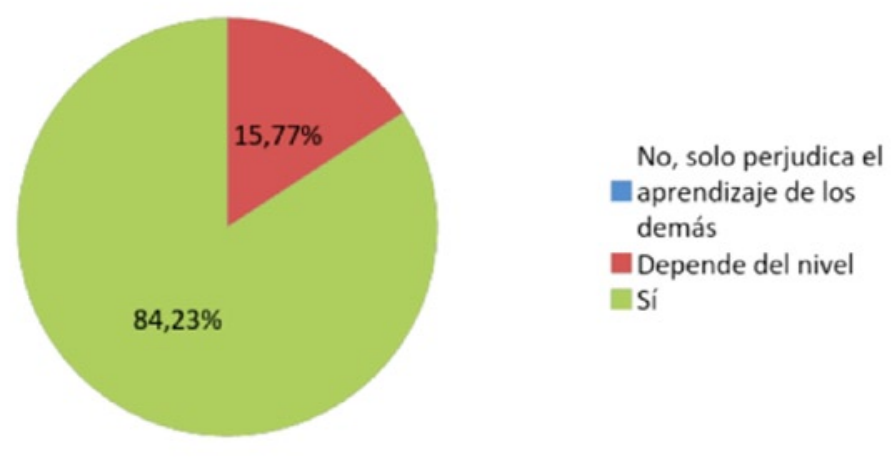

Figura 3. Percepción de los beneficios que aporta el alumnado con TEA

En la siguiente cuestión se presentan diferentes alternativas que responden a la inclusión de este alumnado presentándose diferentes tipos de escolarización para que los participantes respondan qué institución tiene que formar a este colectivo. En la Figura 4, podemos observar como una amplia mayoría considera que los niños autistas deben acceder a escuelas normalizadas dentro de un aula con compañeros de su misma edad $(97,51 \%)$. Siendo sólo un $2,49 \%$ los que piensan que este alumnado necesita de un docente que lo acompañe en el aula para poder ayudarle. Como vemos, ningún participante considera que este grupo de alumnos estudie en centros específicos.

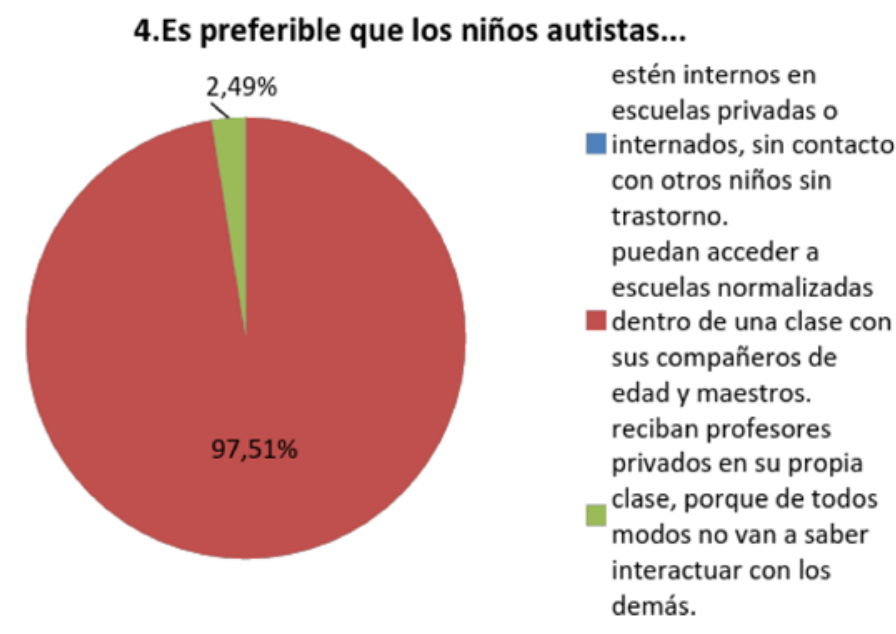

Figura 4. Inclusión de los niños con autismo 
También se les pregunta por la percepción que tienen de este colectivo en cuanto a la interacción que tienen con otras personas (Ver la Figura 5.). La amplia mayoría contesta que no es cierto que estos alumnos no tengan interés por hacer amigos $(93,77 \%)$. Sólo un $6,23 \%$ considera que no tienen interés.

\section{Creo que las personas autistas no tienen interés por los demás, comúnmente no quieren hacer amigos.}

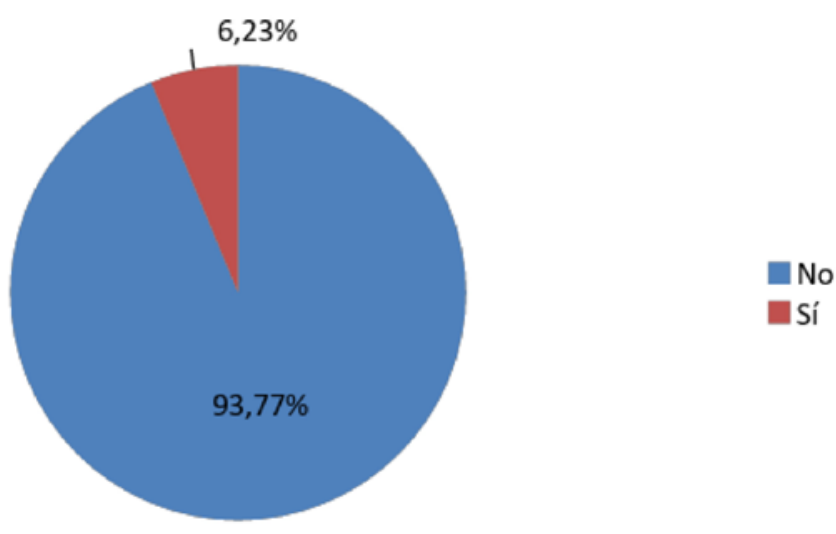

Figura 5. Conceptos básicos sobre el autismo

Por último se plantea una cuestión acerca de los conocimientos que tienen acerca del Trastorno del Espectro Autista. Casi la totalidad de los participantes $(99,17 \%)$ reconoce que existen diferentes niveles según el grado de adaptación del niño o los apoyos que necesite el alumnado. Sólo un $0,41 \%$ considera que todas las personas autistas tienen las mismas características y otro $0,41 \%$ entiende que no hay niveles de diferenciación, solo se diferencia entre TEA o Asperger (Ver la Figura 6.,).

6. Dentro del Trastorno del Espectro Autista...

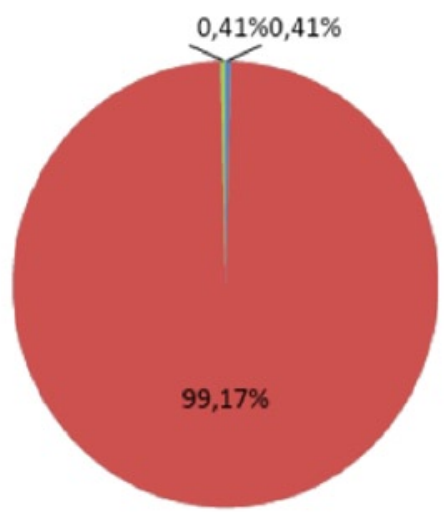

encontramos que todas las

Dersonas autistas tienen las mismas características. existen diferentes niveles según el grado de adaptación del niño o los apoyos que necesite. no hay niveles, simplemente o eres TEA o eres Asperger.

Figura 6. Niveles en el TEA 


\section{Discusión y conclusiones}

Si se recuerda, el objetivo de dicho estudio fue averiguar la percepción sobre el TEA de los participantes del curso MOOC, así como su preparación, formación e ideas sobre la inclusión de estos niños. Analizados los datos se puede concluir que la mayor parte de los participantes han conocido a personas con autismo entre el ámbito profesional y personal.

Otra de las cuestiones importantes a evaluar fue el grado de formación percibida para trabajar adecuadamente con alumnado con autismo. Es importante destacar como una amplia mayoría coincide en que no consideran tener suficiente información. Este dato coincide con los diversos estudios anteriormente citados tanto de carácter internacional como nacional (Avramidis, Bayliss y Burden, 2000; y Jiménez Trens, Díaz, Allué y Carballo, 2006). Tal y como ya se comentó en la introducción, éste puede ser un freno importante para que nuestra realidad escolar no pueda seguir avanzando. Aunque a parte de la praxis, sí que existe una concepción inclusiva acerca del autismo, coincidiendo los encuestados en que el alumno con TEA puede beneficiar al grupo clase, hecho que se corrobora con la creencia de que los participantes también coinciden en que es preferible que los niños con autismo puedan acceder a escuelas normalizadas dentro de una clase con sus compañeros de edad y maestros. Este dato pues, sería contradictorio con la formación percibida, ya que por tanto, como en anteriores estudios se ha citado, el problema estaría más ligado a la falta de recursos y no al de actitud por parte de docentes o estudiantes.

Además, aunque los conocimientos que se preguntaron acerca del autismo fueron más bien básicos, sí que se puede observar que la mayor parte de los participantes tuvieron claros algunos conocimientos, como que: las personas con autismo sí tienen interés por los demás, o que dentro del Trastorno del Espectro Autista existen diferentes niveles según el grado de adaptación del niño o niña o de los apoyos que necesite.

Por último, cabe resaltar la importancia de la formación continua de los profesionales que se dedican a la educación, teniendo ésta relación con el problema más importante discutido anteriormente. $Y$ es que para saber cómo atender a la diversidad en las aulas, tanto estudiantes como profesionales deben estar informados y formados acerca de una realidad presente en la mayoría de nuestras aulas. En este primer estudio sobre la percepción de nuestros participantes ya se ha podido entrever un problema real que estudios con mayor población han detectado, y es que el desconocimiento afecta a la práctica, y es necesaria la formación para actuar de manera adecuada. Aunque la conclusión final parece desfavorable para nuestros nuevos tiempos, cabe destacar que la actitud de nuestros participantes da una mejor visión de transformación y también debería ser un claro indicador de que los tiempos están cambiando, y un aula donde todos los niños y niñas tengan cabida, cada día es más que plausible.

\section{Referencias bibliográficas}

Alemany, I. y Villuendas, M.D. (2004). Las actitudes del profesorado hacia el alumnado con necesidades educativas especiales. Convergenia. Revista de Ciencias Sociales, 11(34), 183-215.

Avramidis, E., Bayliss, P. y Burden, R. (2000). A survey into mainstream teachers' attitudes towards the inclusion of children with special educational need in the ordinary school in on local education authority. Educational Psychology, 20(2), 191-211.

Baron-Cohen, S., Leslie, A. M. y Frith, U. (1985). Does the autistic child have a theory of mind'? Cognition, 21, 37-46. 
Bondy, A. S., y Frost, L. A. (1998). The picture exchange communication system. In Seminars in speech and language. Vol. 19, (4), pp. 373-389.

Cardona, M.C. (2000). Regular classroom teachers' perceptions of inclusion: implication for teachers' preparation programs in Spain. En D. Day y D. Veen (Eds.), Educational research in Europe (pp. 37-47). Lovaina: Garant y European Educational Research Association.

Chiner, E. (2011). Las percepciones y actitudes del profesorado hacia la inclusión del alumnado con necesidades educativas especiales como indicadores del uso de prácticas educativas inclusivas en el aula. Universidad de Alicante.

Fernandez-González, A. (1999). Estudio de las actitudes del profesorado de los centros ordinarios de Vizcaya hacia la integración escolar. Comunicación presentada en las III Jornadas Científicas de Investigación sobre Personas con Discapacidad dentro del Simposio «Retos en la respuesta al retraso mental en la vida adulta: Formación, oportunidades y calidad de vida», Salamanca.

Jiménez Trens, Díaz Allué y Carballo (2006). Respuesta educativa a la diversidad desde la perspectiva del profesorado de la ESO: Estudio en la Comunidad Autónoma de La Rioja. Contextos Educativos, 8-9, 33-50.

Ley Orgánica (1990). 1/1990 de Ordenación General del Sistema Educativo (LOGSE). Ministerio de Educación y Ciencia, 3.

Organización Mundial de la Salud. (2016). Trastornos mentales y del comportamiento. En Organización Mundial de la Salud (Ed.), Revisión internacional de la clasificación internacional de enfermedades.

Scruggs, T. E. y Mastropieri, M. A. (1996). Teacher perceptions of mainstreaming/inclusion, 1958-1995: A research synthesis. Exceptional Children, 63(1), 59-74.

Van Reusen, A. K., Shoho, A. R. y Barker, K. S. (2001). High school teacher attitudes toward inclusion. The High School Journal, 84(2), 7-17.

Wimmer, H. y Perner, J. (1983). Beliefs about beliefs: Representation and constraining function of wrong beliefs in young children's understanding of deception. Cognition, 13(1), 103-128. 



\title{
Plan de cuidados sobre la donación de órganos en pacientes con muerte encefálica
}

\author{
Ma DE los Ángeles Alonso García \\ al286591@uji.es \\ MARINA ALONSO GÓMEZ \\ al289095@uji.es \\ Ma Desamparados Bernat Adell \\ bernatm@uji.es
}

\section{Resumen}

Introducción: La donación de órganos es el acto voluntario mediante el cual una persona en vida, o su familia después de la muerte, autorizan la extracción de órganos y tejidos. La donación puede realizarse tras el diagnóstico de muerte encefálica, entendiéndose ésta como el cese completo e irreversible de las funciones de ambos hemisferios cerebrales y del tronco del encéfalo. Objetivo: Diseñar un plan de cuidados estandarizado basado en la mejor evidencia disponible en el mantenimiento de un donante de órganos con diagnóstico de muerte encefálica en una unidad de cuidados intensivos. Método: El desarrollo del plan de cuidados se ha basado en el modelo «North American Nursing Diagnosis Association». Éste nos permite relacionar los diagnósticos de enfermería, establecer objetivos mediante «Nursing Outcomes Classification» e identificar intervenciones necesarias a través de «Nursing Interventions Classification». Para la evaluación del paciente se ha utilizado los patrones funcionales de Mr. Gordon, a través de los que se ha identificado cada una de las alteraciones características del paciente. Resultados: Se identifican los patrones con mayor afectación en este tipo de pacientes. Entre ellos destacar el patrón nutricional-metabólico, donde se evalúa la temperatura y la nutrición; el patrón actividad-ejercicio, donde se tienen en cuenta las alteraciones hemodinámicas y respiratorias, y el patrón rol-relaciones, centrando las intervenciones de enfermería en el proceso de información a los familiares. Conclusiones: Este plan de cuidados permitirá detectar necesidades, identificar posibles mejoras y actualizar cuidados.

Palabras clave: muerte encefálica, donación de órganos, trasplante de órganos, cuidados enfermería, cuidado crítico.

\section{Abstract}

Introduction: Organ donation is a voluntary decision, made while donors are alive or by their families after death, which gives consent to remove organs and tissues. Donation can be carried out after the diagnosis of brain death, defined as the complete, irreversible loss of all functions of both hemispheres, including the brainstem. Aim: To design a standardized 
nursing care plan, based on the best available evidence, to care for organ donors diagnosed with brain death in an intensive care unit. Method: The developing of the nursing care plan is based on the «North American Nursing Diagnosis Association» model. This allows us to relate nursing diagnoses, to establish aims by «Nursing Outcomes Classification» and to identify necessary measures by means of «Nursing Interventions Classification». Gordon's functional health patterns have been used to assess the patient and to identify each of the characteristic alterations in patients. Results: Patterns with the highest incidence in this type of patients are identified. We can find the nutritional-metabolic pattern, in which temperature and nutrition are assessed, the activity-exercise pattern considering hemodynamic and respiratory alterations and the role-relationship pattern focused on the nursing process of informing the relatives. Conclusion: This care plan will allow us to detect needs, to identify possible improvement and to bring care up to date.

Key words: Brain death, tissue and organ procurement, organ transplantation, critical care nursing, critical care.

\section{Introducción}

La donación de órganos es el acto voluntario mediante el cual una persona en vida, o su familia después de la muerte, autorizan la extracción de órganos y tejidos para trasplantar a otra persona o persones. Se trata de un acto altruista y desinteresado, que tiene como fin último ayudar a otras personas que lo requieren (Ministerio de Salud y Protección Social, 2016; Glosario de términos relativos a la donación de órganos, 2017).

Se identifican dos tipos de donantes según la procedencia del órgano o tejido: el donante vivo y el donante fallecido. El donante vivo es aquel que realiza el procedimiento de donación en vida, sin poner en peligro su salud; siendo los más habituales la donación de sangre de cordón umbilical, de médula ósea y de riñón. En el donante fallecido la donación se realiza tras el diagnóstico de muerte encefálica o asistolia (Servicio Andaluz de Salud, 2017).

La muerte encefálica (ME) se entiende como el cese completo e irreversible de las funciones de ambos hemisferios cerebrales y del tronco encefálico y lleva implícito el deterioro progresivo e inevitable de las funciones orgánicas y la homeostasis interna (Montejo, García de Lorenzo, Marco, y Ortiz, 2013).

En 1980, se procedió al primer intento de legislar el concepto de ME, con el Real Decreto (RD) del 22 de febrero (Ministerio de Sanidad y Seguridad Social, 1980). No es hasta 1993, en el "Dictamen de Candanchú», cuando la Sociedad Española de Neurología reconoce la ME como la muerte del individuo y la define como «el cese total e irreversible de la actividad cerebralı (Pérez-Pérez, Bardalet-Viñals, y Soler-Murall, 2006), quedando especificados los criterios diagnósticos imprescindibles y las pruebas instrumentales complementarias.

Posteriormente, en 1999, en el RD 2070/1999 (Ministerio de la presidencia, 2000) se recoge el diagnóstico de ME junto a actividades relacionadas con la donación y trasplante de órganos, enfatizando la importancia de las pruebas complementarias, con el fin de reducir los tiempos de observación necesarios para el diagnóstico.

En la actualidad, tras el RD 1723/2012, (Boletín oficial del estado. Núm. 313, 2012) además de lo expuesto en los decretos anteriores, se diferencia entre el diagnóstico de muerte encefálica no complicada y el de muerte encefálica en situaciones especiales.

El principal aspecto a la hora de determinar el diagnóstico de muerte encefálica se basa en una rigurosa, sistemática y completa exploración neurológica por parte del staff médico que 
forma parte del equipo de Coordinación de Trasplantes (CTx) del Centro hospitalario (Montejo y cols., 2013; Caballero y Matesanz, 2017; Escudero, 2009).

Los pacientes, potenciales donantes de órganos, y con diagnóstico de ME presentan una gran variabilidad clínica y esto conlleva una multiplicidad de tratamientos y de cuidados, en ocasiones complicados de homogeneizar. Disponer de un plan de cuidados basado en un proceso previo de evaluación por patrones funcionales, permitirá al profesional programar evaluaciones y cuidados necesarios, así como identificar riesgos y resolver problemas de forma eficaz. El objetivo principal es diseñar un plan de cuidados estandarizado basado en la mejor evidencia disponible en el mantenimiento de un donante de órganos con diagnóstico de muerte encefálica en una unidad de cuidados intensivos.

\section{Método}

Para la realización del plan de cuidados se ha llevado a cabo una búsqueda bibliográfica en las bases de datos PubMed, Web of Science, Scopus y Springerlink. Las palabras clave utilizadas han sido muerte encefálica, donación de órganos, trasplante de órganos, cuidados enfermería, cuidado crítico. Se han establecido límites cronológicos del 2010 al 2017 y como límites idiomáticos el inglés y castellano. También se han consultando sitios web de la Organización Nacional de Trasplantes y del Instituto Nacional de Estadística.

Para realizar la valoración del paciente se han utilizado los patrones funcionales de Marjory Gordon (Álvarez Suarez, Del Castillo Arévalo, Fernández Fidalgo, y Muñoz Meléndez, 2010). El Plan de Cuidados desarrollado incluye todos los diagnósticos relacionados con las alteraciones características de ME excepto los relacionados los patrones «autocontrol-autoconcepto y sexualidad», puesto que la situación de gravedad provoca que las funciones relacionadas con los citados patrones no puedan ser desempeñadas por el propio paciente.

Para desarrollar el Plan de Cuidados se ha utilizado el modelo «North American Nursing Diagnosis Association» (Herdman y Kamitsuru, 2014). Este modelo nos permite realizar un diagnóstico, establecer objetivos mediante «Nursing Outcomes Classification» (Moorhead, Johnson, Mass, y Swanson, 2013) e identificar las intervenciones necesarias para su consecución, utilizando en este caso el "Nursing Interventions Classification» (Bulechek G.M., Butcher H.K., Dochterman J.M., 2014). Además, han sido incluidas en la taxonomía, la metodología, los procedimientos y el instrumental necesario para llevar a cabo cada una de las intervenciones.

Finalmente se ha diseñado una herramienta de evaluación dirigida a valorar el cumplimiento del plan de cuidados. Se trata de un checklist desarrollado ad hoc y basado en una publicación previa, de carácter médico (Caballero y Matesanz, 2017). El citado checklist valora los cuidados de enfermería e intervenciones descritas en el Plan de Cuidados.

\section{Resultados}

Patrón Nutricional - Metabólico: En situación de ME se recomienda mantener la temperatura central entre $36,5-37^{\circ} \mathrm{C}$ (considerando hipertermia a la temperatura central superior a $38^{\circ} \mathrm{C}$ ) (Caballero y Matesanz, 2017), nutrición enteral o absoluta (Branch, 2016), normoglucemia (Citerio y cols., 2016), Normovolemia (Caballero y Matesanz, 2017), equilibrio hidroelectrolítico y mantenimiento de la integridad cutánea (Caballero y Matesanz, 2017).

NANDA: 00008 Termorregulación ineficaz ( $\mathrm{r} / \mathrm{c}$ situación de ME) NOC: 1923 Control del riesgo: hipotermia - 1993 Control del riesgo: hipertermia 
NIC: 3800 Tratamiento de la hipotermia.

- Monitorizar de forma continua la temperatura central del paciente (Arteria pulmonar mediante catéter Swan-Ganz, catéter esofágico, catéter vesical, sonda rectal) y registro horario (Branch, 2016; Westphal y cols., 2012)

- Aplicar recalentamiento externo pasivo, ajustar temperatura ambiental (Kumar, 2016), mantas térmicas (Branch, 2016), cubierta de aluminio, sistema ArticSun).

- Aplicar recalentamiento interno activo (líquidos intravenosos calientes $\left(43^{\circ} \mathrm{C}\right)($ Westphal y cols., 2012), oxígeno humidificado (Citerio y cols., 2016$)$ y calentado $\left(42-46^{\circ} \mathrm{C}\right.$ ) (Westphal y cols., 2012), circulación extracorpórea y lavado de las cavidades corporales con suero caliente).

- Monitorización bioquímica de la dosis de fármacos hasta lograr temperatura central objetivo.

- Monitorizar los síntomas asociados con la hipotermia leve (taquipnea, escalofríos, hipertensión arterial), la hipotermia moderada (arritmias auriculares, hipotensión, coagulopatía e hiporreflexia) y la hipotermia grave (oliguria, ausencia de reflejos neurológicos, edema pulmonar y alteraciones acidobásicas).

- Monitorizar el color y la temperatura de la piel.

NIC: 3786 Tratamiento de la hipertermia.

- Monitorizar de forma continua de la temperatura central del paciente (Arteria pulmonar mediante catéter Swan-Ganz, catéter esofágico, catéter vesical, sonda rectal) y registro horario (Westphal y cols., 2012; Colonel R Setlur, Senior Advisor, Anaesthesiology and Critical Care, 2015).

- Suspender tratamiento de recalentamiento y procurar un ambiente más frío (retirar calentamiento activo y pasivo).

- Aplicar métodos de enfriamiento externo (medidas físicas y/o Artic Sun®).

- Aplicar métodos de enfriamiento interno (perfusión intravenosa de sueros fríos, circulación extracorpórea, Cool-Gard ${ }^{\mathrm{TM}}$, lavado gástrico, vesical, peritoneal con suero frio).

- Administrar paracetamol (650 mg c/3h) cuando la temperatura central sea superior a $38^{\circ} \mathrm{C}$ (Caballero y Matesanz, 2017b).

- Administrar medicamentos antiescalofríos, si precisa.

NANDA: 00103 Deterioro de la Deglución (r/c situación de ME)

NOC: 1010 Estado de deglución

NIC: 1100 Manejo nutrición

- Continuar/Iniciar la nutrición enteral (Citerio y cols., 2016).

- Ajustar la dieta a requerimientos calóricos.

- Administrar nutrición enteral programada por dosis/tiempo (bombas nutrición enteral) para preservar la integridad de la mucosa gastrointestinal.

- Dieta absoluta, si no se precisa preservar integridad de la mucosa gastrointestinal.

NIC: 1874 Cuidados sonda gastrointestinal

- Comprobar ubicación catéter nasogástrico (radiografía de tórax, aspirado contenido gástrico).

- Comprobar fijación. 
- Cuidados de la piel en zona inserción/fijación.

- Comprobar permeabilidad.

- Auscultar ruidos intestinales.

- Evaluar pérdidas contenido gástrico.

Patrón Cognitivo - Perceptivo: Registrar los valores neurológicos y observar posibles cambios partiendo de la base que el paciente se encuentra en situación de ME y los parámetros neurológicos estarán todos fuera de rango de normalidad.

NANDA: 00201 Riesgo de perfusión tisular ineficaz (r/c situación de ME)

NOC: 0909 Estado neurológico.

NIC: 2620 Monitorización neurológica.

- Comprobar el tamaño, forma, simetría y capacidad de reacción de las pupilas.

- Monitorizar el nivel de consciencia mediante la Escala de Coma de Glasgow (Muñana-Rodríguez y Ramírez-Elías, 2014).

- Monitorizar el grado de sedación mediante la Escala de Agitación y Sedación Richmond (RASS) (Sessler y cols., 2002).

- Monitorizar dolor mediante la Escala de conductas Indicadoras de Dolor (ESCID) (López López y cols., 2013).

- Monitorizar profundidad de sedación y electroencefalograma (EEG) mediante bisperdal index (BIS).

- Monitorizar la presión intracraneal (PIC), presión de perfusión cerebral (PPC) y presión perfusión tisular de oxígeno (PTiO2), si precisa según indicación médica.

- Mantener cabecera elevada entre $30-40$ grados, siempre que sea posible (Citerio y cols., 2016).

- Manejar el aparataje y ajustar las alarmas en aparataje.

- Registrar datos en gráfica horarios.

Patrón Rol - Relaciones, Patrón Tolerancia al estrés, Patrón Valores y Creencias: El patrón se encuentra alterado en la familia. El objetivo va a ser mejorar el proceso de comunicación.

NANDA: 00172 Riesgo de duelo complicado ( $\mathrm{r} / \mathrm{c}$ muerte inesperada de un ser querido) NOC: 1304 Resolución de la aflicción

NIC: 6260 Obtención de órganos

- Disponer de una información compartida entre todo el equipo de trabajo.

- Colaborar en el proceso de información a familiares durante el periodo de diagnóstico de ME y posterior proceso de donación.

- Dar tiempo a la familia para su proceso de duelo.

- Facilitar a la familia el acceso a la habitación del paciente, de forma continua según necesidades personales del familiar.

- Responder e informar a las cuestiones y dudas planteadas por los familiares acerca de proceso de donación.

- Tras finalizar el proceso reevaluar la actuación del equipo, evaluando fortalezas y debilidades. 


\section{NIC: 7140 Apoyo a la familia}

- Escuchar inquietudes, sentimientos y preguntas.

- Facilitar la comunicación de inquietudes/sentimientos entre los miembros de la familia.

- Aceptar los valores familiares sin emitir juicios.

- Responder a todas las preguntas y ayudarles a obtener las respuestas, en la medida de lo posible.

- Ayudar a los miembros de la familia a identificar y resolver conflictos de valores.

- Respetar y apoyar los mecanismos de afrontamiento utilizados.

- Proporcionar recursos espirituales según creencias.

- Integrar a los miembros de la familia en el proceso de toma de decisiones.

- Proporcionar apoyo emocional a la familia.

Finalmente se incluye el checklist como herramienta de evaluación, ver figura 1.

Figura 1. Checklist para la evaluación del Plan de Cuidados

Box:

Fecha:

\begin{tabular}{|c|c|c|c|c|}
\hline \multirow[t]{2}{*}{ ETIQUETA DEL PACIENTE } & \multirow[b]{2}{*}{ M } & \multirow[b]{2}{*}{$\mathbf{T}$} & \multirow[b]{2}{*}{$\mathbf{N}$} & \multirow[b]{2}{*}{ NP* } \\
\hline & & & & \\
\hline \multicolumn{5}{|l|}{ Higiene } \\
\hline \multicolumn{5}{|l|}{ Se realiza higiene completa } \\
\hline \multicolumn{5}{|l|}{ Se realiza higiene bucodental (al menos 3 veces/dia) } \\
\hline \multicolumn{5}{|l|}{ Se realiza higiene ocular y administración colirio o pomada } \\
\hline \multicolumn{5}{|l|}{ Se vigila el estado de la piel } \\
\hline \multicolumn{5}{|l|}{ Monitorización } \\
\hline \multicolumn{5}{|l|}{ Se realiza monitorización continua de constantes vitales } \\
\hline \multicolumn{5}{|l|}{ Se realiza registro horario de constantes vitales } \\
\hline \multicolumn{5}{|l|}{ Control de la temperatura } \\
\hline \multicolumn{5}{|l|}{ Se aplican métodos de recalentamiento externo pasivo } \\
\hline \multicolumn{5}{|l|}{ Se aplican métodos de recalentamiento interno activo } \\
\hline \multicolumn{5}{|l|}{ Se realiza monitorización bioquimica de dosis de färmacos } \\
\hline \multicolumn{5}{|l|}{ Se monitorizan sintomas de hipotermia/hipertermia } \\
\hline \multicolumn{5}{|l|}{ Se monitoriza el color y temperatura de la piel } \\
\hline \multicolumn{5}{|l|}{ Se aplican métodos de enfriamiento externo } \\
\hline \multicolumn{5}{|l|}{ Se aplican métodos de enfriamiento interno } \\
\hline \multicolumn{5}{|l|}{ Nutrición } \\
\hline \multicolumn{5}{|l|}{ Se administra nutrición enteral } \\
\hline \multicolumn{5}{|l|}{ Se evalúan las pérdidas de contenido gástrico } \\
\hline \multicolumn{5}{|l|}{ Glucemia } \\
\hline \multicolumn{5}{|l|}{ Se monitorizan sintomas de hiperglucemia } \\
\hline \multicolumn{5}{|l|}{ Se monitorizan sintomas de hipoglucemia } \\
\hline \multicolumn{5}{|l|}{ Se administra insulina según requerimientos y pauta } \\
\hline \multicolumn{5}{|l|}{ Liquidos y electrólitos } \\
\hline \multicolumn{5}{|l|}{ Se monitorizan signos de deshidratación } \\
\hline \multicolumn{5}{|l|}{$\begin{array}{l}\text { Se controlan resultados de laboratorio (valores hematologicos y } \\
\text { bioquimicos) }\end{array}$} \\
\hline \multicolumn{5}{|l|}{ Eliminación urinaria } \\
\hline Se monitorizan las pérdidas urinarias & & & & \\
\hline
\end{tabular}

\begin{tabular}{|c|c|c|c|c|}
\hline & M & $\mathbf{T}$ & $\mathbf{N}$ & NP* \\
\hline \multicolumn{5}{|l|}{ Hemodinámica } \\
\hline \multicolumn{5}{|l|}{$\begin{array}{l}\text { Se observan las tendencias y fluctuaciones de los datos } \\
\text { hemodinámicos }\end{array}$} \\
\hline \multicolumn{5}{|l|}{ Se monitoriza si existe cianosis central y/o periférica } \\
\hline \multicolumn{5}{|l|}{ Se administran fármacos inotropos $y / 0$ vasoactivos } \\
\hline \multicolumn{5}{|l|}{ Se avisa médico intensivista en casos de ritmos anómalos } \\
\hline \multicolumn{5}{|l|}{ Se observa frecuencia y duración de arritmia } \\
\hline \multicolumn{5}{|l|}{ Ventilación } \\
\hline \multicolumn{5}{|l|}{ Se monitorizan parámetros gasométricos $\mathrm{c} / \mathrm{h}$} \\
\hline \multicolumn{5}{|l|}{ Se auscultan sonidos respiratorios } \\
\hline \multicolumn{5}{|l|}{ Se programan suspiros $\mathrm{c} / \mathrm{h}$} \\
\hline \multicolumn{5}{|l|}{$\begin{array}{l}\text { Se observa posible aparición de efectos adversos derivados de la } \\
\text { ventilación mecánica }\end{array}$} \\
\hline \multicolumn{5}{|l|}{ Se mantiene la cabecera a $30-40$ grados } \\
\hline \multicolumn{5}{|l|}{ Estado neurológico } \\
\hline \multicolumn{5}{|l|}{$\begin{array}{l}\text { Se comprueba tamaão, forma, simetria y capacidad de reacción de las } \\
\text { pupilas }\end{array}$} \\
\hline \multicolumn{5}{|l|}{ Se monitoriza nivel consciencia (Glasgow) } \\
\hline \multicolumn{5}{|l|}{ Se monitoria sedación (RASS) } \\
\hline \multicolumn{5}{|l|}{ Se monitoriza dolor (ESCID) } \\
\hline \multicolumn{5}{|l|}{ Se monitoriza profundidad de sedación (EEG y BIS) } \\
\hline \multicolumn{5}{|l|}{ Familia } \\
\hline \multicolumn{5}{|l|}{ Se colabora en el proceso de información } \\
\hline \multicolumn{5}{|l|}{$\begin{array}{l}\text { Se permite el acceso de la familia a la habitación del paciente de } \\
\text { forma continua }\end{array}$} \\
\hline \multicolumn{5}{|l|}{ Se responde y se informa sobre cuestiones o dudas } \\
\hline \multicolumn{5}{|l|}{ Se realiza escucha activa } \\
\hline \multicolumn{5}{|l|}{ Se aceptan valores familiares } \\
\hline \multicolumn{5}{|l|}{ Se respeta el proceso de cuelo } \\
\hline \multicolumn{5}{|l|}{ Se respeta y apoya mecanismos de afrontamiento } \\
\hline \multicolumn{5}{|l|}{ Se proporciona recursos espirituales } \\
\hline Se integra a todos los miembros en la toma de decisiones & & & & \\
\hline
\end{tabular}




\section{Discusión y conclusiones}

La complejidad del cuidado que presentan los pacientes críticos en situación de muerte encefálica requiere de unos cuidados específicos y estructurados; además, éstos deben ser realizados en unos tiempos determinados. Resulta imprescindible evaluar sus necesidades funcionales y diseñar planes de cuidados dirigidos a identificar y minimizar los riesgos derivados de la gravedad y de la gran variabilidad de alteraciones que presentan (Caballero y Matesanz, 2017; Berdayes, 2003).

Siguiendo el método enfermero (Berdayes, 2003), el primer paso ha sido evaluar las necesidades del paciente en ME, y para ello hemos utilizado los patrones funcionales de Marjory Gordon. Aunque no todos los patrones han sido utilizados debido a que la situación de ME impedía valorar los referentes a la autonomía, percepción, manejo del propio paciente y sexualidad. Cabe recordar que se trata de pacientes en situación de coma irreversible sin capacidad cognitiva y perceptual.

Para el desarrollo del plan de cuidados se ha utilizado el modelo de la «North American Nursing Diagnosis Association» (Herdman y Kamitsuru, 2014) que permite establecer diagnósticos enfermeros, objetivos a conseguir e intervenciones a desarrollar. Tras la revisión de las distintas fuentes bibliográficas, se ha hecho evidente la falta de consenso acerca de los valores de referencia considerados como óptimos para el mantenimiento/monitorización del paciente en ME. La variabilidad clínica que deriva de esta falta de consenso, provoca ciertas dificultades para el manejo y tratamiento de estos pacientes. Por tanto, resulta de vital importancia conseguir un consenso en los valores de referencia con el fin de estandarizar tratamientos y cuidados. Con el presente plan de cuidados se busca no sólo diseñar una guía de actuación, sino también disponer de una herramienta estructurada que facilite la información a profesionales y motive la formación continuada según los avances científicos; en definitiva, un Plan de Cuidados que facilite el trabajo en equipo, unifique criterios entre profesionales y posiblemente incluso pueda ser de utilidad para identificar de forma precoz riesgos y prevenir eventos no deseados.

Teniendo en cuenta la evaluación e implementación, como fases finales del proceso enfermero, hemos considerado oportuno diseñar una herramienta de evaluación cuyo fin sea valorar el cumplimiento de los cuidados e intervenciones descritos en nuestro Plan de Cuidados. Para ello se ha desarrollado un checklist basado en una publicación de la ONT (Caballero y Matesanz, 2017). Este checklist es de carácter médico y sólo incluye un ítem relacionado con la enfermería. Esto ha planteado la necesidad de crear un instrumento específico para enfermería que contemple de una manera integral todos los cuidados necesarios para el mantenimiento del paciente; tanto los cuidados de tipo técnico como aquellos cuidados que se relacionen con la toma de decisiones en circunstancias complejas y que engloben a la familia.

Para concluir decir que un Plan de Cuidados estandarizado ayudará a identificar alteraciones fisiopatológicas, puesto que la mayor parte de las intervenciones van dirigidas a observar y evaluar al paciente, tanto con el uso de monitorización invasiva como con el uso de la observación de la enfermera. También hay que tener presente que un Plan de Cuidados facilitará la detección precoz de posibles riesgos, puesto que la observación continua permitirá anticiparse a los mismos. Para completar el proceso enfermero las se presenta una herramienta de evaluación, que podría ser de utilidad para los profesionales, si considerasen oportuno, hacer uso del Plan de Cuidados presentado. 


\section{Referencies bibliográficas}

Álvarez Suarez, J. L., Del Castillo Arévalo, F., Fernández Fidalgo, D., y Muñoz Meléndez, M. (2010). Manual de Valoración de Patrones Funcionales Manual de Valoración de Patrones Funcionales.

Berdayes, D. (2003). Bases conceptuales de enfermería: El método científico de enfermería. Proceso de atención de enfermería. Comparación con otros métodos. En Bases conceptuales de enfermería. Recuperado a partir de http://gsdl.bvs.sld.cu/cgi-bin/library?e=d00000-00---off-Oenfermeria--00-0--0-10-0--0-0---0prompt-10---4-----sti-4-0-11--11-es-500--20-about-n1 cido-es-00-0-1-00-2-0-11-10-0-00-00-0-0-11-1-0utfZz-8-00\&a=d\&c=enfer meria\&cl=CL1\&d=HASH010e4e28fdc63d64644ca91

Boletín oficial del estado. Núm. 313. (2012). Ministerio de Sanidad, Servicios Sociales e Igualdad, (313), 89315-89348.

Branch, O. (2016). Management of the Adult Brain Dead Potential Organ and Tissue Donor. Ministry of health, NSW, (02), 9391-9101. Recuperado a partir de http://www.health.nsw. gov.au/policies/

Bulechek G.M., Butcher H.K., Dochterman J.M., W. C. M. (2014). Clasificación de Intervenciones de Enfermería (NIC). (Elsevier Inc., Ed.) (6ed. ed.). Barcelona.

Caballero, F., y Matesanz, R. (2017a). Capítulo 1-Fases Proceso Obtención Órganos de Donantes en ME. ONT. Recuperado a partir de http://www.coordinaciontrasplantes.org/ images/capitulos/01.pdf

Caballero, F., y Matesanz, R. (2017b). Capítulo 5. Mantenimiento Donante. ONT. Recuperado a partir de http://www.coordinaciontrasplantes.org/images/capitulos/05.pdf

Citerio, G., Cypel, M., Dobb, G. J., Dominguez-Gil, B., Frontera, J. A., Greer, D. M., ... Wijdicks, E. F. M. (2016). Organ donation in adults: a critical care perspective. Intensive Care Medicine, 42(3), 305-315. http://doi.org/10.1007/s00134-015-4191-5

Colonel R Setlur, Senior Advisor, Anaesthesiology and Critical Care, A. H. (R\&R). (2015). 10 out of 205 Guidelines for management of the brain dead organ donor in intensive care unit (ICU). Recuperado a partir de http://www.notto.nic.in/WriteReadData/Final_sop/ICU/ ICU_MANAGEMENT_OF_BRAIN_DEAD_ORGAN_DONOR.pdf

Glosario de términos relativos a la donación de órganos. (2017). Recuperado 27 de marzo de 2017 , apartirdehttps://donaciondeorganos.gov/sobre/datos-t\%C3\%A9rminos/1yv2/t\%C3\%A9rminos. html\#div 2

Herdman, T. H., y Kamitsuru, S. (2014). NANDA International. Inc. DIAGNÓSTICOS ENFERMEROS. Definiciones y clasificación. 2015-2017. Barcelona: Elsevier.

Kumar, L. (2016). Brain death and care of the organ donor. Journal of Anaesthesiology Clinical Pharmacology, 32(2). http://doi.org/10.4103/0970-9185.168266

López López, C., Murillo Pérez, M. A., Torrente Vela, S., Cornejo Bauer, C., García Iglesias, M., Orejana Martín, M., ... Alted López, E. (2013). Aplicación de la Escala de conductas indicadoras de dolor (ESCID) en el paciente con trauma grave no comunicativo y ventilación mecánica. Enfermería Intensiva, 24(4), 137-144. http://doi.org/10.1016/j. enfi.2013.07.003

Ministerio de la presidencia. (2000). RD 2070/1999, de 30 de diciembre, por el que se regulan las actividades de obtención y utilización clínica de órganos humanos y la coordinación territorial en materia de donación y trasplante de órganos y tejidos. BOE, 3, 179-190.

Ministerio de Salud y Protección Social. (2016). Preguntas frecuentes sobre Donación de órganos. Recuperado a partir de https://www.minsalud.gov.co/sites/rid/Lists/BibliotecaDigital/RIDE/VS/MET/donacion-trasplantes-organos-tejidos.pdf 
Ministerio de Sanidad y Seguridad Social. (1980). RD 426/1980, de 22 de febrero, por el que se desarrolla la Ley 30/1979, de 27 de octubre, sobre Extracción y Trasplante de Organos. BOE, 5705-5707.

Montejo, J. ., García de Lorenzo, A., Marco, P., y Ortiz, C. (2013). Manual de medicina intensiva ( $4^{\text {a }}$ ed.). Elsevier.

Moorhead, S., Johnson, M., Mass, M. L., y Swanson, E. (2013). Clasificación de Resultados de Enfermería (NOC) (4a ed.). Barcelona: Elsevier España.

Muñana-Rodríguez, J. E., y Ramírez-Elías, A. (2014). Escala de coma de Glasgow: origen, análisis y uso apropiado. Enfermería Universitaria, 11(1), 24-35. http://doi.org/10.1016/ S1665-7063(14)72661-2

Pérez-Pérez, R. M., Bardalet-Viñals, N., y Soler-Murall, N. (2006). Diagnóstico de muerte y trasplante de órganos. Implicaciones jurídicas y médico-legales. Medicina Clínica, 126(18), 707-711. http://doi.org/10.1157/13088773

Servicio Andaluz de Salud. (2017). Donación y donantes de órganos y tejidos - Servicio Andaluz de Salud. Recuperado 27 de marzo de 2017, a partir de http://www.juntadeandalucia.es/servicioandaluzdesalud/principal/documentosAcc.asp?pagina=gr_serviciossanitarios3_6_2_1\#1

Sessler, C. N., Gosnell, M. S., Grap, M. J., Brophy, G. M., O’Neal, P. V., Keane, K. A., ... Elswick, R. K. (2002). The Richmond Agitation-Sedation Scale. American Journal of Respiratory and Critical Care Medicine, 166(10), 1338-1344. http://doi.org/10.1164/rc$\mathrm{cm} .2107138$ 



\title{
Paga setmanal i amics antinormatius
}

\section{Efectes additius i de moderació en la predicció de l'ús de substàncies per part d'adolescents}

\author{
JORDI ORTET WALKER \\ al260584@uji.es \\ ANDREA Cuevas CARDA \\ al260587@uji.es \\ FRANCISCO JAVIER LÓPEZ FERNÁNDEZ \\ al225790@uji.es \\ SíGRID GALLEGO MOYA \\ moyam@uji.es \\ LAURA MEZQUITA GUILLAMÓN \\ Imezquit@uji.es
}

\section{Resum}

Molts estudis mostren que l'alcohol i el cànnabis poden tenir efectes perjudicials per la salut dels adolescents. Els estudis de genètica quantitativa han trobat que a aquesta etapa vital, els factors socials tenen la influència més gran sobre el consum. La variable social més fortament associada a l'ús de drogues en l'adolescència és la pressió social, especialment tenir amics amb conductes antinormatives. Una altra variable important però menys estudiada és la quantitat de paga setmanal percebuda, així com l'ús que se'n fa d'aquesta. Els objectius d'aquest estudi eren estudiar la influència additiva de la conducta antinormativa dels amics i la quantitat de paga setmanal sobre el consum de marihuana i d'alcohol. Amb aquesta finalitat, vam administrar una sèrie de qüestionaris a una mostra de $n=428$ estudiants de secundària espanyols (Mitjana d'edat $=14,36$ anys; DT = 1,63; $48 \%$ dones). Qüestionaris: Deviant Peers Scale (DPS), que avalua la quantitat d'amics amb comportaments antinormatius; CODIS, que avalua la quantitat d'alcohol i cànnabis consumit. Vam demanar als participants que indiquessin la quantitat de paga setmanal percebuda. Anàlisis de regressió van mostrar que, considerades de forma separada, la paga setmanal i els amics antinormatius van predir el consum d'alcohol i cànnabis significativament. La interacció entre ambdues variables va mostrar un efecte sinèrgic. Aquests resultats indiquen que tenir molts amics antinormatius, junt a una alta quantitat de paga setmanal, pot portar a un consum més elevat d'alcohol i cànnabis. Aquests resultats podrien contribuir a desenvolupar intervencions efectives per a la població adolescent.

Paraules clau: alcohol, cànnabis, amics, paga setmanal, antinormativitat. 


\section{Abstract}

Many studies have shown that alcohol and cannabis can have detrimental effects on adolescents' health. Quantitative genetic studies have found that in this stage of life, social factors have the highest influence on consumption. The social variable that is more strongly associated with drug use in adolescence is peer pressure, especially having friends who deviate from social norms. Another influential but less studied variable is the amount of weekly pocket money given to teens and the use they make of it. Therefore, the aims of this work were to study the additive influence of peers' antisocial behavior and the amount of weekly pocket money on the consumption of alcohol and cannabis. We administered a series of questionnaires to a sample of $n=428$ Spanish high school students (Mean age $=14.36$ years; $\mathrm{SD}=1.63 ; 48$ \% girls). Questionnaires: Deviant Peers Scale (DPS), which assesses the amount of friends with socially deviant behavior; CODIS, which assesses the amount of alcohol and cannabis consumed. We requested that participants indicate the amount of money received weekly. Regression analyses revealed that, when considered separately, weekly pocket money and deviant peers predicted alcohol and cannabis consumption significantly. When the interaction between these two variables was accounted for, a synergistic effect was found. These results show that having many socially deviant friends, combined with a high amount of pocket money, can lead to greater consumption of alcohol and cannabis. These findings may contribute to developing effective interventions for the adolescent population.

Keywords: alcohol, cannabis, peers, pocket money, deviance.

\section{Introducció}

L'alcohol és la droga psicoactiva més consumida a Espanya entre els adolescents (Pla Nacional sobre Drogues, 2014). Tot i que el seu ús és illlegal per als menors d'edat, el seu consum s'inicia en l'adolescència (Hall i Degenhardt, 2009). Per tant, al nostre pais, el 63,1\% dels joves d'entre 13 i 14 anys inicien el consum d'aquesta substància. A més a més, trobem que l'ús excessiu també comença a edats molt primerenques. Seguint amb aquesta línia, el $30 \%$ i el $43 \%$ dels estudiants espanyols de 15 i 16 anys, respectivament, han participat en el consum per atracó (o «binge drinking») en l'últim mes (PNSD, 2014).

Segons la OMS (2002), els tipus d'ús de l'alcohol més preocupants o amb més alt risc entre els adolescents és el consum excessiu habitual, caracteritzat per un ús mitjà de l'alcohol per damunt dels nivells establerts, i per episodis de consum excessiu o «binge drinking», caracteritzats per una ingesta molt gran d'alcohol en un periode de temps molt curt.

Aquests patrons de consum excessiu en l'adolescència semblen tenir un impacte molt gran sobre la salut i el desenvolupament social dels joves (Llorens, Barrio, Sánchez \& Suelves, 2011), més concretament, estan associats a un index més alt de violència i d'altres conductes antisocials, incloent-hi l'absentisme escolar (Bellis et al., 2007); també han estat associats a diversos efectes en el desenvolupament del cervell, que es tradueix en dèficits cognitius $\mathrm{i}$, en l'edat adulta, es relaciona amb problemes de salut i a una tendència cap al consum excessiu d'alcohol (Llorens et al., 2011) i amb trastorns de dependència d'aquesta i d'altres substàncies (Bellis et al., 2007). 
Per tant, s'estima que entre els adolescents d'edats compreses entre els 15 i els 19 anys, la principal causa dels Anys de Vida Ajustats per Discapacitat (AVAD, en anglès DALYS: Disability-adjuested Life Years) a una escala global s'atribueix a l'alcohol (Gore et al., 2011). A més dels problemes de salut, l'abús de l'alcohol en els joves s'associaria amb conductes perjudicials per a l'individu i la societat, com la conducta antinormativa, l'ús i abús d'altres drogues, problemes acadèmics i laborals, violència, conducta sexual de risc, o conducció temerària i en un estat d'embriaguesa (Cooper, Agocha \& Sheldon, 2000; Zuckerman \& Kuhlman, 2000).

Lús habitual de l'alcohol en l'adolescència sembla facilitar la iniciació en el consum d'altres drogues ilícites, com el cànnabis o la cocaina (Clark \& Bukstein, 1998). Per tant, el consum d'aquestes substàncies seria un factor predisponent per al consum d'altres drogues il.legals (Hall \& Degenhardt, 2009), i un factor de risc per a la transició cap a la dependència abans dels 18 anys d'edat (Wagner \& Anthony, 2002).

Un dels factors ambientals que sembla relacionar-se amb un ús més elevat de substàncies és la quantitat de diners disponibles per a gastos personals. Quan la font d'aquests diners és la paga semanal rebuda dels pares o tutors, hi ha un risc més elevat per al consum de substàncies com l'alcohol, però no incrementa la probabilitat de consumir drogues dissolvents. Per altra banda, quan els diners s'obtenen "d'altres fonts», la droga que més s'usa és el cànnabis (58 \%), seguit dels dissolvents (30 \%) (McCrystal, Percy \& Higgins, 2007).

Un estudi de Varela, Marsillas, Isorna \& Rial (2013) amb una mostra de 477 adolescents d'edats entre els $14 \mathrm{i}$ els 18 anys va mostrar que la quantitat de diners disponibles per a gastar estava significativa i positivament relacionada amb el consum de drogues com l'alcohol, el tabac o la marijuana. L'estudi també va revelar que la quantitat de diners disponibles estava inversament relacionada amb una orientació cap a la salut i positivament amb les actituds cap a les drogues. Una quantitat més gran de diners disponibles estava relacionada amb una actitud més favorable cap a les drogues junt amb la participació en conductes menys saludables.

El nivell socioeconòmic dels adolescents, principalment a través de la seua paga setmanal percebuda dels seus pares, és un factor rellevant en el consum d'alcohol, marijuana i altres drogues. No obstant, l'efecte que presenta, tot i que significatiu, sembla ser moderat o baix respecte a la importància de la seua magnitud, que indicaria que altres factors biopsicosocials també son rellevants en el desenvolupament d'aquestes conductes.

El grup d'amics és probablement el factor social més influent sobre els joves durant l'adolescència (Borsari \& Carey, 2001). Així, la relació entre el consum d'alcohol i de marijuana i el fet de tenir més amics antinormatius podria ser explicat a través d'un procés d'influència: tenir amics amb més conductes antinormatives influeix el desenvolupament d'un patró més antinormatiu en els adolescents, que inclou el consum d'alcohol i marijuana.

En aquest estudi, vam tractar d'estudiar el paper que certs factors ambientals importants juguen en l'ús de substàncies. Creiem que la paga setmanal i els amics antinormatius s'han de tenir en compte i s'han d'estudiar de forma conjunta, per a descobrir possibles interaccions entre elles a l'hora de predir l'ús de drogues entre els adolescents.

Tenint en compte la literatura disponible, els objectius d'aquest estudi eren:

1) Trobar una relació entre la quantitat de paga setmanal que perceben els adolescents i el seu consum d'alcohol i marijuana.

2) Trobar la relació entre la quantitat d'amics antinormatius i el seu consum d'alcohol i marijuana.

3) Explorar els possibles efectes sinèrgics entre els amics antinormatius i la quantitat de paga setmanal i el consum d'aquestes substàncies. 
Les hipòtesis eren les següents:

1) La quantitat de paga setmanal que perceben els adolescents i la quantitat d'amics antinormatius, de forma separada, cadascuna predirien un consum més elevat d'alcohol i marijuana.

2) La paga setmanal i els amics antinormatius, de forma conjunta, tindrien un efecte interactiu entre ells, resultant en un consum més elevat de substàncies, a través d'un procés sinèrgic.

\section{Mètode}

Els mètodes emprats per a estudiar les variables d'interés, eren l'administració d'una sèrie de questionaris, al curs acadèmic 2015-16, a una mostra de 428 adolescents espanyols d'instituts de Castelló de la Plana. Aquests joves tenien edats compreses entre els 12 i els 21 anys (Mitjana $=14,36 ; \mathrm{DT}=1,63 ; 48 \%$ dones).

Per a procedir a l'administració d'aquests questionaris, els investigadors veterans del grup IDAP de la Universitat Jaume I de Castelló van contactar amb els instituts. Habitualment, els subdirectors dels instituts organitzaven les sessions per a que els estudiants completaren els questionaris. Estudiants fent el Treball de Fi de Grau i altres ja graduats vinculats al grup IDAP van ser els encarregats d'administrar els questionaris en les classes de tutoria (sessions setmanals d'una hora sense dedicació a cap assignatura en particular). Els estudiants universitaris també s'emportaren els questionaris una vegada completats, i van assignar un codi creat aleatòriament a cada adolescent, permetent una confidencialitat i anonimitat total per a cada membre de la mostra en quant a les seves respostes als ítems dels questionaris. Un protocol estricte es va aplicar per a assegurar aquesta confidencialitat, ja que no es va guardar cap document identificatiu dels adolescents.

Els estudiants universitaris també s'encarregaren d'introduir les dades proporcionades pels questionaris a l'ordinador per als posteriors anàlisis. El software emprat per a aquest propòsit va ser l'Excel (per a introduir les dades) i l'IBM SPSS 23 (per a dur a terme els anàlisis estadístics pertinents de les dades importades del programa Excel).

Els questionaris concrets que s'utilitzaren eren:

1) Deviant Peers Scale (DPS), que avalua la quantitat d'amics amb conducta socialment antinormativa. Aquest questionari consta de 22 items que es contesten en una escala de 0 (cap) a 4 (tots), indicant la quantiat d'amics que han dut a terme cada conducta antinormativa indicada, en els últims 6 mesos.

2) Cannabis and Other Drugs Intake Scale (CODIS), que avalua la quantitat d'alcohol i de cànnabis consumits. El questionari inclou items que pregunten per la frequència del consum, número d'unitats estàndard de drogues consumides en una setmana habitual, edat d'inici del consum, una mesura de «binge drinking» en un mes habitual, i el consum del millor amic de l'individu (frequència i quantitat d'unitats estàndard de diverses drogues).

3) Questionari de dades sociodemogràfiques, que avalua diferents dades sociodemogràfiques, incloent-hi la quantitat de paga setmanal percebuda pels pares o tutors, disponible per a l'ús personal.

Els anàlisis estadístics es van dur a terme amb el software IBM SPSS 23. Concretament, es van fer regressions lineals emprant el consum d'alcohol i cànnabis com a variables dependents. Aquests anàlisis van permetre obtenir una predicció significativa de l'ús de substàncies per part de les variables: edat, gènere, paga setmanal, amics antinormatius i la interacció entre paga setmanal $\mathrm{i}$ amics antinormatius. 


\section{Resultats}

Les regressions van mostrar que la paga setmanal i els amics antinormatius, considerats de forma separada, predien el consum d'alcohol de manera significativa i positiva (veure Taula 1). Quan es tractava del cànnabis, la quantitat de paga setmanal percebuda no predia el consum d'aquesta substància de manera significativa, però la quantitat d'amics antinormatius sí ho feia d'una manera positiva i estadísticament significativa (veure Taula 2).

La interacció entre els amics antinormatius i la paga setmanal tenia un efecte sinèrgic, en virtut de la qual es consumia una quantitat molt més elevada d'alcohol i marijuana (veure Taules 1 i 2 )

Anàlisis de regressió lineal

Taula 1

Consum d'Alcohol

\begin{tabular}{|c|c|c|c|c|c|}
\hline & & $\mathrm{R}^{2}$ & $\Delta \mathrm{R}^{2}$ & $\beta$ & $t$ \\
\hline \multirow[t]{2}{*}{1} & Edat & \multirow{2}{*}{,110 } & \multirow{2}{*}{,110 } & ,331 & $6,87^{* * *}$ \\
\hline & Gènere & & &,- 012 &,- 256 \\
\hline 2 & Paga (Z) & ,128 & ,018 & 138 & $2,84^{* *}$ \\
\hline 3 & Amics (Z) & 280, & ,119 & ,351 & $7,76^{* * *}$ \\
\hline \multirow{2}{*}{4} & \multirow{2}{*}{ Paga (Z)Amics (Z) } & \multirow{2}{*}{,247 } & \multirow{2}{*}{,034 } & ,319 & $7,09^{* * *}$ \\
\hline & & & & 188 & $4,22^{* \star *}$ \\
\hline
\end{tabular}

Nota: ${ }^{*} \rho<0.05 ;{ }^{* *} \rho<0.01 ;{ }^{* *} \rho<0.001$

Taula 2

Consum de Cànnabis

\begin{tabular}{|l|l|c|c|c|c|}
\hline \multicolumn{2}{|l|}{} & $\mathrm{R}^{2}$ & $\Delta \mathrm{R}^{2}$ & $\beta$ & $t$ \\
\hline 1 & Edat & \multirow{2}{*}{, 031} &, 031 &, 176 & $3,51^{* * *}$ \\
\cline { 2 - 4 } & Gènere & & &,- 001 &,- 020 \\
\hline 2 & Paga (Z) &, 033 &, 002 &, 045 &, 872 \\
\hline 3 & Amics (Z) &, 177 &, 144 &, 386 & $8,17^{* * *}$ \\
\hline 4 & Paga (Z)Amics (Z) &, 186 &, 010 &, 101 & $2,13^{*}$ \\
\hline
\end{tabular}

Nota: ${ }^{*} \rho<0.05 ;{ }^{* *} \rho<0.01 ;{ }^{* \star *} \rho<0.001$ 
Es van crear gràfiques per a interpretar aquestes interaccions. Les variables independents es van dicotomitzar per damunt i per davall de la mitjana. Aquells estudiants amb una quantitat més elevada de paga setmanal i més amics antinormatius consumien una quantitat significativament més alta d'alcohol (veure Figura 1). La variable que explicava un increment significatiu en el consum de cànnabis era una quantitat més gran d'amics antinormatius (veure Figura 2).

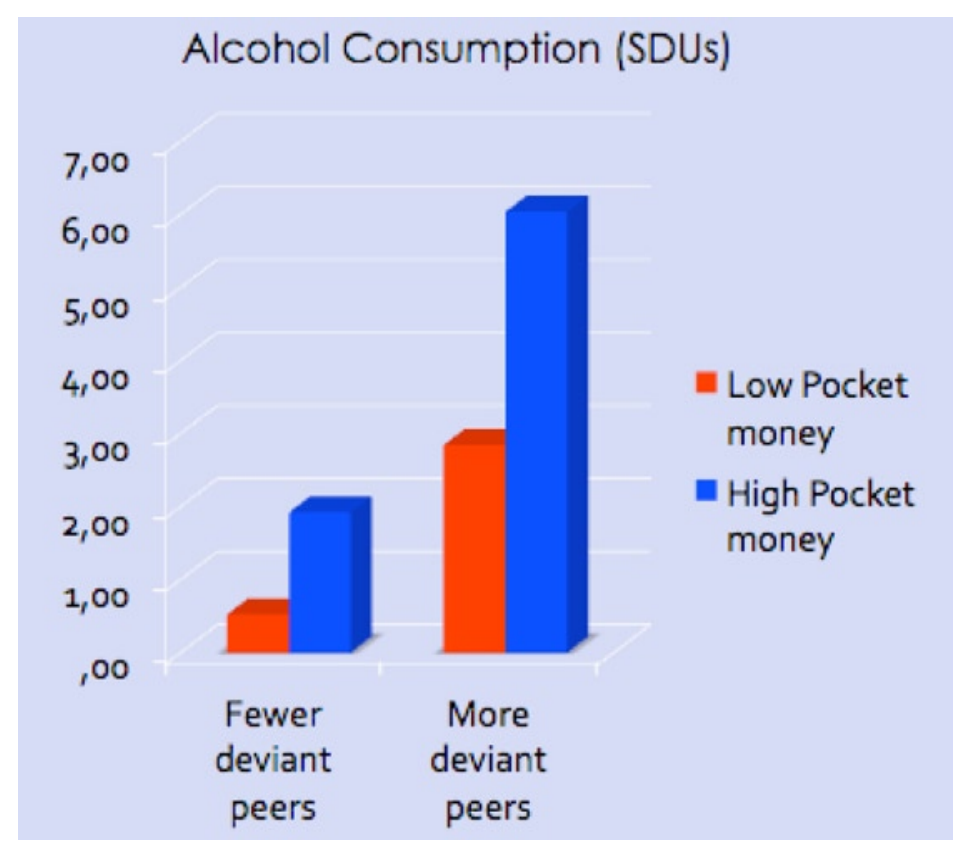

Figura 1. Consum d'Alcohol total en Unitats de Consum Estàndard (SDUs en Anglès)

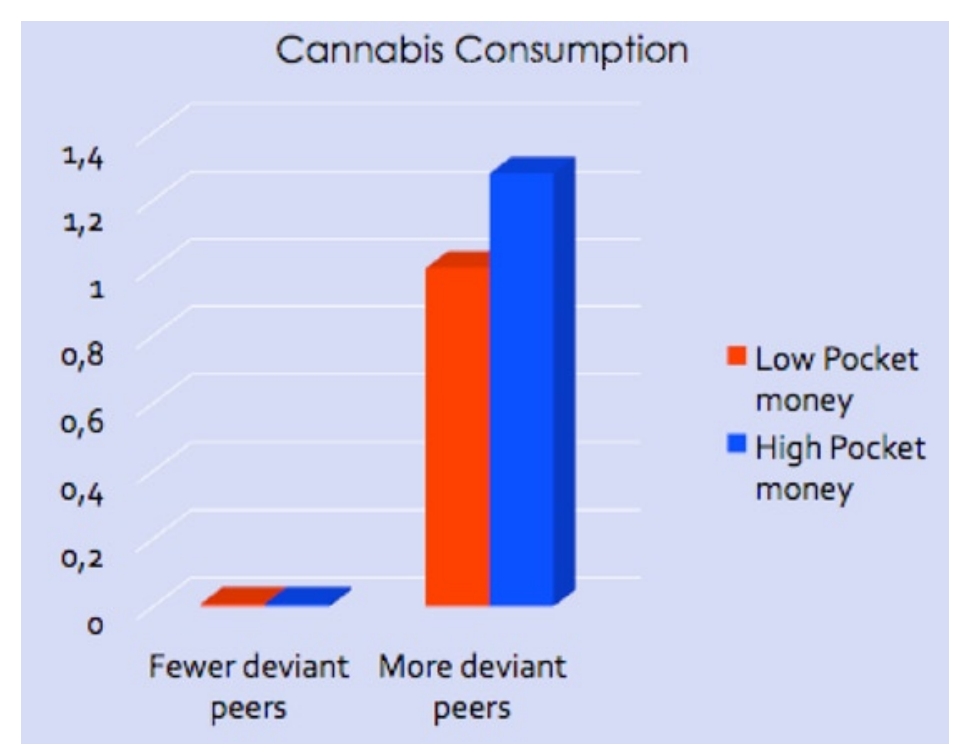

Figura 2. Consum de Cànnabis total en quantitat de porros 


\section{Discussió i conclusions}

Aquests resultats van mostrar, com es predia, la importància de tenir amics socialment antinormatius quan es tracta del consum de substàncies per part dels adolescents. D'acord amb estudis previs, la paga setmanal també va presentar un efecte menut però significatiu en la predicció de l'ús d'alcohol. El resultat més rellevant, no obstant, és l'efecte sinèrgic entre els amics i la paga: aquells adolescents que tenien més amics antinormatius i més paga setmanal, tenien el consum més alt d'alcohol i cànnabis.

Aquests resultats podrien contribuir al desenvolupament de programes de prevenció i intervenció més efectives a través de l'enfocament sobre l'ambient familiar i el grup d'amics. Així, programes de prevenció i intervenció en l'àmbit familiar que se centren en afavorir estils educatius menys permissius i amb una major monitorització del comportament dels fills, especialment en relació al grup d'amics, juntament amb un major control en la quantitat i ús de l'assignació setmanal, podrien esdevindre especialment eficaços.

Futurs estudis haurien d'incloure no només els factors socials i ambientals rellevants en l'estudi de l'ús de substàncies (com en aquest estudi), però també tenir en compte altres variables biopsicosocials tals com els trets de personalitat per a una descripció més ampla i refinada dels factors subjacents a l'ús d'alcohol i altres drogues.

\section{Referències}

Bellis, M. A., Hughes, K., Morleo, M., Tocque, K., Hughes, S., Allen, T., Harrison, D. \& FeRodriguez, E. (2007). Predictors of risky alcohol consumption in schoolchildren and their implications for preventing alcohol-related harm. Substance Abuse Treatment, Prevention, and Policy, 2, 15.

Borsari, B. \& Carey, K. B. (2001). Peer influences on college drinking: A review of the research. Journal of Substance Abuse, 13(4), 391-424.

Clark, D. B. \& Bukstein, O. G. (1998). Psychopathology in adolescent alcohol abuse and dependence, Alcohol Research \& Health, 22(2), 117-121.

Cooper, M. L., Agocha, V. B. \& Sheldon, M. S. (2000). A motivational perspective on risky behaviors: the role of personality and affect regulatory processes. Journal of Personality, 68(6), 1059-1088.

Gore, F. M., Patton, G. C., Ferguson, J., Joseph, V., Coffey, C., Sawyer, S. M. \& Mathers, C. D. (2011). Global burden of disease in young people aged 10-24 years: a systematic analysis. The Lancet, 377(9873), 2093-2102.

Hall, W. \& Degenhardt, L. (2009). Adverse health effects of non-medical cannabis use. The Lancet, 375(9710), 1383-1391.

Llorens, N., Barrio, G., Sánchez, A. \& Suelves, J.M. (2011). Effects of socialization and family factors on adolescent excessive drinking in Spain. Prevention Science, 12(2), 150-161.

McCrystal, P., Percy, A. \& Higgins, K. (2007). The cost of drug use in adolescence: Young people, money and substance abuse. Drugs: Education, Prevention, and Policy, 14(1), 49-68.

Varela Mallou, J., Marsillas Rascado, S., Isorna Folgar, M. \& Rial Boubeta, A. (2013). Attitudes, perceptions and available money explaining drug consumption in adolescents. Health and Addictions, 13(1), 67-78.

Wagner, F. \& Anthony, J. (2002). From first drug use to drug dependence: Developmental periods of risk for dependence upon marijuana, cocaine and alcohol. Neuropsychopharmacology, 26(4), 479-488. 



\title{
Programa de tratamiento integrativo para la fibromialgia: estudio preliminar
}

\author{
AMANDA DÍAZ-GARCÍA \\ amdiaz@uji.es \\ GuAdALUPE MOLINARI \\ molinari@uji.es \\ ADRIANA MIRA \\ miraa@uji.es \\ MACARENA ESPINOZA \\ macaespinoza@gmail.com \\ AZUCENA GaRcía-Palacios \\ azucena@uji.es
}

\section{Resumen}

Uno de los síndromes de dolor crónico más prevalente en la consulta hospitalaria y ambulatoria de reumatología es la fibromialgia (FM). Los programas de tratamiento psicológicos actuales que se han desarrollado para los pacientes que sufren FM están basados en la Terapia Cognitivo Conductual (TCC). Muchos de estos tratamientos han mostrado eficacia de forma aislada en estudios empíricos en entornos de laboratorio. Por esto, es necesario probar la eficacia de estos programas de tratamiento en entornos naturales como es el caso de una Unidad de Salud Mental (USM). Para el presente estudio se ha desarrollado un programa de intervención, aplicado en una USM, dirigido no sólo a la reducción del dolor sino también a dotar al paciente de herramientas para lograr una mejor aceptación del mismo, aumentar sus emociones positivas y su calidad de vida, afrontando así de mejor manera el problema del dolor.

Se realizó un estudio piloto con el fin de valorar la eficacia preliminar de un programa de tratamiento psicológico que integra técnicas de la TCC junto con herramientas de psicología positiva, aceptación, mindfulness e hipnosis (que han mostrado evidencia en el tratamiento del dolor crónico). En el estudio participaron 5 pacientes (4 mujeres y 1 hombre) que recibieron dicho programa en 8 sesiones. Los resultados en el post-tratamiento indicaron que los pacientes aumentaron de manera significativa sus niveles de aceptación del dolor, auto-compasión y calidad de vida. Se observa también una mejora en el estado de ánimo acompañada de una reducción en la interferencia del dolor.

Nuestro trabajo aporta datos preliminares que apoyan la utilidad de incluir nuevos componentes a la hora de abordar la FM.

Palabras clave: dolor crónico, fibromialgia (FM), Terapia Cognitivo Conductual (TCC), Aceptación, Hipnosis. 


\section{Abstract}

One of the most prevalent chronic pain syndromes in the hospital and outpatient rheumatology clinic is fibromyalgia (FM). The current psychological treatment programs that have been developed for patients suffering from FM are based on Cognitive Behavioral Therapy (CBT). Many of these treatments have shown efficacy in isolation in empirical studies in laboratory settings. Therefore, it is necessary to test the effectiveness of these treatment programs in natural settings such as a Mental Health Unit (USM). For the present study, an intervention program has been developed, applied at a USM, aimed not only at reducing pain but also at providing the patient with tools to achieve better acceptance of it, increase their positive emotions and their quality of life, therefore addressing better the problem of pain.

A pilot study was conducted to assess the preliminary efficacy of a psychological treatment program that integrates CBT techniques along with positive psychology, acceptance, mindfulness and hypnosis tools (which have shown evidence in the treatment of chronic pain). The study involved 5 patients ( 4 women and 1 man) who received an 8 session program. Post- treatment results indicate that patients significantly increased their levels of pain acceptance, self-pity, and quality of life. There is also an improvement in mood accompanied by a reduction in pain interference.

Our work provides preliminary data that support the usefulness of including new components when addressing FM.

Key Words: Chronic pain, fibromyalgia (FM), Cognitive Behavioral Therapy (CBT), Acceptance, Hypnosis.

\section{Introducción}

La Fibromialgia (FM) se define como un síndrome de dolor crónico de etiología desconocida (Wolfe y cols., 2011) que se caracteriza por dolor musculoesquelético generalizado acompañado de otros síntomas como la fatiga intensa o las alteraciones del sueño (Bennett, Jones, Turk, Russell, y Matallana, 2007). Así mismo, los pacientes con FM, pueden presentar otras manifestaciones clínicas comunes como la rigidez articular, cefaleas tensionales, parestesias en extremidades o sensación de hinchazón o tumefacción en las manos (Alegre de Miquel, 2006). Esta heterogeneidad de síntomas suele coexistir también con trastornos cognitivos o con la comorbilidad de trastornos del estado de ánimo y trastornos de ansiedad (Fietta, 2004).

La FM constituye un importante problema de salud pública, con una prevalencia que oscila entre el 2 y el $4 \%$ en la población general (Mease, 2005) y es considerada como uno de los síndromes de dolor crónico más prevalentes en la consulta hospitalaria y ambulatoria de reumatología (Nampiaparampil y Shmerling, 2004). En España, la FM afecta al $2.4 \%$ de la población general mayor de 20 años, siendo más frecuente en mujeres (4.2\%) que en hombres $(0.2 \%)$, lo que supone una relación mujer:varón de 21:1 (Mas, Carmona, Valverde, y Ribas, 2008). Además, la FM está asociada con frecuentes repercusiones laborales, resultando en una alta carga tanto económica como social (Spaeth, 2009).

En la actualidad no se conocen con precisión las causas de la FM aunque existen numerosos estudios que han investigado sobre los posibles mecanismos patogénicos que actúan en esta enfermedad. Algunos de estos estudios muestran la existencia de una alteración en 
los mecanismos de procesamiento del dolor debido a posibles desequilibrios en los neuromoduladores del sistema nervioso central (Crofford, 2005), lo que conlleva a que estos pacientes tengan un umbral más bajo hacia el dolor (Price y Staud, 2005).

Los criterios diagnósticos de la FM se establecieron inicialmente en 1990 (Wolfe y cols., 1990) y señalaban una historia de dolor generalizado de más de 3 meses de duración así como múltiples puntos sensibles al dolor (al menos 11 de 18 puntos simétricos: occipital, cervical bajo, trapecio, supraespinoso, segundo espacio intercostal en la unión costocondral, epicóndilo, glúteo, trocánter mayor y rodilla). Actualmente, estos criterios se han modificado y se han propuesto para su diagnóstico el Índice de dolor generalizado (Widespread Pain Index; WPI) y una Escala de gravedad de síntomas (Symptom Severity Score; SS-Score) (Wolfe y cols., 2011), los cuales se basan en la valoración de los principales síntomas y en la información aportada por parte de los pacientes.

Debido a toda la complejidad de síntomas y manifestaciones, el tratamiento interdisciplinario y multicomponente se ha considerado como el tratamiento de elección para la FM, con el objetivo de mejorar la sintomatología del paciente, proporcionar un cuidado de carácter integral y mejorar, en definitiva, la calidad de vida de estas personas (Otis, 2013). Por esta razón, los mayores beneficios en el tratamiento de las personas que sufren FM se logra cuando se combinan diferentes enfoques y tratamientos con un abordaje amplio de profesionales como médicos, especialistas, terapeutas físicos y psicólogos (Gatchel, Peng, Peters, Fuchs, y Turk, 2007). El tratamiento interdisciplinar incluye el tratamiento farmacológico para disminuir el dolor y mejorar el sueño, programas de ejercicio físico moderado para estirar los músculos y mejorar la capacidad cardiovascular y tratamiento psicológico, el cual se aplica a través de una fase educacional (informando al paciente sobre la naturaleza del trastorno), una fase de adquisición de habilidades (mediante el aumento de actividades significativas, técnicas de relajación para aliviar la tensión muscular y la ansiedad, técnicas de solución de problemas, estrategias de afrontamiento comportamental para hacer frente al dolor, etc.) y una fase de puesta en práctica en la que el paciente aplica todo lo aprendido para manejar los síntomas del dolor (Alegre de Miquel, 2006).

Como se ha mencionado anteriormente, dentro de esta perspectiva multidisciplinar, los programas psicológicos juegan un papel fundamental y prometedor para el tratamiento de la FM. En concreto, la Terapia Cognitivo Conductual (TCC) ha demostrado ser eficaz en la reducción del dolor y la fatiga, así como en el alivio del malestar emocional o la mejora del bienestar (Friedberg y Jason, 2001). La TCC tiene como objetivo la modificación de los esquemas de pensamiento y emociones desadaptativos así como de las emociones negativas y repertorios de afrontamiento que el individuo posee para manejar el dolor (Sullivan, Feuerstein, Gatchel, Linton, y Pransky, 2005). En un importante meta-análisis realizado para comprobar la eficacia de los tratamientos psicológicos en la FM (Glombiewski y cols., 2010) se obtuvo que la TCC se asoció con los mayores tamaños del efecto. Los autores concluyeron que la TCC fue significativamente mejor que otros tratamientos psicológicos en la reducción del dolor en la FM tanto a corto como a largo plazo, aunque continúan señalando la necesidad de realizar más estudios de eficacia ya que existen relativamente pocos estudios en el campo de los tratamientos psicológicos para la FM.

Pese a la evidencia mostrada de la TCC para la FM, muchos de estos tratamientos han probado eficacia de forma aislada en estudios empíricos, generalmente en entornos de laboratorio y no suelen ser instaurados en los servicios de atención médica. Por esta razón, es necesario poner a prueba la eficacia de estos programas de tratamiento en entornos más naturales como es el caso de una Unidad de Salud Mental (USM), en el que los pacientes acuden derivados por los servicios de atención primaria. 
Por otro lado, en los últimos años se ha enfatizado la incorporación de otras herramientas psicológicas novedosas que, junto con las técnicas de la TCC, han demostrado ser eficaces en el tratamiento de personas que sufren FM, como es el caso de la hipnosis, la aceptación o el mindfulness (Moix y Casado, 2011).

Para el presente estudio se ha desarrollado un programa de intervención psicológico, aplicado en una USM, dirigido no sólo a la reducción del dolor sino también a dotar al paciente de herramientas para lograr una mejor aceptación del mismo, aumentar sus emociones positivas y su calidad de vida, afrontando así de mejor manera el problema del dolor.

El principal objetivo de este estudio piloto es describir el programa de tratamiento y mostrar datos preliminares de los pacientes que participaron en dicha intervención. La hipótesis marcada es que a través de esta intervención se producirá una reducción significativa en las variables clínicas medidas, mostrando con ello la importancia de implantar un programa basado en TCC, pero incluyendo otras herramientas psicológicas eficaces para la FM, en una USM y desde un abordaje multidisciplinar.

\section{Método}

\section{Participantes}

La muestra estuvo compuesta por 5 pacientes (4 mujeres y 1 hombre) con diagnóstico de FM, de entre 39 y 67 años de edad. La media de edad era de 50,80 años (DT=10,50). La mayoría de los participantes estaban casados $(n=4 ; 80 \%)$ y sólo un participante era viudo ( $n$ $=1 ; 20 \%$ ). En cuanto al nivel de estudios, un participante tenía menos de 8 años de estudios $(20 \%)$, otro participante tenía un nivel de estudios primarios $(20 \%)$ y el resto presentaba nivel de estudios superiores $(n=3 ; 60 \%)$.

Entre los criterios de inclusión para recibir dicho tratamiento se encontraban: a) tener entre 18-70 años; b) tener diagnóstico de FM por un reumatólogo de acuerdo con los criterios del Colegio Americano de Reumatología (Wolfe y cols., 2011); c) no padecer esquizofrenia, trastorno bipolar, discapacidad intelectual y/o abuso/dependencia de sustancias.

\section{Instrumentos de evaluación}

Escala de Medida de la Autocompasión (Self-Compasion Scale, SCS; Neff, 2016). Se trata de una escala que cuenta con dos versiones, una larga de 26 ítems y una corta de 12 ítems. La escala fue desarrollada para representar explícitamente los pensamientos, emociones y comportamientos asociados con los diversos componentes de la autocompasión. Las respuestas se dan en una escala de 5 puntos donde 1 es "casi nunca» y 5 "casi siempre». Existe una amplia evidencia de la fiabilidad y validez de esta escala así como alta consistencia interna (Allen, Goldwasser, y Leary, 2012).

Cuestionario de Aceptación del Dolor (Chronic Pain Acceptance Questionnaire, CPA; McCracken, Vowles, y Eccleston, 2004; versión española: Menéndez, García, y Viejo, 2010). Consta de 20 ítems que evalúan la aceptación del dolor en personas que sufren dolor crónico. Con este cuestionario se obtienen tres puntuaciones: una total, y otras dos subescalas (implicación en las actividades (IA) y apertura al dolor (AD). Estas subescalas han mostrado datos de consistencia interna hallados mediante el alpha de Cronbach (Cronbach, 1951) de .82 para la primera y .78 para la segunda. 
Índice de Calidad de Vida (Quality of Lifelndex, QLI; Mezzich y cols., 2000). Se trata de un autoinforme que mide el nivel de calidad de vida percibido por el paciente en la actualidad. Consta de 10 de ítems con formato de respuesta de opción múltiple tipo Likert en una escala que puntúa de 1 («malo») a 10 («excelente»). Cuenta con buenas propiedades psicométricas (Mezzich y cols., 2000).

Inventario de Depresión de Beck (Inventory on Beck's depression, BDI-II; versión española: Sanz, Navarro, y Vázquez, 2003). Instrumento de autoinforme diseñado para evaluar la gravedad de la sintomatología depresiva. Consta de 21 ítems cada una con cuatro alternativas ordenadas de menor a mayor gravedad (de 0 a 3). Este cuestionario ha mostrado tener buenas propiedades psicométricas con una elevada consistencia interna (coeficiente de alfa de .89) (Sanz y cols., 2003).

Cuestionario de Impacto de la Fibromialgia (Fibromyalgia Impact Questionnaire, FIQ; Burckhardt, Clark, y Bennett, 1991; versión española: (Esteve-Vives, Rivera, Salvat, de Gracia, y Alegre, 2007). Es una de las medidas de autoinforme más utilizadas en el estudio de la FM. Consta de 10 preguntas medidas en una escala tipo Likert de 0 («siempre») a 3 («nunca») y que evalúan: la capacidad de realizar ciertas tareas, el número de días que se sintió bien y el número de días que no pudo realizar el trabajo, la interferencia del dolor, la fatiga, el cansancio por la mañana, la rigidez, la ansiedad y la depresión. Es un instrumento ampliamente validado (Bennett, 2005).

\section{Procedimiento}

Los participantes del estudio eran usuarios de la USM del Centro de Salud de Rafalafena de Castellón. Todos ellos fueron derivados por sus propios psiquiatras tras haberse considerado su inclusión en el estudio de tratamiento psicológico y su posible beneficio del mismo. Tras la explicación del curso del tratamiento, cada uno de ellos firmó un consentimiento informado donde mostraban acuerdo y conformidad con el programa de tratamiento en el que iban a participar. Los participantes formaron finalmente un grupo de tratamiento de 5 pacientes y contaban con dos terapeutas (terapeuta principal y co-terapeuta) que preparaban y aplicaban el tratamiento cada semana. El protocolo de evaluación se aplicó durante el pre-tratamiento y el post-tratamiento, donde los participantes cumplimentaban todos los autoinformes relacionados con el dolor y con el estado de ánimo.

El tratamiento psicológico grupal se desarrolló en colaboración con el Grupo de Investigación LabPsiTec del Departamento de Psicología Básica, Clínica y Psicobiología de la Universitat Jaume I de Castellón.

\section{Tratamiento}

Se trata de un programa de tratamiento psicológico que integra técnicas de la TCC junto con herramientas de psicología positiva, aceptación, mindfulness e hipnosis, las cuales han mostrado evidencia en el tratamiento del dolor crónico (Moix y cols., 2011). El programa se desarrolló en 8 sesiones semanales de una duración aproximada de 2 horas y aplicadas en formato grupal. Cada una de las sesiones se llevó a cabo en la sala de preparación al parto de la USM de Rafalafena, la cual reunía todas las necesidades requeridas en cada sesión. Una descripción más detallada de este tratamiento multicomponente puede observarse en la tabla 1. 
Tabla 1

Componentes terapéuticos del programa

\begin{tabular}{ll}
\hline Componentes & Objetivos \\
\hline Psicoeducación & Explicación de la enfermedad teniendo en cuenta \\
& aspectos médicos, psicológicos y sociales relacionados. \\
& Explicación de las normas de la terapia grupal y de la \\
& base lógica del tratamiento. \\
\hline Aceptación radical & Reconocimiento de las propias limitaciones físicas y \\
& cambios de hábitos. Aprender a estar en contacto con la \\
& propia experiencia, incluso cuando ésta no es agradable, \\
& y aceptarla tal y como es. Aceptación de mi nuevo «yo». \\
\hline Auto-hipnosis & Reducción de la tensión muscular, los problemas de \\
& sueño, el estrés emocional, etc., a través de diferentes \\
& técnicas de relajación. \\
\hline Programación de actividades & Aumentar el número e intensidad de emociones positivas \\
& a través de un nivel de actividad adecuado para afrontar \\
el dolor. Realizar actividades significativas para el \\
individuo.
\end{tabular}

\section{Resultados}

En la Tabla 2 se muestran las medias, desviaciones típicas y la significación estadística de todas las variables clínicas. Los cambios tras la intervención se midieron a través de la prueba no paramétrica de los signos de Wilcoxon para la comparación entre las variables medidas en el pre-tratamiento y en el post-tratamiento. 
Tabla 2

Efectos de la intervención en las distintas variables clínicas

\begin{tabular}{lllllll}
\hline \multirow{2}{*}{ VARIABLE } & \multicolumn{2}{c}{ Pre } & \multicolumn{5}{c}{ Post } & \multirow{2}{*}{ Z } & \multirow{2}{*}{ N } \\
\cline { 2 - 5 } & Media & DT & Media & DT & \\
\hline SCS & 2,25 & 0,63 & 3,20 & 0,45 & $-2,03$ & $0,04^{*}$ \\
\hline CPAQ & 39,40 & 21,65 & 55,20 & 10,57 & $-2,02$ & $0,04^{*}$ \\
\hline QLI & 4,48 & 1,79 & 6,04 & 1,47 & $-2,04$ & $0,04^{*}$ \\
\hline BDI-II & 30,83 & 9,79 & 20,40 & 9,96 & $-1,76$ & 0,08 \\
\hline FIQ & 78,70 & 7,33 & 69,95 & 23,70 & $-0,99$ & 0,35 \\
\hline
\end{tabular}

Nota. $\mathrm{M}=$ media; $\mathrm{DT}$ = desviación típica; Pre = Pre-tratamiento; Post= Post- tratamiento; $\mathrm{SCS}=$ Self Compasssion Scale; $\mathrm{CPAQ=}$ Chronic Pain Acceptance Questionnaire; QLI= Quality of Life Index; BDI-II= Inventory on Beck's depression; FIQ= Fibromyalgia Impact Questionnaire.

Como muestran los resultados, pueden observarse diferencias estadísticamente significativas del pre-tratamiento al post-tratamiento en las variables señaladas $\left(^{*}\right)(p<0.05)$. Esto demuestra que los pacientes aumentaron de manera significativa sus niveles de aceptación del dolor, de auto-compasión y sus niveles de calidad de vida tras la intervención. Así mismo, los resultados obtenidos se encaminan en la dirección de lo esperado observándose también mejoras en el estado de ánimo acompañada de una reducción en la interferencia del dolor, aunque éstas no llegan a ser estadísticamente significativas.

\section{Discusión y conclusiones}

El objetivo de este estudio piloto fue describir un programa de tratamiento novedoso para la FM que integra distintas técnicas psicológicas que han mostrado ser eficaces y presentar datos preliminares de un grupo de pacientes que participaron en dicha intervención.

Teniendo en cuenta la hipótesis planteada al comienzo del estudio, podemos decir que contamos con evidencia preliminar a su favor. Los resultados mostraron que a través de esta intervención se produjo un aumento significativo en los niveles de aceptación del dolor, calidad de vida y auto-compasión. Esto es importante ya que se observan cambios que podrían estar vinculados justamente a aquellos módulos de tratamiento más novedosos, como son el de aceptación radical y de autocompasión, que parecen haber producido cambios significativos en dichas variables. La aceptación del dolor no sólo ha sido estudiada en estudios previos como una importante variable de resultado, sino que también se ha encontrado que es un importante mecanismo de cambio para alcanzar la reducción sintomática en pacientes con FM (Luciano y cols., 2014). En cuanto a la auto-compasión, estudios previos han demostrado la relación entre esta variable y las variaciones en el dolor musculoesquelético (Wren y cols., 2012), sin embargo esta relación no había sido estudiada previamente en pacientes con FM. 
Si bien en el presente estudio no es posible aislar el efecto diferencial de cada uno de los componentes de tratamiento, los cambios en estas variables resultan prometedores. Además, si bien los cambios no fueron estadísticamente significativos, encontramos reducciones en la interferencia producida por el dolor y un aumento en el estado de ánimo.

En cuanto a las limitaciones del presente estudio, es preciso destacar que se trata de un estudio piloto, con un número reducido de participantes, de manera que los resultados deben tomarse con precaución. Además, como se mencionaba anteriormente, con el presente diseño no fue posible aislar los efectos de cada uno de los componentes. Es necesario que futuros estudios pongan a prueba este protocolo de tratamiento en un estudio controlado e incorporando medidas de evaluación que sean capaces de identificar módulo a módulo los cambios alcanzados por los pacientes. En este sentido, en el futuro sería interesante a llevar a cabo estudios con un diseño de desmantelamiento (Papa, Follette, Papa, y Follette, 2015). Este diseño tiene como objetivo investigar terapias que tienen múltiples componentes con el fin de identificar las características de la terapia que son los mecanismos activos de cambio o identificar el grado en que los componentes específicos aumentan la magnitud del cambio atribuible a otros componentes (Papa y cols., 2015).

Por todo lo dicho anteriormente, es posible decir que este programa de tratamiento integrativo (basado en TCC pero que incluye otras herramientas psicológicas eficaces para la FM) no sólo es viable de implementar en una USM desde un abordaje multidisciplinar, sino que además ha demostrado su eficacia preliminar a la hora de promover mejoras significativas en la calidad de vida de personas con FM.

\section{Referencias bibliográficas}

Alegre de Miquel, C. (2006). I Simposio de Dolor en Reumatología. Reumatología Clínica, 2(1), $55-66$.

Allen, A. B., Goldwasser, E. R. y Leary, M. R. (2012). Self-compassion and Well-being among Older Adults. Self and Identity, 11(4), 428-453.

Bennett, R. (2005). The Fibromyalgia Impact Questionnaire (FIQ): A review of its development, current version, operating characteristics and uses. Clinical and Experimental Rheumatology, 23(5 SUPPL. 39), S154-62.

Bennett, R. M., Jones, J., Turk, D. C., Russell, I. J. y Matallana, L. (2007). An internet survey of 2,596 people with fibromyalgia. BMC Musculoskeletal Disorders, 8, 27.

Burckhardt, C. S., Clark, S. R. y Bennett, R. M. (1991). The fibromyalgia impact questionnaire: development and validation. The Journal of Rheumatology, 18(5), 728-33.

Crofford, L. J. (2005). The relationship of fibromyalgia to neuropathic pain syndromes. The Journal of Rheumatology Supplement, 75.

Cronbach, L. J. (1951). Coefficient alpha and the internal structure of tests. Psychometrika, 16(3), 297-334.

Esteve-Vives, J., Rivera Redondo, J., Isabel Salvat Salvat, M., de Gracia Blanco, M. y de Miquel, C. A. (2007). Propuesta de una versión de consenso del Fibromyalgia Impact Questionnaire (FIQ) para la población española. Reumatología Clínica, 3(1), 21-24.

Fietta, P. (2004). Fibromyalgia: state of the art. Minerva Medica, 95(1), 35-47, 47-52.

Friedberg, F. y Jason, L. A. (2001). Chronic fatigue syndrome and fibromyalgia: clinical assessment and treatment. Journal of Clinical Psychology, 57(4), 433-55.

Gatchel, R. J., Peng, Y. B., Peters, M. L., Fuchs, P. N. y Turk, D. C. (2007). The biopsychosocial approach to chronic pain: Scientific advances and future directions. Psychological Bulletin, 133(4), 581-624. 
Glombiewski, J. A., Sawyer, A. T., Gutermann, J., Koenig, K., Rief, W. y Hofmann, S. G. (2010). Psychological treatments for fibromyalgia: A meta-analysis. Pain, 151(2), 280-295.

Luciano, J. V., Guallar, J. A., Aguado, J., López-del-Hoyo, Y., Olivan, B., Magallón, R., ... Garcia-Campayo, J. (2014). Effectiveness of group acceptance and commitment therapy for fibromyalgia: A 6-month randomized controlled trial (EFFIGACT study). PAIN®, 155(4), 693-702.

Mas, A. J., Carmona, L., Valverde, M. y Ribas, B. (2008). Prevalence and impact of fibromyalgia on function and quality of life in individuals from the general population: results from a nationwide study in Spain. Clinical and Experimental Rheumatology, 26(4), 519-26.

McCracken, L. M., Vowles, K. E. y Eccleston, C. (2004). Acceptance of chronic pain: component analysis and a revised assessment method. Pain, 107(1-2), 159-66.

Mease, P. (2005). Fibromyalgia syndrome: review of clinical presentation, pathogenesis, outcome measures, and treatment. The Journal of Rheumatology. Supplement, 75, 6-21.

Menéndez, A. G., García, P. F. y Viejo, I. T. (2010). Aceptación del dolor crónico en pacientes con fibromialgia: adaptación del Chronic Pain Acceptance Questionnaire(CPAQ) a una muestra española. Psicothema, 22(4), 997-1003.

Mezzich, J. E., Ruipérez, M. A., Pérez, C., Yoon, G., Liu, J. y Mahmud, S. (2000). The Spanish version of the quality of life index: presentation and validation. The Journal of Nervous and Mental Disease, 188(5), 301-5.

Moix, J., Casado, I. y Del Manual Del Dolor, C. (2011). Terapias Psicológicas para el Tratamiento del Dolor Crónico Psychological Therapies to Treat Chronic Pain. Clínica Y Salud, 22(1), 41-50.

Nampiaparampil, D. E., y Shmerling, R. H. (2004). A review of fibromyalgia. The American Journal of Managed Care, 10(11 Pt 1), 794-800.

Neff, K. D. (2016). The Self-Compassion Scale is a Valid and Theoretically Coherent Measure of Self-Compassion. Mindfulness, 7(1), 264-274.

Otis, J. D. (2013). Flor, H., \&amp; Turk, D. C. (2011)Chronic Pain: An Integrated Biobehavioral Approach Seattle: IASP Press. Cognitive and Behavioral Practice.

Papa, A., Follette, W. C., Papa, A. y Follette, W. C. (2015). Dismantling Studies of Psychotherapy. In The Encyclopedia of Clinical Psychology (pp. 1-6). Hoboken, NJ, USA: John Wiley \& Sons, Inc.

Price, D. D. y Staud, R. (2005). Neurobiology of fibromyalgia syndrome. The Journal of Rheumatology Supplement, 75.

Sanz Fernández, J., Navarro, M. E. y Vázquez Valverde, C. (2003). Adaptación española del Inventario para la Depresión de Beck-II (BDI-II): propiedades psicométricas en estudiantes universitarios. Análisis Y Modificación de Conducta, ISSN-E 0211-7339, Vol. 29, No. 124, 2003, Págs. 239-288, 29(124), 239-288.

Spaeth, M. (2009). Epidemiology, costs, and the economic burden of fibromyalgia. Arthritis Research \& Therapy, 11(3), 117.

Sullivan, M. J., Feuerstein, M., Gatchel, R., Linton, S. J. y Pransky, G. (2005). Integrating Psychosocial and Behavioral Interventions to Achieve Optimal Rehabilitation Outcomes. Journal of Occupational Rehabilitation, 15(4), 475-489.

Wolfe, F., Clauw, D. J., Fitzcharles, M. A., Goldenberg, D. L., Häuser, W., Katz, R. S., ...Winfield, J. B. (2011). Fibromyalgia criteria and severity scales for clinical and epidemiological studies: A modification of the ACR preliminary diagnostic criteria for fibromyalgia. Journal of Rheumatology, 38(6), 1113-1122.

Wolfe, F., Smythe, H. A., Yunus, M. B., Bennett, R. M., Bombardier, C., Goldenberg, D. L., ... Clark, P. (1990). The American College of Rheumatology 1990 Criteria for the Classifica- 
tion of Fibromyalgia. Report of the Multicenter CriteriaCommittee. Arthritis and Rheumatism, 33(2), 160-72.

Wren, A. A., Somers, T. J., Wright, M. A., Goetz, M. C., Leary, M. R., Fras, A. M., ... Keefe, F. J. (2012). Self-Compassion in Patients With Persistent Musculoskeletal Pain: Relationship of Self-Compassion to Adjustment to Persistent Pain. Journal of Pain and Symptom Management, 43(4), 759-770. 


\title{
Protocolo de actuación ante casos de acoso escolar: Una propuesta de intervención integral
}

\author{
REMEI MONZÓ HERVÁS \\ al260578@uji.es \\ SiLVIA CALERO VALENCIA \\ al263380@uji.es \\ AnA BelÉn GóRriz Plumed \\ gorriz@uji.es
}

\section{Resumen}

A pesar de la preocupación en los colegios en torno al acoso escolar, aún existen casos que necesitan atención. De hecho, según un estudio presentado por Save The Children, el 9,3\% de los niños en edad escolar en España sufrieron acoso en 2015. Estos niños sufren diariamente agresiones directas e indirectas provocadas por compañeros del mismo centro educativo, por lo que es necesaria la inmediata reacción por parte de los equipos directivos y docentes con el objeto de frenar este tipo de acciones. En este trabajo se recoge una propuesta global consistente en la creación de un programa de intervención en casos de acoso escolar para niños de entre 10 y 14 años. Todo ello se lleva a cabo a partir de los datos obtenidos de una comparativa de los protocolos de acoso y ciberacoso escolar de 12 de las Comunidades Autónomas españolas. El programa engloba a todas las partes implicadas: víctima, agresor, espectadores, ayudantes, animadores, defensores, padres y profesores. Éste mejoraría las relaciones interpersonales y el clima social del centro. Se propone un programa de intervención secundaria específico a aplicar en las situaciones de violencia con escolares implicados, el cual incluirá propuestas concretas para desarrollar en el aula para mejorar la calidad de la convivencia, tales como actividades, recursos y métodos de evaluación.

Palabras clave: Acoso escolar, protocolo de actuación, intervención global, relaciones interpersonales, ciberacoso.

\section{Abstract}

Besides of concern in schools about bullying, there are still many cases that need attention. In fact, according to one study made by Save the children Organization, in Spain a 9,3\% of kids in school age suffered bullying in 2015 Daily these kids have received direct and indirect aggressions incited by classmates of the same educative center. That is why is totally necessary that directors and teachers react against that to avoid this kind of reactions. This work collect a global purpose that consist in creation of a program of intervention in those cases of bullying for children between 10 and 14 years. This is elaborated from the comparative data of 12 Spanish Autonomous Communities» pro- 
tocols of bullying and cyberbullying. It englobes every involved part: victims, aggressor, viewers, helpers, animators, spectators, parents and teachers. That one would improve interpersonal relationships and the social climate of the center. It proposes a program about a specific secondary school intervention to be developed in violent situations. This one will include concrete proposals to develop in the classroom and improve the quality of the cohabitation, such as activities, resources and methods of evaluation.

Keywords: bullying, acting program, global intervention, interpersonal relationships, cyberbullying.

\section{Introducción}

Según Avilés (2006) el acoso es la intimidación y el maltrato entre iguales, de forma repetida y mantenida en el tiempo, con la intención de hacer daño y abusar a una víctima indefensa por parte de uno o más acosadores a través de agresiones físicas, verbales o sociales, resultando en victimización y rechazo. El acoso escolar o bullying suele implicar conductas de hostigamiento, burlas, amenazas, intimidación, insultos, aislamiento sistemático, etc.

En cuanto al término ciberbullying, hace referencia al acoso realizado a través de Internet $y$, en general, los dispositivos digitales de tan amplio uso por los adolescentes. Traspasa el espacio y el tiempo, facilita el ataca desde el anonimato, convirtiéndolo en un fenómeno con una alta prevalencia. Las conductas poco seguras en Internet, acompañadas de la falta de control parental, así como los programas como WhatsApp o similares son factores de riesgo fundamentales para este tipo de acoso (Casas, del Rey \& Ortega-Ruiz, 2013; Cerezo, 2009, 2012; Güemes, 2011; Garaigordobil, 2011; Ovejero, Smith \& Yubero, 2013; Schultze-Krumbholz \& Scheithauer, 2015).

Muchas son las definiciones al respecto de ambos conceptos (bullying y ciberbullying), aunque, respecto al bullying es importante considerar los principales indicadores para identificar lo que es y lo que no es acoso escolar. Según diversos autores (Avilés, 2006; Merayo, 2013; Olweus, 1993; Olweus \& Breivik, 2014; Salmivalli, 2010) estos son: conducta agresiva, que perdura en el tiempo, con intencionalidad de causar daño a la víctima y un desequilibrio de poder entre los implicados. Además, causa la indefensión de la víctima, son diversas las consecuencias negativas que conlleva y suele tener lugar sin provocación previa de la víctima.

Respecto a los perfiles de los participantes del acoso escolar, se solía centrar la atención en el o los que agreden y la víctima de las agresiones. Sin embargo, a raíz del trabajo de Salmivalli et al. (1996), han sido muchas las investigaciones que han discrepado de este modelo diádico para incorporar a otros roles que, de un modo u otro, están presentes o participan en este tipo de situaciones (Cerezo \& Ato, 2010; Olweus, 2001; Salmivalli \& Peets, 2010; Villanueva, Górriz, Andrés, Cuervo \& Adrián, 2009) Los roles implicados en el acoso escolar son: agresor, víctima, animador, el ayudante, defensor y espectadores (Trianes, Fernández \& Escobar, 2013).

Son diversas las investigaciones al respecto de la prevalencia de acoso escolar en las aulas. Según la organización Save The Children (2016), en una reciente publicación el 9,3\% de los niños en edad escolar en España sufrieron acoso en 2015. Además, en los datos aportados por el I Estudio sobre Acoso Escolar realizado por la Fundación ANAR y la Fundación Mutua Madrileña (2016), se observa que el $46 \%$ de los casos de acoso ocurridos en 2015 se dieron entre chicos y chicas de 11 a 13 años. Datos del mismo estudio revelan que más del $40 \%$ de 
los afectados sufren acoso durante un año o más, y el 70 \% lo padece a diario. Puede conllevar problemas psicológicos como ansiedad, tristeza, soledad, aislamiento, ideación o intento de suicidio, rabia, disminución del rendimiento escolar, dificultades de relación con compañeros y familia... El bullying es un problema que sigue a la orden del día y que produce dolor en aquel que lo sufre. Esto demuestra que, a pesar de la preocupación por los centros educativos y la población general por combatir el acoso escolar, este sigue sucediendo.

En el mismo sentido, datos de un estudio reciente del Ministerio de Educación, Cultura y Deporte (Arias, Martín \& Díaz-Aguado, 2013) revelan que, ante una agresión, el 80 \% de los alumnos dicen intervenir para detenerla o creen que deberían hacerlo, el $14 \%$ no interviene ni cree que debería y, por último, un $6 \%$ responde que participa de forma activa en la agresión. Es, por esta razón, que se considera importante intervenir con los alumnos que, aunque no estén involucrados directamente en el proceso de abuso, perpetúen de alguna manera el acoso hacia un compañero, y romper así la ley del silencio.

En España, desde la Constitución Española de 1978, la normativa genérica que establece cobertura legal en casos de acoso es el Real Decreto 732/1995, de 5 de mayo, en el que se establecen los Derechos y Deberes de los alumnos y las normas de convivencia en los centros educativos y se señala el carácter educativo y recuperador de las sanciones; el Código Penal (Ley Orgánica 10/1995, de 23 de noviembre, del Código Penal) o la Ley Orgánica reguladora de la Responsabilidad Penal del Menor (LORPM, 2006), entre otros.

Además de una normativa general, las respectivas Comunidades Autónomas Españolas (CCAA) han creado órganos de control, recogidos en decretos y resoluciones, para hacer frente a este fenómeno social. Y se ha fomentado la elaboración de Planes de Convivencia en los centros educativos, estableciendo en algunas de estas comunidades los protocolos de actuación e intervención ante supuestos de violencia escolar. Sin embargo, a día de hoy sigue sin existir en nuestro país una ley específica que los regule.

Por todo ello, el objetivo general de este estudio es describir y comparar los protocolos de actuación vigentes en las Comunidades Autónomas españolas en torno al acoso y al ciberacoso escolar -teniendo en cuenta que contemplen ambos componentes, si abordan medidas preventivas, de detección e intervención y correctivas, y agentes implicados-. Así, se tendrá una visión completa de las medidas propuestas al respecto por cada CCAA. Una vez analizados se elaborará un protocolo de actuación integral que recoja las principales propuestas de los anteriores protocolos.

\section{Método}

Tal y como se ha comentado, se han analizado diferentes protocolos de actuación de las CCAA con el fin de aunar en un mismo documento todas las fases usándolas como criterios de evaluación en la comparativa de protocolos. Se ha desarrollado a partir de 12 de las autonomías, aquellas que utilizan protocolos oficiales creados por sus respectivas Consejerías. El resto de CCAA no proponen protocolos o no los han hecho públicos. Los protocolos revisados pertenecen a las siguientes CCAA: Andalucía, Aragón, Asturias, Canarias, Cantabria, Castilla la mancha, Comunidad Valenciana, Extremadura, Galicia, Comunidad de Madrid, Murcia y País Vasco.

Este trabajo se ha llevado a cabo durante el curso académico 2016/17 a partir de una colaboración en una investigación sobre acoso escolar en el Dpto. Psicología Evolutiva y de la Educación, Social y Metodología de la Universitat Jaume I.

Los criterios y técnicas de análisis utilizados en la comparativa fueron: 
- Para determinar que los protocolos recogían los términos de acoso y ciberacoso, estos debían contener explícitamente dichos términos, y la intervención debía estar dirigida a ellos. También se tuvo en cuenta si el protocolo iba destinado a actuar sobre algún otro fenómeno como el sexting, grooming...

- Por otro lado, para concluir que el protocolo incluía la conceptualización del término "acoso» y/o "ciberacoso» debía reunir una definición concreta de los mismos, los tipos que pueden darse y/o los roles de los implicados.

- En cuanto al criterio del proceso de detección, se tuvo en cuenta si existía una evaluación, previa a la intervención, de la situación para conocer exactamente con qué problemáticas se debe trabajar.

- Las medidas de urgencia son aquellas que se toman inmediatamente después del conocimiento del caso de acoso, con el fin de proteger a la víctima.

- En el caso de los agentes implicados se tomó como factor favorable que recogiera un plan de intervención con la víctima, con el agresor, los seguidores, defensores y público, con el profesorado y con las familias de los implicados.

- Para señalar que el protocolo incluía medidas educativas, este debía tener especificado el uso de las mismas. La misma norma se utilizó en el caso de las medidas disciplinarias.

- Para determinar que el protocolo contenía un seguimiento, tanto del caso como de los afectados por el acoso, debía precisarlo en sus fases. «

- La evaluación debía definir pruebas ya existentes y/o una encuesta a los agentes implicados en la intervención para evaluar su efectividad.

- También se tenía en cuenta si se especificaba el uso de medidas de prevención, ya fueran primarias, secundarias o terciarias.

- Otro criterio fue la inclusión de documentación administrativa -informes, tablas de observación, comunicados, expedientes...- para facilitar la comunicación dentro del centro con la Administración y/o con las familias, así como para obtener información del estado de la situación.

- Por último, se considera si adjuntaban actividades específicas -tales como charlas, programas, métodos, terapias...- con el fin de proveer al orientador/a del centro con material adecuado para la intervención.

\section{Resultados}

Tras la revisión de los protocolos de las 12 Comunidades Autónomas se obtienen los siguientes datos expuestos en las Tablas 1 y 2 , los cuales se definen también a continuación.

El 91,67\% de los documentos tratan de manera directa el acoso. Sólo uno, Murcia, utiliza otros nombres para referirse a este tipo de abuso. El 50 \% incluye el término ciberacoso, y el $33,33 \%$ incluye términos como grooming, sexting y otros tipos de violencia las aulas. Es el caso de una de las Comunidades Autónomas que, en lugar de contener los términos principales, utiliza los protocolos AVE (Actuaciones ante Violencia Escolar) para los casos de violencia entre iguales.

El $75 \%$ de los protocolos abordan cómo se debe actuar en la detección del acoso. El mismo porcentaje explica qué medidas de urgencia deben tomarse cuando el abuso se ha detectado.

Con respecto a los agentes sobre los que se interviene, el 91,67 \% explica cómo intervenir sobre la víctima, el 87,33 \% da ejemplos de intervención sobre el agresor, y el 83,33\% propone intervención sobre seguidores, defensores y público. Por otro lado, el 58,33\% interviene sobre 
los profesores, mientras que el 8,33 \% sólo los nombra para explicar que hay que comunicarles la situación y explicarles cómo se abordará. Por último, el 58,33 \% propone intervención sobre las familias, mientras que el $33,33 \%$ sólo las nombra para explicar que hay que comunicarles la situación y explicarles cómo se abordará.

El 91,67 \% propone medidas educativas; sólo Extremadura propone medidas únicamente disciplinarias. El mismo porcentaje propone medidas disciplinarias; sólo Murcia propone medidas únicamente educativas.

El 66,67 \% propone medidas de prevención y seguimiento, mientras que el $25 \%$ sólo nombra que deben incluirse medidas de seguimiento. El 16,67 \% incluye evaluación del funcionamiento protocolo mediante instrumentos ya existentes.

El $75 \%$ incluye documentos como hojas de seguimiento, ejemplos de entrevistas, peticiones de atención, etc. Y el $25 \%$ incluye actividades específicas que se pueden llevar a cabo con los agentes implicados.

Tabla 1

Comparativa de protocolos de actuación en caso de acoso escolar de Comunidades Autónomas españolas (I)

\begin{tabular}{|c|c|c|c|c|c|c|c|c|c|c|c|}
\hline \multirow[t]{2}{*}{ CCAA } & \multicolumn{3}{|c|}{ QUÉ INCLUYE } & \multirow{2}{*}{$\begin{array}{l}\text { CONCEPTO } \\
\text { AcOSO } \\
\text { Descripción } \\
\text { Tipos } \\
\text { Roles }\end{array}$} & \multirow{2}{*}{$\begin{array}{c}\text { DETECCION } \\
\text { Evaluación } \\
\text { provia a la } \\
\text { intervención }\end{array}$} & \multirow{2}{*}{$\begin{array}{l}\text { MEDIDAS DE } \\
\text { URGENCIA } \\
\text { Medidas de } \\
\text { protección a la } \\
\text { victima }\end{array}$} & \multicolumn{5}{|c|}{ INTERVENCION-AGENTES IMPLICADOS } \\
\hline & $A \cos 0$ & $\begin{array}{l}\text { Ciber } \\
\text { acoso }\end{array}$ & Otros & & & & Victima & Agresor & $\begin{array}{c}\text { Seguidores } \\
\text { Defensores } \\
\text { Público }\end{array}$ & Profesorado & Familias \\
\hline Andalucia & $\mathrm{x}$ & & & $\mathrm{x}$ & & $\mathrm{x}$ & $x$ & $\mathrm{x}$ & $\mathrm{x}$ & $\mathrm{x}$ & $\mathrm{x} * *$ \\
\hline Aragón & $\mathrm{x}$ & & $x$ & & & $x$ & $x$ & $x$ & $x$ & & $\mathrm{x} * *$ \\
\hline Asturias & $x$ & & & $\mathrm{x}$ & $\mathrm{x}$ & & $x$ & $x$ & & & $\mathrm{x} \cdot *$ \\
\hline Canarias & $\mathrm{x}$ & & & $\mathrm{x}$ & $\mathrm{x}$ & $x$ & $\mathrm{x}$ & $x$ & $\mathrm{x}$ & 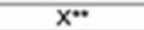 & $x *$ \\
\hline Cantabria & $\mathrm{x}$ & $x$ & & $\mathrm{x}$ & $\mathrm{x}$ & & $\mathrm{x}$ & $\mathrm{x}$ & $\mathrm{x}$ & $\mathrm{x}$ & $\mathrm{x}$ \\
\hline $\begin{array}{l}\text { Castilla la } \\
\text { Mancha }\end{array}$ & $x$ & & & $x$ & & $x$ & $\mathrm{x}$ & $\mathrm{x}$ & $\mathrm{x}$ & $\mathrm{x}$ & $x$ \\
\hline $\begin{array}{l}\text { Valenciana } \\
\text { Comunidad }\end{array}$ & $x$ & $x$ & & $x$ & $x$ & $x$ & $x$ & $\mathrm{x}$ & $\mathrm{x}$ & & $x$ \\
\hline Extremadura & $x$ & $\mathrm{x}$ & $x$ & $x$ & $\mathrm{x}$ & & & & & & \\
\hline Galicia & $\mathrm{x}$ & $x$ & & $\mathrm{x}$ & $\mathrm{x}$ & $x$ & $\mathrm{x}$ & $\mathrm{x}$ & $\mathrm{x}$ & $\mathrm{x}$ & $\mathrm{x}$ \\
\hline Madrid & $x$ & $x$ & $x$ & $x$ & $x^{*}$ & $x$ & $x$ & $x$ & $x$ & $x$ & $\mathrm{x}$ \\
\hline Murcia & & & $x$ & $x$ & $\mathrm{x}$ & $x$ & $x$ & & $\mathrm{x}$ & $x$ & $x$ \\
\hline Pais Vasco & $x$ & $\mathrm{x}$ & & $\mathrm{x}$ & $\mathrm{x}$ & $x$ & $\mathrm{x}$ & $\mathrm{x}$ & $\mathrm{x}$ & $\mathrm{x}$ & $\mathrm{x}$ \\
\hline
\end{tabular}

Así se concluye que los protocolos de actuación están especialmente completos en cuanto a definición del concepto de acoso $(91,67 \%)$, intervención con la víctima $(91,67 \%)$, el agresor $(87,33 \%)$ y los seguidores, defensores y público $(83,33 \%)$, y la propuesta de medidas educativas $(91,67 \%)$ y disciplinarias $(91,67 \%)$. Siendo principalmente necesarias mejoras en relación a la intervención con los padres (8,33\%) y la evaluación del protocolo (16,67 \%); además de incluir actividades específicas en los protocolos de intervención (25\%). 
Tabla 2

Comparativa de protocolos de actuación en caso de acoso escolar de Comunidades Autónomas españolas (II)

\begin{tabular}{|c|c|c|c|c|c|c|c|c|}
\hline \multirow[t]{2}{*}{ CCAA } & \multicolumn{2}{|c|}{ INTERVENCION-MEDIDAS } & \multirow{2}{*}{$\begin{array}{c}\text { SEGUIMIENTO } \\
\text { Recursos }\end{array}$} & \multicolumn{2}{|c|}{ EVALUACION } & \multirow{2}{*}{$\begin{array}{l}\text { MEDIDAS DE } \\
\text { PREVENCION } \\
\text { Primaria } \\
\text { Secundaria } \\
\text { Terciaria }\end{array}$} & \multirow{2}{*}{$\begin{array}{c}\text { DOCUMENTACION } \\
\text { ADMINISTRATIVA } \\
\text { Informe/ Tabla } \\
\text { observación' } \\
\text { Comunicados/ } \\
\text { Expediente }\end{array}$} & \multirow{2}{*}{$\begin{array}{l}\text { ACTIVIDADES } \\
\text { ESPECIFICAS } \\
\text { Charlas/Programas/ } \\
\text { Métodos/ Terapias }\end{array}$} \\
\hline & Educativas & Disciplinarias & & Instrumentos & $\begin{array}{l}\text { Encuesta } \\
\text { protocolo }\end{array}$ & & & \\
\hline Andalucia & $x$ & $x$ & $\mathrm{x}$ & & & & & \\
\hline Aragón & $x$ & $x$ & $x \cdots$ & & & $x$ & $x$ & \\
\hline Asturias & $x$ & $x$ & $x \cdots$ & & & $x$ & $x$ & $x$ \\
\hline Canarias & $x$ & $x$ & $x \cdots$ & & & $\mathrm{x}$ & $\mathrm{x}$ & $x$ \\
\hline Cantabria & $x$ & $x$ & $x$ & & & & $x$ & \\
\hline $\begin{array}{l}\text { Castilla la } \\
\text { Mancha }\end{array}$ & $x$ & $x$ & $x$ & $\mathrm{x}$ & & $x$ & $x$ & \\
\hline $\begin{array}{l}\text { Comunidad } \\
\text { Valenciana }\end{array}$ & $x$ & $x$ & $x$ & & & & & \\
\hline Extremadura & & $x$ & & & & $x$ & $x$ & $\mathrm{x}$ \\
\hline Galicia & $x$ & $x$ & $\mathrm{x}$ & $x$ & & $x$ & $x$ & \\
\hline Madrid & $\mathrm{x}$ & $\mathrm{x}$ & $\mathrm{x}$ & & & $\mathrm{x}$ & $\mathrm{x}$ & \\
\hline Murcia & $x$ & & $x$ & & & & & \\
\hline Pais Vasco & $x$ & $x$ & $\mathrm{x}$ & & & $x$ & $x$ & \\
\hline
\end{tabular}

$X^{*}$ Se especifican criterios, actividades, fases o instrumentos de la fase de detección. $X^{* *}$ Sólo se nombra a estos agentes como receptores de información acerca del caso. $X^{\star \star \star}$ Sólo se nombra que existe una fase de seguimiento, no se desarrolla

A raíz de esta revisión pormenorizada se ha considerado interesante realizar una propuesta integral de un Protocolo de actuación ante casos de acoso escolar, que recoge los puntos fuertes de los protocolos redactados por las autonomías, y complementa aquellos que se consideran incompletos tras el análisis de los criterios. En la Figura 1 se observan las fases del protocolo de intervención propuesto ante un caso de acoso o ciberacoso escolar, las cuales se definen como:

1) Detección: Conocer la realidad de la problemática e intervenir efectivamente. Se hará uso de las herramientas mencionadas en la Figura 1.

2) Medidas de urgencia: Evitar más daños en los afectados y controlar la situación (p. ej., evitar el contacto entre agresor, seguidores y víctima). Si se da ciberbullying, se informará a la víctima y a los padres sobre las pautas a seguir en estos casos: cortar el contacto, recoger las pruebas existentes, denunciarlo en la plataforma y eliminar los comentarios. De no cesar el acoso, denunciar a la policía aportando las pruebas recogidas.

3) Evaluación: Antes de intervenir se evalúa la situación emocional de los implicados, así como el clima del centro, para conocer sobre qué ámbitos se debe actuar y poder reconducir el curso de la agresión. Con las pruebas de la Figura 1.

4) Intervención: Tras la comparativa de los protocolos revisados, cabe destacar la ampliación de la fase de Intervención como gran diferencia con los protocolos existentes. Se propone un tipo de intervención integral, que comprenda tanto el camino institucional y administrativo como la intervención propiamente dicha, mediante el uso de instrumentos adecuados para la modificación de la situación problemática. De esta forma el/la orientador/a trabajaría con la víctima, el agresor, el grupo-clase, la familia y el profesorado implicados. En la Figura 1 podemos observar las estrategias y métodos de intervención concretos para cada uno de los agentes implicados.

5) Reevaluación: Con el fin de comprobar la efectividad del proceso, así como evaluar el protocolo en sí mediante una encuesta, se realiza una reevaluación utilizando las mismas pruebas que se administraron en la fase de Evaluación. 
6) Seguimiento: Para controlar la situación entre los alumnos afectados durante el curso escolar, se llevará a cabo un seguimiento con la tabla de observación indicada en la Figura 1. De manera individual, el/la orientador/a se reunirá con la víctima y el agresor tras la intervención para hablar sobre la evolución del caso. Estas reuniones se irán espaciando en el tiempo, siempre dejando «la puerta abierta» para que acudan si surge algún problema.

7) Prevención: Nos centraremos en la prevención secundaria y terciaria, puesto que el hecho de llevar a cabo el Protocolo conlleva que la situación de acoso ya se ha dado y una prevención primaria no tendría lugar. La prevención secundaria, orientada a toda la comunidad educativa, consistiría en unas jornadas de prevención del acoso escolar. Para ello se propone reservar una semana del curso académico. Con esta medida se pretende sensibilizar a todo el alumnado del centro mediante actividades como charlas y noticias de testimonios reales, video-fórum, role-playing y juegos de identificación de situaciones de acoso. Además, se implantaría el Programa TEI (Tutoría Entre Iguales), con el fin de mejorar la integración escolar y calidad de la convivencia trabajando por una escuela inclusiva y no violenta. Además, se introduciría un Programa de Mediación entre Iguales para prevenir posibles futuras situaciones de bullying en el centro. En cuanto a la prevención terciaria, estaría dirigida al grupo-clase afectado mediante la realización de actividades orientadas a la prevención del acoso escolar.

1 Detección

Comunicación Equipo directivo, docentes y familias

Entrevistas

Instrumentos de diagnóstico

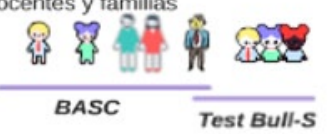

Medidas de urgencia Tabla conductas problema (Gil, B.) cieeracoso

3 Evaluación

8. 8 . $\mathrm{CPQ}$

Prueba de Autoconcepto y Autoestima (Piers-Harris)

\begin{tabular}{l|l} 
AVE & Sociograma (grupo GREI)
\end{tabular}

8des Adivina quién (Escala de roles) Cuestionario HHSS para Niños en Edad Escolar

8. Perfil de estilos educativos

Intervención

Instrucción de Expediente Acto de Conciliación Y3 $\begin{aligned} & \text { Estrategias modificación de conducta } \\ & \text { Actividades de reflexión }\end{aligned}$ HHRP y HHSS

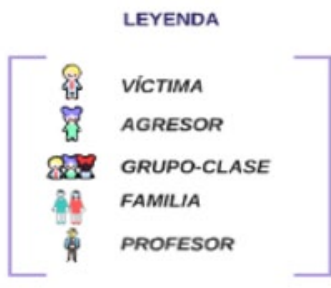

Resolución de Expediente

Medidas Correctoras

$r$ Mas Correctc

Educativas Sancionadoras

\begin{tabular}{l|l} 
HHSS \\
Programa de educación para la covivencia (Acosta, A.) \\
Relacionamos bien (Segura, M. y Arcas, M.) \\
Concienciación/Sensibilización \\
Programa de sensibilización en el maltrato entre iguales \\
(Monjas, M.I. y Avilés, J.M.) \\
Método Pikas
\end{tabular}

Q $\mid \begin{aligned} & \text { Terapia cognitivo-conductua } \\ & \text { Reestructuración cognitiva }\end{aligned}$ HHRP y HHSS

(5) Reevaluación

廿 Encuesta de evaluación del protocolo a TODOS los agentes implicados

6 Seguimiento

$$
\text { Tabla conductas problema (Gil, B.) } \mathbb{1} \text { \& + Reuniones con el orientador }
$$

Prevención

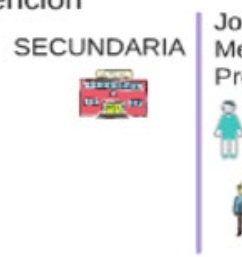

Charlas prevención: bullying y ciberbullying

Orientación estilos educativos parentales

\% 1

Charlas de detección y prevención bullying

Figura 1. Esquema del Protocolo de Intervención en caso de Acoso Escolar. Elaboración propia 


\section{Discusión y conclusiones}

Tras la exploración se puede afirmar que, aun siendo un tema de gran impacto social, gran parte de los documentos propuestos por las autonomías son incompletos o poco exhaustivos. También se observa que el respaldo normativo en que se sustentan es escaso, por lo que sigue siendo imprescindible la creación de legislaciones específicas relativas a los fenómenos de bullying y cyberbullying. Ha llamado la atención que no se encontraran todos los protocolos ya que de algunas comunidades autónomas sí que existen guías, pero no un protocolo oficial redactado por la Consejería pertinente que trate el acoso escolar. Así mismo, destacar la falta de esquemas de intervención en los protocolos encontrados. Por otro lado, es de valorar la existencia de medidas educativas en la mayoría de protocolos y la contemplación de la figura de los observadores en los mismos. El protocolo más completo de los que se han analizado ha sido el de Galicia, pues sólo carece de la inclusión de actividades específicas.

Respecto a las limitaciones del estudio, decir que podría ampliarse con los protocolos de las Comunidades Autónomas restantes y ampliando la información que se recoge de cada protocolo en cada criterio. En relación al protocolo propuesto, se podría ampliar con más actividades, con intervenciones más precisas y ejemplos de documentación administrativa.

\section{Referencias bibliográficas}

Acosta, A. López, J., Segura, I. \& Rodríguez, E. (2003). Programa de educación para la convivencia. Cuaderno de Habilidades sociales. Universidad de Granada.

Arias, R., Martín, J. \& Díaz-Aguado, M. J. (2013, septiembre-diciembre). El acoso entre adolescentes en España: Prevalencia, papeles adoptados por todo el grupo y características a las que atribuyen la victimización. Revista de Educación, 362.

Avilés, J. M. (2006). Bullying: el maltrato entre iguales. Agresores, víctimas y testigos en la escuela. Salamanca: Amarú.

Casas, J. A., Del Rey, R. \& Ortega-Ruiz, R. (2013). Bullying and cyberbullying: Convergent and divergent predictor variables. Computers in Human Behaviour, 29, 580-587.

Cerezo, F. (2009). La violencia en las aulas. Análisis y propuestas de intervención. Madrid, España: Pirámide.

Cerezo, F. \& Ato, M. (2010). Social status, gender, classroom climate and bullying among adolescents pupils. Anales de Psicología, 26 (1), 137-144.

Cerezo, F. (2012). Psique: Bullying a través de las TIC. Boletín Científico Sapiens Research, 2(2), 24-29.

Cerezo, F. \& Rubio, F. J. (2017). Medidas relativas al acoso escolar y ciberacoso en la normativa autonómica española. Un estudio comparativo. Revista Electrónica Interuniversitaria de Formación del Profesorado, 20(1), 113-126.

Consejería de Educación y Empleo (2016). Orientaciones educativas para el plan de actuación en relación con las alteraciones de la convivencia por acoso escolar en los centros escolares. Extremadura, España: Gobierno de Extremadura.

Consejería de Educación y Ciencia. (2006). Protocolo de actuación en caso de maltrato entre iguales. Castilla La Mancha, España: Gobierno de Castilla La Mancha.

Consejería de Educación, Cultura y Deporte (2013). Protocolo de actuación para los centros educativos ante una posible situación de acoso escolar. Cantabria, España: Gobierno de Cantabria.

Consejería de Educación, Juventud y Deportes (2015). Protocolos de Apoyo inmediato y coordinado a Víctimas Escolares. Murcia, España: Región de Murcia. 
Consejería de Educación, Juventud y Deporte. Guía de actuación contra el acoso escolar en los centros educativos. Madrid, España: Comunidad de Madrid.

Consejería de Educación (2011). Protocolo de actuación en supuestos de caso escolar. Andalucía, España: Gobierno de Andalucía.

Consejería de Educación, Universidades y Sostenibilidad (2015). Procedimiento de intervención sobre acoso y maltrato escolar. Canarias, España: Gobierno de Canarias.

Conselleria de Cultura, Educación e Ordenación Universitaria (2015). Protocolo: Prevención, detección e tratamento do acoso escolar e ciberacoso. Galicia, España: Junta de Galicia.

Departamento de Educación, Cultura y Deporte. Protocolos de actuación ante un conflicto grave con violencia entre alumnos. Aragón, España: Gobierno de Aragón.

Departamento de Educación. Guía de actuación en los centros educativos ante el maltrato entre iguales. País Vasco, España: Gobierno Vasco.

Departamento de educación (2011). Protocolo de actuación escolar ante el ciberbullying. País Vasco, España: Gobierno Vasco.

Direcció general d'innovació, ordenació i política lingüística. Procedimientos de intervención ante supuestos de violencia escolar. Valencia, España: Generalitat Valenciana.

Dirección general de Ordenación Académica de la Consejería de Educación y Ciencia (2006).

Maltrato Cero. Orientaciones sobre el acoso escolar. Asturias, España: Gobierno de Asturias.

Fundación Mutua Madrileña y Fundación Ayuda a Niños y Adolescentes en Riesgo (2016). Acoso escolar: I Estudio sobre el bullying según los afectados y líneas de actuación. Madrid, España: Fundación Mutua Madrileña y Fundación ANAR.

Garaigordobil, M. (2011). Prevalencia y consecuencias del cyberbullying: una revisión International Journal of Psychology and Psychological Therapy, 11 (2), 233-254.

Güemes, I. (2011). Evaluación de la eficacia del programa "CONVES» para la mejora de la convivencia en educación primaria. Escuela Abierta: revista de Investigación Educativa, $14,3346$.

Merayo, M. M. (2013). Acoso Escolar. Guía para padres y madres. Confederación Española de Asociaciones de padres y madres de alumnos. Madrid, España: CEAPA

Ministerio de Educación (2011). Actuaciones para el impulso y mejora de la convivencia escolar en las comunidades autónomas. España: Gobierno de España.

Monjas, M. I. \& Avilés, J. M. (2006). Programa de sensibilización contra el maltrato entre iguales.

Olewus, D. (1993). Bullying at school: What we know and what we can do. Malden, MA: Blackwell Publishing.

Olweus, D. (2001). Bullying at school: tackling the problem. OECD Observer (225), 24.

Olweus, D. \& Breivik, K. (2014). An Item Theory Analysis of the Olweus Bullying Scale. Aggressive Behavior, 41, 1-13.

Ovejero, A., Smith, P. \& Yubero, S. (2013). El acoso escolar y su prevención. Perspectivas internacionales. Madrid: Biblioteca Nueva.

Real Decreto 732/1995, de 5 de mayo, sobre los derechos, deberes y normas de convivencia de los alumnos de centros sostenidos con fondos públicos.

Salmivalli, C., Österman, K., Björkqvist, K. \& Kaukiainen, A. O. (1996). Bullying as a Group Process: Participant Roles and Their Relations to Social Status Within the Group. Aggressive Behavior 22, I-15.

Salmivalli, C. \& Peets, K. (2009). Preadolescents' peer-relational schemas and social goals across relational contexts. Social Development, 18, 817-832.

Salmivalli, C. (2010). Bullying and the peer group: A review. Aggression and Violent Behavior, 15(2), 112-12

Schultze-Krumbholz, A. \& Scheithauer, H. (2015). Social-Behavioral Correlates of Cyberbullying in a German Student Sample. Journal of Psychology, 217, 224226. 
Save the Children (2016). Acoso escolar y ciberacoso: propuestas para la acción. Madrid, España: Save the Children.

Segura, M. \& Arcas, M. (2004). Relacionarnos bien. Programas de Competencia Social para niños y niñas de 4 a 12 años. Narcea Ediciones.

Trianes, M. V, Fernández, F. J. \& Escobar, M. (2013). Convivencia escolar: Evaluación e intervención para su mejora. Madrid: Editorial Síntesis.

Villanueva, L., Górriz, A. B., Andrés, C., Cuervo, K. \& Serrano, J. E. (2009). Características descriptivas de los participantes en acoso escolar: agresores, seguidores, víctimas, defensores y público. Psicología de la infancia y la adolescencia, 1 (1), 279-286. 


\title{
Programa de salud para la prevención de enfermedades derivadas de la exposición solar en la infancia
}

\author{
BELÉn MORENO GUILLAMÓN \\ al261475@uji.es \\ BELÉN Flos EXPÓsITO \\ al339176@uji.es \\ ADRIÁN FONTA DE LA FUENTE \\ al339170@uji.es \\ PABlo Salas MEdina \\ psalas@uji.es \\ Águeda Cervera Gasch \\ cerveraa@uji.es
}

\section{Resumen}

Introducción: La evidencia científica respalda que los niños son uno de los grupos de población en los que más debe extremarse la fotoprotección. Una exposición solar irresponsable puede acarrear consecuencias inmediatas como las quemaduras solares. Pero las consecuencias más peligrosas son las que se producen a largo plazo como el fotoenvejecimiento y la fotocarcinogénesis. Por ende, una disminución en la exposición solar en edades tempranas puede disminuir en gran medida la incidencia del melanoma cutáneo en la edad adulta. Por esta razón se realiza un programa de salud con el objetivo de reducir la exposición de rayos ultravioleta (UV) y quemaduras en un $25 \%$ en niños para prevenir una futura aparición de melanomas en edad adulta. Metodología: El programa de salud está dirigido a la población infantil de edades comprendidas entre 6 y 12 años residentes en la Comunidad Valenciana, España (374.555). La captación de los participantes se realizará en las visitas al centro de salud, así como por medio de charlas en los centros docentes. Además, se diseñan trípticos y carteles con el fin de captar la atención de la población. Resultados: Se espera reducir la incidencia de quemaduras en un $25 \%$ en niños entre 6 y 12 años para prevenir futuras apariciones de melanoma en edades adultas en el plazo de 10 años. Discusión: Se considera que la implantación del programa conseguirá que los infantes adquieran hábitos saludables frente a la exposición solar.

Palabras clave: exposición, solar, infancia, prevención, melanoma.

\section{Abstract}

Introduction: The scientific evidence supports that children are one of the population groups in which the photoprotection should be most extreme. Irresponsible sun expo- 
sure can lead to immediate consequences such as sunburn. But the most dangerous consequences are those that occur in the long term such as photoaging and photocarcinogenesis. Thus, a decrease in sun exposure at early ages can greatly decrease the incidence of cutaneous melanoma in adulthood. For this reason, a health program is carried out to reduce the exposure of ultraviolet rays (UV) and burns by $25 \%$ in children to prevent future onset of melanomas in adulthood. Methodology: This health program is aimed at children between 6 and 12 years of age living in the Valencian Community, Spain (374.555). The participation of the participants will be made in the visits to the health center, as well as through talks in the schools. In addition, leaflets and posters are designed to capture the attention of the population. Results: It is expected to reduce the incidence of sunburns to $25 \%$ in children between 6 and 12 years to prevent future occurrences of melanoma in adults ages within the period of 10 years. Discussion: It is considered that the implementation of the program will get that infants acquire healthy habits against exposure to the Sun.

Keywords: exposure, solar, childhood, prevention, melanoma.

\section{Introducción}

La evidencia científica respalda que los niños son uno de los grupos de población en los que más debe extremarse la fotoprotección. En primer lugar, porque los niños son el grupo de población que más tiempo pasa al aire libre. En segundo lugar, porque el principal factor de riesgo de melanoma cutáneo es la radiación ultravioleta que proviene del sol, sobretodo aquella radiación que se produce durante la infancia (Valdevielso-Ramos \& Herranz, 2010). Una exposición solar irresponsable puede acarrear consecuencias inmediatas como las quemaduras solares. Pero las consecuencias más peligrosas son las que se producen a largo plazo como el fotoenvejecimiento y la fotocarcinogénesis, conocida comúnmente como melanoma cutáneo, que es una neoplasia que se origina en los melanocitos de la capa basal de la epidermis, y que se caracteriza por su agresividad y por su alta mortalidad (Lavanderos et al., 2010). La mayoría de los efectos adversos de la exposición al sol son evitables siguiendo unas pautas y utilizando una serie de productos como pueden ser los protectores solares que reducen la incidencia de los rayos UV y consigo los efectos de la radiación sobre la piel. Los protectores solares son sustancias que reducen la incidencia de los rayos UV y consigo los efectos de la radiación sobre la piel. Estos productos se clasifican según el factor de protección solar, que depende de las condiciones del medio y la cantidad de producto aplicado sobre la piel (Martínez et al., 2012). Para considerar que un protector solar es eficaz y proporciona una buena fotoprotección se debe tener en cuenta, en primer lugar, el tipo de filtro solar. Los filtros de los protectores solares se pueden clasificar en: filtros químicos u orgánicos y filtros físicos o inorgánicos. Por una parte, los filtros químicos son sustancias que absorben la radiación ultravioleta y se desencadena una reacción fotoquímica que disminuye los niveles energéticos de dicha radiación tornándose menos dañinos para la piel. Por otra parte, los filtros físicos son sustancias que, por el tamaño y las características de las partículas que lo componen, no dejan pasar la radiación permitiendo así minimizar los efectos de ésta en todas sus longitudes de onda. Los filtros físicos, a diferencia de los químicos, son fotoestables, es decir, no suelen inducir reacciones de hipersensibilidad en la piel por lo que pueden ser usados tanto por adul- 
tos como por niños (Tania et al., 2008). Es importante saber la cantidad correcta de protector solar que se ha de aplicar en la piel ya que de ella depende el factor de protección solar, que nos indica cuánto tiempo más un protector solar aumenta la capacidad de defensa natural de la piel antes de llegar a quemarse (Tania et al., 2008). Por último, hay que tener muy en cuenta la regularidad con la que se usa, así como las re-aplicaciones mientras haya una exposición al sol. Es importante que la protección solar se incorpore a la rutina diaria de la población durante todo el año, especialmente en los niños. Aun así, en niños menores de 6 meses el uso de productos solares se debería evitar ya que podrían ocasionar deficiencias, como por ejemplo la vitamina $D$ que se absorbe gracias a la luz solar, y enfermedades relacionadas con el uso de protectores solares en el bebé (Tania et al., 2008). Por ende, una disminución en la exposición solar en edades tempranas puede disminuir en gran medida la incidencia del melanoma cutáneo en la edad adulta.

\section{Método}

\section{Diseño}

Se diseña un programa de salud, realizado por alumnos de segundo de Enfermería de la Universitat Jaume I en el espacio temporal comprendido desde octubre de 2016 hasta diciembre de 2016. El diseño de este programa de salud se basa en dos pilares, uno de ellos es la formación que recibirán los profesionales sanitarios y escolares, el otro es la captación de los participantes por medio de charlas, trípticos y actividades realizadas en el centro docente.

\section{Población}

El presente programa de salud, dedicado a prevenir la exposición solar, está dirigido a la población infantil de edades comprendidas entre 6 y 12 años residentes en la Comunidad Valenciana, España (374.555). El desarrollo del programa se realizará en las aulas de los centros docentes y en las consultas pediátricas de los centros de atención primaria. En las consultas pediátricas se aprovechará la presencia de los padres, para comentar los aspectos básicos de la protección y proporcionarles un tríptico informativo.

\section{Captación}

Se realizará una captación activa de usuarios aprovechando las visitas de la población al centro de salud para las revisiones pediátricas. Concienciando a la población sobre las consecuencias de una irresponsable exposición solar y la importancia de la protección solar. Por otra parte, durante el curso escolar, se realizarán charlas y actividades periódicas para involucrar en la causa a la población infantil. Además, se intentará recaptar a los usuarios que han participado en el programa pero que han dejado de participar contactando con ellos mediante teléfono o a través de los profesores en los centros escolares. Se diseñarán una serie de carteles y trípticos que serán distribuidos en centros de salud, hospitales y centros docentes con el fin de captar la atención de la población. 


\section{Planificación del programa}

Para la puesta en práctica del programa se deberá planificar tanto la formación de los profesionales como el desarrollo del mismo en los centros de salud y centros docentes.

Planificación de la formación de los profesionales sanitarios:

- Número de sesiones. 5

- Duración de las sesiones. 4 horas

- Lugar. Centro de Salud Pública

- Número de participantes. 20-30

- Anual - entre febrero y marzo

El planteamiento de la ejecución de dicho programa en los centros escolares es:

- Número de sesiones.1

- Duración de las sesiones. 2 horas ( $1^{\circ}$ de primaria) - 3 horas ( $6^{\circ}$ de primaria)

- Periodicidad. Anual - mes de abril ( $1^{\circ}$ y $6^{\circ}$ de primaria)

- Temporalización:

- Tiempo que se destinará a la charla. 45 - 50 minutos.

- Tiempo que se destinará a las actividades. 1 hora ( $1^{\circ}$ primaria) - 2 horas ( $6^{\circ}$ primaria)

- Lugar. Centro escolar (aulas y patio)

- Número de participantes. 20-30

Por lo que respecta al centro de salud, la planificación previa no será igual de necesaria que en los centros escolares. Tanto los pediatras como los enfermeros de pediatría, se encargarán de aprovechar las consultas de los infantes para educarlos en cuanto a exposición solar respecta; para ello los profesionales sanitarios contarán con carteles y trípticos informativos que podrán utilizar como apoyo a la hora de informar a los usuarios.

\section{Recursos necesarios}

En cuanto a recursos humanos, se dispondrá de enfermeros en consultas de pediatría que capten pacientes durante las revisiones del niño sano. Estos enfermeros también realizarán charlas en los centros escolares con el apoyo de los maestros. Además, se contará con pediatras que realicen diagnósticos y, en el caso que fuese necesario, derivasen al dermatólogo para un seguimiento más exhaustivo del caso. Se realizarán cursos de formación de $20 \mathrm{~h}$ para los profesionales sanitarios que vayan a realizar el programa donde se les educará en la detección rápida de melanomas, así como la forma correcta de realizar los talleres, teniendo en cuenta las edades de los usuarios a los que va dirigido, para llevar a cabo unas actividades u otras. Se contará también, con la presencia de profesionales docentes con el fin de que reciban conocimientos básicos sobre el tema, así como identificar y prevenir su aparición. En cuanto a los recursos materiales se diferenciará entre los recursos existentes y los recursos necesarios para ejecutar el programa de salud. 
Recursos existentes:

- Materiales para el aula: pizarra, proyector

Recursos necesarios:

- Guía para el profesorado

- Manual sobre conceptos básicos para la educación en la prevención del melanoma

- Folletos informativos para padres

- Material para centros sanitarios: carteles y trípticos

- Material para el aula: carteles, fichas de actividades, lápices o rotuladores de colores, tarjetas blancas, pegatinas con los distintos colores de piel, pegatinas de objetos relacionados con la exposición solar, gomas elásticas.

- Material de protección: gorras recortables y muestras de cremas solares de $20 \mathrm{ml}$ con factores de protección solar desde FPS 15 hasta FPS 50.

- Material de evaluación: cuaderno de evaluación de las actividades en el aula.

Para poder contar con todas las facilidades explicadas anteriormente, se necesitarán una serie de recursos económicos. Las ayudas económicas se solicitarán en la Conselleria de Sanitat Universal i Salut Pública.

\section{Actividades para conseguir los objetivos}

Para conseguir los objetivos anteriormente mencionados, así como los resultados esperados, el programa de salud se llevará a la práctica tanto en centros sanitarios como en centros docentes.

\section{Plan de actuación en niños de 6-7 años}

En primer lugar, se realizará una charla educativa donde se explicará cómo actúan los diferentes protectores dependiendo de las características físicas de cada niño, teniendo en cuenta el color de pelo, ojos, piel, etc. La charla consistirá en un relato corto «El Sol y los Ladrillos» que explique de forma didáctica los diferentes fototipos. Una vez finalizada la charla, se procederá a la visualización del vídeo «La Piel». (Érase una vez la vida)» desde el minuto 2:45 hasta el 3:45. El vídeo se encuentra en la plataforma Youtube. En cuanto a las actividades, se les repartirá lápices o rotuladores de colores y diferentes hojas de ejercicios para que asienten los conocimientos que se han explicado en la charla. Además, se darán manualidades adecuadas a su edad. Todo este proceso estará guiado por el profesional sanitario y el maestro.

\section{Plan de actuación en niños de 11-12 años}

En el curso escolar de sexto de primaria se realizará una charla de aproximadamente una hora en la que se introducirán los siguientes conceptos: quemadura, melanoma, protector solar, factor de protección solar, fototipo y escala de Fitzpatrick (Sánchez \& Nova, 2017). En esta charla, además de explicarles el significado de cada uno de los conceptos anteriores se 
les explicará la importancia de tener unos buenos hábitos frente a la exposición solar y cómo pueden adquirirlos.

Una vez realizada la charla se desarrollarán una serie de juegos para que los alumnos puedan aprender de una forma práctica la información que se expone en ella. Esta parte constará de dos juegos. Para introducir el concepto de protección solar, factor de protección y las consecuencias de una exposición solar excesiva como las quemaduras y su relación con la aparición de melanomas, el personal sanitario en conjunto con los docentes del centro realizará un juego didáctico que se denomina «Impacto solar». La actividad se desarrollará en el aula. Para una mejor comprensión y resultado de la manualidad se tendrá que haber introducido previamente el concepto de fototipo y la escala de Fitzpatrick (Sánchez \& Nova, 2017). Por otra parte, se desarrollará la actividad «pasaporte solar» que consiste en que los alumnos realicen una tarjeta identificativa en la que figuren sus datos personales (nombre, apellidos y edad), su fototipo y la protección que más se adecúa a su tipo de piel.

\section{Resultados}

Previamente al diseño del presente programa, se indagó sobre cuál era el problema de salud que más preocupaba a los padres respecto a sus hijos se procedió a la creación de un cuestionario con escala tipo Likert donde quedaban reflejados los problemas de salud más relevantes que pueden presentar los niños en edades comprendidas entre 0 a 18 años (Figura 1). Los resultados obtenidos se analizaron estadísticamente y se observó, que, a diferencia de lo esperado, la exposición solar, que debería ser una de las principales preocupaciones en la zona de la Comunidad Valenciana, por su gran cantidad de horas de sol y por tratarse de una zona costera, es de los supuestos cuyo rango de preocupación es de los más bajos.

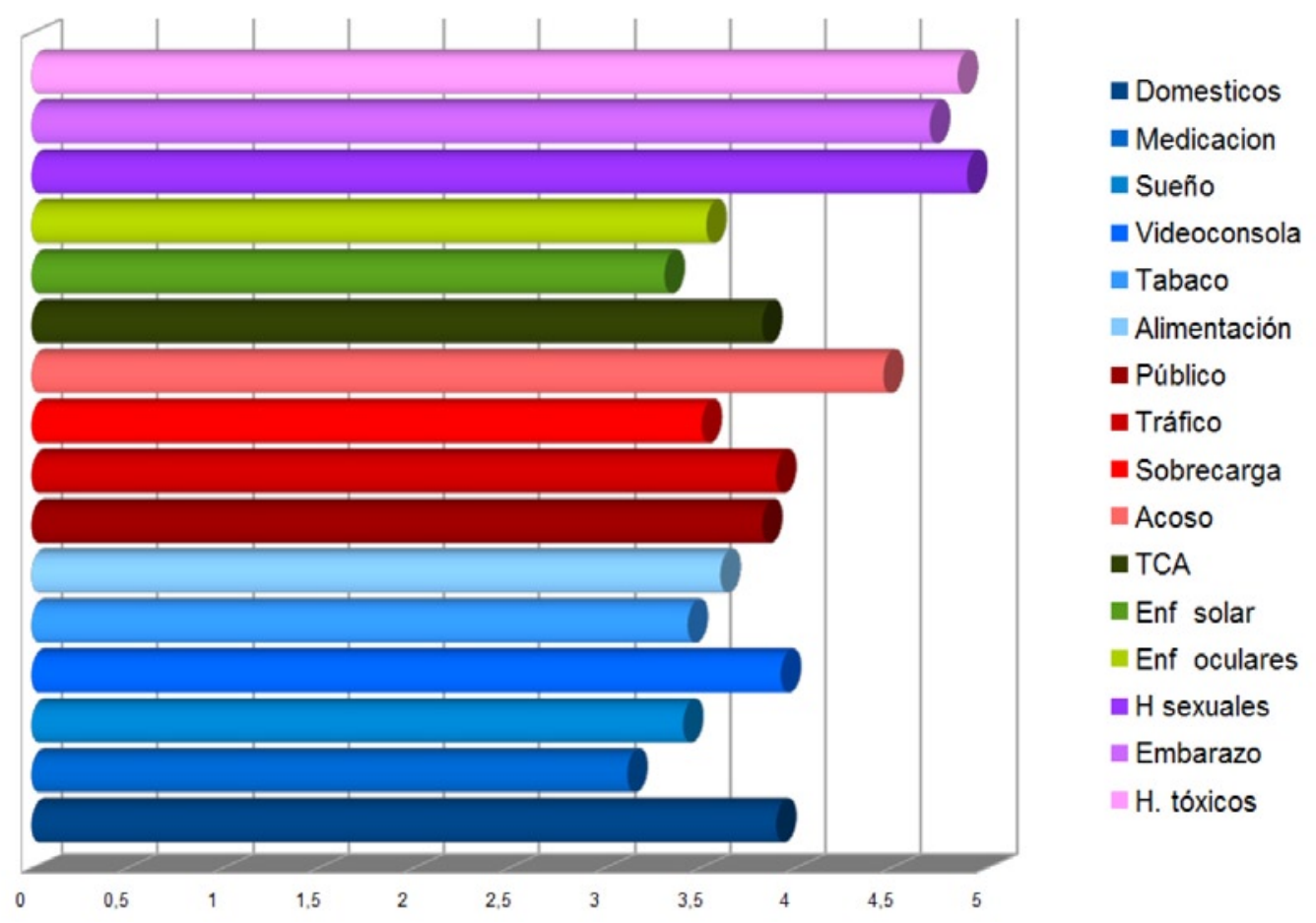

Figura 1. Análisis principales preocupaciones paternales (Elaboración propia) 
Considerando los datos que se obtuvieron, se llegó a la conclusión de que, era de gran importancia desarrollar un programa de salud que abordase la problemática de la exposición solar, así como su prevención durante la infancia.

El programa de salud está dirigido a todos los niños residentes de la Comunidad Valenciana (España) entre los 6 y 12 años, 374.555. Para poder valorar los resultados se deberá conocer aproximadamente cuántos de estos han participado en el mismo por lo que se desarrollará un censo de la población escolar a la que se la realizado la charla. Además, se realizará un recuento de los trípticos informativos que se entregan en las consultas de enfermería. Como último recurso, aunque más utópico se propondría la creación de un apartado específico en el programa Abucasis «asesoramiento prevención exposición solar». Con el fin de poder valorar si los participantes del programa cumplen los nuevos conocimientos adquiridos y los ponen en práctica se les preguntará en cada revisión pediátrica hasta los 14 años (última revisión). Además, se les enviará información en forma de trípticos al comienzo de cada época estival.

Los resultados esperados del programa a largo plazo es el cumplimiento tanto de los objetivos generales como de los específicos. El principal objetivo que se pretendía conseguir con la implantación del presente programa era reducir la incidencia de quemaduras en un 25 $\%$ con el fin de prevenir futuras apariciones de melanoma en edad adulta. Para poder estudiar si ha habido una mejora, se debe conocer la prevalencia de melanoma de la población antes del programa, así como los datos de quemaduras solares recogidas en los niños de 6 y 12 años. En cuanto a las quemaduras, se recogerán los datos obtenidos tras el periodo de un año desde que el programa entre en vigor, y se realizará un seguimiento durante los próximos años con el fin de comprobar si existe una reducción de quemaduras solares y con ello se estén cumpliendo los objetivos marcados. Además, para verificar que la educación para la salud que se ejecutó fue efectiva, se realizará un estudio cada cinco años.

Para comprobar que existe una reducción de la prevalencia del melanoma, se debe dejar un periodo de tiempo más extenso para poder estudiar los datos, puesto que para reducir la prevalencia se debe invertir más tiempo en educación preventiva para poder generar un resultado significativo. Además, en este programa los resultados se valorarán en el momento que los niños que fueron población diana entren en la edad adulta. Por lo tanto, se tendrá que esperar un mínimo de diez años para observar un cambio significativo a nivel evaluable.

\section{Discusión y conclusiones}

La puesta en práctica de un programa de salud desde edades tempranas resulta de gran importancia para promover la salud de los infantes, generando la creación de hábitos saludables en una etapa de vida donde resulta más asequible la adquisición de nuevas costumbres, dada la mayor facilidad de aprendizaje de conductas positivas hacia la salud. (García, 1998). Además, la participación de los centros docentes resulta idónea para la promoción de la salud dado que se puede abarcar una variada población infantil.

Como se ha comentado anteriormente, diversos estudios muestran que una exposición solar irresponsable puede acarrear desde quemaduras hasta consecuencias más peligrosas como el fotoenvejecimiento y la fotocarcinogénesis. (Lavanderos et al., 2010). La decisión de realizar un programa de salud que previene la exposición solar en la infancia fue por dos razones. En primer lugar, porque la Comunidad Valenciana es una zona costera donde las horasde sol abundan y no se cuenta con ningún plan o programa de salud que promocione hábitos saludables frente la exposición solar. En segundo lugar, porque es en los niños donde se 
debe extremar la fotoprotección dado que al pasar más tiempo al aire libre se encuentran más expuestos a la radiación UV (Valdevieso-Ramos \& Herranz, 2010)

Por estas razones, se cree importante, con la aplicación del programa de salud en centros escolares y centros de atención primaria, conseguir que los niños adquieran hábitos saludables en lo que a exposición solar se refiere, puesto que se ha podido comprobar, con el cuestionario sobre los problemas de salud más relevantes en niños de 0 a 18 años, mencionado anteriormente, que este hecho es uno de los que menos preocupa a los padres en la Comunidad Valenciana. Así pues, el único método que utilizan para combatir el problema son los filtros químicos de forma ocasional, siendo estos insuficientes para una adecuada protección solar.

Las últimas revisiones muestran estudios que informan de la existencia de evidencia científica suficiente que asegura que la prevención de melanomas es mayor con el uso diario de filtro solar que con un uso ocasional (Sánchez et al., 2014). Por este motivo se consideramos importante educar a los infantes sobre un buen uso de filtros solares, así como de protección física.

\section{Referencias bibliográficas}

García, I. (1998). Promoción de la salud en el medio escolar. Revista Española de Salud Pública, 72(4), doi: https://scielosp.org/scielo.php?pid=S1135-57271998000400001\&script=sci_arttext\#ModalArticles

Lavanderos, F., Pérez, P., Jeria, N. \& Concha, D. (2010). Actualizaciones en melanoma maligno cutáneo. Cuadernos De Cirugía, 24(1), 47-56, http://dx.doi.org.10.4206/cuad.cir.2010. v24n1-08

Martínez, M. \& Zúñiga, G. (2012). Los efectos de la luz ultravioleta. La Ciencia y el Hombre, 25(3) https://www.uv.mx/cienciahombre/revistae/vol25num3/articulos/efectos-luz/

Sánchez, G. \& Nova, J. (2008). Confiabilidad y reproducibilidad de la escala de fototipos de Fitzpatrick antes y después de un ejercicio de estandarización clínica. Biomédica, 28(4), 544. Doi: https://doi.org/10.7705/biomedica.v28i4.59

Sánchez, G., Nova, J., Rodriguez-Hernandez, A., Solorzano-Restrepo, C., Gonzalez, J. \& Olmos, M. (2014). Sun protection for preventing basal cell and squamous cell skin cancers. Cochrane Database Of Systematic Reviews. CD011161http://dx.doi.org/10.1002/14651858. cd011161

Tania, F., Bruna, B., Aline, R. (2008). Dermatología pediátrica Latinoamericana, Revista Oficial de la Sociedad Latinoamericana de Dermatología Pediátrica. Fotoprotección en la infancia, 6(1), 40-45, doi: http://docplayer.es/18257082-Dermatologia-pediatrica-latinoamericana-revista-oficial-de-la-sociedad-latinoamericana-de-dermatologia-pediatrica.html

Valdivielso-Ramos, M. \& Herranz, J. (2010). Actualización en fotoprotección infantil. Anales de Pediatría, 72(4), 282.e1-282.e9, doi: http://dx.doi.org/10.1016/j.anpedi.2009.06.013 


\title{
Proyecto SHE: School and Home Emotions
}

\author{
JosÉ FRANCISCO SANTAS BONA \\ al152927@uji.es \\ NiEVEs Fuentes-SÁNCHEZ \\ al262229@uji.es \\ IRENE JAÉN PARRILLA \\ ijaen@uji.es \\ JAHEL MOLINA ULLDEMOLINS \\ al287530@uji.es \\ M. CARMEn PAstor VerchiLI \\ mpastor@uji.es
}

\section{Resumen}

Hoy en día, la inteligencia no garantiza la felicidad en nuestro entorno, trabajo o vida social. El éxito personal y profesional no se vincula únicamente a los conocimientos académicamente adquiridos, sino también al dominio de competencias emocionales, cuyo desarrollo ayuda a gestionar las diferentes situaciones estresantes que se dan en el día a día. En este trabajo se describe un programa en educación emocional (SHE) -diseñado e implementado como estudio piloto-, basado en modelos científicos ampliamente conocidos sobre inteligencia (Salovey \&y Mayer, 1997) y regulación emocional (Gross \&y John, 2003). Mediante dicho programa se pretende poner al alcance de los niños las sinergias creadas por una educación emocional global: niños, profesores y padres. Para ello, se seleccionaron tres muestras de participantes: niños/niñas de $4^{\circ}$ de primaria, padres y madres, y profesorado del mismo centro escolar. La intervención consistió en desarrollar e impartir sesiones bi-quincenales sobre educación emocional. Los resultados mostraron efectos significativos sobre el uso de estrategias de regulación emocional -en la muestra de estudiantes y progenitores-, con una disminución de la supresión emocional y un aumento de la reevaluación cognitiva. En el caso de los profesores, disminuyeron las puntuaciones en afecto negativo. Los valores de funcionamiento familiar permanecieron estables tras la intervención. Por último, no se observaron cambios significativos en las habilidades de inteligencia emocional en ninguno de los tres grupos a estudio.

Palabras clave: inteligencia emocional, regulación emocional, estudiantes, profesorado, progenitores

\section{Abstract}

Today, intelligence does not guarantee happiness in our environment, work or social life. Personal and professional success is not only related to academic knowledge but also to 
the domain of emotional competences, whose development helps to manage the different stressful situations that occur on a daily basis. In this paper we describe a program in emotional education (SHE), designed and implemented as a pilot study, based on well-known scientific models of intelligence (Salovey \&and Mayer, 1997) and emotional regulation (Gross \&and John, 2003). This program aims to make available to children the synergies created by a global emotional education: children, teachers and parents. For this purpose, three samples of participants were selected: children from 4th grade primary, a group of parents of 4th grade and a group of teachers from the same school. The intervention consisted of developing and imparting bi-fortnightly sessions on emotional education. The results showed significant effects on the use of emotional regulation strategies - in student and parent samples - with a decrease in emotional suppression and an increase in cognitive reevaluation. In the case of teachers, the scores on negative affection decreased. The values of family functioning remained stable after the intervention. Finally, no significant changes in emotional intelligence skills were observed in any of the three study groups

Keywords: emotional intelligence, emotion regulation, students, teachers, parents

\section{Introducción}

«Sólo se aprende bien aquello que se ama»

(Mora, 2015)

¿Por qué educar emociones? En 1946, la Organización Mundial de la Salud definió el concepto de salud como "estado de completo bienestar físico, social y mental, y no sólo asociado a la ausencia de enfermedades». La educación emocional ha surgido en los últimos 25 años como un concepto clave en las relaciones interpersonales en diferentes contextos de la faceta humana, como indicador del ajuste emocional, bienestar personal y éxito laboral (Fernández-Berrocal \& Ruiz Aranda, 2008). La entrada en el siglo XXI nos ha sumergido de lleno en una nueva era de conocimiento necesitada de cambios en la formación de las personas. De forma análoga surge la conocida como sociedad del riesgo. Los cambios socioeconómicos producidos en la segunda mitad del siglo XX han hecho que los antiguos y nuevos riesgos para la salud se agudicen y estén más presentes, de forma especial, en niños y adolescentes (Weissberg, Kumpfer \&y Seligman, 2003). En España fallecieron 30 usuarios de motocicleta en 2015 por no utilizar casco. Del mismo modo, el consumo intensivo de alcohol (con riesgo de producir problemas agudos) se ha incrementado hasta el $13,4 \%$ de la población de 150 más años, y casi 30.000 adolescentes de entre 15 y 19 años quedan embarazadas cada año sin desearlo, mientras que la tasa de abortos entre menores de edad ha ido aumentando hasta situarse en el 13.47 en 2011. Resulta paradójico pensar que este incremento en las conductas de riesgo esté ocurriendo en la llamada «sociedad de la información». Sin embargo, estas cifras tan alarmantes no se deben a una falta de información, sino que más bien se producen por una mala gestión de habilidades emocionales y sociales ante las diversas situaciones y problemas de la vida diaria (Fernández-Berrocal \&y Ramos, 2004). Esta carencia ha hecho que los nuevos paradigmas de formación vuelvan su foco atencional a los programas basados en la educación emocional. De hecho, las dimensiones emocionales, especialmente la reparación o regulación emocional, han mostrado una asociación positiva con la satisfacción vital 
(Rey, Extremera, Pacheco \&y Pena, 2011). En un entorno en el que la crisis económica y política ha planteado la necesidad de reordenar la escala de valores, una educación socialmente responsable se antoja necesaria para asegurar el bienestar de la sociedad del futuro. Se necesitan personas con competencias sociales y emocionales, que sepan trabajar en equipo, resolver conflictos, que sean creativas, que aprendan a tener una vida satisfactoria. $Y$ para aprender, la emoción y la educación emocional, son la llave de la atención, puerta de la curiosidad, principio del aprendizaje (Mora, 2015).

Precisamente, el objetivo del presente trabajo es diseñar e implementar un programa de educación emocional que mejore la calidad en la educación, tomando para ello una muestra de niños y niñas de $4^{\circ}$ de primaria. Así, pretendemos proporcionar estrategias de regulación emocional comunes a los tres colectivos (alumnado, profesorado y progenitores), crear espacios donde poder reconocer y expresar emociones y favorecer el diálogo sobre los estados afectivos de cada persona. Aprovechar las sinergias creadas por una educación análoga a niños/niñas, profesorado y padres/madres será la principal singularidad que cabe destacar como principal aportación de este trabajo.

\section{Método}

\section{Participantes}

La muestra experimental del presente estudio fue obtenida a través de la colaboración con el CEIP José Soriano de Vila-real (Castellón) . La muestra se dividió en tres grupos: (1) niños/niñas de $4^{\circ}$ de primaria, (2) padres/madres de $4^{\circ}$ de primaria, y (3) profesorado del centro escolar. La muestra final de estudiantes estuvo compuesta por 55 niños (28) y niñas (27), con un rango de edad entre 9 y 10 años (Media $=9.5$ años). Respecto a la muestra de profesorado que participó en el programa fue de 20 personas (19 mujeres y 1 hombre), con un rango de edad entre 27 y 48 años (Media $=33,4$ ). En cuanto a la muestra de progenitores que participaron en el programa, finalmente contamos con un total de 21 ( 3 padres, 18 madres), con un rango de edad entre 41 y 50 años (Media $=44,67$ ).

\section{Instrumentos}

Trait Meta-Mood Scale (TMMS-24; Fernández-Berrocal, Extremera \&y Ramos, 2004; Salovey, Mayer, Goleman, Turvey \&y Palfai, 1995). Esta escala proporciona información sobre el nivel de Inteligencia Emocional a partir de tres subescalas: Atención a los sentimientos, Claridad de los sentimientos y Reparación del estado de ánimo. La escala contiene 24 ítems, con una respuesta tipo Likert de 5 puntos (1 Nada de acuerdo - 5 Totalmente de acuerdo).

Emotion Regulation Questionnaire (ERQ; Cabello, Salguero, Fernández-Berrocal \&y Gross, 2013; Gross \&y John, 2003). Evalúa dos estrategias de regulación emocional: la reevaluación cognitiva y la supresión emocional. Los participantes deben indicar su grado de acuerdo con las afirmaciones utilizando una escala Likert de 7 puntos $(1=$ totalmente en desacuerdo, 7 = totalmente de acuerdo). En nuestro caso, decidimos mantener la versión que contiene una escala Likert de 5 puntos ( $1=$ totalmente en desacuerdo, $5=$ totalmente de acuerdo) para poder comparar resultados con los obtenidos con el ERQ-CA aplicado a los niños.

Emotional Regulation Questionnaire for Children \& Adolescents (ERQ-CA; Gullone \&y Taffe, 2012). (Pastor et al., en preparación). Versión en castellano del cuestionario ERQ para niños y adolescentes. 
Positive and Negative Affect Schedule (PANAS; Robles \&y Páez, 2005). Mide afecto y afecto negativo. Utiliza 20 ítems, 10 de los cuales miden el afecto positivo y los 10 restantes afecto negativo. Estos 20 ítems son palabras o adjetivos que describen diferentes sentimientos y emociones. Las califica la persona, según el grado en que las experimenta, en una escala de cinco puntos, en donde 1 significa «muy poco o nada», y 5 «extremadamente».

Escala PANAS-N (Sandín, 2003; Joiner, Sandín, Chorot, Lostao \&y Marquina, 1999; Watson, Clark \&y Tellegen, 1988): análogamente versión para niños y adolescentes.

Behaviour Assesment System of Children S2 (BASC-S2; González, Fernández, Pérez \&y Santamaría, 2004; Reynolds \&y Kamphaus, 1992). Autoinforme de personalidad para niños de 8-11 años que consta de 146 enunciados que han de ser contestados como verdadero o falso. Son cinco las dimensiones que lo conforman: Inadaptación escolar, Desajuste clínico, Adaptación personal, Otros problemas y un índice global, el índice de síntomas emocionales (ISE).

Behaviour Assesment System of Children P2 (BASC-P2; González, Fernández, Pérez \&y Santamaría, 2004; Reynolds \&y Kamphaus, 1992). Evalúa conductas adaptativas y problemáticas en los ámbitos familiar y comunitario, informado por los padres. Está compuesto por 134 ítems de elección entre cuatro alternativas que evalúan 6 dimensiones: Exteriorizar Problemas, Interiorizar Problemas, Problemas Escolares, Otros Problemas, Habilidades Adaptativas y el Índice de Síntomas Comportamentales (ISC).

Family Adaptability and Cohesión Evaluation Scale (FACES 20-esp; Martínez-Pampliega, Iraurgi, Galíndez \&y Sanz, 2006). Escala breve (20 ítems) de análisis de funcionamiento familiar a partir de la escala americana Family Adaptability and Cohesion Evaluation Scale (FACES II). Recoge las dimensiones de Cohesión y Adaptabilidad del modelo circumplejo (Olson, 1988).

Escala de Satisfacción Laboral Versión para Profesores (ESL-VP; Anaya, 2005). Recoge en 44 ítems información sobre las facetas que los profesores consideran importantes para la satisfacción laboral y el grado en el que estas facetas se encuentran presentes en su trabajo actual. Este modelo se estructura alrededor de cinco dimensiones principales: diseño del trabajo, condiciones de vida asociada al trabajo, realización personal, promoción y superiores.

\section{Procedimiento}

La formación en educación emocional fue impartida a los tres grupos experimentales. Se estructuró en siete sesiones de 50 minutos de duración en el caso de los niños, y nueve sesiones de 60 minutos para el profesorado y progenitores. Las sesiones consistían en talleres teórico-prácticos en los que se impartían contenidos utilizando el juego como herramienta principal. Las sesiones fueron bi-quincenales, coincidiendo temporalmente la temática impartida en los tres grupos. El inicio de los talleres tuvo lugar a inicios de enero de 2016, finalizando en junio de ese mismo año. La evaluación del programa de educación emocional que se describe en el presente trabajo se realizó en dos momentos: pre-intervención -previamente a la implementación del programa- y post-intervención -última de las sesiones impartidas para cada muestra. En el presente estudio se evaluaron diferentes variables afectivas -Inteligencia Emocional Percibida, Estrategias de Regulación Emocional y Afecto Positivo y Negativo-, de clima familiar -Adaptabilidad y Cohesión-, y sobre la satisfacción laboral del profesorado (ver Figura 1). En la última sesión, algunos instrumentos (BASC-S2, BASC-P2) tuvieron que ser reemplazados por otros (TMMS, PANAS) para reducir el número de ítems y, con ello, el tiempo de administración. 


\begin{tabular}{ccc}
\hline & PRE & POST \\
\hline \multirow{3}{*}{ NIÑOSIAS } & BASC S2 & PANAS-N \\
& TMMS-24 & TMMS-24 \\
& ERQ_CA & ERQ_CA \\
\hline \multirow{3}{*}{ PROFESORADO } & PANAS & PANAS \\
& TMMS 24 & TMMS 24 \\
& ERQ & ERQ \\
& ESL-VP & ESL-VP \\
\hline \multirow{3}{*}{ PROGENITORES } & BASC-P2 & PANAS \\
& FACES ॥ & FACES ॥ \\
& ERQ & ERQ \\
& & TMMS 24 \\
\hline
\end{tabular}

Figura 1. Evaluación de la intervención (programa de educación emocional).

\section{Análisis estadístico}

En primer lugar, se calcularon los estadísticos descriptivos (medias y desviaciones típicas) de las diferentes medidas de autoinforme utilizadas en el presente estudio (ERQ/ERQCA, TMMS-24, PANAS/PANAS-N, ESL-VP, FACES-II), por separado para cada una de las muestras experimentales (estudiantes, progenitores y profesorado). En segundo lugar, se realizaron ANOVAS de un factor (Pre- vs. Post-intervención) para analizar si había diferencias en los resultados obtenidos en los diferentes instrumentos entre la primera (pre) y la última sesión (post) del programa de educación emocional. Los análisis fueron realizados con el paquete estadístico IBM SPSS Statistics v.21 y el software JMP 9.0.1.

\section{Resultados}

En las Tablas 1, 2 y 3 se resumen los estadísticos descriptivos para las tres muestras incluidas en nuestro estudio. Para la muestra de estudiantes, los valores obtenidos son comparables a los obtenidos en trabajos anteriores, así como en la validación de los cuestionarios utilizados en este trabajo (Cabello et al., 2013; Fernández- Berrocal et al., 2004; Sandin, 2003). No obstante, las medias obtenidas en las subescalas Supresión Emocional $(12,44)$ y Reevaluación Cognitiva $(23,62)$ del ERQ-CA, así como las subescalas de Atención $(3.57)$, Claridad (3.80) y Reparación emocional del TMMS-24 (3.91) fueron ligeramente más elevados que los obtenidos en las validaciones de estos instrumentos (Medias $=10,49$ y 21,53, respectivamente; Medias = 3,24, 3,24 y 3,30, respectivamente). Por su parte, la media en la dimensión de Afecto Negativo del PANAS (21.2) fue ligeramente inferior comparada con la obtenida en la validación $(18,03)$.

Respecto a la muestra de profesorado, los resultados de nuestro trabajo son totalmente comparables a los de investigaciones anteriores, al igual que en los estudios realizados para 
validar dichos cuestionarios (Gross \& John, 2003; Fernández- Berrocal et al., 2004; Robles \& Páez, 2003). Aun así, cabe resaltar que los promedios obtenidos en las subescalas de Supresión Emocional $(2,14)$ y Reevaluación Cognitiva $(3,44)$ del ERQ fueron ligeramente inferiores a los obtenidos en las validaciones de este instrumento (Medias $=3,15$ y 4,85). Por el contrario, la media obtenida en la subescala de Afecto Negativo del PANAS $(2,60)$ resultó ligeramente superior a la de la validación $(18,03)$.

En el caso de la muestra de progenitores, los valores son equiparables a los obtenidos en trabajos anteriores, así como en la validación de los cuestionarios utilizados en este estudio (Gross \& John, 2003; Fernández- Berrocal et al., 2004; Anaya \& Suárez, 2007; MartínezPampliega et al., 2006). No obstante, las medias obtenidas en las subescalas Supresión Emocional $(2,48)$ y Reevaluación Cognitiva $(3,49)$ del ERQ resultaron ligeramente inferiores a las obtenidas en las validaciones de este instrumento (Medias $=3,15$ y 4,85, respectivamente). Finalmente, se observó que la media en la subescala de Cohesión del FACES II $(4,29)$ resultó superior al valor obtenido en la validación del instrumento $(3,63)$.

En cuanto a los ANOVAs realizados, puede observarse una mejora en la regulación emocional de los estudiantes tras la intervención realizada (ver Tabla 1). Concretamente, el uso de estrategias de Supresión Emocional descendió significativamente para la muestra de estudiantes, acompañado de un aumento en la utilización de estrategias de Reevaluación Cognitiva. Una tendencia similar pudo apreciarse en el caso de los progenitores por lo que se refiere al uso de Reevaluación Cognitiva, mientras que no se encontraron diferencias estadísticamente significativas para la muestra de profesorado (ver Tabla 3). Respecto a las habilidades vinculadas con la inteligencia emocional (Atención, Claridad y Reparación Emocional), no se han observado diferencias significativas entre los valores pre- y post-intervención. En relación a los profesores (ver Tabla 2), se encontró una disminución significativa del Afecto Negativo al finalizar la intervención. Igualmente, se observó una tendencia a la disminución del Afecto Positivo, acompañada de disminuciones significativas en las subescalas Diseño del Trabajo, Realización personal y Promoción post-intervención. Por último, no se encontraron diferencias estadísticamente significativas en cuanto a la percepción del clima familiar por los progenitores.

Tabla 1

Medias, desviaciones típicas y ANOVAS (Pre vs. Post-intervención) de los autoinformes ERQ-CA, TMMS 24 y PANAS-N, para la muestra de estudiantes $(N=55)$

\begin{tabular}{|c|c|c|c|c|c|c|}
\hline & \multicolumn{2}{|c|}{ PRE } & \multicolumn{2}{|r|}{ POST } & \multicolumn{2}{|c|}{ ANOVA } \\
\hline & $\mathrm{N}$ & Media (DT) & $\mathrm{N}$ & Media (DT) & $F$ & $p$ \\
\hline \multicolumn{7}{|l|}{ ERQ-CA } \\
\hline Supresión & 54 & $12,44(3,89)$ & 49 & $10,94(3,99)$ & 3,76 & 055 \\
\hline Reevaluación & 54 & $23,62(4,08)$ & 49 & $24,73(4,51)$ & 3,68 & ,058 \\
\hline \multicolumn{7}{|l|}{ TMMS 24} \\
\hline Atención & 55 & $28,53(5,73)$ & 50 & $26,34(5,94)$ & 3,68 &, 06 \\
\hline Claridad & 55 & $30,44(5,32)$ & 50 & $29,86(6,35)$ & ,25 & ,61 \\
\hline Reparación & 55 & $31,33(5,53)$ & 50 & $31,64(6,02)$ & ,08 & ,78 \\
\hline \multicolumn{7}{|l|}{ PANAS-N } \\
\hline Afecto Positivo & - & - & 50 & $24,38(3,10)$ & - & - \\
\hline Afecto Negativo & - & - & 50 & $18,08(3,03)$ & - & - \\
\hline
\end{tabular}


Tabla 2

Medias, desviaciones típicas y ANOVAS (Pre vs. Post-intervención) de los autoinformes ERQ, PANAS, TMMS-24, ESL-VP, para la muestra de profesores $(N=20)$

\begin{tabular}{|c|c|c|c|c|c|c|}
\hline & \multicolumn{2}{|r|}{ PRE } & \multicolumn{2}{|r|}{ POST } & \multicolumn{2}{|c|}{ ANOVA } \\
\hline & $\mathrm{N}$ & Media (DT) & $\mathrm{N}$ & Media (DT) & $F$ & $p$ \\
\hline \multicolumn{7}{|l|}{ ERQ } \\
\hline Supresión & 20 & $8,55(3.20)$ & 13 & $9,08(3,20)$ & ,21 & ,647 \\
\hline Reevaluación & 18 & $20,61(4.41)$ & 13 & $20,77(3,30)$ & 01 & 914 \\
\hline \multicolumn{7}{|l|}{ TMMS 24} \\
\hline Atención & 20 & $26,85(5.80)$ & 13 & $25,23(5,21)$ & ,67 & ,421 \\
\hline Claridad & 20 & 27,65 (3.73) & 13 & $26,69(6,36)$ & ,30 &, 588 \\
\hline Reparación & 20 & $26,20(5.91)$ & 13 & $26,38(6,21)$ & .01 & .932 \\
\hline \multicolumn{7}{|l|}{ PANAS-N } \\
\hline Afecto Positivo & 20 & $35,90(5.06)$ & 13 & $31,67(6,87)$ & 3,64 & ,066 \\
\hline Afecto Negativo & 20 & $25,60(5.48)$ & 13 & $20,46(5,82)$ & 6,60 & 015 \\
\hline \multicolumn{7}{|l|}{ ESL-VP } \\
\hline Diseño de trabajo & 20 & $41,85(6.06)$ & 13 & $36,23(6,87)$ & 6,10 & 019 \\
\hline Condiciones de vida & 20 & $24,65(5.76)$ & 13 & $21,54(5,16)$ & 2,50 & , 125 \\
\hline Realización personal & 20 & $28,15(4.88)$ & 13 & $23,69(4,63)$ & 6,84 & 014 \\
\hline Promoción & 20 & $13,10(3.99)$ & 13 & $8,62(4,98)$ & 8,20 & ,007 \\
\hline Salario & 20 & $6,35(1.35)$ & 13 & $6,62(1,45)$ & 0,29 &, 595 \\
\hline
\end{tabular}

Tabla 3

Medias, desviaciones típicas y ANOVAS (Pre vs. Post-intervención) de los autoinformes ERQ, PANAS, TMMS-24, FACES II, para la muestra de progenitores $(N=18)$

\begin{tabular}{|c|c|c|c|c|c|c|}
\hline & \multicolumn{2}{|r|}{ PRE } & \multicolumn{2}{|r|}{ POST } & \multicolumn{2}{|c|}{ ANOVA } \\
\hline & $\mathrm{N}$ & Media (DT) & $\mathrm{N}$ & Media (DT) & $F$ & $p$ \\
\hline \multicolumn{7}{|l|}{ ERQ } \\
\hline Supresión & 18 & $9,90(0.56)$ & 9 & $10,00(0.84)$ & 01 & ,92 \\
\hline Reevaluación & 18 & 20,94 (1.06) & 9 & $23,11(1.50)$ & 1,40 & ,25 \\
\hline \multicolumn{7}{|l|}{ TMMS 24} \\
\hline Atención & - & - & 9 & $24,67(6,42)$ & - & - \\
\hline Claridad & - & - & 9 & $22,56(4,00)$ & - & - \\
\hline Reparación & - & - & 9 & $28,78(4,06)$ & - & - \\
\hline \multicolumn{7}{|l|}{ PANAS-N } \\
\hline Afecto Positivo & - & - & 9 & $31,44(6,08)$ & - & - \\
\hline Afecto Negativo & - & - & 9 & $21,11(4,62)$ & - & - \\
\hline \multicolumn{7}{|l|}{ FACES II } \\
\hline Cohesión & 21 & $4,29(0,10)$ & 9 & $4,22(0,15)$ &, 14 & ,71 \\
\hline Adaptabilidad & 21 & $3,68(0,10)$ & 9 & $3,64(0,16)$ & 03 & ,87 \\
\hline
\end{tabular}




\section{Discusión y conclusiones}

El presente estudio pretendía observar los cambios producidos tras una intervención en estudiantes de $4^{\circ}$ de primaria, progenitores y profesores. Aunque los resultados fueron los esperados para la muestra de estudiantes, no se cumplieron las hipótesis planteadas para las muestras de profesores y progenitores. A este respecto, cabe mencionar que el programa de educación emocional tuvo una reducción en el número de horas de formación inicialmente planteadas, pudiendo ser insuficientes para poder observar resultados significativos, tal y como se han obtenido en otros programas (Ruiz-Aranda et al., 2008; Repetto, 2009). No obstante, nuestros resultados apoyan parcialmente la evidencia experimental previa (Fernández Berrocal et al., $2005,2008)$. En cuanto al afecto negativo, la disminución observada en la muestra de profesores estaría de acuerdo con la literatura revisada (Cabello et al., 2010; Fernández Berrocal et al., 2005). Esta disminución podría ser una consecuencia de la formación adquirida en el programa SHE. No obstante, se encontró una importante reducción en afecto positivo para la muestra de profesorado que podría explicarse por el complicado momento en el que se realizó la evaluación post-intervención. Creemos que podría haberse dado una contaminación de los resultados ya que esta recogida de datos coincidió con el final del curso académico, y con la repentina implantación del Plan de Xarxa Llibres. Esta sobrecarga de trabajo afectó seriamente a la disponibilidad de los docentes que participaron voluntariamente en el programa SHE y generó un incremento en sus niveles de estrés. Dicha situación escolar podría igualmente explicar la disminución en los resultados de satisfacción laboral post-intervención (Extremera et al., 2003). En cuanto al funcionamiento familiar, no se observaron variaciones significativas en los niveles de cohesión $y$ adaptabilidad tras la intervención realizada.

En general, el hecho de que las diferencias pre- vs. post-intervención hayan sido marginalmente significativas en nuestro trabajo podría deberse a distintas limitaciones. En primer lugar, al reducido tamaño de la muestra experimental, sobre todo en los grupos de progenitores y profesorado. En segundo lugar, podría deberse a que los instrumentos utilizados no han sido suficientemente sensibles para captar el cambio emocional inducido por el programa diseñado e implementado en el presente estudio. En tercer lugar, podría explicarse a partir del número de sesiones puesto que podría ser insuficiente para notar un cambio significativo, tal y como hemos comentado anteriormente. Debido a la propia dinámica del curso académico, el número total de sesiones fue claramente inferior a lo previsto en el diseño original del programa. En este sentido, debemos considerar su implementación como un estudio piloto, pero entendemos que sería necesaria una intervención más prolongada en el tiempo para poder obtener cambios significativos. En cuarto lugar, la implantación del programa SHE en el horario lectivo del centro escolar ha supuesto un importante handicap para cumplir con el calendario establecido a priori. De hecho, el retraso de varias sesiones al principio del programa hizo que la administración post-intervención de los instrumentos coincidiera con el final del curso académico. Este momento pudo haberse visto contaminado por la presencia de elevados niveles de estrés, no sólo en el profesorado sino también en los propios estudiantes. A este respecto, se podría haber introducido algún instrumento para evaluar el estrés percibido en las diferentes muestras y cuantificar este efecto no previsto inicialmente, ayudando a obtener una visión más objetiva del impacto del programa en educación emocional. 


\section{Referencias bibliográficas}

Cabello, R., Fernández-Berrocal, P., Gross, J. J., \& Salguero, J. M. (2013). Spanish adaptation of the Emotion Regulation Questionnaire. European Journal of Psychological Assesment, 29(4), 234-240.

Extremera, N. \& Fernández-Berrocal, P. (2003b). La inteligencia emocional en el contexto educativo: hallazgos científicos de sus efectos en el aula. Revista de Educación, (332), 97-116

Fernández-Berrocal, P., Extremera, N. \& Ramos, N. (2004) Validity and realibility of the spanish modified version of the trait meta-mood scale. Psychological Reports, (94), 751-755.

Fernández-Berrocal, P. \& Extremera, N. (2005). La Inteligencia Emocional y la educación de las emociones desde el Modelo de Mayer y Salovey. Revista Interuniversitaria de Formación Del Profesorado, 19(3), 63-94.

Fernández-Berrocal, P. \& Ruiz Aranda, D. (2008). La inteligencia emocional en la educación. Electronic Journal of Research in Educational Psychology 6 (15), 421-436.

González, J., Fernández, S., Pérez, E. \& Santamaría, P. (2004). Spanish adaptation of Behavior Assessment System for Children and Adolescents: BASC. Madrid: TEA Ediciones.

Gross, J. J. \& John, O.P. (2003). Individual differences in two emotion regulation processes: Implications for affect, relationships, and well-being. Journal of Personality and Social Psychology, (85), 348-362.

Martínez-Pampliega, A., Iraurgi, I., Galíndez, G. \& Sanz, M. (2006). Family Adaptability and Cohesion Evaluative Scale (FACES): desarrollo de una versión de 20 ítems en español. International Jounal of Clinical and Health Psychology, 6, 2, 317-338.

Mayer, J. D. \& Salovey, P. (1997). What is emotional intelligence? Eln P. Salovey \& D. J. Sluyter (Eds.), Emotional development and emotional intelligence: Educational implications (pp. 3-34). New York: Harper Collins.

Olson, D. H. (1988). Capturing family change: Multi-system level assesment. En L. C. Wynne (Ed.), The state of the art in family therapy research: controversies and recommendations. (pp. 75-80). Nueva York: Family process press.

Pastor, M. C., López-Penadés, R., Cifre, E. \&Y Moliner- Urdiales, D. (en preparación). Response-focused regulation of emotions is associated with psychological maladjustment: Evidence from a Spain Adolescent Sample.

Repetto, E. (2009) Formación en competencias Socioemocionales. Ed. La Muralla, Madrid.

Rey, L., Extremera-Pacheco, N. \& Pena, M. (2011). Perceived Emotional Intelligence, Self-Esteem and Life Satisfaction in Adolescents. Psychosocial Intervention, 20(2), 227-234.

Reynolds, C. R. \& Kamphaus, R. W. (1992). Sistema de Evaluación de la Conducta de niños $y$ adolescentes (BASC). Madrid: TEA.

Robles R. \& Páez F. (2003). Estudio sobre la traducción al español y las propiedades psicométricas de las escalas de afecto positivo y negativo (PANAS). Salud Mental. 26. $\mathrm{n}^{\circ} 1$.

Ruiz-Aranda, D., Fernández-Berrocal, P., Cabello, R. \& Salguero, J. M. (2008). Educando la Inteligencia emocional en el aula: Proyecto Intemo. Electronic Journal of Research in Educational Psychology, (6), 240-251.

Sandín, B., Chorot, P., Lostao, L., Joiner, T. E., Santed, M. A. \& Valiente, R. M. (1999). Escalas Panas de afecto positivo y negativo: validación factorial y convergencia transcultural. Psicothema, (11), 37-51.

Sandín, B. (2003). Escalas PANAS de Afecto Positivo y Afecto Negativo para niños y adolescentes (PANASN). Revista de Psicopatología y Psicología Clínica, (8), 173-182. 
Watson, D., Clark, L. A. \& Tellegen, A. (1988). Development and validation of brief measures of positive and negative affect: The PANAS scales. Journal of Personality and Social Psychology, 54, 1063-1070.

Weissberg, R. P., Kumpfer \& Seligman, M. E. (2003). Prevention that works for children and youth: An introduction. American Psychologist, ( 58), 425-432. 


\title{
Rehabilitación de la marcha en el paciente con ictus Revisión bibliográfica
}

\author{
MANUEL José PINAZO LLOBET \\ manuelpi94@gmail.com \\ MARÍA ARANTZAZU RUESCAS NiCOLAU \\ arancha.ruescas@uv.es
}

\section{Resumen}

Introducción: La rehabilitación de la marcha es el objetivo principal de la fisioterapia en el ictus. Dos de los tratamientos más utilizados son el entrenamiento convencional de la marcha (ECM) y el entrenamiento de la marcha sobre cinta rodante con soporte de peso (EMSP). El objetivo principal de esta revisión ha sido realizar una revisión bibliográfica de la literatura científica, sobre la comparación entre el EMSP y el ECM en función de los resultados de las variables velocidad de la marcha, capacidad funcional y equilibrio. Y secundariamente, se ha pretendido evidenciar su eficacia en función de la cronicidad del ictus. Metodología: Se realizó una búsqueda bibliográfica en siete bases de datos EMBASE, Scopus, Literatura Latinoamericana y del Caribe en Ciencias de la Salud (LILACS), Web of Science (ISI), Physiotherapy Evidence Database (PEDro) y Cochrane, limitándola a estudios experimentales, prospectivos, aleatorizados y controlados, publicados entre enero de 2010 y diciembre de 2015 en lengua inglesa o española. Resultados: Se incluyeron 11 artículos. Nuestros resultados parecen indicar una tendencia hacia la mejoría superior en el tratamiento EMSP. No obstante, no existen diferencias estadísticamente significativas que lo abalen. Conclusión: No hemos encontrado evidencia para confirmar que el EMSP es un tratamiento más eficaz que el ECM, aunque clínicamente parece haber una mayor mejoría con el EMSP. La respuesta al tratamiento varía en función de la cronicidad. De modo que, los pacientes agudos tienen una mayor progresión en su capacidad de deambular, mientras que los crónicos mantienen la funcionalidad de la marcha.

Palabras clave: Ictus, rehabilitación de la marcha, soporte de peso, entrenamiento sobre el suelo, tapiz rodante.

\section{Abstract}

Introduction: Gait rehabilitation is the main objective of the physiotherapy in the stroke. Two of the most used treatments in conventional walking training (ECM) and treadmill training with bodyweight support (EMSP). The main objective of this review has been to analize the scientific literature on the comparison between EMSP and ECM in the function of the results of variables gait velocity, functional capacity and balance. Secondarily, it has been tried to show its efficacy in the function of the chronicity of the stroke. Methodology: A bibliographic search was conducted in seven databases EMBASE, Scopus, 
Latin American and Caribbean Literature in Health Sciences (LILACS), Web of Science (ISI), Physiotherapy Evidence Database (PEDro) and Cochrane, limiting it to experimental, prospective, randomized and controlled studies, published between January 2010 and December 2015 in English or Spanish. Results: Eleven articles were included. Our results seem to indicate a trend toward superior improvement in EMSP treatment. However, there are no statistically significant differences between the two treatments. Conclusion: We found no evidence to confirm that PFME is a more effective treatment than ECM, although clinically there seems to be a greater improvement with PFME. The response to treatment depends on the chronicity of the stroke. Acute patients have a greater progression in their ability to ambulate, while the chronic ones maintain gait functionality.

Keywords: gait rehabilitation, treadmill, bodyweight support, overground training.

\section{Introducción}

La incidencia del ictus en España es de 128 casos por cada 100.000 habitantes. En cuanto a la prevalencia, se estima que es de un $6,4 \%$, siendo mayor en hombres $(7,3 \%)$ que en mujeres $(5,6 \%)$.

En España, la mortalidad ha disminuido y la morbilidad ha aumentado (Brea et al., 2013). Seis meses después del ictus, el $26,1 \%$ de los pacientes han fallecido y el $44 \%$ de los supervivientes quedan con una dependencia funcional (Heras et al., 2004). Se estima que el coste socioeconómico de esta enfermedad supone entre el $3 \%$ y el $4 \%$ del gasto sanitario total de los países con rentas elevades (Mar et al., 2013) alrededor de 6.000 millones de euros anuales a nivel español (Jorgensen et al., 2008).

El objetivo principal de la fisioterapia en el ictus es la recuperación de la funcionalidad del paciente. Para ello, se debe centrar el proceso de rehabilitación en la reeducación de la marcha.

Para la reeducación de la marcha, el enfoque terapéutico con mayor repercusión, ha sido el reaprendizaje motor orientado a tareas. Dos de las técnicas fundadas bajo este enfoque terapéutico que más se utilizan en la actualidad son el entrenamiento de la marcha sobre el suelo $(E C M)$ y entrenamiento de la marcha sobre una cinta rodante con soporte del peso corporal del paciente (EMSP).

En la actualidad se ha generalizado la utilización de la técnica EMSP. Este tipo de tratamiento consiste en utilizar un sistema de suspensión unido a un arnés para soportar un porcentaje del peso del paciente mientras éste camina sobre una cinta de marcha. El sistema permite ejercitar la marcha de forma rítmica y repetitiva. Este tipo de tratamiento se presenta como más completo ya que, reduce la carga que debe desplazar el paciente durante la marcha y permite dar un numero de pasos por sesión mayor que el ECM (Hesse et al., 2003).

Las revisiones existentes hasta la fecha, no compararon de forma exclusiva los dos tipos de entrenamiento de la marcha, ECM y EMSP, que en la presente revisión se pretenden comparar. Además, en la práctica clínica los principales indicadores de los cambios en la funcionalidad de la marcha en los pacientes con ictus son la velocidad, la capacidad funcional y el equilibrio (Brandstater et al., 1983). La velocidad y la capacidad funcional sí han sido estudiadas, sin embargo, a pesar de la vital importancia del equilibrio en la adquisición de una marcha segura y funcional, ninguna revisión hasta el momento ha evaluado la eficacia de ambos tratamientos sobre esta variable. 
Por lo anteriormente expuesto, la presente revisión parte de la hipótesis de que el método EMSP es una forma de reeducación de la marcha más eficaz que el método ECM para mejorarla velocidad de la marcha, capacidad funcional y equilibrio en personas con secuelas de ictus.

Así pues, el presente trabajo tiene como objetivo principal realizar una revisión bibliográfica de la literatura científica publicada entre 2010 y 2015 sobre la eficacia del EMSP versus el ECM en la reeducación de la marcha de pacientes con secuelas de ictus. Concretamente se pretende analizar su eficacia a nivel de velocidad de marcha, capacidad funcional y equilibrio. Secundariamente, se pretende evidenciar la eficacia de estos tratamientos en función de la cronicidad del ictus.

\section{Método}

\section{Estrategia de búsqueda}

Se llevó a cabo una búsqueda sistemática en las siguientes bases de datos electrónicas: EMBASE, Scopus, Literatura Latinoamericana y del Caribe en Ciencias de la Salud (LILACS), Web of Science (ISI), Physiotherapy Evidence Database (PEDro) y Cochrane.

Para establecer los términos de búsqueda se empleó el tesauro Descriptores en Ciencias de la Salud (DeCS) y el propio de cada base de datos. Una vez definidos, se combinaron los términos de búsqueda relacionados con la rehabilitación de la marcha (gaitrehabilitation, treadmill, bodyweight, exercicetherapy, musclestrenght, balance, gaitspeed y overground training) con los términos que representaban a la población estudiada (stroke) a través del uso de los operadores booleanos AND y OR.

La búsqueda se limitó a estudios experimentales, prospectivos, aleatorizados y controlados, publicados entre enero de 2008 y diciembre de 2015 en lengua inglesa o española.

\section{Criterios de inclusión y exclusión}

Se incluyeron aquellos ensayos clínicos que estaban disponibles a texto completo y que estudiaban a sujetos con secuelas de ictus tanto en fase subaguda como crónica, y donde se comparara el ECM y el EMSP. Se seleccionaron las publicaciones que valoraron el efecto del entrenamiento aplicado en ambos grupos sobre, al menos, una de las siguientes variables: equilibrio estático, velocidad de la marcha y capacidad funcional.

Se excluyeron aquellos trabajos en los que la muestra no estuviera compuesta por personas con secuelas de ictus, aquellos que no contemplaban ninguna de las variables anteriormente mencionadas, aquellos cuyos pacientes pertenecientes al grupo de entrenamiento con soporte de peso fueran asistidos por robots y aquellos en los que el grupo control no realizara ningún tipo de tratamiento o bien el tratamiento que recibían no incluía la marcha sobre el suelo.

\section{Selección de los artículos}

Tras realizar la búsqueda bibliográfica, se procedió a la lectura del título, y del resumen, si era necesario. A continuación, cuando fue posible localizar el texto completo, se procedió a la lectura integra de éste. Por último, si el trabajo cumplía los criterios de inclusión, se realizó el proceso de extracción de datos. 


\section{Evaluación del riesgo de sesgo}

La evaluación del riesgo de sesgo de los estudios seleccionados se realizó mediante las escalas de Jadad (Jadad et al., 1996) y PEDro (De Morton et al., 2009). Ningún estudio fue excluido del análisis final tras la evaluación del riesgo de sesgo.

\section{Extracción de datos}

La extracción de datos se hizo en base a un formulario, previamente definido, donde se recogía información correspondiente a la población estudiada, variables analizadas, intervenciones aplicadas, resultados obtenidos y riesgo de sesgo.

\section{Resultados}

\section{Selección de estudios}

A partir de los resultados obtenidos en cada base de datos tras la aplicación de la estrategia de búsqueda, se identificaron un total de 221 publicaciones, 37 de las cuales estaban duplicadas (Figura 1). Después de realizar una revisión del título y resumen de cada publicación, se excluyeron 169 estudios por no cumplir los criterios de inclusión: población inadecuada $(n=19)$, intervención inapropiada $(n=90)$, diseño inadecuado $(n=29)$ y variables inapropiadas $(n=31)$. De modo que, finalmente, 15 estudios fueron seleccionados para la evaluación del texto completo. De estos, se excluyeron 4 artículos por imposibilidad de recuperación del texto completo $(n=2)$, intervención inadecuada $(n=1)$ o variables inadecuadas $(n=1)$. Finalmente 11 estudios fueron incluidos para su revisión.

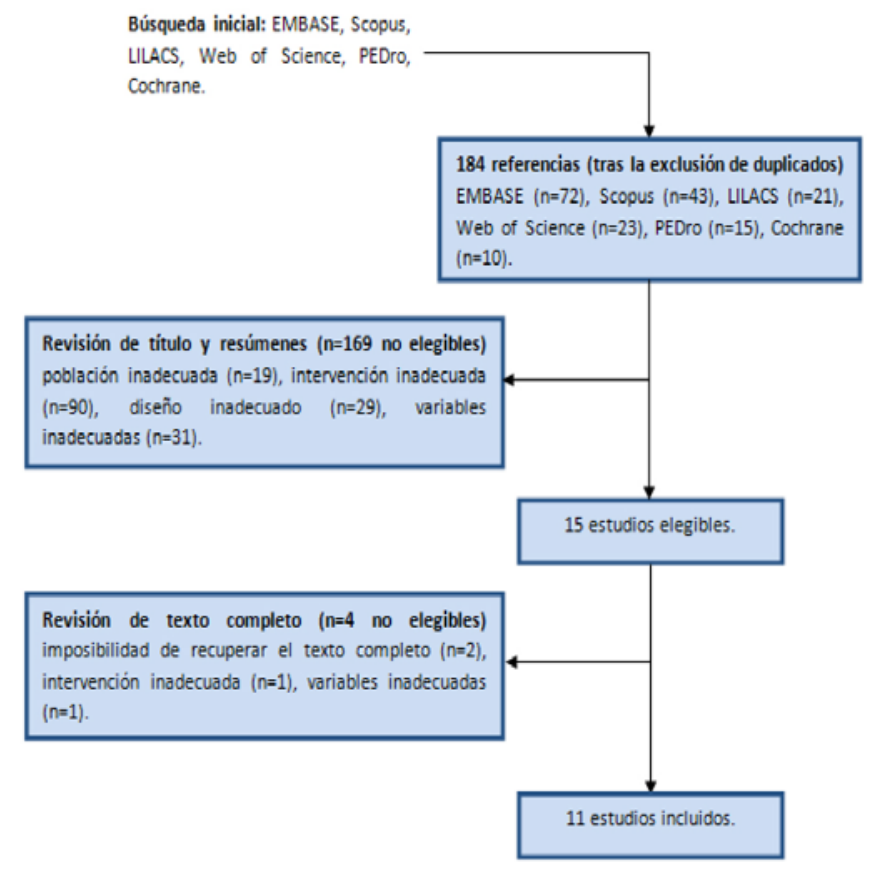

Figura 1. Diagrama de flujo de la selección de artículos 


\section{Riesgo de sesgo en los estudios incluidos}

Atendiendo a la puntuación mínima establecida por cada escala para determinar que un estudio tiene una calidad metodológica aceptable ( $\geq 7$ para la escala PEDro, $\geq 3$ para la escala Jadad), cinco investigaciones superaron ambas puntuaciones (Combs-Miller et al., 2014; De Paul et al., 2015; Duncan et al., 2011; MacKay-Lyons et al., 2013; Middleton et al., 2014), otras dos (Høyery et al., 2012; Mao et al., 2015;) superaron la puntuación de la escala PEDro pero no la de la escala Jadad y una (Takami \& Wakayama, 2010) superó la de la escala Jadad, pero no la de la escala PEDro. Así pues, de los once artículos incluidos en esta revisión, solo tres (Middleton et al., 2014; Ribeiro et al., 2013; Park et al., 2015) no presentaron una calidad metodológica aceptable.

\section{Efecto de las intervenciones}

a) Velocidad de la marcha

Los 11 estudios incluidos en esta revisión analizaron la velocidad de la marcha, 9 midieron esta variable con el test 10 metros marcha, uno (Middleton et al., 2014) con el test 3 metros marcha y otro (De Paul et al., 2015) con el test 5 metros marcha.

Los resultados de los 11 estudios muestran que el grupo EMSP tiende a tener una mejoría clínica mayor, ya que solo en dos estudios (Combs-Miller et al., 2014; Park et al., 2015) ocurrió lo contrario. No obstante, solo se encontraron diferencias estadísticamente significativas en tres trabajos (Combs-Miller et al., 2014; Mao et al., 2015; Langhammer \& Stanghelle, 2010).

\section{b) Capacidad funcional}

En siete estudios (Combs-Miller et al., 2014; De Paul et al., 2015; Duncan et al., 2011; Høyer et al., 2012; Langhammer \& Stanghelle, 2010; MacKay-Lyons et al., 2013; Middleton et al., 2014;) se evaluó la capacidad funcional mediante el test 6 minutos marcha. Aunque en los siete estudios la mejoría fue mayor en el grupo EMSP, solo en el trabajo de MacKay-Lyons et al., (2013) las diferencias fueron estadísticamente significativas a favor del grupo EMSP.

c) Equilibrio estático

Cuatro de los once estudios incluidos en esta revisión valoraron el equilibrio (Duncan et al., 2011; MacKay-Lyons et al., 2013; Middleton et al., 2014; Takami \& Wakayama, 2010) utilizando la escala de Berg. Ningún estudio encontró diferencias estadísticamente significativas, aunque en tres de los cuatro estudios el grupo ECM obtuvo mejor puntuación que el grupo EMSP y, solo en el trabajo de Takami y Wakayama (2010) ocurrió lo contrario.

\section{Discusión y conclusiones}

Los resultados del presente trabajo no han sido concluyentes. Por lo tanto, a la espera de futuras investigaciones más esclarecedoras, no podemos afirmar que el EMSP sea una técnica más eficaz que el ECM. Respecto a la cronicidad del ictus, como cabía esperar, las 
mejorías son superiores en los pacientes agudos en ambos tratamientos. No obstante, los pacientes crónicos también mejoran, en los dos tratamientos, de modo que ambos tienen una función de mantenimiento de la capacidad de marcha en este grupo poblacional.

La ausencia de evidencia científica a favor de la técnica EMSP, sugiere que las decisiones de los terapeutas deberían tomarse considerando las preferencias del paciente, así como el equipamiento y personal disponible. EI ECM es un tratamiento más económico, ya que requiere un equipamiento menor, pero es cierto que los pacientes que reciben este tratamiento necesitan un número de sesiones mayor para igualar los resultados del grupo EMSP. Si traducimos este dato al gasto sanitario total, la balanza económica podría igualarse, de modo que descartar el EMSP por razones económicas no sería un motivo de peso suficiente, aunque sí lo podrían ser las instalaciones y el personal del que se disponga.

\section{Limitaciones y futuras líneas de investigación}

Esta revisión presenta varias limitaciones. Primero, en cuanto a la realización de este trabajo, haber limitado la búsqueda a textos disponible a texto completo, redactado en inglés o español y publicado en los últimos 5 años, puede haber sido un factor determinante que ha limitado el acceso a la totalidad de la evidencia disponible.

Por otra parte, respecto a la metodología de los estudios, una debilidad importante de esta revisión ha sido la elevada variabilidad metodológica en la aplicación de las intervenciones. La ausencia de homogeneidad a la hora de aplicar cada tipo de tratamiento, así como la falta de consenso en la dosificación y protocolización de ambas intervenciones, han sido un obstáculo. Otra limitación fue que la mayoría de los estudios incluidos tuvieron un tamaño muestral reducido y esto, posiblemente haya producido un aumento de la dificultad para establecer diferencias estadísticamente significativas entre los dos tratamientos a comparar.

A pesar de esto, la elevada calidad metodológica de la mayoría de los estudios analizados, avala los resultados que en esta revisión se presentan.

Los resultados de la presente revisión han evidenciado la necesidad de futuros ensayos clínicos en este campo que limiten ambas intervenciones únicamente a los dos tipos de tratamiento, sin introducir otro tipo de terapias como el entrenamiento de la fuerza y sobretodo el equilibrio, ya que esto puede alterarlos resultados e impedir una correcta comparación entre tratamientos. También sería conveniente estudiar las características más apropiadas para la dosificación de los parámetros del entrenamiento (intensidad, duración, frecuencia). Asimismo, consideramos importante realizar futuros ensayos clínicos con un mayor tamaño muestral y donde se haga un seguimiento a largo plazo para poder observar el mantenimiento de los beneficios de ambas intervenciones.

\section{Conclusiones}

A partir de los resultados obtenidos en la presente revisión podemos concluir que:

1) No existe evidencia que afirme que, para reeducar la marcha en personas con secuelas de ictus, el entrenamiento con soporte de peso sea más eficaz que el entrenamiento convencional.

2) Parece que el entrenamiento de suspensión tiende a producir una mejoría en la velocidad de la marcha, clínicamente superior, al entrenamiento convencional. 
3) El entrenamiento con soporte de peso, parece ser más eficaz que el entrenamiento de la marcha sobre el suelo para la mejora de la capacidad funcional.

4) Parece que ambos tratamientos son útiles para la mejoría del equilibrio, aunque no hemos hallado evidencia para afirmar que un tratamiento es superior al otro.

5) En pacientes agudos parece que hay una tendencia a una recuperación de la capacidad de deambular más rápida con el tratamiento de suspensión. En pacientes con secuelas crónicas de ictus parece que este tratamiento es más eficaz para el mantenimiento de la funcionalidad de la marcha.

\section{Referencias bibliográficas}

Brandstater, M. E., De Bruin, H., Gowland, C. \& Clark, B. M. (1983). Hemiplegic gait: analysis of temporal variables. Archives of Physical Medicine and Rehabilitation, 64(12), 583-587.

Brea, A., Laclaustra, M., Martorell, E. \& Pedragosa, À. (2013). Epidemiología de la enfermedad vascular cerebral en España. Clínica e Investigación en Arteriosclerosis, 25(5), 211-217.

Combs-Miller, S. A., Kalpathi Parameswaran, A., Colburn, D., Ertel, T., Harmeyer, A... Schmid, A. A. (2014). Body weight-supported treadmill training vs. overground walking training for persons with chronic stroke: a pilot randomized controlled trial. Clinical Rehabilitation, 28(9), 873-884.

De Morton, N. A. (2009). The PEDro scale is a valid measure of the methodological quality of clinical trials: a demographic study. Australian Journal of Physiotherapy, 55(2), 129-133.

De Paul, V. G., Wishart, L. R., Richardson, J., Thabane, L., Ma, J. \& Lee, T. D. (2015). Varied Overground Walking Training Versus Body-Weight-Supported Treadmill Training in Adults Within 1 Year of Stroke A Randomized Controlled Trial. Neurorehabilitation and Neural Repair, 29(4), 329-340.

Duncan, P. W., Sullivan, K. J., Behrman, A. L., Azen, S. P., Wu, S. S., Nadeau, S. E...Hayden, S.K. (2011). Body-weight-supported treadmill rehabilitation after stroke. New England Journal of Medicine, 364(21), 2026-2036.

Heras, M. A., de la Cámara-González, C., Tacsir, A. \& García, J. R. (2004). Informe sobre el impacto social de los enfermos dependientes por ictus: Informe ISEDIC, 2004. Madrid: Egraf.

Hesse, S., Werner, C., Seibel, H., von Frankenberg, S., Kappel, E. M., Kirker, S. \& Käding, M. (2003). Treadmill training with partial body-weight support after total hip arthroplasty: a randomized controlled trial. Archives of Physical medicine and Rehabilitation, 84(12), $1767-1773$.

Høyer, E., Jahnsen, R., Stanghelle, J. K. \& Strand, L. I. (2012). Body weight supported treadmill training versus traditional training in patients dependent on walking assistance after stroke: a randomized controlled trial. Disability and Rehabilitation, 34(3), 210-219.

Jadad, A. R., Moore, R. A., Carroll, D., Jenkinson, C., Reynolds, D. J., Gavaghan, D. J. \& McQuay, H. J. (1996). Assessing the quality of reports of randomized clinical trials: is blinding necessary? Controlled Clinical Trials, 17(1), 1-12.

Jorgensen, N., Cabañas, M., Oliva, J., Rejas, J. \& León, T. (2008). Los costes de los cuidados informales asociados a enfermedades neurológicas discapacitantes de alta prevalencia en España. Neurología, 23(1), 29-39.

Langhammer, B. \& Stanghelle, J. K. (2010). Exercise on a treadmill or walking outdoors? A randomized controlled trial comparing effectiveness of two walking exercise programmes late after stroke. Clinical Rehabilitation, 24(1), 46-54. 
MacKay-Lyons, M., McDonald, A., Matheson, J., Eskes, G. \& Klus, M. A. (2013). Dual effects of body-weight supported treadmill training on cardiovascular fitness and walking ability early after stroke: a randomized controlled trial. Neurorehabilitation and Neural Repair, 27(7), 644-653.

Mao, Y. R., Lo, W. L., Lin, Q., Li, L., Xiao, X., Raghavan, P. \& Huang, D. F. (2015). The effect of body weight support treadmill training on gait recovery, proximal lower limb motor pattern, and balance in patients with subacute stroke. BioMedi Research International, 175719.

Mar, J., Álvarez-Sabín, J., Oliva, J., Becerra, V., Casado, M. A., Yébenes, M... MasJuan, J. (2013). Los costes del ictus en España según su etiología. El protocolo del estudio CONOCES. Neurología, 28(6), 332-339.

Middleton, A., Merlo-Rains, A., Peters, D. M., Greene, J. V., Blanck, E. L., Moran, R. \& Fritz, S.L. (2014). Body Weight-Supported Treadmill Training Is No Better Than Overground Training for Individuals with Chronic Stroke: A Randomized Controlled Trial. Topics in stroke rehabilitation, 21(6), 462-476.

Park, B. S., Kim, M. Y., Lee, L. K., Yang, S. M., Lee, W. D., Noh, J. W... Kim, J. (2015). Effects of conventional overground gait training and a gait trainer with partial body weight support on spatiotemporal gait parameters of patients after stroke. Journal of Physical Therapy Science, 27(5), 1603-1607.

Ribeiro, T., Britto, H., Oliveira, D., Silva, E., Galvão, E. \& Lindquist, A. (2013). Effects of treadmill training with partial body weight support and the proprioceptive neuromuscular facilitation method on hemiparetic gait: a randomized controlled study. European Journal of Physical and Rehabilitation Medicine, 49(4), 451-461.

Takami, A. \& Wakayama, S. (2010). Effects of partial body weight support while training acute stroke patients to walk backwards on a treadmill-a controlled clinical trial using randomized allocation. Journal of Physical Therapy Science, 22(2), 177-187. 


\title{
Relación entre la regulación emocional y la autoestima
}

\author{
NÚRIA BALAGUER PICH \\ al313720@uji.es \\ MARTÍN SÁNCHEZ GÓMEZ \\ martin.sanchez@uji.es \\ AZUCEnA García Palacios \\ azucena@uji.es
}

\section{Resumen}

Introducción: Autoestima y regulación emocional son constructos psicológicos relacionados con la salud mental. El presente estudio pretende explorar la relación existente entre estos dos constructos. Objetivo: Analizar la relación entre la autoestima y distintas dimensiones de la regulación emocional y conocer cuáles tienen más relación con la autoestima. Método: Cien personas, entre 20 y 30 años, de la población general participaron en el estudio (51 mujeres y 49 hombres). Fueron evaluadas a través del Cuestionario de Autoestima de Rosenberg (Rosenberg, 1965) y la Escala de Dificultades en la Regulación Emocional (DERS, Gratz y Roemer, 2004). Resultados: Los resultados muestran una correlación significativa entre la autoestima y las subescalas del DERS: Atención, Claridad, Aceptación, Funcionamiento y Regulación. El análisis de regresión reveló que las dimensiones más relacionadas con la autoestima fueron la Aceptación y la Atención. Conclusión: Es esperable encontrar una relación entre la capacidad de regular las emociones y un constructo que supone una valoración positiva de uno mismo, la autoestima. En concreto, la capacidad de prestar atención a las emociones y aceptarlas podrían ser aspectos fundamentales en la construcción de un autoconcepto y una valoración de sí mismo positivos. En investigaciones futuras se propone estudiar en profundidad estas relaciones con el fin de poder realizar recomendaciones sobre qué aspectos de la regulación emocional trabajar con el fin de potenciar autoestima y bienestar.

Palabras clave: Autoestima, regulación emocional, emociones, aceptación, salud mental.

\section{Abstract}

Introduction: Self-esteem and emotional regulation are psychological constructs relate to mental health. The current research pretends to explore the relation between these two constructs. Objective: Analyze the relation between self-esteem and differents dimensions of emotional regulation, and knowing which have more relation with the self-esteem. Method: one hundred people from the general population participated in this study (51 women and 49 men), with ages between 20-30 years were evaluated through the Rosenberg self-esteem questionnaire (Rosenberg, 1965) and Scale of dif- 
ficulty in emotional regulation (DERS, Gratz \& Roemer, 2004). Results: The results show a significant correlation between self-esteem and the subscales of the DERS: attention, clarity, acceptance, operation and regulation. Regression analysis revealed that most related to self-esteem dimensions were acceptance and attention. Conclusion: It is expected to find a relationship between the ability to regulate emotions and a construct that implies a positive evaluation of one's own, the self-esteem. In particular, the ability to pay attention to emotions and accept could be key aspects in constructing a positive self-concept and self-assessment. In future research it is proposed to study in depth these relationships in order to be able to make recommendations about which aspects work in emotional regulation in order to enhance self-esteem and well-being.

Key Words: Self-esteem, emotional regulation, emotions, acceptance, mental health.

\section{Introducción}

Como indican recientes investigaciones, el modelo transdiagnóstico es una propuesta multidimensional que aborda el estudio y tratamiento de los trastornos emocionales en base a dimensiones psicopatológicas comunes a distintos trastornos (Kirszman y del Carmen Salgueiro, 2015).

Existen ya diversos modelos transdiagnósticos que están proporcionando mejoras en la comprensión y tratamiento de distintos trastornos. En este trabajo mencionaremos dos modelos que consideramos importantes, ya que en ellos se indican los constructos objetivo de este trabajo, autoestima y regulación emocional. Estos modelos son el modelo transdiagnóstico para los trastornos alimentarios de Fairburn (Fairburn, Cooper y Shafran, 2003) y el modelo transdiagnóstico para los trastornos emocionales de Brown y Barlow (2009). Las investigaciones más recientes han coincidido en encontrar diversos problemas de regulación emocional en la población clínica. En concreto, estos problemas se han encontrado en pacientes con trastornos depresivos, en la mayoría de los trastornos de ansiedad y en los trastornos de la personalidad, sobre todo en el trastorno límite de personalidad. Las personas que sufren estos trastornos presentarían déficits de regulación emocional, es decir, desregulación afectiva. Estos avances en las propuestas de clasificación están dando lugar a perspectivas novedosas en el tratamiento de los trastornos emocionales, como el protocolo unificado para el tratamiento transdiagnóstico de los trastornos emocionales (Barlow y cols., 2010), el cual propone que hay evidencia que atestigua la amplia comorbilidad diagnóstica entre los trastornos de ansiedad y estado de ánimo. Estudios longitudinales indican que la covariación temporal de estos trastornos puede explicarse por cambios en Neuroticismo/Inhibición conductual (N/IC) y, en algunos casos, niveles iniciales de N/IC son predictivos en el curso temporal de los trastornos emocionales. La superposición de los trastornos de ansiedad y estado de ánimo del DSM-IV (APA, 2000) es una fuente frecuente de falta de fiabilidad diagnóstica (por ejemplo, superposición temporal de las características comunes del trastorno de ansiedad generalizada y trastornos del ánimo, situación específica de ataques de pánico en el trastorno de pánico y fobia específica). Aunque las propuestas dimensionales pueden abordar algunos inconvenientes asociados a la nosología del DSM (por ejemplo, inadecuada evaluación de las diferencias individuales en la severidad de la enfermedad), estas propuestas no reconcilian los problemas 
clave en la clasificación actual, como una modesta fiabilidad y una alta comorbilidad (Brown y Barlow, 2009).

Déficits en la regulación emocional son comunes a estos trastornos y los pacientes con trastornos emocionales habitualmente utilizan estrategias desadaptativas de regulación emocional que contribuyen al mantenimiento de los síntomas.

También existen protocolos transdiagnósticos en otros trastornos como los trastornos alimentarios (Fairburn, 2008). Este protocolo se refiere a los procesos psicopatológicos que son responsables de la persistencia de graves trastornos de la alimentación. Se desarrollan dos líneas argumentales independientes pero interrelacionadas. Uno es que se amplíe la teoría basada en la evidencia principal del mantenimiento de los trastornos alimentarios, la teoría cognitiva conductual de la bulimia nerviosa. En concreto, se propone que en ciertos pacientes, uno o más de cuatro procesos interactúan con el trastorno base y que cuando esto ocurre es un obstáculo para el cambio. Los procesos de mantenimiento adicionales son el perfeccionismo clínico, la baja autoestima, la intolerancia a las emociones y las dificultades interpersonales. La segunda línea de argumentación es que en el caso de trastornos alimentarios compartidos, pero distintivos, algunas características clínicas tienden a ser mantenidas por procesos psicopatológicos similares. Por consiguiente, se sugiere qu e esos mecanismos comunes están implicados en la la bulimia nerviosa, la anorexia nerviosa y los trastornos atípicos. Juntas, estas dos líneas de argumentación llevan a proponer una nueva teoría transdiagnóstica del mantenimiento de toda la gama de trastornos alimentarios, una teoría que abarca una gama más amplia en mantener los mecanismos de la teoría actual sobre la bulimia nerviosa (Fairburn, 2003).

En este trabajo estamos interesados en estudiar dos constructos relevantes en estos modelos transdiagnósticos, la autoestima y la regulación emocional.

En la literatura científica revisada, es posible apreciar la inexistencia de un acuerdo en relación al concepto de regulación emocional y autoestima. Sin embargo, hemos considerado la definición de Bonet acerca de la autoestima y la definición de Thompson sobre la regulación emocional, como las más cercanas a nuestra perspectiva de estudio. Así pues, Bonet (1997) define autoestima como un "sentimiento valorativo dirigido a nosotros mismos y nuestro conjunto de rasgos construido a través de la influencia de múltiples factores y experiencias a lo largo de la vida»(Bonet, 1997), y Thompson (1994), define regulación emocional como el «proceso de iniciar, mantener, modular o cambiar la ocurrencia, intensidad o duración de los estados afectivos internos y los procesos fisiológicos, a menudo con el objetivo de alcanzar una meta» ( $p$. 106). Esta definición se considera como base, ya que permite conceptualizar la regulación emocional como un proceso que ayuda al ser humano a manejar sus estados emocionales, para lo que puede utilizar distintos tipos de estrategias que conducen a ese objetivo.

Nuestro objetivo es demostrar que estos dos constructos correlacionan y podemos categorizarlos como dimensiones que poseen diferentes trastornos emocionales. La hipótesis del estudio es la existencia de correlación negativa entre la autoestima y las dificultades en regulación emocional. Es decir, demostrar que la autoestima que posee una persona y las dificultades de gestión emocional que pueda tener son dos factores que correlacionan entre sí e influyen en la salud mental, puesto que presentar dificultades en regulación emocional junto con una baja autoestima podrían favorecer el inicio de trastornos emocionales como depresión o trastornos de ansiedad, así como el mantenimiento de éstos. Profundizando en este estudio correlacional, veremos si algunas subdimensiones de la regulación emocional correlacionan más que otras con la autoestima mediante un análisis de regresión lineal paso a paso.

Las subdimensiones de la escala DERS son habilidades conceptualizadas como elementos centrales para la regulación emocional, y las altas puntuaciones en estas habilidades mostrarán en los participantes, dificultades en la gestión emocional. Los diferentes aspectos 
del proceso de la regulación emocional en los que pueden existir dificultades son: Descontrol emocional, Interferencia cotidiana, Desatención emocional, Confusión emocional y Rechazo emocional. Por contra, estas cinco subdimensiones tienen su lado opuesto: Control emocional, Funcionamiento emocional. Atención emocional, Claridad emocional y Aceptación emocional (Hervás y Jódar, 2008).

\section{Método}

\section{Participantes}

Como criterios de inclusión se establecieron: a) no estar o haber estado en tratamiento psicológico o psiquiátrico, de este modo nos aseguramos de no contar con población clínica; b) Con respecto al rango de edad, se requirió tener una edad comprendida entre 20 y 30 años.

Después de aplicar los criterios de selección, la muestra inicial de 168 personas se redujo a 100 participantes, de los cuales 51 eran mujeres. La media de edad fue de 22,1 años con un $90 \%$ de población universitaria, concretamente estudiantes de la Universidad Jaume I debido a la accesibilidad. Los objetivos y fines del estudio fueron presentados durante el primer contacto con la población.

\section{Instrumentos de evaluación}

La regulación emocional fue evaluada mediante la escala DERS (Escala de Dificultades en la Regulación Emocional (DERS, Difficulties in Emotion Regulation Scale) (Gratz y Roemer, 2004 ), que cuenta con un alto índice de confiabilidad $(\alpha=.93)$, y sus cinco subescalas (atención-desatención; claridad-confusión; aceptación-rechazo; funcionamiento-interferencia; regulación-descontrol) para evaluar diferentes aspectos de la desregulación emocional a través de una escala Likert de 5 puntos (de "Casi nunca / 0-10\% de las veces» a "Casi siempre / 90$100 \%$ de las veces»). La escala DERS permite medir diferentes aspectos de la regulación desadaptativa, aspectos considerados clínicamente relevantes, y que al mismo tiempo abarcan las dificultades funcionales y déficits más importantes que pueden presentarse en el transcurso del procesamiento emocional de un suceso.

En cuanto a la autoestima, fue medida a través del Cuestionario de Autoestima de Rosenberg (RSQ; Rosenberg, 1965) ( $\alpha=.92$; Fernández-Montalvo y Echeburúa, 1997), que evalúa el sentimiento de satisfacción que una persona tiene sobre sí misma a través de una escala Likert de 4 puntos.

\section{Procedimiento}

El procedimiento se inició estableciendo los criterios de selección muestral para obtener una población que cumpliera con las características de planteadas para el estudio. Después se procedió a la recogida de datos. Esta se alargó alrededor de un mes, los participantes no obtuvieron ninguna retribución y su colaboración fue totalmente anónima para cumplir con la confidencialidad. La totalidad de los test se realizaron de manera online. 
Los instrumentos de medida utilizados fueron transformados a formato online a través del Google Forms para cuestionarios y se difundieron por diferentes canales de comunicación como la mensajería móvil, las redes sociales y el correo electrónico.

Análisis de datos

Una vez obtenidas las respuestas se procedió a almacenar los datos y posteriormente a su análisis mediante el programa estadístico SPSS (versión 24.0). Tras ello, efectuamos las correspondiente correlaciones bivariadas mediante la $r$ de Pearson y análisis de regresión paso a paso (stepwise).

\section{Resultados}

En primer lugar, cuando analizamos mediante la correlación de Pearson las diferentes subescalas del DERS y la escala de autoestima de Rosenberg, observamos que las correlaciones (ver Tabla 1) eran significativamente altas en sentido negativo. Este resultado nos mostró que dificultades en atención emocional, claridad emocional, aceptación de las emociones, funcionamiento y, por último, dificultades en la regulación emocional, tienen una relación negativa significativa con el nivel de autoestima.

Tabla 1

Correlación de las variables de estudio (Pearson)

\begin{tabular}{cccccc}
\hline Variable & Atención & Claridad & Aceptación & Funcionamiento & Regulación \\
\hline Autoestima &,$- 547^{* *}$ &,$- 469^{* *}$ &,$- 583^{* *}$ &,$- 327^{* *}$ &,$- 463^{* *}$ \\
\hline
\end{tabular}

${ }^{* *}$ La correlación es significativa en el nivel 0,01

En segundo lugar, teniendo en cuenta los resultados obtenidos anteriormente, se llevó a cabo un análisis de regresión Stepwise en el que se incluyeron las variables del DERS para evaluar el valor predictivo de las dimensiones de regulación emocional con respecto a la autoestima. En la tabla 2 se ofrecen los resultados de dicho análisis. Tras realizar el análisis de regresión sobre las variables implicadas, se obtuvo que las dos que mayor relación tenían con la autoestima fueron la aceptación y la atención. 
Tabla 2

Análisis de regresión Stepwise

\begin{tabular}{|c|c|c|c|c|c|c|}
\hline Modelo & & \multicolumn{2}{|c|}{$\begin{array}{c}\text { Coeficientes no } \\
\text { estandarizados }\end{array}$} & $\begin{array}{c}\text { Coeficientes } \\
\text { estandarizados }\end{array}$ & $\mathrm{t}$ & $\mathrm{p}$ \\
\hline & & $\mathrm{B}$ & Error típico & Beta & & \\
\hline \multirow{2}{*}{2} & (Constante) & 42,882 & 1,351 & & 31,731 & 0,000 \\
& DERS: & $-0,378$ & 0,065 & $-0,450$ & $-5,777$ & 0,000 \\
& Aceptación & $-0,666$ & 0,131 & $-0,396$ & $-5,082$ & 0,000 \\
& DERS: & & & & & \\
& Atención & & & & & \\
\hline
\end{tabular}

Variable dependiente: Autoestima

\section{Conclusión}

El objetivo de este trabajo era analizar la relación entre dos constructos, autoestima y regulación emocional, mediante la evaluación de distintas subdimensiones como la claridad emocional (o por contra confusión), la aceptación emocional (o por contra rechazo), la atención a las emociones (o por contra desatención), el funcionamiento emocional (o por contra interferencia), el control emocional (o por contra descontrol) y finalmente, la autoestima. Los resultados obtenidos muestran que todas las subdimensiones relacionadas con las dificultades en la regulación emocional correlacionan de forma significativa y en sentido negativo con la dimensión de autoestima, siendo las subdimensiones de aceptación y atención emocional las que guardan una relación mayor, según indica el análisis de regresión. Ambas subdimensiones son muy importantes para la regulación emocional, ya que están relacionadas con prestar atención a las emociones y no huir de ellas. Nuestros resultados podrían indicar que la aceptación de una esfera tan importante como es la afectividad, nuestras emociones, contribuiría a la aceptación y valoración de nosotros mismos en términos globales, es decir, contribuiría a una autoestima sana.

Nuestros datos indican que existe una gran covariación entre los dos constructos claves del estudio, autoestima y regulación emocional. Tras haber analizado los resultados de forma pormenorizada podemos decir que, se encuentran en consonancia con la hipótesis planteada.

Nos detendremos ahora en explicar más detalladamente cada subdimensión de la regulación emocional, la autoestima, y la relación entre ambos constructos. Por una parte, Gratz y Roemer (2004) definen la atención emocional como la habilidad de atender y entender respuestas emocionales. Esta es la categoría para medir las dificultades en reconocer y darse cuenta de sus propias emociones. Sin embargo, hay algunas definiciones alternativas de atención desde una perspectiva analítica conductual. Por ejemplo, León y Diego (2006) definen atención emocional como una habilidad para experimentar la propia emoción, reconocerla y observarla. Para reducir la brecha en la definición, Caycedo, Gutiérrez, Ascencio y Delgado (2005) plantearon que esta se relaciona con las habilidades de regulación emocional. Por esto, cuando los individuos reconocen las emociones, el contexto donde ocurren y otros repertorios conductuales emitidos para manejar las respuestas emocionales, ellos pueden modular eficazmente sus propios comportamientos. Esto significa que la consciencia de esa atención emocional puede ser un prerrequisito conductual para la regulación emocional, como una habilidad amplia e independiente (Weis, Gratz y Lavender, 2015). Por otra parte, la aceptación 
emocional es la habilidad de experimentar emociones sin intentar controlarlas o cambiarlas. Por lo tanto, hay un estrecho vínculo con la experiencia emocional, por lo que es responsable de alguna parte de las habilidades para regular la emoción. La categoría de no-aceptación (rechazo) emocional hace referencia a la reacción negativa, a las respuestas emocionales de uno mismo y de otros. El rechazo emocional está estrechamente relacionado con la intolerancia al malestar, que se destaca por ejemplo en las personas con trastorno límite de la personalidad. La dificultad en conductas dirigidas a metas implica una interferencia emocional en una acción efectiva hacia una meta, mientras las personas están experimentando emociones negativas. El descontrol o la impulsividad emocional se refiere a los problemas para controlar el propio comportamiento cuando se experimenta una emoción con alta intensidad. Finalmente, la claridad emocional mide las dificultades para diferenciar las emociones mientras estas son experimentadas (Gratz y Roemer, 2004).

El acceso limitado a estrategias de regulación emocional hace referencia a la pobre percepción de habilidades para modular las emociones y conlleva a una estrecha relación con la baja autoestima. Podemos concluir que la íntima relación de la autoestima con la capacidad de gestión emocional convierte a estas dos dimensiones en pilares básicos para poder trabajar en emociones específicas y estrategias de regulación emocional y poder así potenciar el bienestar de las personas. De este modo, las estrategias utilizadas para sentir, expresar y regular nuestras emociones estarán íntimamente ligadas a nuestra autoestima.

La autoestima es otra de las variables que ha demostrado estar relacionada con la regulación emocional (Smith y Petty, 1995; Heimpel y cols., 2002; Setliff y Marmurek, 2002). A través de diferentes investigaciones, se ha demostrado que una baja autoestima está asociada a importantes déficits de regulación afectiva (Hervás y Vázquez, 2006). Por ejemplo, algunos de los síntomas psicopatológicos más preocupantes como las conductas autolesivas o el consumo de sustancias, constituyen, a veces, intentos desadaptativos de regulación emocional (McNally, Palfai, Levine, y Moore, 2003; Gratz, 2003). Dada la relación entre la autoestima y la regulación emocional, es conveniente incluir este constructo en las intervenciones dirigidas a mejorar las estrategias de regulación emocional.

El presente estudio cuenta con algunas limitaciones que nos gustaría destacar. El instrumento de medida DERS, herramienta para conocer dificultades de regulación emocional, es una medida de autoinforme, este tipo de autoevaluación ha generado dudas acerca de su utilidad para evaluar habilidades, ya que son difícilmente medibles a través de preguntas escritas. Sería conveniente combinar los datos de autoinforme con alguna tarea más objetiva en la que la persona fuera expuesta a emociones y tuviera que regularlas. Otra limitación en nuestro estudio es que es meramente correlacional y, por tanto, no podemos establecer relaciones de causa-efecto entre los constructos estudiados.

Entre nuestras líneas futuras pretenden ampliar esta investigación y realizar análisis causales (por medio de paradigmas experimentales) para conocer en qué sentido y de qué forma se relacionan entre ellas estas variables o qué influencias mutuas ejercen entre sí.

\section{Referencias bibliográficas}

Barlow, D. H., Farchione, T. J., Fairholme, C. P., Ellard, K. K., Boisseau, C. L., Allen, L. B., y May, J. T. E. (2010). Unified protocol for transdiagnostic treatment of emotional disorders: Therapist guide. Oxford University Press.

Bonet, J. V. (1997). Sé amigo de ti mismo: manual de autoestima. Santander: Sal Terrae. 
Brown, T. A. y Barlow, D. H. (2009). A proposal for a dimensional classification system based on the shared features of the DSM-IV anxiety and mood disorders: implications for assessment and treatment. Psychological assessment, 21(3), 256.

Caycedo, C., Gutiérrez, C., Ascencio, V. y Delgado, A.(2005). Regulación emocional y entrenamiento en solución de problemas sociales como herramienta de prevención para niños de 5 a 6 años. Suma psicológica, 12(2), 157-173.

Fairburn, C. G., Cooper, Z. y Shafran, R. (2003). Cognitive behaviour therapy for eating disorders: $A$ «transdiagnostic» theory and treatment. Behaviour research and therapy, 41(5), 509-528.

Fairburn, C. G. (2008). Cognitive behavior therapy and eating disorders. Guilford Press.

Gratz, K. L. y Roemer, L. (2004). Multidimensional assessment of emotion regulation and dysregulation: Development, factor structure, and initial validation of the difficulties in emotion regulation scale. Journal of psychopathology and behavioral assessment, 26(1), 41-54.

Hervás, G. y Jódar, R. (2008). Adaptación al castellano de la Escala de Dificultades en la Regulación Emocional. Clínica y Salud, 19(2), 139-156.

Hervás, G. y Vázquez, C. (2006). La regulación afectiva: modelos, investigación e implicaciones para la salud mental y física. Revista de psicología general y aplicada, 59(1-2), 9-36.

Kirszman, D. y Del Carmen Salgueiro, M. (2015). Body image. Mediating dimensions in psychopathology and types of intervention. Revista Mexicana de Trastornos Alimentarios, 6(2), 129-136.

León, R. y Diego, A. (2006). ¿Es explicable la conciencia sin emoción?: una aproximación biológico-afectiva a la experiencia consciente. Revista latinoamericana de Psicologia, 38(2), 361-381.

McNally, A. M., Palfai T. P., Levine, R. V. y Moore, B. M. (2003). Attachment dimensions and drinking-related problems among young adults: The mediational role of coping motives. Addictive Behaviors, 28, 1115-1127.

Muñoz-Martínez, A. M., Vargas, R. M. y Hoyos-González, J. S. (2016). Escala de dificultades en regulación emocional (DERS): Análisis factorial en una muestra colombiana. Acta Colombiana de Psicología, 19(1), 237-248.

Rosenberg, M. (1965). Rosenberg self-esteem scale (RSE). Acceptance and commitment therapy. Measures package, 61, 52.

Thompson, R. A. (1994). Emotion regulation: A theme in search of definition. Monographs of the society for research in child development, 59(2 - 3), 25-52.

Weiss, N. H., Gratz, K. L. y Lavender, J. M. (2015). Factor structure and initial validation of a multidimensional measure of difficulties in the regulation of positive emotions: the DERSpositive. Behavior modification, 39(3), 431-453. 


\title{
Respuesta cardíaca de defensa y emocionalidad negativa en población normal
}

\author{
Nieves Fuentes-SÁNCHEZ \\ al262229@uji.es \\ IRENE JAÉN \\ al119335@uji.es \\ BEATRIZ GARCÍA-CARRIÓN \\ al289008@uji.es \\ EVA CIFRE \\ cifre@uji.es \\ M. CARMEN PASTOR \\ mpastor@uji.es
}

\section{Resumen}

La Respuesta Cardíaca de Defensa (RCD) es un patrón dinámico de reactividad cardíaca en respuesta a un estímulo aversivo, intenso e inesperado que consiste en dos componentes sucesivos acelerativos y decelerativos, cuya significación psicológica se atribuye tanto a procesos atencionales como emocionales. De acuerdo con el modelo de la cascada defensiva propuesto por Lang (1995), el segundo componente acelerativo de la RCD puede interpretarse como un indicador de activación del sistema motivacional defensivo. Esta investigación tiene como objetivo analizar la relación entre la RCD y los niveles de ansiedad y depresión, como indicadores de emocionalidad negativa. La muestra experimental fue de 100 participantes, estudiantes de Psicología y Criminología de la Universitat Jaume I. La tarea experimental consistió en la presentación de un sonido intenso y aversivo $(500 \mathrm{~ms}, 105 \mathrm{~dB})$ tras un periodo de reposo de 6 minutos. El registro de los componentes acelerativos y decelerativos se realizó durante los $80 \mathrm{~s}$ posteriores a la presentación del estímulo acústico. Al finalizar la sesión experimental se administró una batería de cuestionarios, entre ellos el BDI y el STAI-R. Los análisis preliminares muestran una mayor reactividad cardíaca en los participantes con mayores puntuaciones en ansiedad y depresión. Estos datos sugieren que una mayor reactividad del sistema motivacional defensivo podría interpretarse como un factor de vulnerabilidad para desarrollar trastornos de ansiedad y depresión. Podemos concluir, por tanto, que la RCD parece ser un indicador fiable y válido de la hiperactividad del sistema motivacional defensivo en personas que presentan una mayor predisposición a reaccionar con sintomatología ansiosa o depresiva.

Palabras clave: Respuesta Cardíaca de Defensa, ansiedad, depresión, emocionalidad negativa, población normal 


\section{Abstract}

The Cardiac Defense Response (CDR) is a dynamic pattern of cardiac reactivity in response to an aversive, discrete, intense and unexpected stimulus consisting of two successive accelerative and decelerative components whose psychological significance is attributed to both attentional and emotional processes. According to the model of the defensive cascade proposed by Lang (1995), the second accelerative component of the CDR can be interpreted as an indicator of activation of the defensive motivational system. This study aims to analyze the relationship between CDR and levels of anxiety and depression as indicators of negative emotionality. The sample consisted of 100 participants, students of Psychology and Criminology, from Jaume I University. The experimental task consisted in the presentation of intense and aversive sound (500 ms, $105 \mathrm{~dB}$ ) after a 6-minute rest period. Accelerative and decelerative components were obtained during the $80 \mathrm{~s}$ after the presentation of the acoustic stimulus. At the end of the experimental session, a battery of questionnaires was administered, including BDI and STAI-R. Preliminary results show higher cardiac reactivity in participants with higher scores both on anxiety and depression. These data suggest that a greater reactivity of the defensive motivational system can be a factor of vulnerability to develop anxiety and depression disorders. We can conclude, therefore, that CDR may be interpreted as an index of the hyperactivity of the defensive motivational system in people with greater predisposition to react with anxious or depressive symptoms.

Key Words: Cardiac Defense Response, Anxiety, Depression, negative emotionality, normal population.

\section{Introducción}

El origen del concepto de defensa está relacionado con la idea de que los organismos reaccionan fisiológicamente ante la presencia de peligro o amenaza con el objetivo de protegerse a sí mismos del daño o la muerte. Entre las respuestas típicas de defensa en numerosas especies podemos encontrar el freezing, la reacción de sobresalto, el desmayo y la respuesta de lucha-huida. Todas estas reacciones pueden ser categorizadas en dos formas generales de defensa: inmovilidad y defensa activa (Vila, y cols., 2007).

La Respuesta Cardíaca de Defensa (RCD) constituye un patrón de reactividad cardíaca observado después de la presentación de un estímulo intenso y aversivo (mayoritariamente auditivo o electrocutáneo). Este patrón cardíaco implica dos componentes acelerativos (una aceleración de corta latencia y una segunda aceleración de larga latencia), y dos componentes decelerativos -que aparecen secuencialmente durante los 80 segundos después de la presentación del estímulo aversivo. Los mecanismos fisiológicos de este patrón de respuesta incluyen influencias simpáticas y parasimpáticas. La primera aceleración/deceleración es controlada por influencias parasimpáticas (i.e., inhibición durante la primera aceleración y activación durante la subsecuente deceleración). Por su parte, la segunda aceleración/deceleración es controlada dualmente por las ramas simpáticas y parasimpáticas que actúan de manera recíproca, observándose activación simpática -acompañada por inhibición parasimpática- durante la segunda aceleración, e inhibición simpática -acompañada por activación parasimpáticadurante la segunda deceleración (Vila, y cols., 2007). 


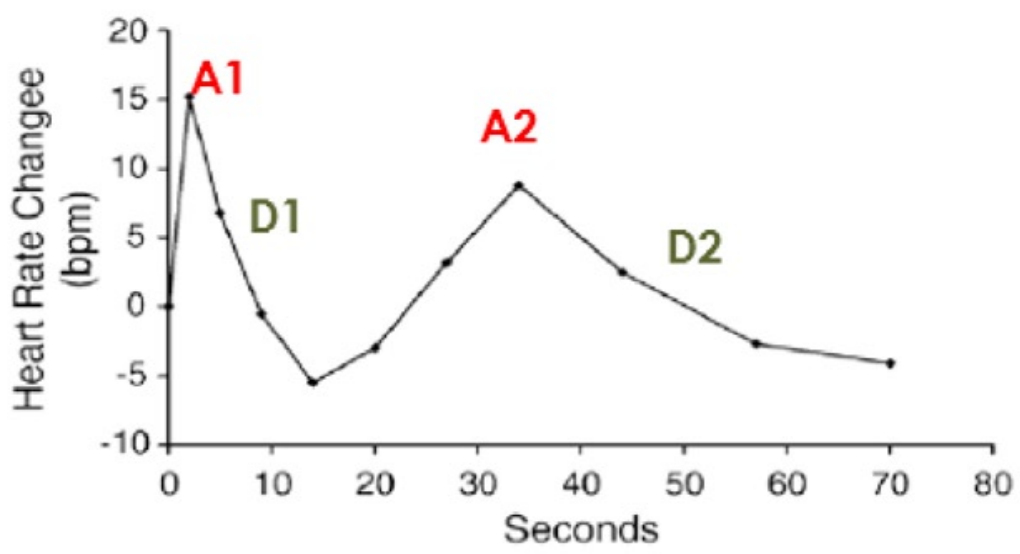

Figura 1. Componentes acelerativos y decelerativos del patrón de RCD (Adaptado de Vila, y cols., 2008)

Existen dos aproximaciones tradicionales que intentan explicar esta respuesta autonómica. La aproximación cognitiva distingue entre el reflejo de orientación y el reflejo defensivo, asumiendo que los cambios cardíacos en respuesta a los estímulos del ambiente reflejan mecanismos atencionales y perceptivos. Desde esta aproximación, el reflejo de orientación (una deceleración de la tasa cardíaca) facilita la atención hacia el estímulo, mientras que la respuesta defensiva (una aceleración de la tasa cardíaca) reduce la atención hacia el estímulo como una forma de protección contra el estímulo amenazante (Vila, y cols., 2007)). Por su parte, la aproximación motivacional asume que los cambios cardíacos en respuesta a los estímulos ambientales reflejan mecanismos metabólicos con el objetivo de proporcionar al organismo la energía necesaria para actuar. Cuando se requiere una respuesta activa, tanto psicológica como fisiológica, la reacción se acompañará de aceleración cardíaca, pero si es más apropiado responder con una conducta pasiva el organismo presentará una clara deceleración cardíaca (Vila, y cols., 2007).

Sin embargo, en los últimos años han ido surgiendo nuevas investigaciones que están facilitando la integración de ambas tradiciones psicológicas clásicas dentro de un mismo modelo teórico atencional-motivacional de defensa cardíaca (Vila, y cols., 2009). Concretamente, nos referimos al modelo de la cascada defensiva, desde el cual se entiende que las reacciones defensivas siguen un proceso secuencial con fases iniciales atencionales dirigidas a la detección y análisis de la posible amenaza, seguidas de fases posteriores en las que predominan los factores motivacionales dirigidos a facilitar las acciones defensivas de lucha o huida (Blanchard y Blanchard, 1989; Fanselow, 1994; Lang, Davis y Öhman, 2000).

Desde esta perspectiva, la respuesta cardíaca de defensa -al igual que sucede con otras respuestas defensivas, como el reflejo de sobresalto- está modulada tanto por factores atencionales como emocionales. Así, los componentes acelerativos y decelerativos parecen reflejar la sucesión de dos fases: (1) una primera fase defensiva atencional, dirigida a interrumpir la actividad y analizar el peligro potencial, y (2) una fase defensiva motivacional, dirigida a preparar al organismo para la defensa activa. De esta forma, el patrón de respuesta cardíaca de defensa representa una transición desde la atención (orientación) a la acción (respuesta abierta). La primera aceleración/deceleración implica la interrupción de la actividad y el aumento de la atención hacia los estímulos externos, mientras que la segunda aceleración/deceleración prepara al organismo para la defensa y permite su recuperación en el caso de que el peligro no sea real (Vila, y cols., 2007). 


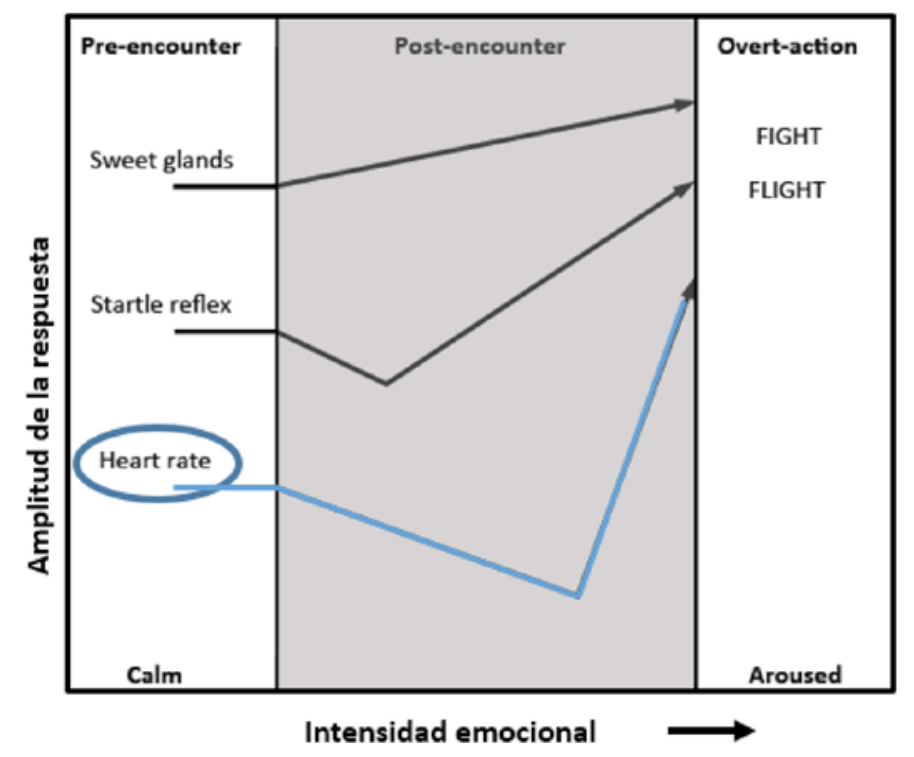

Figura 2. Modelo de la cascada defensiva (Adaptado de Bradley y Lang, 2000)

Debido a su significado emocional, el presente estudio se centra en el segundo componente acelerativo, el cual tiene un pico de máxima respuesta entre los 20 y 45 segundos posteriores a la presentación del estímulo intenso y aversivo que provoca la reacción defensiva. Esta segunda aceleración cardíaca refleja la movilización de los recursos del organismo para dar una respuesta de afrontamiento y se ha interpretado como un buen indicador de la activación del sistema motivacional defensivo (López, y cols., 2016). De relevancia para nuestro trabajo, los resultados de la investigación previa han mostrado importantes diferencias individuales en el patrón de respuesta cardíaca a partir de dicho componente acelerativo. Más concretamente, teniendo en cuenta la presencia o ausencia de esta segunda aceleración, podemos clasificar a las personas como aceleradoras o deceleradoras. Mientras que las «aceleradoras» se caracterizan por presentar una clara aceleración cardíaca con una mayor latencia, las «deceleradoras» presentan una marcada deceleración (Pérez Marfil, Fernández-Santaella, León García, Turpin y Vila, 1999).

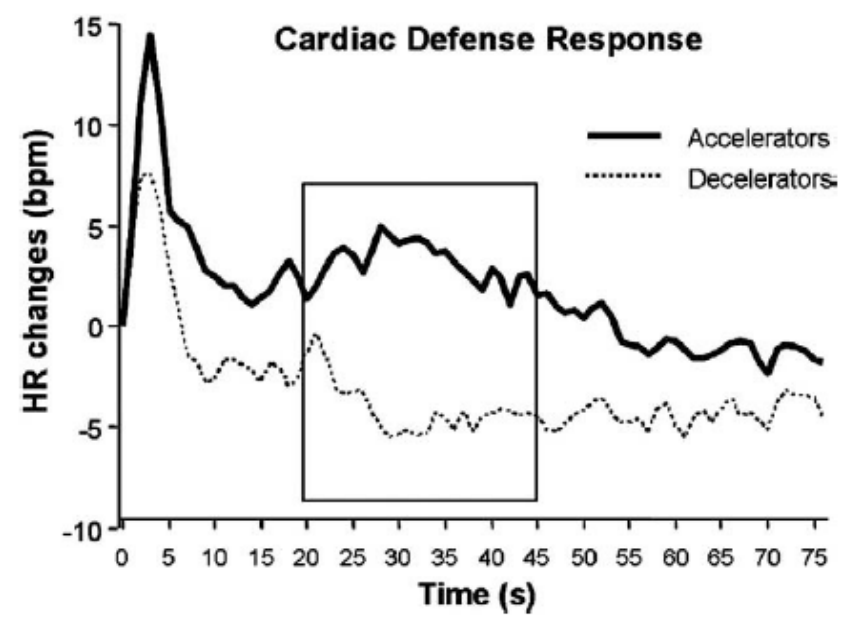

Figura 3. Patrones de RCD para aceleradores y deceleradores en el test de reactividad cardíaca

(Tomado de López-Penades, y cols., 2008) 
Estas diferencias en el patrón de la respuesta han sido asociadas con factores tanto biológicos como psicológicos, como pueden ser el ciclo menstrual, el género, los rasgos de personalidad, la preocupación excesiva o la ansiedad patológica. En concreto, se han encontrado patrones marcadamente acelerativos en hombres comparado con mujeres, en mujeres fóbicas durante la fase premenstrual vs. la fase inter-menstrual, en personas con altas puntuaciones en preocupación e inestabilidad emocional, así como en pacientes con trastornos de ansiedad (Vila, y cols., 2009). Concretamente, los datos indican que tanto las personas con elevadas puntuaciones en preocupación como los pacientes con ansiedad generalizada tienden a mostrar un patrón acelerativo prolongado (con ausencia del primer componente decelerativo). Sin embargo, las personas con una elevada ansiedad subclínica y los pacientes con fobias específicas tienden a mostrar el patrón típico de RCD con ambos componentes de manera secuencial (acelerativo/desacelerativo) (Vila, y cols., 2009; Vila, y cols., 2003).

El presente trabajo de investigación pretende explorar si se cumplen dos hipótesis formuladas a partir de la revisión de la literatura experimental previa. En primer lugar, se espera replicar el patrón de RCD (con sus dos componentes) en una muestra de estudiantes representativa de la población normal y, en segundo lugar, se pretende explorar si existen diferencias entre las personas aceleradoras y deceleradoras (clasificadas en función de la segunda aceleración de la RCD) en su emocionalidad negativa, evaluada a partir de varios cuestionarios de afecto. En relación con el segundo objetivo y, de acuerdo con la literatura, esperamos encontrar mayores puntuaciones en los distintos instrumentos de autoinforme para el grupo de aceleradores comparado con el grupo de deceleradores.

\section{Método}

\section{Participantes}

En este estudio participaron voluntariamente 100 estudiantes del grado de Psicología y Criminología (30 varones y 70 mujeres) de la Universitat Jaume I. Los participantes tenían una media de edad de 21.15 años (DT $=2.64$ ), sin observarse diferencias de edad significativas entre la muestra de varones (Media $=21.73$; DT $=2.54$ ) y la de mujeres (Media $=20.87$; DT $=$ 2.66). Previamente se comprobó que ningún participante tuviera problemas auditivos o cardiovasculares, ni tampoco se encontrara bajo tratamiento farmacológico o psiquiátrico. El presente estudio forma parte de un proyecto de investigación más amplio aprobado por el Comité Deontológico de la Universidad Jaume I.

\section{Materiales}

Inventario de la Depresión de Beck [BDI-II] (Beck, y cols., 1996): cuestionario formado por 21 ítems relacionados con síntomas depresivos (sentimientos de culpa, sentimientos físicos relacionados con la depresión, etc.) para evaluar la severidad de la depresión. Todos los ítems tienen como escala de respuesta $0,1,2,3$-excepto dos ítems (el 16 y 18), cuya escala de respuesta es $0,1,1,2,2,3,3$. Un ejemplo de ítem es el siguiente: «Me siento triste gran parte del tiempo».

Cuestionario de Regulación Emocional [ERQ] (Cabello, y cols., 2013): cuestionario de 10 ítems que evalúa dos estrategias específicas de regulación emocional, reevaluación cognitiva (6 ítems; "Cuando quiero incrementar mis emociones positivas (p.ej. alegría, diversión), cambio el tema sobre el que estoy pensando») y supresión emocional (4 ítems; "Cuando estoy 
sintiendo emociones positivas, tengo cuidado de no expresarlas»). Los ítems presentan una escala tipo Likert de 5 puntos (totalmente en desacuerdo; en desacuerdo; neutral; de acuerdo; totalmente de acuerdo).

Cuestionario de Ansiedad-Estado [STAI-E] (Spielberger, y cols., 1970; Spielberger, y cols., 1982): cuestionario de 20 ítems que evalúa la ansiedad estado, es decir, un estado emocional transitorio. Los ítems presentan una escala tipo Likert de 4 puntos (nada; algo; bastante; mucho). EL STAI-E tiene en cuenta una serie de síntomas en el momento en el que se administra el cuestionario. "Me siento descansado» es un ejemplo de ítem.

Cuestionario de Ansiedad-Rasgo [STAI-R] (Spielberger, y cols., 1970; Spielberger, y cols., 1982): cuestionario de 20 ítems que evalúa la ansiedad rasgo, es decir, componentes cognitivos y somáticos de la ansiedad como un rasgo general de la personalidad. Los ítems presentan una escala escala tipo Likert de 4 puntos (nada; algo; bastante; mucho). "Soy una persona tranquila, serena y sosegada» es un ejemplo de ítem.

Escala PANAS de afecto positivo y negativo (Watson, y cols., 1988): escala que consta de 20 ítems y evalúa afecto positivo y afecto negativo. Cada ítem presenta una escala de 5 puntos (muy ligeramente o nada; un poco; moderadamente; bastante; mucho). «Preocupado», «Fuerte», «Nervioso», «Activo», etc. son algunos ejemplos de ítems.

\section{Adquisición y reducción de datos fisiológicos}

Para la adquisición y el análisis de las distintas señales fisiológicas se utilizó un sistema de registro Biopac MP36 y el software Acqknowledge 4.1. La tasa cardíaca fue registrada mediante sensores de tamaño estándar ( $8 \mathrm{~mm}$ de diámetro) colocados según la derivación II: dos electrodos activos -en la muñeca derecha y en el tobillo izquierdo- y un electrodo de tierra en el tobillo derecho. Previamente se limpiaron las zonas descritas frotando con un algodón impregnado en alcohol. Los valores de tasa cardíaca se expresaron como puntuaciones de cambio respecto a la media de los 15 segundos previos a la presentación del estímulo auditivo (línea de base).Con ello, se obtuvieron 80 valores (correspondientes a los 80 segundos tras la aparición del estímulo auditivo). Para facilitar el análisis estadístico, estos 80 valores de tasa cardíaca fueron reducidos a 10 valores, correspondientes a las medianas de los 10 intervalos siguientes: 2 intervalos de 3 segundos, 2 intervalos de 5 segundos, 3 intervalos de 7 segundos, y 3 intervalos de 13 segundos.

\section{Procedimiento}

El estudio se llevó a cabo en el laboratorio del grupo MPAGER situado en la Facultad de Ciencias Humanas y Sociales de la Universitat Jaume I. Unos días antes del experimento, se enviaba a los/las participantes un correo electrónico donde se les indicaba el día y hora a la que estaban citados, así como unas recomendaciones que debían seguir antes de venir al experimento. Una vez en el laboratorio, debían firmar el consentimiento informado donde se les explicaba en qué iba a consistir la sesión experimental. A continuación, se limpiaban las zonas donde se colocaban los sensores y se procedía a leer las instrucciones de la tarea en las que se indicaba que debían estar en reposo (pero no se les avisaba de la presentación del estímulo aversivo). Todos los participantes realizaron un test de reactividad fisiológica para provocar la Respuesta Cardíaca de Defensa (Ver Figura 4). Esta tarea consistió en la presentación de un sonido intenso y aversivo (ruido blanco de 500 ms de duración, 105 dB y rise time instantáneo), administrado biauralmente a través de auriculares (Sennheiser HD 205), tras un 
periodo de reposo de 6 minutos. Después del sonido intenso hubo un periodo de registro de 80 segundos adicionales. Tras finalizar la tarea, se administraron diferentes cuestionarios de personalidad (BDI-II, ERQ, STAI-R, STAI-E, STAI-R y PANAS, en este orden), y se despedía a los participantes explicando brevemente el objetivo del estudio.
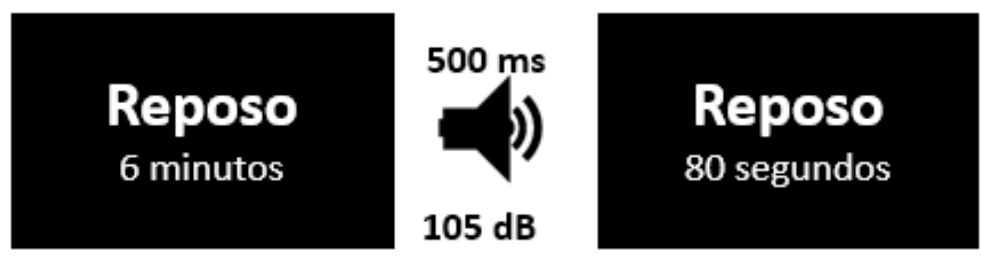

Figura 4. Test de reactividad cardíaca utilizado para provocar la Respuesta Cardíaca de Defensa (RCD)

\section{Análisis estadístico}

Para clasificar a la muestra experimental en dos grupos (aceleradores vs. deceleradores) se llevó a cabo un análisis de Cluster jerárquico (método de Ward y datos estandarizados) a partir del valor obtenido en la Mediana 7 (correspondiente a la segunda aceleración). A continuación, para cada uno de los cuestionarios por separado (BDI-II, ERQ, STAI-R, STAI-E, STAI-R y PANAS), se realizaron Análisis de Varianza de medidas repetidas (ANOVA) con el factor Grupo (Aceleradores vs. Deceleradores). Se fijó el nivel de significación de $p<.05$ usando la corrección Greenhouse-Geisser. Los análisis estadísticos se llevaron a cabo mediante el software JMP 5.0.1.

\section{Resultados}

\section{Patrón de Respuesta Cardíaca de Defensa (RCD)}

El análisis de Cluster realizado mostró la existencia de dos clusters que diferían significativamente en sus puntuaciones en el componente acelerativo utilizado para clasificarlos $[F$ $(1,98)=3.39, p<0.0002)$.

A partir de este análisis, la muestra experimental se clasificó en dos grupos: aceleradores $(N=49)$-con un patrón de reactividad cardíaca marcadamente acelerador-, y deceleradores $(\mathrm{N}=51)$-caracterizados por un patrón cardíaco básicamente decelerativo a lo largo de los 80 segundos posteriores a la presentación del sonido aversivo y, por tanto, por mostrar ausencia del segundo componente acelerativo entre 20 y 40 segundos. 


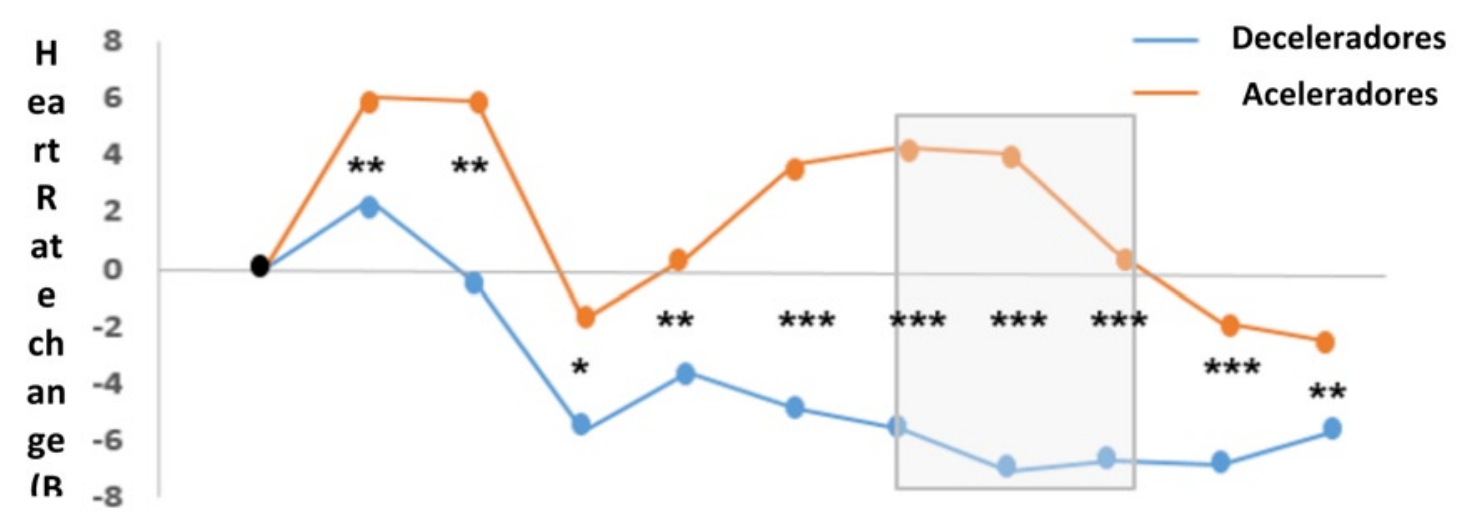

LB Md1 Md2 Md3 Md 4 Md 5 Md 6 Md 7 Md 8 Md 9 Md 10

Figura 5. Patrones de RCD en el test de reactividad cardíaca para aceleradores y deceleradores

Respuesta Cardíaca de Defensa (RCD) y Emocionalidad negativa

Los ANOVAs realizados mostraron la ausencia de diferencias estadísticamente significativas entre los dos grupos (aceleradores vs. deceleradores) para los distintos instrumentos de autoinforme administrados al finalizar el experimento $(F s<1)$.

No obstante, tal y como se esperaba, se observó una tendencia congruente en la dirección de las diferencias al comparar las medias obtenidas en ambos grupos experimentales, tanto para el BDI como para el STAI (subescalas de Ansiedad Estado y Rasgo). Más concretamente, las personas aceleradoras puntuaron más alto tanto en depresión $[F(1,98)=0.11, p$ $<0.64)]$ como en ansiedad estado $[F(1,98)=0.23, p<0.63)]$ y en ansiedad rasgo $[F(1,98)=$ $0.41, p<0.55]$, en comparación con las personas deceleradoras (ver Figura 6).

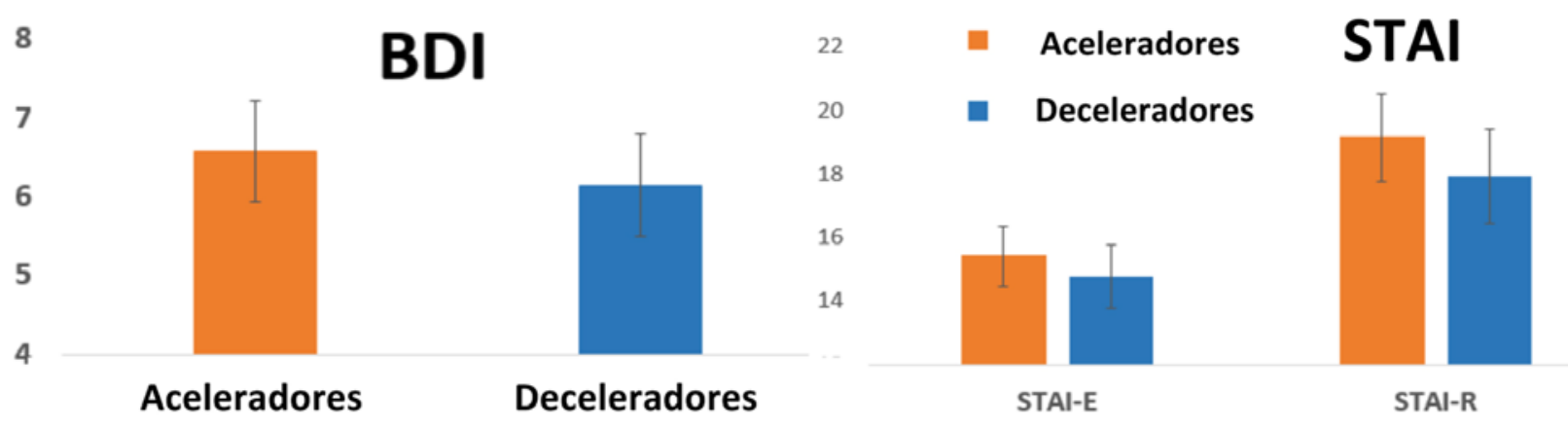

Figura 6. Medias en los cuestionarios BDI y STAI para los dos clusters (deceleradores y aceleradores)

Además, tampoco se obtuvieron diferencias estadísticamente significativas entre aceleradores y deceleradores en las puntuaciones en las escalas de Reevaluación Cognitiva [ $F$ $(1,98)=0.26, p<0.61)$ y Supresión $[F(1,98)=0.30, p<0.59]$ del ERQ (ver Figura 7$)$. 


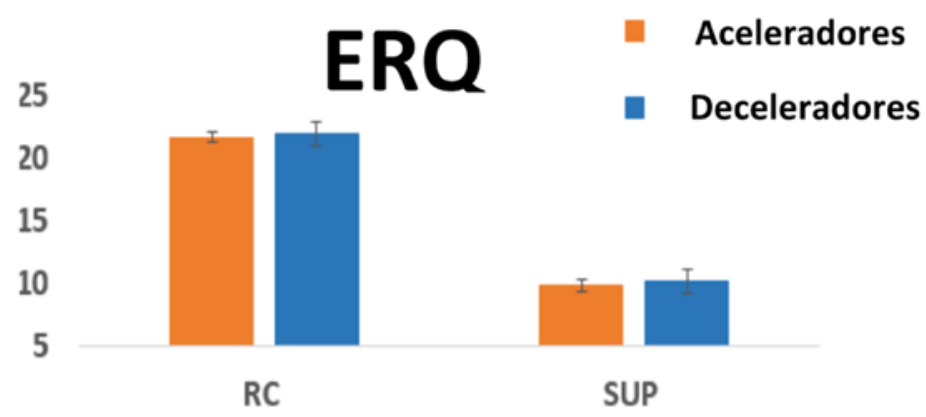

Figura 7. Medias en el cuestionario ERQ para las estrategias de Supresión (SUP) y Revaluación Cognitiva (RC), para los dos clusters (deceleradores y aceleradores)

Finalmente, no se observaron diferencias estadísticamente significativas entre ambos grupos en las puntuaciones del PANAS para las escalas de afecto negativo $[F(1,98)=0.57$, $p<0.45]$ y afecto positivo $[F(1,98)=0.12, p<0.72]$ (Ver Figura 8).

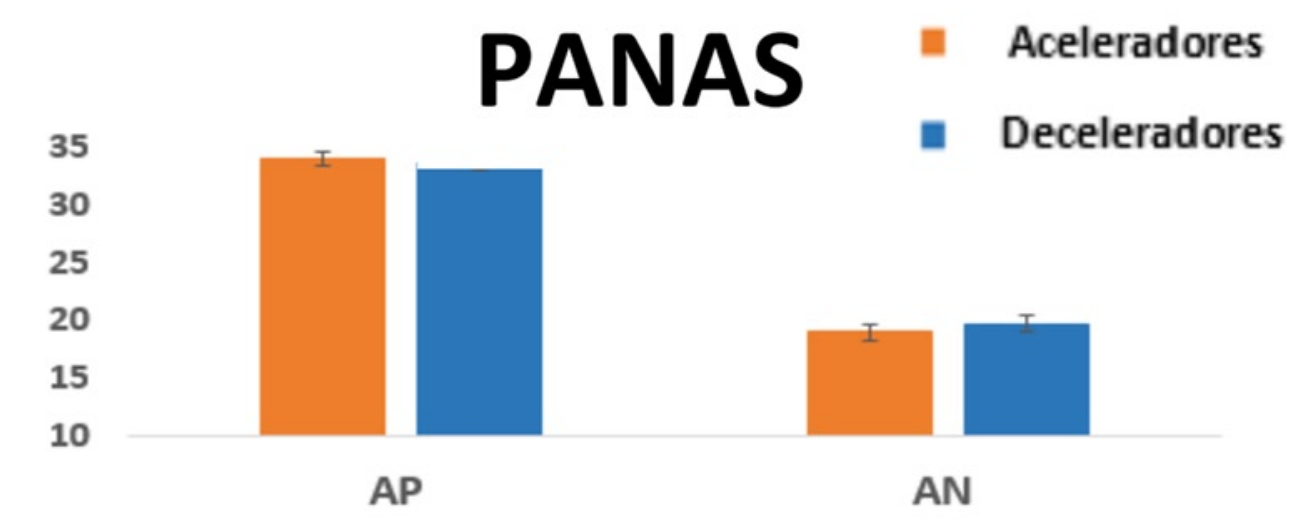

Figura 8. Medias en el cuestionario PANAS para las escalas de Afecto Negativo y Afecto Positivo, para los dos clusters (deceleradores y aceleradores).

\section{Discusión y Conclusiones}

En general, los datos del presente estudio han permitido replicar el patrón de RCD en una muestra de estudiantes, en el que se observan claramente dos componentes acelerativos y decelerativos de manera secuencial, de acuerdo con los resultados de trabajos previos (Vila, y cols., 2007; Vila, y cols., 2003). Asimismo, se ha conseguido replicar la existencia de dos clusters diferenciados a partir del segundo componente acelerativo de la RCD (Eves y Gruzelier, 1984; Fernández y Vila, 1989, López-Penades, y cols., 2009). En esta línea, los resultados muestran un grupo de personas claramente aceleradoras y un grupo de personas deceleradoras, que difieren significativamente en la segunda aceleración cardíaca. Esta segunda aceleración representa la preparación para la defensa activa en caso de que ocurriera un peligro real y, por tanto, refleja la activación del sistema motivacional defensivo. 
Por otro lado, cuando se analizan si existen diferencias entre aceleradores y deceleradores en diferentes instrumentos de autoinforme utilizados para evaluar emocionalidad negativa no se encuentran diferencias significativas entre ambos clusters. Sin embargo, al analizar el sentido de las diferencias, sí se observa un patrón acorde con la literatura previa (López, y cols., 2016; Pérez, Fernández, Vila, y Turpin, 2000). En concreto, las personas con mayor reactividad cardíaca presentaron mayores puntuaciones en las escalas de ansiedad y depresión. Estos datos muestran cómo el patrón de RCD puede verse alterado por el estado emocional de la persona. Cuando la persona se encuentra en un estado emocional negativo se produce una segunda aceleración pronunciada y una ausencia (o una menor) segunda deceleración. Esto sugiere, siguiendo el modelo de la cascada defensiva, el inicio de la fase motivacional -lo cual se acompaña de una aceleración cardíaca que facilitaría, por tanto, la reacción defensiva.

No obstante, aunque estos datos van en la línea de la literatura previa, en nuestro estudio no se encuentran diferencias significativas entre ambos grupos de participantes a partir de los cuestionarios utilizados para evaluar afecto. Este resultado podría explicarse por el reducido tamaño de la muestra experimental que podría resultar inadecuado cuando se utiliza una batería de autoinformes. A esta primera limitación se suma el hecho de que se trata de una muestra no clínica, observándose claramente que las puntuaciones obtenidas en las distintas escalas están dentro de la normalidad. En consecuencia, los valores medios obtenidos en los cuestionarios fueron muy similares entre sí (con una desviación típica muy baja), dificultando de este modo la aparición de diferencias estadísticamente significativas entre aceleradores y deceleradores. Por último, cabe mencionar una limitación referida al propio test de reactividad cardíaca utilizado en el presente estudio, ya que la tarea original cuenta con 10 minutos de reposo antes de la presentación del sonido intenso (Vila, y cols., 2007; Vila, y cols., 2003). Sin embargo, en el presente trabajo se tomaron únicamente 6 minutos de reposo como línea de base, de acuerdo con estudios previos (López, y cols., 2009), para reducir la duración de la tarea dado que iba seguida de otro experimento psicofisiológico. En consecuencia, cabe explorar si el tiempo de reposo antes de la aparición del estímulo aversivo utilizado para provocar la respuesta cardíaca de defensa puede ser un factor a tener en cuenta en futuros estudios.

Aunque la investigación sobre las reacciones defensivas ha sido muy extensa en los últimos años, aún se desconocen numerosos aspectos básicos referentes a dichas respuestas, por lo que es necesario continuar el estudio de estos procesos. Por ejemplo, una posible línea futura es el estudio de los mecanismos corticales y vegetativos de los diferentes patrones acelerativos y decelerativos, así como su papel en los estilos defensivos activo/pasivo en los distintos trastornos emocionales.

\section{Referències bibliogràfiques}

Bradley, M.M., y Lang, P.J. (2000). Affective reactions to acoustic stimuli. Psychophysiology, 37, 204-215.

Eves, F.F. y Gruzelier, J.M. (1984). Individual differences in the cardiac response to high intensity auditory stimulation. Psychophysiology, 21, 342-352.

Fernández, M.C. y Vila, J. (1989). La respuesta cardíaca de defensa en humanos: diferencias sexuales e individuales. Boletín de Psicología, 22, 59-89.

Lang, P.J. (1995). The emotion probe: Studies of motivation and attention. American Psychologist, 50, 372-385. 
Lang, P., Bradley, M. M., y Cuthbert, B.N. (1997). Motivated attention: Affectm activation, and action. In P. Langm R.F. Simons, y M.Balaban (Eds.), Attention and orienting: Sensory and motivational processes (pp. 97-136). Hillsdale, NJ: Erlbaum.

López, R., Poy, R., Pastor, M.C., Segarra, P., y Moltó, J. (2009). Cardiac defense response as a predictor of fear learning. International Journal of Psychophysiology, 74, 229-235.

López, R., Poy, R., Segarra, P., Esteller, À., Fonfría, A., Ribes, P., Ventura, C., y Moltó, J. (2016). Gender-specific effects of trait anxiety on the cardiac defense response. Personality and Individual Differences, 96, 243-247.

Pérez Marfil, M.N., Fernández Santaella, M.C., León García, A., Turpin, G., y Vila Castellar, J. (1999). Individual differences associated with cardiac defence response: psychophysiological and personality variables. Psychology in Spain, 3, 54-62.

Pérez, M.N., Fernández, M.C., Vila, J., y Turpin, G. (2000). Cognitive and emotional modulation of the cardiac defense response in humans. Psychophysiology, 37, 275-282.

Vila, J., Fernández, M.C., Pegalajar, J., Vera, M.N., Robles, H., Pérez, N., Sánchez, M.B., Ramírez, I., y Ruiz-Padial, E. (2003). A new look at Cardiac Defense: Attention or Emotion?. The Spanish Journal of Psychology, 6, 60-78.

Vila, J., Guerra, P., Muñoz, M.A., Vico, C., Viedma-del Jesús, M.I., Delgado, L.C., Perakakis, P., Kley, E., Mata, J.L., y Rodriguez, S. (2007). Cardiac defense : From attention to action. International Journal of Psychophysiology, 66, 169-182.

Vila, J., Guerra, P., Muñoz, M.A., Perakakis, P., Delgado, L.C., Figueroa, M., y Mohamed, S. (2009). La dinámica del miedo: la cascada defensiva. Escritos de Psicología, 3(1), $37-42$. 



\title{
Revisió d'estudis qualitatius sobre violència laboral en els serveis d'urgències hospitalàries
}

\author{
KAREN SORRIBES ORTÍ \\ al286596@uji.es \\ PABlo SALAs MEdina \\ psalas@uji.es \\ Alicia de los ÁNGELES TORRES GonZÁleZ \\ altorres@uji.es
}

\section{Resum}

Introducció: La violència laboral sanitària és un problema professional i social que afecta als sistemes de salut. La literatura diu que les infermeres del servei d'Urgències tenen un major índex de violència laboral. Objectius: Revisar la literatura qualitativa sobre percepció i sentiments dels infermers front als episodis de violència laboral en el context del departament d'Urgències Hospitalàries. Així com, conèixer les seves opinions sobre les possibles causes i pròpies actituds a l'hora de reportar-los. Metodologia: Revisió d'estudis qualitatius. Avaluació de qualitat mitjançant graelles de lectura crítica. Població: Infermeres d'emergències Hospitalàries. Es fan recerques amb combinació de llenguatge controlat i natural limitant publicacions dels últims 5 anys, en anglès i espanyol, amb "texto completo» en les bases de dades: Cochrane Libary Plus, CINHAL, PubMed, Scopus i Scielo. Resultats: Es recuperen 6 articles, analitzats mitjançant la ferramenta de lectura crítica CASPe. Es va determinar que $50 \%(n=3)$ d'ells complien els requisits de qualitat marcats pels revisors (puntuació de la graella igual o superior a 6 punts) descartant el $50 \%(n=3)$ articles restants amb puntuacions inferiors. Discussió i conclusions: La percepció de violència laboral és inherent als infermers com una part inevitable de la seva practica clínica habitual. Aquesta percepció empitjora els sentiments de culpabilitat i por davant incidents de violència, possibilitant l'afectació emocional profunda, fet coincident amb la literatura consultada sobre conseqüències de la violència laboral. A més, els infermers verbalitzen que la ferramenta on es reporten els incidents és complexa d'utilitzar i requereix més temps del que disposen.

Paraules clau: Infermers; Infermers d'urgències; Servei d'urgències hospitalàries; Violència laboral.

\section{Abstract}

Introduction: Workplace violence against health personnel is a professional and social problem which affects the Health Systems. The scientific literature shows that nurses who work on the emergency department have higher index of workplace violence Ob- 
jectives: To review the qualitative literature about the perceptions and feelings of the nurses among workplace violence in the hospital emergency department and to explore their opinions about their own attitudes when they report them. Method: This is a qualitative studies revision. The quality of the articles is analysed by tools for critical lecture. Population: nurses working in hospitals emergency departments. The authors make a research with a combination of natural and controlled language. The publications are limited to the last 5 years, English, Spanish or Catalan. The data base used are: Cochrane Library Plus, CINAHL, PubMed, Scopus and Scielo. Results: 6 articles are analysed by the Critical Appraisal Skills Programme CASPe. It was determined that the $50 \%(n=3)$ of them accomplished the quality requirements selected by the researchers (punctuation equal or above 6$)$. The other $50 \%(n=3)$ were rejected. Discussion and conclusions: The perception of workplace violence is inherent to the nurses as an inevitable part of their regular clinical practise. This perception deteriorates the feelings of guilt and fear in front of workplace violence incidents. This can produce a deep emotional affectation, which agrees with the cheeked literature about consequences of workplace violence. Moreover, the nurses demand that the tool used to report the incidents is difficult to use and it requires more time than the one they have to do it.

Key Words: Nursing; Emergency Nursing; Emergency Service, Hospital; Workplace violence.

\section{Introducció}

La violència laboral és un problema personal i social que afecta la dignitat i la salut de milions de treballadors arreu del món (Martino, 2003). La violència genera un ventall de repercussions, tant en l'àmbit individual com a escala organitzativa, provocant un empitjorament del rendiment del treballador. Fins i tot, pot arribar a alterar la salut mental causant entre d'altres depressió i ansietat (Ferri, Silvestri, Artoni, y Di Lorenzo, 2016).

La Comissió Europea proporciona una definició sobre la violència laboral que ha adaptat a partir de les dades de la OMS, afirmant que: «la violència laboral està constituïda per incidents en els quals el personal sofreix abusos, amenaces o atacs en circumstàncies relacionades amb la seva feina que posen en perill implícitament o explícitament la seua seguretat, benestar o salut» (Martino, 2003, p.1). Dins d'aquesta definició de violència laboral s'inclou tant la violència física com la psicològica.

A continuació es defineixen els diferents tipus de violència laboral existents. La violència física es defineix com «l'ús de la força física contra una persona o un grup de persones, que produeix danys físics, sexuals o psicològics» (Martino, 2003, p.1-2). Alguns exemples són les empentes, estirades, mossegades o pessics, entre d'altres. D'altra banda, la violència psicològica es refereix a «l'ús deliberat del poder o amenaces de recórrer a la força física contra una persona o un grup de persones que poden danyar el desenvolupament mental, espiritual, moral o social» (Martino, 2003, p 1-2).

Durant el període de pràctiques clíniques que vaig realitzar a l'Hospital General Universitari de Castelló vaig observar l'elevada freqüència amb què es produïen episodis de violència envers les infermeres al servei d'urgències. La principal inquietud que vaig tindre escollint aquesta temàtica va ser visibilitzar aquesta situació. 
Aquest treball s'ha elaborat amb l'objectiu general de revisar la literatura qualitativa sobre percepció i sentiments dels infermers front als episodis de violència laboral en el context del departament d'Urgències Hospitalàries. Així com, conèixer les seves opinions sobre les possibles causes i pròpies actituds a l'hora de reportar-los.

Pel que fa als objectius secundaris, els dividim en:

- Descriure els sentiments dels infermers després d'un episodi de violència laboral.

- Conèixer la utilització (per part de les infermeres) de plataformes de registre dins del sistema de salut a nivell institucional i identificar les principals barreres que troben a l'hora de registrar els incidents

\section{Mètode}

Per tal de de donar resposta als objectius plantejats es realitza una revisió integradora de la literatura qualitativa existent. En aquest treball es realitza una recerca de la bibliografia existent sobre violència labora envers les infermeres dels serveis d'Urgències hospitalàries a les següents bases de dades: Cochrane Library Plus, CINAHL, Scielo, Scopus i PubMed. S'empra una combinació de llenguatge natural i controlat, amb la finalitat d'abastir el nombre més gran d'articles disponibles sobre el tema a tractar (Taula 1):

Taula 1

Taula de descriptors utilitzats per a la recerca

\begin{tabular}{|c|c|c|c|}
\hline Llenguatge natural & $\begin{array}{l}\text { Llenguatge } \\
\text { controlat: } \\
\text { DeCS }\end{array}$ & $\begin{array}{l}\text { Llenguatge } \\
\text { controlat: } \\
\text { MeSH }\end{array}$ & Sinònims \\
\hline Infermeria & Enfermería & Nursing & \\
\hline $\begin{array}{l}\text { Servei d'Urgències } \\
\text { Hospitalàries }\end{array}$ & $\begin{array}{l}\text { Servicios médicos } \\
\text { de Urgencias }\end{array}$ & $\begin{array}{l}\text { Emergency } \\
\text { Service, Hospital }\end{array}$ & $\begin{array}{l}\text { Emergency Service, Emergency } \\
\text { Department, Emergency Room, } \\
\text { Emergency Medical Services }\end{array}$ \\
\hline Violència laboral & Violencia laboral & $\begin{array}{l}\text { Workplace } \\
\text { violence }\end{array}$ & \\
\hline Infermers d'Urgències & $\begin{array}{l}\text { Enfermería de } \\
\text { Urgéncias }\end{array}$ & $\begin{array}{l}\text { Emergency } \\
\text { nursing }\end{array}$ & \\
\hline
\end{tabular}

( ( ( «Emergency Medical Services» OR «Emergency Service») OR ( «Emergency service, hospital» OR «Emergency department» OR «Emergency room» OR «Hospital emergency service») ) AND ( «Emergency nursing» OR «nursing» ) ) AND ( «Workplace violence»).

La recerca es limita als últims 5 anys, a articles publicats en llengua anglesa, castellana o catalana i a text complet, per tal d'aconseguir els últims articles amb la major evidència possible.

Als articles obtinguts en la recerca se'ls apliquen uns criteris d'inclusió i exclusió, per a seleccionar els articles que més s'adeqüen al tema d'estudi d'aquest treball. 
Els criteris d'inclusió considerats per a aquest treball són:

- Treballs publicats entre els anys 2012 i 2017

- Treballs que estudien la situació dels infermers d'urgències hospitalàries respecte a la violència laboral

- Treballs escrits en llengua castellana, catalana i/o anglesa

- Articles originals

S'exclouen per a aquesta revisió aquells el articles que compleixen els requisits següents:

- Treballs on la població diana siguin professionals d'infermeria d'urgències extrahospitalàries.

- Articles que tracten sobre violència laboral horitzontal: definida pel DeCS com «un comportament hostil i agressiu de cara a una infermera o grup d'infermeres provocat per altres infermeres».

Els articles seleccionats, 6 estudis qualitatius es sotmeten a una lectura critica per a valorar la seva qualitat metodològica mitjançant la ferramenta crítica CASPe (CASPe per a estudis qualitatius i CASPe per a revisions sistemàtiques). Es seleccionen aquells estudis amb una puntuació igual o superior a $6 \mathrm{i}$, per tant, considerats com a qualitat metodològica alta. En la Taula 2 poden observar-se les diferents puntuacions obtingudes pels articles.

Taula 2

Puntuació graella de lectura crítica CASPe

\begin{tabular}{|c|c|c|c|}
\hline Titol & Autors & ANY & CASPe \\
\hline $\begin{array}{l}\text { Nothing changes, nobody cares: understanding the } \\
\text { experience of emergency nurses physically or verbally } \\
\text { assaulted while providing care }\end{array}$ & $\begin{array}{l}\text { Wolf, L., } \\
\text { Delao, A }\end{array}$ & 2014 & $4 / 10$ \\
\hline $\begin{array}{l}\text { Nursing management of aggression in a Singapore } \\
\text { emergency department: A qualitative study }\end{array}$ & $\begin{array}{l}\text { Tan, M., } \\
\text { Lopez, V., } \\
\text { Cleary, M }\end{array}$ & 2015 & $4 / 10$ \\
\hline $\begin{array}{l}\text { Violence against nurses in the triage area: An Italian } \\
\text { qualitative study }\end{array}$ & $\begin{array}{l}\text { Ramacciati, N., } \\
\text { Ceccagnoli, A., } \\
\text { Addey, B. }\end{array}$ & 2015 & $7 / 10$ \\
\hline $\begin{array}{l}\text { Nurses' perceptions of the factors which cause } \\
\text { violence and aggression in the emergency department: } \\
\text { A qualitative study }\end{array}$ & $\begin{array}{l}\text { Angland, S., } \\
\text { Dowling, M., } \\
\text { Casey, D. }\end{array}$ & 2014 & $4 / 10$ \\
\hline $\begin{array}{l}\text { Nurses' experiences and understanding of workplace } \\
\text { violence in a trauma and emergency department in } \\
\text { South Africa }\end{array}$ & $\begin{array}{l}\text { Kennedy, M., } \\
\text { Julie, H. }\end{array}$ & 2013 & $6 / 10$ \\
\hline $\begin{array}{l}\text { Nurses' attitudes towards the reporting of violence in } \\
\text { the emergency department }\end{array}$ & $\begin{array}{l}\text { Hogarth, K., } \\
\text { Beattie, J., } \\
\text { Morphet, J. }\end{array}$ & 2016 & $7 / 10$ \\
\hline
\end{tabular}




\section{Resultats}

Pel que fa als resultats obtinguts després de la recerca, a continuació es mostra un diagrama amb la relació d'articles seleccionats i descartats per a aquesta revisió després de la seva lectura crítica.

\section{Resultats lectura crítica}

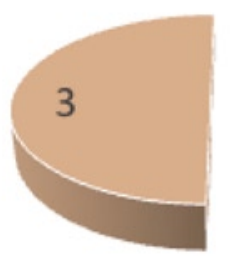

- Escollits " Descartats

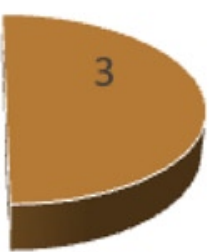

Figura 1. Relació d'articles escollits i descartats després de la lectura crítica

En total un $50 \%(n=3)$ dels articles posseeixen una qualitat metodològica alta i són inclosos en aquesta revisió (Hogarth, Beattie, y Morphet, 2016; Kennedy y Julie, 2013; Ramacciati, Ceccagnoli, y Addey, 2015), quedant excluits de la mateixa el $50 \%(n=3)$ restant (Angland, Dowling, y Casey, 2014; Tan, Lopez, y Cleary, 2015; Wolf y Delao, 2014). En la Taula 3 es presenten les idees claus de cadascun dels articles.

Taula 3

Articles inclosos en la revisió

\begin{tabular}{|c|c|c|}
\hline Títol & Metodologia & Idees clau \\
\hline $\begin{array}{l}\text { Violence against nurses in the triage } \\
\text { area: An Italian qualitative study }\end{array}$ & Fenomenologia & $\begin{array}{l}\text { La violència laboral afecta a la esfera } \\
\text { emocional dels infermers que la } \\
\text { sofreixen }\end{array}$ \\
\hline $\begin{array}{l}\text { Nurses' experiences and understanding } \\
\text { of workplace violence in a trauma and } \\
\text { emergency department in South Africa }\end{array}$ & Fenomenologia & $\begin{array}{l}\text { La violència laboral afecta a la pràcti- } \\
\text { ca assistencial de les infermeres }\end{array}$ \\
\hline $\begin{array}{l}\text { Nurses' attitudes towards the reporting of } \\
\text { violence in the emergency department }\end{array}$ & Fenomenologia & $\begin{array}{l}\text { Els professionals d'infermeria no es } \\
\text { senten recolzats pels alts càrrecs del } \\
\text { centre a l'hora de registrar aquests } \\
\text { incidents. }\end{array}$ \\
\hline
\end{tabular}




\section{Discussió i conclusions}

Els resultats mostrats per aquests estudis coincideixen en el fet que els infermers dels serveis d'urgències perceben la violència laboral com una part inherent de la seva pràctica assistencial habitual.

Les infermeres participants en un dels estudis referien sentir-se constantment en perill, amb una sensació de violència imminent (Kennedy \& Julie, 2013). Aquesta percepció també es fa present als altres dos estudis analitzats, on les infermeres manifesten que la violència es una part ineludible de la seva feina, especialment la violència psicològica (Hogarth y col., 2016; Ramacciati et al., 2015).

La violència sobre els infermers té, per part dels mateixos, una aspecte de justificació. Es a dir, els infermers excusen els comportaments violents d'alguns pacients que es troben clínicament desorientats o sota els efectes de drogues. Aquest fet es reflecteix en els tres estudis (Hogarth y col., 2016; Kennedy y Julie, 2013; Ramacciati y col., 2015).

Pel que fa al registre dels episodis de violència laboral, segons l'estudi de Kennedy y Julie (2013) les infermeres perceben el registre de la violència laboral verbal com una activitat inútil, ja que, es veuen exposades a ella diàriament. Aquest fet es relaciona amb les opinions que expressen les infermeres en l'estudi de Hogarth y col. (2016) on comenten que la ferramenta emprada per a registrar els incidents consumeix més temps del que disposen per a aquesta tasca i, finalment, molts incidents no queden enregistrats formalment.

Relacionat amb els episodis de violència laboral les infermeres de triatge refereixen no sentir-se escoltades pels supervisors després de sofrir un atac, fins i tot, comenten que no es senten escoltades quan comenten propostes de millora per a evitar que es produeixin incidents similars (Ramacciati y col., 2015). Aquest sentiment també es verbalitzat en l'estudi de Hogarth y col. (2016) on les infermeres reconeixen no estar motivades per a registrar els incidents de manera formal i a més a més el fet de no rebre un «feedback» del seu registre desmotiva al personal per a registrar els episodis de violència laboral. Caldria una major investigació per tal d'estudiar de quina manera poden adaptar-se les ferramentes formals de registre d'aquest tipus d'incidents, de manera que els infermers pogueren fer un ús adequat i responsable d'elles.

No obstant això, les infermeres comenten sentir-se ajudades pel seus companys després de sofrir algun incident de violència, sobretot pel que fa a poder verbalitzar el que ha ocorregut (Kennedy y Julie, 2013; Ramacciati y col., 2015).

A més a més les infermeres de triatge refereixen que la violència laboral produeix un dany emocional profund, del qual és difícil recuperar-se (Ramacciati y col., 2015). En definitiva, tots aquests factors esmentats anteriorment afecten a la pràctica assistencial d'aquestes infermeres, que entre altres aspectes comenten que després de sofrir agressions verbals tracten d'evitar al pacient (Kennedy y Julie, 2013).

A continuació es presenten les diferents conclusions a les quals s'ha arribat en aquest treball:

1. Els infermers perceben la violència laboral com una part inherent de la seva pràctica clínica assistencial, aquest fet provoca que durant la seva jornada laboral tinguin sensacions de perill imminent.

2. Després dels incidents de violència laboral les infermeres experimenten sensacions de culpa, que fins i tot, poden arribar a afectar a la seva qualitat assistencial.

3. Les infermeres demanden ferramentes més pràctiques per al registre formal de les agressions, que s'adapten al temps que disposen per a enregistrar el incidents. A més a més verbalitzen la necessitat de rebre un «feedback» sobre el seu incident. 
En definitiva, la violència laboral és un àmbit que requereix una major investigació per part dels propis infermers, són necessaris més estudis de caràcter qualitatiu que aborden el tema per tal de comprendre millor com ajudar als infermers a evitar els incidents i com ajudar-lo una volta s'ha produït.

\section{Limitacions}

Pel que fa a les limitacions d'aquest treball cal destacar que es tracta d'una part d'un Treball de Fi de Grau (TFG). Per aquest motiu hi ha 6 articles qualitatius exclosos en aquesta revisió, quedant exclòs un setè que va ser descartat amb posterioritat per no complir en un dels nous criteris d'inclusió estipulats.

\section{Referències bibliogràfiques}

Angland, S., Dowling, M., y Casey, D. (2014). Nurses' perceptions of the factors which cause violence and aggression in the emergency department: A qualitative study. International Emergency Nursing, 22, 134-139. https://doi.org/10.1016/j.ienj.2013.09.005

Ferri, P., Silvestri, M., Artoni, C., y Di Lorenzo, R. (2016). Workplace violence in different settings and among various health professionals in an Italian general hospital: a crosssectional study. Psychology Research and Behavior Management, 9, 263-275. https:// doi.org/10.2147/PRBM.S114870

Hogarth, K. M., Beattie, J., y Morphet, J. (2016). Nurses' attitudes towards the reporting of violence in the emergency department. Australian Emergency Nursing Journal, 19, 75-81. https://doi.org/10.1016/j.aenj.2015.03.006

Kennedy, M., y Julie, H. (2013). Nurses' experiences and understanding of workplace violence in a trauma and emergency department in South Africa. In South Africa', Health SA Gesondheid, 18(1), 1-9. https://doi.org/10.4102/hsag.v18i1.663

Martino, V. (2003). Relationship between work stress and workplace violence in the health sector Workplace violence in the health sector. Recuperado de: http://www.who.int/violence_injury_prevention/violence/interpersonal/WVstresspaper.pdf

Ramacciati, N., Ceccagnoli, A., y Addey, B. (2015). Violence against nurses in the triage area: An Italian qualitative study. International Emergency Nursing, 23(4), 274-280. https://doi. org/10.1016/j.ienj.2015.02.004

Tan, M. F., Lopez, V., y Cleary, M. (2015). Nursing management of aggression in a Singapore emergency department: A qualitative study. Nursing \& Health Sciences, 17(3), 307-312. https://doi.org/10.1111/nhs.12188

Wolf, L. A., y Delao, A. M. (2014). Nothing changes, nobody cares: understanding the experience of emergency nurses physically or verbally assaulted while providing care. Journal of Emergency Nursing, 40, 305-310. https://doi.org/10.1016/j.jen.2013.11.006 



\title{
Sexo y amor: cuando la forma de entender el amor se convierte en un riesgo para la salud sexual de los jóvenes
}

\author{
JUAN ENRIQUe NEBOt-GaRcia \\ juan.nebot@uji.es \\ MARTA GARCÍA-BARBA \\ barbam@uji.es \\ ESTEFANÍA RUIZ-PALOMINO \\ eruiz@uji.es \\ CRISTINA GIMÉNEZ-GARCÍA \\ gimenezc@uji.es
}

\section{Resumen}

Introducción: Los mitos del amor romántico abordan maneras estereotipadas de sentir y comportarnos en las relaciones afectivo-sexuales. Las investigaciones demuestran cómo puntuaciones superiores en romanticismo parecen relacionarse con un mayor rechazo al uso del preservativo y a otros métodos anticonceptivos. Por este motivo, sería necesario estudiar cómo influyen estos mitos en el comportamiento sexual de los jóvenes para diseñar intervenciones preventivas eficaces. Metodología: Se evaluó a 654 jóvenes ( $M=20,63$; $D T=2,267)$, mediante el Cuestionario sobre Mitos del Amor Romántico (Ferrer y cols., 2010). Los participantes fueron distribuidos en 2 grupos: GR-Grupo de Riesgo (no siempre usan preservativo) y GNR-Grupo de No Riesgo (siempre usan preservativo). Resultados: Los análisis diferenciales indican que los jóvenes que realizan conductas sexuales de riesgo muestran mayor acuerdo en casi todos los mitos del amor romántico, siendo significativos a nivel estadístico, el mito de la pasión intensa $(p=0,006)$ y el de la justificación de la violencia $(p=0,049)$. Conclusiones: Los jóvenes presentan creencias distorsionadas sobre el amor y la pareja, lo que influye en sus primeras relaciones. Estos mitos y, principalmente aquellos relacionados con la visión de las emociones, podrían actuar como factores de riesgo en el desarrollo sexual y en la propia salud, puesto que se observan diferencias entre el grupo que realiza prácticas sexuales desprotegidas y el que refiere tener sexo seguro. Sería necesario incorporar estos resultados en los programas de promoción salud sexual.

Palabras clave: mitos del amor romántico, jóvenes, conducta sexual de riesgo, preservativo. 


\begin{abstract}
Introduction: The myths of romantic love describe stereotypical ways of feeling and acting in affective-sexual relations. Researches show a relation between a higher score for romanticism and a minor use of condoms and other contraception methods. Studying how those myths affect the individual's sexual behaviour is needed, in order to create an effective prevention. Method: 654 young people were evaluated by the Myths of Romantic Love Questionnaire (Ferrer y cols., 2010). These participants were divided into two groups: RG-Risk Group (they do not use a condom systematically) and NRGNo Risk Group (they always use a condom). Results: The differential analyses revealed that young people who are involved in risky sexual behaviours show concordance for most of the myths of romantic love; the myth of intense passion $(p=0,006)$ and the justification of violence $(p=0,049)$ reveal statistical significant differences. Conclusion: Young people show distorted believes of love and partner, which affects their first relationships. Those myths and the ones related to a vision of emotions, may facilitate risky factors in sexual development and health. There are differences between a group that practices unprotected sex and the one that practices safe sex. Including these results into the sexual health programmes is required.
\end{abstract}

Key Words: myths of romantic love, young people, risky sexual behaviour, condom.

\title{
Introducción
}

El amor ha sido una temática ampliamente investigada durante el siglo pasado, abordando diferentes vertientes dentro del afecto, la amistad y la pareja (Rodríguez-Castro, LameirasFernández, Carrera-Fernández y Vallejo-Medina, 2013). Y entre los aspectos que se han estudiado se encuentran los mitos del amor romántico.

Los mitos son creencias formuladas como si fueran una verdad absoluta (Ferrer, Bosch y Navarro, 2010). En concreto, los mitos del amor romántico se describen como aquellas concepciones acerca de cómo es realmente la naturaleza del verdadero amor. Estas creencias son compartidas por gran parte de la sociedad y suelen ser engañosas, infundadas y difíciles de cumplir (Yela, 2003).

Entre los mitos del amor más relevantes se encuentran algunos como (Ferrer y cols., 2010):

- Mito de la «media naranja». Existe la creencia de que hay una persona que está predestinada a ser nuestra pareja, y que esta es la mejor opción. Aceptar esta premisa puede llevarnos a un nivel de exigencia y unas expectativas con nuestra pareja que puede causarnos decepción cuando no veamos nuestros ideales cumplidos. Además, puede que intentemos llegar a esas expectativas de cualquier forma, permitiendo conductas peligrosas o esforzándonos en exceso.

- Mito de la pasión eterna. Creencia de que la pasión de los primeros meses de relación puede y debe durar durante toda la vida. Este mito puede acarrear consecuencias en la estabilidad de la pareja al comprobarse que está disminuyendo ese amor romántico y pasional que se concebía como duradero y perdurable.

- Mito de la omnipotencia o creencia de que «el amor lo puede todo». Este mito afirma que el verdadero amor puede combatir cualquier obstáculo, y que es suficiente con el 
amor para solucionar los problemas que aparecen en la pareja. Al quitarle importancia a los contratiempos, esta creencia puede dificultarnos el afrontamiento de los conflictos de pareja, llegando incluso a aceptar ciertas conductas o actitudes desagradables.

- Mito del matrimonio. Creencia de que el amor romántico de una pareja debe culminar en el matrimonio. Aquí se unen dos elementos, la pasión y el matrimonio, ambos considerados como permanentes y duraderos. Pero como hemos dicho antes, la pasión es un estado emocional transitorio. Por tanto, al darnos cuenta de que la pasión no se mantiene estable, puede ser difícil de gestionar y puede llevarnos a la decepción.

- Mito del emparejamiento o de la pareja. Creencia de que estar en pareja - concebida como heterosexual y monógama - es algo natural, universal e inherente a las personas. La aceptación de esta premisa puede crear conflictos en las personas que se salgan de la norma, por ejemplo, personas solteras que no encuentren pareja, parejas homosexuales o incluso relaciones de pareja abiertas, donde se tiene sexo con gente fuera de la pareja.

- Mito de los celos. Creencia de que los celos son una muestra de amor y que son indispensables en una pareja «de verdad». Los celos suelen ser característicos de personas con baja confianza y autoestima, y si se permiten y no se abordan adecuadamente pueden desembocar en comportamientos egoístas, represivos e, incluso, violentos.

Por otro lado, Luzón, Ramos, Recio y de la Peña (2011), destacan la importancia del Mito de la ambivalencia, creencia de que el amor y el maltrato es compatible: agredir o dañar a alguien no está reñido con que lo quieras. Este mito concibe que la pasión y el afecto, al igual que el carácter fuerte, a veces son incontrolables y desbordan, pudiendo llegar a la violencia.

Como hemos dicho anteriormente, aceptar estas creencias como ciertas puede conllevar determinados problemas, como por ejemplo, la aceptación del maltrato dentro de la pareja. Se ha demostrado que existe relación entre los mitos del amor romántico y la violencia de género en el entorno de pareja (Power, Koch, Kralik y Jackson, 2006). Más concretamente, estos mitos podrían estar actuando como mantenedores del problema, ya que la violencia sería considerada como algo normal e inherente a las relaciones (Rubio-Garay, Carrasco, Amor y López-González, 2015).

Por otra parte, también se ha observado que en las relaciones románticas y de pareja se toman más riesgos, como el rechazo a utilizar el preservativo durante las relaciones sexuales (Larrañaga, Yubero y Yubero, 2012). De hecho, cuanto más altos son los niveles de romanticismo, mayor es la tendencia a rechazar el uso del condón (Larrañaga y cols., 2012). Uno de los motivos por los que se tienen relaciones sexuales sin precaución es porque se considera que la relación es estable y se sienten seguros (Calafat, Juan, Becoña, Mantecón y Ramón, 2009; Teva, Bermúdez y Buela-Casal, 2009). Además, para estas personas, no utilizar el preservativo es una forma de generar confianza e intimidad en la pareja (Corbett, Dickson $\square$ Gómez, Hilario y Weeks, 2009). Este patrón parece independiente de la orientación sexual ya que lo encontramos también en hombres gays o bisexuales (Bauermeister, Ventuneac, Pingel y Parsons, 2012; Golub, Starks, Payton y Parsons, 2012). En cualquier caso, si bien existe una mayor cantidad de estudios que profundizan en la influencia que los mitos románticos pueden tener para el establecimiento del vínculo de pareja y la salud psicosocial de las personas, todavía no contamos con muchos trabajos que analicen su impacto en la salud sexual y en el desarrollo de conductas sexuales de riesgo. Sin embargo, este aspecto también es crucial para la salud de los jóvenes. 
En este sentido, el objetivo de este estudio es analizar los mitos del amor romántico en jóvenes y evaluar en qué medida existen diferencias en la concepción de dichos mitos, entre las personas que realizan prácticas sexuales de riesgo y las que no.

Teniendo en cuenta los estudios anteriormente citados (Calafat y cols., 2009; Corbett y cols., 2009; Larrañaga y cols., 2012; Teva y cols., 2009), nuestra hipótesis es la siguiente: 1) Las personas que realizan prácticas sexuales de riesgo mostrarán mayor acuerdo con los distintos mitos del amor romántico, en comparación con aquellas personas que no realizan prácticas sexuales de riesgo.

\section{Método}

\section{Participantes}

En el estudio, participaron 654 jóvenes, de los cuales un 31,7\% fueron hombres, un $68 \%$ mujeres y un $0,3 \%$ se identificaron como "otro sexo». La edad de los participantes oscilaba entre los 17 y los 27 años, con una edad media de 20,63 (DT=2,27). De todos ellos, un 49,2\% manifestó tener pareja estable en la actualidad. Todos los jóvenes eran estudiantes universitarios, procedentes de la Universitat Jaume I de Castellón.

\section{Instrumentos}

- Cuestionario sobre Mitos del Amor Romántico (Bosch y cols., 2007). Este cuestionario explora la aceptación de distintas ideas relacionadas con el amor y los vínculos de pareja, a través de 10 ítems tipo Likert, con escala que oscila desde 1 (completamente en desacuerdo) hasta 5 (completamente de acuerdo). Según Bosch y cols. (2007), este instrumento cuenta con propiedades psicométricas adecuadas. Para más información, ver Tabla 1.

- Escala ad-hoc sobre conductas sexuales de riesgo. En esta escala se explora el uso del preservativo en distintas conductas sexuales de riesgo como el coito vaginal, el sexo oral y el coito anal. En concreto, se analiza su frecuencia de uso a través de una escala tipo likert que oscila de 0 (Nunca) a 3 (Siempre). La opción 4, se reservaba para aquellos casos en los no hubieran realizado la práctica. Para el presente estudio, solamente se utilizó el ítem relacionado con el coito vaginal. La consistencia interna de esta escala, según el Alpha de Cronbach, es de .77.

Tabla 1

Ítems del Cuestionario sobre Mitos del Amor Romántico (Ferrer y cols., 2010)

\begin{tabular}{ll}
\hline Mito evaluado & Ítem \\
\hline Mito de la media naranja & $\begin{array}{l}\text { 5) En alguna parte hay alguien predestinado para cada per- } \\
\text { sona («tu media naranja). }\end{array}$ \\
\hline Mito de la pasión eterna & 2) La pasión intensa de los primeros tiempos de una rela- \\
& ción debería durar siempre. \\
\hline
\end{tabular}




\begin{tabular}{ll}
\hline Mito evaluado & Ítem \\
\hline Mito de la omnipotencia & 4) El amor es ciego. \\
& 1) El amor verdadero lo puede todo. \\
\hline Mito del matrimonio & 8) El matrimonio es la tumba del amor (inverso). \\
\hline Mito del emparejamiento & $\begin{array}{l}\text { 3) Se puede ser feliz sin tener una relación de pareja (inver- } \\
\text { so). }\end{array}$ \\
& 10) Separarse o divorciarse es un fracaso. \\
\hline Mito de los celos & 9) Los celos son una prueba de amor. \\
\hline Mito de la ambivalencia & 6) Se puede amar a alguien a quien se maltrata. \\
& 7) Se puede maltratar a alguien a quien se ama. \\
\hline
\end{tabular}

\section{Procedimiento}

El presente estudio se llevó a cabo entre 2016 y 2017. Los participantes fueron informados del estudio en actividades desarrolladas, en el campus de la Universitat Jaume I de Castellón, con motivo del Día Mundial de la Lucha Contra el Sida.

Una vez obtenido el consentimiento de los participantes, se administraron los cuestionarios que contestaron de forma anónima, confidencial y voluntaria. Los participantes no recibieron ningún tipo de remuneración. Los criterios de inclusión fueron: comprender la lengua castellana, tener entre 17 y 27 años y haber practicado coito vaginal. En un inicio, participaron 720 jóvenes pero 66 de ellos no cumplieron el último criterio, por lo que fueron excluidos del estudio.

Para facilitar la interpretación de los resultados, las respuestas al Cuestionario de Mitos del Amor Romántico se agruparon en dos categorías: Acuerdo («completamente de acuerdo» y «de acuerdo») y No de acuerdo («completamente desacuerdo», «en desacuerdo» e «indiferente»).

Por su parte, las respuestas a la escala de frecuencia de utilización del preservativo durante el coito vaginal también fueron recodificadas en dos categorías, en función de la posible exposición al riesgo: Riesgo («nunca», «a veces» y «casi siempre») y No Riesgo («Siempre»).

\section{Análisis estadísticos}

En primer término, se llevaron a cabo análisis de frecuencias sobre los mitos. Después, se realizaron análisis diferenciales para determinar si existían diferencias entre ambos grupos («Riesgo» y «No Riesgo») en el grado de acuerdo con los mitos del amor romántico. Para todo ello, se utilizó el programa estadístico SPSS (versión 20).

\section{Resultados}

Los mitos en los que se observó mayor grado de acuerdo fueron: «Se puede ser feliz sin tener una relación de pareja» $(81,7 \%)$, «La pasión intensa de los primeros tiempos de una 
relación debería durar siempre» $(72,9 \%)$, «El amor es ciego» $(57,2 \%)$ y «el amor verdadero lo puede todo» $(46,9 \%)$.

Por su parte, los mitos menos frecuentes fueron: «Se puede maltratar a alguien a quien se ama» $(4,1 \%)$, "Los celos son una prueba de amor» $(4,7 \%)$ y «Se puede amar a alguien a quien se maltrata» $(7,3 \%)$, relacionados con la violencia en el entorno de pareja y la justificación de los celos.

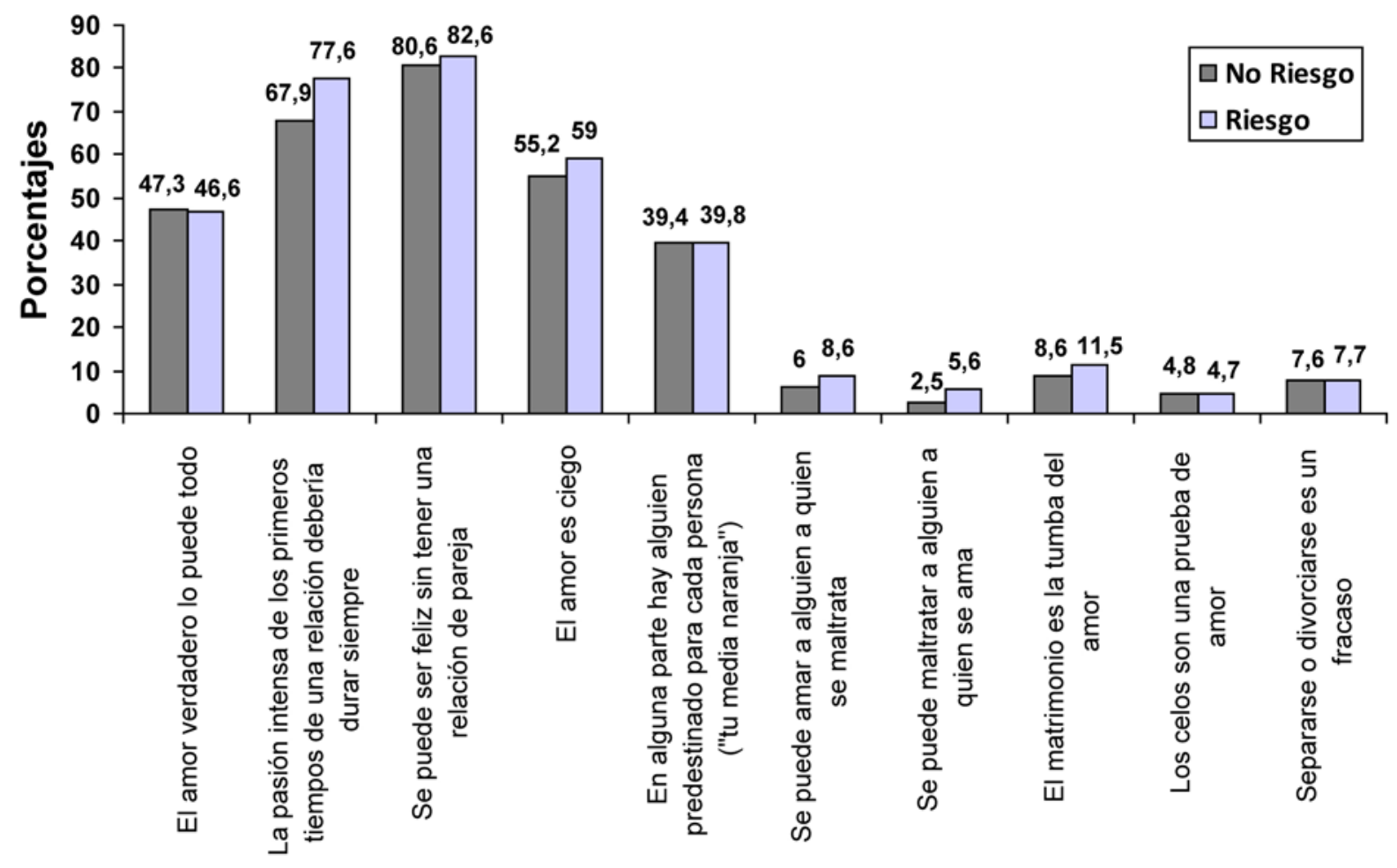

Figura 1. Distribución de los participantes según su acuerdo con los mitos del amor romántico.

En líneas generales, en ambos grupos se observan los mismos patrones en cuanto a creencias más extendidas y las menos valoradas, aunque con distintas prevalencias. Existe una tendencia del Grupo de Riesgo a presentar mayor acuerdo con los mitos respecto a sus compañeros del Grupo de No Riesgo (Ver Figura 1), si bien no muestran diferencias significativas a nivel estadístico. En este sentido, dos mitos obtuvieron diferencias significativas: "La pasión intensa de los primeros tiempos de una relación debería durar siempre» $\left(X^{2}=7,694\right.$; $p=0,006)$ y «Se puede maltratar a alguien a quien se ama» $\left(x^{2}=3,876 ; p=0,049\right)$ (Ver Tabla 2). 
Tabla 2

Chi-cuadrado y significación de los mitos del amor romántico

\begin{tabular}{lcc}
\hline \multicolumn{1}{c}{ Ítem } & $\mathrm{X}^{2}$ & $\mathrm{p}$ \\
\hline El amor verdadero lo puede todo & 0,032 & 0,859 \\
La pasión intensa de los primeros tiempos de una relación debería durar & 7,694 & $0,006^{*}$ \\
siempre & & \\
Se puede ser feliz sin tener una relación de pareja & 0,419 & 0,517 \\
El amor es ciego & 0,942 & 0,332 \\
En alguna parte hay alguien predestinado para cada persona («tu media & 0,014 & 0,905 \\
naranja») & & \\
Se puede amar a alguien a quien se maltrata & 1,528 & 0,216 \\
Se puede maltratar a alquien a quien se ama & 3,876 & $0,049^{*}$ \\
El matrimonio es la tumba del amor & 1,548 & 0,213 \\
Los celos son una prueba de amor & 0,001 & 0,980 \\
Separarse o divorciarse es un fracaso & 0,001 & 0,981 \\
\hline
\end{tabular}

\section{Discusión y conclusiones}

A partir de este estudio se ha profundizado en el análisis de los mitos del amor romántico, diferenciando entre aquellos jóvenes que practican relaciones sexuales de riesgo en el coito vaginal y aquellos que no.

Los resultados obtenidos apoyan parcialmente nuestra hipótesis. En línea con Teva y colaboradores (2009), se observa una tendencia general, en la que las personas del Grupo de Riesgo muestran mayor acuerdo con los mitos, aunque estas diferencias solo hayan sido significativas en dos de los mitos: el mito de la pasión eterna y uno de los mitos de la ambivalencia (amor-maltrato), ítems que, a su vez, podrían compartir el carácter volátil y explosivo con el que se concibe a la pasión y a la violencia, que en ocasiones son incontrolables y desbordan (Luzón y cols., 2011).

Como habíamos mencionado anteriormente, varios estudios han encontrado una baja utilización del preservativo durante las relaciones sexuales mantenidas con una pareja estable (Calafat y cols., 2009; Larrañaga y cols., 2012; Teva y cols., 2009). Este hecho podría explicarse por la pasión existente durante los inicios de las relaciones de pareja, que les haría sentir una seguridad excesiva. $Y$ en este sentido, la creencia de que la pasión en una relación debe ser eterna, podría mantener la confianza a lo largo del tiempo, y seguir realizando prácticas sexuales sin protección. Además, el hecho de proponer la utilización del preservativo, en el contexto de una pareja estable, podría ser visto como una baja confianza en el otro miembro o como se ha cometido una infidelidad, o incluso, que se tiene alguna infección de transmisión sexual (Ballester, Gil-Llario, Ruiz-Palomino y Giménez-García, 2013).

Por otra parte, es verdad que en otros estudios el papel que jugaban los mitos del amor romántico era mucho más notorio, y las diferencias entre grupos eran destacables (Ferrer y cols., 2010; Luzón y cols., 2011). No obstante, en el presente estudio no hemos observado las mismas diferencias en todos los ítems. Esto podría explicarse por el hecho de no haber tenido en cuenta si tenían pareja estable o no. 
En todo caso, estos resultados deben ser tomados en consideración teniendo en cuenta sus limitaciones. En primer lugar, habría que aumentar el número de participantes para conseguir unos datos más generalizables. Por otra parte, el hecho de utilizar una medida de autoinforme puede facilitar que los participantes contesten en base a la deseabilidad social. Además, también debería tenerse en cuenta la situación sentimental en la que se encuentren los participantes, ya que tener o no pareja estable puede influir en la utilización del preservativo. Y por último, cabría evaluar las expectativas que tienen en cuanto a su pareja y el nivel de estabilidad que perciben en ella, porque puede esa cuestión podría tener relación con el hecho de no tomar precauciones en las relaciones sexuales, como consecuencia de un nivel de confianza muy elevado. Todos estos aspectos deberían ser considerados en futuras líneas de investigación.

En conclusión, este estudio aporta información relevante para la prevención de conductas sexuales de riesgo, ya que analiza un factor que no siempre se tiene en cuenta, como son los mitos del amor romántico. Lógicamente, existen otros factores que median en la exposición a conductas de riesgo, como pueden ser la búsqueda de sensaciones sexuales, la autoeficacia a la hora de negociar el uso del preservativo o las habilidades sociales, pero es innegable que los mitos del amor romántico ejercen un papel importante en tomar o no precauciones, teniendo en cuenta los estereotipos de género y del «verdadero amor» que todavía existen en la sociedad (Ferrer y cols., 2010). Por tanto, es necesario que las políticas y estrategias preventivas y de promoción de la salud sexual tengan en cuenta el contexto de pareja en el que se llevan a cabo las relaciones sexuales, y que aborden las creencias que los y las jóvenes tienen sobre ellas, para que la prevención de las ITS sea eficaz.

\section{Referencias bibliográficas}

Ballester, R., Gil-Llario, M. D., Ruiz-Palomino, E., y Giménez-García, C. (2013). Autoeficacia en la prevención sexual del Sida: la influencia del género. Anales de psicología, 29(1), 76-82.

Bauermeister, J. A., Ventuneac, A., Pingel, E., y Parsons, J. T. (2012). Spectrums of love: Examining the relationship between romantic motivations and sexual risk among young gay and bisexual men. AIDS and Behavior, 16(6), 1549-1559.

Bosch, E., Ferrer, M. V., García, M. E., Ramis, M. C., Mas, M. C., Navarro, C. y Torrens, G. (2007). Del mito del amor romántico a la violencia contra las mujeres en la pareja. Madrid: Instituto de la Mujer.

Calafat, A., Juan, M., Becoña, E., Mantecón, A., y Ramón, A. (2009). Sexualidad de riesgo y consumo de drogas en el contexto recreativo. Una perspectiva de género. Psicothema, 21(2), 227-233.

Corbett, A. M., Dickson-Gómez, J., Hilario, H., y Weeks, M. R. (2009). A little thing called love: Condom use in high-risk primary heterosexual relationships. Perspectives on sexual and reproductive health, 41(4), 218-224.

Ferrer, V. A., Bosch, E., y Navarro, C. (2010). Los mitos románticos en España. Boletín de psicología, 99, 7-31.

Golub, S. A., Starks, T. J., Payton, G., y Parsons, J. T. (2012). The critical role of intimacy in the sexual risk behaviors of gay and bisexual men. AIDS and Behavior, 16(3), 626-632.

Larrañaga, E., Yubero, S., y Yubero, M. (2012). Influencia del género y del sexo en las actitudes sexuales de estudiantes universitarios españoles. Summa psicológica UST, 9(2), 5-13. 
Luzón, J. M., Ramos, E., Recio P., y de la Peña E. M. (2011). Factores de riesgo y de protección en la prevención contra la violencia de género en la pareja: Un estudio de investigación en la población adolescente de Andalucía. Proyecto Detecta Andalucía. Sevilla: Instituto Andaluz de la Mujer.

Power, C., Koch, T., Kralik, D., y Jackson, D. (2006). Lovestruck: Women, romantic love and intimate partner violence. Contemporary Nurse, 21(2), 174-185.

Rodríguez-Castro, Y., Lameiras-Fernández, M., Carrera-Fernández, M. V., y Vallejo-Medina, P. (2013). La fiabilidad y validez de la escala de mitos hacia el amor: las creencias de los y las adolescentes. Revista de Psicología Social, 28(2), 157-168.

Rubio-Garay, F., Carrasco, M. Á., Amor, P. J., y López-González, M. A. (2015). Factores asociados a la violencia en el noviazgo entre adolescentes: una revisión crítica. Anuario de Psicología Jurídica, 25(1), 47-56.

Teva, I., Bermúdez, M. P., y Buela-Casal, G. (2009). Characteristics of sexual behavior in Spanish adolescents. The Spanish journal of psychology, 12(02), 471-484.

Yela, C. (2003): La otra cara del amor: mitos, paradojas y problemas. Encuentros en Psicología Social, 1(2), 263-267. 



\title{
Uso de nuevos anticoagulantes orales (NACO) en la prevención del ictus y la embolia sistémica en pacientes con fibrilación auricular no valvular (FANV)
}

\author{
PAULA RodRíGuez GÁlVEZ \\ al318135@uji.es \\ LAURA VALERO VERCHE \\ al316975@uji.es \\ SONIA PI RUANO \\ al321875@uji.es \\ ALBA SÁNCHEZ MARTíN \\ al316975@uji.es \\ LUIS LIZÁN TUDELA \\ lizan@uji.es
}

\section{Resumen}

Introducción: Las herramientas de ayuda para la toma de decisiones compartidas son materiales, con información fiable basada en estudios científicos, sobre una determinada enfermedad o problema de salud en cuestión. Las herramientas son utilizadas para ayudar a las personas a sentirse más informadas y cómodas, para tomar decisiones sobre un tema de salud como el expuesto en el trabajo, teniendo en cuenta sus preferencias y valores. Además, facilitan la relación de las personas afectadas por una enfermedad y los profesionales sanitarios con el objetivo de llegar a una toma de decisiones conjunta. Metodología: En este artículo se ha creado una herramienta para la toma de decisiones compartidas, realizándose un análisis y una comparación de los distintos anticoagulantes presentes en la actualidad para la prevención del ictus y la embolia sistémica en pacientes con fibrilación auricular no valvular (FANV). Resultados: La presente herramienta, que consta de un tríptico para poder ser utilizado en Atención Primaria, quiere ser probado dentro de las prácticas que realicemos el próximo curso y de esta manera comprobar su utilidad.

Palabras clave: FANV; anticoagulantes; toma de decisiones compartidas; herramienta; preferencias.

\section{Abstract}

Introduction: Shared decision-support tools are materials, with reliable scientificbased information, about a given disease or health problem. Tools are used to help people feel more informed and comfortable, Make decisions on a health issue such as the one exposed in the work, taking into account their preferences and values, and 
facilitate the relationship of people affected by a disease and health professionals with the goal of reaching joint decision-making. Methodology: This article has created a tool for shared decision making, with an analysis and comparison of the different anticoagulants present for the prevention of stroke and systemic embolism in patients with non-valvular atrial fibrillation (FVAC). Results: This tool, which consists of a triptych to be used in Primary Care, wants to be tested within the practices that we perform the next course and thus prove their usefulness.

Key Words: FANV; Anticoagulants; Decision-making; tool; preferences.

\section{Introducción}

Las herramientas de ayuda para la toma de decisiones compartidas son materiales (cuadernillos, folletos, vídeos, DVD, páginas Web) con información fiable (basada en estudios científicos) sobre una determinada enfermedad o problema de salud. Las herramientas sirven para ayudar a las personas a sentirse más informadas y capaces de tomar decisiones sobre su salud, teniendo en cuenta sus valores y preferencias. Además facilitan la relación de las personas afectadas por una enfermedad y los profesionales sanitarios que la asisten, facilitando el proceso de toma de decisiones conjunta (PyDeSalud, 2015).

Las herramientas de ayuda se desarrollan porque muchos problemas de salud cuentan con distintas opciones de tratamiento, cada una con diferentes beneficios y efectos secundarios, que no afectan ni importan a todas las personas de la misma forma. UWHealth, el centro médico académico y el sistema de salud de la Universidad de Winsconsin, es consciente de estos hechos e introduce herramientas de ayuda que proporcionan información clave al paciente (sus opciones, información sobre los medicamentos y cómo pueden ayudarles en su patología, alternativas a la toma de la medicación...) (Healthwise Staff, 2016).

En las enfermedades en las que no existe una única o «mejor» opción de tratamiento, es necesario informar e incorporar las preferencias de las personas afectas para que tomen decisiones junto con los profesionales sanitarios que los asisten (PyDeSalud, 2015).

La herramienta de ayuda sobre anticoagulantes está dirigida a personas con previas patologías cardíacas o riesgo de padecerlas.

La fibrilación auricular (FA) es definida por Medlineplus como una arritmia cardíaca crónica, es decir, un problema con la velocidad o el ritmo de los latidos del corazón. Es debida a una alteración en la contracción de la aurícula, que es una parte del corazón. Esta arritmia es la más frecuente, afecta a un 1-2\% de la población. Su prevalencia se incrementa con la edad, de modo que se estima que la padece un $8,5 \%$ de la población española mayor de 60 años. Los factores de riesgo de la fibrilación auricular son:

- Ser mayor de 60 años de edad.

- Diabetes.

- Problemas cardíacos como: presión arterial alta, enfermedad de las arterias coronarias, ataques al corazón previos, insuficiencia cardíaca congestiva.

- Apnea del sueño.

- Abuso de alcohol o estimulantes. 
Los síntomas de la FA son diferentes para cada persona, muchas no presentan ningún tipo de síntoma. Algunos de ellos son:

- Sentirse demasiado cansado o con falta de energía (el más común).

- Pulso más rápido que el normal o que alterna entre rápido y lento.

- Falta de aire.

- Palpitaciones del corazón (sensación de que el corazón está agitado, late con rapidez o que aletea).

- Problemas al hacer ejercicio o actividades diarias.

- Dolor, presión, opresión o molestia en el pecho.

- Mareos, aturdimiento o desmayos.

La FA confiere a los pacientes que la padecen un riesgo de ictus y embolia sistémica superior en 5 veces al de la población general. Se estima que 1 de cada 5 ictus isquémicos están asociados a la presencia de FA.

El ictus, también llamado accidente cerebrovascular, sucede cuando el flujo de sangre a una parte del cerebro se detiene. Si el flujo sanguíneo se detiene por más de pocos segundos, el cerebro no puede recibir nutrientes y oxígeno. Las células cerebrales pueden morir, lo que causa daño permanente (Tidy, 2017).

La embolia sistémica es una interrupción repentina del flujo de sangre a un órgano o parte del cuerpo debido a un coágulo (émbolo) que viene de otra parte del cuerpo.

Como estas dos patologías pueden provocar daños irreversibles e incluso la muerte del paciente es importante su prevención. Para esta se administran, entre otros fármacos, anticoagulantes.

Los anticoagulantes son fármacos que impiden la coagulación de la sangre, es decir, la formación de coágulos, favoreciendo su disolución con el fin de evitar taponamientos que pueden tener consecuencias graves como ictus, infarto, tromboembolismo pulmonar, entre otras. En general podemos hablar de tres tipos de anticoagulantes: los anticoagulantes orales clásicos (sintrom), los nuevos anticoagulantes orales y las heparinas de bajo peso molecular que se administran por vía subcutánea.

\section{Materiales y métodos}

Con el fin de investigar cuáles son las preferencias de los pacientes en cuanto a lo que ellos considerarían su mejor tratamiento anticoagulante, hemos desarrollado una serie de tablas a modo de cuestionario para que puedan orientar sus decisiones contestando a estas preguntas, y de esta manera hacerlos partícipes de la relación médico-paciente a la hora de decidir dicha terapia. Como se puede observar en la Tabla 1, en primer lugar, nos centramos en los conocimientos que tienen las personas afectadas sobre los diferentes tipos de anticoagulantes: 
Tabla 1

Conocimientos del Paciente: ¿Qué conozco?

Por favor, responda «Sí», «No» o «No lo sé» a las afirmaciones relacionadas con los tratamientos anticoagulantes. No se preocupe si no conoce la respuesta, conteste en base a lo que usted crea correcto, señalando con una $\mathrm{X}$ en la casilla que considere oportuna.

Pregunta
1. ¿Conoce la función de los anticoagulantes y para que
patologías se administran?
2. ¿Existen distintas formas u opciones de administrar los
anticoagulantes?
3. ¿Puede causar la tensión arterial alta problemas para
el corazón?
4. ¿Es la hemorragia un efecto secundario de la toma de
anticoagulantes?
5. ¿Debe ser la toma de anticoagulantes igual para todas
las personas independientemente de sus característi-
cas?

Tras la rellenar este cuestionario, se le dará a cada paciente información sobre los diferentes tipos de anticoagulantes:

Anticoagulantes en la Prevención del Ictus en pacientes con FANV:

En primer lugar debemos diferenciar entre 3 tipos de anticoagulantes:

- Anticoagulantes clásicos

- Heparina

- Nuevos anticoagulantes orales (NACOs)

Entre los anticoagulantes clásicos diferenciamos la Warfarina y el Sintrom. Estos presentan como beneficios principales que son los más baratos, que tienen un antídoto específico, que al ser los más antiguos se tiene un mayor conocimiento del fármaco y que existen métodos de control validados. Además se ha comprobado que la warfarina es eficaz para prevenir el accidente cerebrovascular isquémico en pacientes con fibrilación auricular en la práctica clínica diaria. Los resultados de los ensayos aleatorios de anticoagulación se traducen bien en la atención clínica de pacientes con fibrilación auricular (Go y cols., 2003). La vía de administración para ambos es oral, pero varía la posología. Mientras que en la warfarina se pautan $5 \mathrm{mg} /$ día, en el caso del Sintrom debemos variar la dosis según el valor de Quick de cada paciente (más 50\% 2 comprimidos= $8 \mathrm{mg}, 30 \%-40 \% 1$ comprimidos $=4 \mathrm{mg}, 15-30 \% 1 / 4$ o 1 comprimidos $=1-4 \mathrm{mg}$ ).

Entre los inconvenientes que presentan ambos medicamentos destacan:

- Seguimiento de la dieta basado en la ingesta de Vit K. 
- Revisiones médicas periódicas, en el caso del Sintrom para revisar el valor de Quick, y en caso de la Warfarina para el mantenimiento de los niveles del IRN (2-3) (Tidy, 2017).

Ambos presentan ciertos riesgos y efectos secundarios. En el caso del Sintrom destaca el riesgo frecuente de hemorragias y el mal control de la dosis en 1/3 de los pacientes. En el caso de la warfarina existe un mayor riesgo de hemorragias, con mayor incidencia en el cerebro.

En cuanto a la heparina nos centramos en la heparina sódica, que es aquella que presenta una vía de administración intravenosa o subcutánea profunda. La posología de la misma son $250 \mathrm{UI} / \mathrm{Kg} / 12 \mathrm{~h}$. Entre los beneficios de la heparina destaca que no debemos realizar un seguimiento de nuestra dieta ni realizar revisiones médicas periódicas. Además, otro de los beneficios es que es el anticoagulante de elección en embarazadas. En cuanto a los riesgos y efectos secundarios destaca la aparición de hemorragias frecuentes y de edemas si no se rota de zona de pinchazo en la administración de la misma (García, 2013).

Por otro lado, nos encontramos con los nuevos anticoagulantes orales, entre los que podemos destacar el Dabigatrán, Rivaroxabán, Apixabán, Edoxabán. Todos estos nuevos anticoagulantes orales, han surgido teniendo en cuenta que los pacientes con rangos de anticoagulación bajo del nivel terapéutico presentan riesgo de trombosis, mientras que los que tienen niveles superiores al normal, la probabilidad de presentar un sangrado patológico puede llegar a más de $30 \%$ al año. Por todo ello, se están desarrollando nuevos anticoagulantes con farmacocinética y farmacodinamia más predecibles, mayor rango terapéutico y dosis fija que no requieren monitorización. Estos nuevos anticoagulantes se han enfocado en la inhibición específica del factor $X$ (FXa) y de la trombina (Ila), enzimas claves en la vía final de la coagulación (Berkovits, Aizman, Zúñiga, Pereira y Mezzano, 2011) (Mateo, 2013).

En conjunto, los nuevos anticoagulantes presentan algunas ventajas tales como que tienen un rápido inicio de acción, un efecto anticoagulante predecible, así como pocas interacciones con alimentos y con fármacos. Además, todas ellas presentan una serie de consecuencias clínicas, como que no es necesaria una terapia puente, tampoco es necesaria una monitorización rutinaria, existen bajos riesgos de efectos adversos, tasas de sangrado menores, así como que no implican grandes limitaciones en los fármacos y en los alimentos consumidos. Otra característica positiva a destacar, es que el Dabigatran es el único nuevo anticoagulante sin riesgo para la insuficiencia hepática (García, 2013) (Mateo, 2013).

Por otro lado, otra de las consideraciones importantes de cada uno de ellos, es su posología pudiendo variar su administración oral de 1 a 2 dosis diarias, como por ejemplo:

- Apixabán: 2-5 mg/2 día.

- Edoxabán: 60 mg/1 día.

- Rivaroxabán: 20 mg/1 día.

- Dabigatrán: 75 mg/2 día.

Sin embargo, también estos nuevos anticoagulantes orales presentan unos riesgos y efectos secundarios como podrían ser:

- Menor riesgo de hemorragias frecuentes, pero con mayor incidencia en hemorragias gastrointestinales.

- No existe un método de monopolización validado.

- No existe antídoto para estos nuevos anticoagulantes orales. 
- El Dabigatrán está contraindicado en la insuficiencia hepática (Vidal Vademecum Spain, 2017)

Tabla 2

Comparación de los anticoagulantes clásicos y heparina vs. nuevos

\begin{tabular}{|c|c|c|c|c|c|c|c|}
\hline Anticoagulantes & & Beneficios & Vía & Posologia & $\begin{array}{c}\text { Dleta } \\
\text { (Control } \\
\text { Vitamina K) }\end{array}$ & $\begin{array}{l}\text { Revisiones } \\
\text { Médicas }\end{array}$ & $\begin{array}{c}\text { Riesgos y efectos } \\
\text { secundarios }\end{array}$ \\
\hline $\begin{array}{l}\text { Anticoagulantes } \\
\text { Clásicos }\end{array}$ & Simtrom & $\begin{array}{l}\text { Barato y antidoto } \\
\text { especifico } \\
\text { Mayor conocimiento } \\
\text { del fármaco y método } \\
\text { de control validado }\end{array}$ & Oral & $\begin{array}{c}\text { Según el valor de } \\
\text { Quick: } \\
\text { - más } 50 \% 2 \text { comp. } \\
8 \mathrm{mg} \\
-30 \%-\% 50 \% 1 \\
\text { comp. }-4 \mathrm{mg} \\
-15-30 \% \% \circ 1 \\
\text { comp- } 1-4 \mathrm{mg}\end{array}$ & $\mathrm{SI}$ & $\begin{array}{l}\text { Periódicas para } \\
\text { seguimiento del } \\
\text { valor de Quick }\end{array}$ & $\begin{array}{l}\text { Riesgo de hemorragias } \\
\text { frecuentes, } 1 / 3 \text { no está bien } \\
\text { controlado. }\end{array}$ \\
\hline $\begin{array}{l}\text { Anticoagulantes } \\
\text { Clásicos }\end{array}$ & Warfarina & & & $5 \mathrm{mg} / 1 \mathrm{dla}$ & & $\begin{array}{l}\text { Periodicas para } \\
\text { mantenimiento del } \\
\text { IRN }\left(\begin{array}{ll}2.0 & 3.0\end{array}\right)\end{array}$ & $\begin{array}{c}\text { Alto riesgo de hemorragias, } \\
\text { con mayor incidencia en } \\
\text { Corobro }\end{array}$ \\
\hline \multirow[t]{4}{*}{$\begin{array}{l}\text { Anticoagulantes } \\
\text { Nuevos }\end{array}$} & Aplxaban & $\begin{array}{c}\text { Pocas interacciones } \\
\text { farmacológicas/ } \\
\text { alimentarias } \\
\text { Rápido inicio de acción } \\
\text { No requieren control } \\
\text { de la coagulación } \\
\text { rutinario } \\
\text { Tasas de sangrado } \\
\text { menores } \\
\text { Dabigatrán: Único sin } \\
\text { riesgo para la } \\
\text { insuficiencia hepática }\end{array}$ & & $2-5 \mathrm{mg} / 2 \mathrm{dla}$ & NO & & $\begin{array}{c}\text { Menor riesgo de } \\
\text { hemorragias frecuentes, con } \\
\text { mayor incidencia en } \\
\text { ESTOMAGO } \\
\text { No existe método de } \\
\text { monopolización validado } \\
\text { No antidoto }\end{array}$ \\
\hline & Edoxaban & & & $60 \mathrm{mg} / 1 \mathrm{dla}$ & & & \\
\hline & Rlvaroxaban & & & $20 \mathrm{mg} / 1 \mathrm{dla}$ & & & \\
\hline & Dobigatrán & & & $75 \mathrm{mg} / 2 \mathrm{dla}$ & & & \\
\hline Heparina & $\begin{array}{l}\text { Heparina } \\
\text { sódica }\end{array}$ & $\begin{array}{c}\text { Uso durante embarazo } \\
\text { y lactancia }\end{array}$ & $\begin{array}{c}\text { Intravenosa/ } \\
\text { subcutánea } \\
\text { profunda en } \\
\text { grasa } \\
\text { abdominal }\end{array}$ & 250 UU/Kg/12 hora & & & $\begin{array}{l}\text { Riesgo de hemorragias } \\
\text { frecuentes, aparición de } \\
\text { edemas sí no se rota la } \\
\text { zona de administración }\end{array}$ \\
\hline
\end{tabular}

Con toda esta información los pacientes serán capaces de contestar el siguiente cuestionario, que se centra en saber las preferencias según las características de cada tipo de anticoagulante tabla 3-6.

Atributos como la eficacia, dosis fija y seguridad de los AO son los más valorados por los pacientes con fibrilación auricular no valvular. Estas preferencias deberían considerarse al instaurar o cambiar el tratamiento con AO para mejorar el cumplimiento y prevención en pacientes (González-Rojas y cols., 2012) 
Tabla 3

Preferencias: cuestionario para el paciente (PyDeSalud, 2015)

A continuación, le presentamos una serie de cuestiones para comprobar sus preferencias sobre los anticoagulantes. Lea atentamente las preguntas y conteste con total sinceridad, valorando cada una del 1 al 10.

1. ¿Qué importancia tiene para usted...

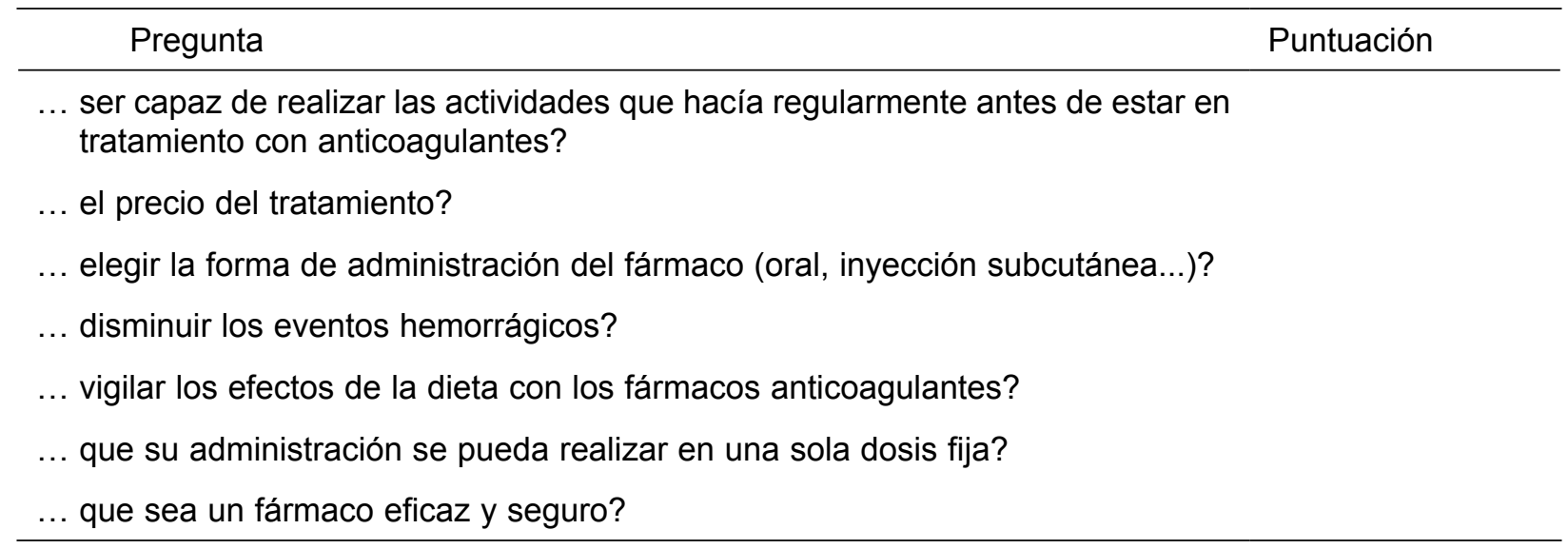

2. ¿Cuánto le preocupa...

\begin{tabular}{l}
\hline Pregunta \\
\hline$\ldots$ interrumpir sus actividades cotidianas para realizarse controles de la \\
coagulación? \\
... tener un evento trombótico? \\
... poder seguir la prescripción del medicamento? \\
$\ldots$... que el tratamiento interfiera en el embarazo?
\end{tabular}

Tabla 4

Decidiendo el tratamiento

Considerando las opciones de tratamiento (SINTROM, heparina, nuevos anticoagulantes) por favor, conteste a las siguientes preguntas marcando la opción de la escala que más se adecúe a su preferencia (PyDeSalud, 2015).

\begin{tabular}{llllll}
\hline Enunciado & $\begin{array}{c}\text { 1.Total } \\
\text { desacuerdo }\end{array}$ & 2 & 3 & 4 & 5.Total acuerdo \\
\hline
\end{tabular}

Conozco los tratamientos

disponibles para mí

Conozco los beneficios de cada opción

Conozco los riesgos y

efectos secundarios de cada

opción 


\begin{tabular}{|c|c|c|c|c|c|c|}
\hline Enunciado & $\begin{array}{c}\text { 1. Total } \\
\text { desacuerdo }\end{array}$ & 2 & 3 & 4 & 5.Total & acuerdo \\
\hline \multicolumn{7}{|l|}{$\begin{array}{l}\text { Tengo claro qué beneficios } \\
\text { son los que más me } \\
\text { importan }\end{array}$} \\
\hline \multicolumn{7}{|l|}{$\begin{array}{l}\text { Tengo claro qué riesgos y } \\
\text { efectos secundarios son los } \\
\text { que más me importan }\end{array}$} \\
\hline $\begin{array}{l}\text { Tengo claro qué es más } \\
\text { importante para mí: los } \\
\text { beneficios o los riesgos/ } \\
\text { efectos secundarios }\end{array}$ & & & & & & \\
\hline
\end{tabular}

Tabla 5

Opciones de tratamiento. Rodee la opción que contempla contestando a la siguiente pregunta (PyDeSalud, 2015)

Si tuviera que elegir un tratamiento ahora, ¿cuál elegiría?

Anticoagulantes Clásicos (Sintrom)

Heparina

Nuevos Anticoagulantes orales

Tabla 6

De acuerdo a sus preferencias, ¿quién prefiere usted que tome la decisión sobre el tratamiento a seguir? (marque con una $X$ sólo una de las siguientes opciones) (PyDeSalud, 2015)

Prefiero ser yo quien tome la decisión sobre el tratamiento que recibiré.

Prefiero ser yo quien tome la decisión sobre mi tratamiento, tras considerar seriamente la opción del profesional sanitario (médico de atención primaria).

Preferiría que el profesional sanitario (médico de atención primaria) y yo compartamos la responsabilidad de elegir cuál es el tratamiento que más me conviene.

Prefiero que el profesional sanitario (médico de atención primaria) tome la decisión final sobre mi tratamiento, pero considerando seriamente mi opinión.

Prefiero dejar todas las decisiones sobre mi tratamiento al profesional sanitario (médico de atención primaria).

Prefiero ser yo quien tome la decisión sobre el tratamiento que recibiré.

\section{Resultados}

Esta herramienta está pensada para utilizarla sobretodo en las consultas de Atención Primaria dado que es aquí dónde más se prescriben estos fármacos. Por tal razón, la idea inicial era probarla en dichas consultas durante nuestro período de prácticas, sin embargo, cuando la tuvimos lista ya las habíamos terminado. 
Hay varios parámetros a explorar en los resultados. El primero sería tener una idea general de los conocimientos de la población acerca de los anticoagulantes antes de que se les haya dado la información. La importancia de ello es saber si los pacientes conocen algo de estos fármacos a priori, y si la mayoría no los conocen, plantearse la educación social mediante la realización de charlas y/o talleres en el centro de salud.

El segundo parámetro se centraría en investigar si los pacientes son capaces de, con la información facilitada, discernir cuál sería el mejor tratamiento para ellos valorando cómo puede afectar el fármaco a cada aspecto de su vida, y de esta manera, llegar a elegir por sí mismos el anticoagulante idóneo para ellos. Si fuera así, se demostrarían dos cosas: el gran entendimiento que se puede alcanzar sobre cada fármaco que llevaría a una mayor adherencia por parte de los pacientes, facilitando así la faena del médico; y la gran independencia que pueden llegar a tener los pacientes si se les explican correctamente las cosas de manera que puedan entenderlas.

En tercer lugar y en referencia al último punto del cuestionario, nos planteamos cuán importante es para los usuarios la relación con su médico de Atención Primaria y el grado de satisfacción en esta. Así, dependiendo de quién prefieran que elija el tratamiento, veremos distintos tipos de relación. Por ejemplo, si el paciente quiere elegir por sí mismo podemos imaginar que se trata de una relación en la que el paciente no está muy satisfecho y hay poca confianza, por ello prefiere no contar con el médico; si decide que sea una responsabilidad compartida entre los dos, pensaremos que estamos ante una buena relación médico-paciente, ya que son capaces de dialogar y decidir entre los dos qué es lo mejor; y si el paciente prefiere que decida el médico por él, tal vez estemos ante una relación con demasiada confianza depositada en el profesional sanitario y seguramente con un alto grado de satisfacción por parte del usuario, sin embargo no se trataría de la relación horizontal que se busca actualmente con nuestros pacientes.

\section{Referencias bibliográficas}

Berkovits, A., Aizman, A., Zúñiga, P., Pereira, J. y Mezzano, D. (2011). Nuevos anticoagulantes orales. Revista médica de Chile, 139(10), 1347-1355.

Dabigatran etexilato (2017). Vidal Vademecum Spain. Recuperado de: www.vademecum.es// principios-activos-dabigatran+etexilato-b01ae07.

Fibrilación auricular. Recuperado de: www.medlineplus.gov/spanish/atrialfibrillation.

García, J. P. (2013). Nuevos anticoagulantes frente a anticoagulantes clásicos: ventajas e inconvenientes. SEMERGEN-Medicina de Familia, 39(1), 10-16.

Go, A.S., Hylek, E.M., Chang, Y., Phillips, K.A., Henault, L.E., Capra, A.M., Jensvold, N.G., Selby, J.V. y Singer, D.E. (2003). Anticoagulation Therapy for Stroke Prevention in Atrial Fibrillation: How Well Do Randomized Trials Translate Into Clinical Practice?. JAMA, 290(20), 2685-2692.

González-Rojas, N., Giménez, E., Fernández, M.A., Heineger, A.I., Martínez, J.L., Villar, J. y Lizán, L. (2012). Preferencias por los tratamientos anticoagulantes orales para la prevención a medio y largo plazo del ictus en la fibrilación auricular no valvular. Revista de Neurología, 55 (1), 11-19.

Healthwise Staff. Atrial Fibrillation: Should I Take an Anticoagulant to Prevent Stroke? (2016). UW Health. Recuperado de: www.uwhealth.org/health/topic/decisionpoint/atrial-fibrillation-should-i-take-an-anticoagulant-to-prevent-stroke/tx2209.html.

Mateo, J. (2013). Nuevos anticoagulantes orales y su papel en la práctica clínica. Revista Española de Cardiología, 13(C), 33-41. 
Tidy, C. Preventing Stroke When You Have Atrial Fibrillation. (2017). Patient.info. Recuperado de: www.patient.info/health/preventing-stroke-when-you-have-atrial-fibrillation.

Toma de decisiones en depresión (2015). PyDeSalud. Recuperado de www.pydesalud.com/ toma-de-decisiones-compartida-en-depresion. 

